UNIVERSIDADE DE SÃO PAULO

FACULDADE DE FILOSOFIA, LETRAS E CIÊNCIAS HUMANAS

DEPARTAMENTO DE GEOGRAFIA

PROGRAMA DE PÓS-GRADUAÇÃO EM GEOGRAFIA HUMANA

Fernanda Mello Sant'Anna

\title{
GOVERNANÇA MULTI-ESCALAR DOS RECURSOS HÍDRICOS TRANSFRONTEIRIÇOS NA AMAZÔNIA
}




\section{GOVERNANÇA MULTI-ESCALAR DOS RECURSOS HÍDRICOS TRANSFRONTEIRIÇOS NA AMAZÔNIA}

Tese apresentada ao Programa de PósGraduação em Geografia Humana, do Departamento de Geografia, da Faculdade de Filosofia, Letras e Ciências Humanas da Universidade de São Paulo; para obtenção do título de Doutora em Geografia Humana.

Orientador: Wagner Costa Ribeiro. 


\section{GOVERNANÇA MULTI-ESCALAR DOS RECURSOS HÍDRICOS TRANSFRONTEIRIÇOS NA AMAZÔNIA}

Tese apresentada ao Programa de PósGraduação em Geografia Humana, do Departamento de Geografia, da Faculdade de Filosofia, Letras e Ciências Humanas da Universidade de São Paulo; para obtenção do título de Doutora em Geografia Humana.

Aprovada em:

BANCA EXAMINADORA

Prof. Dr. Wagner Costa Ribeiro

Prof.(a) Dr.(a)

Prof.(a) Dr.(a)

Prof.(a) Dr.(a)

Prof.(a) Dr.(a)

São Paulo 
Dedico este trabalho aos meus pais, Otavio e Odete, minha geração passada, que me ensinaram muito, e aos meus sobrinhos Eduardo e Sofia, minha geração futura, para os quais eu pretendo, com este trabalho, contribuir para melhorar as condições deste planeta que deixaremos para eles. 


\section{AGRADECIMENTOS}

Agradeço ao Professor Dr. Wagner Costa Ribeiro, meu orientador, pelo apoio, incentivo, paciência, e pelos ensinamentos e encorajamentos durante todo o processo da pesquisa e desenvolvimento deste trabalho.

Agradeço à Fundação de Amparo à Pesquisa do Estado de São Paulo (FAPESP) e a Universidade de São Paulo (USP) pelo apoio, sem o qual seria impossível realizar este trabalho.

Agradeço ao Professor Dr. André Martins e ao Professor Dr. Wanderley Messias da Costa, do Departamento de Geografia da USP, pelas contribuições ao meu trabalho durante o exame de qualificação, bem como pelos ensinamentos durante as aulas. Agradeço aos professores e funcionários do Departamento de Geografia da USP pelo apoio durante a realização deste trabalho. Agradeço aos meus colegas do Departamento de Geografia e, principalmente, do Laboratório de Geografia Política pelas discussões, debates, e encorajamento ao longo de toda a pesquisa. Agradeço ao meu colega Tito Lívio Barcellos Pereira pela ajuda com os mapas.

Agradeço às pessoas que durante as minhas entrevistas e trabalhos de campo realizados em Brasília, no Acre, na Bolívia, no Peru e no Equador, me receberam e me apoiaram ao fornecer informações e dados essenciais para a realização deste trabalho. $\mathrm{Eu}$ sou muito grata pelo tempo que me disponibilizaram e pelas informações compartilhadas.

Agradeço a Professora Dra. Vera Reis, da Universidade Federal do Acre, por me receber e compartilhar seus conhecimentos sobre o rio Acre. Agradeço aos funcionários da Secretaria Estadual de Meio Ambiente do Acre (SEMA), e ao Engenheiro Júlio Mattos do Departamento Estadual de Águas, pelas importantes informações sobre os recursos hídricos do Acre. Aos funcionários da Prefeitura de Brasiléia e de Assis Brasil, no Acre, e de Iñapari, no Peru, meus agradecimentos pelas informações compartilhadas. Agradeço ao diretor da SENASA Armando Muñante pelo compartilhamento de informações e apoio. Meus agradecimento a César Aguillar, da Herencia, pelo apoio e informações compartilhadas.

Ao Professor Dr. Alfredo Vicente Seoane Flores, da Universidad Mayor de San Andrés, em La Paz, que compartilhou comigo seu amplo conhecimento e contribuiu demasiado para este trabalho, meu muitíssimo obrigado. Agradeço também ao Professor Me. Jorge Molina Carpio do Instituto de Hidrologia e Hidraulica da Universidad Mayor de San Andrés, em La Paz. Meus agradecimentos aos funcionários dos Ministérios de Água e Meio Ambiente, e de Relações Exteriores da Bolívia, que me receberam e contribuíram muito para minha pesquisa. Meus agradecimentos aos Professores do Centro Agua, da Universidad Mayor de San Simón, de Cochabamba, por me receberem e compartilharem informações e conhecimento que me ajudaram muito em minha pesquisa. Agradeço também a Silvia Molina, do FOBOMADE, pelo apoio e informações compartilhadas.

Agradeço ao Professor Dr. Jaime Roberto Llosa Lambure, da Universidad Agraria La Molina, pelo apoio durante a minha estadia em Lima, e pelos ensinamentos que muito contribuíram para a minha pesquisa. Ao Professor Dr. Enrique Amayo Zevallos, meus agradecimentos pela ajuda durante minha estadia em Lima, e pelos contatos, ensinamentos e apoio durante minha pesquisa. 
Agradeço ao Professor Dr. Paul van Lindert, da Universidade de Utrecht (Países Baixos), pelos ensinamentos e apoio à minha pesquisa. Agradeço ao Professor Dr. Rutgerd Boelens e a Professora Dra. Cora Van Oosten da Universidade de Wageningen (Países Baixos) pelo apoio e ensinamentos.

Agradeço ao Engenheiro Juan Recalde, da SENAGUA do Equador, pelo tempo dispendido para me ajudar, pelas informações e contribuições que me ajudaram muito na pesquisa e também na minha estadia no Equador. Agradeço aos funcionários da Oficina de Orellana da SENAGUA pelos mapas e informações. Agradeço ao advogado Pablo Fajardo, Wilmer Meneses e Juan Espejos, da FDA, pelas informações compartilhadas para minha pesquisa.

Agradeço a Carlos Cuenca, meu guia do Parque Yasuni, no Equador, e da viagem de barco pelo rio Napo desde Nuevo Rocafuerte até Iquitos, pela viagem e também por me ajudar a compreender as relações e problemas enfrentados pelas populações ribeirinhas.

Agradeço ao Engenheiro Jorge Edwin Benites Agüero da Autoridad Nacional de Agua do Peru e sua equipe que me receberam e dispensaram seu tempo para me assistir com informações e conhecimento essenciais para a realização do meu trabalho.

Agradeço ao Dr. Humberto Cardoso Gonçalves, da Agência Nacional de Águas do Brasil, pelos ensinamentos e informações que compartilhou comigo e que contribuíram para este trabalho.

Agradeço ao Coordenador de Meio Ambienta da OTCA, Antonio Matamoros, pelas informações e pelo tempo concedido para a entrevista, que contribuíram muito para minha pesquisa.

Agradeço à minha mãe, a bióloga Maria Odete Aparecida Moreira Mello, pela companhia e encorajamentos durante a pesquisa, pela grande ajuda nos trabalhos de campo, pelos ensinamentos, pela disposição em me ajudar, enfim, por todas as suas ações que me ajudaram e permitiram que eu realizasse este trabalho.

Agradeço a minha querida tia a Professora Dra. Maria das Graças Ribeiro Petrucci, pela ajuda desde a formulação do projeto de pesquisa até as correções do trabalho final, pelo apoio e ensinamentos durante toda a minha vida acadêmica.

Agradeço ao meu companheiro João Paulo, pelo apoio, ajuda e compreensão durante todos esses anos de pesquisa e de desenvolvimento deste trabalho. 
Trago o grito enlouquecido dos pássaros de asas queimadas pelas brasas dos desumanos; o suor contente das quebradeiras de coco, das fazedouras de farinha d'água, das amassadouras de açaí.

E termino este aceno de mãos agradecidas com o abraço das crianças amazônicas que ainda vão nascer, abençoadas pelo majestoso arco-íris de amor que se ergue, úmido da seiva, das terras firmes do alto Xapuri, com as cores de todas as raças humanas

(Thiago de Melo) 


\section{RESUMO}

A Bacia Amazônica é compartilhada por sete países (Bolívia, Brasil, Colômbia, Equador, Guiana, Peru e Venezuela) e tem sido foco de diversos projetos de infraestrutura e de atividades de exploração econômica que causam contaminação e degradação, demonstrando a necessidade de governança e gestão de seus recursos hídricos. Este trabalho busca compreender a governança multi-escalar como forma de regulação do uso dos recursos hídricos transfronteiriços na Bacia Amazônica, por meio da análise das ações dos Estados e demais atores sociais em duas bacias compartilhadas: a Bacia do rio Acre e a Bacia do rio Napo. A governança de uma bacia transfronteiriça envolve diversos atores sociais na escala local, nacional e internacional que deveriam coordenar suas ações no intuito de regular o uso da água. Na escala local encontram-se as regiões de fronteira onde foram estudas a governança na bacia do rio Acre e na bacia do rio Napo. Na escala nacional buscou-se compreender o arcabouço institucional para a gestão dos recursos hídricos na Bolívia, no Brasil, no Equador e no Peru, pois são os países que compartilham as duas bacias estudadas. $\mathrm{Na}$ escala internacional foram analisadas as instituições regionais que abarcam os países amazônicos e desenvolvem projetos que influenciam a governança dos recursos hídricos transfronteiriços na Bacia Amazônica, em especial nas bacias do Acre e do Napo. Ao analisar a cooperação entre os Estados e entre os demais atores sociais envolvidos na regulação do uso dos recursos hídricos transfronteiriços nas diferentes escalas geográficas que se sobrepõem na Bacia Amazônica demonstrou-se que apesar da existência de cooperação nas bacias analisadas a governança ainda é incipiente. Portanto, a cooperação não é o único fator que garante a emergência de um processo de governança dos recursos hídricos transfronteiriços na Amazônia.

Palavras-chave: governança, cooperação, recursos hídricos, Amazônia, multi-escalar. 


\begin{abstract}
Amazon River Basin is shared by seven countries (Bolivia, Brazil, Colombia, Ecuador, Guyana, Peru and Venezuela) and has been the focus of infrastructure projects and economic activities that cause contamination and degradation demonstrating need for water resources governance and management. This work aims to comprehend the multi-scalar governance, understood as a mean for regulating the use of transboundary water resources, in the Amazon Basin analyzing actions taken by states and other social actors in two shared basins: the Acre River Basin and the Napo River Basin. Transboundary river basin governance involves different social actors in local, national and international scales that must coordinate their actions in order to regulate water use. Border regions are located at the local scales where the Acre River Basin and the Napo River Basin were studied. At the national scale it was analyzed the institutional framework of water resources management in Bolivia, Brazil, Ecuador and Peru, which are the countries that share the two river basins studied. At the international scale it was analyzed the cooperation and regional institutions of Amazon countries that have projects in the Amazon Basin which influence water governance in the basin, especially in the Basins of Rivers Napo and Acre. By analyzing the cooperation among Amazon countries and other social actors involved in the regulation of transboundary water resources uses in different scales overlapped in the Amazon Basin, this study demonstrated that despite the existence of cooperation in the basins analyzed, water governance is still incipient. Therefore, cooperation is not the only factor that ensures the emergence of a process of transboundary water resources governance in the two River Basins studied.
\end{abstract}

Key-words: governance, cooperation, water resources, Amazonia, multi-scale. 


\section{RESUMEN}

La Cuenca del río Amazonas es compartida por siete países (Bolivia, Brasil, Colombia, Ecuador, Guyana, Perú y Venezuela) y ha sido objeto de varios proyectos de infraestructura y actividades de explotación económica que causan contaminación y degradación, lo que demuestra la necesidad de gobernanza y gestión de sus recursos hídricos. Este trabajo busca comprender la gobernanza multi-escalar como un medio para regular el uso de los recursos hídricos transfronterizos en la cuenca amazónica, mediante el análisis de las acciones de los estados y otros actores sociales en dos cuencas compartidas: la cuenca del río Acre y la cuenca del río Napo. La gobernanza de una cuenca transfronteriza implica diversos actores sociales en las escalas local, nacional e internacional, que deben coordinar sus acciones con el fin de regular el uso del agua. En la escala local existen regiones fronterizas donde se estudió la gobernanza de las cuencas del río Acre y del río Napo. En la escala nacional se buscó comprender el marco institucional para la gestión de los recursos hídricos en Bolivia, Brasil, Ecuador y Perú, que son los países que comparten las dos cuencas analizadas. En la escala internacional fueron analizados los países amazónicos y las instituciones regiones que desarrollan proyectos que impactan la gobernanza de los recursos hídricos transfronterizos en la cuenca Amazónica, especialmente en las cuencas del Napo y del Acre. Mediante el análisis de la cooperación entre los Estados miembros y entre otros actores sociales involucrados en la regulación del uso de los recursos hídricos transfronterizos en las distintas escalas que se superponen en la cuenca del Amazonas fue demostrado que a pesar de la existencia de cooperación en las cuencas analizadas la gobernanza es aún incipiente. Por lo tanto, la cooperación no es el único factor que garantiza el surgimiento del proceso de gobernanza de los recursos hídricos transfronterizos en la Amazonía.

Palabras-clave: gobernanza, cooperación, recursos hídricos, Amazonía, multi-escala. 


\section{LISTA DE FIGURAS}

Figura 1: Formação das Fronteiras Políticas na Amazônia...................................... 102

Figura 2: Formulação do Programa de Ação Estratégica (PAE).............................. 155

Figura 3: Governança multi-escalar dos recursos hídricos transfronteiriços da

Bacia do rio Acre........................................................................................... 216

Figura 4: Governança multi-escalar dos recursos hídricos transfronteiriços da

Bacia do rio Napo..................................................................................... 268 


\section{LISTA DE FOTOS}

Foto 1: O rio Acre na fronteira entre Assis Brasil (Brasil) e Bolpebra (Bolivia)...... 162

Foto 2: Ponte da Integração entre Assis Brasil, Brasil, e Iñapari, Peru, vista desde Iñhapari.......................................................................................................... 170

Foto 3: Ponte sobre o rio Madre de Dios, em Puerto Maldonado, Peru.................... 171

Foto 4: Estrada do Pacífico vista desde Assis Brasil, Brasil.................................... 172

Foto 5: Fazenda de gado vista da rodovia BR-317 no Acre, Brasil ......................... 176

Foto 6: As cidades gêmeas de Brasiléia (Brasil) e Cobija (Bolívia) cortadas pelo rio Acre ................................................................................................. 180

Foto 7: Vista aérea de parte da cidade de Francisco de Orellana, no Equador .......... 225

Foto 8: Embarcadouro fluvial de Santa Clotilde na margem do rio Napo, no Peru .. 226

Foto 9: Porto de Francisco de Orellana no rio Napo, no Equador ........................... 233

Foto 10: Embarcação brasileira no rio Napo, na fronteira entre Equador e Peru....... 236

Foto 11: Porto de empresa petroleira na margem do rio Napo, no Equador.............. 243

Foto 12: Oleoduto na estrada que liga Nueva Loja (Lago Agrio) a Francisco de Orellana, no Equador .................................................................................. 243 


\section{LISTA DE MAPAS}

Mapa 1: Bacia Hidrográfica do Rio Acre .............................................................. $\quad 160$

Mapa 2: Os Grupos de Projetos do Eixo Peru-Brasil-Bolívia da IIRSA .................. 168

Mapa 3: Projetos de Infraestrutura na Região MAP .............................................. 173

Mapa 4: Bacia Hidrográfica do Rio Napo ......................................................... 218

Mapa 5: Eixo do Amazonas - Grupo de Projetos (IIRSA) .................................... 231

Mapa 6: Projetos de exploração econômica na bacia do rio Napo entre Equador e

Peru 


\section{LISTA DE TABELAS}

Tabela 1: Estrutura do Projeto OTCA/GEF

154

Tabela 2: Análise comparada da governança das Bacias dos rios Acre e Napo 


\section{LISTA DE SIGLAS}

$\mathrm{ABC}$

ADEMAF

AECA

AECA

AGA

AIA

AIC

AIDESEP

AIRH

ALADI

ALALC

ALT

ANA

ANA-Peru

APA

BID

BNDES

CAF

CAMAREN

CAN

$\mathrm{CBH}$

CCA

CCA

CCA

CCS

CDB

CDI

CDIF

CDS

CEAIA

CEAIA

CEBAF

CECTA

CEEDA

CEMAA

CEPE

CESAM

CESO

CETICAM

CETURA

$\mathrm{CH}$

CHS

CI

CIAMA
Agência Brasileira de Cooperação

Agência para o Desenvolvimento das Macro-regiões e Zonas

Fronteiriças

Agenda Estratégica de Cooperação Amazônica

Agenda Estratégica de Cooperação Amazônica

Agências de Agua

Agenda Indígena Amazônica

Agenda de Implementação Consensual

Associação Interétnica de Desenvolvimento da Selva Peruana

Associação Internacional de Recursos Hídricos

Associação Latino-Americana de Integração

Associação Latino-Americana de Livre Comércio

Autoridade Binacional Autônoma do Lago Titicaca

Agência Nacional de Água

Autoridad Nacional del Agua

Associação dos Povos Ameríndios da Guiana

Banco Interamericano de Desenvolvimento

Banco Nacional de Desenvolvimento Econômico e Social

Corporação Andina de Fomento

Consórcio de Capacitação para o Manejo dos Recursos Naturais

Renováveis

Comunidade Andina de Nações

Comitê de Bacia Hidrográfica

Conselho Consultivo de Aguas

Conselho de Cooperação Amazônica

Conselho de Cooperação Amazônica

Coca Codo Sinclair

Convenção sobre Diversidade Biológica

Comissão de Direito Internacional

Comissão Permanente para o Desenvolvimento e Integração da

Faixa de Fronteira

Comissão sobre Desenvolvimento Sustentável

Comissão Especial de Assuntos Indígenas da Amazônia

Comissão Especial de Assuntos Indígenas

Centro Binacional de Atenção de Fronteira

Comissão Especial de Ciência e Tecnologia

Comissão Especial de Educação

Comissão Especial de Meio Ambiente

Corporación Estatal Petrolera del Ecuador

Comissão Especial de Saúde

Canadian Executive Services Organization

Comissão Especial de Transporte, Infraestrutura e Comunicações

Comissão Especial de Turismo

Complexo Hidropolítico

Complexo Hidropolítico de Segurança

Conservation International

Conferência Internacional sobre Água e Meio Ambiente 
CIDESC

\section{CIDOB \\ CMA \\ CMB \\ CMMAD \\ CNP \\ CNRH \\ CNS \\ CNUMAD}

CNUMC

COIAB

COICA

CONAM

CONAMA

CONDIAC

CONFENAE

CONIVE

COSIPLAN

CTGRHT

\section{CTR \\ CTs \\ DDF \\ DEAS \\ DGCH \\ DNAE \\ DQA \\ ECORAE \\ EMAAP-Q \\ ENARSA \\ FDA \\ FEMCIDI}

FIF

FIRII

FMA

FOAG

FOBOMADE

FONPLATA

FUNAI

GATT

GEF

GIRH

GRDE

GRL

GRRNGMA
Convenção Internacional sobre Direitos Econômicos, Sociais e

Culturais

Confederação dos Povos Indígenas da Bolívia

Conselho Mundial da Água

Convenção Mundial de Barragens

Comissão Mundial para o Meio Ambiente e Desenvolvimento

Comissões Nacionais Permanentes

Conselho Nacional de Recursos Hídricos

Conselho Nacional dos Seringueiros

Conferência das Nações Unidas para o Meio Ambiente e

Desenvolvimento

Convenção das Nações Unidas sobre as Mudanças Climáticas

Coordenação das Organizações Indígenas da Amazônia Brasileira

Coordenação das Organizações Indígenas da Bacia Amazônica

Consejo Nacional del Medio Ambiente (Peru)

Conselho Nacional de Meio Ambiente (Brasil)

Consórcio de Desenvolvimento Intermunicipal do Alto Acre e

Capixaba

Confederação das Nacionalidades da Amazônia Equatoriana

Conselho Nacional Índio da Venezuela

Conselho de Infraestrutura e Planejamento

Câmara Técnica sobre o Gerenciamento de Recursos Hídricos

Transfronteiriços

Organização Territorial por meio da Comissão Técnica Regional

Corporações Transnacionais

Direção de Desenvolvimento e Integração Fronteiriça

Departamento Estadual de Águas e Saneamento

Dirección de Cuencas Hidrográficas

Departamento Nacional de Águas e Energia

Diretiva Quadro sobre Água

Instituto para o Desenvolvimento Regional Amazônico

Empresa Municipal de Agua Potável e Saneamento de Quito

Compañia Energía Argentina S.A.

Frente de Defensa de la Amazonia

Fundo Especial Multilateral do Conselho Interamericano para o

Desenvolvimento Integral

Foro Intergovernamental sobre Florestal

Fundo para o Financiamento de Operação de Cooperação Técnica

para Iniciativas para a Integração da Infraestrutura

Fórum Mundial da Água

Federação das Organizações Autóctones da Guiana Francesa

Foro Boliviano sobre Medio Ambiente y Desarrollo

Fundo Financeiro para o Desenvolvimento da Bacia do Prata

Fundação Nacional do Índio

General Agreement on Tariffs and Trade

Global Environmental Facility

Gestão Integrada dos Recursos Hídricos

Gerência Regional de Desenvolvimento Econômico

Governo Regional de Loreto

Gerência Regional de Recursos Naturais e Gestão do Meio 


\begin{tabular}{|c|c|}
\hline GTA & Grupo de Trabalho Amazônico \\
\hline GWP & Global Water Partnership \\
\hline IBAMA & $\begin{array}{l}\text { Instituto Brasileiro do Meio Ambiente e dos Recursos Naturais } \\
\text { Renováveis }\end{array}$ \\
\hline IBC & Instituto para el Bien Común \\
\hline ICOLD & International Comissiono $\mathrm{n}$ Large Dams \\
\hline IDEAM & $\begin{array}{l}\text { Instituto Nacional de Hidrologia, Meteorologia e Estúdios } \\
\text { Ambientales }\end{array}$ \\
\hline IIAP & Instituto de Investigação sobre a Amazônia Peruana \\
\hline IIRSA & Iniciativa de Integração da Infraestrutura da Sul-Americana \\
\hline INADE & Instituto Nacional de Desenvolvimento \\
\hline INAR & Instituto Nacional de Irrigação \\
\hline INCRA & Instituto Nacional de Colonização e Reforma Agrária \\
\hline INECEL & Instituto Equatoriano de Eletrificação \\
\hline INERHI & Instituto de Recursos Hidráulicos \\
\hline Infraeco & Empresa de Consultoria Infraestrutura e Ecologia \\
\hline INRENA & Instituto Nacional de los Recursos Naturales \\
\hline IPAM & Instituto de Pesquisa Ambiental da Amazônia \\
\hline IRN & International Rivers Network \\
\hline ISA & Instituto Sócio Ambiental \\
\hline IUCN & International Union for the Conservation of Nature \\
\hline IUCN & World Conservation Union \\
\hline IUPN & International Union for the Protection of Nature \\
\hline IWE & Institute for Water Education \\
\hline IWRA & International Water Resources Association \\
\hline IWRA & International Water Resources Association \\
\hline LBA & $\begin{array}{l}\text { Experimento de Larga Escala na Biosfera Atmosfera na Amazônia } \\
\text { - Large Scale Biosphere-Atmosphere Experiment in Amazonia }\end{array}$ \\
\hline MA & Ministerio del Ambiente \\
\hline MAB & Movimento dos Atingidos por Barragens \\
\hline MAP & Madre de Dios, Acre, Pando \\
\hline MARNR & Ministério para o Meio Ambiente e Recursos Naturais Renováveis \\
\hline MERCOSUL & Mercado Comum do Sul \\
\hline MIDUVI & Ministério de Desenvolvimento Urbano e Vivenda \\
\hline MIN & Ministério da Integração Nacional \\
\hline MIRH & Manejo Integral de Recursos Hídricos \\
\hline MMA & Ministério do Meio Ambiente \\
\hline MSP & Ministério de Sáude Pública \\
\hline OEA & Organização dos Estados Americanos \\
\hline OIS & Organização Indígena do Suriname \\
\hline OMC & Organização Mundial do Comércio \\
\hline OMPI & Organização Mundial da Propriedade Intelectual \\
\hline OMSTs & Organizações de Movimentos Sociais Transnacionais \\
\hline ONG & Organização Não Governamental \\
\hline ONGIs & Organizações Não-Governamentais Internacionais \\
\hline ONU & Organização das Nações Unidas \\
\hline OPIAC & Organização dos Povos Indígenas da Amazônia Colombiana \\
\hline OT & Ordenamento Territorial \\
\hline OTCA & Organização do Tratado de Cooperação Amazônica \\
\hline
\end{tabular}




\begin{tabular}{|c|c|}
\hline PAE & Programa de Ação Estratégica \\
\hline PARLAMAZ & Parlamento Amazônico \\
\hline PBDRF & Plano Binacional de Desenvolvimento da Região Fronteiriça \\
\hline PCCP & Potential Conflict to Cooperation Potential \\
\hline PDF Bloco B & Project Development Facility \\
\hline PDFF & Programa de Desenvolvimento da Faixa de Fronteira \\
\hline PDOT & Plan Departamental de Ordenamiento Territorial \\
\hline PEA & População Economicamente Ativa \\
\hline PELT & Projeto Especial do Lago Titicaca \\
\hline PK & Protocolo de Kyoto \\
\hline PMAE & Programa Marco de Ações Estratégicas \\
\hline PNBV & Plano Nacional do Bem Viver \\
\hline PNMA & Política Nacional do Meio Ambiente (Brasil) \\
\hline PNRH & Política Nacional de Recursos Hídricos (Brasil) \\
\hline PNUD & Programa das Nações Unidas para o Desenvolvimento \\
\hline PNUMA & Programa das Nações Unidas para o Meio Ambiente \\
\hline PPA & Plano Plurianual \\
\hline PPG7 & Programa Piloto para a Proteção das Florestas Tropicais do Brasil \\
\hline PRAS & Programa de Reparação Ambiental e Social \\
\hline PRONAR & Programa de Manejo Integral de Cuencas \\
\hline PUNAMUDT & Pueblos Indígenas Unidos en Defensa de sus Territorios \\
\hline SAERB & Serviços de Água e Esgoto de Rio Branco (Acre) \\
\hline SAG & Superintendência de Apoio à Gestão dos Recursos Hídricos \\
\hline SEIN & Sistema Elétrico Interconectado Nacional \\
\hline SEMA & Secretaria Estadual de Meio Ambiente (Acre) \\
\hline SENAGUA & Secretaria Nacional de Água \\
\hline SENAMHI & Servicio Nacional de Metereologia \\
\hline SENAMHI & Servicio Nacional de Meteorologia e Hidrologia \\
\hline SIPAS & Sistema de Indicadores de Passivos Ambientais e Sociais \\
\hline SIRENARE & Sistema de Regulación de los Recursos Naturales Renovables \\
\hline SISNAMA & Sistema Nacional de Meio Ambiente (Brasil) \\
\hline SNAP & Sistema Nacional de Áreas Protegidas \\
\hline SNGRH & Sistema Nacional de Gerenciamento de Recursos Hídricos \\
\hline SP & Secretaria Permanente \\
\hline SPT & Secretaria Pro Tempore \\
\hline SRH & Secretaria de Recursos Hídricos \\
\hline SUBCOMILAGO & Desenvolvimento da Zona de Integração do Lago Titicaca \\
\hline TCA & Tratado de Cooperação Amazônica \\
\hline TI & Terras Indígenas \\
\hline Tis & Territórios Indígenas \\
\hline TNC & The Nature Conservancy \\
\hline UAAOPT & $\begin{array}{l}\text { Unión de los Afetacdos y Afestadas por las Operaciones de la } \\
\text { Petrolera Texaco }\end{array}$ \\
\hline UDAPT & Afetadas pelas Operações da Petroleira Texaco \\
\hline $\mathrm{UE}$ & União Européia \\
\hline UFAC & Universidade Federal do Acre \\
\hline UNAMAZ & Associação de Universidades Amazônica \\
\hline UNASUL & União das Nações Sul-Americanas \\
\hline UNCP & Unidades Nacionais de Coordenação do Projeto \\
\hline UNESCO & Organização das Nações Unidas para a Educação \\
\hline
\end{tabular}


UOB

Unidade Operacional Boliviana

WFD

Water Framework Directive

WHRC

Woods Hole Research Center

WWF

World Wide Fund for Nature

ZEE

Zoneamento Ecológica Econômica

ZIF

Zona de Interação Fronteiriça 


\section{SUMÁRIO}

INTRODUÇÃO

1 GOVERNANÇA E COOPERAÇÃO INTERNACIONAL PARA A REGULAÇÃO DO USO DOS RECURSOS HÍDRICOS TRANSFRONTEIRIÇOS …………………………………………………….....

1.1 A hidropolítica e a geopolítica dos recursos hídricos transfronteiriços ................ 26

1.1.1 Território, fronteira e limite ...................................................................... 29

1.2 Recursos hídricos transfronteiriços: segurança e arranjos cooperativos ............. 33

1.2.1 Segurança hídrica e os conflitos interestatais por recursos hídricos ................. 36

1.2.2 Arranjos cooperativos e institucionais para a regulação do uso dos recursos hídricos compartilhados .................................................................................... 46

1.3 As instituições internacionais e o modelo de governança global da água ........... 54

1.3.1 As instituições derivadas das grandes conferências sobre a água e ambientais 55

1.3.2 O processo de mercantilização da água e a privatização dos serviços .............. 59

1.3.3 Os conflitos em torno das barragens e o papel da Comissão Mundial sobre

Barragens

1.3.4 O direito humano à água: mudança de paradigma?......................................... 64

1.3.5 A convenção da ONU sobre cursos d'água internacionais ............................... 67

1.3.6 O papel da ciência e das redes transnacionais de especialistas......................... 69

1.4 A governança dos recursos hídricos ................................................................ 71

1.4.1 O modelo de gestão integrada dos recursos hídricos por bacia hidrográfica .... 76

1.5 A problemática do conflito e da cooperação na governança dos recursos hídricos transfronteiriços ................................................................................. 80

1.6 Análise multi-escalar da governança dos recursos hídricos transfronteiriços ..... 83

1.6.1 O papel dos atores transnacionais não-estatais .............................................. 89

2 BACIA AMAZÔNICA: FORMAÇÃO TERRITORIAL, INTEGRAÇÃO FRONTEIRIÇA E COOPERAÇÃO INTERNACIONAL ………………………….. 92

2.1 Ocupação e delimitação das fronteiras amazônicas .............................................. 92

2.1.1 A integração fronteiriça da Bacia Amazônica ................................................ 103

2.2 Cooperação entre os países amazônicos: relações multilaterais e bilaterais ....... 111

2.2.1 As relações bilaterais entre os países amazônicos: Bolívia, Brasil, Equador e Peru

2.2.1.1 As relações entre Bolívia e Brasil ............................................................... 113

2.2.1.2 As relações entre Brasil e Peru .................................................................. 118

2.2.1.3 As relações entre Bolívia e Peru .................................................................. 123

2.2.1.4 As relações entre Equador e Peru ............................................................. 126

2.2.2 Relações multilaterais: o Tratado de Cooperação Amazônica ........................... 130

2.2.3 A IIRSA e a UNASUL e seus impactos para a cooperação amazônica .......... 133

2.3 Atores não-estatais transnacionais na Bacia Amazônica .................................... 138

2.3.1 As organizações indígenas na Bacia Amazônica ............................................ 138

2.3.2 A atuação das ONGs na Bacia Amazônica .................................................... 142 
2.3.3 As corporações transnacionais

2.4 Principais problemas e conflitos envolvendo os recursos hídricos transfronteiriços na Amazônia

2.5 Iniciativa internacional de gestão dos recursos hídricos transfronteiriços da Bacia Amazônica: o Projeto OTCA/GEF

3 BACIA DO RIO ACRE: A FORMAÇÃO DA GOVERNANÇA TRANSNACIONAL

3.1 A bacia do rio Acre

3.2 A região MAP e os projetos de infraestrutura e integração regional

3.3 Principais problemas socioambientais relacionados aos recursos hídricos transfronteiriços da Bacia do rio Acre

3.4 Arcabouço institucional da gestão dos recursos hídricos na Bolívia

3.4.1 Instituições e gestão dos recursos hídricos em Pando

3.5 Arcabouço institucional da gestão dos recursos hídricos no Brasil ................... 191

3.5.1 Instituições e gestão dos recursos hídricos no Acre ....................................... 196

3.6 Arcabouço institucional da gestão dos recursos hídricos no Peru ..................... 201

3.6.1 Instituições e gestão dos recursos hídricos em Madre de Dios ........................ 204

3.7 Formação do processo de governança transnacional da Bacia do rio Acre ........ 208

4 BACIA DO RIO NAPO: CONFLITOS SOCIOAMBIENTAIS E A CONSTRUÇÃO DA GOVERNANÇA

4.1 A bacia do rio Napo: quadro físico e social ...................................................... 217

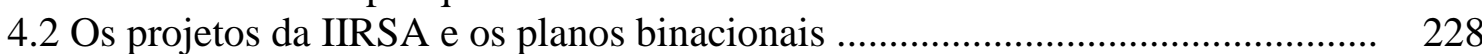

4.3 Os principais conflitos e impactos socioambientais pelo uso dos recursos hídricos

4.4 Arcabouço institucional da gestão dos recursos hídricos no Equador ............... 257

4.5 Arcabouço institucional da gestão dos recursos hídricos em Loreto - Peru ....... 263

4.6 Formação de um processo de governança dos recursos hídricos transfronteiriços da Bacia do rio Napo 


\section{INTRODUÇÃO}

A Amazônia ocupa quase a metade da América do Sul e pode ser identificada como uma região que abarca um mesmo domínio morfoclimático, como uma bacia hidrográfica, ou pela definição política-administrativa dos Estados ${ }^{1}$. A Bacia do rio Amazonas é compartilhada por sete países (Bolívia, Brasil, Colômbia, Equador, Guiana, Peru e Venezuela), enquanto que o domínio morfoclimático amazônico é compartilhado por oito países sul-americanos e um território ultramarino francês (Bolívia, Brasil, Colômbia, Equador, Guiana, Peru, Suriname, Venezuela e Guiana Francesa).

A Bacia Amazônica é objeto de estudo deste trabalho que busca compreender a governança multi-escalar como forma de regulação do uso dos recursos hídricos transfronteiriços em uma bacia compartilhada. O objetivo é analisar as ações dos Estados e demais atores sociais para regularem o uso dos recursos hídricos transfronteiriços amazônicos por meio de uma perspectiva multi-escalar em duas bacias: a Bacia do rio Acre e a Bacia do rio Napo.

A escolha do tema justifica-se, em primeiro lugar, pela lacuna existente nas análises sobre as bacias hidrográficas compartilhadas onde pode ser identificada uma corrente que considera que a cooperação prevalece sobre o conflito no compartilhamento de bacias e outra que considera que a situação de conflito predomina nos casos em que existe escassez dos recursos hídricos, como é o caso do Oriente Médio. Ambas as correntes apresentam problemas a serem aplicadas na Bacia Amazônica, pois apesar da abundância de água ainda ocorrem conflitos, que não estão ligados à escassez, e sim aos diferentes usos dos recursos hídricos e seus efeitos.

A Bacia Amazônica tem sido foco de diversos projetos de infraestrutura, principalmente usinas hidrelétricas, que tem gerado conflitos, e de atividades de exploração econômica que causam contaminação, o que demonstra a necessidade de governança e gestão de seus recursos hídricos. Nesta bacia existem milhares de quilômetros de fronteiras políticas, e diversos cursos d'água, que em alguns casos, são o próprio limite entre os países, e em outros, atravessam esses limites, gerando

\footnotetext{
${ }^{1}$ O Brasil, por exemplo, define pelo critério político-administrativo a sua área amazônica (Lei 1806 de 1953) pela denominação de Amazônia Legal (correspondente aos estados do Acre, Amapá, Amazonas, Mato Grosso, Pará, Rondônia, Roraima, Tocantins e parte do estado do Maranhão). Para informações mais detalhadas sobre as diversas áreas de cada critério utilizado para definir a Amazônia, consultar: EVA e HUBER, 2005; SANT’ANNA, 2009; e PNUMA, OTCA, CIUP, 2009.
} 
interdependência entre as comunidades que vivem nas regiões de fronteira que lidam cotidianamente com o compartilhamento dos recursos hídricos.

A cooperação internacional que prevalece na Bacia Amazônica é para o aproveitamento de infraestruturas como hidrelétricas e hidrovias, o que não garante uma gestão adequada dos recursos. Ademais os acordos internacionais existentes não há mecanismos específicos para a regulação do uso da água por parte de cada Estado, o que pode resultar no surgimento de conflitos no futuro, principalmente, se medidas para evitarem a degradação do recurso não forem tomadas.

Em segundo lugar, a existência do Tratado de Cooperação Amazônica (TCA) não tem demonstrado ser indicativo de cooperação para a governança dos recursos hídricos na Bacia Amazônica, por isso, existe a necessidade de testar a hipótese de que a existência de acordos internacionais sobre uma bacia já são suficientes para demonstrar que a cooperação leva à governança. Embora a governança de uma bacia transfronteiriça deva ser analisada em todas as escalas sobrepostas e nas ações dos atores sociais em cada uma delas, em geral, os trabalhos relacionados a este tema analisam apenas as relações entre os países no âmbito intergovernamental. Essas análises que se concentram apenas nas relações que se dão entre os altos escalões dos governos muitas vezes não levam em conta o que ocorre no território, em especial nas fronteiras e regiões fronteiriças, onde o compartilhamento de recursos hídricos é um fato cotidiano. Desse modo, essas análises acabam levando em consideração apenas documentos assinados pelos países como indicativo de cooperação e governança, sem analisar o que ocorre no local, o que pode em alguns casos contradizer a evidência de cooperação e governança. A cooperação entre os países que compartilham uma bacia pode não levar à melhoria das condições ambientais, pelo contrário, pode levar a construção de infraestruturas que causem grandes impactos ambientais.

São poucos os trabalhos que se dedicaram a analisar as relações interescalares, ou melhor, as articulações entre as diferentes formas de cooperação e governança dos recursos hídricos transfronteiriços nas diversas escalas. Portanto, há uma lacuna nos estudos sobre o compartilhamento de bacias transfronteiriças sob uma perspectiva multi-escalar.

Ao analisar a cooperação entre os Estados e entre os demais atores sociais envolvidos na regulação do uso dos recursos hídricos transfronteiriços nas diferentes escalas geográficas que se sobrepõem em uma bacia compartilhada, buscou-se verificar a hipótese de que a cooperação leva à governança de uma bacia compartilhada. Apesar 
da existência de cooperação nas bacias analisadas a governança ainda é incipiente, demonstrando que a cooperação não é o único fator que garante a emergência de um processo de governança da água.

A governança envolve diversos atores sociais na escala local, nacional e internacional que deveriam coordenar suas ações no intuito de regular o uso da água. $\mathrm{Na}$ escala local, encontram-se as regiões de fronteira onde foram estudas a governança da bacia do rio Acre e da bacia do rio Napo. Na escala nacional, buscou-se compreender o arcabouço institucional para a gestão dos recursos hídricos na Bolívia, no Brasil, no Equador e no Peru, pois são os países que compartilham as duas bacias estudadas e os Estados são os responsáveis pela regulação dos usos e da gestão dos recursos hídricos em seu território. Na escala internacional, foram analisadas as instituições regionais que abarcam os países amazônicos e que desenvolvem projetos que influenciam a governança dos recursos hídricos transfronteiriços da Bacia Amazônica, em especial das bacias do Acre e Napo.

Os atores sociais envolvidos na governança dos recursos hídricos variam dependendo da escala analisada, assim como as políticas e as formas de ver e lidar com o tema dos recursos hídricos transfronteiriços. Todavia, nem sempre existe articulação entre os atores nas diferentes escalas, o que dificulta a coordenação para a governança da água.

Este trabalho utilizou elementos da pesquisa qualitativa e dados primários e secundários. Foi baseado em pesquisa bibliográfica à luz de um diálogo interdisciplinar entre a geografia política, as relações internacionais e a ecologia política. Também se baseou na análise documental do conteúdo de documentos governamentais e também de instituições internacionais. Foram realizadas dois trabalhos de campo nas bacias do rio Acre e do rio Napo, além de entrevistas em Brasília (Brasil), Lima (Peru), Quito (Equador), La Paz, Santa Cruz de la Sierra e Cochabamba (Bolívia). Nos trabalhos de campo também foram realizadas entrevistas dirigidas semi-estruturadas e o levantamento de dados e bibliografia com a visita a universidades e centros de pesquisa nos quatro países estudados. No trabalho de campo na Bacia do rio Acre, foram visitadas as principais localidades nos três países (Bolívia, Brasil e Peru), e foi realizado o levantamento de bibliografia e dados, assim como as entrevistas. $\mathrm{O}$ mesmo ocorreu no trabalho de campo na Bacia do rio Napo, que incluiu entrevistas também em Iquitos (Peru). 
O trabalho está dividido em quatro capítulos. No primeiro capítulo é apresentada uma revisão bibliográfica de autores da geografia política, das relações internacionais e da ecologia política para estabelecer um marco contextual e um quadro de referência analítica, onde são discutidos os conceitos de hidropolítica, território e fronteiras. A partir deste quadro teórico é apresentada a definição de governança da água e a construção de um modelo internacional para a governança e gestão dos recursos hídricos, bem como as principais instituições internacionais que contribuíram para a construção deste modelo. Em seguida, examina-se as implicações do uso da bacia hidrográfica como unidade de planejamento e gestão e o modelo de gestão integrada dos recursos hídricos, além da problemática da cooperação e do conflito nas bacias hidrográficas compartilhadas. Finalmente, a governança multi-escalar é analisada desde o conceito de escala até a compreensão dos atores que participam da governança nas diferentes escalas e o papel dos atores transnacionais.

O segundo capítulo trata da ocupação e formação das fronteiras amazônica, o que permite contextualizar as iniciativas de cooperação internacional multilaterais e bilaterais entre os países amazônicos, mais especificamente entre Bolívia, Brasil, Equador e Peru e a integração fronteiriça. Examina-se as ações dos atores não-estatais transnacionais, como as organizações indígenas, as ONGs e as corporações transnacionais. Em seguida, discute-se o projeto conjunto OTCA/GEF de gestão compartilhada da Bacia Amazônica e são apresentados os principais problemas relativos aos recursos hídricos transfronteiriços na Bacia Amazônica que podem gerar tensões e conflitos.

No terceiro capítulo é analisado o processo de formação da governança dos recursos hídricos transfronteiriços da Bacia do rio Acre. É apresentada a região MAP, onde está localizada a bacia, na tríplice fronteira entre Bolívia, Brasil e Peru, discutindo suas principais caraterísticas e os projetos de infraestrutura presentes na região. A partir desta contextualização são analisados os principais problemas relacionados aos recursos hídricos transfronteiriços da bacia. Discute-se o arcabouço institucional nacional e subnacional de gestão da água nos três países que compartilham a bacia. Por último é estudada a formação de uma governança transnacional na bacia que abarca instituições e atores do governo e da sociedade civil dos três países.

No quarto e último capítulo são analisados os conflitos socioambientais e o processo de construção da governança dos recursos hídricos transfronteiriços na Bacia do rio Napo, compartilhada entre Equador e Peru. São apresentados e discutidos os 
principais conflitos socioambientais relacionados aos usos, e seus efeitos, dos recursos hídricos, bem como os projetos de infraestrutura existentes na bacia. Também analisa o arcabouço institucional nacional e subnacional de gestão dos recursos hídricos nos dois países e a construção da governança dos recursos hídricos nesta bacia que apresenta pouca articulação transnacional da sociedade civil.

A comparação entre as duas bacias amazônicas estudas permitiu concluir que falta articulação e coordenação entre os atores envolvidos na governança dos recursos hídricos transfronteiriços na Bacia Amazônica nas escalas internacional, nacional e local, para que se possa configurar um processo de governança efetivo para a regulação do uso dos recursos hídricos transfronteiriços amazônicos. A existência da cooperação entre os países que compartilham a Bacia Amazônica não garantiu a construção de um processo de governança, pois através da comparação entre as duas bacias analisadas foi possível concluir que ainda não existe uma governança consolidada. 


\section{GOVERNANÇA E COOPERAÇÃO INTERNACIONAL PARA A REGULAÇÃO DO USO DOS RECURSOS HÍDRICOS TRANSFRONTEIRIÇOS}

Este capítulo trata da hidropolítica das águas transfronteiriças em sua dimensão multi-escalar. Primeiramente, são discutidos os conceitos de hidropolítica, território e fronteiras. Em seguida, apresenta-se uma revisão da literatura sobre a problemática em torno da cooperação e do conflito por recursos hídricos transfronteiriços, analisa-se o conceito de governança e sua aplicação na temática dos recursos hídricos, definindo o que seria a governança da água. Analisa-se também a construção de um "modelo" internacional de governança e gestão dos recursos hídricos transfronteiriços, bem como as principais instituições internacionais que contribuíram para a construção deste modelo. A seguir, tendo como pano de fundo essa discussão, examina-se as implicações do uso da bacia hidrográfica como unidade de planejamento e gestão e o modelo de gestão integrada dos recursos hídricos. A problemática da cooperação e do conflito em bacias hidrográficas transfronteiriças é discutida dentro do contexto geopolítico internacional. E, finalmente, a governança multi-escalar é analisada desde o conceito de escala até a compreensão dos atores que participam da governança nas diferentes escalas e o papel dos atores transnacionais.

\subsection{A hidropolítica e a geopolítica dos recursos hídricos transfronteiriços}

Já se sabe que atualmente existem 263 bacias hidrográficas, além de um número ainda não calculado de aquíferos, que ultrapassam as fronteiras políticas dos Estados, e que se configuram como bacias transfronteiriças (DELLI PRISCOLI e WOLF, 2009). Estas 263 bacias hidrográficas compartilhadas correspondem a 45,3\% da área total de terra da superfície de nosso planeta, onde vivem cerca de $40 \%$ da população mundial e correspondem a aproximadamente $60 \%$ do fluxo de água doce superficial global, de acordo com dados apresentados por Delli Priscoli e Wolf (2009). Para estes autores:

water is one of the few scarce resources for which there is no substitute, over which there is poorly developed international law, and the need for which is overwhelming, constant, and immediate (Bingham, Wolf and Wohlgenant, 1994). [...] These resource conflicts will gain in frequency and intensity as water resources become relatively scarcer and their use within jurisdictions can no longer be insulated from having an impact on neighboring jurisdictions" (DELLI PRISCOLI e WOLF, 2009, p. ). 
Embora a água seja de interesse de toda comunidade humana, o caráter político do seu acesso e uso nem sempre é explicitado. Cabe destacar que ela é vista também como um recurso, por isso, a utilização do termo recursos hídricos referindo-se às várias propriedades e usos da água. Como explica Raffestin:

\begin{abstract}
o homem não se interessa pela matéria como massa inerte indiferenciada, mas na medida em que ela possui propriedades que correspondem a utilidades. Nessas condições, não é a matéria que é um recurso. Esta, para ser qualificada como tal, só pode ser o resultado de um processo de produção: é preciso um ator (A), uma prática ou, se preferirmos, uma técnica mediatizada pelo trabalho (r), e uma matéria $(\mathrm{M})$. A matéria só se torna recurso ao sair de um processo de produção complexo, que se pode formular de maneira rudimentar:ArM $\rightarrow$ P (conjunto de propriedades ou recurso). [...] A relação com a matéria é política, no sentido de que r é um produto coletivo. A relação interessa ao acesso de um grupo à matéria. Esse acesso modifica tudo de uma só vez, tanto o meio quanto o próprio grupo. Toda relação com a matéria é uma relação de poder que se inscreve no campo político por intermédio do modo de produção. [...] Um recurso é uma relação. [...] é uma concepção histórica da relação com a matéria que cria a natureza sócio-política e sócioeconômica dos recursos (RAFFESTIN, 1990, p. 225)
\end{abstract}

Portanto, os recursos hídricos são fruto de uma relação histórica com os seres humanos que atribuíram valor de acordo com os diversos usos da água (espiritual, lazer, agrícola, industrial, abastecimento doméstico, urbano, hidroeletricidade, entre outros). No entanto, cabe lembrar que a água não é produzida no sentido de gerar um novo produto, porém, é utilizado trabalho humano para sua captação, tratamento, transporte, etc. De acordo com Ribeiro: "trata-se de uma substância que ocorre na natureza. Ela não é processada e sintetizada em um laboratório. Tampouco é alterada de maneira expressiva, embora possa receber elementos químicos que modifiquem algumas de suas características" (2008, p. 24). E como aponta Raffestin, o uso de novas técnicas pode levar a manifestação de novas propriedades de um recurso, que altera a relação com a matéria e o território onde ela esta inserida, assim:

a tecnicidade pode se definir como o conjunto de relações que o homem, enquanto membro de um grupo, mantém com as matérias às quais pode ter acesso. A tecnicidade, em relação à matéria, é o apêndice da territorialidade, e até mesmo um subconjunto da territorialidade. Da mesma forma que a territorialidade, a tecnicidade de uma sociedade pode ser simétrica ou dissimétrica. Uma tecnicidade simétrica se caracteriza por relações não destrutivas do meio material, enquanto uma tecnicidade dissimétrica será caracterizada por relações destrutivas do meio material (RAFFESTIN, 1990, p. 227).

Além do que:

a tecnicidade nos introduz diretamente na esfera do poder, e tanto mais quanto ela exprime relações de poder não somente com a matéria, mas também com os homens para os quais essa matéria é um trunfo. A produção dos recursos supõe, pois, uma dominação mínima de uma porção do quadro 
espaço-temporal dentro do qual, e para o qual, a tecnicidade interage com a territorialidade. [...] É todo o problema do acesso que assim se coloca: acesso no espaço e/ou acesso na duração (RAFFESTIN, 1990, p. 227-228).

A primeira questão política que se coloca em relação à água é o acesso, depois sua distribuição natural - que é desigual - e sua utilização por meio de diversas técnicas. Como afirmam Warner e Wegerich (2010), nem sempre se define o que é a "política da água" ("water politics") na vasta literatura sobre os recursos hídricos. Ela também tem sido chamada de "hidropolítica". Este termo foi utilizado pela primeira vez na obra de Waterbury (1979) e usado no caso das relações entre os Estados que compartilham uma bacia hidrográfica transfronteiriça. Para Turton:

hydropolitics as a discipline is relativelly new and generally lacks conceptual
rigor. It is also being developed by scholars from a variety of disciplines,
each of their own set of core concepts and perceptions of reality, resulting in
the fact that many hydropolitical concepts are used interchangeable with high
degree of ambiguity (2003, p. 7).

Apesar de seu uso aplicado às relações internacionais, como propõe Delli Priscoli e Wolf (2009), para quem ela se relaciona com a habilidade de instituições geopolíticas de gerir os recursos hídricos compartilhados evitando tensões e conflitos entre as entidades políticas, outros autores se referem a um conceito mais amplo da política da água. Mollinga (2001) aponta que a política da água deve ser abordada como um conceito mais amplo de política, que englobe não apenas a ação oficial do Estado e das relações entre Estados, mas também as políticas públicas de recursos hídricos e a noção da política cotidiana do uso destes recursos.

$\mathrm{O}$ fato de a água ser entendida como uma questão política demonstra que existem diversos interesses em relação à água que produzem discursos de acordo com estratégias políticas. Tais discursos podem conter uma estratégia emancipatória que busca romper com o "status quo", do mesmo modo, como existe um discurso de que a água não é um problema político, que pode servir a uma estratégia que busca esconder os problemas e conflitos de interesses em relação à água (WARNER e WEGERICH, 2010).

Além disso, Ribeiro (2008) vai apontar a existência de uma geografia política da água marcada pela distribuição desigual dos recursos hídricos. Ele aponta ainda que a ausência da regulação de seu uso na escala internacional permite sua comercialização 
em larga escala ${ }^{2}$, o que desencadeia tensões e conflitos entre os Estados, na disputa pelo seu acesso e uso.

\title{
1.1.1 Território, fronteira e limite
}

A questão do acesso e uso da água está diretamente relacionada ao território, pois os recursos hídricos estão distribuídos desigualmente em diferentes territórios que pertencem a Estados. Entende-se como território uma área apropriada por um grupo social, onde há o exercício de um poder. Além disso:

\begin{abstract}
o território é, concomitantemente, uma construção militar (um resultado da conquista espacial, que tem de ser reiterada sempre que contestada) e uma construção política (como área de exercício de um poder soberano), mas também uma construção econômica (como suporte de estruturas e atividades produtivas como um mercado) e uma construção jurídica (que tem que ser legitimada em fóruns adequados de relacionamento internacional), e ainda uma construção ideológica (que fundamenta uma identidade social de base espacial e uma psicologia coletiva) (MORAES, 2005, p. 59).
\end{abstract}

Muitos autores da geografia política se dedicaram a discussão sobre o conceito de território. Ratzel, considerado um dos fundadores da geografia política, afirmou que todo grupo social precisa se apropriar de uma área e delimitá-la, deste modo, "o território, sendo um fator constante em meio à variação dos acontecimentos humanos, representa em si e por si um elemento universal" (RATZEL, apud MORAES, 1990, p.80).

As ações da sociedade sobre o território implicam o exercício de um poder, o que configura uma territorialidade, entendida como, "an attempt by an individual or group to affect, influcence, or control people, phenomena, and relationships, by delimiting and asserting control over a geographic area" (SACK, 1986, p. 6). Para Sack, a construção de um território requer a territorialidade, que o utiliza como uma estratégia para influenciar e controlar pessoas e coisas, ou seja, "a poweful geographic strategy to control people and things by controlling area" (SACK, 1986, p. 5). Desta forma, são atributos fundamentais da territorialidade o controle do acesso ao território e as fronteiras.

Raffestin afirmou que enquanto o espaço era a "prisão original" dos homens, o território "é a prisão que os homens constroem para si" (1990, p. 144). A partir da visão

\footnotetext{
${ }^{2}$ A água pode ser comercializada in natura, mas também por meio da venda de produtos que a utilizam para seu desenvolvimento, como ocorre na agricultura, por exemplo, gerando o conceito de água virtual (RIBEIRO, 2008; ALLAN, 2011).
} 
do poder como "o controle e a dominação sobre os homens e as coisas", o território "é a cena do poder e o lugar de todas as relações, mas sem a população, ele se resume a apenas uma potencialidade" (RAFFESTIN, 1990, p. 58). Portanto, quando dois Estados disputam a posse de uma área, este conflito não é "apenas um conflito pela aquisição de um pedaço de território, mas também pelo que ele contém de população e/ou recursos" (RAFFESTIN, 1990, p. 58).

Para Haesbaert, o território numa perspectiva integradora "pode ser concebido a partir da imbricação de múltiplas relações de poder, do poder mais material das relações econômico-políticas ao poder mais simbólico das relações de ordem mais estritamente cultural" (2004, p. 79). Haesbaert também aponta que para uma perspectiva relacional do espaço, o território "é visto completamente inserido dentro de relações socialhistóricas, ou, de modo mais estrito, para muitos autores, de relações de poder" (2004, p. 80).

Resultado da apropriação e controle de uma extensão espacial por um grupo social, o território é transformado pela ação dos agentes sociais, o que também implica o reconhecimento social de seu uso, isto é, a legitimidade da apropriação (SANCHEZ, 1992). No caso do Estado moderno:

\begin{abstract}
a forma moderna - estatal nacional - de organização política das sociedades implica uma definição clara e explícita dos âmbitos espaciais de exercício desse poder, ou seja, na conformação objetiva dos territórios. Por isso, a par da base militar, indispensável até hoje, a formação dos Estados nacionais necessita transitar bastante pelas instâncias de legitimação e convencimento. A afirmação moderna dos Estados passa cada vez mais pela afirmação de identidades nacionais que, por sua vez, necessitam de bases espaciais estabelecidas (MORAES, 2005, p. 77).
\end{abstract}

E no caso dos países com um passado colonial a conquista territorial acaba fazendo parte da história e compondo a própria questão nacional. A construção desses Estados "se faz a partir das heranças coloniais existentes, seja no que importa aos sistemas de produção, à estrutura político-administrativa, ou mesmo à mentalidade vigente entre os operadores desse processo" (MORAES, 2005, p. 81).

Atualmente os territórios contemporâneos são "espaços de exercício do poder estatal principalmente" (MORAES, 2005, p. 53), pois "a fragmentação dos impérios a partir da Primeira Guerra Mundial implicou a consagração do Estado territorial como forma de organização política básica em todo o mundo" (MORAES, 2005, p. 60).

Um aspecto fundamental dos territórios é a fronteira, que na era moderna são os limites entre os Estados. As fronteiras políticas entre os Estados apresentam um caráter 
histórico essencial. Atualmente, o mundo possui 332 mil quilômetros de fronteiras (FOUCHER, 2009). No entanto, ao longo da história as fronteiras foram se modificando com a criação de novos Estados ou com a sua dissolução até chegarmos a este número atual.

Para o Estado moderno, a fronteira é concebida como uma questão de segurança nacional, já que é garantia da soberania e da integridade territorial do país. A partir dela o Estado tem o controle sobre o seu território, que é regido pelas leis internas, ao mesmo tempo em que controla a entrada e saída de seu território. Como define Martin:

[...] os Estados modernos necessitam de limites precisos onde possam exercer sua soberania, não sendo suficientes as mais ou menos largas faixas de fronteira. Assim, hoje o 'limite' é reconhecido como linha, e não pode portanto ser habitada, ao contrário da 'fronteira' que, ocupando uma faixa, constitui uma zona, muitas vezes bastante povoada onde os habitantes de Estados vizinhos podem desenvolver intenso intercâmbio (1992, p. 47).

López e Benito (1999) reafirmam este caráter histórico da fronteira que em sua origem não tinha a conotação de limite, como foi o caso durante o Império Romano. Para estes autores:

el límite de frontera no ha sido nunca una línea regular, sino más bien una zona estratégica y elástica, hasta que en época moderna prevalezca la idea nacional y se traduzca en este caso por precisar poco a poco esa zona/confin en límites fijos y precisos, apareciendo las fronteras políticas de los Estados nacionales. [...] He aquí que los términos frontera y límite no son intercambiables en su origen, pero poco a poco vienen a serlo, pues de hecho esta diferenciación se puede recoger en los idiomas francés frontière, portugués fronteira o castellano <frontera>, distinto en todos ellos de <límite> [...]. (LÓPEZ e BENITO, 1999, grifo dos autores).

Os limites muitas vezes parecem arbitrários, no entanto, ainda que sejam convencionados, refletem o resultado do jogo de forças em um dado momento histórico, e fazem parte de um projeto sociopolítico (RAFFESTIN, 1990; SÁNCHEZ, 1992). Assim: pela demarcação, elimina-se não um conflito geral, mas um conflito do qual a
fronteira pudesse ser o pretexto. A linearização da fronteira é uma tendência
do Estado moderno, que não foi desmentida desde o século XV, para
culminar, no século XX, nas linhas "rígidas", por vezes impermeáveis porque
contornadas por "muros" (Muro de Berlim, por exemplo). [...] A demarcação
(a delimitação também, mas com riscos de contestação) permite o exerćcio
das funções legal, de controle e fiscal. Com efeito, a linha fronteiriça adquire
diferentes significados segundo as funções das quais foi investida
(RAFFESTIN, 1990, p. 167).

As fronteiras tem um caráter de separação entre unidades políticas, e sua legitimidade, embora esteja embasada em leis internacionais, é assegurada muito mais 
pelas lealdades construídas por seus cidadãos, e pelas formas de vigilância e controle empreendidas pelo Estado. Hoje, a fronteira funciona mais como uma "membrana assimétrica", autorizando a saída dos seus cidadãos, mas protegendo contra a entrada dos estrangeiros (FOUCHER, 2009, p.19). Isto porque a fronteira é simultaneamente uma área de limite e contato e contém um fator separador e um fator integrador (LÓPEZ e BENITO, 1999).

Apesar de a fronteira apresentar um aspecto de restrição (restrição da circulação de pessoas, bens, etc.) a integração regional é marcada pela atenuação das fronteiras, cuja meta é aumentar a circulação de pessoas e mercadorias entre os países integrados. Para Seoane (2009):

\begin{abstract}
los procesos de integración, si bien no tienden a la disolución completa de las fronteras si determinan una relativa disminución del efecto frontera, es un fenómeno consustancial al concepto mismo de integración y requisito imprescindible para incentivar los flujos de comercio, inversiones y factores, que son su objetivo (pp. 36-37).

[...] Todo ese proceso requiere una visión renovada en muchos aspectos centrales y accesorios. Uno de particular transcendencia se refiere al estatuto de la frontera y el tema fronterizo en general. La visión estrechamente nacionalista, que desarrolla una percepción de "frontera separación", no es congruente con la integración, que requiere una visión de "frontera enlace", y que en su desarrollo propende a la desaparición misma de las fronteras en la región integrada (p. 39).
\end{abstract}

A fronteira é, em geral, concebida a partir das estratégias e interesses do Estado central, porém, devido a algumas transformações nas últimas décadas, ela passa a ser, em certa medida, idealizada e transformada, também, pelas comunidades de fronteira, e pelos governos subnacionais. Isto ocorre em áreas de fronteira não militarizada e em que não há presença de muros nas linhas-limites, e sim, uma relação amistosa entre os países fronteiriços, o que permite a participação de outros atores sociais além do governo central nas decisões sobre a fronteira. Trata-se da "possibilidade real de comunidades locais estenderem sua influência e reforçarem sua centralidade além dos limites internacionais e sobre a faixa de fronteira" (MACHADO e STEIMAN, 2002, p. 8). Estas transformações são mais informais e de intercâmbio com as comunidades vizinhas locais, mas também são impulsionadas por políticas nacionais e de integração regional, e pelo próprio funcionamento do sistema econômico que faz com que o limite territorial assuma "não só o papel de regulador, mas de produtor de redes de intercâmbio de todo tipo" (MACHADO, 2005, p. 252).

Os efeitos diretos das fronteiras, tanto positivos quanto negativos, para as populações que nelas habitam, permitem a utilização dos termos "região fronteiriça" e 
"zona fronteiriça". Estas regiões são delimitadas pelas circunstancias dos fluxos que cruzam as fronteiras. No caso dos estudos das regiões fronteiriças da Comunidade Europeia dos anos 1990, estes apontavam que elas se caracterizavam por: sua localização periférica que as deixaram distantes dos centros dinâmicos; possuírem menos infraestruturas de transporte e comunicação; receberem menos recursos e seus serviços sociais e empresariais serem menos desenvolvidos; existir diferenças jurídicas, político-administrativas, culturais e sociais entre os dois lados da fronteira que impedem ações de cooperação transfronteiriça (LÓPEZ e BENITO, 1999).

As regiões fronteiriças apresentam uma dinâmica bem diferente daquela imaginada nos centros de autoridade dos países, que as imaginam como barreiras. $\mathrm{Na}$ perspectiva dos atores das regiões fronteiriças estas são "scenes of intense interactions in which people from both sides work out everyday accomodations based on face-toface relationships" (BAUD, 2000). Em sua maioria, estas regiões estão isoladas dos centros nacionais de seus respectivos Estados e, também, do centro do Estado vizinho. Culturalmente, ocorre um

\footnotetext{
<metamorfismo de contacto> en cuanto a la interpenetración de comportamientos y de culturas en los espacios que podemos llamar con propriedad <regiones fronterizas>, en cuanto se dan en ellos contactos culturales y comportamientos que favorecen las relaciones y la cooperación, tal como la aparición de migraciones residenciales, medios de difusión bilingües, actitudes sociales por encima de los límites internacionales, en donde los ejemplos de Europa y Norteamérica son nuevamente relevantes (LÓPEZ e BENITO, 1999).
}

Embora a fronteira delimite os territórios políticos, o que evidencia o seu caráter político, ela não consegue barrar ou separar alguns aspectos físicos da área em que está situada como, por exemplo, os recursos hídricos que fluem de um território ao outro. Por isso a denominação de recursos hídricos transfronteiriços, ou seja, são recursos que atravessam a fronteira entre os Estados. Após esta discussão de conceitos chave para compreender a problemática da cooperação e do conflito por recursos hídricos transfronteiriços, será discutido a seguir a literatura sobre esta temática.

\subsection{Recursos hídricos transfronteiriços: segurança e arranjos cooperativos}

Várias áreas do conhecimento têm abordado a problemática da cooperação e do conflito em torno do uso dos recursos hídricos transfronteiriços, ou seja, a hidropolítica internacional. Entre elas destacam-se as abordagens das Relações Internacionais, da 
Geografia Política e da Ecologia Política, dedicadas ao tema dos recursos hídricos transfronteiriços que serão abordadas neste trabalho.

As Relações Internacionais são um campo das Ciências Sociais marcado por ampla interdisciplinariedade e influência de orientações meta-teórica e metodológicas de vários campos das Ciências Sociais. No entanto, a história desta disciplina foi amplamente marcada pelos chamados grandes debates, entre realistas e liberais, entre tradicionalistas e behavioristas e entre realistas, liberais e marxistas. Estes debates têm se intensificado nas últimas décadas:

\begin{abstract}
Until recently, these debates were conducted within certain limits (Holsto 1985). Despite their differences, most traditionalists and behavioralists adopted a realist world view (Vasquez 1983; Schimidt 2000). Similarly, the "paradigm wars", particularly between neoliberalism and neorealism, were conducted within and underlying rationalist consensus (Waever 1998; Ruggie 1998). In the lasta decade, however, that consensus came under sharp attack by various forms of postpositivism, including postmodernism, poststructuralism, feminism, and constructivism, This so-called third debate (Lapid 1989) is in many respects more profound than earlier ones, because underlying ontological and epistemological issues are at the core of the debate" (LEVY, 2007, p. 177).
\end{abstract}

Quando analisadas as abordagens das diferentes teorias sobre as questões ambientais nas Relações Internacionais, estes debates se tornam evidentes. No entanto, ao invés de dividir a literatura sobre a questão ambiental e dos recursos naturais nas relações internacionais entre estas diferentes abordagens teóricas, a política ambiental internacional será abordada a partir de duas vertentes, uma que parte da análise do conflito por recursos escassos e outra que parte da cooperação para a gestão destes recursos e do meio ambiente. A partir da análise sobre os conflitos por recursos entre Estados e grupos sociais tem origem as preocupações que levaram à análise da segurança ambiental. Já as análises derivadas das teorias sobre cooperação e da teoria dos jogos, têm se dedicado aos temas dos regimes internacionais, da governança ambiental e das instituições.

Laferriere e Stoett (2006) argumentam que, apesar da agenda da disciplina de Relações Internacionais ter tratado da temática ambiental há pelo menos três décadas, ainda não existe um mapa teórico que realmente guie as pesquisas sobre o tema. Para eles, "the limited conceptual frameworks in popular textbooks involve problems of cooperation and the scarcity-conflict link" (p. 3). Em outra obra (1999), estes autores vão defender as bases teóricas ecológicas de algumas abordagens teóricas das Relações Internacionais. Como a aproximação entre a corrente realista e a abordagem ecológica autoritária, entre a corrente liberal e a perspectiva ecológica utilitarista e entre a corrente 
crítica e a abordagem ecológica radical. E também defendem a perspectiva crítica das relações internacionais e sua contribuição para uma teoria "ecopolítica" internacional:

It is indeed to such revisions to IR theory emphasizing local-global connections from a historicist perspective that we owe an ecological awakening in the field, raising the importance of new social movements (including environmental activism) to the changing global political landscape. [...] critical perspectives offer the most congruent, interesting, and ultimately promising path, and that ecological thinkers, radical and conservative alike, have much to learn from critical perspectives on global politics. What is needed then, is the generation of a literary exploration of critical international ecopolitical perspectives and further critical reflections on them [...]. (LAFERRIERE e STOETT, 2006, pp. 8-9).

A Geografia Política, área do saber dedicado ao estudo da "relação entre a política - expressão e modo de controle dos conflitos sociais - e o território - base material e simbólica da sociedade" (CASTRO, p. 41), tem contribuições importantes para analisar a relação entre a sociedade e o ambiente, especialmente, em relação à política da água. Para Castro (2005, p. 53):

[...] a geografia política analisa como os fenômenos políticos se territorializam e recortam espaços significativos das relações sociais, dos seus interesses, solidariedades, conflitos, controle, dominação e poder. Numa linguagem geográfica, estes espaços podem ser identificados como fronteiras, centro, periferia, guetos, unidades políticas, etc.. Para a análise desses espaços, o recurso ao artifício metodológico da escala tem sido uma perspectiva adequada porque identifica o significado das escalas de ação institucional e os recortes territoriais produzidos por esta ação.

No campo da Geografia Política dedicado ao estudo das águas transfronteiriças nota-se o predomínio de análises de estudos de caso sobre a cooperação e o conflito em torno dos recursos hídricos de uma bacia hidrográfica compartilhada específica. Além destes estudos, uma significativa contribuição tem sido as análises em diferentes escalas que permitem "delimitar que as questões e conflitos de interesses na sociedade produzem disputas e tensões que se materializam em arranjos territoriais adequados aos interesses que conseguem se impor em momentos diferenciados" (CASTRO, 2005, p. 79). A obra de Ribeiro (2008) demonstra como na escala internacional o compartilhamento dos recursos hídricos ainda não foi regulado por um acordo significativo entre os Estados.

A Ecologia Política também é um campo que tem se dedicado aos estudos sobre a política da água. Derivada da Ecologia, que é o "estudo da relação da humanidade com o meio ambiente" (LIPIETZ, 2003, p. 17), mas lembrando que a humanidade e sua relação com o meio é mediatizada por formas de organização social com dispositivos políticos, é que nasce a Ecologia Política. De acordo com Martinez-Alier (2007, p. 110): 
os conflitos ecológicos distributivos - isto é, os conflitos pelos recursos naturais ou serviços ambientais, comercializados ou não - são estudados pela ecologia política, um novo campo nascido a partir dos estudos de caso locais pela geografia e antropologia rural, hoje estendidos aos níveis nacional e internacional.

Assim, a Ecologia Política passou a questionar a modernidade e o funcionamento das sociedades industriais e, inclusive, se interrogar sobre a oposição natureza/sociedade (Lipietz, 2003). Esses questionamentos e as análises sobre os conflitos ecológicos distributivos têm contribuído para o entendimento da relação política entre os recursos hídricos e a sociedade. Entre estes destacam-se as análises sobre justiça ambiental e justiça hídrica, como é o caso dos estudos de Rutgerd Boelens acerca dos direitos coletivos e políticas hídricas na região andina, que tem demonstrado como comunidades andinas tem seus direitos de acesso a água privados pelas novas políticas hídricas de seus países (BOELENS, 2010; BOELENS e URTEAGA, 2006; BOELENS e HOOGENDAM, 2007).

Para esta revisão da literatura sobre a hidropolítica dos recursos hídricos transfronteiriços, foram consultados livros, artigos de revistas científicas e documentos de instituições internacionais. Como resultado desta revisão, no que se refere ao compartilhamento dos recursos hídricos transfronteiriços destacam-se as análises focadas no conflito e segurança internacionais e as análises centradas na cooperação, nos regimes, instituições e governança global, que serão apresentadas a seguir.

\subsubsection{Segurança hídrica e os conflitos interestatais por recursos hídricos}

As análises sobre conflitos internacionais por recursos naturais estão, em sua maioria, centradas na ideia de que o sistema internacional é composto por Estados soberanos e na ausência de uma autoridade acima deles que possa regular as suas ações (anarquia internacional ${ }^{3}$ ). Portanto, quando alguns recursos se tornam escassos, ou quando o acesso a determinado recurso é negado para um Estado, existe a possibilidade de um conflito internacional (LE PRESTRE, 2000). Este seria o caso da água que está distribuída desigualmente pela superfície terrestre resultando em abundância de água em alguns países e escassez em outros. Além do que, o compartilhamento de bacias

\footnotetext{
${ }^{3}$ Para Bull (2002), a sociedade internacional é anárquica já que é composta por estados soberanos que não estão sujeitos a um governo comum. Ver; BULL, H. A sociedade anárquica. Brasília: Unb e IPRI. São Paulo: Imprensa Oficial, 2002.
} 
hidrográficas por dois ou mais países também pode ocasionar conflitos quando o uso em um país tenha impactos negativos no outro.

$\mathrm{Na}$ ausência de um regime internacional dos recursos hídricos transfronteiriços, proliferam-se tensões sobre o uso das águas compartilhadas, colocando em risco a segurança hídrica parte expressiva da população mundial. Neste cenário em que a soberania e as questões de desenvolvimento e segurança nacional são muitas vezes um empecilho à cooperação internacional, atores domésticos e não-estatais tem se destacado ao protagonizar papéis importantes para a gestão e governança da água:

\begin{abstract}
Unresolved political tensions over the use of transboundary waters, however, continued to simmer and new ones continue to emerge along with changing water needs, values and governance structures in riparian states. These tensions constitutes significant obstacles to undertaking the often muchneeded development and utilization of international waters, on which the water security of more than half of the world's population depends. The national sovereignty and security considerations of states have long been noted as critical causes of international water tensions and disputes. In the context of the process of post-Cold War democratization and globalization, non-state domestic actors have come to play a much more prominent role in national decision-making on traditionally foreign policy debates. Furthermore, the definitions of the concepts of sovereignty and security have evolved. These changes entail new threats but also new opportunities for ensuring international water security (JANSKY, NAKAYAMA e PACHOVA, 2008, p. 2).
\end{abstract}

As preocupações com conflitos interestatais por recursos naturais e a ampliação do conceito de segurança no contexto pós-Guerra Fria, levou a formulação do conceito de segurança ambiental. O conceito de segurança foi bastante desenvolvido pela Escola de Copenhague ${ }^{4}$, em especial pelos trabalhos de Buzan (1991), Buzan et al. (1998) e Buzan e Waever ( 2003), que incorporaram novos temas e atores aos estudos sobre este assunto. Os autores definem a securitização como um processo de extrema politização de um tema, que passa a ser visto como uma situação de ameaça, exigindo a utilização de quaisquer meios necessários para ser contido, inclusive aqueles acima das regras ordinárias do jogo político (BUZAN et al., 1998).

O conceito de segurança ambiental passou a ter mais destaque na agenda internacional e acadêmica a partir da década de 1980, principalmente após a publicação do Relatório "Nosso Futuro Comum" (1988), também conhecido como Relatório Brundtland, elaborado pela Comissão Mundial para o Meio Ambiente e

\footnotetext{
${ }^{4}$ A Escola de Copenhague corresponde ao Copenhagen Peace Research Institute (COPRI) criado em 1985 como um instituto de pesquisa estabelecido pelo Parlamento dinamarquês, em 1996 se tornou um instituto de pesquisa do governo dinamarquês e em 2003 se fundiu no Instituto Dinamarquês de Estudos Internacionais (Danish Institute for International Studies - DIIS). Disponível em: $<$ http://www.diis.dk/sw152.asp>.
} 
Desenvolvimento (CMMAD) das Nações Unidas, que aponta que os efeitos de um desenvolvimento insustentável poderiam aprofundar os conflitos internacionais.

O grande desafio imposto pela segurança ambiental para as relações interestatais tradicionais é que o ambiente e muitos dos problemas ambientais não reconhecem fronteiras políticas entre Estados. Portanto, o mesmo tratamento dado às questões de segurança militares tradicionais não se aplicam ao caso da segurança ambiental (DYER, 1996). Para Dyer (1996, p. 25):

any proposal for addressing environmental security must surely take into account the challenges that arise from both changes in the global environment and changes in the international political system following the end of the Cold War. The question is not, then, about changes themselves but rather about what these changes mean for our conception of security.

Existe uma série de definições, até mesmo contraditórias e ambíguas, do conceito de segurança ambiental. O Relatório Brundtland aponta, por exemplo, que não existem soluções militares para a segurança ambiental. Apesar de alguns autores apontarem a segurança ambiental como a disputa entre Estados por recursos naturais. Para o Relatório, a segurança ambiental vai muito além do conceito tradicional de segurança. A segurança ambiental diz respeito às ameaças ao ambiente que causam sua degradação, com efeitos para os seres humanos e não necessariamente às ameaças para os Estados ou para as relações interestatais (DYER, 1996; GRASA 1994). Outros autores apontam que pode haver mudanças globais que afetariam as relações entre os Estados (LE PRESTRE, 2000; RIBEIRO, 2002).

Para Elliot (2004), o significado do termo segurança ambiental, os processos que o descrevem e as políticas prescritas continuam sendo contestadas. Existem duas abordagens principais da segurança ambiental. A primeira se caracteriza pela securitização da temática ambiental, onde a crise ecológica é vista como uma ameaça para a segurança nacional e internacional. Assim, os problemas ambientais são vistos dentro da ótica tradicional da segurança. A segunda abordagem se refere a proteger o ambiente, deixa-lo em segurança, "by which the integrity of the environment is both security referent and security goal and in which environmental degradation is to be taken at least as seriously as traditional military threats" (ELLIOT, 2004, pp. 201-202). Para esta segunda abordagem a interpretação tradicional de segurança ambiental representa um problema, pois estreita as opções políticas ao focar nos sintomas e não nas causas da insegurança, o que leva a respostas inadequadas aos desafios da degradação ambiental. Reforçando, assim, um conjunto de ideias que são, direta ou 
indiretamente, a causa de muitos problemas ambientais, como é o caso dos conflitos militares que geram grande degradação ambiental no local onde ocorrem.

Esta perspectiva está mais próxima do conceito de segurança humana, pois os problemas ambientais são vistos como ameaças a segurança dos seres humanos (SANCHEZ, 1998), e não ao Estado em si. Para Buzan (1991, p. 19-20):

The security of human collectivities is affected by factors in five major sectors: military, political, economic, societal and environmental. [...] Environmental security concerns the maintenance of the local and the planetary biosphere as the essential support system on which all other human enterprises depend. These five sectors do not operate in isolation from each other. Each defines a focal point within the security problematique, and a way of ordering priorities, but all are woven together in a strong web of linkages.

Lorraine Elliot (2004) vai mais a fundo e propõe a desmilitarização da segurança e novas formas para se pensar o que é que deve ser protegido. A segurança ambiental deve estar baseada em abordagens que não procurem identificar o "inimigo" e que não identifiquem a segurança apenas em termos de Estado, conflito, militares e segurança territorial. O foco deve estar em um significado integrado de segurança, onde a segurança ambiental seja um componente indispensável para a segurança humana.

Dentro deste debate sobre a securitização da temática ambiental, a água tem sido apontada como o recurso natural que mais trará conflitos num futuro próximo (GLEICK, 1993; HOMER-DIXON, 1994, GLEDITSCH et al. 2006, ; YOFFE et al. 2004). Os recursos hídricos passaram por um processo de securitização em diversas partes do mundo, dando origem ao conceito de segurança hídrica, que tem sido utilizado por uma série de atores e em documentos internacionais. De acordo com Pachova e Jansky, a segurança hídrica envolve uma multiplicidade de objetivos, em especial em bacias compartilhadas:

International water security is a complex term that involves the multiple goals of ensuring peace, human security and environmental protection in the process of planning and implementation of water resources development and management of basins shared by two or more states (Second World Water Forum 2000) (PACHOVA e JANSKY, 2008, p. 61).

De acordo com Cook e Bakker (2012), o conceito de segurança hídrica tem recebido uma atenção crescente na última década:

Multiple definitions of this concept exist, promoted by a range of international organizations - notably the Global Water Partnership and the World Economic Forum. Other groups identifying the importance of water security include UNESCO's Institute for Water Education, which has made water security one of its research themes (UNESCO-IHE, 2009) and the Asia-Pacific Water Forum that, in 2007, held its first summit entitled "Water 
Security: leadership and commitment" (Asia-Pacific Water Forum, 2007). Water security has also come to the fore of some domestic water management agendas in the past decade, particularly associated with (bio)terrorism concerns, leading some to characterize it as "a key objective of a range of governmental and nongovernmental agencies across the spectrum of governance levels" (Jansky et al., 2008, p. 289). Moreover, [...] there has been a significant increase in the employment of "water security" within the academic community over the past decade (COOK e BAKKER, 2012, p. 94).

Para Mirumachi (2008), a segurança hídrica se tornou importante tanto para agenda política nacional quanto internacional. Diversos documentos de instituições internacionais tentam definir segurança hídrica. De acordo com o Relatório de Desenvolvimento Humano de 2006 (PNUD, 2006), a segurança hídrica tem como objetivo assegurar que cada pessoa tenha acesso a uma quantidade suficiente de água de qualidade a um preço acessível que possa contribuir para uma vida saudável, digna e produtiva, enquanto mantém a qualidade dos ecossistemas ecológicos para que continuem proporcionando água e que também dependem da água para sua sobrevivência (MIRUMACHI, 2008).

O termo segurança hídrica também reconhece que o acesso à água pode levar a competição e ao conflito, por isso, também está associado à paz. Em especial, a segurança hídrica é mais complexa em bacias hidrográficas compartilhadas, pois o número e a complexidade das ameaças aumentam porque envolvem interesses conflitantes na escala interestatal e doméstica. É por isso que Mirumachi (2008) defende que a estabilidade política dos Estados ribeirinhos é importante para a cooperação e, portanto, para a segurança hídrica internacional.

A ideia de segurança hídrica traz também certas preocupações por parte de alguns autores, como Davidsen (2010), que notaram como os discursos da política da água têm cada vez mais usado a linguagem da segurança, como é o caso da maior parte da literatura sobre a gestão de recursos hídricos transfronteiriços. Davidsen (2010) parte do conceito de segurança formulado por Waever e Buzan (apud DAVIDSEN, 2010) que a definem como um ato de discurso porque, ao utilizar a palavra "segurança", o ator que a emprega, insere-a em uma área específica, em uma situação de ameaça, o que demanda um direito especial para utilizar os meios necessários para combater tal ameaça:

security becomes a matter of survival, which arises when an issue is presented as posing an existential threat to a designated referent object (traditionally, but not necessarily, the state, incorporating government, territory and society). The special nature of security threats justifies the use of extraordinary measures to handle them. The essential quality of existence will vary greatly across different sectors and levels of analysis; therefore, so 
will the nature of existential threats (Buzan et al. 1998, 21-22). The distinguishing feature of securitization is a specific rhetorical structure including such issues as survival, priority of action and urgency, because if the problem is not handle now it will be too late, and we will not exist to remedy our failure"” (DAVIDSEN, 2010, p. 75).

A securitização da questão hídrica traz preocupações, pois, os Estados, ao definirem ameaças, podem utilizar quaisquer meios necessários para combatê-las e isto pode significar o uso da força. Neste sentido, Ribeiro formula a questão de "até que ponto eles podem vir a empregar o uso da força para conseguir água?” (RIBEIRO, 2008, p. 129) argumentando que o limite para o uso da força é a não degradação do recurso que buscam obter ou defender. De acordo com este autor:

\begin{abstract}
uma das grandes dificuldades em usar a força para ter acesso aos recursos hídricos de outro país é justamente a capacidade de destruição do ecossistema que uma guerra possui. Se ela ocorrer em uma região rica em água, pode contaminar cursos d'água, o lençol freático ou até mesmo reservas subterrâneas (RIBEIRO, 2008, p. 129).
\end{abstract}

Muitos autores se dedicaram a investigar estes conflitos envolvendo os recursos hídricos, entre eles Peter Gleick (1993) demonstra que existem vários exemplos ao longo da História de disputas, competições e conflitos por água. Para este autor, existem diversas razões para se acreditar que novos conflitos surgirão no futuro, pois mais pessoas estarão competindo por um recurso limitado e insubstituível, com uma demanda cada vez mais crescente impulsionada pelo modo de vida cada vez mais consumidor de água, além das mudanças climáticas que poderão causar mudanças no fornecimento e qualidade da água, ainda num cenário de grande incerteza (GLEICK, 1993).

Gleick aponta também para a existência da desigualdade entre ricos e pobres no acesso à água, e como isto pode ser observado também nas relações entre os Estados, como causa de disputas e conflitos. Outro fator que pode levar a conflitos são as obras de infraestrutura para o aproveitamento dos recursos hídricos como canais de irrigação, usinas hidrelétricas, reservatórios para controle de cheias, entre outros. Estas obras:

\footnotetext{
displace large local populations, affect downstream water users, change control over local resources, and cause economic dislocations. These impacts may, in turn, lead to disputes among ethnic or economic groups, between urban and rural populations, and across borders (GLEICK, 1993, 110).
}

A relação entre degradação ambiental e conflitos (tanto civis como internacionais) foi estudada por vários autores. Mas até que ponto "a destruição ambiental pode se tornar uma fonte importante de conflitos que, por sua vez, ameaçariam a estabilidade dos Estados?" (LE PRESTRE, 2000, p. 427). Entre estes 
autores, Homer-Dixon (1994) se destaca com a criação de um modelo conceitual para apresentar a relação causal entre degradação ambiental e conflito violento. Como resultado, ele percebeu que o grande problema girava em torno da "redução do acesso aos recursos ambientais necessários à satisfação das necessidades fundamentais, particularmente alimentarias" (LE PRESTRE, 2000, p. 428).

Para Homer-Dixon (1994), a escassez de recursos é resultado de três fatores: mudanças ambientais (causadas pela degradação do recurso e do meio), crescimento populacional e distribuição desigual dos recursos. Quando um recurso natural apresenta uma diminuição em sua qualidade e quantidade, devido às mudanças do meio, aliada ao crescimento populacional e as elites o utilizam de acordo com seus interesses, ocorre uma distribuição desigual do recurso gerando o que Homer-Dixon (1994) chamou de interação de "açambarcamento do recurso". O crescimento populacional combinado com o acesso desigual aos recursos pode levar a migrações para áreas ecologicamente vulneráveis. A falta de conhecimento e capital para proteger estes recursos nestas áreas tem causado prejuízos ambientais severos e pobreza crônica. Este processo é chamado de "marginalização ecológica".

Em relação à primeira hipótese de que haverá conflitos interestatais por recursos escassos, Homer-Dixon afirma que é mais provável que sejam conflitos por recursos não-renováveis como petróleo e minérios, e que entre os recursos renováveis apenas a água poderia ser motivo de conflitos interestatais:

\footnotetext{
[...] the renewable resource most likely to stimulate interstate resource war is river water. Water is a critical resource for personal and national survival; furthermore, since river water flows from one area to another, one country's access can be affected by another's actions. Conflict is most probable when a downstream riparian is highly dependent on river water and is strong in comparison to upstream riparians. Downstream riparians often fear that their upstream neighbors will use water as a means of coercion. This situation is particularly dangerous if the downstream country also believes it has the military power to rectify the situation (HOMER-DIXON, 1994, p. 19).
}

No entanto, o acesso ao recurso natural não é a causa maior do conflito, ele é apresentado como um agravante que pode estimular o conflito entre Estados. Além do que, a água parece ser mais propensa a estimular conflitos internos do que internacionais (HOMER-DIXON, 1994). Para Le Prestre (2000), os estudos de HomerDixon mostram o quanto as variáveis sociopolíticas são importantes para entender os conflitos que "aparentemente" são por recursos. Isto demonstra que a escassez de um recurso, como a água, não levará diretamente ao conflito, pois depende também de variáveis sociopolíticas, para ele: 
apesar da retórica de alguns altos dirigentes, os conflitos sobre a água raramente degeneram em conflitos violentos. Os casos examinados aqui não são talvez emblemáticos do futuro ou de outras dinâmicas em outras partes do globo. Nem por isso deixam de representar casos-limite. É verdade que a rivalidade Leste-Oeste sufocou, no passado, essas disputas e que as pressões sobre estes recursos se agravarão por motivo do crescimento demográfico e do desenvolvimento econômico. Mas os conflitos internacionais tem sempre causas múltiplas, sendo, pois, ilusório querer isolar um fator ambiental particular. É mais proveitoso refletir sobre o papel que podem ter tais disputas no agravamento dos conflitos. Por exemplo, podem acrescentar uma questão de tensões suplementares no seio de relações já conflituosas e, por conseguinte, desencadear crises e conflitos violentos ou complicar sua solução (LE PRESTRE, 2000, p. 461).

$\mathrm{Na}$ literatura sobre os conflitos por água, os autores em geral, relacionam a possibilidade de conflito com a situação de escassez. Conforme Delli Priscoli e Wolf (2009), conflito pode ser definido como uma situação social em que um mínimo de dois atores disputam ao mesmo tempo um conjunto acessível de recursos escassos. Para Mirumachi e Allan (2010) quando os recursos hídricos não são percebidos como escassos as relações entre os países é não-conflituosa. Quando a escassez hídrica compartilhada passa a ser um tema da agenda política dos Estados, significa que as relações internacionais sobre os recursos hídricos compartilhados se tornou politizada. E se a escassez hídrica é percebida como uma ameaça existencial, a securitização do tema revela que é parte da segurança nacional e medidas além das convencionais podem ser tomadas para garantir o acesso e à água necessária. Além da securitização, o Estado ribeirinho mais forte, ou hegemônico, pode utilizar da violência para garantir este recurso. A partir do momento em que os recursos hídricos transfronteiriços se tornam politizados sua negociação passa a ser liderada pelo Ministério de Relações Exteriores:

at the point where transboundary relations move from the non-politicized to the politicized, responsibility for international water relations move out of the departments of state responsible for managing water resources - namely the water, agriculture, planning and finance ministries responsible to investing in them - and from the ministries responsible for protecting them to the Ministry of Foreign Affairs. [...] A consequence of moving relations and negotiations over water resources into the remit of Ministries of Foreign Affairs is that the issues and priorities on the agenda change from the possibilities of hydrological and economic mutuality and compensation to sovereignty. In the absence of international water law the Ministry of Foreign Affairs of upstream states insist on principles of ownership of - that is sovereignty over - the water resource in its territory and over the water that flows out of it. Downstream states insist on continuing access to water resources on which they have become economically dependent. They argue for the principle of prior use. These approaches, based on a very poor understanding of both hydrology and economics, have proved to be a recipe for enduring deadlock and the tendency for the hegemon to accumulate water (MIRUMACHI e ALLAN, 2010, p. 22). 
Peter Gleick apresenta uma cronologia de conflitos por água ${ }^{5}$ no mundo que tem início com eventos de 3.000 anos antes de Cristo até o ano de 2012. Os conflitos estão classificados por região, período e tipo, que podem ser por: razões religiosas, disputa sobre obras de desenvolvimento (infraestrutura), objetivo militar, alvo militar, ferramenta militar, ferramenta política, e terrorismo. Além disso, os recursos hídricos podem estar relacionados a conflitos de diversas formas:

\begin{abstract}
there is a long history of water-related disputes, from conflicts over access to adequate water supplies to international attacks on water systems during wars. Water and water-supply systems have been the roots and instruments of war. Access to shared water supplies has been cut off for political and military reasons. Sources of water supply have been among the goals of military expansionism. And inequities in water use have been the source of regional and international frictions and tensions. These conflicts will continue - and in some places grow more intense - as growing populations demand more water for agricultural, industrial, and economic development. While various regional and international legal mechanisms exist for reducing water related tensions, these mechanisms have never received the international support or attention necessary to resolve many conflicts over water (GLEICK, 1993, p. 83).
\end{abstract}

Gleditsch e Brochmann (2012) apontam que as bacias hidrográficas transfronteiriças as relações entre os Estados ribeirinhos sempre serão assimétricas devido à situação de montante/jusante. O Estado a montante da bacia sempre terá acesso às suas águas, enquanto que qualquer ação tomada por este Estado terá impactos no Estado a jusante. Isto significa um impacto negativo para o Estado a jusante sem custo nenhum para o Estado a montante. No entanto, nem sempre as assimetrias nas relações pelos recursos hídricos transfronteiriços favorecem o Estado a montante, no caso da navegação de um rio internacional, o Estado a jusante pode controlar a saída para o mar, ou a entrada na bacia pelo mar, o que pode limitar o comércio internacional do Estado a montante.

Além da análise sobre os conflitos, os estudos de segurança aplicados aos recursos hídricos levaram a formulação do conceito de Complexo Hidropolítico de Segurança (CHS), por Schulz (1995) e também utilizado por Turton (2003) e Allan (2001). Para Schulz (1995, p. 97), quando "a set of states that are geographically part owners and technically users of shared rivers start to consider as a consequence this water body to be a major security issue", está se formando um CHS. Portanto, a existência de um CHS pressupõe uma interdependência entre os Estados ribeirinhos, e que estes Estados percebam os recursos hídricos compartilhados como uma questão de

\footnotetext{
${ }^{5}$ A cronologia de conflitos por água no mundo está disponível no endereço eletrônico do Instituto do Pacífico: http://www.worldwater.org/conflict/list/. Acesso em: 14 março de 2013.
} 
segurança. Este conceito foi derivado do conceito de Complexo Regional de Segurança formulado por Buzan e Waever (2003). Sendo assim, o CHS é sempre um integrante de uma estrutura mais ampla que é o Complexo Regional de Segurança.

O conceito de CHS foi refinado por Allan (2001) e Turton (2003, 2008) que passaram a distinguir o CHS de um Complexo Hidropolítico $(\mathrm{CH})$. Para eles:

\begin{abstract}
A hydro-political complex (of which there are two distinct types) is defined as existing when a nation's dependence starts to drive interstate relations of potential cooperation (amity) or competition (enmity) in a discernible manner (Turton, 2003b, 2008b). If it is in the direction of amity, then a hydropolitical complex emerges, such as that found in the SADC region (Turton, $2003 \mathrm{~b}, 2008 \mathrm{~b}$ ). If it is in the direction of enmity, then a hydro-political security complex emerges, such as that found between Turkey, Syria and Iraq at least until a decade ago (Schulz, 19995) (TURTON, 2008, p. 188).
\end{abstract}

Um Complexo Hidropolítico, portanto, existe quando há cooperação entre os Estados ribeirinhos derivados de uma grande interdependência do uso dos recursos hídricos compartilhados. Somente quando essas relações se tornam de competição/inimizade, é que existe a securitização da questão levando a formação de um Complexo Hidropolítico de Segurança.

No caso da América do Sul, dentro do Complexo Regional de Segurança sulamericano, Queiroz (2012) afirma que na Bacia do Prata havia um Complexo Hidropolítico de Segurança, mas que a partir dos anos 1980, se torna um Complexo Hidropolítico, resultado da des-securitização da questão dos recursos hídricos compartilhados que passam a ser objeto de cooperação entre os Estados ribeirinhos. $\mathrm{Na}$ Bacia Amazônica o cenário é diferente pois não há uma securitização da temática e nem mesmo uma ampla cooperação entre os países ribeirinhos, o que leva o autor a classifica-la como um Protocomplexo Hidropolítico Amazônico (QUEIROZ, 2012).

O debate sobre os conflitos em bacias hidrográficas internacionais apresenta análises sobre a existência de uma "hidro-hegemonia". Para Zeitoun e Warner (2006), o controle dos recursos hídricos transfronteiriços não é feito por meio de guerras e sim de estratégias e táticas de poder, pois em grande parte dessas bacias há assimetrias de poder entre os Estados ribeirinhos. Os autores defendem que existem três tipos de controle sobre os recursos hídricos: compartilhado (existe alguma forma de cooperação), consolidado à favor do mais forte (a cooperação é mínima e a competição foi encerrada), ou contestado (a competição é acirrada). Nestas relações:

the most stable situation in terms of riparian relations is likely to be when the riparian share control of the resource, as the case whereby the hegemon has negotiated a water-sharing agreement that is perceived positively by all riparians. This can be taken as the "positive/leadership" form of hydro- 
hegemony $[\ldots]$. At the other hand of the spectrum, the stronger competitor may seek to attain and consolidate maximum control of water resources, through unilateral action. Such negative/dominative, exploitative configurations of hydro-hegemony inevitably lead to the weaker competitor having less control. The dominative form of hydro-hegemony is thus associated with induced relative scarcity for the weaker riparians and unstable hydro-relations. Particularly when the riparians are roughly equal in power, the established control of the resources may become contested, with the resulting competition leading to either a reversal of the dominative form of hydro-hegemony or progression towards a leadership form (ZEITOUN e WARNER, 2006, p. 444).

As relações de poder entre os ribeirinhos são os principais determinantes do grau de controle sobre o recurso que cada Estado obtém, e pode ser caracterizada pela sua natureza: cooperação, conflito ou uma forma particular de hidro-hegemonia.

\title{
1.2.2 Arranjos cooperativos e institucionais para a regulação do uso dos recursos hídricos compartilhados
}

As análises que refutam a ideia de guerras internacionais por água têm se dedicado ao estudo dos arranjos cooperativos e de governança, bem como à criação de instituições que visem evitar os conflitos por água. De acordo com Ken Conca (2006), existem problemas globais relacionados à água, ademais do compartilhamento de bacias hidrográficas e aquíferos por dois ou mais países, que exigem uma regulação global de seu uso. No entanto, como afirma Ribeiro:

\begin{abstract}
a ausência de uma regulação internacional para o acesso à água por meio de uma convenção internacional, um pacto político entre os países, permite sua comercialização em escala global e, se for preciso, o uso da força para conseguir abastecer a população dos países (2008, p. 19).
\end{abstract}

A cooperação internacional já foi e continua sendo amplamente estudada como um fenômeno relevante das relações internacionais ${ }^{6}$. Na política ambiental internacional o tipo de interação entre os Estados dependerá do tipo da questão ambiental em jogo. Para Elliot (2004, p. 93), “environmental governance needs to be cooperative and collective because unilateral action by states is ultimately ineffective in the face of

${ }^{6} \mathrm{O}$ tema da cooperação internacional foi sintetizado na Dissertação de Mestrado da autora, ver: SANT'ANNA, F. M. Cooperação internacional e gestão transfronteiriça da água na Amazônia. Dissertação (Mestrado em Geografia Humana) Faculdade de Filosofia Letras e Ciências Humanas, Universidade de São Paulo. São Paulo: USP, 2009. Neste trabalho analisam-se as posições de: AXEROLD, R. The evolution of cooperation. New York: Basic Books, 1984. KEOHANE, R. O. After hegemony: cooperation and discord in the world political economy. Princeton: Princeton University Press, 1984. MILNER, Helen. International theories of cooperation among nations: strengths and weaknesses. World Politics. John Hopkins University Press, v. 144, n. 3, apr. 1992, p. 466-496. 
transboundary and global problems and inefficient in the face of shared or common problems".

Le Prestre (2000) apresenta quatro tipos de posições que os Estados podem tomar frente às negociações ambientais internacionais multilaterais. A primeira, chamada de imperialista, ocorre quando um Estado se dá conta de que realização de seus interesses nacionais depende da ação de outros Estados do sistema internacional e, por isso, tenta impor seus valores e modelos nacionais para serem adotados pela comunidade internacional. O segundo tipo é chamado de defensivo e se refere ao comportamento de Estados que veem a imposição de valores e objetivos políticos e econômicos por outros Estados como uma limitação de sua autonomia, portanto, adotam uma posição defensiva tentando se proteger. Em geral, os países evitam a imposição de compromissos e novas obrigações. Um terceiro tipo de comportamento envolve concessões em uma área para ganhar em outra, ou seja, barganha em um domínio para garantir resultados em outro. Trata-se de uma atitude instrumental, pois a preocupação com o domínio é vaga, não é a motivação prioritária. E a última posição seria a internacionalista, em que os Estados acordariam sobre a definição e a busca de um objetivo comum dado o caráter transnacional dos problemas e suas soluções.

O tema dos recursos hídricos, apesar de cada vez mais urgente e de despertar conflitos sociais pelo seu uso, tem sido amplamente discutido em fóruns internacionais, mas foi incapaz de mobilizar um regime internacional como nos moldes do regime internacional de mudanças climáticas. No entanto, como aponta Conca (2006), isto não significa que não existam iniciativas de governança transnacionais para os recursos hídricos compartilhados que fogem ao formato tradicional de regimes internacionais.

Entende-se regime internacional como "um conjunto de princípios, normas, regras e de procedimentos de decisão, implícitos ou explícitos, em torno dos quais as expectativas dos atores convergem em um domínio específico", sendo estes atores os Estados soberanos, de acordo com a definição de Stephen Krasner (apud SMOUTS, 2004, p. 139).

Para Conca (2006), a teoria dos regimes internacionais é a que mais predomina na literatura de Relações Internacionais sobre a temática ambiental. Todavia, esta teoria tem se apresentado falha ao explicar várias características das iniciativas de governança transnacionais dos recursos hídricos que não se configuram como um regime internacional. Conca afirma que os regimes internacionais: 
are rarely enforceable in a strictly legal sense. The standard response to this concern is that what matters is not the legal instrument per se but rather the institutionalization around that legal instrument of a bundle of common understandings, shared expectations, and cooperative norms. This is hoped will shape behavior through subtler channels than formal, legalistic enforcement procedures. [...] Regimes are thus instruments of governance without government; they promote rule-conforming behavior in an international system marked by the absence of centralized governmental authority. (2006, p. 11).

Para Conca (2006), a abordagem da teoria dos regimes internacionais está profundamente baseada no direito internacional, na ciência moderna e na administração burocrática, o que leva a ignorar os conflitos que estão centrados em torno do território, da autoridade e do conhecimento, como são os conflitos e problemas ambientais, em geral. Por exemplo, no caso dos recursos hídricos, o território se refere ao acesso à água, e a autoridade a quem tem o poder legitimo de tomar as decisões relativas ao acesso, distribuição e uso dos recursos hídricos.

Ainda, segundo Conca (2006), existem uma série de práticas, políticas e regras relacionadas à água que vem sendo praticadas por diferentes forças políticas: pelo direito internacional de águas compartilhadas (marcado pelas responsabilidades e direitos de Estados soberanos); ajustes estruturais neoliberais (que incluem privatização, mercantilização e "commoditização"); rede de especialistas em recursos hídricos (propagadores da gestão integrada dos recursos hídricos); ativismo transnacional dos direitos das comunidades locais (que lutam também pelos direitos humanos, pela democracia de base e a preservação da cultura e ecossistemas locais). Esta variedade de forças diferentes e contraditórias que faz parte da governança da água, apresenta algumas características em comum:

First, each has been thoroughly transnationalized. Second, each is sufficiently well embedded in important spaces of international life to constitute a set of protonorms bidding to govern, shape, influence, and "normalize" water practices around the world. They share a third feature as well; none has generated a dominant frame governing watershed practices. To the extent that watershed governance is being normalized across national boundaries, that process is taking place at the intersection of these forces (CONCA, 2006, p. 373-374).

O trabalho do grupo de pesquisa da Universidade de Oregon (Estados Unidos) chamado "Basins at Risk" ganhou notoriedade no tema das relações entre países que compartilham bacias hidrográficas. Este trabalho analisou as relações entre os países classificando-as em uma escala que varia do conflito à cooperação, chegando à 
conclusão de que existem mais eventos cooperativos do que conflitivos nas relações internacionais envolvendo o tema dos recursos hídricos compartilhados:

[...] despite the potential for dispute in international basins, the record of acute conflict over international water resources is historically overwhelmed by the records of cooperation. [...] The total number of water related events among nations of any magnitude is likewise weighted toward cooperation: 507 conflict-related events versus 1.228 cooperative, implying that violence over water is not strategically effective, or economically viable. [...] Second, despite the fiery rhetoric of politicians, often aimed at their own constituencies rather than at an enemy, most actions take over water are mild. [...] Another way to look at this is that almost two-thirds of all events are only verbal and, of these events, more than two-thirds are reported as having no official sanction at all (DELLI PRISCOLI e WOLF, 2009, p. 12).

Para Giordano e Wolf (2003), a comunidade internacional tem reconhecido os benefícios da gestão cooperativa da água e, ao longo do século vinte, desenvolveu e refinou os princípios da gestão compartilhada. Desta forma, acreditam que é necessário assistir os Estados que compartilham bacias hidrográficas na criação e desenvolvimento de redes de gestão cooperativas que levem em consideração os seguintes aspectos: estrutura de gestão flexível e adaptável; critérios flexíveis e claros para alocação de água e gestão da qualidade da água; distribuição equitativa dos benefícios do uso dos recursos hídricos; mecanismos concretos para forçar o cumprimento dos acordos; e mecanismos de resolução de conflitos bem detalhados (GIORDANO e WOLF, 2003).

Duda e Uitto (2002) que trabalharam com os projetos do GEF e PNUMA em diferentes bacias internacionais, afirmam que projetos estratégicos, como aqueles financiados pelo GEF, são importantes para quebrar as barreiras e aproximar os países que compartilham água criando uma visão compartilhada da bacia e comprometimento entre os países. Também afirmam que, para fortalecer a cooperação, é importante envolver instituições de diferentes escalas na gestão de uma bacia compartilhada e envolver organizações regionais existentes e organizações não-governamentais.

O processo de negociação de acordos e resolução de conflitos é um tema também bastante abordado na literatura sobre hidropolítica. Jarvis e Wolf (2010) afirmam que a gestão da água é basicamente a gestão de conflitos. Para estes autores:

there is room for optimism, notably in the global community's record of resolving water-related disputes along international waterways and over transboundary aquifers. For exemple, the record of acute conflict over international water resources is overwhelmed by the record of cooperation. Despite the tensions inherent in the international setting, riparian countries have shown tremendous creativity in approaching regional development, often through preventive diplomacy, and the creation of "basket of benefits" which allow for positive-sum, integrative allocations of joint gains. Vehement enemies around the world have negotiated water-sharing agreements, and once cooperative water regimes are established through 
treaty, they turn out to be impressively resilient over time, even as conflict rages over other issues. Shared interests along a waterway seem to consistently outweigh the conflict-inducing characteristics of water (JARVIS e WOLF, 2010, p. 138).

Daoudy (2010) aponta o compartilhamento dos benefícios ("benefit-sharing") como uma forma de evitar conflitos e criar oportunidades para a cooperação em bacias hidrográficas internacionais. Ela acredita que levantar os benefícios advindos do uso dos recursos hídricos de bacias compartilhadas é crucial. Ela define o compartilhamento dos benefícios como uma ação designada para mudar a alocação dos custos e benefícios associados com a cooperação. Para a autora, os benefícios podem ser divididos em quatro categorias: para o rio (qualidade, quantidade, regulação, conservação do solo, etc); do rio (hidroeletricidade, agricultura, gestão de seca-inundação, entre outros); além do rio (mercados e comércio, estabilidade regional, etc.); por causa do rio (cooperação versus conflito, desenvolvimento econômico, segurança alimentar, entre outros). Os benefícios podem ser monetários e não-monetários.

Em geral os autores que defendem o princípio do compartilhamento dos benefícios citam alguns casos como o Lesotho Highlands Water Project, entre Lesoto e África do Sul, e o acordo entre os Estados Unidos e o Canadá sobre o rio Columbia (DAOUDY, 2010), e o caso da bacia do rio Senegal (ALAM, DIONE e JEFFREY, 2009). Daoudy (2010) conclui que os casos apresentados demonstram que este princípio pode ser bem sucedido, mas sua efetividade depende de assimetria de poder limitada entre os países que compartilham água, ou contar com a presença de uma sociedade civil bastante ativa. E também afirma que o compartilhamento de benefícios tem uma natureza multidirecional e só será possível se a dinâmica montante-jusante que domina a maioria das relações em uma bacia hidrográfica compartilhada, for transcendida pelos países que a compartilham com vistas a prevenir conflitos, combater a pobreza e promover o desenvolvimento social e econômico.

Uma parte da literatura sobre a cooperação em bacias compartilhadas vai focar a análise no direito internacional. Tanto abordando os princípios da Convenção sobre o Direito Relativo à Utilização dos Cursos de Água Internacionais para Fins Diversos dos de Navegação (MACHADO, 2009), como também de acordos regionais de determinadas bacias hidrográficas transfronteiriças (CAUBET, 2006).

McIntyre (2010) apresenta quatro teorias dentro do direito internacional concernentes aos direitos dos Estados ribeirinhos sobre a utilização dos recursos 
hídricos de cursos de água internacionais: soberania territorial absoluta, integridade territorial absoluta, soberania territorial limitada e a gestão comum. A teoria da soberania territorial absoluta defende que os Estados que compartilham uma bacia podem utilizar livremente suas águas sem se preocupar com os direitos dos demais países ribeirinhos. A integridade territorial absoluta garante que um Estado ribeirinho a jusante possa demandar ao Estado à montante a continuidade do fluxo de água em seu território. Está baseado na equidade entre os Estados e é compatível com o princípio de igualdade de soberania, como presente no artigo segundo da Carta das Nações Unidas. A teoria da soberania territorial limitada também é conhecida como o princípio da utilização equitativa, que determina que cada país ribeirinho use os recursos hídricos que fluem para seu território de modo equitativo e racional. E na perspectiva da gestão comum:

\begin{abstract}
the drainage basin is regarded as an economic unit, with the Waters either vested in the community or divided among co-basin states by agreement, accompanied by the establishment of international machinery to formulate and implement common policies for the management and development of the basin. The institutional structure and purposes of common management regimes vary from basin to basin with most having a clear role in environmental management. Common management is an approach to managing water problems rather than a normative principle of international law, and as such it has been widely endorsed by the international community [...] and adopted by international codification bodies, including the Institute of International Law and the International Law Commission (McINTYRE, 2010, p. 67).
\end{abstract}

Kathryn Furlong (2006) fez uma revisão e crítica importante dos trabalhos sobre águas transfronteiriças no campo nas relações internacionais. Sua crítica foca basicamente em quatro pontos: teorização implícita; "armadilha territorial"; hegemonia; e despolitização dos fatores ecológicos. Ela aponta que apesar das novas abordagens das relações internacionais como a teoria crítica e o construtivismo, grande parte da literatura sobre águas transfronteiriças se baseia no neorrealismo e/ou no neoliberalismo, que partem de uma mesma visão racionalista e positivista. No entanto, em geral, o uso destas teorias está implícito nas análises, e:

the reality, however, is that theory guides the analysis, how it is framed and the lines of inquiry pursued. As such, it also guides the data collected as well as their refinement, presentation and interpretation; other data may have been collected (guided by other theoretical constructs) that may have led to other conclusions. Secondly, explicit theorization might broaden the intellectual approach [...] by clarifying which theories are being used and which theories are not. The application of different theoretical approaches would lead to new - and potentially important - lines of inquiry as well as alternate data. Third, explicit theorization enables the contextualization of arguments and findings within debates in IR. This would equip one to more clearly evaluate the applicability of these theories to hydro-politics, assessing what modifications 
may be necessary. In this way, explicit theorization could contribute to a mutual advancement of hydro-political analyses as well as IR theory (FURLONG, 2008, p. 812).

A autora também afirma que os construtos teóricos mais utilizados são: teorias normativas para entender os acordos sobre bacias compartilhadas; a teoria realista da estabilidade hegemônica para explicar a criação destes acordos; as teorias dos jogos para prever a propensão ao conflito versus à cooperação; e teorias liberais da interdependência e da reciprocidade para elucidar o funcionamento de longo prazo e a estabilidade de alguns "regimes" de águas transfronteiriças. Mas diz que as teorias de relações internacionais são importantes para entender o processo de tomada de decisão em política externa (FURLONG, 2006). Ela aponta que perspectivas da geopolítica crítica, da ecologia política e da produção social da natureza apresentam importantes pontos que complementam a análise. Estas perspectivas ajudam a identificar a "armadilha territorial" e identificar as diferentes escalas pertinentes, e permitem uma visão diferenciada da hegemonia. Também abordam a questão da injustiça distributiva em relação à água e das condições ecológicas e sociais.

Dentre as abordagens sobre a cooperação internacional em bacias transfronteiriças cabe analisar os estudos sobre a governança da água. O termo governança tem sido apresentado em diversas áreas e ocasiões por diferentes instituições nacionais e internacionais. Nas relações internacionais ele foi popularizado pela obra de James Rosenau e Ernst-Otto Czempiel "Governança sem governo: ordem e transformação na política mundial" (2000). Rosenau apresenta a governança como um sistema de ordenação eficaz, que não depende apenas de mecanismos e instituições formais e também congrega atores e mecanismos não-governamentais, aceito pela maioria e que faz com que tenham uma conduta determinada.

Partindo deste conceito foi criado o termo governança ambiental global como a soma das organizações, instrumentos políticos, mecanismos de financiamento, regras, procedimentos e normas que regulam o processo da proteção do ambiente global, segundo Najam, Papa e Taiyab (2006). Para eles, a governança ambiental global tem se desviado do seu desenho e intento originais. Possui necessidades de manutenção altas, redundâncias internas e ineficiências inerentes que tem desviado o curso de seu objetivo: melhorar as condições ambientais do planeta. Por isso, propõem uma série de reformas nas instituições ambientais internacionais para melhorar a governança ambiental global. 
O termo governança foi logo adotado pela área de recursos hídricos e passou-se a falar da governança da água, sem mesmo tentar esclarecer o seu significado. Como afirma Lautze et al:

Water governance has emerged as perhaps the most important topic in the international water community in the 21th century [...] Although acknowledge and appreciation for water governance's importance is widespread, definitions of the concept can be broad and fuzzy, and inconsistencies in usage and interpretation are common (LAUTZE et al. 2011, p. 1-2).

A proliferação de regras, papéis e práticas de governança da água tem influenciado decisões e políticas, além de inúmeras lutas sociais em todo o mundo. Constitui-se em iniciativas que surgem em diferentes escalas e contam com a participação de atores variados. São tanto resultado de lutas locais de comunidades tradicionais, como também da sociedade civil organizada em diversos municípios, e bacias hidrográficas, incluindo movimentos transnacionais em bacias transfronteiriças e também, na escala internacional, de instituições para a cooperação e gestão de bacias transfronteiriças como no caso dos rios Danúbio, Reno e Mekong. Estas diversas iniciativas podem se configurar como uma forma de governança global da água:

The net effect of this panoply of increasingly embedded roles and rules is not a neat, uncontested set of water norms of the sort proffered by the World Water Vision, but the result, nevertheless, is a form of global governance. Water-related struggles are being bounded, channeled, regularized, and normalized, with tangible consequences for the behavior of national governments and other actors. If global governance consists of governing acts that have a broadly international reach, and if those acts include such things as the framing of policy, the setting of standards, and the mobilization and allocation of resources, then water is indeed subject to governance that is increasingly, though certainly not exclusively, global" (CONCA, 2006, p. 5).

Devido a esta característica plural das iniciativas de governança da água, em especial em bacias compartilhadas, é que se faz necessário uma análise multi-escalar para entender como essas experiências de governança ocorreram nas diferentes escalas e a articulação entre elas. Outra justificativa para a abordagem multi-escalar é evitar o risco de generalizações e simplificações dos contextos em que se dão os conflitos, bem como das tentativas de cooperação em torno dos recursos hídricos transfronteiriços.

Esta revisão da literatura permitiu revelar que não existe um consenso entre os especialistas na política da água sobre o conflito e a cooperação entre os países que compartilham uma bacia transfronteiriça. É importante notar a questão da securitização do discurso sobre a água e também as diferentes visões sobre como a cooperação pode 
ser mais eficaz. A seguir será apresentado o modelo internacional de governança e gestão dos recursos hídricos pelas instituições internacionais envolvidas nesta temática.

\subsection{As instituições internacionais e o modelo de governança global da água}

Vários autores tem afirmado que os recursos hídricos adquirem cada vez mais uma dimensão global, não apenas devido ao compartilhamento de bacias hidrográficas e aquíferos, mas também pelo fato de que problemas relacionados com escassez, poluição, acesso e uso dos recursos hídricos têm gerado conflitos e também iniciativas que envolvem diversos atores e diversas escalas geográficas. Castro, em seu artigo sobre os desafios para a governança da água no século vinte e um, inicia seus argumentos levantando que: "the challenges facing water management have become increasingly global in scope since the 1970s" ( 2007, p. 97).

As soluções para os problemas e a gestão dos recursos hídricos também têm sido apresentadas como um "modelo" global de gestão fruto das conferências, instituições, organizações e fóruns e dos inúmeros estudos de agências internacionais e institutos de pesquisa sobre o assunto. Além disso, o tema da privatização e da atuação de empresas multinacionais no ramo e na gestão dos recursos hídricos, juntamente com a atuação cada vez mais global de outros atores, como Organizações Não-Governamentais (ONG), tem levantado à necessidade de uma abordagem global sobre os recursos hídricos.

As instituições internacionais que participam da governança global da água são relativamente recentes. Esta governança foi composta por diferentes processos de criação de instituições que podem ser sintetizados em cinco (MOLLINGA, 2008). Primeiramente pode-se destacar o processo de criação de instituições a partir de 1977, com a Conferência de Mar del Plata, mas que foi intensificado nos anos 1990 com a Conferência das Nações Unidas sobre Meio Ambiente e Desenvolvimento (CNUMAD) realizada no Rio de Janeiro e a Conferência Internacional sobre Água e Meio Ambiente (CIAMA) celebrada em Dublin, ambas em 1992. Entre estas destacam-se: os Fóruns Mundiais da Água (FMA), o Conselho Mundial da Água (CMA) e o Global Water Partnership (GWP). Um segundo processo está relacionado às negociações da Organização Mundial do Comércio (OMC) em relação à privatização da água e dos serviços de água e saneamento e o terceiro envolve a Comissão Mundial sobre Barragens. Por último, há o processo referente ao debate sobre o direito humano à água 
Além da proposta Mollinga (2008), deve-se acrescer o papel das comunidades epistêmicas da governança da água que tiveram papel destacado no processo.

\subsubsection{As instituições derivadas das grandes conferências sobre a água e ambientais}

Em 1977 foi realizada a primeira e única conferência intergovernamental sobre a água, em Mar del Plata, Argentina, trata-se da Conferência das Nações Unidas sobre Água. Ela foi proposta pelo Conselho Econômico e Social da ONU e contou com representantes de 116 países e mais de 1500 participantes. Esta conferência resultou no Plano de Ação de Mar del Plata que, dentre os muitos assuntos que abordou, já trazia prerrogativas sobre a cooperação internacional em bacias hidrográficas compartilhadas.

Já em 1992, duas importantes conferências, a CIAMA em Dublin, e a CNUMAD realizada no Rio de Janeiro, tiveram grande repercussão sobre o tema dos recursos hídricos compartilhados. É importante lembrar que a CNUMAD foi uma conferência intergovernamental, enquanto que a de Dublin foi uma reunião entre especialistas na temática dos recursos hídricos. A Agenda 21 foi um importante documento derivado da CNUMAD e que apresenta um capítulo todo, o dezoito, dedicado à temática da água e de sua gestão integrada. A conferência de Dublin teve como resultado uma Declaração que continha quatro princípios e uma Agenda de Ação. Em relação aos conflitos por água, declara que:

\footnotetext{
The most appropriate geographical entity for the planning and management of water resources is the river basin, including surface and groundwater. Ideally, the effective integrated planning and development of transboundary river or lake basins has similar institutional requirements to a basin entirely within one country. The essential function of existing international basin organizations is one of reconciling and harmonize the interests of riparian countries, monitoring water quantity and quality, development of concerted action programs, exchange of information, and enforcing agreements. In the coming decades, management of international watersheds will greatly increase in importance. A high priority should therefore be given to the preparation and implementation of integrated management plans, endorsed by all affected governments and baked by international agreements (DUBLIN STATEMENT, 2013).
}

A Associação Internacional de Recursos Hídricos (AIRH), também conhecida pela sigla em inglês IWRA, organizou uma sessão especial em 1994 em que foi aprovada uma resolução para a criação de um Conselho Mundial da Água (CMA). Este conselho teve sua primeira reunião no ano seguinte em Montreal, Canadá, e em 1996 
estabeleceu sua sede em Marselha, França. Em 1997 ele realizou o primeiro Fórum Mundial da Água em Marrakesh, Marrocos. O CMA é:

\begin{abstract}
an international multi-stakeholder platform. It was established in 1996 on the initiative of renowned water specialists and international organisations, in response to an increasing concern about world water issues from the global community. The World Water Council's mission is to promote awareness, build political commitment and trigger action on critical water issues at all levels, including the highest decision-making level, to facilitate the efficient conservation, protection, development, planning, management and use of water in all its dimensions on an environmentally sustainable basis for the benefit of all life on earth. By providing a platform to encourage debates and exchange of experience, the Council aims to reach a common strategic vision on water management amongst all stakeholders in the water community. In the process, the Council also catalyses initiatives and activities, whose results converge toward its flagship product, the World Water Forum (WWC, $\left.2013^{7}\right)$.
\end{abstract}

Já foram realizados seis Fóruns Mundiais da Água, entre 1997 e 2012. O sexto Fórum Mundial da Água, realizado em Marselha (França) em 2012, teve mais de 35.000 participantes e contou com a presença de representantes de 145 países, e cerca de 3.500 organizações não-governamentais e da sociedade civil. Durante este fórum ocorreu também outro fórum paralelo, chamado de "Fórum Alternativo Mundial da Água", que contou com a presença de mais 150 organizações não-governamentais (FAME, 2013), que apresentam visões diferentes daquelas defendidas pelo fórum oficial e pelo CMA.

O CMA tem se juntado às instituições da ONU que trabalham com a temática da água em diversas iniciativas, entre elas destaca-se o UN-Water. Trata-se de uma iniciativa criada em 2003 como um mecanismo guarda-chuva para coordenar a implementação de ações propostas no plano de ação acordado em 2002 na Cúpula Mundial sobre Desenvolvimento Sustentável e nas Metas do Milênio:

UN-Water endorses activities like the UNESCO-led World Water
Assessment Program (WWAP), which has since 2003 published a triennial
World Water Development Report (WWDR), In 2005, the UN launched the
Water for Life Decade (2005-2015) to promote the achievement of the
MDGs. Other initiatives fall fully under the aegis of one UN body (e.g.
UNESCO's International Hydrological Program [IHP]) or are jointly led by
two or more bodies (e.g. the Global International Water Assessment overseen
by UNEP and GEF) (PAHL-WOSTL et. al., 2008, p. 426).

Fazem parte como membros desta iniciativa 30 organizações do sistema das Nações Unidas, e são parceiros demais organizações de fora da ONU, como o CMA e o GWP. Entre as publicações apoiadas por esta iniciativa esta o "World Water

\footnotetext{
${ }^{7}$ WWC. World Water Council. Disponível em: <http://www.worldwatercouncil.org/about-us/visionmission-strategy/>. Acesso em março 2013.
} 
Development Report", este relatório faz uma revisão do estado atual dos recursos hídricos do planeta, com o intuito de auxiliar os tomadores de decisões com ferramentas para implementar o uso sustentável da água (UNESCO, 2013).

De acordo com o documento temático da UN-Water (2008) sobre águas transfronteiriças, existem sete pilares em que deve se basear a cooperação sobre recursos hídricos transfronteiriços: instrumentos legais, estrutura institucional e desenvolvimento de capacidade, abordagem integrada, troca de informações, avaliações e monitoramentos conjuntos, abordagem participativa, compartilhamento de custos, benefícios e financiamento. Este tipo de documento demonstra o que as instituições internacionais entendem como deve ser a cooperação em bacias compartilhadas e a regulação de seu uso:

achieving transboundary cooperation is Always a long and complex journey, there is no single path and there are few short cuts. Instead, there are many routes that can be followed and any arrangements must be tailored to a given basin's characteristics and reflect a range of environmental, hydrological, political, economic, social and cultural circumstances. Water resources policy must also be coordinated with other natural resources and sectorial policies, such as land-use management and spatial planning. Political will and commitment from all Governments, at all levels, are prerequisites for successful transboundary water management. While there is no universal solution, the following seven pillars are usually considered as necessary for long-term, sustainable and reliable transboundary cooperation (UN-Water, 2013).

Um dos parceiros da UN-Water é o Global Water Partnership (GWP), estabelecido em 1996, com seu secretariado em Estocolmo (Suécia). Trata-se de uma rede global sem fins lucrativos cujo objetivo é promover a gestão integrada dos recursos hídricos definidos como a gestão e o desenvolvimento coordenado da água, terra e outros recursos relacionados, com vistas a maximizar o bem-estar econômico e social sem comprometer a sustentabilidade de ecossistemas vitais (GWP, 2013). O GWP participou da preparação do segundo Fórum Mundial da Água, bem como de suas publicações decorrentes. O GWP tem 13 Parcerias Regionais em 83 países e conta com mais de 2.800 parceiros localizados em 167 países. Fazem parte do GWP instituições governamentais, organizações não-governamentais, agências da ONU, bancos de desenvolvimento, associações de profissionais, instituições de pesquisa e o setor privado.

Dentro da UN-Water cabe também destacar o papel da UNESCO como uma organização que tem trabalhado para a governança global da água. A UNESCO possui um Instituto de Educação sobre Água (Institute for Water Education - IWE) que foi 
criado em 2003, continuando os trabalhos que começaram em 1957 com o primeiro curso de pós-graduação sobre água. Trata-se do maior instituto de pesquisa e educação sobre água do mundo e está situado em Delft (Países Baixos). O instituto oferece diversos cursos e também mestrados e doutorados em campos do conhecimento relacionados aos recursos hídricos.

A UNESCO também congrega o Programa Hidrológico Internacional, que é o único programa dentro do sistema das Nações Unidas devotado à pesquisa sobre água, gestão de recursos hídricos, educação e construção de capacidades. Este programa possui diversas publicações sobre várias temáticas relacionadas aos recursos hídricos, entre elas estão publicações em parceria com outro programa "From Potential Conflict to Cooperation Potential" (PCCP) que estuda a relação entre o compartilhamento de águas e o potencial para conflitos.

Além da UNESCO, outras instituições do sistema da ONU que fazem parte do UN-Water são também relevantes para a governança global da água, como o PNUD, o PNUMA, entre outros.

O Global Environmental Facility (GEF) tem uma grande importância entre todas essas instituições por ser um dos principais fundos de financiamento para projetos em bacias internacionais. Ele atua com suporte financeiro e também técnico, em parceria com outras instituições em projetos de gestão dos recursos hídricos que apresentem uma importância global. O GEF define seu papel para as questões das águas internacionais como: "a "catalyst [to the] implementation of a more comprehensive, ecosystem-based approach to managing international waters and their drainage basins as a means to achieve global environmental benefits" (GEF apud GERLAK, 2007, p. 58). Gerlak (2004) afirma que o GEF é a maior fonte multilateral de ajuda para questões ambientais globais, incluindo questões relacionadas aos recursos hídricos.

Os projetos de recursos hídricos regionais correspondiam a $65 \%$ do total de projetos do GEF para águas internacionais, e 74\% do total de recursos financeiros da instituição para águas internacionais em 2004 (GERLAK, 2007). Cada vez mais os projetos financiados pelo GEF tem incorporado o conceito de Gerenciamento Integrado dos Recursos Hídricos e estão cada vez mais baseados numa perspectiva de participação de múltiplos stakeholders e de construção de capacidades (GERLAK, 2007).

Para Gerlak (2007), a maioria dos projetos apoiados pelo GEF demonstrou ser mais bem sucedida nas áreas de construção de uma visão compartilhada da bacia e na criação de capacidade e instituições de governança. No entanto, existe uma preocupação 
de que o Programa de Águas Internacionais do GEF se torne orientado apenas por projetos, sem que se transformem em políticas de longo prazo, e que se mantenham ao longo do tempo.

Estas instituições internacionais apresentadas aqui compartilham uma visão sobre a gestão dos recursos hídricos que teve uma grande influência da comunidade acadêmica e da visão científica sobre a água. Trata-se da gestão dos recursos hídricos por bacia hidrográfica, de forma integrada com a gestão do uso do solo e demais recursos naturais, incluindo todos os envolvidos na gestão e uso da água (múltiplos stakeholders), de forma descentralizada, atribuindo valor econômico à água, e com a criação de organizações de bacias para o caso das bacias compartilhadas. Em alguns casos, os documentos destas instituições são escritos como verdadeiros modelos a serem seguidos, cujas recomendações já estavam presentes na Declaração de Dublin e na Agenda 21, como foi o caso das publicações do Segundo Fórum Mundial da Água, "World Water Vision" e "Framework for Action" (2000). Para atingir os objetivos de gestão integrada e sustentável dos recursos hídricos recomendam:

Five primary actions are needed to achieve these objectives:

- Involve all stakeholders in integrated management [...].

- Move to full-cost pricing of water services for all human uses. Because of its scarcity, water must be treated as an economic good. [...].

- Increase public funding for research and innovation in the public interest. [...].

- $\quad$ Recognise the need for cooperation on integrated water resource management in international river basins [...].

- Massively increase investments in water [...]. (WWC, 2000, p. 2-3).

Para Ken Conca (2006) estes dois relatórios ("World Water Vision" e "Framework for Action") oferecem um modelo para um regime global dos recursos hídricos. Estes relatórios apresentam um conjunto de normas, regras e padrões de comportamento apropriados que devem guiar as ações relativas à água na escala global. Ele argumenta, no entanto, que existe uma completa desconexão entre o que está nestas publicações e a política contenciosa que existe em torno dos recursos hídricos em todo o mundo. Em ambos os relatórios não há menção sobre a existência de diferentes tipos de conhecimentos que tratam de forma bastante diversa sobre os fatos, mecanismos causais, as origens e soluções dos problemas relacionados à água no mundo (CONCA, 2006).

\subsubsection{O processo de mercantilização da água e a privatização dos serviços}


Um dos temas que mais levanta controvérsias na governança global dos recursos hídricos é a questão da mercantilização da água e a privatização dos serviços de água e saneamento. Enquanto diversas instituições internacionais como o CMA e o GWP defendem a água como um bem econômico e a privatização dos serviços de água, diversos movimentos e redes sociais se colocam contrários, bem como o governo de alguns países como o Uruguai e a Bolívia.

Para Conca (2006), a governança da água sofre influência do neoliberalismo global:

when applied to water, structural-adjustment conditionality and neoliberal policy reform have produced pressures for what I will refer to as the marketization of water. The result is a set of strong pronouncements as to how water should be managed, emphasizing its character as a natural resource good with economic value" (CONCA, 2006, p. 29).

Tanto o CMA, quanto o GWP, defendem que a água é um bem, com valor econômico, e não deve ser tratada como simplesmente um recurso que a natureza nos oferece. Para estas instituições, colocar um valor econômico que leve à cobrança da água irá garantir que ela seja preservada. Esta é a posição destas instituições e também defendida nos Fóruns Mundiais da Água, e apoiada pelo Banco Mundial e a Organização Mundial do Comércio (OMC).

A cobrança da água pode ser a simples cobrança pelo seu uso in natura, ou pelos serviços aplicados à ela, tais como a coleta, tratamento e distribuição, bem como a coleta e tratamento da água residual (esgoto). Conca (2006) chama de "mercantilização da água" o processo de criação de infraestruturas políticas e econômicas para tratar a água como uma commodity. Ele afirma que:

water marketization is not synonymous with water privatization, nor does it
refer simply to changing the way in which water is priced. The term refers,
rather, to a broader set of linked transformations related to prices, property
rights, and the boundary between the public and private spheres (2006, pp.
$215-216)$.

Castro (2009) afirma que a mercantilização da água:

Hace referencia a la circulación del agua como un bien privado cuyo valor de cambio incluye una ganancia que es apropiada por un agente privado quien detenta el derecho de propiedad. El ejemplo más notable contemporáneamente lo constituye el agua embotellada o envasada, que con muy pocas excepciones [...] circula precisamente como una mercancía "producida" por empresas privadas (p. 11-12).

Entre os elementos que confirmam o processo de mercantilização da água, estão: o estabelecimento de direitos de propriedade privada para ter ou usar água; o preço da 
água baseado no custo total para recuperar o capital da operacionalização, infraestrutura e custo de capital associados com a produção, tratamento e distribuição; a criação e utilização de mecanismos de mercado para o comércio de bens e serviços relacionados à água; o crescente envolvimento dos atores do setor privado na produção, distribuição e marketing da água e a intensificação do investimento privado na manutenção, melhoramento e expansão do fornecimento de água; políticas para liberalizar e facilitar as transposições de uma bacia hidrográfica à outra, incluindo o comércio internacional de água; e o papel cada vez menor do Estado em suas tradicionais funções de provedor de serviços, regulador, e mantenedor do sistema (CONCA, 2006).

Conca (2006) afirma que foram os programas de ajuste econômico neoliberal a principal fonte das normas de mercantilização da água com início nos anos 1970, que atingiu principalmente os países em desenvolvimento e as economias em transição da ex-União Soviética. Para ele, o paradigma neoliberal do Consenso de Washington, que enfatizou a necessidade dos ajustes estruturais, gerou pressões nestes governos para implementar duas grandes mudanças: retirar o Estado do seu papel tradicional de provedor da água como um bem público e implementar reformas nos preços para buscar o chamado "full cost recovery" (CONCA, 2006).

Se um dos maiores efeitos das pressões pela privatização foi enfraquecer o papel do Estado na alocação da água, o principal efeito da liberalização do comércio foi criar uma estrutura de regras que promovem a mobilização da água como uma commodity (CONCA, 2006, p. 223). Na estrutura global das regras do comércio internacional institucionalizadas pelo Acordo Geral de Tarifas e Comércio (de 1947) e pela Organização Mundial de Comércio (OMC), a água é tratada como uma commodity. Os impactos da liberalização do comércio no fornecimento dos serviços de água atingiu inclusive o fornecimento de água municipal e os serviços de saneamento. A liberalização do comércio de serviços que tem estado na agenda do comércio internacional deste a Rodada do Uruguai nos anos 1980, e no GATT, criou um compromisso de liberalizar o comércio de serviços e diferenciar entre regulações legitimas e ilegítimas no setor de serviços (CONCA, 2006). De acordo com Ribeiro:

\footnotetext{
a OMC produziu um grave retrocesso frente às conquistas da sociedade organizada no ciclo de conferências da ONU. Ela estabeleceu regras em diversas áreas, as quais se chocam com convenções internacionais, como, por exemplo, ao aceitar a patente de seres vivos, enquanto a Convenção de Diversidade Biológica a condena. No caso dos recursos hídricos, a ausência de acordos internacionais facilitou ainda mais seu papel de regulador dos interesses do grande capital (2008, pp. 136-137).
} 
Ao combinar as pressões sobre os governos para a privatização e a liberalização das regras para o investimento externo, foram criadas oportunidades lucrativas para as maiores empresas do mundo capturarem novos mercados. Este foi o caso das grandes corporações do ramo da água:

\begin{abstract}
Suez Lyonnaise des Eaux, for example, was built from a merger between entities active in water, waste management, energy, and telecommunications (horizontal integration). The firm engages in water services, water engineering, water treatment engineering, water treatment chemicals, and waste collection and disposal (vertical integration). It has been an active agent in promoting concentration in the water sector, forming joint ventures or other collaborative arrangements with at least nine other water sector multinationals (collusive behavior) (CONCA, 2006, p. 228).
\end{abstract}

Os autores que defendem a água como um bem econômico utilizam o argumento de que ao não pagar pela água as pessoas desperdiçam água, um bem escasso. Por isso, com o intuito de racionalizar o uso da água e assim conservá-la é que as pessoas devem pagar pela água. No caso da agricultura Gleick (2000) aponta que os subsídios encorajaram a produção agrícola ineficiente com alto consumo de água. Em todo o mundo a agricultura corresponde pelo consumo de $75 \%$ de toda a água consumida. Sendo assim, mudanças na prática agrícola para limitar o consumo disponibilizaria mais água para as cidades que tem uma demanda cada vez maior. E mesmo nas cidades seria preciso medidas que colocassem um preço na água impedindo o seu desperdício. No entanto, Gleick afirma:

While the new emphasis on treating water as an economic good can eliminate wasteful practices and encourage increased efficiency and conservation, a purely market approach cannot adequately protect the natural ecosystems that also depend upon water. Nature provide services that help keep humans alive, but these services are not "purchased", rarely quantified, and routinely excluded from official economic accounts (Daily, 1997). In the drive toward economic rationality, care must be taken to preserve and protect those services that may fall outside of traditional economic measures (2000, p. 134).

Castro (2009) chama a atenção para as diversas resistências que existem no mundo ao processo de mercantilização da água. Os exemplos mais conhecidos seriam das municipalidades que continuam oferecendo os serviços de água e saneamento através de empresas públicas. Nos Estados Unidos, por exemplo, $85 \%$ da população recebe água destas empresas públicas (CASTRO, 2009).

\title{
1.3.3 Os conflitos em torno das barragens e o papel da Comissão Mundial sobre
}

\section{Barragens}


As comunidades humanas ao longo de sua história realizaram grandes obras de barragem e canalização de água. Todavia, no século 20 devido à maior capacidade tecnológica, administrativa e financeira, estas alterações nos fluxos dos rios alcançaram uma escala muito maior e mais agressiva. A maior parte das 40.000 grandes barragens do mundo foi construída na segunda metade do século vinte. Para Conca (2006, p. 81), "massive damming and water diversion projects became central to twentieth-century paradigms of progress and development - in both capitalist and socialist systems, and in both the industrialized world and the global South".

O Banco Mundial, e outros bancos de desenvolvimento, tiveram um papel importante nestas grandes obras:

\begin{abstract}
with the emergence of the World Bank and other development-financing mechanisms after the World War II, the model of water diversion projects being fueled by state power and public finance went global. [...] Yet the figure dramatically understated the catalytic role of the Bank, other multilateral development organs, and bilateral aid agencies from those donor countries with large dam-building industries. They have played that role in several ways: financing some of the largest projects, advancing the state of the art of water infrastructure planning, and validating the notion of largescale water diversion as developmental progress (CONCA, 2006, p. 83).
\end{abstract}

Outro aspecto que teve grande influência neste modelo global de grandes barragens foi a emergência de uma rede transnacional de especialistas na construção de barragens, canais, sistema de irrigação de larga escala e outras infraestruturas ligadas à água. A Comissão Internacional sobre Grandes Barragens (International Comissiono $\mathrm{n}$ Large Dams - ICOLD) foi criada em 1928 como:

\begin{abstract}
a non-governmental international organization which provides forum for the exchange of knowledge and experience in dam engineering. The Organization leads the profession in ensuring that dams are built safely, efficiently, economically, and without detrimental effects on the environment. Its original aim was to encourage advances in the planning, design, construction, operation, and maintenance of large dams and their associated civil works, by collecting and disseminating relevant information by studying related technical questions. [...] ICOLD was founded in 1928 and has National Committees from more than 90 countries with approximately 10.000 individual members. ICOLD members are essentially practicing engineers, geologists and scientists from governmental or private organizations, consulting firms, universities, laboratories and construction companies (ICOLD, 2013).
\end{abstract}

Conca (2006) aponta também a emergência de empresas multinacionais engajadas na construção de infraestruturas de diversão de águas e equipamentos para barragens. McCully (apud Conca, 2006, p. 85) estimou que em 1990 a indústria das 
barragens movimentava 20 bilhões de dólares, cuja maior parte pertencia a um número pequeno de consultoras multinacionais de engenharia, industrias de equipamentos e construtoras.

A construção de barragens sempre foi realizada com resistências, em especial, das pessoas afetadas pelas barragens, mas se tratavam de uma oposição localizada. Esta oposição começou a se organizar de forma transnacional a partir dos protestos para uma reforma do Banco Mundial em suas ações de financiamento de projetos com grande impacto ambiental e humano, na segunda metade da década de 1980. Juntamente com a emergência de ONGs como a International Rivers Network (IRN) a transnacionalização do movimento anti-barragens foi se consolidando. Em 1996 o Banco Mundial publica a primeira fase da revisão de seu Departamento de Avaliação de Operações intitulado "World Bank's Experience with Large Dams: a preliminar review of impact", que recebe muitas críticas inclusive da IRN. No ano seguinte o Banco Mundial realiza em conjunto com a World Conservation Union (IUCN) e outros stakeholders relacionados às barragens para um workshop. Neste ano de 1997, foi realizada também a Primeira Reunião Internacional de Afetados por Barragens, onde se reuniram ativistas em Curitiba, Brasil. Esta reunião foi organizada pelo Movimento dos Atingidos por Barragens (MAB) brasileiro (CONCA, 2006; DUBASH et al., 2001).

Esta mobilização levou a decisão de se criar uma organização mundial sobre barragens que congregasse todos os stakeholders para debateram as questões que envolvem a construção de barragens. Em 1998 foi então criada a Comissão Mundial sobre Barragens. Esta lançou seu primeiro relatório em 2000, "Dams and Development: a new framwork for Decision-Making”, que contém diversas recomendações sobre a construção de barragens fruto do consenso entre seus membros (MOORE, DORE e GYAWALI, 2010). A CMB é considerada uma plataforma de múltiplos stakeholders pois:

\footnotetext{
the WCD stood out from previous commissions in its diversity - including pro-dam lobbyists and anti-dam protesters - rather than limiting itself to participants from a broad middle ground. By the standards of global commissions generally it also marked a notable departure from the "eminent persons" model of distinguished public servants. It comprised instead active practitioners whose personal legitimacy derived itself from their prominence in international stakeholder networks (DUBASH, et al., 2001, p. 2).
}

\subsubsection{O direito humano à água: mudança de paradigma?}


Com a água ocupando um lugar significativo na agenda internacional e com a criação de instituições para tratar desta temática, o debate a respeito da quantidade de pessoas no mundo que ainda não possuem acesso à água potável ganhou proeminência nas últimas décadas. Os anos entre 1980 e 1990 foram declarados pela ONU como a Década da Água e do Saneamento (international drinking water and sanitation decade). A universalização do acesso à água potável passou a ser um tema de destaque que levou a sua discussão no âmbito do Comitê dos Direitos Econômicos, Sociais e Culturais, que visa monitorar a implementação da Convenção Internacional sobre Direitos Econômicos, Sociais e Culturais (CIDESC). O comitê publicou o numero 15 do seu General Comments, em 2002, constatando que o direito à água é um pré-requisito para a garantia de outros direitos humanos.

$\mathrm{O}$ direito ao acesso à água potável e ao saneamento foi reconhecido pela Assembleia Geral da ONU em julho de 2010, por meio de sua Resolução 64/292, como um direito humano. A resolução:

1. Declares the right to safe and clean drinking water and sanitation as a human right that is essential for the full enjoyment of life and all human rights;

2. Call upon States and international organizations to provide financial resources, capacity-building and technology transfer, through international assistance and cooperation, in particular to developing countries, in order to scale up efforts to provide safe, clean, accessible and affordable drinking water and sanitation for all.

Inicialmente no debate sobre os direitos humanos o Direito Humano à Água era visto como um direito implícito decorrente de outros direitos e considerado subordinado e necessário para se alcançar outros direitos humanos, como o direito à vida. Ou seja, ele era entendido como parte dos Direitos Humanos. Mas foi somente com a publicação de General Comments número 15 que o direito humano à água passou a ser adotado mais explicitamente nos debates sobre o direito humanitário. Em 2008 o Conselho das Nações Unidas de Direitos Humanos iniciou um processo de três anos para investigar o direito humano à água. No entanto, a resolução da Assembleia Geral de 2010 veio antes da conclusão desse processo que culminou com a Resolução 18/1 de outubro de 2011 do Conselho reconhecendo o direito humano à água e ao saneamento.

De acordo com Ribeiro (2008), o reconhecimento do direito humano à água não resultará em ações efetivas se não estiver vinculado às outras iniciativas de governança da água. Por isso, implementar o direito humano à água é uma tarefa complexa já que:

Water governance arena is a mobius web arena engaging many actors with competing discourses and approaches and it is fragmented. Water governance 
is fragmented because, first it is spread through $28 \mathrm{UN}$ agencies and although coordinated lightly by UN-Water, the policies and approaches of these bodies are different. Second, the UN Watercourses Convention was initially developed by yet another UN body - the International Law Commission and it is not rooted in the normal water work of the UN. Third, the human rights angle is also being developed in other for a - the UN Human Rights Council and the UNGA [...]. Even the UNGA Resolution itself does not reflect universal consensus as several developed countries (including the USA and UK) abstained from voting. [...] Still others argue against the link to universal responsibilities as predicted earlier. The developing countries were expected to be reluctant to accept such a heavy burden, but most have accepted the UNGA Resolution and only a few have abstained (GUPTA, AHLERS e AHMED, 2011, pp. 298-299).

Os autores ainda acrescentam dois aspectos que contribuem para a fragmentação da governança e que dificultam a implementação do direito humano à água. Os atores que defendem a água como um bem econômico e o "full-cost recovery" como bancos de desenvolvimento, indústria e agências de desenvolvimento, evitam a discussão sobre o direito humano à água argumentando que não tem uma posição sobre o assunto sobre a política dos direitos humanos. A publicação do General Comments em 2002, por exemplo, teve pouco impacto sobre o World Panel on Financing Water Infrastructure em 2003. E o último aspecto está relacionado às brechas nos contratos internacionais para fornecimento de água e saneamento que, na maioria dos casos, levou à arbitragem em favor das indústrias e contra o direito humano à água (GUPTA, AHLERS e AHMED, 2011).

O direito humano à água também precisa ser elaborado no sentido de abordar questões sobre a disponibilidade/quantidade, qualidade e acessibilidade à água e de forma não discriminatória. $\mathrm{O}$ saneamento também precisa ser pensado em termos de higiene/saúde, segurança, acessibilidade, privacidade, sensibilidade cultural, dignidade, não-discriminatório e ambientalmente sustentável. Portanto, resta a pergunta: o reconhecimento do direito humano à água gerou melhorias na universalização dos serviços e água e saneamento?

The answer is no. The next step is considered elaboration of this right in terms of indicators and action by the UM Human Rights Council, the adoption of this right in national laws or through national courts, the promotion of awareness of this right among the disadvantaged communities, and support for organizations that represent these communities in national courts and administrative systems. [...] Unless a mass movement is launched to implement this right, it will only remain a symbolic acceptance of the challenges that face the poorest peoples in the world (GUPTA, AHLERS e AHMED, 2011, pp. 304-305). 
Apesar disso, verifica-se uma mobilização inicial que pode resultar na implementação do Direito Humano à Água em diversas escalas.

\subsubsection{A convenção da ONU sobre cursos d'água internacionais}

Além do direito humanitário, que agora inclui o direito humano à água e ao saneamento, no direito internacional também tem sido abordada a temática dos recursos hídricos. A Convenção Internacional sobre a Utilização de Rios Internacionais para Fins Diferentes da Navegação, foi acordada em 1997, pela Assembleia Geral fruto de um processo de elaboração de mais de 20 anos por parte da Comissão de Direito Internacional (CDI) da ONU.

A iniciativa de se elaborar um quadro jurídico sobre os recursos hídricos transfronteiriços partiu da Resolução 2.669 de 1970 adotada pela Assembleia Geral intitulada "Desenvolvimento Progressivo e Codificação das Regras do Direito Internacional Relativas às Vias de Águas Internacionais”. A partir desta resolução é que teve início na CDI a elaboração do "Projeto de Artigos sobre o Direito Relativo à Utilização dos Cursos de Água Internacionais para Fins Distintos da Navegação”. O projeto finalizado e adotado pela CDI foi então enviado à Assembleia Geral em 1994, que criou um Grupo de Trabalho Pleno para a elaboração de uma Convenção baseada no projeto da CDI.

A convenção foi então adotada pela Assembleia Geral em 21 de maio de 1997, e é considerada um importante instrumento jurídico por conter princípios-chave para a gestão compartilhada dos recursos hídricos transfronteiriços. No entanto, o seu formato atual resultou em poucas ratificações e, portanto, ainda não entrou em vigor. Isto pode ter acontecido, de acordo com alguns autores, devido ao seu caráter idealista:

\footnotetext{
a proposição, elaboração, discussão e definição de uma Convenção a partir da Assembléia Geral resultou em um corpo normativo extremamente idealista. [...] Uma convenção idealista que encontre dificuldades em ser ratificada mantém o problema sem solução. Enquanto isso perdurar, as práticas políticas e ambientais de países que compartilham recursos hídricos serão baseadas na sua capacidade de intervenção militar, impondo o realismo político clássico e, o que é pior, o uso desigual dos recursos hídricos na escala mundial (RIBEIRO, 2008, p. 99).
}

A Convenção adota o termo "curso de água internacional" ao invés de "bacia hidrográfica internacional" e o define como aquele curso de água cujas partes estão em Estados diferentes (art.2). Também de acordo com a convenção "curso de água significa 
um sistema de águas de superfície e subterrâneas que, em virtude de sua relação física, constitui um conjunto unitário e normalmente flui para uma desembocadura comum" (CONVENÇÃO apud MACHADO, 2009, p. 39).

Para Machado (2009) ao utilizar o termo "curso de água" como um "sistema" e formando um "conjunto unitário":

a definição da Convenção leva em conta somente as águas, e não o território adjacente a essas águas. As consequências internacionais das características físicas da água mostram que a água não fica contida nas fronteiras políticas e que ela tem a propriedade de transmitir a uma região as modificações ou as repercussões das modificações que se produzem numa outra região. [...] a ideia de conjunto unitário das águas expressa uma concepção sui generis de gestão dos recursos hídricos. É um continuum (p. 41).

Assim, optou-se na Convenção por não utilizar o termo "bacia hidrográfica", pois:

os defensores da não-inclusão do conceito de "bacia hidrográfica" na Convenção argumentam que "não se deve considerar como internacionais senão as vias de água que separam ou atravessam o território dos Estados, e não a porção física da terra. As bacias fluviais podem estender-se em porções limitadas, mas também muito extensas. Neste caso a CDI - Comissão de Direito Internacional não poderia formular regras para regiões tão vastas, e impor uma espécie de soberania dupla ou múltipla”. O $3^{\circ}$ Relator Especial Jens Evesen acentua que houve receio de que o conceito de "bacia" pudesse abranger as terras que fazem parte do conjunto da bacia, o que levaria a pensar que elas poderiam ser regulamentadas pelas regras jurídicas dos recursos hídricos internacionais (MACHADO, 2009, pp. 44-45).

A Convenção possui 37 artigos agrupados em sete partes: introdução, princípios gerais, planejamento, manejo, proteção e preservação, situações de emergência e risco de danos, provisões diversas e cláusulas finais. De acordo com Delli Priscoli e Wolf, a convenção apresenta bons princípios que deveriam ser seguidos não apenas nas relações internacionais, mas também na relação entre estados de uma federação, todavia, ainda existem muitas duvidas em relação à aplicação destes princípios:

in summary, they call for: equitable and reasonable use; obligations not to cause significant harm; general obligation to cooperate; regular exchange of data and information; examination of relations between users. They are good principles. They could be useful in all transboundary water management, whether within a federal state with competing jurisdictions or among sovereign nations. However, they present operational questions: Which principle will prevails when equitable use conflicts with the obligation not to cause appreciable harm? What is appreciable harm? What are the standards of responsibility for a breach of principles? What should we do when there is no internationally recognized legislation and no compulsory enforcement jurisdiction? (DELLI PRISCOLI e WOLF, 2009, p. 2-3). 
Ainda que a Convenção não esteja em vigor é importante notar que muitos dos princípios contidos nela têm sido empregados em tratados de bacias hidrográficas compartilhadas.

\title{
1.3.6 O papel da ciência e das redes transnacionais de especialistas
}

É importante também reconhecer o papel da rede transnacional de especialistas, e instituições formadas por especialistas em recursos hídricos, que têm um papel fundamental para a governança global dos recursos hídricos. Este conjunto propagou o conceito de gestão integrada dos recursos hídricos. Para Conca:

\begin{abstract}
water expertise, based on a fundamentally different normative orientation than water diplomacy, has also fostered international institution building. The primary engine for this has been the emergence and growing influence of an interlinked set of transnational networks of water experts. Beyond the confines of formal diplomacy, these networks exercise and channel power through knowledge-based advocacy. Grounded in a technically expert, rationalist understanding of the problem of water, expert networks have put into play a rhetorically powerful, all-encompassing concept of integrated water resources management (CONCA, 2006, p. 375).
\end{abstract}

A relação entre a política ambiental internacional e a comunidade científica é um tema importante a ser analisado. Peter Haas (1992) se dedicou à investigação do que ele chamou de "comunidades epistêmicas". Ele as define como:

\begin{abstract}
a network of professional with recognized expertise and competence in a particular domain and an authoritative claim to policy-relevant knowledge within that domain or issue-area. [...] they have (1) a share set of normative and principled beliefs, which provide a value-based rationale for the social action of community members; (2) shared causal beliefs, which are derived from their analysis of practices leading or contributing to a central set of problems in their domain and which then serve as the basis for elucidating the multiple linkages between possible policy actions and desired outcomes; (3) shared notions of validity - that is, intersubjective, internally defined criteria for weighing and validating knowledge in the domain of their expertise; and, (4) a common policy enterprise - that is, a set of common practices associated with a set of problems to which their professional competence is directed, presumably out of the conviction that human welfare will be enhanced as a consequence (HAAS, 1992, p. 3).
\end{abstract}

No caso dos recursos hídricos a comunidade epistêmica tem se organizado institucionalmente como é o caso da Associação Internacional de Recursos Hídricos (International Water Resources Association - IWRA). A IWRA foi fundada em 1971 nos Estados Unidos como uma organização não-governamental sem fins lucrativos de cunho educacional. Seu objetivo é: 
continually improve water resources decision-making, by improving our collective understanding of the physical, ecological, chemical, institutional, social and economic aspcets of water. IWRA is deeply committed to the sound management of water resources through: providing an international forum for water resources issues; advancing water resources and related environmental research; promoting water education throughout society by improving global access to relevant data and information; enhancing the quality of knowledge used in decision-making; improving exchanges of information and expertise; networking with other organizations to advance common interests and goals (IWRA, 2013).

A comunidade de epistêmica, formada pelos profissionais e cientistas da área de recursos hídricos, tem contribuído para a elaboração e difusão do conceito de gestão integrada dos recursos hídricos por bacia hidrográfica. Este conceito ganhou maior visibilidade com a Conferência de Dublin de 1992 e é amplamente divulgado por organizações internacionais como o GWP. Para Conca (2006), a Gestão Integrada dos Recursos Hídricos (GIRH) é hoje a linguagem dominante pela qual o desafio da governança da água passou a ser concebido.

A comunidade epistêmica dos recursos hídricos passou então a advogar a GIRH e com isso ditar normas para a governança da água, pois influenciaram o processo de tomada de decisão e a criação de instituições para a governança da água. O fórum central para a discussão sobre a GIRH não é a arena diplomática e sim os fóruns de profissionais especialistas. No entanto, o debate em torno da ideia da GIRH é complexo:

For all practical purposes, most international institutions have endorsed this concept, either explicitly or implicitly, without seriously analysis of its usability and implementability. This is in spite of the facts that there is no agreement at present among the various international institutions that endorse it as to what exactly is meant by integrated water resources management, or whether this concept has improved water management practices anywhere in the world, which would not have occurred otherwise without the explicit use of this concept. Furthermore, in which countries, if any, this concept has been successfully implemented, and, if so, under what conditions, over what periods, and what have been its impacts (positive, negative and neutral) on human lives, the environment and other appropriate development indicators. Even the donors who have been promoting this concept vigorously will be hard-pressed to identify even one good case at successful implementation of integrated water resources management in their own countries. Not surprisingly, increasingly more and more national and international institutions and water professionals have started to question the relevance and the appropriateness of the implementation potential of integrated water resources management (BISWAS, 2008, p. 12-13).

A influência da ciência é evidente no caso da difusão da ideia de GIRH e sua ampla aceitação na sociedade moderna revela o seu poder como conhecimento válido. Outro exemplo seria a aceitação da GIRH como a mais racional e que seria portanto a melhor solução para a governança da água. Analisando a crença na gestão racional da 
água a partir da importação do modelo francês de gestão para o Brasil, mais especificamente para o estado de São Paulo, Rodrigo Constante Martins (2012) analisa o processo de cientifização da política que ocorre no processo de consolidação deste modelo de gestão em três níveis:

\begin{abstract}
O primeiro deles, [...] tem por base a difusão de representações sobre os limites físicos necessários para os interesses sociais em torno do recurso. Estes limites físicos, previamente demarcados na noção de bacia hidrográfica, se constituíram em uma importante garantia para a gerência científica e racional da natureza. O segundo nível, [...] relaciona-se com a crença nas regras da ciência como critério estrito para a tomada de decisões nas práticas de governança, visto que a "política" é notadamente mal vista em círculos técnicos, associada irremediavelmente a jogos de interesses que prejudicariam a racionalidade das decisões. Por fim, o terceiro nível relaciona-se com a participação no parlamento das águas e, nos termos do depoimento supra, com o próprio exercício da cidadania. Mas, assim como a própria água, esta crença não brota do vazio. Ao contrário disso, esta se harmoniza com outras crenças e disposições assimetricamente partilhadas entre os agentes interessados na governança deste recurso natural. Por isso, mesmo o desconhecimento sobre leis econômicas não implica em necessária descrença na racionalidade da gestão. Isso porque, como bem sugeriu Durkheim (2003) acerca dos conceitos e do conhecimento nas sociedades modernas e diferenciadas, o selo da ciência é, em geral suficiente para que certos valores de verdade obtenham crédito privilegiado (p. 484-485).
\end{abstract}

A ciência e a comunidade epistêmica tem um papel importante para a governança dos recursos hídricos e representam atores com interesses e poder que influenciam o processo de tomada de decisão. A comunidade epistêmica aparentemente é neutra, mas, em geral, defende posições "científicas" que justificam pesquisas em andamento e/ou consultorias às próprias instituições multilaterais. Mesmo quando um aparente consenso está presente, como parece ser o caso do GIRH, a comunidade epistêmica tende a reforçar a necessidade de sua revisão, muitas vezes sem ampliar a base social envolvida com o tema. Ou seja, quando a comunidade epistêmica resolve falar em nome dos envolvidos nos conflitos, ela perde seu papel de elucidar e analisar os contextos em que eles foram criados e acaba mostrando uma visão sobre o problema que pode ou não atender aos interesses da maioria.

\title{
1.4 A governança dos recursos hídricos
}

Pahl-Wostl et. al. (2008) identifica quatro abordagens em relação à governança da água. Tradicionalmente, a governança da água é vista como uma questão local, onde os direitos, necessidades e regras locais devem ser entendidos e levados em conta. Portanto, os problemas relacionados à água devem ser resolvidos no nível mais local 
possível de governança, de onde resultam os conceitos de subsidiariedade e descentralização. Para Lautze el al. (2011): "the primary role for water governance stipulated by the formal definition would be to define water management goals, aligning them with local preferences” (p. 5). Outra abordagem aponta que a governança da água deve ser a nível nacional, pois são os interesses nacionais que devem estar em primeiro lugar. Uma terceira abordagem foca a governança da água na escala da bacia hidrográfica, que tem sido utilizada e recomendada por muitas instituições, por ser a "escala natural" para tratar as questões sobre recursos hídricos. E por último, a abordagem recente da governança global da água chama a atenção para o fato de que as questões relativas à água nas escalas locais, nacionais e de bacia, estão interligadas com um sistema global da circulação da água, o que requer instituições multilaterais e políticas internacionais para sua gestão (PAHL-WOSTL et. al., 2008).

Além disso, um dos desafios mais complexos enfrentados pelos países em relação aos recursos hídricos transfronteiriços é estabelecer instituições efetivas para gerir bacias hidrográficas compartilhadas, o que tem gerado uma ampla literatura sobre o tema. Merrey (2009) observa que um importante aspecto da construção de instituições de bacias compartilhadas em países em desenvolvimento é que são conduzidos pelos governos nacionais, apoiados pelas agências de cooperação de países desenvolvidos e instituições internacionais, como o Banco Mundial. Portanto, os princípios, valores e procedimentos em que se baseiam são externos aos países da bacia em questão. Instituições como o Banco Mundial, o CMA, o GWP, a UNESCO propagam modelos e normas ocidentais e internacionais de como estes problemas devem ser solucionados, de como os recursos hídricos devem ser utilizados, compartilhados ou conservados, de como as disputas pelos recursos hídricos devem ser resolvidas. São esses valores que definem quem tem direito a participar e falar e quem tem precedência sobre quem (MERREY, 2009).

Retomando o conceito de governança, quando aplicado aos recursos hídricos, é usado com diferentes sentidos dependendo das visões e valores dos atores que o definem baseados em diferentes projetos e estratégicas políticas, que podem até mesmo ser contraditórios. Por isso, existe um embate político sobre o conteúdo da governança da água, visto que reflete políticas diferentes e até opostas. Pode-se então concluir que o processo de governança "or, to be more precise, democratic governance, is a political process characterized by the confrontation of rival political projects grounded on different values and principles" (CASTRO, 2007, p. 102). 
Outros autores como Pahl-Wostl et. al. (2008), apontam que governança pode ser um conceito normativo e um conceito analítico para a pesquisa sobre políticas, pois existe uma demanda por avaliações analíticas de processos políticos. E neste caso, governança se difere de governo e apresenta uma condição policêntrica e multi-nível em que diferentes atores e redes contribuem para o desenvolvimento de políticas e sua implementação.

Todavia, em grande parte da literatura sobre a política da água o conceito de governança é entendido de forma instrumental partindo de uma visão idealizada das relações entre os setores sociais, menosprezando as relações de poder e assimetrias entre os atores:

[...] in water policy literature governance is often understood instrumentally, as a mean to achieve certain objectives, as a policy strategy rather than as a complex process of democratic dialogue, negotiation, and citizen participation that includes the discussion about what objectives must be pursued by society. Also, and closely related to the previous point, the conceptualization of governance that tends to prevail in this literature often presents an idealized vision of the interrelations between the main spheres involved: the state, the market, and "civil society". This idealized version of governance presents the state, the market and "civil society" as partners participating in symmetric, triangular interaction, as in the notions of "publicprivate partnership" and "tri-partite partnership", which have become central in mainstream public policy (CASTRO, 2007, p. 103).

Esta visão instrumentalizada vê a governança da água como a melhor política para a gestão dos recursos hídricos, ao invés de ser o processo de discussão e debate para a construção de uma política, isto é, dos valores, princípios e metas a serem perseguidos e os meios para se atingir tais objetivos (LAUTZE et. al., 2011; WARNER e WEGERICH, 2010). A instrumentalização da governança da água é uma forma de aplicar uma política e estratégia apresentada como neutra e racional, numa tentativa de despolitizar as questões relacionadas aos recursos hídricos. Porém, como bem analisa Warner e Wegerich (2010), a própria despolitização da água é uma estratégia de certos atores, pois na verdade a racionalidade contida nestas ideias de governança da água é a racionalidade econômica do mercado. E a água, com seus múltiplos usos, não pode ser reduzida a uma única racionalidade, a econômica (CASTRO, 2007; BOELENS, 2005). Daí a necessidade de se adotar uma perspectiva crítica em relação à governança da água, como aponta Castro:

[...] there is a need for adopting a critical perspective of the understanding of water governance as an instrument, a supposedly neutral policy tool, which aims at depoliticising what is essentially a political process. The idealized 
and instrumental approaches to water governance tend to neglect in their analysis, despite rhetorical recognition to the contrary, the existence of fundamental social divisions underpinning water insecurity, injustice, and inequality, which are major drivers of water conflict. Thus, a truly interdisciplinary approach to the problem must strive to make observable those processes that create and reproduce the structural socio-economic and political inequalities that continue to preclude a large sector of the world's population not only from participating in the governance of water, but even from accessing essential volumes of safe water for daily survival (CASTRO, 2007, p. 113).

Portanto, governança não é apenas um instrumento de políticas e sim o processo de tomada de decisão relacionado à formulação de políticas de como gerir os recursos hídricos. Este é um processo político em que diversos atores debatem e tentam acordar os objetivos a serem perseguidos, os valores e princípios e os instrumentos utilizados para a gestão dos recursos hídricos. O modo como estas questões são tratadas e discutidas e a forma de tomada de decisões, é que configuram o processo de governança da água. Quem participa, como participa e como são tomadas as decisões é o que realmente configura a governança.

Entretanto, é preciso levar em conta o contexto social em que o processo de governança ocorre, pois as relações entre os atores são, em geral, assimétricas, tanto no que concerne o poder político e econômico, quanto em relação a obtenção de informações e conhecimento. E muitas vezes, certas políticas para a gestão dos recursos hídricos são formuladas sem levar em conta estas relações assimétricas e as diferenças de valores e objetivos entre os atores e grupos sociais envolvidos. Como menciona Molle (2007): "Basin interconnectedness also has a sociopolitical dimension, as individuals and groups that find themselves in interaction do not have the same decisional power and access to water" (p. 360). O que se observa na prática é que:

[...] water policies that have often a significant political content are designed and implemented with disregard for the values, opinions, and preferences of the citizens and in the absence of democratic governance arrangements. In practice, water governance consists in the interaction between governments, large businesses, political parties, civil and other organizations representing sectorial interests (e.g. worker's unions, religious organizations, peasant movements, etc), international agencies (e.g. international financial institutions and other agents of the process of "global governance"), NGOs, and other relevant powerholders" (CASTRO, 2007, p. 107).

Para Lautze et. al. (2011) em uma governança efetiva da água estão presentes elementos que facilitam os processos de tomada de decisão, de forma que, os 
princípios de governança são aqueles que refletem um bom processo, tais como a transparência, participação, comunicação, responsabilidade, ética, entre outros.

A questão principal da governança é definir quem participa do processo de tomada de decisão e quem realmente decide. Ou seja, a governança depende do foro de discussão que deve ter legitimidade, bem como os atores sociais, que devem ter legitimidade perante seu grupo social, com mobilização social (RIBEIRO, 2009). Porque o problema do acesso e distribuição dos recursos hídricos está relacionado com o processo de tomada de decisão, isto é, o grupo de atores que decide de acordo com os seus interesses, valores e princípios sobre os direitos sobre os recursos hídricos, seu acesso, distribuição e, portanto, gestão.

$\mathrm{Na}$ escala internacional a governança ganha ainda maior complexidade, pois "para construir a governança ambiental internacional é preciso compatibilizar decisões de fóruns diferentes que resultaram de arranjos políticos próprios configurados em momentos distintos" (RIBEIRO, 2009, p. 115).

Essa diversidade de fóruns está presente nas bacias estudadas nesse trabalho, pois, em diversos deles os atores atuam para defender seus pontos de vista. Essa profusão de atores sociais ainda não conseguiu estabilizar um foro de "governança", mas ao menos contribuiu para expressar suas inquietações.

Isso não impede que, como afirma Boelens, muitas vezes os sistemas hídricos de grupos marginalizados não são levados em consideração nas políticas nacionais e internacionais sobre recursos hídricos, pois estes atores em geral não participam efetivamente das decisões:

It is common to find, across the globe, that local water control rules and management arrangements, as they exist in farmer-controlled irrigation systems, indigenous territories or local village drinking water supply systems, are ignored by international policy plans, national legislation, and locally intervening companies or development projects (BOELENS, 2010, p. 161).

A diferença entre governança da água e gestão da água é que a governança é o conjunto de processos e instituições que definem e identificam quais são as metas de gestão a serem perseguidas. A gestão trata das práticas utilizadas para atingirem as metas traçadas e, portanto, atingir melhores resultados (LAUTZE, 2011). Dito de outra forma, a governança da água fornece a estrutura para decidir quais serão as atividades de gestão dos recursos hídricos que serão implementadas (LAUTZE, 2011). Assim, pode-se inferir que uma crise de governança de água é uma crise nos processos de tomada de decisão e das instituições. Além do que: 
an effective governance process is first needed to determine which tenets of IWRM, if any, are desirable for a specific location. Moreover, disregarding local conditions, preferences and values to uniformly apply IWRM principles everywhere actually reflects poor water governance (Lautze et al., 2011, p. $5)$.

Portanto, a governança da água deve ser definida como o processo político de tomada de decisão em que diversos atores determinam os valores e objetivos que direcionam a regulação e o gerenciamento do uso da água e a escolha dos meios para atingir estes objetivos. Por isso ele é entremeado pela participação social. No caso das bacias transfronteiriças, é necessário agregar mais um elemento, o que define a governança como multi-escalar: a cooperação internacional que pode levar à construção de um foro das partes envolvidas, com maior ou menor presença da sociedade civil, a depender da tradição democrática dos países envolvidos e da capacidade de mobilização social.

As diversas características da gestão dos recursos hídricos devem ser comandadas pelo processo político instaurado pela governança. Mas ainda assim é necessário conhecer o modelo mais aplicado de gestão.

\subsubsection{O modelo de gestão integrada dos recursos hídricos por bacia hidrográfica}

Do ponto de vista ambiental, a gestão dos recursos hídricos por bacia hidrográfica permite uma abordagem territorialmente integrada e mais holística ao relacionar os problemas hídricos com a questão do uso e ocupação do solo e do planejamento territorial em toda a área da bacia. Muitos focos de poluição ou degradação dos recursos hídricos se situam mais distantes dos cursos d'água, mas dentro da área territorial da bacia afetando os recursos hídricos desta. Todavia, existem limitações também ambientais para a gestão de bacias hidrográficas, pois nem sempre se consegue definir a área exata de uma bacia e, às vezes, ela não coincide com a área das águas subterrâneas (aquíferos), além de outras questões apontadas por Leal (2003).

Além do que, a gestão de bacia hidrográfica cria outros problemas de escala e de fronteiras políticas, assim como, de interação institucional. A decisão de gerir os recursos hídricos de acordo como uma unidade espacial biofísica como a bacia hidrográfica ao invés de seguir as fronteiras político-administrativas apresenta sérios problemas de "encaixe" e fragmentação espacial (MOSS, 2003; 2004). É preciso 
também levar em conta os interesses que levaram a criação desta nova escala espacial de gestão e planejamento.

Miller e Hirsch apontam que a gestão integrada de bacias hidrográficas internacionais tem sido feita de acordo com modelos utilizados nos países desenvolvidos, de modo que:

\begin{abstract}
International development is increasingly focused on "best practice", an on international experience, in wealthier countries in order to provide technical assistance packages for poorer parts of the world. In the case of IRBM (integrated river basin management), this can cast river basin development into a 'blue-print' mold, where river basin developments is viewed more as a matter of getting the model right, about defining institutions, action plans and policy agendas largely in the absence of public consultation and participation in this process. Out of this process more centralized and top-down institutions are often created, institutions established in the name of basin-wide approaches for more efficient coordination of resource use. Such institutions fall short of an integration of the multiple values and objectives held by the various stakeholders involved in river basin management. This reveals a tension in the interpretation of IRBM between the recognition of the need for more basin-wide approaches and the trend towards more participatory, decentralized resource management" (2003, p. 5).
\end{abstract}

A gestão de bacias, muitas vezes, leva a criação de novas instituições responsáveis pela gestão dos recursos hídricos na escala da bacia hidrográfica e a substituição de outras, o que gera novos problemas de fronteira e de interação entre as instituições. Isto porque envolve as fronteiras políticas das responsabilidades e esferas de influência, onde há uma sobreposição de jurisdições e interesses de atores sociais, que pode gerar conflitos entre as instituições formais (MOSS, 2003; 2004).

A bacia hidrográfica como unidade de planejamento e gestão dos recursos hídricos faz parte do pacote de elementos que configuram a chamada gestão integrada dos recursos hídricos. Este tem sido o modelo mais recomendado de gestão da água pelas instituições internacionais.

A gestão integrada dos recursos hídricos (GIRH) pode ser definida como:

\begin{abstract}
as the coordinated planning, development and management of water, land and related resources, through multi-level and multi-sectoral dynamic and interactive problem-solving approaches, has been proposed as a mechanism for maximizing the economic and social welfare benefits from water development and use in an equitable and sustainable manner (JANSKY, NAKAYAMA e PACHOVA, 2008, p. 1).
\end{abstract}

De forma a integrar a gestão da água com o uso do solo e demais recursos, a GIRH reconhece a bacia hidrográfica como a unidade natural de gerenciamento da água e encoraja o desenvolvimento de gestão, planos, estratégias e instituições na escala da bacia. A GIRH foi proposta inicialmente no capítulo dezoito da Agenda 21, acordada 
durante a Conferência das Nações Unidas para o Meio Ambiente e Desenvolvimento (CNUMAD) realizado no Rio de Janeiro em 1992. E desde então o conceito se espalhou tanto em instituições internacionais quanto no interior dos países (JANSKY, NAKAYAMA e PACHOVA, 2008).

Apesar de sua ampla aceitação, inclusive no meio científico, a aplicação do conceito de GIRH para os recursos hídricos transfronteiriços, tanto superficiais quanto subterrâneos, tem se provado extremamente desafiador. Ainda que a cooperação em bacias compartilhadas tenha uma longa história e os benefícios da cooperação têm se mostrado interessantes para os países, a GIRH em bacias transfronteiriças parece ser um ideal longe de ser alcançado (JANSKY, NAKAYAMA e PACHOVA, 2008).

Conca aponta também para o aspecto da coordenação inerente a GIRH entre as várias escalas de gestão. Para este autor, a GIRH

\begin{abstract}
typically stresses three interrelated themes: recognition of the full range of social, economic, and ecological uses of water; "cross-sectoral" water management, in the sense of integrating planning and practices related to agricultural, industrial, municipal, and ecossystemic or in-stream demands for water; and water management at multiple scales and levels, in the sense of coordinating local, regional, national, and transnational practices and institutions (CONCA, 2006, p. 124).
\end{abstract}

\title{
Segundo a instituição Global Water Partnership:
}

IWRM is a process which promotes the coordinated development and management of water, land and related resources in order to maximize the resultant economic and social welfare in an equitable manner without compromising the sustainability of vital ecosystems (GWP, 2000b, p. 22).

Como os recursos hídricos apresentam diversos usos - irrigação, pecuária, aquicultura, pesca, recreação, navegação, geração de energia elétrica, uso industrial, abastecimento doméstico - existem também diversos usuários e, praticamente todas as pessoas da área da bacia hidrográfica são afetadas pela sua gestão. Neste caso também existe uma interdependência entre os usuários, pois alguns usos impossibilitam outros, ou precisam de certa coordenação para que possam todos utilizar os mesmos recursos de uma bacia hidrográfica.

Para que haja uma proteção e gestão efetiva dos recursos hídricos não basta a ação das instituições de gestão da água, porque os recursos hídricos são afetados por uma série de atividades humanas que são reguladas por suas próprias instituições setoriais (Moss, 2004). Por isso, é necessário que haja uma interação e coordenações de ações das instituições de gestão da água com as demais instituições setoriais relevantes. Neste sentido, a criação de mecanismos de coordenação institucional para melhorar a 
interação entre as instituições pode também ajudar a resolver os problemas de ajuste espacial entre as diferentes escalas de gestão (MOSS, 2004).

A gestão dos recursos hídricos de uma bacia hidrográfica para ser efetiva precisa antes passar pelo o processo de governança, que siga os princípios da chamada "boa governança”. As qualidades de boa governança da água incluem transparência, ampla participação dos atores afetados para a tomada de decisões de forma democrática, observância da lei, ética e controle da corrupção. A partir do processo de governança que se tomam as decisões de como gerenciar os recursos hídricos e que possibilita a resolução dos conflitos que possam emergir entre os usuários.

Em relação ao problema de escala, torna-se também necessária a coordenação e interação entre as instituições de diferentes unidades políticos administrativas, como também de diferentes setores. Portanto, as instituições de gestão de uma bacia hidrográfica têm um grande desafio de coordenação política. Elas dependem de outras instituições para que haja uma governança e gestão efetiva dos recursos hídricos.

Atualmente, existem no mundo várias instituições de gerenciamento de bacias hidrográficas compartilhadas espalhadas nos vários continentes. Uma iniciativa inédita neste tipo de gestão de bacias transfronteiriças foi a Diretiva Quadro sobre Água (DQA) da União Europeia criada em 2000, que busca estabelecer um quadro normativo transparente, eficiente e coerente para a política de recursos hídricos da Comunidade (MOSS, 2003). Ainda segundo o autor, o objetivo geral da diretiva é estabelecer uma estrutura legislativa para proteger as águas superficiais e subterrâneas na União Europeia através de uma abordagem comum da gestão com objetivos, princípios, medidas básicas e valores comuns.

Esta DQA traz um rompimento com as normas anteriores da União Europeia e preenche os vazios que haviam ficado para trás e harmoniza a legislação entre os paísesmembros. Além disso, a DQA:

\begin{abstract}
establishes the river basin as the unit for water management planning across $\mathrm{EU}$, strengthens the combined approach to pollution prevention, introduces economic analyses of water use, provides the general public with rights of participation in planning processes and establishes a detailed system of monitoring and reporting. These innovative elements relate, therefore, not simply to standards of water protection but above all to organizational aspects of water management (MOSS, 2003, p. 97).
\end{abstract}

Em termos teóricos, Moss (2003) define a DQA como uma reforma de uma instituição formal que foi criada para induzir a gestão dos recursos hídricos aos níveis mais baixos na hierarquia espacial. Trata-se, portanto, de uma iniciativa de "cima para 
baixo". A preocupação do autor se refere ao fato de que muitas vezes, as instituições formuladas de cima para baixo estão muitas vezes distantes dos usuários e pessoas envolvidas na gestão dos recursos em questão.

Para Moss (2003) a primeira questão crucial que a nova diretiva europeia impõe aos Estados é o estabelecimento da bacia hidrográfica como unidade de planejamento e gestão dos recursos hídricos. No caso de bacias compartilhadas, a diretiva coloca grande ênfase em buscar a solução de problemas conjuntamente. De acordo com os autores Mylopoulos e Kolokytha, "the management of transboundary river basins emerges as one of the most challenging issues related to the WFD implementation process" (2008, p. 349).

\subsection{A problemática do conflito e da cooperação na governança dos recursos hídricos transfronteiriços}

Nas bacias que englobam múltiplos Estados soberanos, uma das preocupações mais importantes é o desenvolvimento e a manutenção de instituições que permitam o compartilhamento dos recursos hídricos transfronteiriços de maneira igualitária. No entanto, apesar de uma série de acordos multilaterais já assinados que buscam promover a cooperação em rios internacionais, ainda existe uma grande preocupação com guerras e conflitos por água (DELLI PRISCOLI e WOLF, 2009).

Para Delli Priscoli e Wolf (2009, p. 22), a "vulnerabilidade hidropolítica" é o risco de ocorrer uma disputa política sobre um sistema hídrico compartilhado, e "resiliência hidropolítica" é a habilidade de um complexo sistema humano-ambiental de se adaptar a mudanças dentro deste sistema. Estes autores analisam nas bacias compartilhadas a existência de vulnerabilidade e/ou resiliência hidropolítica que possa levar a cooperação ou ao conflito entre os países que as compartilham.

Em grande parte da bibliografia sobre as relações envolvendo recursos hídricos de uma bacia hidrográfica compartilhada por dois ou mais países, os autores se concentram apenas na escala internacional do fenômeno, analisando as relações interestatais e pouco acrescentam sobre o caráter multi-escalar e de múltiplos atores da política da água. Tal como posto por Sneddon e Fox: "these and similar works understand conflicts over water as limited almost exclusively to inter-state conflicts, and thus have very little to say about the multi-scalar, multi-actor character of water politics" (2006, p. 182). 
Esta análise que privilegia as relações internacionais entre os governos nacionais, não dá visibilidade às outras iniciativas criadas por outros atores estatais (principalmente sub-nacionais), não-governamentais localizados em bacias compartilhadas que interagem e formam redes e instituições transnacionais. Nem sempre a cooperação é positiva para a preservação das condições ambientais das bacias compartilhadas. Em geral, na maioria dos países em desenvolvimento, os acordos de cooperação internacional sobre bacias compartilhadas é para propósitos de desenvolvimento, como construção de barragens para aproveitamento hidrelétrico e outros projetos de infraestrutura. Os acordos de cooperação sobre bacias transfronteiriças podem estar contribuindo para a intensificação da alteração das condições ambientais e também para a degradação socioambiental de populações que dependem dos recursos da bacia para sustentar o seu modo de vida (SNEDDON e FOX, 2006).

A simples existência de um acordo internacional não significa que esteja ocorrendo uma gestão compartilhada real dos recursos hídricos da bacia compartilhada. Para verificar se ocorre uma gestão compartilhada é preciso uma análise multi-escalar que permita ver como tais acordos afetam as políticas nacionais e locais de gestão dos recursos hídricos, em especial nas áreas de fronteira que são mais impactadas por alterações feitas nos Estados vizinhos, como foi aplicada neste trabalho nos capítulos três e quatro nos quais são analisadas as Bacias do rio Acre e do rio Napo.

Zeitoum e Mirumachi (2010) apresentam uma nova perspectiva para discutir as relações entre os países que compartilham uma bacia. Para estes autores, várias formas de conflito ocorrem, quase sem exceção, intercaladas com várias formas de cooperação. Eles afirmam que muitas pesquisas têm apontado para a coexistência entre o conflito e a cooperação, mas nas análises eles são tratados como formas de interação separadas. De modo que: "the less ugly faces of conflict and less pretty faces of cooperation are over looked, and the political aspects of interaction routinely ignored" (ZEITOUM e MIRUMACHI, 2010, p. 98).

Após uma análise da literatura sobre o assunto, estes autores concluem que a discussão separada da cooperação e do conflito como continuidades nas relações entre os Estados ribeirinhos leva ao estreitamento da reflexão sobre o tema ao simplificar demasiadamente situações de grande complexidade. Entender a cooperação e/ou conflito como um contínuo dificulta as explicações em situações em que há mudanças nos contextos políticos e que influenciam as relações ao longo do tempo. E, também, 
acabam por não dar visibilidade às múltiplas dimensões políticas da interação entre os países.

Outros autores (Kristin, 2007, apud ZEITOUM e MIRUMACHI, 2010) também concordam que este tipo de análise pode levar a uma visão de que todo o conflito é ruim e de que todo tipo de cooperação é inerentemente boa. Ou seja, o conflito pode demonstrar uma situação desigual ao acesso aos recursos hídricos. Sua deflagração pode servir para a solução desse problema, para além dos interesses nacionais.

Mylopoulos e Kolokytha (2008) ao analisar o caso dos rios transfronteiriços da Grécia apontam que os acordos internacionais bilaterais são importantes, mas não resolvem todo o problema. Para eles é necessário também um tratamento comum da integração dos aspectos quantitativos e qualitativos da água, dos diversos usos e, ainda, do fornecimento e da demanda de água na escala da bacia hidrográfica compartilhada:

\begin{abstract}
common will and especially political willingness and public participation can covert the existence of shared water resources from a problematic issue to a Strong motivation for transboundary co-operation. [...] The improvement of the existing legal framework or the creation of a legal agreement where it is missing, will enhance current transboundary co-operation. A series of issues will be regulated by the agreement such as: water protection and use, institutional arrangements, management plans, harmonization of programs and measures, monitoring and research, transfer of know-how and technology as well as joint projects. Of course it should be mentioned, that legal agreements per se are welcomed but cannot solve transboundary problems. Integration of qualitative and quantitative water aspects, water uses as well as water supply and demand issues confronted on a river basin scale and treated commonly is the only way that can guarantee transboundary coordination and co-operation (MYLOPOULOS e KOLOKYTHA, 2008, p. $352)$.
\end{abstract}

A cooperação internacional parece ser um requisito para a existência da governança nas bacias transfronteiriças, porém, ela precisa ser analisada em sua complexidade. A coexistência da cooperação e do conflito explica o porquê de algumas experiências de governança em bacias compartilhadas sofrerem retrocessos ou mesmo paralisarem. A existência de um acordo internacional sobre a bacia compartilhada, conforme já foi destacado, não é garantia de que não ocorram conflitos especialmente se este acordo não trouxer especificações sobre o uso, a qualidade e quantidade de água para cada país. Acordos internacionais que só contenham princípios gerais não irão prevenir a ocorrência de conflitos. Em alguns casos apesar da existência de cooperação entre os países que compartilham a bacia hidrográfica na escala internacional, ainda podem ocorrer conflitos na escala local das sub-bacias transfronteiriças, relacionados 
com problemas cotidianos do uso da água. A análise multi-escalar permite uma compreensão mais aprofundada da cooperação nas diversas escalas.

\subsection{Análise multi-escalar da governança dos recursos hídricos transfronteiriços}

Ao se escolher estudar o fenômeno da gestão de bacias hidrográficas transfronteiriças, a escala a ser considerada é a da bacia hidrográfica. No entanto, podese abordar este mesmo fenômeno em diferentes escalas, isto é, dentro da escala da bacia hidrográfica existem outros níveis de análise que devem ser considerados. Por exemplo, ao estudar a gestão dos recursos hídricos transfronteiriços da bacia amazônica, pode-se compreender o fenômeno na escala internacional, na interação entre os países amazônicos, na escala nacional, como cada país estabelece normas para este tipo de gestão, na escala regional e também na escala local de uma sub-bacia. Neste caso dos recursos hídricos transfronteiriços, outra escala deve ser analisada, a da região fronteiriça de uma sub-bacia transfronteiriça, ou seja, uma escala transnacional, tanto pelo aspecto físico da bacia como também pela rede social transnacional que se forma pelos atores envolvidos que nem sempre são transnacionais, embora atuem nessa escala.

Para isso é preciso delimitar as escalas geográficas do tema e, antes disso, o que se entende por escala, e quais as implicações de se estudar um mesmo fenômeno em diferentes escalas e a articulação que existe entre estas escalas.

O termo escala é utilizado em diferentes áreas da Ciência e da Filosofia, mas adquire uma importância fundamental para a Geografia. Por muito tempo a Geografia se utilizou da abordagem cartográfica da escala como uma representação do real a partir de um raciocínio matemático. Para Castro (2007) a Geografia apresenta grande dificuldade para definir um conceito operatório de escala, e aponta algumas questões relevantes sobre isso, como:

a escassez bibliográfica sobre o assunto; a geografia não dispõe de um conceito próprio de escala; há poucos autores que se preocupam com a escala como um problema metodológico essencial; a escala como problema metodológico na geografia é difícil e requer ainda grande esforço de reflexão e abstração (2007, p. 129).

Continua, todavia, sua discussão da escala como um problema epistemológico:

a palavra escala é frequentemente utilizada para designar uma relação de proporção entre objetos (ou superfícies) e sua representação em mapas, maquetes e desenhos, e indica o conjunto infinito de possibilidades de representação do real, complexo, multifacetado e multidimensional, constituindo um modo necessário para abordá-lo. A prática de selecionar 
partes do real é tão banalizada que oculta a complexidade conceitual que esta mesma prática apresenta (2007, p. 129).

A representação gráfica, o significado mais usual de escala, é apenas uma simplificação matemática que pode esconder a complexidade de se recortar a realidade espacial, que é mais complexa. A partir das formulações de Merleau-Ponty, Castro (2007) argumenta que a seleção de um recorte da realidade indica um ponto de vista que atribui pertinência ao objeto recortado. E formula a seguinte pergunta: "que porção do espaço deve ser considerada?" Para ela, cada recorte implica a constituição de uma "unidade de concepção" "que não tem necessariamente o mesmo tamanho ou a mesma dimensão, mas que coloca em evidência relações, fenômenos, fatos que em outro recorte não teriam a mesma visibilidade" (CASTRO, 2007, p. 134-135).

De fato, a escala tem sido abordada na geografia como uma questão metodológica, sendo tratada, muitas vezes, como naturalmente dada em um determinado estudo ou simplesmente como uma escolha metodológica. Ela pode ser vista como uma escala espacial e temporal, isto é, como uma medida física do espaço, como um "container" territorial (MOLLE, 2007). Também pode ser utilizada para analisar um fenômeno próprio de uma determinada escala, como a escala local ou a escala nacional.

As novas teorias sobre a escala na geografia humana têm apontado cada vez mais para o seu caráter de construção social e política. Mesmo que seja escolhida uma escala para abordar um tema, já é reconhecido que este mesmo tema pode apresentar características diferentes quando olhado em uma escala diferente. Nas últimas décadas, observam-se eventos que desafiam o uso tradicional da escala, como o princípio de hierarquia entre elas. Estes eventos são chamados na língua inglesa de "jumping scales" ou de "scale bending". Em sua análise dos eventos econômicos, Neil Smith (2004) aponta que não se trata apenas do fenômeno da globalização, e sim de mudanças profundas numa restruturação multidimensional das escalas geográficas nas quais é organizada a economia social.

A abordagem construtivista de escala, como a desenvolvida por Swyngedouw (2004) e Smith (2004), aponta que a configuração de uma escala é fruto de um processo sócio-espacial que organiza e regula as relações de poder na sociedade. Por isso, a importância em se estudar o processo em que uma escala é configurada e também transformada, pois este é o resultado do movimento das dinâmicas sociais e ambientais na luta pelo seu controle e dominação. De acordo com Swyngedouw (2004): 
Struggling to command a particular scale in a given sociospatial conjuncture can be of eminent importance. Spatial scales are never fixed, but are perpetually redefined, contested and restructured in terms of their extent, content, relative importance and interrelations. The continuous reshuffling and reorganization of spatial scales are integral to social strategies and an arena for struggles for control and empowerment (p. 133).

Este conceito de escala é importante para entender a utilização da escala da bacia hidrográfica para o gerenciamento dos recursos hídricos e os impactos que isto gera para a organização das instituições estatais dispostas em diferentes escalas. A construção de uma configuração escalar muitas vezes é utilizada para favorecer uma análise particular ou para justificar certas "soluções", ou ainda, para legitimar certos atores e suas estratégias (MOLLE, 2007).

Portanto, a ideia da operacionalização do termo escala "surge no processo operativo de pesquisa, ou seja, no desenrolar das diferentes etapas que constituem a experimentação, a análise e a síntese em diferentes campos científicos" (CASTRO, 2007, 135). É importante então delimitar os quatro campos fundadores da escala que são o referente, a percepção, a concepção e a representação.

A escala é fruto de uma escolha para recortar/dividir o espaço a partir da qual se percebe e concebe a realidade espacial, que é muito mais ampla, mas não pode ser apreendida em sua globalidade. A escala adquire uma figuração, uma representação, que modifica a percepção do espaço e substitui este espaço observado.

Castro (2007) afirma que:

\begin{abstract}
a escala introduz o problema da poliformia do espaço, sendo o jogo de escalas um jogo de relações entre fenômenos de amplitude e natureza diversas. A flexibilidade espacial institui, portanto, uma dupla questão: a da pertinência das relações como sendo também definida pela pertinência da medida na sua relação com o seu espaço de referência. Este é um problema fundamental na busca de compreensão da articulação de fenômenos em diferentes escalas [...] Portanto, para o campo de pesquisa da geografia não há recortes territoriais sem significado explicativo, o que há, muitas vezes, são construtos teóricos que privilegiam a explicação de fenômenos pertinentes a determinadas escalas territoriais $(2007,138)$.
\end{abstract}

Tendo em vista essas considerações, este trabalho busca utilizar a análise multiescalar do fenômeno da gestão dos recursos hídricos transfronteiriços. A maior parte da bibliografia sobre este tema tende a analisar somente a escala internacional da relação entre os Estados, esquecendo de considerar a articulação desta escala com outras de extrema relevância para a compreensão do problema, como, por exemplo, a análise das regiões fronteiriças que trabalham com questões mais cotidianas do compartilhamento dos recursos hídricos. 
É preciso compreender a articulação deste fenômeno em diferentes escalas, pois o mesmo problema adquire características diferentes na variação delas. Ou como apontado por Castro (2007) "quando o tamanho muda, as coisas mudam, o que não é pouco, pois tão importante como saber que as coisas mudam com o tamanho, é saber como elas mudam, quais os novos conteúdos nas novas dimensões" (p. 137). Justificase, assim, a importância de se analisar como se dá a gestão dos recursos hídricos transfronteiriços em cada escala envolvida, identificando os diferentes atores, as diferentes estruturas sociais, instituições e as variações que ocorrem de uma escala para outra.

Em seu estudo Swyngedouw (2004) demonstra como foi criada na Espanha uma nova escala para a gestão da água, a bacia hidrográfica, no período da passagem do século XIX para o século XX, mas que só foi possível de ser implementada durante a mudança para o governo ditatorial de Francisco Franco (1939-1975), que engendrou uma modernização do Estado e mudanças nas relações de poder. A divisão espacial da gestão por bacias hidrográficas foi apoiada por discursos científicos de que seria a divisão natural para a gestão da água e defendida pelo discurso hidráulico modernizador. De aproximadamente 900 barragens que existem na Espanha atualmente, 800 foram construídas a partir da segunda metade do século XX, ou seja, durante o período em que os engenheiros modernizadores estavam no poder e puderam implantar o novo modelo de gestão por bacia hidrográfica:

\footnotetext{
the history of the delimitation of Hydrological Divisions based on the river basin is infused with the influence of the modernizing hydraulic discourse, on the one hand, and the "scientific" insights gained from hydrology and orography on the other. The attempt to "naturalize" political territorial organizations was part and parcel of a strategy of the modernizers to challenge existing social and political power geometries. The construction of and command over a new territorial scale might permit them to implement their vision and by-pass more traditional and reactionary power configurations. Indeed, the older and historically constructed administrative political scales (municipality, province, and nation-state) were firmly under the hegemonic control of traditional semifeudal elites who held a tight grip over society and resisted the structural transformations called for by modernizers (Swyngedouw, 2004, p. 143).
}

Isto não significa que a mudança para uma gestão da água por bacia hidrográfica ocorra sempre de forma centralizadora e autoritária. No caso brasileiro, muitos autores apontam para o carácter descentralizador e participativo dos Comitês de Bacias Hidrográficas, criados pela recente lei da Política Nacional de Recursos Hídricos (PNRH) de 1997. Porém, uma nova configuração escalar vai sempre representar o 
resultado de um processo de luta de forças entre vários grupos e setores da sociedade. $\mathrm{O}$ surgimento de eventos de "scale bending" ou de "jumping scales" estão relacionados com um período de reorganização escalar, em que a estrutura territorial em questão já não serve para as funções para as quais foi criada ou não consegue se adaptar às novas demandas. Portanto, novas atividades sociais podem desestabilizar as antigas configurações escalares e criar novas.

Esta visão das escalas é importante para entender porque a utilização da escala da bacia hidrográfica para a gestão dos recursos hídricos vai gerar conflitos com as já configuradas fronteiras político-administrativas das escalas municipais, estaduais e nacionais. É o que Moss (2003) vai chamar de "problems of spatial fit", que podemos traduzir por problemas de ajuste espacial que ocorrem quando se quer gerenciar um sistema biofísico em territórios político-administrativos e os limites do sistema nem sempre coincidem com as fronteiras políticas.

Neste campo da geografia política diferentes escalas podem ser escolhidas para se analisar um fenômeno, como no caso deste trabalho, a governança da água. A escolha da escala da bacia hidrográfica revela que é preciso também observar outras escalas. Este recorte permite analisar tensões políticas entre as escalas territoriais políticoadministrativas e a nova escala da bacia hidrográfica.

Para Castro (2005), esses aspectos podem ser usados na análise da Geografia Política, o que revela um novo momento para a disciplina:

\footnotetext{
a escolha de apenas uma escala explicativa para a geografia política resultará numa visão incompleta, uma vez que, de acordo com Cox (1998), a política produz, ela mesma, escalas territoriais que devem ser analisadas enquanto tais. Na realidade, os fenômenos políticos não se confinam a uma ou outra escala, mas ao contrário podem ser, além de globais, também, nacionais, regionais ou locais. Cada uma dessas escalas define recortes significativos para a análise em geografia política. [...] Esta opção de dar visibilidade e consistência explicativa a múltiplas escalas dos fenômenos políticos no espaço reflete o momento epistemológico atual da disciplina, marcado pela superação do que Giddens chama de consenso ortodoxo, dominado por modelos explicativos abrangentes, e a possibilidade de recorrer a outros marcos teóricos mais adequados à complexidade daqueles fenômenos (2005, p. 86).
}

A configuração da escala da bacia hidrográfica não compreende a totalidade do problema. É também preciso analisar as outras escalas territoriais em que se formulam políticas e também se dão as tensões e conflitos sobre o uso dos recursos hídricos.

Usualmente se trata do tema de uma forma hierárquica, sendo a escala internacional a mais importante para se observar o fenômeno, como também para se 
resolver os conflitos que possa haver pelo uso dos recursos. No entanto, como se explica esta hierarquia? Na gestão dos recursos hídricos transfronteiriços, quais atores ou instituições são mais eficazes na tentativa de resolução de conflitos? Qual escala é mais impactada pelos conflitos pelo uso dos recursos hídricos transfronteiriços? Estas perguntas são importantes para a problematização da questão da hierarquia de escalas. Embora não haja uma explicação que possa confirmar que existe uma hierarquia, podese analisar como cada questão é tratada em cada escala.

A escolha da análise multi-escalar para o estudo da governança e gestão de uma bacia hidrográfica compartilhada, como a bacia amazônica, se deve porque a maioria dos trabalhos que analisam este tema se concentram apenas nas negociações entre os países envolvidos e os acordos e instituições gerados por elas. Trata-se uma visão muito parcial e simplificada do problema, em que muitas vezes se oculta o papel fundamental dos atores locais e nacionais para a mobilização, tomada de decisão e a própria resolução de conflitos. Além do mais, a própria governança da água possui um caráter multi-escalar.

Como aponta Trottier (2003) analisar os conflitos por águas compartilhadas apenas na escala internacional pode ser enganoso e tornar invisíveis as competições, tensões e conflitos em outras escalas que influenciam e, às vezes, determinam as relações externas. Ela argumenta que:

\begin{abstract}
in recent years, the water war and water Peace discourses have focused on whether or not interstate wars will be (or have been) waged over water. Restricting the analysis of water conflicts to the international scale can be quite misleading. It prevents us from observing and analyzing the intricate array of competitions and cooperations that are woven around water over many widely different scales by a great variety of social actors. The mechanisms at work within this intricate set of relations are driving water conflicts and/or their resolution. Understanding them necessarily requires a multiscalar analysis (TROTTIER, 2003, p. 1).
\end{abstract}

Esta autora defende a análise multi-escalar para se entender qualquer conflito internacional por recursos hídricos, bem como qualquer proposta de cooperação para a utilização em comum dos mesmos. Esta abordagem permite conhecer os conflitos e competições por água que ocorrem nas várias escalas e também as interações entre os atores (TROTTIER, 2003).

Entre os atores que atuam nas diferentes escalas da governança dos recursos hídricos transfronteiriços, além das instituições do Estado em seus diferentes níveis, nacional e subnacional, destacam-se os atores transnacionais. Os atores transnacionais 
que atuam na Bacia Amazônica são principalmente as ONGs ambientalistas, os movimentos sociais, as organizações indígenas e as corporações transnacionais.

$\mathrm{Na}$ escala local, mais especificamente, nas regiões fronteiriças a gestão dos recursos hídricos está fortemente ligada à gestão do território, isto é, ao uso e ocupação do solo. No entanto, a estrutura da gestão da água é elaborada no nível nacional e estadual. Além do que, é preciso se levar em conta o que o outro município, ou a outra parte da bacia separada pela fronteira está fazendo, pois pode impactar os dois lados. Em geral, a gestão local não possui recursos financeiros e técnicos suficientes para realizar a gestão dos recursos hídricos e a territorial além de não ter competência para trabalhar em cooperação com a parte da bacia do território vizinho.

Neste caso dos recursos hídricos transfronteiriços a escala local se dá nestas regiões fronteiriças, na qual a população tem que enfrentar cotidianamente os problemas resultantes do compartilhamento dos recursos hídricos e da falta de mecanismos eficientes para a sua gestão. Trata-se de uma escala muito peculiar e também muito diversificada, pelo significado das fronteiras políticas que separam os Estados e seus territórios.

\subsubsection{O papel dos atores transnacionais não-estatais}

As relações transnacionais podem ser definidas como interações regulares através das fronteiras nacionais quando ao menos um dos atores é um agente não-estatal ou não opera em nome de um governo nacional ou organização internacional. No entanto, esta definição é considerada por alguns autores, como Risse-Kappen (1995), como ampla demais para uma análise científica das relações transnacionais. Para ele é importante que os pesquisadores delimitem quais os atores estão sendo analisados quando se referem às relações transnacionais.

Segundo Risse-Kappen (1995) o que é interessante analisar nos atores transnacionais são as relações destes com os Estados e as instituições interestatais. Este autor procura analisar em quais circunstâncias os atores transnacionais são bem sucedidos ou falham ao tentar atingir seus objetivos. Ele se concentra em dois tipos de atores, o primeiro é motivado por objetivos instrumentais (que seriam as empresas transnacionais) e o segundo tem como objetivo influenciar as ideias, o conhecimento e a criação de normas. 
Ainda, Risse-Kappen (1995) aponta que os atores e as coalizões transnacionais podem ser diferenciados de acordo com o seu grau de institucionalização. Os atores mais institucionalizados são as Organizações Não-Governamentais Internacionais (ONGIs) e as corporações transnacionais (CTs). Estes atores são definidos por ele como estruturas burocráticas com regras explícitas e papeis específicos para os indivíduos e grupos trabalhando dentro da organização.

Khagram, Riker e Sikkink (2003) afirmam que as ONGIs são as formas essenciais de ação coletiva transnacional, bem como as redes de ativistas transnacionais, as coalizões transnacionais e os movimentos sociais transnacionais. Para estes autores as formas adotadas de ação coletiva transnacional podem influenciar as metas dos atores e sua efetividade. A dimensão transnacional pode diferir em cada caso, isto é, pode envolver fontes transnacionais dos problemas ou resultados transnacionais da ação coletiva. Os atores transnacionais são considerados relativamente fracos (se comparados com os Estados) e, por isso, o seu modo de influenciar e provocar mudanças nas instituições internacionais e nos governos é baseado principalmente na pressão moral, persuasão, e no uso da informação.

Para Sidney Tarrow (2005), os chamados movimentos sociais globais ou transnacionais estão conectados com a globalização e, no entanto, não podem ser explicados somente a partir dela. Um movimento social pode ser definido como um esforço público organizado e sustentado de reivindicações coletivas sobre determinadas autoridades utilizando para isso um repertório de argumentação por parte de um grupo de pessoas (TILLY, apud TARROW, 2005, p. 6).

Tarrow (2005) argumenta que apesar de ser a globalização o foco das reivindicações das mobilizações, é o internacionalismo, em sua forma complexa, que deu abertura a canais de resistência a globalização e oportunidades para a formação de movimentos e coalizões transnacionais. Com o crescimento da internacionalização, esta pode trazer novas oportunidades para estes movimentos, mas também novas ameaças (TARROW, 2005).

De acordo com Eschle e Stammers (2004), o primeiro problema no estudo dos movimentos sociais é exatamente esta confusão em torno da definição destes atores que são geralmente identificados como organizações de movimentos sociais transnacionais (OMSTs), redes de ativistas transnacionais e ONGIs. Para estes autores, deve haver uma distinção entre as organizações formais e o ativismo menos formal, pois, os OMSTs e as 
ONGIs não são o mesmo tipo de entidade organizacional, além disso, muitas ONGIS não têm qualquer vínculo com um movimento social.

Segundo Slater, os novos movimentos sociais surgem como arquipélagos de resistência que "têm o potencial de se conectar através dos espaços, mas que também são distintos, específicos e arraigados em contextos locais e regionais" (SLATER, 2000, p. 503). Essas novas formas de mobilização, de resistência e de movimento têm como característica marcante o senso de fluidez e flexibilidade, ou seja, ressaltam a necessidade de ir além das fronteiras nacionais. Estes movimentos aparecem em um contexto em que a sociedade civil começa a ganhar uma nova visibilidade. Por isso, os novos movimentos buscam "formas alternativas de 'fazer política' numa variedade de contextos culturais e contra um pano de fundo de projetos normalizadores da ordem e o poder global" (SLATER, 2000, p. 504).

A questão territorial assume uma posição central nos movimentos indígenas, pois como demonstra Slater (2000), a legitimidade e o funcionamento tido como normal do sistema político é passível de contestação. O movimento indígena na América Latina tem o potencial de revelar certos significados velados, como a aparente naturalidade do território nacional negando os territórios indígenas que existiam muito antes da chegada dos colonizadores europeus. É o que Slater (2000) chama de "guerras de interpretação".

Os movimentos sociais transnacionais, o movimento indígena e outros atores transnacionais estão presentes nas diversas escalas em que ocorre a governança dos recursos hídricos transfronteiriços da Bacia Amazônica, como será discutido nos próximos capítulos. Nos capítulos três e quatro sobre as Bacias do rio Acre e Napo, por exemplo, nota-se tanto a presença de ONGs, movimentos sociais, movimentos indígenas, quanto de corporações transnacionais, que estão geralmente envolvidas em atividades de exploração econômica que impactam diretamente os recursos hídricos. Esses atores sociais atuam na escala local e cada um tem um papel importante para a governança da água. 


\section{BACIA AMAZÔNICA: FORMAÇÃO TERRITORIAL, INTEGRAÇÃO TRANSFRONTEIRIÇA E COOPERAÇÃO INTERNACIONAL}

Este capítulo tem como objetivo compreender o contexto que permitiu o surgimento de iniciativas de cooperação e governança dos recursos hídricos transfronteiriços na Bacia Amazônica. Discute-se o processo de ocupação e formação das fronteiras amazônicas e suas adjacências. Posteriormente são analisadas as relações entre os países amazônicos multilaterais e bilaterais, e também as ações dos atores nãoestatais transnacionais, como as organizações indígenas e as Organizações NãoGovernamentais (ONGs). Esta discussão do contexto histórico e dos atores que atuam na Bacia Amazônica na escala internacional é a base para o estudo dos casos que serão analisados nos capítulos três e quatro deste trabalho, buscando compreender os atores e fatores envolvidos nesse processo de governança e gestão compartilhada da bacia nos dias atuais. Por último, são apresentados alguns dos principais problemas relativos aos recursos hídricos transfronteiriços na Bacia Amazônica que podem gerar tensões e conflitos.

\subsection{Ocupação e delimitação das fronteiras amazônicas}

Os países amazônicos herdaram características do período colonial como o imaginário e os mitos sobre a Amazônia que continuam permeando as políticas de ocupação, desenvolvimento e integração da região. A recuperação da história de ocupação da Amazônia permite compreender a situação recente das regiões fronteiriças e o processo de delimitação das fronteiras políticas entre os Estados. Entender a formação das fronteiras na Bacia Amazônica é essencial para compreender o contexto em que se dá a relação dos atores sociais presentes nela nos diferentes países, e que proporciona um processo de governança de seus recursos hídricos. Como pontua Coelho (1992, p. 73), “o tratamento da questão fronteiriça na Amazônia, como em qualquer outra parte, vincula-se ao processo de desenvolvimento e ocupação da região".

Para Amayo, a Amazônia precisa ser pensada como uma totalidade, pois, "sólo la totalidad posibilita la comprensión de la historia de la parte amazónica que pertenece a cada uno de los ocho países" (AMAYO, 1999, p. 76). E, de acordo com Moraes (2005): 
é importante recuperar a história da formação dos territórios atuais, num resgate retrospectivo dos processos que levaram à conformação das áreas de dominação estatal, movimento que a partir de certo momento (variável em cada caso, mas passível de ser periodizado em diferentes porções do planeta) cruza e amalgama-se com a questão nacional (p. 53).

Assim, por meio do contexto histórico compreendem-se "os processos sociais que resultaram em intervenções humanas nos lugares e na criação de materialidades e ordenamentos" (MORAES, 2005, pp. 52-53), que fragmentaram a Bacia Amazônica em diferentes Estadose, também, os processos no interior destes Estados que conformaram as diferentes "Amazônias” nacionais. A partir da compreensão da formação territorial das diversas "Amazônias" é que se torna possível entender o estabelecimento das fronteiras, as dinâmicas das regiões fronteiriças amazônicas e até mesmo as relações bilaterais e multilaterais entre os países amazônicos.

Como parte da América Latina, a Amazônia foi palco de disputa de várias potências europeias, principalmente Espanha e Portugal, mas também Inglaterra, Holanda e França. Sendo assim a área foi palco do colonialismo, "sistema de dominação política formal de algumas sociedades sobre outras" (QUIJANO, 2006, p. 416). Com a independência das colônias a região amazônica se fragmentou ainda mais em diferentes Estados. Moraes lembra que:

\footnotetext{
Nos países de formação colonial a dimensão espacial adquire considerável potência na explicação de suas dinâmicas históricas, pois a colonização é em si mesma um processo de relação entre a sociedade e o espaço. A colonização envolve uma sociedade que se expande e os espaços onde se realiza tal expansão, implicando apropriação da terra e submissão das populações autóctones defrontadas (2005, p. 92).
}

O território colonial é formado também por áreas onde não existe ainda uma ocupação, ou melhor, que ainda não foram incorporadas aos fluxos colonizadores: denominados de fundos territoriais. Com a independência das colônias esses fundos territoriais são objeto de diversas políticas para serem incorporados ao território nacional (MORAES, 2006). No Brasil, as ideias de conquista do território e construção do país são vistas como heranças do período colonial, que tem como objetivo ocupar os fundos territoriais. Esta ideia de conquista é evidente no caso da Amazônia brasileira, peruana, equatoriana, entre outras.

Apesar de o colonialismo ter ficado no passado, ainda permanecem certas crenças, ideias e imagens da Amazônia como um lugar "não-civilizado", inóspito, o "inferno verde", um "vazio demográfico" onde só há "mato", que fazem parte do imaginário sobre a região. Grande parte dessas ideias e crenças foram utilizadas como 
justificativas para a colonização e depois ocupação e "desenvolvimento" da região Amazônica. Faz parte deste imaginário a ideia de que a Amazônia é um vazio, uma ampla floresta com pouca gente, e que os povos que nela vivem são inferiores, nãocivilizados, incapazes de desenvolver a região. Mesmo dentro dos Estados independentes este imaginário da Amazônia continua e permeia as políticas e geopolíticas desenhadas para a região.

O Tratado de Cooperação Amazônica (TCA) publicou em 1992 uma obra intitulada "Amazonia sem mitos", que visa desconstruir os mitos sobre a região e oferecer um panorama da realidade naquele período (CADMA, 1992). Neste documento, é afirmado que:

\begin{abstract}
desde la llegada de los conquistadores la Amazonia há sido objeto de uma interpretación mitológica que se há alimentado del desconocimiento y del miedo, de verdades a medias y de generalizaciones o extrapolaciones falsas. Esos mitos han sido, con demasiada frecuencia, los principales motivadores de las concepciones para la ocupación y desarrollo de la Amazonia. [...] Entre estos destacan: (i) La homogeneidad de la Amazonia; (ii) El mito del vacío o de la virginidad amazónica; (iii)El mito de la riqueza y, a la par, el mito de la pobreza amazónica; (iv) El de la Amazonia "pulmón de la Tierra"; (v) El mito del indígena "freno para el desarrollo"; (vi) El mito de la Amazonia como solución o panacea para los problemas nacionales y por último, (vii) El mito de la "internacionalización de la Amazonia" (CADMA, 1992, p. 3).
\end{abstract}

Estes mitos sobre a Amazônia podem ser identificados nos relatos de viajantes e colonizadores europeus pela região ainda nos séculos dezesseis e dezessete. Tais mitos se misturam com os mitos de todo o continente americano, o chamado "Novo Mundo":

Também na América, a lenda das amazonas foi associada a existência do ouro. Aparecem no diário de Colón; Fernán Cortez as localizou na província de Ciguatán (costa ocidental do México) e, em carta a Carlos V, informava sobre o envio de expedições em busca de ouro e para resolver o mistério das amazonas. [...] O El Dorado, por outro lado, foi um mito americano. Foi também um mito "geográfico": em sua busca, como foi visto, organizaram-se expedições responsáveis por inúmeros descobrimentos no continente sulamericano (MACHADO, 1988, p. 11).

Os europeus chegaram e se estabeleceram primeiramente no litoral da América do Sul, e logo depois os espanhóis conseguiram chegar aos Andes. A conquista da Amazônia se deu décadas depois, com as primeiras entradas nas décadas de 1530 e 1540:

Dessas entradas (as expedições sob o comando de Alonso Mercadillo, Gonzalo Pizarro e de Francisco de Orellana) ficaram as impressionantes histórias sobre o País da Canela, o Reino do El Dorado, o Reino de Omágua e o Reino das Amazonas. Eram lugares fantásticos que haviam impulsionado, e alguns dos quais continuariam a impulsionar ou, pelo menos, a interessar aos conquistadores dos espaços amazônicos (UGARTE, 2009, p. 19). 
De acordo com Quijano (2006), mesmo com o fim do colonialismo, os povos da América Latina continuaram em uma relação de dominação colonial com a cultura ocidental (europeia). Para este autor ainda se vive a colonialidade na América Latina:

\begin{abstract}
trata-se de uma colonização das outras culturas, embora sem dúvida em intensidade e profundidade diferentes segundo os casos. Consiste, em primeiro lugar, em uma colonização do imaginário dos dominados. Ou seja, atua na interioridade desse imaginário. De certa forma, é parte dele. [...] As formas e os efeitos dessa colonialidade cultural têm sido diferentes dependendo dos momentos e dos casos. Na América Latina, a repressão cultural e a colonização do imaginário foram acompanhadas de um extermínio maciço e gigantesco dos indígenas, principalmente por seu uso como mão-de-obra desejável, além da violência da conquista e das doenças (QUIJANO, 2006, pp. 417-418).
\end{abstract}

Ainda que independentes permaneceram nos países latino-americanos muitos elementos de herança colonial, pois a "nova ordem política é construída sobre o arcabouço econômico e social gerado no período colonial” (MORAES, 2005, p. 91). Pode-se observar, por exemplo, no caso brasileiro que "os condicionantes da conquista espacial mantêm-se ativos num país marcado pelo domínio de vastos fundos territoriais" (MORAES, 2005, p. 91).

Essa ideia de expansão e conquista territorial é muito presente nos países amazônicos, o que pautou a visão destes sobre a Amazônia. Para Gonçalves (2001), as imagens da Amazônia a mostram como homogênea porque foram construídas a partir de fora da região. Ele identifica algumas visões mais comuns: a Amazônia como natureza imaginada, a Amazônia como região periférica, a Amazônia como questão nacional, a Amazônia como vazio demográfico e a Amazônia como reserva de recursos. Assim, "esse verdadeiro consenso que existe a respeito do que seja a Amazônia é, na verdade, uma imagem que foi contraditoriamente construída ao longo da História" (GONÇALVES, 2001, p. 17).

A partir destas imagens é que a Amazônia vai ser incorporada aos territórios nacionais. Apesar da falta de controle desta porção do território por parte dos Estados, que a herdaram do território colonial, foi preciso garantir a integridade territorial dos países recém-independentes com tentativas de integração territorial. É neste sentido que a Amazônia representa um fundo territorial para os países amazônicos. Esses países se formaram a partir de um território colonial que é formado também por áreas onde não existia ainda uma ocupação, ou melhor, que ainda não haviam sido incorporadas aos fluxos colonizadores, e desta foram, são denominados de fundos territoriais. Com a 
independência das colônias esses fundos territoriais são incorporados ao território nacional (MORAES, 2006).

Este processo ocorreu de forma semelhante em todos os países amazônicos, como é o caso da Colômbia, demonstrado no estudo de Serje (2011) acerca do projeto geopolítico colombiano. Para esta autora, o território nacional colombiano é fruto da área de ocupação colonial, no entanto, este território nacional tinha limites muito maiores do que aqueles da ocupação colonial de fato, e incluía áreas que o Estado não tinha o menor controle sobre elas. E, da mesma forma que no Brasil, um dos maiores objetivos do Estado colombiano era a integração nacional e o controle de todo o território nacional:

El proyecto geopolítico se podría resumir entonces, tomando prestadas las ideas que propone J. J. González en la resolución de "este secular desequilibrio entre estructura territorial, sociedad y Estado [en el que] está la raíz misma del conflictivo proceso de conformación del Estado Nacional". Así, la "construcción de la nación" depende en buena medida de la consolidación del "espacio nacional efectivo o integrado, es decir aquel sobre el cual el Estado despliega con toda su legitimidad". El logro de todo lo anterior depende de "un proyecto de integración nacional que vincule a todas las regiones equilibradamente a su desarrollo" y, sobre todo, que garantice su participación en las políticas macroeconómicas y sectoriales, lo que garantizaría la superación de "la diferenciación entre áreas centrales, vinculadas estrechamente al desarrollo nacional y beneficiárias directas de las políticas de desarrollo asumidas por el Estado, y estas áreas periféricas, marginales o de atraso" (SERJE, 2011, p. 145).

Todavia, a tentativa de ocupação dos fundos territoriais por parte dos países amazônicos não elimina o caráter periférico da Amazônia que:

será sempre vista nos novos Estados com um peso político marginal nos blocos de poder nacional e, portanto, sem voz própria. É uma região periférica de países periféricos. Em outras palavras, é uma região subordinada na hierarquia de poder no interior dos seus próprios países. Ela é sempre vista a partir dos interesses nacionais e estes estão definidos nos centros hegemônicos do poder nacional (GONÇALVES, 2001, p. 25).

As tentativas de integração da Amazônia ao território nacional dos países amazônicos correspondem ao processo de modernização do território. Porque integrar a região amazônica significava integrar a região à economia nacional. Este processo carrega em si uma colonialidade, pois está baseado no modelo europeu de modernização do território que apresenta um conteúdo de segregação tanto social quanto territorial. Não se trata de um processo simplesmente de valorização do espaço entendido como um "processo universal de apropriação do espaço natural e de construção de um espaço social pelas diferentes sociedades ao longo da história" (MORAES, 2005, p. 41). E sim, 
de uma modernização do território baseado no modelo de modernidade europeu em que a colonização fez parte de sua construção.

Para Guillaume Fontaine:

La irrupción de la modernidad en la Amazonia se produjo en cuatro etapas: el período que separa el descubrimiento y establecimiento de las primeras misiones católicas en los siglos XVI-XVIII, el auge de la economía mundial del caucho en el siglo XIX, la colonización agrícola y la creación de los primeros centros de comercio en la primer mitad del siglo XX, y la irrupción del capitalismo moderno con la entrada de las empresas nacionales y multinacionales en la región en la segunda mitad del siglo XX (2007, p. 251).

É preciso entender esse processo de modernização do território que ocorre na Amazônia para compreender como, atualmente, a imensa Bacia Amazônica espraia-se por territórios de sete países e é classificada como uma bacia internacional, ou transfronteiriça, e os desafios à governança dos seus recursos hídricos. O fato é que seus recursos hídricos são compartilhados por estes sete países, e tal compartilhamento é fruto da história que levou a formação das fronteiras políticas e que teve início com a conquista e colonização da América.

Quando os colonizadores europeus chegaram à Amazônia no século XVI, ela estava povoada por diversos povos nativos. $\mathrm{O}$ encontro entre os europeus e estes povos levou ao genocídio de milhares de indígenas.

Os diversos povos, com suas diferentes culturas e línguas, que habitavam a Amazônia, em geral viviam próximos às águas. Os inúmeros cursos d'água que existem na imensa Bacia Amazônica foram fundamentais para a ocupação indígena. E, posteriormente, com a chegada dos europeus, para a colonização desta região, pois foi através dos rios que eles começaram a ocupar a Amazônia:

Grandes e médios rios a oriente dos Andes, navegáveis na maior parte de
suas extensões, levaram os adventícios das diferentes expedições
descobridoras/conquistadoras às entranhas da verdejante e gigantesca Hileia.
Sua navegabilidade permitiu aos conquistadores chegarem à principal artéria
do sistema fluvial amazônico, o Paraná Guaçu (Rio Grande) dos indígenas
de fala tupi, que os espanhóis batizaram, em diferentes momentos, com as
denominações de Santa Maria del Mar Dulce, Marañon, rio de Orellana e,
finalmente, rio das Amazonas. E mais do que qualquer outro, o rio Amazonas
foi o caminho cenário, o fio condutor das tramas narrativas elaboradas pelos
cronistas, tanto dos êxitos quanto dos insucessos ocorridos aos
descobridores/conquistadores ibéricos que percorreram a Amazônia nos
séculos XVI e XVII (UGARTE, 2009, p. 169).

A primeira fronteira internacional a ser demarcada na Bacia Amazônica foi entre Espanha e Portugal que já haviam repartido a América entre si com a assinatura do Tratado de Tordesilhas, em 1494. E alguns anos depois, já no século XVI, a região 
começa a ser disputada não apenas entre estes dois países, mas também por outras potências europeias, com a chegada dos franceses, holandeses e ingleses que também tentaram conquistar a porção no Novo Mundo.

Os franceses fundaram São Luís, em 1612, e tentaram ocupar o litoral da colônia portuguesa, mas foram expulsos pelos portugueses. No entanto, já haviam se estabelecido em Caiena desde fins do século XVI dando origem à colônia da Guiana Francesa, hoje território ultramarino francês. Os ingleses e holandeses disputaram a região que hoje pertence ao Suriname e Guiana. Esta disputa foi em parte solucionada com a assinatura do Tratado de Breda em 1667, passando o Suriname para o controle holandês e a Guiana foi oficialmente comprada em 1813 e chamada oficialmente de Guiana Inglesa em 1831.

No entanto, grande parte da Bacia Amazônica ficou sob domínio das Coroas Portuguesa e Espanhola. Se o Tratado de Tordesilhas tivesse realmente sido cumprido, praticamente toda a bacia ficaria para os espanhóis. O expansionismo português, e sua diplomacia, levaram à conquista portuguesa desta parte do território sul-americano. Além disso, a geografia beneficiava os portugueses já que partiram desde a foz do Amazonas e puderam subir o rio e seus afluentes que são navegáveis por uma longa extensão. Ao contrário dos espanhóis, que para chegar à planície amazônica tiveram que transpor a Cordilheira dos Andes.

O primeiro europeu a percorrer o rio Amazonas foi o espanhol Francisco de Orellana, que alcançou a sua foz no ano de 1542, vindo dos Andes, pelo rio Napo. Os portugueses só passaram realmente a se interessar por conquistar e ocupar esta área após a segunda década do século XVII com a criação dos estados do Maranhão e Grão-Pará, visando conter o avanço dos franceses, holandeses e ingleses que já se instalavam pela região. O primeiro viajante português em viagem oficial para o reconhecimento do rio foi Pedro Teixeira, que subiu seu curso rumo ao Peru entre 1637 e 1639. Também o bandeirante Raposo Tavares chegou à região percorrendo os rios Mamoré, Madeira e Amazonas, alguns anos mais tarde (MATTOS, 1980; COSTA E VLACH, 2007; GADELHA, 2002).

Os espanhóis, assim como os portugueses, buscaram estabelecer fortes ao longo dos rios, já que estes eram a principal via de acesso ao território amazônico, e precisavam garantir o domínio do território contra as outras potências europeias. Estes fortes deram origem às vilas e pequenas cidades. No entanto, os forte militares não bastavam para garantir o controle do território, por isso, as Coroas espanholas e 
portuguesas deixaram a cargo das ordens religiosas a "pacificação" dos indígenas, que estabeleceram as missões (PAREDES, 1994; MACHADO, 1997; HEMMING, 2009; FONTAINE, 2006). Muitas missões também deram origem a cidades, principalmente depois que o Marques de Pombal assumiu o governo da colônia portuguesa do GrãoPará e expulsou os jesuítas, acabou com as missões e instituiu o Diretório ${ }^{8}$.

Foi devido a esta ocupação dos fortes e missões transformados em vilas e cidades que Portugal teve argumentos para revogar o Tratado de Tordesilhas. No início do século XVIII, durante o Congresso de Utrecht que visava regular a sucessão da Coroa espanhola, Portugal buscou garantir a sua posse sobre a Amazônia:

a diplomacia portuguesa, num dos seus lances de maior brilho, conduzida, no evento, pela astúcia e pertinácia de Dom Luís da Cunha e do Conde de Tarouca, obteve o assentimento expresso da França e da Inglaterra no sentido de que renunciavam a ampliar seus estabelecimentos coloniais na América do Sul, desistindo, pois, de se fixarem na foz do Rio Amazonas e de o navegarem livremente, contra a vontade da Coroa Lusitana (PALM, 2009, p. $15)$.

Alguns anos mais tarde o princípio do utis possedetis, isto é, a ocupação do território que determina a sua posse, foi utilizado para demarcar os domínios espanhóis e portugueses pelo Tratado de Madri, assinado em 1750. Este tratado praticamente delimitou o território que viria a ser do Brasil, apenas com algumas modificações que ocorreram após a independência brasileira.

No século XIX a independência das colônias espanholas e portuguesas e a formação dos novos Estados acabaram dividindo a Bacia Amazônica em diferentes territórios nacionais, que passaram a delimitar e demarcar suas fronteiras. Em muitos casos constituíram-se comissões de fronteira para definir e demarcar exatamente os limites. A última fronteira a ser delimitada no Brasil na região amazônica foi o território do Acre, antes pertencente a Bolívia, que após um conflito com os habitantes locais, acordou-se a compra do território pelo Brasil, através do Tratado de Petrópolis de 1903, negociado pelo Barão do Rio Branco. Os outros limites do Brasil com o Peru, França, Inglaterra, Holanda, Venezuela e Colômbia foram negociados e acordados

\footnotetext{
${ }^{8}$ A Lei da Liberdade promulgada pelo rei português Dom José I em 1755 visava libertar os indígenas das missões, mas na verdade passava a sua dominação para os Diretórios, criados pelo governo: "Mendonça Furtado esperou até fevereiro de 1757 antes de publicar o decreto que libertava as aldeias indígenas do controle missionário. Em seguida anunciou que determinava um período de transição de seis anos antes de conceder a liberdade aos índios. Essa liberdade nunca se consumou; a ousada experiência de tratar os índios como cidadãos e de conceder-lhes o controle de sua própria aldeia foi nulificada. Em maio de 1757, Mendonça Furtado promulgou um longo decreto mediante o qual os "diretores" brancos passavam a encarregar-se das aldeias indígenas. Esse novo sistema ficou conhecido como Diretório e vigorou nas 66 aldeias do Maranhão e do Amazonas durante quarenta anos. Em breve se estenderia ao resto do Brasil" (HEMMING, 2009, p. 40).
} 
pacificamente. A fronteira amazônica entre Equador e Peru, por outro lado, foi palco de um conflito que durou quase cem anos, encerrado em 1998. Também a fronteira entre Peru e Colômbia foi palco de conflitos que foram encerrados após a assinatura de um tratado em 1934.

No entanto, a criação de novos Estados não levou à ocupação e consolidação definitiva dos territórios amazônicos em seus respectivos países. A região amazônica passou por décadas sem ser explorada, ou ocupada de forma intensiva, sem grande integração com o restante do território nacional, e muito menos com os países vizinhos.

Como explica Fontaine, as missões religiosas cumpriam o papel do Estado naquela parte do território:

Las misiones fueron entonces intentos para compensar, en diversas épocas, esa debilidad de la administración estatal, pero lo que caracteriza la época moderna y va desde la primera expulsión de los jesuitas hasta su regreso en la región (1767-1870), es un vacío administrativo por el cual el Estado perdió el control adquirido bien o mal por la burocracia real (2007, p. 261).

Foi o ciclo da borracha que impulsionou o interesse sobre a região e intensificou a sua ocupação:

O boom da borracha modificou as condições locais de tal forma que pela primeira vez o termo "Amazônia" foi empregado para designar o extremo Norte. A economia da borracha marcou o início da intervenção norteamericana na região amazônica e, de forma geral, na América do Sul e, além disso, foi responsável pela integração da área ao mercado internacional (MACHADO, 1997, p. 22).

A comercialização da borracha gerou uma pressão, principalmente, por parte dos Estados Unidos da América, o maior comprador de látex do Brasil, para a abertura do rio Amazonas à navegação internacional. Esta foi uma das primeiras questões relativas ao compartilhamento dos recursos hídricos da Bacia Amazônica que os países tiveram que resolver. O governo brasileiro receava abrir o rio Amazonas à navegação internacional por se tratar de uma área de baixa ocupação e, portanto, um alvo fácil para ser tomado por outros países. Assim, criou a província autônoma do Alto Amazonas em 1852 e autorizou a navegação a vapor por parte de uma empresa brasileira que contava também com fundos públicos (MACHADO, 1997; PALM, 2009). Todavia, sob grande pressão internacional:

o monopólio sobre a navegação a vapor por parte da firma brasileira foi anulado e a navegação do rio Amazonas finalmente aberta em 1866, enquanto a navegação a vapor tornou-se, mais tarde, monopólio de uma firma estrangeira (1874). O governo imperial havia concluído que a única forma de manter a Amazônia como parte do país seria harmonizar sua política nacional 
com "os ideais do século que condenavam a exclusão da região do comércio mundial" (MACHADO, 1997, p. 23).

O ciclo da borracha intensificou a colonização da Amazônia no Brasil, Peru, Colômbia, Equador e Bolívia. Neste período, a mão-de obra utilizada, seja a indígena ou a dos imigrantes, sofria condições de trabalho pré-capitalistas semelhantes à escravidão. No Equador, esta colonização impulsionada pela borracha permitiu ao governo multiplicar as concessões de mineração e petroleiras a empresas estrangeiras no início do século vinte (FONTAINE, 2007). No caso do Brasil:

Com a valorização da borracha e a integração de sua área produtora ao
mercado internacional modificaram-se as condições locais e, pela primeira
vez, o termo "Amazônia" é utilizado para designar as províncias do extremo-
norte do país. A integração econômica com o exterior parecia indicar a
continuidade do passado colonial, quando os laços com Portugal eram mais
fortes do que com o resto do país. No entanto, não foi assim. O governo
central, composto em sua maior parte, por representantes das regiões nordeste
e sudeste, se beneficiou largamente através da aplicação de altas tarifas de
importação-exportação. [...] A disposição espacial das árvores produtoras da
borracha [...] e a organização da economia gomífera, provocaram a expansão
do povoamento numa escala desconhecida até então. Três aspectos
sobressaem: o desenvolvimento da forma urbana, mesmo que de maneira
restrita e difusa; a municipalização do território; e a configuração de uma
"fronteira móvel" (MACHADO, 1989, p. 325-326).

Com a decadência do ciclo da borracha no início do século $\mathrm{XX}$, os países amazônicos criam novos projetos para a ocupação da área e para a expansão das fronteiras internas. No Equador e no Peru, a exploração do petróleo na Bacia Amazônica teve início na década de 1920. No caso do Brasil, o governo estabeleceu grandes incentivos para a ocupação da Amazônia a partir da década de 1950, intensificando os esforços a partir dos anos 1970 com projetos de colonização agrária, construção de rodovias, a criação da Zona Franca de Manaus, entre outros (BECKER, 2007). No Peru teve início na década de 1940, com a construção da estrada conectando Lima a Pucallpa (PAREDES, 1994).

Os países amazônicos buscavam formas de integrar suas respectivas porções amazônicas ao restante do território nacional, principalmente com a construção de estradas e outras vias de acesso. Estes esforços de ocupação e integração continuaram a expulsar as populações indígenas de seus territórios, impulsionaram a ida de imigrantes de outras regiões dos países amazônicos, o que ocasionou diversos conflitos pelo uso da terra, como no caso dos seringueiros no Brasil, que viram suas terras serem ocupadas por fazendeiros (de gado, principalmente). A figura 1 demonstra a formação das fronteiras políticas na Bacia Amazônica que a fragmentou em diferentes países. 
Figura 1:

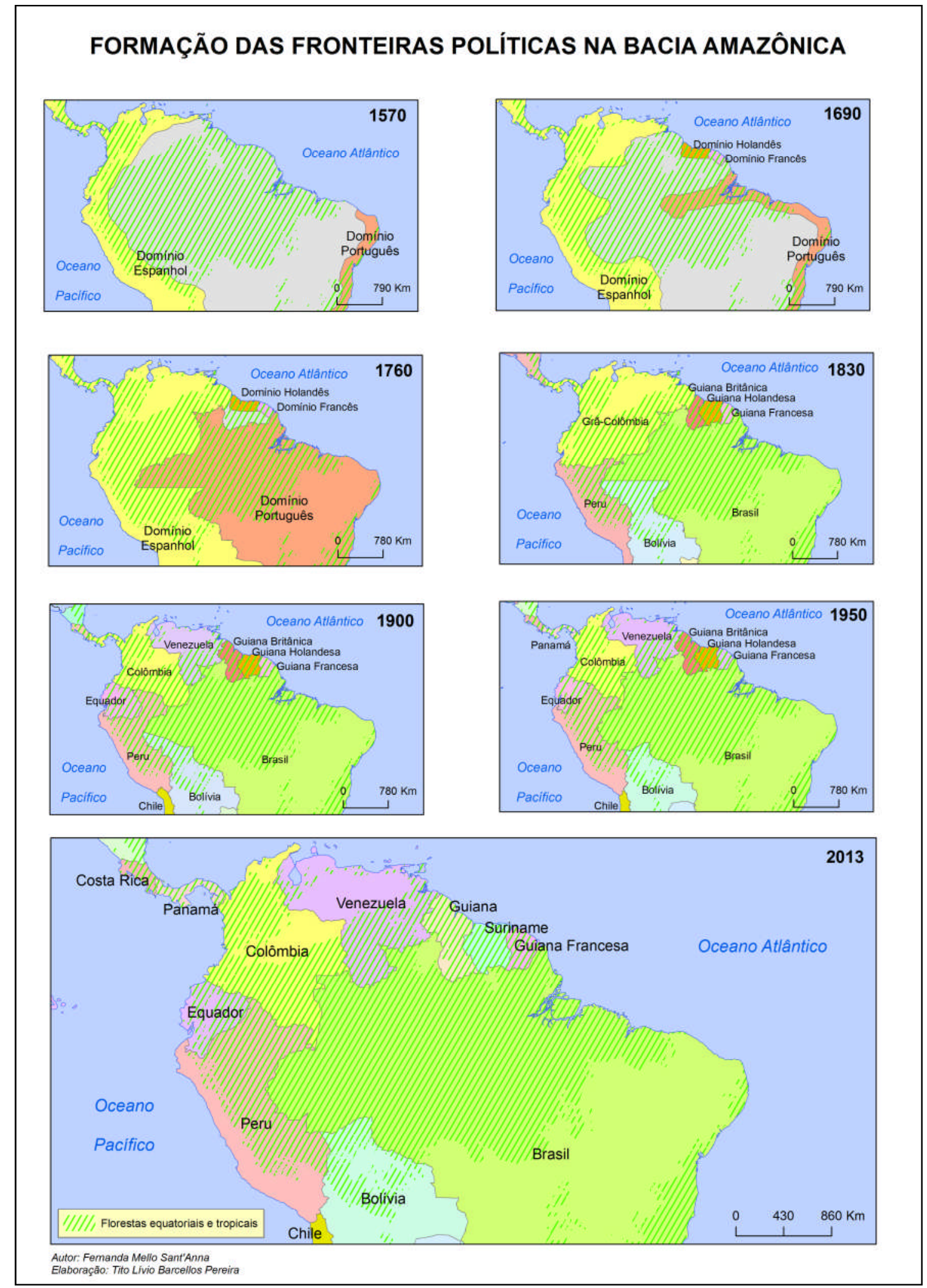

Os intentos para delimitar as fronteiras na Amazônia, desde a época colonial, e depois com os países independentes resultaram em tensões e conflitos entre os Estados 
recém-independentes. Mas a consolidação das fronteiras não evitou que nelas se formassem regiões fronteiriças com diferentes tipos de interação.

\title{
2.1.1 A integração transfronteiriça da Bacia Amazônica
}

Os países amazônicos, baseados em uma visão de vazio demográfico, já comentada, preocuparam-se em propor estratégias de interiorização das atividades econômicas na Amazônia, e também para evitar a cobiça internacional. Após o estabelecimento das fronteiras internacionais na Amazônia, os países amazônicos se voltaram para o que denominaram de fronteira interna. Como bem salienta Parodi, “"empty space', 'void', and 'frontier' were central concepts used by South American state officials to define Amazonia. Because the boundary treaties already existed, each state viewed Amazonia as an 'internal frontier'” (PARODI, 2002, p. 111). Este período é sintetizado no caso da Amazônia brasileira da seguinte forma:

\begin{abstract}
O estado toma para si a iniciativa de um novo e ordenado ciclo de devassamento amazônico, num projeto geopolítico para a modernização acelerada da sociedade e do território nacionais. Nesse projeto, a ocupação da Amazônia assume prioridade por várias razões. É percebida como solução para as tensões sociais internas decorrentes da expulsão de pequenos produtores do Nordeste e do Sudeste pela modernização da agricultura. [...] Para acelerar a ocupação regional, modernizam-se as instituições. [...] Entre 1968 e 1974, o Estado brasileiro implantou tal tipo de malha na Amazônia, visando completar a apropriação física e controlar o território (Becker, 1990). [...] Esta fase foi ainda marcada por imensos conflitos sociais e impactos ambientais negativos: conflitos de terra entre fazendeiros, posseiros, seringueiros, e índios, desflorestamento desenfreado pela abertura de estradas, exploração de madeira seguida da expansão agropecuária e intensa mobilidade espacial da população (BECKER, 2007, p. 26-27).
\end{abstract}

Este processo de ocupação e integração da Amazônia aos territórios nacionais gerou diversos conflitos socioambientais. Enquanto que os conflitos fronteiriços internacionais foram se solucionando nos últimos anos, um processo de integração regional ganhou um novo impulso a partir dos anos 2000. Essa integração, todavia, não invalida e nem minimiza o significado das fronteiras internacionais, mas adiciona um novo aspecto à elas.

No caso sul-americano, muitas regiões fronteiriças apresentam ausência (ou precariedade) de redes de transporte e de comunicação, pois possuem um peso político e econômico menor em relação aos centros nacionais. E são poucas as iniciativas de integração regional que têm incorporado a integração fronteiriça em seus objetivos e arcabouço institucional. Desta forma, "a cooperação entre países vizinhos em regiões de 
fronteira tem sido feita informalmente, e através de acordos tácitos entre as autoridades locais dos países fronteiriços" (MACHADO e STEIMAN, 2002, p.7-8).

Existe um potencial nas regiões fronteiriças para intensificar a cooperação internacional entre os países vizinhos, porém também existe uma influência sobre elas do contexto internacional, por exemplo, das relações bilaterais/multilaterais entre os países fronteiriços. Coexistem nestas regiões elementos de integração e de desintegração. As iniciativas de integração são, em muitas regiões fronteiriças, fruto do interesse de suas próprias elites e governos. E muitas vezes, os fatores que geram um afastamento são fruto de decisões tomadas a nível nacional, muito longe e sem conexão com as regiões de fronteira (MACHADO e STEIMAN, 2002).

Os processos de integração regional na América Latina iniciaram nos anos 1960 e pouco mencionavam as fronteiras, como foi o caso da Associação Latino-Americana de Livre Comércio (ALALC) e da Associação Latino Americana de Integração (ALADI). Com o tempo, a integração fronteiriça passou a fazer parte das preocupações relativas à integração regional, como foi o caso com a Comunidade Andina de Nações (CAN) e o Mercado Comum do Sul (Mercosul) (SELA, 2011). A Iniciativa para a Integração da Infraestrutura Regional Sul-Americana (IIRSA) ${ }^{9}$ e o Projeto Mesoamérica $^{10}$ que visam a integração física dos países membros também são vistas como importantes para a integração fronteiriça na América Latina:

\begin{abstract}
Las iniciativas de inversión en infraestructura que representan el Proyecto Mesoamérica y la IIRSA, deberán constituirse en los factores detonantes de las posibilidades de mejora de la calidad de vida y de crecimiento de las economías fronterizas en ALC (América Latina y Caribe); desde ya, algunas de las fronteras de la región están empezando a beneficiarse de las dinámicas que representa la opción de contar con infraestructuras que conectan grandes regiones interiores de ALC con los puertos y los mercados de exportación, dado el incremento de los tráficos y la demanda de servicios cada vez más diversificados y en mayor cantidad que ellos suponen (SELA, 2011, p. 60).
\end{abstract}

A integração física e construção de infraestruturas nas regiões fronteiriças certamente as afetarão, por isso, uma questão de grande importância para elas é a de "se inserir nas diversas redes transnacionais que as atravessam, sem desempenharem

\footnotetext{
${ }^{9}$ A IIRSA foi estabelecida em 2000 pelos governos dos doze países sul-americanos visando integrar a infraestrutura dos países da América do Sul, e desde 2010 faz parte da União das Nações Sul-Americanas (UNASUL) por meio do Conselho de Infraestrutura e Planejamento (COSIPLAN), como seu fórum técnico (IIRSA, 2013).

${ }^{10}$ O Projeto de Integração e Desenvolvimento de Mesoamérica, conhecido como Projeto Mesoamérica, foi lançado oficialmente em 2008, com o objetivo de integrar fisicamente os territórios de seus países membros mediante projetos de infraestrutura, e inclui o seguintes países: México, Belize, Guatemala, El Salvador, Honduras, Nicarágua, Costa Riva, Panamá, Colômbia e República Dominicana (CEPAL, 2009).
} 
fatalmente o papel de mero ponto de passagem" (MACHADO e STEIMAN, 2002, p. 10). Porque apenas a construção de estradas e hidrovias, por exemplo, cortando as fronteiras não irá garantir mudanças significativas para o desenvolvimento regional e a qualidade de vida dessas populações se não houver um planejamento e ações para evitar que elas se tornem apenas "pontos de passagem".

É preciso também notar outro aspecto das zonas de fronteira relativas à consolidação das soberanias nacionais, pois são áreas que estão afastadas do centro de governo e, que, portanto, podem desenvolver interesses diferenciados do governo central, além de ser uma constante preocupação para o Estado que deve zelar pela sua garantia, controle e fiscalização. Isto se evidencia no caso de atividades ilegais que cruzam as fronteiras dos Estados e são ameaças à ordem constituída (BECKER, 2007). Por isso, por mais que os países busquem formas de integração física e maior cooperação com os países vizinhos, sempre vai existir uma preocupação em tentar barrar aquilo que não é de interesse, e assegurar o controle e a soberania sobre as fronteiras e o território.

Cuisinier-Raynal (2001) propõe uma tipologia das interações fronteiriças de acordo com sua análise na América do Sul, no Peru. Ele propõe cinco cenários para classificação dessas interações: "marges”, "marches”, "fronts”, "synapses" e “capillaires". No documento brasileiro da Proposta de Reestruturação do Programa de Desenvolvimento da Faixa de Fronteira (MIN, 2005), esta tipologia é traduzida e aplicada ao caso do Brasil, propondo os mesmo cinco tipos de interações fronteiriças: margem, zona-tampão, frente, capilar e sinapse. No caso das interações de "margem" o contato entre os dois lados da fronteira é praticamente inexistente, sendo apenas familiar ou pequenas trocas comerciais. O Estado não investe nesta zona, que não possui infraestrutura de conexão e, portanto, as relações mais fortes são as nacionais, no interior de cada Estado. Na interação fronteiriça da "zona-tampão" existem relações esporádicas entre os dois lados da fronteira, mas o Estado restringe ou interdita o acesso a esta zona, seja por meio da criação de um Parque Nacional, ou de um Território Indígena. As interações tipo "frentes" podem corresponder a uma frente militar que ocupa as faixas de fronteira, mas também são as frentes pioneiras na escala nacional ou frentes de povoamento, e também as frentes indígenas tanto na escala nacional quanto bilateral. No cenário "capilar" existe interação entre os dois lados apenas no nível local, trata-se de uma integração fronteiriça espontânea, onde o Estado central intervém pouco. E por último, a fronteira caracterizada pela interação tipo "sinapse" corresponde 
aquela com alto grau de interação transfronteiriça, com apoio do Estado para a construção de infraestrutura de conexão e comunicação, onde as cidades gêmeas são o melhor exemplo. De acordo com este documento:

praticamente todas as cidades gêmeas articuladas por pontes pertencem a este tipo, sendo eles estratégicos para o comércio bilateral. No caso dos vizinhos do Cone Sul, muitas cidades do outro lado do limite internacional ganharam o estatuto de Zona Franca exatamente para estimular as trocas internacionais (MIN, 2005, p. 147).

As cidades gêmeas são adensamentos populacionais que pertencem a países diferentes, pois são cortados pela linha de fronteira e são "o meio geográfico que melhor caracteriza a zona de fronteira” (MIN, 2005, p. 21). A zona de fronteira:

É composta pelas "faixas" territoriais de cada lado do limite internacional, caracterizadas por interações que, embora internacionais, criam um meio geográfico próprio de fronteira, apenas perceptível na escala local/regional das interações transfronteiriças (MIN, 2005, p. 21).

As cidades gêmeas são parte de diferentes redes sobrepostas, pertencem a uma rede regional, nacional e transnacional. São cortadas por diversos fluxos, como de trabalho, capital, serviços, recursos naturais, etc. Além disso, nelas também podem atuar redes ilegais nas zonas de fronteira, como as redes de drogas ilícitas e de armamentos ilegais.

As regiões fronteiriças também lidam cotidianamente com $o$ fato de compartilharem recursos naturais, já que a natureza não obedece às convenções políticas. Este é o caso dos recursos hídricos de bacias hidrográficas transfronteiriças, pois a água flui de um território ao outro, não importando a existência das linhas divisórias. Isto acarreta uma interdependência entre as cidades e comunidades que os compartilham, que, em geral, acabam criando mecanismos informais de cooperação para gerir os recursos compartilhados. Esta situação está presente na Bacia Amazônica que, por ser transfronteiriça requer esforços de cooperação e coordenação para a gestão e uso de seus recursos.

Para Becker:

A coordenação de esforços entre os países amazônicos é um elemento central no novo enfoque para o desenvolvimento da região, por permitir maior eficiência na execução de programas que promovam o seu desenvolvimento interno, nas negociações internacionais e no "uso de bens públicos internacionais". Este enfoque está explícito no IIRSA (2002) para toda a América do Sul, e implícito no resgate do Tratado de Cooperação Amazônica (TCA) como Organização do Tratado de Cooperação Amazônica (OTCA) para os países amazônicos (2007, p. 54). 
Observa-se nos últimos anos que os países amazônicos têm se esforçado para integrar-se, depois de anos de negociações e conflitos para a demarcação e controle de suas fronteiras. Hoje as fronteiras apresentam mais um significado para a região, pois é cada vez mais estimulada a sua permeabilidade pelos fluxos do comércio, pelos corredores econômicos e iniciativas de integração regional.

Os projetos estruturais de integração física e regional afetam diretamente as regiões de fronteira na Amazônia, alterando a organização territorial destas áreas. Como aponta Seoane:

[...] es necesario distinguir entre "integración fronteriza", con alcance limitado y aquella integración desarrollada entre países y que afecta directamente a las regiones fronterizas. La situación óptima se define como aquella donde "integración fronteriza" está enmarcada o se complementa con procesos de integración de mayor magnitud y alcance $(2009$, p. 70$)$.

A integração fronteiriça é concebida como:

Cuando los países que comparten un límite internacional emprenden acciones conjuntas que impliquen algún efecto en los territorios colindantes, se está ante una política de integración fronteriza. Ya sea que las autoridades de los gobiernos centrales o las de gobiernos locales emprendan entendimientos que permitan acciones conjuntas, es posible hablar de programas de integración fronteriza. La integración fronteriza es un instrumento apto para encarar proyectos y acciones que aumenten las relaciones económicas y sociales entre zonas o regiones nacionales contiguas, y mejoren la calidad de vida de los pobladores de esos territorios. La integración fronteriza cuenta con objetivos precisos, que no siempre son asimilables a los más generales de la integración en sentido amplio (SEOANE, 2009, pp. 54-55).

Portanto, nem sempre a integração fronteiriça está vinculada a uma iniciativa de integração regional. A integração fronteiriça pode ser apoiada pelo Estado central ou ser apenas uma iniciativa informal dos governos subnacionais, às vezes com objetivos nem sempre contemplados na integração regional, por serem muito pontuais.

No início da década de 1990, Coelho (1992) afirmava a falta de conhecimento sobre as fronteiras amazônicas, pois "se sabemos pouco sobre a Amazônia, menos ainda acerca dos confins da Amazônia, exceto possivelmente por seus aspectos puramente geográficos" (p. 14). Neste trabalho, o autor aponta que:

no caso da Amazônia, a marginalidade e o abandono que caracterizam as zonas fronteiriças poderiam tanto explicar a falta de ação, como até mesmo justifica-la. [...] A indagação de verificar se vale ou não a pena ir até a fronteira esbarra, ademais, no caso da Amazônia, na evidência de que, em múltiplos pontos daquela fronteira, já existe a conformação de um quadro sócio-econômico complexo, com uma ocupação muitas vezes desordenada, mas de ineludível dinâmica, que não comporta ser ignorada, a não ser com custos cada vez menos suportáveis. Tais custos, objeto de referência mais adiante, estariam nos crescentes atritos fronteiriços, decorrentes de invasões (garimpo), de desequilíbrios comerciais não gerenciados devidamente, do 
aumento das atividades ilegais; estariam também no atraso nas articulações entre instituições culturais, de saúde, de desenvolvimento regionais, de pesquisa científica, [...] estariam, ainda, na capacidade de aproveitamento de potenciais locais para a ação coordenada, com economia de recursos nas áreas de saneamento, educação e saúde; [...] e, acima de tudo, na adoção de ações que, por serem conjuntas, exploram a convergência de interesses entre dois ou mais países vizinhos, criando um clima evidentemente mais propício para ações em planos mais amplo (p. 23-24).

Recentemente, nas últimas décadas, os países amazónicos tem buscado estabelecer políticas de desenvolvimento de suas faixas de fronteira, aproveitando o contexto favorável da integração regional e os projetos de interligação física existentes, pois estes também têm afetado as regiões de fronteira. O Brasil, por exemplo, elaborou o Programa de Desenvolvimento da Faixa de Fronteira (PDFF) coordenado pelo Ministério da Integração Nacional (MIN) e que foi contemplado com investimentos pelo Plano Plurianual (PPA) 2004-2007. Neste programa a faixa de fronteira brasileira é dividida em Arco Norte, Arco Central e Arco Sul, que por sua vez são subdivididos em 17 Sub-regiões. Em 2010 o Grupo de Trabalho Interfederativo de Integração Fronteiriça elaborou uma proposta para o desenvolvimento da faixa de fronteira que previu a criação da Comissão Permanente para o Desenvolvimento e Integração da Faixa de Fronteira (CDIF) (GTIIF, 2010). A CDIF foi criada por decreto em 8 de setembro de 2010 .

A Bolívia e o Peru, como membros da CAN, que por meio das Decisões 459 e 501 estabeleceu uma política de integração fronteiriça e a regulação da implementação de Zonas de Integração Fronteiriça, elaboraram Planos Binacionais de Desenvolvimento de suas faixas de fronteira com seus respectivos vizinhos, como é o caso, por exemplo, do Plano de Desenvolvimento da Zona de Integração Fronteiriça Peru-Bolívia.

A Bolívia, no plano nacional, criou a Agência para o Desenvolvimento das Macro-regiões e Zonas Fronteiriças (ADEMAF), em 2010. Esta agência esta encarregada de formular e executar, bem como acompanhar projetos e programas para o desenvolvimento regional e das zonas fronteiriças de acordo com o Plano Nacional de Desenvolvimento (ADEMAF, 2013). Também o Ministério de Relações Exteriores boliviano tem uma instância que se ocupa das fronteiras e integração fronteiriça, a Direção Geral de Limites, Fronteiras e Águas Internacionais.

O Peru aprovou em 2011 a Lei Marco 29778 para o Desenvolvimento e Integração Fronteiriça, que estabelece a Política Nacional de Desenvolvimento e Integração Fronteiriça e regula o Sistema Nacional de Desenvolvimento das Fronteiras e 
Integração Fronteiriça. Este Sistema está estruturado tendo como órgão de coordenação a Direção de Desenvolvimento e Integração Fronteiriça (DDF) do Ministério das Relações Exteriores, e o Conselho Nacional de Desenvolvimento de Fronteiras e Integração Fronteiriça é a instância multi-setorial máxima encarregada de formular, conduzir e avaliar a política nacional em matéria de desenvolvimento das fronteiras e integração fronteiriça (RREE, 2012).

O Equador participa de dois Planos Binacionais para projetos na faixa de fronteira com o Peru e a Colômbia. Entre Equador e Peru foi estabelecida a Comissão de Vizinhança Equatoriano-Peruana, após a assinatura do Acordo de Paz, em 1998. Alguns dos projetos equatorianos de integração fronteiriça fazem parte do Banco de Projetos de Integração e Desenvolvimento Fronteiriço da CAN, tais como: o "Programa de Melhoramento das Condições Sanitárias e Ambientais nas Fronteiras Pacífica, Andina e Amazônica do Equador com Colômbia"; e o "Manejo integrado para o desenvolvimento sustentável do corredor de gestão tri-nacional das áreas protegidas La Paya (Colômbia), Cuyabeno (Equador) e Güeppi (Peru)".

Estas políticas nacionais de desenvolvimento da faixa de fronteira e de integração fronteiriça têm um impacto para as regiões fronteiriças amazônicas e, também para a gestão dos recursos hídricos transfronteiriços nestas regiões. Já que aproximam os atores sociais e impulsionam a cooperação transfronteiriça necessária para coordenar ações de gestão.

Grande parte das fronteiras na Amazônia, e também em toda a América do Sul, apresentam os rios como a linha divisória da fronteira entre os países. Em diversos casos existem, separadas por estes rios divisórios, cidades gêmeas. Elas "devem constituir-se em um dos alvos prioritários das políticas públicas para a zona de fronteira" (MACHADO, 2005, p. 260-261).

Na Amazônia brasileira:

[...] a Faixa de fronteira é aquela onde a densidade de ocupação é das mais baixas. Contudo, o padrão não é homogêneo. Uma concentração populacional maior pode ser identificada na faixa sudoeste da região e em alguns pontos isolados. Explica esta concentração, a presença não só de capitais estaduais dentro do limite fronteiriço, como a dos municípios produtivamente mais dinâmicos, seja devido a atividades legais, seja atividades ilegais. É significativa, no contexto fronteiriço, a magnitude do processo de municipalização que ocorreu na década de 1990, em consonância com o restante da Amazônia, processo acompanhado de crescimento urbano. [...] Esse crescimento demonstra que a Faixa de Fronteira acompanhou, num ritmo próprio, a dinâmica urbana regional, contrapondo-se às baixas densidades vigentes (BECKER, 2007, p. 58). 
Becker (2007) distingue quatro regiões na faixa de fronteira norte do Brasil que possuem características distintas: a) a região da fronteira entre Brasil, Venezuela, Guiana e parte da Colômbia e Suriname; b) a região da fronteira entre Amapá e Guiana Francesa; c) A região da fronteira entre Brasil, Colômbia e Peru; e, d) a região da fronteira entre Brasil, Peru e Bolívia. Estas regiões apresentam graus diferentes de integração com o território do país vizinho, bem como de acessibilidade viária e de redes de relações. A presença de cidades gêmeas nelas relativiza o papel das condições naturais presentes nas fronteiras amazônica.

Existem temas que são característicos das regiões de fronteira, e que estão presentes na Amazônia, tais como; fluxos migratórios e de trabalhadores, águas transfronteiriças, comércio transfronteiriço, condições para o transporte de mercadorias, infraestrutura de comunicação, exploração de recursos naturais, entre outros (SEOANE, 2009). Quando não existe a possibilidade de diálogo entre as comunidades vizinhas sobre os problemas comuns, existe a possibilidade do surgimento de conflitos, que são internacionais por sua natureza. Além do que também é comum surgirem nestas regiões interesses comuns, que nem sempre são contemplados pelos planos de integração regional dos governos centrais, pois a agenda das comunidades de fronteira apresentam questões muito mais pontuais do que aquelas dos Acordos de Cooperação e Integração firmados pelos governos nacionais (SEOANE, 2009).

As iniciativas para o diálogo entre as cidades gêmeas, que têm se institucionalizado na América do Sul, são os Comitês de Fronteira, que são estabelecidos depois da assinatura de Acordos Bilaterais ou Multilaterais, necessários também para sua regulamentação. A coordenação destes Comitês fica a cargo do Ministério de Relações Exteriores, mas a participação de outros atores pode variar, incluindo os governos municipais, estaduais, representantes da sociedade civil e de comunidades indígenas. Os Comitês de Fronteira "son instancias creadas para permitir la solución de conflictos fronterizos o en caso necesario el encauce de los problemas planteados a instancias con capacidad de aportar con soluciones" (SEOANE, 2009). Estes Comitês têm tratado também, em muitos casos, dos temas relacionados aos recursos hídricos transfronteiriços.

Outro tipo de instituição criada em regiões de fronteira são as Comissões Bilaterais ou Multilaterais de determinada Bacia Hidrográfica transfronteiriça. Estas comissões também são coordenadas pelo Ministério de Relações Exteriores, como os comitês, pois é a única instância governamental que tem competência para assinar 
tratados internacionais e tratar dos temas de política externa. Existe uma diferença temporal entre o funcionamento destes Comitês e Comissões para tomar decisões, pois envolvem muitos atores e instituições de diferentes níveis do governo, e as consequências dos problemas locais transfronteiriços que são muitas vezes imediatos e cotidianos.

Na Bacia Amazônica as regiões de fronteira são escassamente povoadas, mas contam com a presença de algumas cidades gêmeas. Nestas localidades podem-se observar iniciativas baseadas em interesses comuns para a solução de problemas transfronteiriços, mas, em geral, os governos e comunidades locais não possuem competência jurídica para firmar acordos com as comunidades dos países vizinhos e carecem de meios técnicos e financeiros para lidar com os problemas relacionados ao compartilhamento dos recursos hídricos. Muitas vezes são firmados acordos informais, ou seja, não geram um documento que sele os termos acertados, o que caracterizam um tipo de cooperação não institucionalizada.

Neste sentido, algumas instituições nacionais buscam dar apoio para enfrentar temas relacionados aos recursos hídricos compartilhados. No caso do Brasil, o Conselho Nacional de Recursos Hídricos (CNRH) possui uma Câmara Técnica sobre Gestão dos Recursos Hídricos Transfronteiriços que visa auxiliar as decisões do Conselho no caso das águas transfronteiriças. Na Bolívia, o Ministério de Relações Exteriores possui uma

Divisão de Águas Internacionais, responsável por negociar os Acordos sobre recursos hídricos compartilhados e coordenar os Comitês e Comissões de Bacias compartilhadas.

As assimetrias entre os países e entre as cidades gêmeas e regiões fronteiriças, dificultam a cooperação em matéria ambiental e de recursos hídricos, por exemplo. Nem sempre as instituições responsáveis pela gestão dos recursos hídricos encontram correspondente no país vizinho, e muitas vezes, as legislações são bem diferentes. Esta integração fronteiriça que começa a se desenvolver entre os países amazônicos tem ocorrido em paralelo com as iniciativas multilaterais de cooperação regional. As relações bilaterais entre os países amazônicos também começam a incluir a integração fronteiriça em sua pauta.

\subsection{Cooperação entre os países amazônicos: relações multilaterais e bilaterais}


Em qualquer análise sobre as relações entre os países amazônicos é preciso levar em conta o significado da Amazônia para cada país e também o peso que tem para cada território nacional. Isto porque, como argumenta Costa-Filho (2003),

\begin{abstract}
a heterogeineidade real com que os oito Países Membros (da OTCA) priorizam seus programas amazônicos. Os problemas de exploração ou conservação dos seus recursos os afetam de forma necessariamente diferenciada. Os próprios pesos relativos de suas áreas amazônicas sobre os totais nacionais, tanto em extensão territorial como em densidade demográfica, são significativamente distintos entre eles, afetando inexoravelmente suas decisões de prioridades (p. 386).
\end{abstract}

Para começar, em termos de superfície territorial existe uma grande diferença, o Brasil abarca $63 \%$ da área total da bacia, que representa 45,5\% do território nacional (excluindo a Bacia do rio Tocantins), enquanto o Equador detém apenas 2,4\% da área total da bacia, o que representa $52 \%$ da área de seu território nacional. No entanto, em alguns casos a área da bacia amazônica chega a 75\% e 66\% das áreas totais dos territórios nacionais do Peru e da Bolívia, respectivamente (PNUMA. OTCA e CIUP, 2009).

Outra diferença a ser considerada é o desenvolvimento econômico dos países, e também institucional, que tem influência no modo de ocupação e desenvolvimento econômico implantado nas respectivas áreas amazônicas. Além disso, é também preciso levar em conta os diferentes interesses em disputa no interior dos Estados sobre a utilização dos recursos e modelo de desenvolvimento para as regiões amazônicas.

São nítidos os conflitos entre interesses conservacionistas que visam à criação de unidades de conservação e projetos sustentáveis e, por outro lado, os interesses de exploração econômica que veem a região como uma área rica em recursos a serem explorados e como fronteira agropecuária. Estes são conflitos pelo uso do território, que na visão de Becker são direcionados "segundo interesses dos diferentes atores, que impulsionam diferentes fronteiras na região. Tais conflitos [...] dificultam a formulação e a execução de políticas públicas" (2007, p. 125).

Tais interesses sobre a Amazônia se refletem nos acordos de cooperação bilaterais entre os países amazônicos. A seguir serão analisadas as relações bilaterais entre quatro países amazônicos, com o foco nos acordos e eventos que tem maior impacto para a Bacia Amazônica. Esses quatro países foram escolhidos por serem os países envolvidos nos dois estudos de caso analisados neste trabalho. 


\subsubsection{As relações bilaterais entre os países amazônicos: Bolívia, Brasil, Equador e Peru}

As relações bilaterais entre os quatro países amazônicos (Bolívia, Brasil, Equador e Peru), abarca uma série de assuntos, não apenas aqueles relacionados aos recursos hídricos compartilhados. Por isso, o histórico dessas relações bilaterais é analisado de forma sintética neste trabalho, atentando apenas para os fatos que são mais relevantes para contextualizar o cenário em que se desenvolve a governança dos recursos hídricos transfronteiriços na Bacia Amazônica.

\subsubsection{As relações entre Bolívia e Brasil}

Bolívia e Brasil possuem $3.423 \mathrm{~km}$ de fronteiras entre si, dos quais $750 \mathrm{~km}$ são linhas convencionais e, $2.672 \mathrm{~km}$ são fronteiras aquáticas, o que representa $78 \%$ da linha de fronteira (SCDL, 2012). O primeiro tratado assinado entre os dois países para a demarcação das fronteiras foi o "Tratado de Amizade, Limites, Navegação, Comércio e Extradição", de 27 de março de 1867, também conhecido como Tratado de Ayacucho. De acordo com Vergara (2010), este tratado foi assinado sem muito conhecimento sobre a região e localização dos rios, por isso "foi uma tentativa de garantir o território brasileiro em um espaço desconhecido" (p. 346). De modo que, o território do atual do estado do Acre pertencia à Bolívia neste período. Os trabalhos de demarcação só se iniciaram a partir de 1870. No entanto, o conflito do Acre que tem início com a exploração da borracha no fim do século XIX e a ocupação da área por brasileiros, chega ao fim em 1903 com a negociação entre Brasil e Bolívia e a assinatura do Tratado de Petrópolis em 17 de novembro de $1903^{11}$. Com este tratado o território do Acre passa a ser do Brasil e, em contrapartida, a Bolívia ficou com parte do que seria hoje o Mato Grosso, o pagamento de dois milhões de libras esterlinas (preços correntes) e a promessa de construção da estrada de ferro Madeira-Mamoré (400 km).

Além destes acordos mencionados, ainda foram assinados entre os dois países, referentes à demarcação de fronteiras e à navegação fluvial: o "Tratado de Comércio e Navegação Fluvial”, de 1910; o "Acordo para a Demarcação das fronteiras BrasilBolívia na Bacia do Amazonas", de 1911; o "Tratado de Limites e Comunicações

\footnotetext{
${ }^{11}$ Para mais informações detalhadas sobre este tratado e a questão do Acre, ver: BANDEIRA, 2000.
} 
Ferroviárias", de 1928; o "Acordo sobre instruções à Comissão Mista Demarcadora de Limites brasileira-boliviana", de 1941; e as "Notas Reversais" de 29 de março de 1958.

Orias, Seoane e Torres (2001), sintetizam as relações entre Bolívia e Brasil do seguinte modo:

\begin{abstract}
Con una historia diplomática bilateral que ha transitado de la indiferencia en el siglo XIX, al conflicto de inicios del siglo XX, pasando por una frondosa experiencia de relación cooperativa, durante la mayor parte del pasado siglo y evolucionado, en los años recientes, a una situación de interdependencia e integración, el futuro de la agenda bilateral se presenta cargado de aspectos positivos y colaboración, bajo esquemas de ganancias mutuas y emprendimientos cooperativos. Las relaciones diplomáticas entre Bolivia y Brasil han atravesado por diferentes fases, pudiéndose distinguir tres grandes períodos: i) un período geográfico que culmina con el trazado de los límites fronterizos, ii) un período de acercamiento e inicio de un relacionamiento cooperativo en el que se emprenden proyectos bilaterales de desarrollo y vinculación física y, iii) el período de integración caracterizado por una incrementa acción cooperativa, cuyo basamento fundamental emerge de la integración energética y que impulsa una diversificación y profundización de la agenda que se traduce en una mayor interdependencia (p. 107).
\end{abstract}

A agenda bilateral boliviana-brasileira tem como temas principais: a venda de gás natural boliviano para o Brasil através do gasoduto Santa-Cruz-São Paulo; os corredores interoceânicos; a possibilidade de venda de hidroeletricidade da Bolívia para o Brasil; as relações comerciais e econômicas no âmbito do Mercosul; a Hidrovia Paraguai-Paraná; os problemas de contrabando e narcotráfico; e questões ambientais (Seoane, Torres e Orias, 2009).

Desde a década de 1990 que as relações bilaterais entre Bolívia e Brasil foram fortemente marcadas pela comercialização do gás natural boliviano e a construção do gasoduto até o Brasil. Como afirmou Vizentini, "a questão energética é o que move as relações bilaterais entre o Brasil e a Bolívia" (2004, p. 370).

Em relação à temática dos recursos hídricos transfronteiriços amazônicos cabe destacar alguns acordos que são relevantes, tais como: o "Ajuste Complementar ao Acordo Básico de Cooperação Econômica e Técnica Relativo à Central Hidrelétrica de Cachuela Esperanza”, de 1984. Trata-se de um acordo para a realização de estudos sobre o projeto de construção da hidrelétrica de Cachuela Esperanza em território boliviano. Além deste, também destaca-se: o "Convênio para a preservação, Conservação e Fiscalização dos Recursos Naturais nas Áreas de Fronteira”, de 1990; o “Acordo, por troca de Notas, Relativo ao Convênio entre o INPE e o SENAMHI", de 1996; o "Memorando de Entendimento para o Estabelecimento de um Subprograma de 
Cooperação Técnica em Desenvolvimento Sustentável e Transferência de Informações Temáticas”, de 1997.

O “Ajuste Complementar ao Acordo Básico de Cooperação Técnica e Científica para Implementação do Projeto Apoio à Legislação dos Recursos Hídricos”, de 2001, teve como objetivo a troca de experiências entre Brasil e Bolívia, com vistas à apoiar o governo boliviano na formulação de sua legislação de recursos hídricos.

O "Acordo para a Construção de uma Ponte sobre o Rio Acre, nas Proximidades das Cidades de Brasiléia e Cobija", de 2003, criou uma Comissão Mista com o objetivo de desenvolver o projeto de construção de uma ponte sobre o rio Acre e implementá-lo. Trata-se do projeto da IIRSA do Eixo Peru-Brasil-Bolívia e que já se encontra construída. Outras pontes entre os dois países estão previstas para serem construídas como, a Ponte sobre o Rio Mamoré entre as cidades de Guajará-Mirim (Rondônia) e Guayaramerín (Beni) (acordo de 14 de fevereiro do 2007), e a Ponte sobre o Igarapé Rapirrá, entre as cidades de Plácido de Castro (Acre) e Montevideo (Pando) (Acordo de 17 de dezembro de 2007). Em visita à Bolívia, cidade de Riberalta, o então presidente brasileiro Luis Inácio Lula da Silva, em agosto de 2007, faz uma Declaração em que reitera a importância da integração física para as relações bilaterais, bem como o financiamento deste integração por parte do Brasil de infraestruturas como o Projeto da Rodovia "Hacia el Norte".

Para a Bolívia, os recursos hídricos da Bacia Amazônica tem uma grande importância já que grande parte de seu território esta nesta bacia. Desta forma, vários projetos estão em curso que podem impactar estes recursos. Para Torres:

Con relación al futuro, en la Cuenca del Amazonas es previsible el incremento de proyectos destinados a permitir la navegación por los principales ríos de dicha cuenca. La próxima hidrovía con la que contará Bolivia probablemente unirá a través del río Madre de Dios, las ciudades de Puerto Maldonado en el Peru, Riberalta en Bolívia y Porto Velho en Brasil. Si se logra superar el problema de las cachuelas en el río Madeira, Bolivia podría lograr una segunda vía de navegación y salida para su comercio exterior por el Océano Atlántico. No obstante, se trata de un proyecto complejo y extremamente oneroso. [...] Por otra parte, aunque ya se han planteado posibilidades de generación y exportación de energía hidroeléctrica al Brasil, como ocurro, por ejemplo, con los casos del Proyecto del Bala o de Cachuela Esperanza, para su concreción hace falta superar problemas técnicos, financieros, y medio ambientales. En el caso de Brasil, basta señalar que tener un límite acuático casi tan extenso como el total de la frontera que Bolivia comparte con la Argentina induce a pensar que el tema de los recursos hídricos tarde o temprano, ocupará un lugar privilegiado en la agenda bilateral (2003, p. 21). 
A principal sub-bacia amazônica compartilhada entre Bolívia e Brasil é a bacia do rio Madeira, que é um afluente do rio Amazonas, sendo um dos mais importantes, pois é o mais caudaloso e o maior em longitude. A área total da bacia do rio Madeira é de $1.420 .000 \mathrm{~km}^{2}$, sendo que drena toda a superfície da bacia amazônica em território boliviano correspondente a $724.000 \mathrm{~km}^{2}$ e $66 \%$ do território nacional da Bolívia (PNUMA, OTCA e CIUP, 2009). Esta bacia também é compartilhada pelo Brasil (onde ocupa parte dos estados do Acre, Rondônia, Amazonas e Mato Grosso) e Peru (Departamento de Madre de Dios).

Entre os projetos da IIRSA e também do Programa para Aceleração do Crescimento (PAC), encontram-se duas usinas hidrelétricas Santo Antônio e Jirau, em território brasileiro no rio Madeira. Estas usinas são parte de um estudo mais amplo sobre diversos projetos na bacia do rio Madeira, chamado de Complexo do rio Madeira, que incluía também outras usinas hidrelétricas, uma ferrovia, uma hidrovia, e um gaseoduto. O projeto das duas usinas Santo Antônio e Jirau foi o mais caro da IIRSA orçado em mais de 20 bilhões de dólares em 2007, além de ter gerado grande polêmica devido ao seu impacto socioambiental e também transfronteiriço:

as duas usinas em construção no complexo do rio Madeira - Santo Antônio e Jirau - foram responsáveis pela condenação simbólica do Brasil, em 2009, pelo Fórum Mundial da Água realizado em Istambul, devido aos prejuízos para a vida de populações indígenas, alteração de ciclos fluviais e da biodiversidade. Estas preocupações foram também levantadas pela Bolívia, país vizinho cuja fronteira dista cerca de $100 \mathrm{~km}$ da primeira usina e $200 \mathrm{~km}$ da segunda (BERMANN et al., 2010, p.12).

Os estudos para a construção de usinas hidrelétricas na bacia do Madeira começaram na década de 1970 no Brasil e na década de 1980 na Bolívia. A usina de Santo Antônio está a aproximadamente $10 \mathrm{~km}$ de Porto Velho e $200 \mathrm{~km}$ da fronteira com a Bolívia e terá 3.150 MW de potencia instalada, mas com 2.140 MW de energia firme (BERMANN et al., 2010; IIRSA, 2011). O reservatório da usina ocupará uma área de $271 \mathrm{~km}^{2}$. Esta usina iniciou suas operações em março de 2012 e até junho de 2013 já tinha autorização para iniciar as operações da $13^{\mathrm{a}}$ de suas 24 turbinas (SAE, 2013). Já a usina hidrelétrica de Jirau está a $130 \mathrm{~km}$ de Porto Velho e a $100 \mathrm{~km}$ aproximadamente da fronteira boliviana. O reservatório da usina terá $258 \mathrm{~km}^{2} \mathrm{com}$ uma potência instalada de 3.450 MW e 2.184,6 MW médios de energia firme (IIRSA, 2011; BERMANN et al., 2010). As duas usinas terão um custo de cerca de 25 bilhões de reais (IIRSA, 2011; PAC, 2012; BERMANN et al., 2010; COMEGNA e LUCHINO, 2010). Apesar destes dados: 
[...] Especialistas apontam um sub-dimensionamento da área de alagamento o que caracteriza consequências ambientais transfronteiriças do projeto da Usina de Jirau. Houve conflito diplomático, atenuado por reuniões governamentais de cúpula, o que em nada modificou o licenciamento ambiental unilateral de um conjunto hidroelétrico de consequências transfronteiriças (BERMANN et al., 2010, p. 13).

Os estudos de impacto ambiental consideraram apenas o território brasileiro e não houve estudos sobre possíveis impactos em território boliviano, devido ao subdimensionamento dos reservatórios apresentado nesses estudos. No entanto, organizações da sociedade civil e acadêmicos bolivianos se dedicaram ao estudo destes impactos na Bolívia.

Além destas hidrelétricas também estava prevista a construção de uma usina hidrelétrica binacional Guajará-Mirim na fronteira entre Bolívia e Brasil, e a usina boliviana de Cachuela Esperanza, como consta nos projetos da IIRSA do Eixo PeruBrasil-Bolívia, do grupo de projetos do Corredor Fluvial Madeira-Madre de Dios-Beni (IIRSA, 2011). O projeto da usina de Cachuela Esperanza ainda está em estudo já que em 2008 foi contatada a empresa canadense Tecsult por parte do governo boliviano para realizar os estudos de exploração hidrelétrica e de navegabilidade, bem como analisar os impactos que poderiam ser ocasionados em território boliviano pelas duas usinas brasileiras de Santo Antônio e Jirau. O objetivo principal tanto da usina de GuajaráMirim quanto a Cachuela Esperanza seria que a Bolívia exportasse a energia para o Brasil (BERMANN, et al., 2010). Assim, as quatro hidrelétricas previstas na bacia do Madeira serviriam também para compor a grande hidrovia Madeira-Madre de DiosBeni:

significativamente, para formar o caminho fluvial Madeira-Madre de DiosBeni, e permitir a navegação de balsas de Porto Velho à Bolívia, outras corredeiras acima do reservatório de Jirau também teriam que ser inundadas. $\mathrm{E}$, para fazer isso, outras duas barragens precisariam ser construídas rio acima. Estas seriam as barragens de Guajará-Mirim (binacional BolíviaBrasil), construída nas corredeiras Ribeirão, com uma capacidade instalada estimada de $3.000 \mathrm{MW}$, e a barragem da Cachuela Esperanza, no rio boliviano Beni (600 MW). A barragem de Guajará-Mirim poderia inundar uma porção significativa das cidades de Guajará-Mirim e Guayaramerin (Bolívia), que, somadas têm uma população de 100.000 habitantes. Cachuela Esperanza são corredeiras na província de Pando.

Os únicos dados disponíveis publicamente para o custo das barragens de Guajará-Mirim (US\$ 2 bilhões) e Cachuela Esperanza (US\$ 1,2 bilhão), divulgados em 2003, são provavelmente sub-estimados. O Complexo Madeira é considerado o "projeto âncora" da IIRSA para o eixo Peru-BrasilBolívia (SWITKES, 2008, p. 25). 
Em entrevistas com representantes do Ministério das Relações Exteriores e do Ministério de Meio Ambiente e Água da Bolívia ${ }^{12}$, tornou-se evidente que o governo boliviano procurou explicações do governo brasileiro sobre os impactos em território boliviano que as hidrelétricas de Jirau e Santo Antônio poderiam ocasionar. No entanto, o governo boliviano não tomou medidas mais drásticas como levar o caso para uma corte internacional, afinal ainda espera o financiamento brasileiro para as outras hidrelétricas que poderão ser construídas em território boliviano e na faixa de fronteira, bem como a hidrovia que seria uma saída boliviana para o Atlântico.

Cabe também destacar a realização de reuniões entre grupos da sociedade civil tanto da Bolívia quanto do Brasil para a discussão dos projetos do Complexo do Madeira, inclusive a reunião de 2007 em Cobija onde foi redigida uma carta assinada por 38 representantes de organizações da sociedade civil, em que ponderam os impactos negativos das barragens e pediram aos governos boliviano e brasileiro que desistissem da construção das represas (FURTADO, 2008).

De acordo com Krukoski (2013), a hidrovia Guaporé-Mamoré-Madeira é importante para o escoamento da produção, principalmente de grãos, dos estados de Rondônia e Mato Grosso, no Brasil. No Grupo de Projetos da IIRSA do Corredor Fluvial Madera-Madre de Dios-Beni, estão previstos projetos de melhoramento do transporte fluvial neste corredor com vistas também a melhorar a exportação de grãos destes estados (IIRSA, 2008).

\subsubsection{As relações entre Brasil e Peru}

As relações entre Brasil e Peru também se iniciaram com as iniciativas de demarcação de limites, cujo primeiro acordo, o Tratado de Comércio Navegação Fluvial, Extradição e Limites, foi assinado em 1851. Somente em 1861 que começam a serem organizadas as Comissões brasileira e peruana para integrar a Comissão Mista para fixação dos limites. Em 1871 são iniciadas as reuniões da Comissão e em 1904 os dois países assinam um acordo para fixar os limites desde a nascente do rio Javari, abarcando as bacias do Alto Juruá e Alto Purus, cuja fixação dos limites contou com a participação de Euclides da Cunha, do lado brasileiro.

\footnotetext{
${ }^{12}$ Foi solicitado pelos entrevistados sigilo de fonte. As entrevistas foram realizadas no mês de fevereiro de 2011 pela autora, em La Paz.
} 
Na época do conflito do Acre com a Bolívia, o governo peruano tentou participar das negociações em conjunto com a Bolívia, o que não foi aceito pelo Barão do Rio Branco (José Marinho da Silva Paranhos). Rio Branco preferiu negociar com a Bolívia e resolver o problema com o Bolivian Syndicate, assinando o Tratado de Petrópolis, para depois iniciar a conversação com o Peru. Todavia:

\begin{abstract}
as pretensões não se restringiam à área, que objeto fora do Tratado de Petrópolis, por ele considerado lesivo aos seus direitos territoriais. O Peru reclamava igualmente os territórios que a Bolívia cedera ao Brasil, com o Tratado de 1867, e começara entre fins de 1902 e meados de 1903 a apoderar-se тапи militari daquelas regiões em litígio, habitadas quase que exclusivamente por brasileiros, por crer que tais invasões e a tomada de posse pela violência modificariam a situação e lhe favoreceriam em caso de recurso ao arbitramento (BANDEIRA, 2000, p. 161).
\end{abstract}

Assim, o Peru tentou dominar o Alto Juruá e reconquistar a posição perdida na Boca do Chandless, e atacou os brasileiros e suas propriedades ao longo do rio Purus. Rio Branco se recusou a negociar enquanto as tropas peruanas permanecessem no Alto Juruá e Alto Purus. O Brasil deslocou soldados então para a área para garantir a soberania brasileira, cujo "propósito do governo brasileiro era deflagrar represálias caso o Peru não quisesse evacuar aquelas regiões" (BANDEIRA, 2000, p. 162). O conflito tomou proporções maiores e a crise entre Brasil e Peru se agravou. O Brasil conseguiu obter a simpatia da Bolívia e negociou uma aliança secreta com o Equador, que também tinha litígios fronteiriços com o Peru. O Peru tentou uma aproximação com os Estados Unidos esperando uma arbitragem e prometendo concessões do mesmo tipo que a do Bolivian Syndicate, mas este não se interessou. Assim, o Peru se mostrou propenso à negociação, mas reivindicava uma compensação financeira igual a que recebera a Bolívia:

Rio Branco, porém rechaçou qualquer acordo a esse preço, uma vez que, diferentemente da Bolívia, o Peru não possuía título válido e definido e não firmara com o Brasil nenhum tratado que lhe concedesse o mínimo direito sobre o Acre. Apenas formulara um protesto que, segundo Euclides da Cunha, não passou de um "murmúrio vacilante e medroso de uma conjectura", dizendo que a Bolívia cedera ao Brasil territórios que pueden ser de la propriedad del Peru. [...] Evidentemente, em tais condições, Rio Branco não podia aceitar nenhum acordo que implicasse compensação financeira, e formulou uma proposta, cedendo ao Peru uma área triangular considerável, formada pelos rios Curanja, Santa Rosa e Purus. O governo de Lima [...] concordou com essas bases. Com data de 8 de setembro de 1909, o ministro Hernán Velarde assinou sigilosamente com o barão do Rio Branco, no Palácio do Itamaraty, o tratado que permitiu ao Brasil estender sua soberania sobre uma superfície de $152.000 \mathrm{~km}^{2}$ (BANDEIRA, 2000, p. 164). 
Em 1909 é assinado, portanto, o Tratado Complementar à Delimitação das Fronteiras, Estabelecendo Princípios Gerais sobre Comércio e Navegação na Bacia do Amazonas. Por meio deste tratado e do Protocolo de 1913 é formada a Comissão Mista Demarcadora de Limites para a fixação dos limites entre as nascentes do rio Javari e o rio Acre, onde começava a fronteira entre Peru e Bolívia. Esta comissão trabalhou até o ano de 1927 quando seu trabalho se deu por encerrado e ela foi dissolvida. Em 1925, um litígio entre Peru e Colômbia alterou a fronteira entre estes dois países e a fronteira entre Brasil e Peru passou a compreender a linha entre o rio Amazonas e o rio Acre, numa extensão de $2995 \mathrm{~km}$, com a presença de 86 marcos instalados (PCDL, 2013). Esta linha-limite é composta por $2.003 \mathrm{~km}$ de rios e canais, $708 \mathrm{~km}$ por divisores de águas e $283 \mathrm{~km}$ por linhas convencionais.

Devido ao abandono em que se encontrava esta parte da fronteira dos dois países, estes decidiram que havia a necessidade dela ser inspecionada e criaram em 1975 a "Comissão Mista de Inspeção dos Marcos da Fronteira", cujo objetivo é “inspecionar os 86 marcos [...], reparando-os e reconstruindo-os segundo novo modelo, e quando necessário, verificar a necessidade de densificação da linha, nos trechos da fronteira seca" (PCDL, 2013, sem página).

É importante lembrar que as relações bilaterais do Peru com seus vizinhos foram dominadas até os anos 1990 por conflitos fronteiriços, em especial com o Equador e o Chile (Guerra do Pacífico - de 1879 a 1883). De acordo com Herz (2004, p. 526), “a integridade territorial e o desenho das fronteiras foram até os anos 90 questões em aberto, entendidas pelas elites peruanas como fontes de ameaça".

As relações bilaterais com o Brasil não tinham muita relevância até a década de 1990, pois ambos os países ignoravam a sua fronteira amazônica. Enquanto a política externa do Brasil foi voltada para o Oceano Atlântico, a política externa peruana foi voltada para o Oceano Pacífico. Anteriormente ao período de maior cooperação entre os dois países, o Brasil acabou tendo um papel de garante do Protocolo assinado entre Equador e Peru em 1942, e depois no Acordo de Paz de 1998, que encerrou o conflito equatoriano-peruano (HERZ, 2004).

Em 1975 é assinado entre Brasil e Peru o "Acordo Básico de Cooperação Científica e Técnica”, e em 1979 o “Tratado de Amizade e Cooperação”. Em 1981 uma série de acordos são assinados na ocasião da visita do presidente brasileiro João Batista Figueiredo à Lima, que impulsionou a cooperação no âmbito econômico. Neste momento também foi mencionado a necessidade de melhorar a integração física entre os 
dois países. Em 1987, a visita do presidente brasileiro José Sarney a Puerto Maldonado, no Peru, levou a assinatura do "Programa de Ação de Puerto Maldonado", que tratava sobre: cooperação fronteiriça, cooperação técnica, incentivos ao intercâmbio comercial; cooperação amazônica, trânsito de pessoas, veículos e mercadorias, projetos específicos e, narcotráfico.

Já no final dos anos 1990 as relações se estreitam:

O Plano de Ação de Lima, criado durante a visita do Presidente Fernando Henrique Cardoso à Lima, em 1999, contempla sete grupos de trabalhos e compreende programas de ação para a fronteira comum, para a segurança e desenvolvimento da Amazônia, cooperação entre as Forças Armadas, combate ao tráfico de drogas, cooperação técnica e relações culturais. Ademais, o comércio entre os dois países cresceu de forma significativa durante a década de 90 (HERZ, 2004, p. 531).

Em relação aos recursos hídricos compartilhados na Bacia Amazônica, destacam-se os seguintes acordos bilaterais: o "Acordo, por troca de notas, para a Criação de Comitês de Fronteira”, de 1999; o "Ajuste Complementar na Área de Meio Ambiente Amazônico", de 1999; o "Ajuste Complementar ao Acordo Básico de Cooperação Técnica e Científica para a Implementação do Projeto Fortalecimento Institucional de Entidades Prestadoras de Serviços de Saneamento do Peru”, de 2003; o "Memorando de Entendimento sobre a Integração Física e Econômica", de 2003; o "Memorando de entendimento sobre cooperação em matéria de proteção e vigilância da Amazônia”, de 2003.

$\mathrm{O}$ “Acordo, por troca de notas, que modifica o Acordo para a Construção de uma Ponte sobre o Rio Acre, nas proximidades das Cidades de Iñapari e Assis Brasil, de 11/04/2003", possibilitou a construção da ponte e foi o primeiro projeto da Carta de Projetos da IIRSA a ser concretizado. A Declaração sobre Integração Física e Conservação do Meio Ambiente, assinada em 2006, pelos dois países afirmava que:

A integração dos setores de infraestrutura do Brasil e do Peru, inclusive as obras na Rodovia Interoceânica, ligando Assis Brasil, no Brasil, aos portos de Ilo e Matarani, no Peru, será conduzida com respeito ao meio ambiente e às populações tradicionais, através da implementação de um Programa de Desenvolvimento Sustentável na área de influência dos investimentos. Para elaboração e implantação do Programa, os Governos do Brasil e do Peru poderão solicitar a colaboração das autoridades locais e regionais, universidade da região, sociedade civil, Comitês de Fronteira e comunidade indígenas. Os governos buscarão também estimular a importante cooperação já existente em matéria ambiental, em particular o Grupo de Cooperação Sócio-Ambiental Fronteiriça MAP - Madre de Dios, Acre, Pando (DECLARAÇÃO, 2010). 
Foi criado um Grupo de Trabalho Binacional sobre Cooperação em matéria do Projeto de Sensoriamento Remoto e Hidrologia da Amazônia Peruana, com o objetivo de desenvolver mecanismos eficientes de transferência de tecnologia entre Brasil e Peru, no âmbito de instituições de monitoramento ambiental e hídrico. Assim, foi importante o intercâmbio entre a Agência Nacional de Águas (ANA) brasileira e o Servicio Nacional de Metereologia (SENAMHI) do Peru na área de Gestão de Recursos Hídricos. A Política Nacional de Recursos Hídricos do Peru, aprovada em 2009, tem muitas semelhanças com a Política brasileira, inclusive com a criação no Peru da Autoridad Nacional de Águas (ANA-Peru ${ }^{13}$ ), similar à ANA brasileira.

Ainda está em tramitação o acordo assinado em 2010, “Ajuste Complementar ao Acordo Básico de Cooperação Científica e Técnica para Implementação do Projeto "Fortalecimento Institucional para a Gestão Integrada dos Recursos Hídricos PeruBrasill”, mas este prevê o fortalecimento das instituições e da governabilidade da gestão integrada dos recursos hídricos.

Em 2010 também foi assinado entre Brasil e Peru o acordo de integração energética que visa o fornecimento de eletricidade ao Peru e exportação de excedentes ao Brasil, por meio da interconexão elétrica. Este acordo prevê a construção de cinco grandes hidrelétricas na Amazônia peruana, próximas à fronteira com o Brasil. Foi acordada a exportação de $6.000 \mathrm{MW}$, por um período de 30 anos de contrato fixo a partir do início das operações de cada central hidrelétrica. O primeiro projeto a ser executado é o da hidrelétrica de Inambari, que será instalada na fronteira entre os Departamentos de Madre de Dios, Cuzco e Puno, a uma distância de 300 km da fronteira do Acre, no Brasil. Esta central terá uma capacidade instalada de 2.200 MW (ALVAREZ e FADIGAS, 2010, p.4). Este projeto prevê a inundação de parte da recéminaugurada Rodovia Interoceânica, um dos projetos da IIRSA.

De acordo com Bermann et al., para a sociedade civil peruana neste acordo existem desvantagens para o Peru que acaba ficando com todos os impactos socioambientais das represas, sendo que praticamente toda a energia será exportada para o Brasil:

as resistências peruanas e bolivianas, da mesma maneira como ocorre no Brasil, reprovam os projetos de usinas hidrelétricas planejadas atualmente em seu território amazônico por conta dos grandes e diversos impactos sócioambientais que as mesmas irão causar, no entanto, a isso se adiciona um agravante: grande parte da energia gerada por essas usinas será exportada (ao

\footnotetext{
${ }^{13}$ Para diferenciar a Autoridad Nacional de Águas (ANA) do Peru da Agência Nacional de Água (ANA) do Brasil será usada a sigla ANA-Peru para designar a instituição peruana.
} 
Brasil) e será destinada a suprir atividades como a minero-exportadora, de baixo valor agregado e vinculada ao interesse do capital internacional. Por conta dessa situação, diversos grupos de resistência da região dos rios Madeira, Mamoré, Beni, Guaporé e Madre de Dios, incluindo movimentos brasileiros, vem tentando uma articulação para fazer ouvir suas demandas com relação aos projetos (BERMANN et al., 2010, p. 32).

Este acordo ainda não foi implementado devido à oposição de parte da sociedade peruana, principalmente devido às resistências dos ambientalistas à construção da usina de Inambari que está localizada em uma área próxima a reservas ecológicas na Amazônia peruana.

\title{
2.2.1.3 As relações entre Bolívia e Peru
}

As relações entre Bolívia e Peru sempre foram muito próximas desde a época pré-colombiana e colonial. Esta história de relações bastante próximas pode ser sintetizada da seguinte forma:

\begin{abstract}
históricamente las relaciones bilaterales entre Bolivia y Perú han desarrollado un carácter especial. Esta particular vecindad se construye a partir de un pasado compartido en el Imperio Inca, el Virreinato en tiempos de la Colonia, la Confederación Perú-Boliviana a principios de la República, su alianza en la Guerra del Pacifico de 1879 y los "intereses" de ambos países sobre el Puerto de Arica; además del origen común de su población y su pertenencia geográfica y cultural a la región andina. A esto cabe agregar ciertos elementos de un presente cooperativo en torno a cuenca hidrográfica del Lago Titicaca, los denominados "Acuerdos de Ilo", las iniciativas de integración comercial, física y fronteriza, y su membresía compartida en la "Comunidad Andina de Naciones" y el "Tratado de Cooperación Amazónica"; así como de un futuro promisorio dado por la complementación de sus regiones vecinas, la articulación de la economía boliviana con los puertos peruanos más cercanos, como parte del proyecto de corredores interoceánicos y la proyección conjunta hacia la Cuenca del Pacífico (ORIAS, SEOANE e TORRES, 2001, p. 273).
\end{abstract}

A fronteira entre Bolívia e Peru foi definida em 1902 com a assinatura do Tratado sobre Demarcação Fronteiriça. Posteriormente também foram assinados outros acordos, frutos de litígios, arbitragem e negociação: o Protocolo de Retificação de Fronteira, em 1909; o Protocolo Ratificatório da Demarcação da Segunda Seção da Fronteira, em 1932; e o Acordo sobre o Regime Fronteiriço, em 1940 (SEOANE, ORIAS e TORRES, 2009).

Esta demarcação dos limites não foi isenta de tensões e conflitos, pois ambos países sofreram perdas territoriais com a Guerra do Pacífico para o Chile, e depois se envolveram no litígio do Acre. Quando o Chile ocupou o litoral boliviano em 1879, o 
Peru se aliou a Bolívia e declarou guerra ao Chile, com base no Pacto de Aliança de 1873 entre Peru e Bolívia. Com o fim da Guerra e a perda da saída para o mar da Bolívia, e as perdas territoriais peruanas, a questão do Acre também contribuiu para o distanciamento entre os dois países:

\begin{abstract}
Es así, que se conviene el Tratado de 30 de diciembre de 1902, por el que se somete la cuestión de límites a la decisión arbitral de derecho del Presidente de la República Argentina, quien el 9 de julio de 1909 pronuncia su Laudo fijando una línea de frontera en base a la equidad, fundado en que la zona controvertida se encontraba inexplorada en 1810, por lo que no sería aplicable el principio del "uti posidetis juris", lo que ocasionó que en algunas zonas se tomarán como territorio peruano donde poblaciones bolivianas vivían asentadas mucho tiempo atrás. Este fallo generó inmediatamente la protesta y rechazo del Gobierno de Bolivia, ya que excedía el pacto arbitral [...]. No obstante, Bolivia - pese a sus reservas - a fin de cumplir su compromiso arbitral expreso su conformidad con el Laudo [...] y seguidamente se negoció y suscribió el Tratado de 17 de septiembre de 1909 de Rectificación de fronteras, por el cual ambos países, en base al Laudo, fijan sus límites y Bolivia logra salvaguardar parte de sus posesiones en la zona de litigio (ORIAS, SEOANE e TORRES, 2001, p. 276).
\end{abstract}

A situação começa a se reverter com uma nova aproximação entre Bolívia e Peru que assinam em 1936 o Pacto de Amizade e Não-Agressão que incluía como pontos principais: a segurança territorial, a solução pacífica de controvérsias, o respeito ao Direito Internacional, o livre transito irrestrito e liberdade de navegação recíproca, e a cooperação fronteiriça.

O livre trânsito passa a ter uma importância fundamental para a Bolívia que necessitava ter acesso ao mar para suas exportações, o que foi viabilizado por sua aliança com o Peru e a assinatura do Convênio de Transito de 1948:

esta libertad de tránsito se ejerce "por las vías habilitadas ente los dos países y por las que se habiliten en el futuro". Así, se diversifican las posibilidades de tránsito para Bolivia, ya que se amplía a los puertos de Mantarani e Ilo. De forma simultánea se va mejorando la infraestructura vial con esos puntos, se pone en funcionamiento la ferrovía Puno-Matarani y se habilita el tramo carretero La Paz-Ilo. Posteriormente, en la década de los setenta se le ofrece a Bolivia facilidades portuarias y zonas francas en los Puertos de Mantarani e Ilo. Sin embargo, en los hechos el impacto de estas iniciativas no fue relevante, debido a la falta de infraestructura eficiente y su menor competitividad, en relación a los puertos del norte de Chile (ORIAS, SEOANE e TORRES, 2001, p. 277-278).

Nos anos 1990 a cooperação entre Bolívia e Peru se intensifica. Destacam-se os Acordos "Mariscal Andrés de Santa Cruz", também conhecidos como Acordos de Ilo, pois estabelecem o Projeto Binacional de Amizade, Cooperação e Integração sobre o uso do Porto de Ilo. E em 1996 é criada a Comissão Binacional de Coordenação Política, Cooperação e Integração, substituindo a anterior Comissão Permanente de 
Coordenação Peruano-Boliviana, que se encarrega do diálogo político entre os dois países e da formulação de programas e projetos bilaterais. Desta forma:

\begin{abstract}
algunos de los principales temas en la agenda boliviano-peruana son: i) El proyecto de Ilo; ii)Los corredores interoceánicos y, sobre todo, la carretera La Paz-Ilo; iii) El aprovechamiento conjunto de las aguas del Lago Titicaca; iv) la complementaridad económica y las interaciones recíprocas en el marco de la CAN; v) El contrabando; vi) La lucha contra el narcotráfico, el terrorismo y la guerrilla y vii) El Programa de Acción Integrado PeruanoBoliviano (PAIPB) (ORIAS, SEOANE e TORRES, 2001, p. 279).
\end{abstract}

Cabe ressaltar que foi assinado um Protocolo Complementar e Ampliador dos Acordos de Ilo em 2010, e depois um Adendo a este Protocolo foi assinado em 2012, por exigências do Poder Legislativo peruano. Em abril de 2013 o presidente Evo Morales deu uma declaração sobre a importância estratégica da Estrada que liga La Paz a Ilo. De acordo com o jornal boliviano:

el mandatario Evo Morales consideró estratégica la construcción de la
carretera La Paz-Ilo para llegar al Pacífico por Perú, por lo que no sólo
instruyó acelerar las obras, sino que también envió una misión a Lima para
concretar los convenios que pongan en marcha el Acuerdo de Ilo. "Esta es
una ruta que se ha convertido en estratégica (para la) integración económica
entre Brasil, Bolivia y Perú (corredor Atlántico-Pacífico). Por razones
geopolíticas hemos decidido acelerar la construcción de la carretera", explicó
ayer en el acto de firma de contrato de edificación de obras en el tramo
Chama-Nazacara, parte de la carretera La Paz-Hito IV, desde donde se
conectará a Bolivia con puertos de Ilo (LA RAZÓN, 2013) ${ }^{14}$.

Em relação aos recursos hídricos transfronteiriços, Bolívia e Peru compartilham o Sistema formado pelo lago Titicaca (T), o rio Desaguadero (D), o lago Poopó (P) e o Salar de Coipasa (S), denominado de Sistema TDPS. Em 1955 Bolívia e Peru fazem uma declaração sobre a importância dos estudos de diagnóstico sobre a situação da bacia do Lago Titicaca. Dois anos depois os países assinam a "Convenção Preliminar para o Estudo do Uso das Águas do Lago Titicaca”. A convenção foi ratificada pelo Peru no mesmo ano, mas a Bolívia só a ratificou depois de quase 30 anos, em 1986. Tal decisão foi influenciada pelas secas de 1982-1983 e as inundações de 1986-1987 que resultaram em grandes perdas econômicas para a Bolívia (DELLI PRISCOLI e WOLF, 2009).

Esta ratificação permitiu a criação da Subcomissão Mista para o Desenvolvimento da Zona de Integração do Lago Titicaca (SUBCOMILAGO), e de suas entidades nacionais, o Projeto Especial do Lago Titicaca (PELT) no Peru, e a

\footnotetext{
${ }^{14}$ LA RAZÓN. Evo considera estratégica la vía hacia Ilo y decide acelerar obras. Disponível em: $<$ http://www.la-razon.com/nacional/Evo-considera-estrategica-Ilo-acelerar_0_1811218881.html>. Acesso em maio 2013.
} 
Unidade Operacional Boliviana (UOB) na Bolívia. Em 1992 a Bolívia e o Peru decidiram estabelecer a Autoridade Binacional Autônoma do Lago Titicaca (ALT), que começou a funcionar efetivamente apenas a partir de 1996, por meio da assinatura de Notas Reversais $^{15}$, que também estabeleceram seu Estatuto. A ALT é uma organização de direito público internacional cujas decisões estão a cargo dos Ministérios de Relações Exteriores da Bolívia e do Peru.

Em relação aos recursos hídricos amazônicos compartilhados, a Bolívia e o Peru esperam melhorar a sua integração física através do rio Madre de Dios. Além disso, existem iniciativas fronteiriças entre os dois países com grande impacto para a Bacia Amazônica. A Zona de Interação Fronteiriça (ZIF) Peru-Bolívia foi estabelecida após as decisões 459 e 501, de 1999 e 2001 respectivamente, da Política Comunitária para a Integração e o Desenvolvimento Fronteiriço da CAN.

A ZIF Peru-Bolívia compreende uma área muito grande (70\% do território peruano e $82 \%$ do território boliviano) o que levou os países a realizar o planejamento de implementação da ZIF em duas etapas. Na primeira etapa seriam atendidos os Departamentos de Tacna, Puno e Madre de Dios, no Peru, e La Paz e Pando, na Bolívia, e a intervenção estaria dividida em duas regiões, uma Altiplanica e outra Amazônica. De 2003 a 2005 foi elaborado o Plano de Desenvolvimento da ZIF, quando os países elaboraram sua visão, objetivos, programas e projetos na primeira fase.

A segunda fase correspondeu à adoção por consenso dos programas e projetos. O Peru conseguiu completar essa fase e definiu os projetos para a região amazônica em quatro categorias: meio ambiente e desenvolvimento sustentável; desenvolvimento social e infraestrutura; desenvolvimento da produção; e gestão do programa binacional. Estes projetos se referem aos Departamentos de Madre de Dios, no Peru e Pando, na Bolívia (MEZA, 2011). Destacam-se para a questão dos recursos hídricos amazônicos, os seguintes projetos: o manejo integrado da bacia do Rio Acre; o manejo integrado da bacia do Rio Madre de Dios; o manejo integrado da bacia do rio Tahauamanu; o melhoramento das condições de navegabilidade do Rio Madre de Dios e seus afluentes; e a rodovia interoceanica em Madre de Dios.

\subsubsection{As relações entre Equador e Peru}

\footnotetext{
${ }^{15}$ Um tipo de nota diplomática.
} 
As relações entre Equador e Peru foram marcadas, historicamente, por tensões e conflitos envolvendo o problema dos limites entre os dois países herdados desde o período de suas independências. Os conflitos envolveram incidentes militarizados e alguns enfrentamentos armados tiveram grande repercussão como o de 1995, conhecido como "Guerra del Cenepa".

Após a independência do Equador, este ofereceu concessões em seu território amazônico, o que gerou uma reação peruana, pois o Peru afirmava que esses territórios pertenciam a ele:

En 1830, Ecuador hizo secesión con la Gran Colombia y, en 1832 firmó un tratado de Paz con Perú, con la promesa de un futuro reglamento amistoso de límites fronterizos. Pero el fracaso de las negociaciones en 1841 dio lugar a una crisis entre los dos países y, en 1842, el Perú exigía, en vano, el reconocimiento de su soberanía sobre Mainas y Jaén. En 1853, Quito proclamaba la libertad de navegación sobre los ríos Mainas, disputados con Lima y tributarios del Amazonas. Pero Lima rechazó esta pretensión que marcaba ya la voluntad del Ecuador (recurrente hasta el Tratado de Paz y Amistad de 1998) de disponer de un acceso fluvial hasta el Amazonas. De esta manera, el problema de la libertad de navegación era presentado diplomáticamente (ROUX, 2001, p. 522).

Em 1858 o Peru chegou a mobilizar tropas para o Equador e os países chegaram a firmar o Tratado de Mapasingue, onde todo o oriente equatoriano foi cedido ao Peru. Nos anos seguintes novas tentativas de solucionar o litígio fronteiriço não tiveram êxito, inclusive a tentativa da arbitragem pelo rei espanhol. De acordo com Morales, "las posturas maximalistas no permitían um arreglo y alentaban, de hechos, los avances peruanos en los territórios em disputa" (1999, p. 14). O Equador tenta alianças com o Brasil e com a Colômbia, mas não obtém êxito para a disputa com o Peru. As negociações são reiniciadas em 1924 e se estendem por mais de uma década e fracassam novamente.

Em 1941 há um novo enfrentamento militar, chamado de "Guerra de Zarumilla", em que as forças peruanas derrotam as equatorianas. Esta situação de conflito se manteve por vários meses até a intervenção dos Estados Unidos e dos países garantes que convocaram a Conferência de Chanceleres no Rio de Janeiro em 1942 para tentar solucionar o conflito. Argentina, Brasil, Chile e Estados Unidos atuaram como os países garantes, isto é, os países que iriam zelar pelo cumprimento dos acordos de paz. Nesta ocasião, o Equador e o Peru assinaram o Protocolo de Amizade e Limites, conhecido como Protocolo do Rio de Janeiro. No entanto, o Equador não saiu satisfeito com o resultado deste Protocolo. Este Protocolo: 
Differed from other boundary treaties in that it provided both means of settling the controversy and a new boundary line. In the area of the Cordillera del Cóndor, for example, the agreement provided for a boundary line from the Quebrada de San Francisco, the divortium aquarum between the Zamora y Santiago Rivers, to the confluence of the Santiago with the Yaupi River. Finally, in recognition of the fact that the frontier between Ecuador and Peru was unknown or poorly known in many areas, the protocol included a provision for reciprocal concessions where convenient to adjust to geographic conditions. Such rectifications were to be enacted with the collaboration of the four guarantor states (ST JOHN, 1996, p. 78).

Após este Protocolo ocorrem outros incidentes militarizados incluindo o de meados de 1977 e 1978, no setor do rio Cenepa e da quebrada Chiqueiza. Outro enfrentamento ocorreu em 1981, chamado de "Guerra del Paquisha" ou de "Falso Paquisha". A partir de então:

Nuevos incidentes militarizados se producirían en 1983, 1984, 1985, 1988, y 1989. Posteriormente, desde principios de 1991, tuvieran lugar nuevos roces entre las fuerzas armadas de ambos países que vigilaban el sector ubicado entre los hitos Cusumaza-Bumbuiza y Yaupi-Santiago, hasta llegar al $13 \mathrm{de}$ enero de 1995, cuando se desencadena la denominada Guerra del Cenepa, que provocó la creación de la Misión de Observadores Militares EcuadorPerú (NOVAK e NAMIHAS, 2008, p. 12).

O último incidente militarizado foi em 1998 na zona da Cordilheira do Condor, o que gerou a intervenção da Missão de Observadores Militares Equador-Peru. Em 1997 os países assinaram a Declaração de Brasília em que se comprometiam a abordar quatro áreas no esforço de alcançar um acordo: um tratado de navegação e comercio, um acordo de integração fronteiriça, a fixação das fronteiras, e uma comissão binacional para medidas de confiança mútua e segurança. O papel da diplomacia, da Missão de Observadores e dos países garantes (Argentina, Brasil, Chile e Estados Unidos) foi importante no processo de negociação que se seguiu (DONOSO, 2009).

Para Bonilla (1999), o processo de negociação que se inicia em 1995 após a Guerra de Cenepa, se dá em três etapas:

En la primera, los dos estados nacionales ponen de acuerdo en los procedimientos que como se sostiene en este texto, definen desde el principio el resultado final de la negociación. Cuando las partes admiten la necesidad de negociar, se genera un cambio central en la política exterior convencional de Ecuador y Perú. Ecuador reconoce la vigencia del Protocolo de Rio de Janeiro y el Perú la posibilidad de interpretaciones diferentes de ese instrumento. Además, Ecuador y Perú reconocen tácitamente la posibilidad de recurrir a los garantes en calidad de árbitros. En la segunda etapa, los dos países desarrollan posiciones que reiteran su clásica y contradictoria política exterior, pero someten sus posturas al juicio de los garantes. Esto abre la tercera fase que consiste en la ejecución de la posición política de los garantes y la interacción con las sociedades domésticas para construir las condiciones de admisión del resultado (BONILLA, 1999, p. 13-14). 
O Acordo de Paz entre Equador e Peru é assinado no dia 26 de outubro de 1998 em Brasília. Na Acta Presidencial de Brasília, os presidentes:

1. Expresan su convencimiento acerca de la histórica transcendencia que para el desarrollo y bienestar de los pueblos Hermanos del Ecuador y Perú tienen los entendimientos alcanzados entre ambos Gobiernos. Con ellos culmina el proceso de conversaciones sustantivas previsto en la Declaración de Paz de Itamaraty del 17 de febrero de 1995 y se da término, en forma global y definitiva, a las discrepancias entre las dos Repúblicas de manera que, sobre la base de sus raíces comunes, ambas Naciones se proyecten hacia un compromiso futuro de cooperación y mutuo beneficio.

2. Declaran que con el punto de vista vinculante emitido por los Jefes de Estado de los Países Garantes, en su carta de fecha de 23 de octubre de 1998, que forma parte integrante de este documento, quedan resueltas en forma definitiva las diferencias fronterizas entre los dos países. [...]

3. Simultáneamente, manifiestan su compromiso de someter los acuerdos que se suscriben en esta fecha, a los procedimientos de derecho interno [...]. Estos acuerdos son:

- $\quad$ Tratado de Comercio y Navegación [...]

- Acuerdo Amplio Peruano Ecuatoriano de Integración Fronteriza, Desarrollo y Vecindad [...]

- Intercambio de notas sobre el Acuerdo de Bases respecto de la rehabilitación o reconstrucción de la bocatoma y obras conexas del Canal de Zarumilla, así como el Reglamento para la Administración del Canal de Zarumilla y la Utilización de sus Aguas,

- Intercambio de Notas con relación a los aspectos vinculados a la navegación en los sectores de los Cortes de los ríos y del Río Napo,

- Intercambio de Notas sobre el Acuerdo de Construcción de la Comisión Binacional Peruano-Ecuatoriana sobre Medidas de Confianza Mutua y de Seguridad (ACTA PRESIDENCIAL, 1999).

\section{O Acordo Amplo Peruano-Equatoriano de Integração Fronteiriça,}

Desenvolvimento e Vizinhança previu a elaboração de um Plano Binacional de Desenvolvimento da Região Fronteiriça. Os objetivos do Plano visam melhorar a qualidade de vida das populações fronteiriças, no entanto, como afirma Toche (2008), ele foi formulado de cima para baixo, e distante da realidade e das elites locais. Meza (2011) sintetiza os projetos contidos no Plano da seguinte forma:

los proyectos de mayor importancia del Plan Binacional [...] tienen que ver con la construcción de infraestructura vial hasta de $3397 \mathrm{~km}$ de longitud, organizados en 5 ejes viales, destinados a establecer una red de interconexión terrestre entre ambos países como soporte del desarrollo de la zona fronteriza común. Cada eje incluye la construcción de puentes y centros binacionales de atención en frontera (CEBAF) bajo responsabilidad compartida. Asimismo, incluye grandes obras referidas a interconexiones eléctricas, ordenamientos y manejo de cuencas, programas de cooperación zoo-sanitaria, desarrollo urbano, obras de riegos, entre otros (2011, p. 115).

Cabe ressaltar que o Plano Binacional a pesar de suas falhas tem impulsionado a cooperação entre os dois países, modificando suas relações que estiveram marcadas pelo conflito por quase todo um século. 
Apesar do conflito entre Equador e Peru ter se estendido durante quase todo o século vinte, isto não impediu que os dois países participassem de iniciativas de integração regional multilaterais, como foi o caso do Tratado de Cooperação Amazônica na década de 1970.

\title{
2.2.2 Relações multilaterais: o Tratado de Cooperação Amazônica
}

A cooperação regional entre os oito países amazônicos foi inaugurada com a assinatura do Tratado de Cooperação Amazônica em 1978, que entrou em vigor em 1980. Após anos de poucas atividades e relações em torno do TCA, os países assinam em 1998 um Protocolo de Emenda ao tratado visando impulsionar e ampliar a cooperação, com a criação da Organização do Tratado de Cooperação Amazônica $(\text { OTCA })^{16}$. A OTCA possui uma Secretaria Permanente com sede permanente em Brasília, o que encerra o período de Secretarias Pro Tempore rotativas entre os países membros. A organização inicia suas atividades em 2002, quando entra em vigência o Protocolo. No entanto, a organização já nasce com deficiências estruturais:

\begin{abstract}
a cooperação - neste momento - é tanto mais imprescindível quanto é desproporcional a força da nova Organização ante a amplitude da Agenda de prioridades para toda a Amazônia continental. Uma região que adquire relevo crescente a escala mundial, confronta riscos formidáveis e obriga a ser encarada distintamente do passado (COSTA-FILHO, 2003, p. 383).
\end{abstract}

As vantagens da cooperação amazônica seria juntar esforços nas áreas de interesse comum dos países, que passa a ser ampliada com a criação da organização:

\begin{abstract}
a OTCA, pretende viabilizar e ampliar o TCA. Este já assegura a mais ampla liberdade de navegação comercial no curso do Amazonas e demais rios amazônicos internacionais, respeitadas as regras de cada Estado, os tratados bilaterais e os princípios de Direito Internacional. Estabelece também que as partes contratantes promoverão a coordenação dos atuais serviços de saúde e tomarão medidas para a melhoria das condições sanitárias, bem como para a prevenção e o combate de epidemias (BECKER, 2007, p. 54).
\end{abstract}

O TCA possui 28 artigos que, para Mattos (1982), podem ser agrupados segundo o assunto de que tratam: território e recursos naturais (arts. I, II e IV); rios: recursos hídricos, transportes e comunicação (arts. III, V, VI e X); pesquisa e equilíbrio ecológico (arts. VII e IX); saúde (art. VIII); recursos humanos e naturais: ação conjunta e ação isolada (arts. XI, XV, XVI, XVII, XVIII, XIX); comércio e varejo (art. XII);

\footnotetext{
${ }^{16}$ Para maiores informações sobre a história e instituições do TCA e da OTCA ver: SANT'ANNA, , 2009; ANTIQUERA,, 2006; ARAGÓN, 1994; ROMAN, 1998; OTCA, 2004; SILVEIRA, 2005.
} 
turismo e conservação de riquezas etnológicas e arqueológicas (arts. XIII e XIV). Os demais artigos se ocupam de aspectos organizacionais.

A instância máxima tanto do TCA como da OTCA é a Reunião dos Ministros de Relações Exteriores. Com pouca frequência também ocorre a Reunião de Presidentes dos países amazônicos. A OTCA já teve cinco Secretários-gerais, Rosalia Arteaga, Francisco José Luis Marmolejo (interino), Manuel Picasso, Alejandro Gordillo e Robby Dewnarain Ramlakhan. A Secretaria Permanente da OTCA possui cinco coordenações para cada temática: saúde; meio ambiente; assuntos indígenas; educação, ciência e tecnologia; e transporte, infraestrutura, comunicação e turismo.

Para Silveira (2005), está muito presente no texto do tratado o termo “desenvolvimento". Este autor afirma que "o texto se vê inegavelmente marcado por uma preocupação muito mais desenvolvimentista - de cunho ocupacional, exploratório e econômico - do que propriamente preservatório do meio ambiente" (p. 66).

Coelho (1992) aponta que o TCA soube já na década de 1970 equacionar a tensão que iria dominar agenda internacional nas próximas décadas ao colocar o desenvolvimento sócio-econômico aliado à preservação ambiental e no contexto das soberanias nacionais:

\begin{abstract}
o fato é que o TCA soube absorver a tensão intrínseca aos grandes momentos de transição paradigmática, evitando, não sem dificuldades, reveladas no complexo processo de sua negociação, o enrijecimento de concepções equívocas (entre elas os receios de hegemonia ou expansionismos brasileiros), ou defasadas no tempo (como a visão essencialmente interiorizada, vigente um pouco, aqui e acolá, em cada país, limitada a um nacionalismo pouco dinâmico, que havia contribuído junto com heranças coloniais, ao distanciamento entre os países amazônicos e ao desestímulo das relações regionais entre eles) (p. 117).
\end{abstract}

Com o passar dos anos a temática ambiental ganha um maior espaço dentro do TCA e também proporciona maior visibilidade internacional do próprio tratado (COELHO, 1992; ROMÁN, 1998).

O TCA foi concebido como um acordo quadro, amplo e com princípios gerais para depois ser complementado por acordos bilaterais, visando assim, ter uma "flexibilidade necessária para ajustarse a los câmbios y necessidades de la región" (GAFNER-ROJAS, 2007, p. 269). Desta forma, como complementa a autora:

los países miembros encontraron en el TCA un marco adecuado para promover la cooperación binacional en las zonas fronterizas a través de proyectos de integración. A fin de establecer mecanismos para la ejecución de las acciones fronterizas, fueron suscritos acuerdos bilaterales de cooperación, que sirvieron de base para la realización de estudios integrados binacionales. Hasta el momento se han celebrado cinco acuerdos bilaterales: 
Colombia-Ecuador y Colombia-Perú, ambos suscritos en marzo de 1979; Brasil-Colombia, en marzo de 1981; Brasil-Perú, en octubre de 1979, y Bolivia-Brasil en agosto de 1988”. (GAFNER-ROJAS, 2007, p. 269).

A complementação com acordos bilaterais visava, em termos gerais:

- Promover la gestión ambiental del área correspondiente e incentivar su desarrollo autónomo y sostenible utilizando correctamente las potencialidades y respetando las limitaciones que presentan los recursos naturales.

- Contribuir a mejorar la calidad de vida de la población mediante la generación de actividades productivas y de fuentes de trabajo, así como el mejoramiento o la instalación de infraestructura física y social básica que satisfaga las aspiraciones de los habitantes.

- Promover la integración de cada área nacional en los respectivos países, asegurando que esa integración sirva como elemento dinamizador del desarrollo.

- Realizar la zonificación ambiental como base para ordenamiento territorial y para la implementación de modelos de producción que consideren la capacidad de los ecosistemas amazónicos, dentro de un proceso de desarrollo sostenible en el cual participen, activamente los grupos humanos asentados tradicionalmente en la región, incluyendo las comunidades indígenas y nativas.

- Conservar la biodiversidad de la región.

- Fortalecer los organismos nacionales vinculados a la planificación ambiental y al uso de recursos naturales e incentivar la creación de mecanismos de trabajo interinstitucional.

En la práctica estos acuerdos y proyectos, cuyos objetivos son loables, deberían en el futuro considerar la participación popular con el fin de acercarse más a las necesidades locales y tomar en cuenta los conocimientos tradicionales. Adicionalmente, el número de acuerdos adoptados es insuficiente, a la vez que las necesidades son muchas". (GAFNER-ROJAS, 2007, p. 269-270).

Outra iniciativa multilateral dos países amazônicos foi a criação do Parlamento Amazônico, o PARLAMAZ, em 1989, por iniciativa do Peru. O PARLAMAZ é composto por representantes das Assembleias Legislativas dos países membros da OTCA. Em 2006 a OTCA buscou a reativação do PARLAMAZ e sua maior institucionalização. Como afirmou Rosalía Arteaga, a primeira secretaria-geral da OTCA:

Faz-se também necessário dar ênfase à importância que, no dia de hoje, ganham certas instâncias que foram criadas quase paralelamente ou em estreita relação com o tratado e com as quais a OTCA precisa contar, para cumprir seus objetivos; referimo-nos aqui, em primeiro lugar, ao Parlamento Amazônico, cuja institucionalização ainda depende da decisão política dos governos e cuja reativação é fundamental, caso esposemos o princípio de que qualquer processo de desenvolvimento precisa da participação ativa dos mecanismos de decisão nacional e de que o poder legislativo é a instância que, por representar as aspirações da sociedade, pode contribuir nas reflexões e na busca de soluções para o desenvolvimento sustentável da região e, também, apoiar a consolidação das políticas de integração e desenvolvimento regional (OTCA, 2006, p. 95-96). 
O TCA e a OTCA representam a principal organização intergovernamental que reúne os oito países amazônicos e que desenvolve projetos de âmbito regional em questões estratégicas para a Amazônia, como, por exemplo, meio ambiente, populações indígenas, e infraestruturas. No entanto, depois de um período de inatividade a OTCA é criada, mas ainda com fragilidades instituições como a dependência de financiamento externo para seus projetos regionais e, também a falta de pessoal técnico, que são contratados como consultores em cada projeto.

\subsubsection{A IIRSA e a UNASUL e seus impactos para a cooperação amazônica}

Outro processo multilateral de integração que abarca os países amazônicos é a Iniciativa para a Integração da Infraestrutura Regional Sul-americana (IIRSA) que foi estabelecida em 2000 pelos governos dos doze países sul-americanos visando integrar a infraestrutura dos países da América do Sul. Quase dez anos após a sua criação, na Terceira Reunião da União das Nações Sul-Americanas (UNASUL) foi estabelecido o Conselho de Infraestrutura e Planejamento (COSIPLAN), cuja instalação ocorreu em 2010. Este Conselho, por sua vez, incluiu a IIRSA como seu fórum técnico.

A IIRSA teria como propósito "prover a região de uma infraestrutura básica, nas áreas de transporte, comunicações e energia, disponibilizando as bases para uma maior integração comercial e social do continente" (COUTO, 2009, p. 62). De acordo com Wanderley Messias da Costa, trata-se de "aproveitar a antiga e incipiente rede de circulação macro-regional (mais densa na sua porção meridional) e as redes nacionais disponíveis nas demais escalas dos países-membros" (2009, p. 7).

A carteira de projetos da IIRSA apresentava 524 projetos até o ano de 2011, e os primeiros anos de seu funcionamento foram dedicados à seleção e priorização dos projetos a serem implementados. Estes projetos são divididos em 10 Eixos de Integração e Desenvolvimento, sendo eles: Eixo Andino; Eixo do Escudo das Guianas; Eixo Peru-Brasil-Bolívia; Eixo do Amazonas; Eixo da Hidrovia Paraguai-Paraná; Eixo Interoceânico Central; Eixo de Capricórnio; Eixo Mercosul-Chile; Eixo Andino do Sul; e Eixo do Sul. Em 2004 foi elaborada a Agenda de Implementação Consensual (AIC) para o período de 2005 a 2010, com um total de 31 projetos prioritários.

Em geral, os projetos de infraestrutura da IIRSA têm gerado impactos nas áreas em que incidem, muitos em regiões fronteiriças. Como a construção de infraestruturas de comunicação, conexão e de energia podem contribuir para aumentar as interações 
fronteiriças, existe um grande potencial para que este tipo de integração regional impulsione a integração fronteiriça.

Entre os Eixos de Integração da IIRSA que incluem projetos na região amazônica estão: o Eixo do Amazonas, o Eixo do Escudo das Guianas e o Eixo PeruBrasil-Bolívia. Há também outros eixos que em sua área de influencia incluem uma parte na região amazônica como é o caso do Eixo Interoceânico Central.

Os projetos de infraestrutura têm causados impactos tanto positivos quanto negativos sobre o território e as relações entre os países sul-americanos. Para Costa:

essa nova estrutura de relações tem provocado impactos positivos nos paísesmembros do Bloco, no que concerne às suas respectivas políticas públicas territoriais. Isto tem sido observado, notadamente, em alguns projetos bilaterais - casos das ligações Brasil-Venezuela, Brasil-Peru e ArgentinaChile - e nos respectivos programas nacionais em logística e transporte, já que, doravante, eles tendem a incluir as várias possibilidades de projeção externa das suas novas redes de circulação. [...] trata-se de programa que envolverá ao menos duas ou três décadas, devendo-se considerar os agravantes, daqui, representados pelas conhecidas limitações das economias nacionais, as enormes distâncias envolvidas e as dificuldades representadas pelas características físico-naturais peculiares da região para ligações terrestres, como são os casos da Cordilheira dos Andes e da Floresta Amazônica (2009, p. 8).

A IIRSA e a OTCA compartilham o mesmo objetivo de integração física, como pode ser visto nos documentos da OTCA e, mesmo no TCA, que em seu artigo 10 afirma que:

As Partes Contratantes coincidem na conveniência de criar uma infraestrutura física adequada entre seus respectivos países, especialmente nos aspectos de transporte e comunicações. Consequentemente, comprometem-se a estudar as formas mais harmônicas de estabelecer ou aperfeiçoar as interconexões, rodoviárias, de transporte fluviais, aéreos e de telecomunicações, tendo em conta os planos e programas de cada país para lograr o objetivo prioritário de integrar completamente seus territórios amazônicos às suas respectivas economias nacionais (TCA, 2004).

Román (1998) também afirma que uma das razões pela qual o Brasil decidiu propor a elaboração do TCA aos demais países amazônicos na década de 1970 teria sido o objetivo da integração física, que serviria para os propósitos econômicos e estratégicos brasileiros:

[...] the ACT proposal may also have been an attempt to achieve a physical integration of the region, intended to support the Brazilian economic ambitions to win new markets for trade from a more practical perspective. This argument is based on the fact that any economic development requires appropriate means of communications for the transportation of goods. This matter was not only related to the Brazilian leaders' efforts to increase regional trade, but it also concerned the execution of national development programs in the Amazonia. [...] the key element to this strategy was the Amazonian rivers. [...] One can assume that the ACT, additionally, was 
intended as an instrument to achieve total control over inter-continental transportation and trade. This ambition to open up commercial routes to the Pacific had been a Brazilian dream for centuries. Still, it is clear that the emphasis on external trade made it a priority issue by the mid-1970s (p. 168).

O Plano Estratégico 2004-2012 da OTCA previa que a Secretaria Permanente da OTCA deveria trabalhar em conjunto com a Coordenação da IIRSA, da CAF e do BID, para a criação de uma Rede de Transportes na Amazônia que priorizasse os sistemas multimodais e a facilitação da navegação dos rios da Bacia Amazônica. Também a Agenda Estratégica de Cooperação Amazônica (AECA) de 2010 aponta como seu principal objetivo na área de infraestrutura e transportes a coordenação das atividades com o COSIPLAN da UNASUL. E o Plano de Trabalho de 2013 da Coordenadoria de Assuntos Sociais, Infraestrutura, Transporte e Turismo propôs reiniciar o diálogo com as instituições regionais de integração física, como o COSIPLAN.

Além da integração física referente aos transportes e a comunicação, uma parte da IIRSA se refere à integração energética, e no caso amazônico, os principais projetos neste âmbito são de usinas hidrelétricas e interligação elétrica. Apesar de existirem grandes usinas hidrelétricas já construídas na parte brasileira da Bacia Amazônica, a maior parte deste território não está conectada do Sistema Nacional e depende da energia gerada em centrais térmicas locais. Estas consistem, em geral, em geradores a diesel em pequenas cidades, centrais térmicas em cidades maiores ou até mesmo centrais hidráulicas locais. Théry e Mello (2005, p. 230-231) afirmam que "existem planos para remediar essa situação mas a distância e os investimentos necessários são tão imensos que seriam necessários anos para assegurar a cobertura completa do País por uma rede bem distribuída".

Outros países amazônicos também dependem de geradores a diesel para a geração de energia elétrica em suas respectivas porções amazônica, mas, em sua maioria, esses países possuem planos de construção de usinas hidrelétricas aproveitando os potenciais energéticos das sub-bacias amazônicas. Este é o caso da Bolívia, do Equador e do Peru, por exemplo. Como já foi mencionados nos sub-itens anteriores, o Brasil e a Bolívia têm acordos para construção de usinas na Bacia do rio Madeira, o Peru tem um acordo com o Brasil para a construção de hidrelétricas na Amazônia peruana e com a exportação de energia para o Brasil, e o Equador já está construindo a hidrelétrica Coca-Codo-Sinclair, e prevê a construção de outras, com a exportação de excedentes para a Colômbia e Peru. 
A navegação fluvial é o principal meio de transporte na Amazônia, onde ainda existem áreas que só são acessíveis por via fluvial. Recentemente os governos dos países amazônicos tem buscado melhorar as condições de navegação na Amazônia promovendo obras de infraestruturas para garantir uma maior integração física dos territórios:

\begin{abstract}
no total, a bacia amazônica oferece 50 mil $\mathrm{km}$ de rios navegáveis para embarcações com deslocamento médio de 100 toneladas, porém, cerca de 10 mil $\mathrm{km}$ desses rios podem ser navegados por navios com deslocamento médio de 1.000 toneladas ou mais. É impressionante observar em Letícia, porto colombiano no Amazonas, a mais de $3 \mathrm{mil} \mathrm{km}$ do mar, o atracamento de transatlânticos provenientes da Europa ou dos Estados Unidos ou as grandes canhoneiras que sobem o rio Putumayo até Porto Leguízamo, próximo aos Andes (DOMINGUEZ, 2003, P. 162).
\end{abstract}

É importante notar que o transporte fluvial é considerado o meio de transporte de menor impacto para a floresta amazônica, principalmente se comparado às estradas, que em alguns casos leva ao desmatamento em forma de "espinha de peixe", isto é, da estrada principal saem caminhos perpendiculares por onde avança o desmatamento (AB'SABER, 2004). Becker e Stenner (2008) apontam que os rios são "estradas naturais" da Amazônia, pois:

existem milhares de quilômetros de vias navegáveis na bacia Amazônica: alguns são apenas flutuáveis. Outros oferecem condições para uma navegação rudimentar, e os principais rios são francamente navegáveis. Alguns destes, como o Amazonas/Solimões e o Madeira, apresentam elementos de balizamento e sinalização que os caracterizam como hidrovias. A rede hidrográfica da região forma um sistema hierarquizado de transporte, com uma gigantesca rede de rios menores, o que permite a navegação de pequenas embarcações e garante capilaridade ao transporte hidroviário. Além da navegabilidade, existem nas cidades ribeirinhas amazônicas dezenas de pequenas estruturas portuárias que são fundamentais para o transporte de pessoas e as relações comerciais e políticas dessas cidades" (BECKER e STENNER, 2008, p. 84-85).

São previstas várias hidrovias nos projetos da IIRSA como no Corredor MantaManaus que seria a ligação entre os rios Napo-Solimões-Amazonas, e entre os rios Putumayo-Iça-Solimões-Amazonas. No eixo Peru-Brasil-Bolívia há também o projeto da hidrovia Madeira-Mamoré-Beni-Madre de Dios. O projeto de melhoramento da navegabilidade da hidrovia do rio Napo será analisado no capítulo 4 deste trabalho.

Embora seja considerado um meio de transporte com menor impacto ambiental que o rodoviário, as hidrovias também geram impactos ambientais negativos em seus quatro principais elementos físicos: as vias, as embarcações, as cargas e os terminais. De acordo com Santana e Tachibana (2004), o transporte de cargas perigosas nas hidrovias pode causar um grave dano ambiental em caso de acidentes com o 
derramamento de combustíveis e de cargas químicas. Os autores também apontam que "entre as intervenções realizadas para a melhoria da navegabilidade, o melhoramento do leito e das margens dos rios é considerado o mais polêmico em termos ambientais" (SANTANA e TACHIBANA, 2004, p. 80), e pode incluir obras de regularização dos rios, obras de estabilidade e proteção de margens, dragagens e derrocamentos de pontos específicos, e até mesmo canalizações.

Os projetos da IIRSA em território amazônico têm gerado conflitos que envolvem, em geral, as populações e não os governos dos países amazônicos. Neste caso, existem diversas organizações, inclusive indígenas que tem se posicionado contra alguns projetos e propostas da IIRSA, como, por exemplo, a "Resolução dos Povos Indígenas sobre a IIRSA”, elaborada pela Coordenadoria Andina de Organizações Indígenas e endereçada aos presidentes de bancos BNDES, BID, CAF, Fonplata e Banco Mundial. Esta organização indígena explicita a questão da justiça social e ambiental, para ela:

nosso conceito de bem viver deve ser respeitado como alternativa legítima de bem-estar em equilíbrio com a natureza - que, na língua Quechua, chamamos "Sumaq Kawsay/Sumaq Qamaña - e é algo muito distante daquilo que a IIRSA quer nos transformar: em territórios de trânsito de mercadorias, crateras da mineração e rios mortos pela poluição do petróleo (apud SEVÁ FILHO, 2010, p. 139).

A mobilização de ONGs com sede nos países desenvolvidos contra os projetos da IIRSA em áreas sensíveis também tem obtido repercussão:

\begin{abstract}
one of the major platforms against IIRSA has formed among northern NGOs, spearheaded by the Bank Information Center (BIC). With funding from the Moore Foundation, BIC has developed a major civil society initiative called BICECA (Building Informed Civic Engagement for Conservation in the Andes-Amazon). [...] The primary outgrowth of this initiative is the generation of a transnational activist network. BIC hosted a meeting of northern and southern civil society organizations in Lima, Peru in July 2005, which culminated in the Articulación Frente a IIRSA (Platform against IIRSA) (PIECK, 2011, p. 188-189).
\end{abstract}

Os projetos da IIRSA possuem um papel relevante não apenas para a integração regional da América do Sul, mas também para os territórios em estão localizados afetando tanto a organização social, econômica e política, como também territorial. Serão analisados nos estudos de caso deste trabalho nos capítulos três e quatro alguns projetos da IIRSA na Bacia Amazônica, e seus impactos para a governança dos recursos hídricos transfronteiriços amazônicos. A seguir serão apresentados os principais atores não-estatais transnacionais que atuam na Bacia Amazônica. 


\subsection{Atores não-estatais transnacionais na Bacia Amazônica}

Entre os atores transnacionais não-estatais que tem atuado na Bacia Amazônica destacam-se as organizações indígenas, as ONGs, principalmente as ambientalistas, e as corporações transnacionais que têm empreendido ações com impactos para a governança dos recursos hídricos amazônicos. Neste trabalho, o movimento indígena transnacional e as ONGS que atuam na Bacia Amazônica são entendidos como diferentes entre si, variando de acordo com suas reivindicações e objetivos, sua estrutura organizacional, e suas estratégias para tentar atingir seus objetivos.

\subsubsection{As organizações indígenas na Bacia Amazônica}

A apropriação dos recursos hídricos na Bacia Amazônica se deu primeiramente pelos povos nativos, indígenas, e posteriormente com a chegada dos europeus e depois com a formação de Estados independentes outros grupos sociais também se apropriaram destes recursos para diversos fins. Para os povos nativos os rios e seus recursos hídricos têm um caráter multidimensional, devido à sua importância cultural, simbólica, econômica, alimentar, doméstica, e de comunicação e transporte.

Com a colonização e, posteriormente, com a formação dos Estados, os povos indígenas na Bacia Amazônica foram sendo exterminados, ou forçados a se submeterem às missões e depois a organização estatal que delimitou seus territórios em reservas, as Terras Indígenas. Atualmente, grande parte dos povos indígenas na Bacia Amazônica tem reivindicado seus territórios ancestrais e vivem nas reservas ou Terras Indígenas (Brasil), onde possuem certa autonomia para continuar com seu modo de vida e identidade. Nas últimas décadas os povos indígenas tem se organizado em instituições para defender suas reivindicações:

\footnotetext{
los Orígenes e historia de las organizaciones indígenas en la selva de Ecuador, Perú y Bolivia, así como de las organizaciones de la costa, son diferentes a los que tienen los andinos. Los grupos étnicos en la Amazonía tienen diversas formas de organización social y se caracterizan por una gran dispersión y movilidad espacial. Para estas organizaciones no existe la propiedad privada de los recursos naturales" (ORSEL y VOS, 2009, p. 378).
}

$\mathrm{Na}$ Amazônia os povos indígenas têm se organizado em associações locais e federações regionais e nacionais para reivindicar seus direitos e seus territórios. De 
acordo com os dados da Coordenação das Organizações Indígenas da Bacia Amazônica (COICA), de 2004, existem aproximadamente 390 povos indígenas na Amazônia com 2.779.478 habitantes em uma extensão geográfica de mais de 7 milhões de $\mathrm{km}^{2}$. Nem todos os países amazônicos reconhecem as terras indígenas e a autonomia administrativa e cultural dos povos indígenas.

O movimento indígena se transnacionalizou na Amazônia a partir da criação da COICA. Ela foi criada no dia 14 de março de 1984, em Lima (Peru), durante o I Congresso das Organizações Indígenas da Bacia Amazônica. De 1984 a 1992 a cidade de Lima foi a sede da organização, mas no ano de 1993 esta se muda para Quito, no Equador, onde permanece até hoje.

A partir de 1992 fazem parte da COICA as organizações indígenas dos nove países amazônicos (incluindo a França), sendo elas a Confederação dos Povos Indígenas da Bolívia (CIDOB), a Coordenação das Organizações Indígenas da Amazônia Brasileira (COIAB), a Organização dos Povos Indígenas da Amazônia Colombiana (OPIAC), a Confederação das Nacionalidades da Amazônia Equatoriana (CONFENAE), a Associação dos Povos Ameríndios da Guiana (APA), a Federação das Organizações Autóctones da Guiana Francesa (FOAG), a Associação Interétnica de Desenvolvimento da Selva Peruana (AIDESEP), a Organização Indígena do Suriname (OIS) e o Conselho Nacional Índio da Venezuela (CONIVE).

Os objetivos gerais da COICA são:

\begin{abstract}
a) Promover, desarrollar e impulsar los mecanismos necesarios para la interacción de los Pueblos y organizaciones Indígenas miembros de la COICA; b) Defender las reivindicaciones territoriales, la autodeterminación de los Pueblos Indígenas y el respeto a los derechos humanos de sus integrantes; c) Coordinar con las organizaciones miembros, ante las diversas instancias intergubernamentales y organizaciones no gubernamentales de nivel internacional, las diferentes acciones dentro de la Cuenca Amazónica; d) Fortalecer la unidad y la colaboración mutua entre todos los Pueblos Indígenas de la región; y, e) Promover la revalorización y reivindicación cultural de sus miembros (COICA, 2007, p. 10).
\end{abstract}

No cenário internacional a COICA tem atuado em instituições internacionais que discutem temas ambientais e de direitos humanos. Atuaram na Conferência das Nações Unidas sobre Meio Ambiente e Desenvolvimento (CNUMAD), no Rio, em 1992; na Convenção sobre Diversidade Biológica (CDB); na Organização Mundial da Propriedade Intelectual (OMPI); na Comissão de Direitos Humanos das Nações Unidas; no Foro Intergovernamental sobre Florestas (FIF); na Convenção das Nações Unidas sobre as Mudanças Climáticas (CNUMC); no Protocolo de Kyoto (PK); na Comissão 
sobre Desenvolvimento Sustentável (CDS) do Programa das Nações Unidas para o Meio Ambiente (PNUMA); no Protocolo de Biossegurança da CAN; na Organização do Tratado de Cooperação Amazônica (OTCA); e no Fundo de Desenvolvimento dos Povos Indígenas da América Latina e Caribe, na comissão de chefes de Estado e de Governo, da Organização dos Estados Americanos (OEA). E atualmente também contribuíram para o estabelecimento do Foro Permanente para Questões Indígenas, no âmbito da Organização das Nações Unidas (ONU).

A COICA, no período de 2002 a 2004, elaborou, ratificou e iniciou a implementação da Agenda Indígena Amazônica (AIA), que traz as orientações políticas da organização. Seus objetivos específicos são definir as relações com os governos e as instituições de cooperação internacional com base nos reais interesses dos povos indígenas, gerar iniciativas concretas que melhorem a qualidade de vida destes povos, e criar acordos com os governos para a sustentabilidade da Amazônia.

Para a COICA a questão do território é central e parte da compreensão que os indígenas têm de seu território. Para eles o território "es el espacio que compartimos con otros seres vivos, una relación directa con garantía de sostenibilidad mutua, es la libertad incondicional para la manifestación de nuestras espiritualidades, culturas y ancestralidad (COORDINACIÓN, 2007). A COICA ao falar de territorio indígena está se referindo ao poder exercido sobre aquele espaço determinado, porém, com a preocupação de não ferir a soberania do Estado: "hablamos de ejercer un poder, así como un ente público, un municipio por ejemplo, ejerce dentro de los límites de su jurisdicción y competencia, sin atentar a la soberanía del Estado nacional" (COORDINACIÓN, 2007). A COICA defende que o controle do território e dos recursos naturais existentes nele seja dos povos indígenas, e que estes também têm o direito de participar nas decisões que venham a afetar seus territórios e os recursos naturais. Defende também o direito de aplicar suas normas, costumes e tradições dentro do seu território, e de auto-regular as suas formas de organização, e administração de seus recursos naturais de forma a evitar a degradação ambiental.

Desde a sua criação a COICA tem atuado junto ao TCA em propostas a organismos internacionais e agências de financiamento para projetos que visam melhorar a qualidade de vida das populações indígenas e o reconhecimento de seus territórios. Dando continuidade a esta cooperação, em 2004, a OTCA assinou um Memorando de Entendimento com a COICA. O memorando se refere às atividades que podem ser realizadas em conjunto entre as duas instituições, como: estabelecer e 
consolidar vínculos de relação e cooperação institucional; promover os devidos níveis de relação e participação mútua nos processos de definição e implementação dos Planos Estratégicos da OTCA e da COICA, nos assuntos de suas respectivas competências.

Em 1992 a COICA participou na elaboração de um projeto do TCA para a demarcação de Terras Indígenas (TIs) nos países amazônicos. O projeto denominado "Programa regional de consolidação de territórios indígenas através do Tratado de Cooperação Amazônica -TCA", foi resultado dos esforços das organizações indígenas, dos avanços ocorridos no âmbito do TCA, e da linha de cooperação com a União Européia (UE). A iniciativa partiu da Comissão Especial de Assuntos Indígenas da Amazônia (CEAIA) do TCA, que em 1991 na sua segunda reunião contou com a participação da COICA e suas filiais nacionais, que aprovaram e priorizaram os programas e projetos que deveriam ser promovidos e coordenados pela Secretaria do TCA.

É importante notar que as organizações indígenas defendem os interesses destes grupos e que, em alguns casos, há uma aliança temporária com grupo e ONGs ambientalistas, mas nem sempre os interesses de indígenas e ambientalistas se harmonizam. MacChapin (2008) aponta as dificuldades que emergiram na aliança entre a COICA e algumas ONGs conservacionistas. Para ele, os conservacionistas elaboraram a sua própria agenda e a submeteram aos indígenas, além dos que, os conservacionistas não tinham experiência em trabalhar com as comunidades locais e indígenas o que levou os projetos a fracassarem:

o fato é que os povos indígenas e os conservacionistas têm agendas muito distintas. As agendas indígenas invariavelmente começam com a necessidade de proteger e legalizar suas terras para seu próprio uso. Eles enfatizam a importância de se encontrar meios para viver na sua terra sem destruir os recursos naturais. E dão alta prioridade na documentação da história de seus povos, tradições e identidade cultural. As agendas conservacionistas, ao contrário, muitas vezes começam com a necessidade de se estabelecer áreas protegidas sem moradores e de se elaborar planos de manejo. [...] Eles raramente querem apoiar lutas legais em relação à posse da terra e ao apoio das organizações indígenas; eles consideram essas ações muito politizadas e fora de seu mandato conservacionista (MacCHAPIN, 2008, 34).

As organizações indígenas também tem um papel fundamental nas iniciativas locais de governança dos recursos hídricos transfronteiriços na Bacia Amazônica como será mostrado nos próximos capítulos deste trabalho acerca dos estudos de caso.

É preciso mencionar que os conservacionistas são apenas um grupo dentro do conjunto de ONGs ambientalistas existentes. Na verdade existem diferentes tipos de 
organizações que defendem causas ambientais e não podem ser generalizadas, como é analisado a ser a atuação de algumas ONGs na Bacia Amazônica.

\subsubsection{A atuação das ONGs na Bacia Amazônica}

As ONGs têm atuado na Bacia Amazônica desde que o movimento ambientalista se transnacionalizou. Existem diferentes tipos de ONGs ambientalistas que tem trabalho de diversas formas na Amazônia. É importante não generalizar a sua atuação, pois existem grandes ONGs transnacionais, como Greenpeace, WWF, entre outras, e também redes de organizações pequenas como o GTA. Além de organizações que combinam reivindicações ecológicas com as das comunidades locais e nativas como o Instituto Sócio Ambiental (ISA).

Para Diegues (2008), o grupo das grandes ONGs conservacionistas transnacionais tem grande peso sobre as políticas ambientais de governos como o Brasil. Estas ONGs propagaram, por exemplo, a ideia de corredor ecológico. O termo se institucionaliza no Brasil na virada do século XXI. De acordo com a lei brasileira 9.985, de 2001, que implementa o Sistema Nacional de Unidades de Conservação (SNUC), os corredores ecológicos são áreas de ecossistemas naturais que ligam UCs e possibilitam o fluxo de genes e movimento da biota entre elas, contribuindo para a dispersão de espécies e garantindo a manutenção de populações que necessitam de áreas com maior extensão para sobreviver.

Trata-se de uma iniciativa ampla de conservação da diversidade biológica, isto é, de uma estratégia de preservação ambiental concebida numa escala global. Esta ideia de conservação da natureza foi a primeira corrente ambientalista, de acordo com MartinezAlier, que pregava o culto à natureza intocada e que este autor chama de "culto ao silvestre" (2007). No início do século XX, se baseava no amor às belas paisagens, mas a partir da década de 1960, a biologia da conservação forneceu uma base científica:

os biólogos da conservação contam com conceitos e teorias - hot spots, espécies cruciais - evidenciando que a perda da biodiversidade caminha a passos largos. [...] Os biólogos e filósofos ambientais atuantes nessa primeira corrente ambientalista, que irradia suas poderosas doutrinas desde as capitais do Norte, como Washington e Genebra, até a África, Ásia e América Latina, apoiados por organizações bem estruturadas como a International Union for the Conservation of Nature (IUCN), o Worldwide Fund for Nature (WWF) e Nature Conservancy (MARTINEZ-ALIER, 2007, p. 24). 
Os grandes propagadores desta corrente ambientalista foram as ONGs conservacionistas, sendo a primeira delas a International Union for the Protection of Nature (IUPN), fundada em 1948 e conhecida atualmente como International Union for the Conservation of Nature (IUCN). A popularização da temática ambiental favoreceu a estruturação de redes políticas e de fluxos de recursos financeiros e humanos cujos protagonistas são as grandes ONGs conservacionistas. A World Wide Fund for Nature (WWF), a Conservation International (CI) e a The Nature Conservancy (TNC), por exemplo, contam com orçamentos de peso e com grandes equipes presentes em diversos países. A WWF, em especial, desenvolve diversos projetos nos países da América do Sul, e no Brasil alguns deles são em parceria com o governo federal, outros com o governo dos estados. De acordo com MacChapin:

a renda combinada da WWF, TNC e CI em 2002 para trabalhar em países do Terceiro Mundo chegou a mais da metade dos 1,5 bilhões de dólares disponíveis para a conservação naquele ano; e o investimento das três grandes ONGs na conservação aumentou de aproximadamente 240 milhões de dólares em 1998 para cerca de 490 milhões de dólares em 2002 (2008, p. 36).

Esta vertente conservacionista está presente no Projeto Corredores Ecológicos do Programa Piloto para a Proteção das Florestas Tropicais do Brasil, conhecido como PPG7. O PPG7 foi uma iniciativa criada na reunião da cúpula do G-7 de 1990 e aceita pelo governo brasileiro no ano seguinte. Para Kohlhepp (2005), “de acordo com os objetivos do PPG7, seria possível oferecer um modelo de cooperação Norte-Sul em questões ambientais globais, tentando provar a possibilidade de harmonizar os objetivos econômicos e ecológicos nas florestas tropicais" (p. 76). O programa é gerenciado pelo governo brasileiro juntamente com o Banco Mundial, que administra o Rain Forest Trust Fund (financiado pelo G-7, Comissão Européia e Países Baixos), um fundo para projetos que visem o fortalecimento da política e das instituições ambientais nacionais, o gerenciamento de áreas protegidas que visem à conservação da natureza e aumentar o conhecimento sobre a floresta tropical e sua conservação (MMA, 2002). Além desses atores, fazem parte do PPG7, com funções distintas, vários setores do governo brasileiro (federal, estadual e municipal) e ONGs nacionais e internacionais (como a rede do Grupo de Trabalho Amazônico). De acordo com Mello (2006):

o PPG7 caracterizou-se como um programa de grande vulto, pois além de destinar àquela época um elevado volume de recursos voltados unicamente à conservação da floresta (ainda que o montante comprometido tenha ficado muito aquém das primeiras cifras), propôs-se a atingir objetivos importantes, como a redução da produção de gases de efeito estufa, do 
desmatamento, e, especialmente, o fortalecimento da cooperação internacional em matéria de meio ambiente (p. 112).

Um dos seus objetivos específicos é a conservação da floresta e da diversidade biológica, onde se insere o projeto dos corredores ecológicos, além de outros projetos vinculados com o objetivo de melhorar o manejo em áreas protegidas como parques, reservas extrativistas, florestas nacionais e terras indígenas. Neste projeto dos corredores ecológicos, a proposta para a região amazônica é de cinco corredores cuja superfície total excede 1,5 milhões de $\mathrm{km}^{2}$ (MMA, 2002).

No mesmo período em que se estabeleceu o PPG7, anos 1990, também se formou o Grupo de Trabalho Amazônico (GTA), que reúne várias organizações e movimentos da sociedade civil amazônica. No princípio seu objetivo era se envolver nas negociações do PPG7 com as instituições parte do programa para influenciar sua configuração e implementação. Para Almeida:

\begin{abstract}
In the mid-1990s, the GTA turned to other activities that allowed it to consolidate and grow. It strengthened networks links through regional organizing meetings, exchange visits among associations, and Internet communication. The rank of the GTA grew quickly in the following years, as the network spread to new regions of the Amazon and attracted new organizational members. Today the GTA is made up of several distinct groups of beneficiary populations; rubbers tappers, Ameridians, rural workers, environmental NGOs, fishermen, women nut gatherers, and AfroBrazilians (who reside in former runaway slave communities known as quilombos), with the former four being the strongest constituencies within the network (2000, p. 58).
\end{abstract}

As contribuições e ações do GTA acabaram indo muito além do PPG7, como explica Mello:

\begin{abstract}
As contribuições do GTA extrapolam as ações do PPG7, colaborando com amplas discussões na análise das políticas públicas, insistindo na necessidade de coerência entre elas. Durante os 10 anos de implantação do PPG7, investiram fortemente na mobilização de diferentes segmentos sociais, tanto regionais como nacionais. A incitação à organização da sociedade pelo GTA resultou positivamente numa dispersão de associações, cobrindo quase toda a região (2006, p. 242).
\end{abstract}

As ONGs também tem atuado como importantes fontes de informação e pesquisa. Cabe destacar o trabalho da Red Amazónica de Información Socioambiental Georreferenciada, que produziram em 2009 um Mapa das Áreas Protegidas e Territórios Indígenas de toda a Amazônia, abarcando nove países (o que incluiu a Guiana Francesa).

Destaca-se na área específica dos recursos hídricos o trabalho da ONG International Rivers. Ela possui uma página da internet sobre todas as barragens 
presentes na Bacia Amazônica ${ }^{17}$. Seu trabalho é focado principalmente nos impactos negativos da construção de barragens para energia hidrelétrica na Amazônia. Teve um papel destacada na articulação junto com outras ONGs no debate sobre as hidrelétricas brasileiras nos rios Madeira e Xingu. De acordo com a International Rivers:

\begin{abstract}
once built, projected dams and industrial waterways would provide the power and transport needed to move large quantities of resources out of the Amazon-and accelerate its destruction. Many of these projects are being built by Brazilian construction companies and financed by the Brazilian National Development Bank (BNDES). And some are included in the Initiative for the Integration of Regional Infrastructure in South America (IIRSA), a program supported by international financial institutions which regards the vast natural areas of the continent as "obstacles to development". International Rivers works with threatened communities, indigenous peoples, social movements, NGOs, independent researchers and other partners to fight destructive dams planned for the Amazon, while promoting dialogue and policy reform for alternative strategies to meet legitimate energy needs in the region (INTERNATIONAL RIVERS, 2013b).
\end{abstract}

A International Rivers publicou um livro intitulado "Águas Turvas: alertas sobre as consequências de barrar o maior afluente do Amazonas" (SWITKES e BONILHA, 2008), sobre as hidrelétricas de Santo Antônio e Jirau, no rio Madeira. Nesta publicação são elencados os principais impactos socioambientais negativos destas barragens.

Além desta ONG, existem muitas outras que atuam na Bacia Amazônica por países. Como não é o foco deste trabalho mapear todas as ONGs existentes na Bacia Amazônica, e sim apenas pontuar estas organizações como atores sociais importantes que impactam os processos políticos e os processos de tomada de decisão na Amazônia, cabe apenas citar algumas que estarão presentes ao longo deste trabalho. Na Bolívia, destaca-se a Fundação Natura, o FOBOMADE, a Herencia, a WWF, a CARE, a Conservation Internacional, entre outras. O FOBOMADE (Foro Boliviano sobre Medio Ambiente y Desarrollo) também publicou um livro sobre os impactos das represas no rio Madeira (ARNÉZ et al., 2009). No Peru, o Instituto del Bien Común tem realizado um importante trabalho que tem como produto o Sistema de Informações sobre Comunidades Nativas da Amazônia Peruana. No Equador destaca-se o trabalho da Frente de Defensa de la Amazonía, que tem lutado em conjunto com a União de Afetados e Afetadas pelas Operações da Petroleira Texaco (UDAPT) em um processo para indenização dos afetados pelas ações desta empresa na Amazônia Equatoriana.

As ONGs e as Organizações Indígenas possuem um papel importante na governança dos recursos hídricos amazônicos, pois representam grupos da sociedade

\footnotetext{
${ }^{17}$ International Rivers. Barragens na Amazônia. Disponível em: <http://www.dams-info.org/pt>. Acesso em abril de 2013a.
} 
que estão envolvidos neste processo. Algumas delas atuam de forma transnacional na Bacia Amazônica e estão envolvidas com a OTCA, e estarão presentes ao longo deste trabalho por sua atuação na governança dos recursos hídricos transfronteiriços amazônicos nos estudos de caso. A seguir será apresentado o projeto de gestão compartilhada da Bacia Amazônica.

\subsubsection{As corporações transnacionais}

As corporações transnacionais se configuram como parte do setor privado e têm atuado na Bacia Amazônica em determinadas atividades de exploração econômica e na construção de infraestruturas, entre elas destacam-se: a mineração, a exploração da madeira, a exploração de gás e petróleo, a construção e operação de usinas hidrelétricas, a construção de rodovias e pontes, e o agronegócio. Estas empresas tem um papel importante para a governança dos recursos hídricos da Amazônia, principalmente pelos impactos das atividades que realizam que causam, muitas vezes, contaminação da água e conflitos socioambientais. Existem também empresas transnacionais do setor de água e saneamento na Bacia Amazônica como é o caso da cidade de Manaus onde atua o Grupo Suez (OLIVEIRA, 2007).

Nos estudos de casos analisados nos capítulos três e quatro serão abordadas a atuação de algumas corporações transnacionais e seus impactos para a governança dos recursos hídricos amazônicos. A empresa Texaco e depois a Chevron, por exemplo, exploraram petróleo e gás na Amazônia equatoriana por décadas, o que gerou um grave impacto ambiental com a contaminação de muitas áreas em diversas sub-bacias amazônicas, entre elas a Bacia do rio Napo.

Em alguns casos, como o setor da madeira certificada, as empresas tem se aliado à algumas ONGs ambientalistas para tentar melhorar a produção em termos ambientais. Como explica Carneiro, no caso de empresas que atual na Amazônia brasileira:

\footnotetext{
a análise das trajetórias empresariais aponta para uma outra característica comum dos empresas certificadas; sua relação privilegiada com as organizações promotora do mercado de madeiras certificas (ONGs, agências de cooperação internacional, instituições de apoio à difusão da tecnologia EIR). Por conseguinte, o processo de certificação de cada uma dessas empresas esteve associado a algum tipo de acesso a financiamento institucionais ou a subsídios diretos e indiretos, como o treinamento da força de trabalho nos cursos da FFT e a contratação de profissionais formados pelo curso de Pós-Técnico Florestal (2007, p. 702).
} 
A atuação das corporações transnacionais no setor de água e saneamento pode ser ilustrado pelo caso do Grupo Suez S.A. em Manaus, no Brasil. Neste caso, a Suez atua por meio de sua subsidiária DRMA Participações e Empreendimentos S. A. Como afirma Oliveira, sobre a atuação das empresas Suez S. A. e a Veólia Environment no Brasil:

\begin{abstract}
os pontos em comum na atuação destes grandes grupos em território brasileiro, no que concerne ao saneamento básico são a localização geográfica em áreas de grande ocorrência de água e o alinhamento às políticas de saneamento básico do governo federal no que se refere à opção pela privatização $(2007$, p. 75$)$.
\end{abstract}

No caso do saneamento básico, enquanto estas empresas precisam ter lucro elas, em geral, estão presentes em grandes ou médias cidades, com uma parcela suficiente da população que obtenha renda para pagar pelos serviços que oferece. No caso das pequenas cidades da Bacia Amazônica, elas não são atrativas para este tipo de empresa por não terem um numero suficiente de pessoas que possa justificar os gastos da implantação de uma infraestrutura de saneamento. Geralmente são empresas públicas que implantam e operam os sistemas de saneamento nas pequenas cidades, como será mostrado no capítulo três deste trabalho, o caso do estado do Acre, no Brasil.

\title{
2.4 Principais problemas e conflitos envolvendo os recursos hídricos transfronteiriços na Amazônia
}

A exploração dos recursos naturais e o desenvolvimento das atividades econômicas tiveram um impacto nos recursos hídricos compartilhados da bacia:

\begin{abstract}
a ciclagem da água na Amazônia tem sido perturbada, analogamente ao que ocorre em outras partes do mundo, pela construção de estradas, agricultura, pecuária, mineração, urbanização e industrialização. Poucos dados estão disponíveis na literatura científica sobre os efeitos na microescala hidrológica $\mathrm{e}$, menos ainda, sobre os efeitos cumulativo dessas atividades humanas nos recursos hídricos regionais. Todavia, é importante destacar essas ações como vetores da destruição da floresta nativa e de mudanças qualitativas evidentes na distribuição de água, localmente (COHEN, ROCHA e SOUZA, 2003, p. $81)$.
\end{abstract}

Entre os principais problemas que envolvem os recursos hídricos transfronteiriços na Bacia Amazônica e que apresentam potencial para geração de conflitos, estão agrupados a seguir em cinco categorias: 1) contaminação (mineira, por hidrocarbonetos, por resíduos domésticos e industriais, etc.); 2) fatores que afetam o ciclo hidrológico como o desmatamento, erosão e assoreamento; 3) a pesca em rios 
transfronteiriços amazônicos; 4) construção de barragens e usinas hidrelétricas; e 5) a navegação fluvial e os projetos para as hidrovias como corredores de integração.

A mineração nos rios amazônicos transfronteiriços também apresenta potencial para gerar conflitos, pois os efeitos danosos para os ecossistemas e para a saúde humana podem ser "carregados" para os países vizinhos. O caso do garimpo do ouro e os efeitos do mercúrio à saúde humana são um tema que vem sendo abordado por vários pesquisadores:

En la Amazonía, la minería aurífera contamina los ríos con mercurio. Esta contaminación es uno de los problemas más graves de la cuenca amazónica. El $72 \%$ de los peces piscívoros (que se alimentan de otros peces) y carnívoros colectados en los tributarios del río Beni sobrepasaron hasta en cinco veces el valor límite de mercurio establecido por la OMS. Solo en el departamento de Pando, entre 1979 y 1997 se echaron a los ríos trescientas toneladas de mercurio (Muñoz, 2004). La extracción de oro en la Amazonía se hace tanto en forma artesanal (pequeños mineros) como tecnificada (empresas grandes y medianas). La minería artesanal se caracteriza por extraer el oro con uun cernidor o a veces una motobomba. Ese trabajo necesita mucha mano de obra y muy poca inversión. Las empresas grandes y medianas usan maquinaria pesada y cuentan con profesionales (Urteaga, 2003). La explotación aurífera informal en el Perú se concentra en Madre de Dios y remueve millones de metros cúbicos de tierra, arena y grava de riberas y lechos de ríos, así como áreas boscosas hasta profundidades que van de tres a seis metros. También existen yacimientos auríferos en los ríos Santiago Morona, Tigre y Napo, en la selva norte. La actividad de los buscadores de oro en los ríos tiene consecuencias ambientales muy graves, como la contaminación de los ríos por sedimentos, mercurio y aceite; la destrucción de las cuencas y tierras agrícolas; la deforestación; la caza y la pesca sin control y la invasión de territorios indígenas" (VAN ORSEL e VOS, 2009, p. 279).

No caso do petróleo e gás não é diferente, a exploração destes recursos na Amazônia tem deixado um rastro de contaminação dos recursos hídricos e conflitos sociais. Em especial no Peru e no Equador os conflitos chegaram a ser violentos. Também existem zonas petrolíferas em regiões de fronteira:

Duas zonas petrolíferas, uma no Peru e outra no Equador, são vizinhas nas bacias dos rios Tigre e Napo e também na Bacia do Rio Putumayo, que faz as divisas Peru-Colômbia e Equador-Colômbia, e ambas estão ligadas ao litoral do Pacífico por meio de oleodutos (SEVÁ FILHO, 2010, p. 122).

As regiões produtoras de petróleo na Amazônia sofrem com os passivos ambientais e o Estado pouco consegue fazer para reverter o quadro de contaminação e de conflitos;

durante los cuarenta años de atividades de extracción de gas y petróleo, esta industria ha causado un daño sustancial en los ecosistemas de las selva, la costa norte del Perú y el Chaco de Bolívia. Estos pasivos ambientales no tienen una solución fácil por las siguientes razones: el costo de limpieza es alto, las empresas han abandonado el lugar - y a veces el país - y niegan sus responsabilidades, y el Estado no exige el cumplimiento, además de no tener 
la capacidad ni el presupuesto para limpiar. No obstante la existencia de una normatividad más exigente en materia de impactos ambientales, la gran envergadura de los proyectos de inversión en desarrollo y previstos anuncia que este sector va a ser uno de los más contaminantes en los países andinos en las próximas décadas (VAN ORSEL e VOS, 2009, p. 281).

Na Amazônia equatoriana e peruana a contaminação pela exploração de petróleo e gás gerou diversos conflitos socioambientais. No caso do Equador o conflito que mais ganhou evidência internacional foi o processo contra a Chevron-Texaco e no Peru há diversos casos:

\footnotetext{
- En el departamento de Loreto, los pueblos indígenas protestan contra las empresas petroleras por la contaminación de sus ríos (río Corrientes) con petróleo. En el año 2006, el pueblo indígena Ashuar y la empresa Pluspetrol llegaron a un acuerdo después de años de lucha.

- En el departamento de Ucayali, la comunidad Shipiba portesta contra la empresa Maple Gas por la contaminación petrolera y la deforestación.

- En el año 2007, los asháninkas del río Tambo (Ucayali) tomaron las instalaciones del campamento base de Repsol YPF. El lote 57 concesionado a Repsol YPF se superpone a las reservas comunales de los pueblos Machiguenga y Asháninka.

- El proyecto de Gas de Camisea en Urubamba, Cusco, afecta a los territorios de las comunidades indígenas Machinguenga, Yine y Asháninka (ORSEL e VOS, 2009, p. 289).
}

A militarização de algumas fronteiras amazônicas também tem gerado conflitos transfronteiriços e até mesmo internacionais como é o caso da fronteira entre Equador e Colômbia. Neste caso, o Plano Colômbia tem utilizado herbicidas e fumigadores para combater o plantio da coca em território colombiano, no entanto, estes agrotóxicos contaminam os recursos hídricos na região fronteiriça contaminando também as populações do outro lado da fronteira.

O conflito internacional entre Colômbia e Equador se deu:

quando em março de 2008 , a fronteira equatoriana foi violada pelo "ataque" de forças colombianas treinadas e equipadas pelos Estados Unidos, à caça do segundo homem das FARC, Raul Reyes, criou-se mais um conflito diplomático grave, que pode um dia virar mais uma guerra em uma região petrolífera em expansão. Pois, num raio de 300 a 400 quilômetros em torno do povoado mais próximo do bombardeio, Santa Rosa, na Bacia do Rio Putumayo, ficam áreas produtoras de petróleo dos três países - colombiana, no rio Caquetá, equatoriana, entre a cidade de Lago Agrio, a Bacia do Rio Napo e o Parque Yasuní, e uma área peruana em fase de intensa prospecção (SEVÁ FILHO, 2010, p. 130-131).

Apesar das autoridades estadunidenses e colombianas afirmarem que não existem riscos à saúde humana pelo uso destes agrotóxicos, diversos estudos e documentos relatam o contrário. Como o estudo sobre "El sistema de aspersiones aéreas 
del Plan Colombia y sus impactos sobre el ecosistema y la salud en la frontera ecuatoriana", realizado pela Comisión Científica Ecuatoriana:

En el centro de su defensa el gobierno de Colombia insiste en esgrimir la tesis de que las aspersiones aéreas - siempre reducidas por éste al tema del glifosato - son absurdamente inocuas e inofensivas, de tal manera que las quejas de los afectados, a uno y otro lado de la frontera, son apreciados como actitud exagerada y desproveída de fundamento. Frente a esta problemática, la Comisión Científica del Ecuador realizó constataciones y verificaciones; receptó testimonios de la población afectada y determinó una inobjetable afectación en su territorio. [...] que sustentan científicamente el reclamo que el Ecuador hace a Colombia para que cesen definitivamente las aspersiones aéreas con el paquete herbicida, en la zona fronteriza en una franja de seguridad de por lo menos $10 \mathrm{~km}$ (CCE, 2007, p. 8).

\section{O narcotráfico contamina os recursos hídricos devido aos produtos utilizados}

para a produção da cocaína que são jogados nos cursos d'água da floresta amazônica.

Diversas pesquisas já demonstraram a interdependência e interligação que existe entre o ciclo hidrológico e a floresta na Bacia Amazônica:

el bosque amazónico tiene una función importante en la regulación del ciclo hidrológico. A pesar de que la Amazonía recibe mucha precipitación, el suelo sin protección de vegetación se seca rápidamente, porque es muy pobre y no tiene mucha capacidad de retención de humedad. Esta implica que, una vez talado el bosque tropical, el suelo se degeneré rápidamente y el bosque tropical se convierta en una sabana improductiva (VAN ORSEL e VOS, 2009, p. 235).

O desmatamento, portanto, apresenta sérios impactos para o ciclo hidrológico nesta bacia. E grande parte do desmatamento se deve ao ciclo de atividades madeireirapecuária-agricultura. O problema da atividade madeireira ilegal é o desmatamento descontrolado:

en los três países estudiados (Bolivia, Ecuador y Peru), la explotación de madera se realiza a través de concesiones a largo plazo. El Estado es propietario del área forestal. En Bolivia y el Perú, la ley dispone que el otorgamiento de concesiones para todo tipo de actividades forestales - con excepción del uso doméstico - demanda la elaboración de un plan de manejo, el que debe ser aprobado por la Superintendencia Forestal en el caso de Bolivia, y el INRENA en el caso del Perú. [...] En los tres países bajo estudio hay mucha tala ilegal. En el Perú y Bolivia, los troncos van mayormente por río al Brasil y se venden en el mercado doméstico de ese país. En el Perú, el INRENA no siempre cuenta con recursos para realizar el control de los planes de manejo, como dispone la ley. [...] En Bolivia, el órgano fiscalizador es la Superintendencia Forestal. Esta comparte competencias con las municipalidades, las prefecturas y las subprefecturas. El sistema de control es poco efectivo por falta de recursos y de voluntad política" (ORSEL e VOS, 2009, p. 237-238). 
A pesca tem sido motivo de conflitos em rios amazônicos transfronteiriços, em especial, em rios que são os limites entre países, e devido, principalmente, a divergências de legislações ambientais.

No caso do Brasil, por exemplo, a pesca é proibida no período de defesa, para permitir a reprodução das espécies e, assim, garantir a sua sustentabilidade. No entanto, outros países vizinhos, como é o caso do Peru e da Bolívia, não apresentam a mesma lei, e nos rios que são utilizados por pescadores de ambos os países surge o conflito, pois os pescadores bolivianos e peruanos continuam pescando, enquanto que os brasileiros não podem pescar (e recebem um salário mínimo para compensar este período em que não trabalham). Em alguns casos, o número de peixes nestes rios tem diminuído cada vez mais, o que aumenta as tensões. Isto foi constado em entrevistas com pescadores da Associação de Pescadores de Assis Brasil, na tríplice fronteira entre Brasil, Bolívia e Peru.

As barragens são um tema de constante conflito no interior dos países amazônicos devido, principalmente, ao contingente de pessoas que são retiradas de seu território para a construção das represas das usinas hidrelétricas. Outro fator gerador de conflito é a consequente degradação ambiental da área a ser alagada pela represa, bem como os efeitos sobre a hidrologia do curso d'água, para a vida aquática e para o sustento das populações que sobrevivem da pesca.

No caso de rios transfronteiriços, a área alagada pode atingir o território do país vizinho, como é o caso do rio Madeira que nasce na Bolívia e adentra em território brasileiro. A construção de duas usinas, Santo Antônio e Jirau, pode levar ao alagamento de áreas adjacentes a este rio e seus afluentes ao longo do tempo, devido à carga de sedimentos transportadas por estes rios que serão depositados na represa elevando o nível da água e alagando as áreas ao redor.

A navegação internacional do rio Amazonas já foi motivo de conflitos no século XIX durante o ciclo de exploração da borracha. A pressão dos Estados Unidos para a abertura do rio Amazonas à navegação internacional, já que era o maior comprador de borracha brasileira (MACHADO, 1997, p. 19).

Mais recentemente, em 2005 a navegação comercial dos rios da bacia amazônica foi tema da Reunião de Ministros de Relações Exteriores da OTCA, que por meio de Resolução decidiram que era preciso formular um projeto de "Regulamento Geral de Navegação Comercial nos Rios Amazônicos”. De forma que, em 2010 foi criado um Grupo de Trabalho para avançar nas negociações do Regulamento. 


\subsection{Iniciativa internacional de gestão dos recursos hídricos transfronteiriços da Bacia Amazônica: o projeto OTCA/GEF}

Um dos grandes desafios à governança dos recursos hídricos na Bacia Amazônica é a falta de informação e dados sobre a bacia, bem como a falta de monitoramento das condições ambientais e hidrológicas da bacia em todos os países amazônicos. Em geral, as universidades localizadas na Bacia Amazônica são recentes, se comparadas às universidades das outras regiões dos países amazônicos, e recebem poucos fundos para pesquisa, assim como os institutos de pesquisa. Por isso, a importância para a cooperação interuniversitária tem sido um aspecto bastante defendido na região amazônica, que conta com a Associação de Universidades Amazônica, a UNAMAZ ${ }^{18}$. Por isso, qualquer iniciativa para a governança dos recursos hídricos amazônicos tem que levar em consideração este aspecto.

A OTCA, que iniciou suas atividades em 2002, neste mesmo ano, mostrou interesse pelo tema dos recursos hídricos quando, durante a XI Reunião do Conselho de Cooperação Amazônica (CCA), a Agência Nacional de Água do Brasil (ANA), apresentou uma proposta de projeto de "Gerenciamento Sustentável e Desenvolvimento dos Recursos Hídricos da Bacia Amazônica”. Como resultado desta reunião, foram realizadas reuniões técnicas, no ano seguinte, para a elaboração de um projeto a ser apresentado ao GEF para a possibilidade de financiamento.

Em julho de 2003 ocorreu a $1^{\text {a }}$ Reunião de Trabalho de Instituições Responsáveis pelo Gerenciamento de Recursos Hídricos dos Países da OTCA, que contou com o apoio da Organização dos Estados Americanos (OEA) e da ANA em conjunto com o Comitê Diretor do Projeto DELTAmérica ${ }^{19}$. Como resultado desta reunião foi produzido um documento preliminar contendo as bases conceituais para um Projeto de Gerenciamento Sustentável dos Recursos Hídricos na Bacia Amazônica.

\footnotetext{
${ }^{18}$ A UNAMAZ foi criada em 1987 como uma rede de instituições de educação superior, e é definida como "uma sociedade civil, não governamental, sem fins lucrativos, que visa objetivos essencialmente educativos e culturais, mediante cooperação científica, tecnologia e cultural como meio de integração das universidades e instituições dos países amazônicos para o aprofundamento da solidariedade amazônica e como instrumento de promoção para o desenvolvimento em benefício das populações humanas e da ecologia amazônica, sem discriminação de nenhuma índole" (LOURENÇO, 2003, p. 79).

${ }^{19}$ O Projeto DELTAmérica de Desenvolvimento e Implantação de Mecanismos para Disseminar Lições Aprendidas e Experiências em Gerenciamento Integrado de Recursos Hídricos Transfronteiriços na América Latina e no Caribe, tem a participação dos 34 países membros da OEA, foi financiado pelo GEF e executado pelo PNUMA, com duração de 2003 a 2005.
} 
Este produto foi então apresentado na reunião da Comissão de Coordenação do CCA, na qual os países decidiram seguir em frente com o projeto, devido ao caráter estratégico da proposta. Foi então aprovado o Documento Conceitual para o Gerenciamento Integrado e Sustentável dos Recursos Hídricos Transfronteiriços na Bacia do Rio Amazonas, e aprovado pela Secretaria do GEF em novembro de 2003 (PNUMA, GEF e OTCA, 2004).

Este documento foi a base do Project Development Facility (PDF Bloco B) que é a parte da elaboração do documento final do "Projeto de Gerenciamento Integrado e Sustentável dos Recursos Hídricos Transfronteiriços da Bacia do Rio Amazonas considerando a Variabilidade e as Mudanças Climáticas" ${ }^{20}$, que teve a duração de dois anos de 2005 a 2007. Nesta primeira fase foram elaborados relatórios técnicos por consultores, e também relatórios elaborados pelos países sobre a visão nacional da bacia amazônica (OTCA, 2007a).

Já em 2007 foi apresentada a proposta da fase de implementação do projeto. E em 2009 ela é reapresentada ao GEF. Todavia, ainda em 2010 esta fase não tinha sido aprovada e operacionalizada, pois havia divergências entre os países sobre alguns aspectos do projeto. Em entrevistas realizadas com funcionários da ANA, da OTCA e do Ministério de Relações Exteriores do Brasil em julho de 2010, constatou-se que havia divergências de interesses, em especial por parte da Colômbia, sobre certos aspectos do projeto.

Foi somente no ano seguinte, em agosto de 2011, que ocorreu a "Oficina da Fase Inicial" e Comitê Diretivo do Projeto "Manejo Integrado e Sustentável dos Recursos Hídricos Transfronteiriços da Bacia do rio Amazonas considerando a Variabilidade e as Mudanças Climáticas”. Durante esta reunião “os representantes governamentais dos Países Membros debateram os pontos do projeto, além de fazer apresentações a respeito dos contextos legal, institucional e nacional" (OTCA, 2011a). Além disso, "ficaram acordadas medidas sobre as contrapartidas, termos de referência do Comitê Diretivo e das Unidades Nacionais de Coordenação do Projeto (UNCP), entre outras decisões" (OTCA, 2011a).

Este Projeto se insere dentro do Programa de Área Focal de Águas Internacionais do GEF. Os projetos deste Programa seguem o mesmo modelo: elaboração de um Programa de Ação Estratégica (PAE). No caso do Projeto da Bacia

\footnotetext{
${ }^{20}$ Chamado de Projeto OTCA/GEF ao longo deste trabalho.
} 
Amazônica, o PAE vai conectar a adaptação às mudanças climáticas com o gerenciamento das águas transfronteiriças e recursos relacionados. Também prevê a criação de um arcabouço institucional para sua implementação (GEF, 2009).

A duração total do Projeto é de doze anos, dividido em três fases com duração de quatro anos cada. Ele ficou conhecido pela sigla GEFAM, refletindo a importância da atuação do GEF neste processo:

\begin{abstract}
as the only multilateral financing mechanism available for long term sustainable development interventions, GEFAM plans to respond to these shortcomings by looking at reconciling competing resource uses and formulate agreed actions by the Basin's governments and their communities in order to resolve shared transboundary concerns. This will include three central axes, the first one being geared towards understanding the Amazon society and building a shared Vision, the second one towards understanding the Amazon resource base through a scientifically-sound and technically appropriate environmental assessment, and finally the development of response strategies incorporating experiences gained through a number of targeted pilot projects (REGENASS, 2008, p. 5).
\end{abstract}

Os projetos regionais do GEF de gerenciamento de águas transfronteiriças têm, em geral, contado com o PNUMA como agência implementadora, e a OEA ou outra organização regional como agência executora. Eles têm incorporado o conceito de gestão integrada dos recursos hídricos.

Tabela 1: Estrutura do Projeto OTCA/GEF.

\begin{tabular}{|c|c|}
\hline \multicolumn{2}{|c|}{$\begin{array}{c}\text { Gerenciamento Integrado e Sustentável dos Recursos Hídricos Transfronteiriços da Bacia do rio } \\
\text { Amazonas considerando a Variabilidade e as Mudanças Climáticas }\end{array}$} \\
\hline Componente & Subprojeto \\
\hline $\begin{array}{l}\text { I. Entendendo a } \\
\text { Sociedade } \\
\text { Amazônica }\end{array}$ & $\begin{array}{l}\text { I.1. Visão para a Bacia Amazônica } \\
\text { I.2. Fortalecimento dos contextos institucional e legal da Bacia Amazônica }\end{array}$ \\
\hline $\begin{array}{lr}\text { II. } & \text { Compreender } \\
\text { a base } & \text { dos } \\
\text { recursos naturais } \\
\text { da } & \text { Bacia } \\
\text { Amazônica } & \end{array}$ & $\begin{array}{l}\text { II.1. Pesquisas focalizadas } \\
\text { II.2. Avaliação da vulnerabilidade hidroclimática da Bacia Amazônica } \\
\text { II.3. Análise de Diagnóstico Transfronteiriço (TDA - Transboundary Diagnostic } \\
\text { Analysis) }\end{array}$ \\
\hline $\begin{array}{l}\text { III. Respostas } \\
\text { Estratégicas }\end{array}$ & $\begin{array}{l}\text { III.1. Projetos Pilotos de GIRH na Bacia Amazônica } \\
\text { III.2. Medidas Especiais Prioritárias de Adaptação na Bacia Amazônica } \\
\text { III.3. Sistema de Informação integrada } \\
\text { III.4. Comunicação, alcance e finanças }\end{array}$ \\
\hline $\begin{array}{l}\text { IV. Gestão do } \\
\text { Projeto }\end{array}$ & IV.1. Gestão do Projeto \\
\hline
\end{tabular}

Fonte: GEF, 2009; OTCA, 2011b. 
Figura 2: Formulação do Programa de Ação Estratégica (PAE)

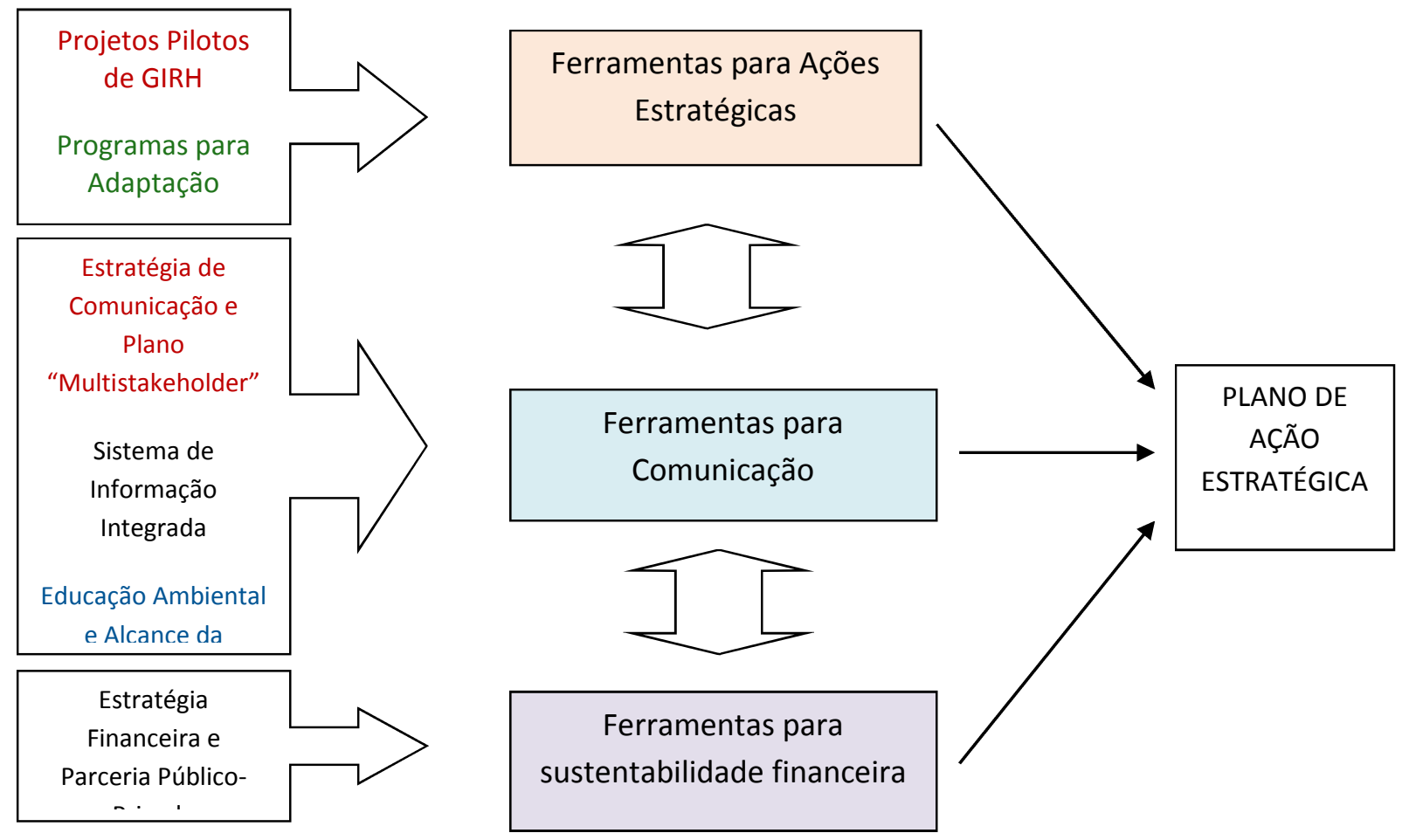

Fonte: GEF, 2009 (adaptado).

O Plano de Trabalho da Coordenadoria de Meio Ambiente da OTCA para 2011 apresenta o mesmo projeto, mas com algumas modificações. A mais significativa das mudanças, para os objetivos deste trabalho, é a dos projetos pilotos, relativo ao Subprojeto "Projetos Pilotos em Manejo Integral de Recursos Hídricos (MIRH) na Bacia Amazônica" (OTCA, 2011b). Pois, no documento de 2009, constavam como projetos pilotos: o gerenciamento integrado das bacias transfronteiriças das regiões amazônica do Napo e MAP. Já no Plano de Trabalho de 2013, constava como projeto piloto o "Uso conjunto de águas subterrâneas e superficiais na região das três fronteiras (Brasil, Colômbia, Peru)" (OTCA, 2013, p. 3).

A região MAP continua fazendo parte do Projeto OTCA/GEF, porém não mais como um projeto piloto para a gestão compartilhada dos recursos hídricos, e sim, apenas no "Subprojeto III.2. Medidas Prioritárias de Adaptação", que consta como a atividade “Adaptação às mudanças climáticas na região transfronteiriça do MAP (Madre de Dios, Acre, Pando) (OTCA, 2013).

Em entrevistas com representantes da OTCA e do MRE do Brasil, realizadas em julho de 2010, uma das partes envolvidas no Projeto OTCA/GEF expressou desejo de retirar-se da execução deste,o que levou a reformulação dos projetos pilotos 
O Projeto OTCA/GEF foi formulado e elaborado durante a primeira gestão da OTCA, cuja Secretária-Geral era Rosalía Arteaga. Com o fim de sua gestão os países elegeram o então Diretor Executivo Francisco Ruiz como Secretário-geral interino, e começaram a discutir a possibilidade de algumas alterações na condução das ações da OTCA.

Em 2009 foram discutidas e aprovadas algumas mudanças na organização, cujas propostas estão presentes na Agenda Estratégica aprovada pelos Ministros de Relações Exteriores em 2010, que tem efeitos sobre o projeto de gestão da bacia e para a cooperação internacional, em geral.

A cooperação internacional tanto em termos de ajuda financeira quanto técnica para projetos bilaterais ou multilaterais de interesse regional, sempre teve, desde o início do TCA, uma grande importância para as atividades do TCA e da OTCA.

A partir da X Reunião de Ministros das Relações Exteriores, realizada em 30 de novembro de 2010, foi aprovada uma resolução (RES/XMRE-OTCA 7) que visa estabelecer novos "procedimentos, mecanismos e os termos para consideração, negociação e execução de propostas" para a cooperação internacional.

$\mathrm{Na}$ Agenda Estratégica de Cooperação Amazônica (AECA) também está previsto que a Secretaria Permanente (SP), juntamente com os Países-Membros da OTCA "deverá explorar e identificar como alternativa de financiamento as oportunidades relativas à cooperação triangular" (OTCA, 2010, p. 65). De acordo com a Agência Brasileira de Cooperação $(\mathrm{ABC})$ a cooperação triangular ou triangulação: "é a modalidade de Cooperação Técnica na qual dois países implementam ações conjuntas com o objetivo de prover capacitação profissional, fortalecimento institucional e intercâmbio técnico para um terceiro" (ABC, 2011).

Para Becker (2007), nos tempos atuais a cooperação internacional tem um papel importante, pode ser tanto uma forma de controle das potências, como também pode ser usada conforme os interesses dos países que a recebem. De acordo com a geógrafa:

\footnotetext{
a incidência das pressões da globalização [...] faz-se através da cooperação internacional técnica, científica e financeira, seja em projetos bilaterais, em grandes projetos com poderosos aliados, ou em redes locais-globais de parcerias não devidamente conhecidas. É certo que tal cooperação assume por vezes autonomia excessiva, mas vale registrar o esforço do Ministério da Ciência e Tecnologia em assumir o comando nessa relação. É certo também que não há hoje condições no mundo de prescindir da cooperação internacional. A Organização do Tratado de Cooperação Amazônica (OTCA) pode constituir instituição-chave para essa resistência e integração (BECKER, 2007, p. 55-56).
} 
Esta dependência do financiamento externo foi abordada por alguns autores (ARAGÓN, 1994; COSTA-FILHO, 2003; ANTIQUERA, 2006; SANT'ANNA, 2009; AMAYO, 1999) e consiste em grande preocupação dos Países-Membros que tem buscado incentivar a busca por financiamento nos próprios Países-Membros. Na AECA está presente esta preocupação, pois:

\begin{abstract}
em atenção aos resultados do processo de discussão interna relativos às fontes de financiamento e considerando a complexidade associada ao tema, a prioridade e as sérias restrições atuais associadas ao financiamento da estrutura básica da operação da SP, os Países-Membros destinarão recursos financeiros específicos para permitir à SP/OTCA realizar um estudo de avaliação das fontes de financiamento disponíveis, visando superar a dependência do financiamento externo para a operação da SP e para o desenvolvimento dos projetos estratégicos da Organização. Esta análise de oportunidade, que deverá ser realizado preferentemente de forma periódica, deverá receber financiamento de um ou mais Países Membros e ter apoio complementar destinado a ela por meio da oferta de profissionais nacionais especialista (OTCA, 2010, p. 65).
\end{abstract}

E a Resolução RES/X MRE-OTCA 7 também considera:

O mandato da SP para fazer um estudo em coordenação com os PaísesMembros com o intuito de avaliar possíveis fontes de financiamento provenientes dos próprios países, a fím de superar a dependência do financiamento externo no desenvolvimento dos projetos estratégicos da Organização (OTCA, 2010).

No caso do Projeto de gestão da bacia amazônica, a sustentabilidade do financiamento é uma questão chave. Para Regenass (2008), o problema é que este tipo de projeto, em geral, não é pensado para gerar investimento em áreas que levariam a um retorno financeiro, o que permitiria ao projeto se tornar independente das doações de instituições estrangeiras e se auto-sustentar.

Um desafio importante para o projeto é assimetria entre os marcos legais e instituições, bem como a sua fragmentação no caso dos recursos hídricos. Em alguns contextos domésticos como é o caso da Guiana e do Suriname a competência legal da agência encarregada de tratar dos recursos hídricos não está bem definida, o que tem gerado conflitos e contradições. Em outros casos os recursos hídricos são abordados por diferentes setores e instituições que muitas vezes competem entre si por financiamento e possuem interesses políticos conflitantes (REGENASS, 2008).

Apesar dos problemas instituições enfrentados para a implementação do projeto, é importante notar o papel das Unidades Nacionais de Coordenação do Projeto (UNCP), pois estas são as instituições responsáveis pela implementação e execução das atividades previstas no projeto em território nacional. No caso brasileiro a UNCP é a 
Agência Nacional de Águas (ANA), que desde o início teve um papel ativo, pois foi a instituição que apresentou a proposta do governo brasileiro de realizar um projeto de gestão compartilhada da bacia amazônica.

A articulação entre as instituições nacionais de gestão dos recursos hídricos é um passo importante como forma de troca de informações sobre a Bacia Amazônica em cada território nacional. No caso dos recursos hídricos transfronteiriços a transparência no compartilhamento das informações é importante para estabelecer confiança e relações duradouras de cooperação. A cooperação entre os países amazônicos é fundamental para o sucesso do projeto, pois terá que enfrentar algumas situações envolvendo os recursos hídricos transfronteiriços que podem gerar tensões e conflitos, como os que serão apresentados nos capítulos a seguir. 


\section{BACIA DO RIO ACRE: A FORMAÇÃO DA GOVERNANÇA TRANSNACIONAL}

Neste capítulo é analisado o processo de formação da governança transnacional dos recursos hídricos transfronteiriços da Bacia do rio Acre, localizada na tríplice fronteira entre Bolívia, Brasil e Peru. No início é descrita a Bacia do rio Acre, seguida pela discussão das principais caraterísticas da região MAP, onde está localizada a bacia, e os projetos de infraestrutura construídos e planejados para a região. A partir desta contextualização são analisados os principais problemas relacionados aos recursos hídricos transfronteiriços da bacia. Diante deste quadro discute-se o arcabouço institucional de gestão da água nos três países que compartilham a bacia e em suas respectivas unidades subnacionais implicadas. Finalmente, é analisada a formação de uma governança transnacional na Bacia impulsionada, principalmente, pela Iniciativa MAP, que abarca instituições e atores do governo e da sociedade civil dos três países.

\subsection{A Bacia do rio Acre}

O rio Acre origina-se no Peru, em uma altitude de aproximadamente $400 \mathrm{~m}$ próximo à fronteira com o Brasil (DUARTE, 2008; MT; 2008; REIS et al., 2007), com o nome de rio Eva. A topografia de sua bacia varia de $300 \mathrm{~m}$ a $430 \mathrm{~m}$ nas proximidades da cabeceira e de $150 \mathrm{~m}$ a $300 \mathrm{~m}$ ao longo do seu curso até a jusante (SEMA, 2012). É um afluente da margem esquerda do rio Purus e este último é um afluente da margem esquerda do rio Solimões. O rio Acre flui no sentido Sudoeste-Nordeste, atua como divisa entre o Brasil e o Peru até a cidade de Brasiléia, depois como divisa entre Brasil e Bolívia quando adentra em território brasileiro até desaguar no rio Purus, no município de Boca do Acre (Amazonas, Brasil). Ele percorre mais de $1.190 \mathrm{~km}$ de sua nascente até o rio Purus, sua desembocadura (DUARTE, 2007).

A bacia do rio Acre (Mapa 1) tem como divisores de água:

as regiões do seringal São Pedro do Icó e Projeto de Assentamento Oriente, do INCRA, que separam as águas que correm para o rio Acre daquelas que vão para o rio Yaco; as regiões de fronteira com o Departamento de Madre de Dios, que separam as águas que correm para o rio Acre das que vão para as bacias Yarua e Purus (no Peru); as regiões de fronteira com o Noroeste da Bolívia, que separam as águas que correm para o rio Acre daquelas que vão para o rio Abunã; as regiões ao Sul do Amazonas, que separam as águas que correm para o rio Acre das que vão para o rio Purus (DUARTE, 2007). 


\section{BACIA HIDROGRÁFICA DO RIO ACRE}

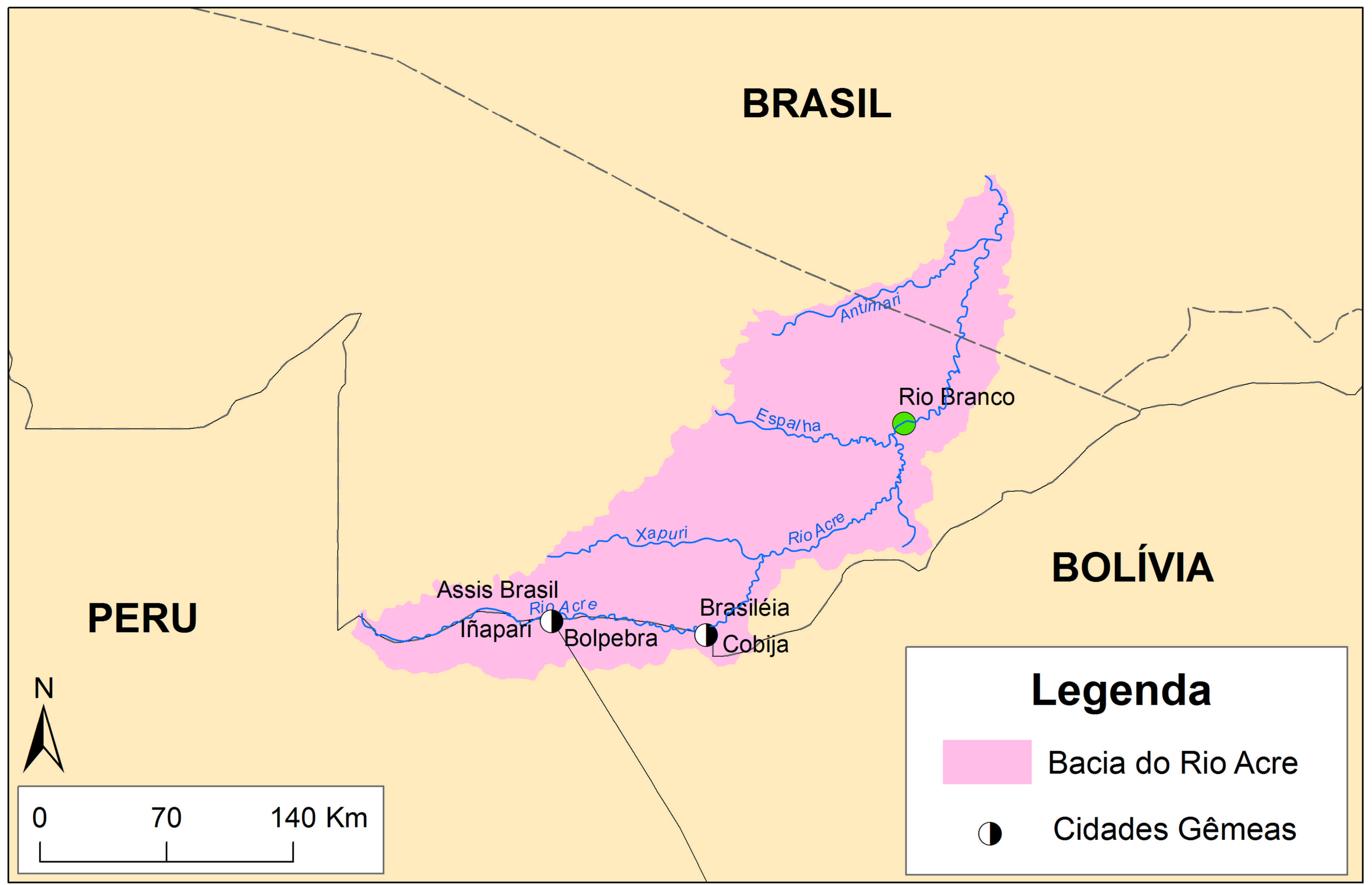


A bacia do rio Acre está formada pelos afluentes: rio Xapuri, rio Riozinho do Rola, Arroyo Bahia e outros afluentes menores, igarapés, córregos e cursos de escoamento, inclusive de esgotos urbanos. Existem vários canais de primeira ordem que confluem para o rio Acre, e alguns deles chegam a secar no período de estiagem (DUARTE, 2007). Sua rede de drenagem é composta por rios volumosos e sinuosos, "e por estreitas planícies fluviais de deposição de sedimentos retirados das margens, em sua maioria" (SEMA, 2012, p. 126).

O período de cheia do rio Acre se estende de janeiro a maio e o de águas baixas se estende de junho a dezembro (DUARTE, 2007). Este regime hídrico de cheias e vazantes mantém um ciclo que regula a vida animal e vegetal, bem como a base de sustentação das populações ribeirinhas (SEMA, 2012). A elevação máxima do rio Acre foi de 17,60m em 1997 e a altura média de duas margens é de 12,90m. Sua elevação mínima nos períodos de estiagem tem níveis médios de 1,90m. A descarga média do rio Acre é de $350 \mathrm{~m}^{3} / \mathrm{s}$, sendo a máxima nos períodos de cheia de $1.700 \mathrm{~m}^{3} / \mathrm{s}$ e nos períodos de estiagem de 80m3/s (SEMA, 2012). A pluviosidade média anual na área da Bacia do Rio Acre é de $1900 \mathrm{~mm}$ e o período com maior concentração de chuvas se estende de novembro a março.

O trecho do rio Acre que vai de Rio Branco a Boca do Acre é navegável, com $311 \mathrm{~km}$ de extensão e uma profundidade de $0,8 \mathrm{~m}$ em quase todo o percurso. É considerado como continuação da hidrovia do rio Purus que permite a chegada até Rio Branco, capital do estado de Acre. Já no trecho de Rio Branco a Brasiléia a profundidade é menor, portanto a navegação é possível apenas durante as cheias. Este trecho tem $635 \mathrm{~km}$ e apresenta acentuada sinuosidade (DUARTE, 2007). No entanto, a população ribeirinha e indígena utiliza o rio como meio de transporte e comunicação com o uso de pequenas embarcações e canoas (Foto 1). 
Foto1: O rio Acre na fronteira entre Assis Brasil (Brasil) e Bolpebra (Bolívia).

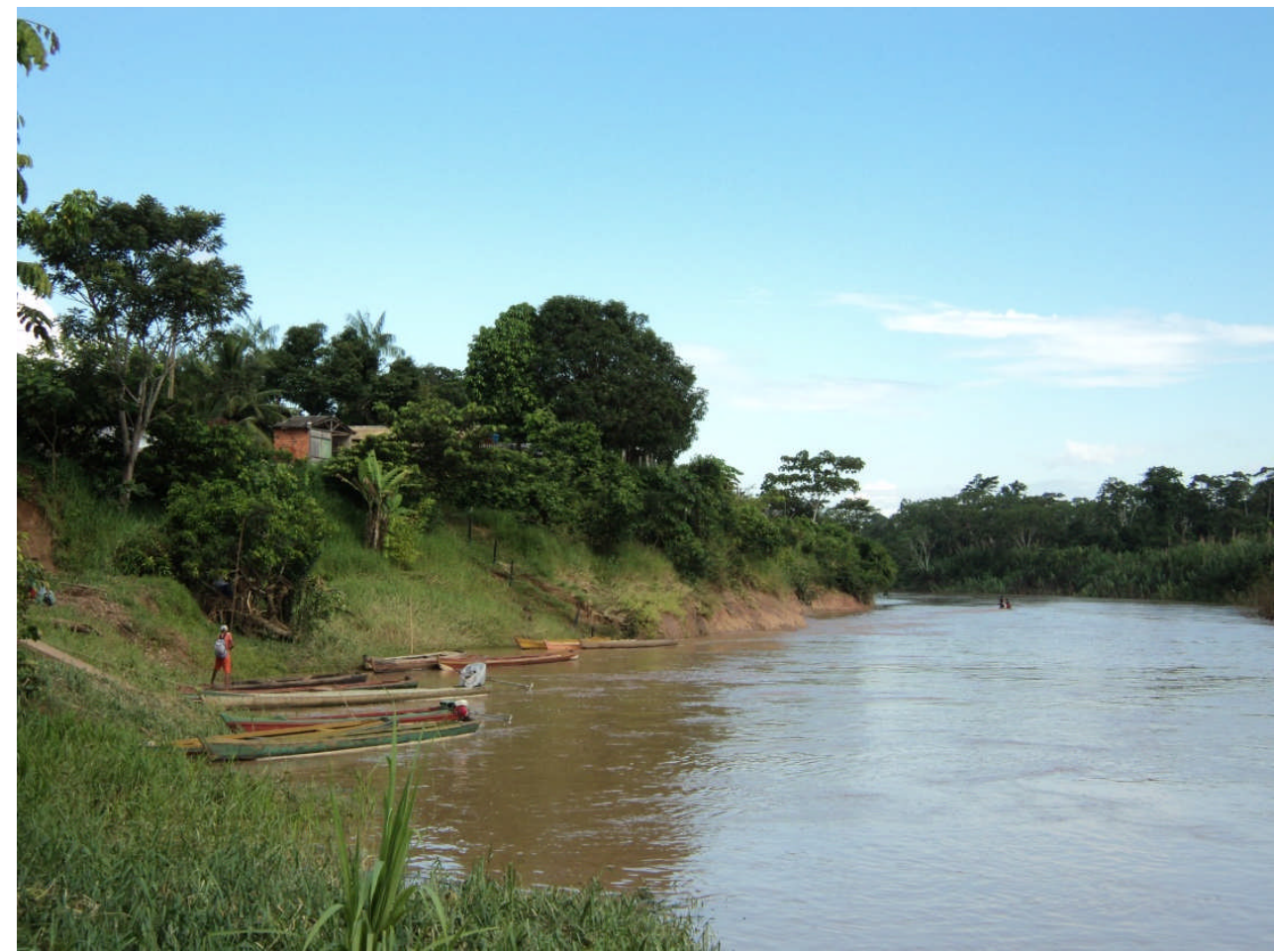

Fonte: Fernanda Mello Sant'Anna, 2010. Observa-se o uso de canoas motorizadas pela população local ribeirinha como meio de transporte e comunicação.

$\mathrm{O}$ rio Acre tem um perfil longitudinal de meandros, com alguns trechos em forma retilínea, denominados estirões pela população local. À beira do rio estão instaladas os municípios de Cobija, na Bolívia e, Brasiléia, Xapuri, Rio Branco, Porto Acre e Boca do Acre, no Brasil, entre outros de menor expressão (DUARTE, 2007).

A rede fluvial de drenagem da bacia do rio Acre drena uma região formada, em sua maior parte, por "unidades geológicas muito jovens, a Formação Solimões e os Terraços Aluvionares Antigos que acompanham as principais drenagens e os sedimentos recentes dos rios" (DUARTE, 2007).

A bacia hidrográfica do rio Acre é dividida em Alto Acre e Baixo Acre. O Alto Acre compreende a área desde a origem do rio Acre no Peru, até próximo às cidades gêmeas de Brasiléia e Cobija, e tem aproximadamente $7.577 \mathrm{~km}^{2}$, correspondente a $3.181 \mathrm{~km}^{2}$ no Brasil (41\% da áreada bacia), $2.560 \mathrm{~km}^{2}$ no Peru (33\% da área da bacia), e $1.936 \mathrm{~km}^{2}$ na Bolívia (26\% da área da bacia). O restante da bacia corresponde ao Baixo Acre e banha os municípios de Xapuri, Capixaba, Senador Guiomar, Rio Branco, Porto Acre, no estado do Acre, e Boca do Acre, no estado do Amazonas. No estado do Acre a área total da Bacia do rio Acre é de $27.263 \mathrm{~km}^{2}$ e se estende por dez municípios: Assis 
Brasil, Brasiléia, Epitaciolândia, Xapuri, Capixaba, Porto Acre, Rio Branco, Bujari, Sena Madureira e Senador Guiomar.

O clima na bacia é de zona tropical úmida, com variação entre um período mais seco de abril a agosto, e um período com precipitações mais intensas de dezembro a março. A temperatura média anual é de $26^{\circ} \mathrm{C}$, mas há ocorrência de friagens temporais (REIS et al., 2007). A pluviosidade média anual varia de $2.352,5 \mathrm{~mm}$ a $1.114,2 \mathrm{~mm}$ (NASCIMENTO, 2011).

$\mathrm{Na}$ área da bacia distinguem-se duas principais unidades geomorfológicas: planícies aluviais e terraços, e Platô da Amazônia. Nas áreas de planície predomina a vegetação de tipo Floresta Aberta com Palmeiras, e nos terraços, além deste tipo, encontra-se também a Floresta Aberta de Cipó. Nas áreas de platô predomina a Floresta Densa, com cobertura frondosa onde destaca-se a presença da Castanheira (Berthollettia Excelsa), pela importância da castanha como produto de valor comercial na região. A seguir será apresentada a região MAP onde está localizada a Bacia do rio Acre, suas principais características sociais e o Projeto da Estada do Pacífico da IIRSA, que corta a área da bacia.

\subsection{A região MAP e os projetos de infraestrutura e integração regional}

A Bacia do rio Acre localiza-se na tríplice fronteira entre Peru, Brasil e Bolívia, ocupando uma parte do território do Departamento de Madre de Dios (Peru), do estado do Acre (Brasil) e do Departamento de Pando (Bolívia). Esta área ficou conhecida como região MAP, uma sigla que representa estas três unidades subnacionais da tríplice fronteira e se estende por uma área cerca de $300 \mathrm{~km}^{2}$ com aproximadamente $822 \mathrm{mil}$ habitantes (BROWN, 2005).

No período anterior à colonização europeia esta área estava povoada por diferentes povos indígenas. Durante a colonização ela ficou em poder da Coroa Espanhola e passou por formas diversificadas de territorialização, com a chegada de jesuítas e outras ordens religiosas que estabeleceram missões, bem como, de militares, colonizadores, viajantes e exploradores que também passaram ou se estabeleceram na área.

Após a independência dos países sul-americanos a região passa a ser de domínio das Repúblicas da Bolívia e do Peru. No entanto, havia pouco conhecimento sobre esta área, considerada remota e a delimitação das fronteiras não contava com tecnologias 
que pudessem precisar a localização da linha-limite, o que resultou na imprecisão da linha de fronteira. Quando os países da região, Bolívia, Peru e Brasil, se voltaram para ocupação da área, impulsionados pelo "boom" da borracha, é que emergiram os conflitos territoriais entre estes países, como já foi apontado no segundo capítulo deste trabalho.

O ciclo da borrada atraiu imigrantes de outras regiões para trabalharem na produção do látex. Conforme a borracha ganhava importância no cenário internacional com o desenvolvimento da indústria automobilística e as exportações aumentavam, os países que antes não davam tanta importância à sua porção amazônica periférica passaram a se preocupar com a sua ocupação e exploração econômica. Esta ocupação foi feita principalmente por imigrantes vindos do Nordeste do Brasil, de Santa Cruz da Bolívia, e dos Andes peruano e boliviano, que se tornaram seringueiros, em sua maioria, trabalhando para um seringalista, que era o dono das terras do seringal.

A ocupação desta área, fruto da exploração da borracha, gerou conflitos territoriais com enfrentamentos violentos, que exigiram um acordo entre Brasil e Bolívia. Como a área do que hoje corresponde ao Acre pertencia à Bolívia, mas estava ocupada por brasileiros, a resolução do conflito foi acordada com a compra do Acre pelo governo brasileiro em 1903 por meio do Tratado de Petrópolis, como já mencionado no capítulo dois deste trabalho. Este acordo envolveu também outros compromissos como a promessa do governo brasileiro de construção de uma ferrovia, a Madeira-Mamoré.

Com a decadência da borracha, os seringalistas abandonaram a região e os seringueiros formaram colônias agrícolas ou se mudaram para as cidades como Rio Branco (Brasil) e Porto Maldonado (Peru). Até a década de 1970 os governos dos três países da região MAP não estabeleceram outras políticas para a exploração econômica e desenvolvimento da região, mas a partir desta data começaram a incentivar a colonização agrícola, quando também foi descoberto ouro aluvial nos rios da Bacia do Madre de Dios. A ida de novos imigrantes que adquiriram terras para a colonização agrícola gerou conflitos pela posse da terra e novos impactos socioambientais. A expansão da fronteira agrícola na região gerou desmatamento para abarcar as novas fazendas, que se dedicaram, principalmente, à criação de gado.

Nos anos 1980, esta região despertou maior atenção dos governos nacionais e também internacional com o conflito envolvendo seringueiros e fazendeiros no estado do Acre, no Brasil. O movimento social dos seringueiros se organizou para defender 
seus direitos de posse da terra, com destaque para a atuação do líder seringueiro Chico Mendes. Tanto o governo estadual como nacional buscaram criar alternativas para o conflito como a criação das Reservas Extrativistas (Resex) para os seringueiros. No entanto, essas alternativas não frearam a expansão da criação de gado que também se expandiu para os Departamentos de Pando na Bolívia e Madre de Dios no Peru. A exploração da castanha também é uma atividade econômica que foi ganhando importância na região, e atualmente seu preço é superior ao da seringa ambos de exploração extrativista.

Outro aspecto que tem despertado maior atenção sobre a região MAP são os projetos de integração física regional impulsionados pela IIRSA. O primeiro projeto da IIRSA a ser implementado foi nesta região, a Estrada do Pacífico.

Bertha Becker (2007) ao classificar a fronteira da porção amazônica do Brasil, enquadra a região MAP como a região fronteiriça Brasil (Acre e Rondônia) - Bolívia Peru. Trata-se, segundo a geógrafa, de uma região caracterizada pelas sub-bacias que serviram de vias de integração entre os territórios brasileiro e boliviano, com a presença de cidades gêmeas e outras em processo de germinação. É onde também estão em desenvolvimento iniciativas inovadoras no campo social e nas relações econômicas, o que resultou em um movimento social transnacional de integração (Iniciativa MAP), com a participação da sociedade, governos e pesquisadores das universidades locais. Em relação às atividades econômica da região:

\begin{abstract}
a fronteira agrícola do sudoeste da Amazônia, ao se expandir em direção à fronteira da Bolívia e penetrar na faixa boliviana, criou uma nova realidade transfronteiriça, gerando uma dinâmica de fluxos entre as comunidades localizadas em cada um dos lados. Assis Brasil geminou-se a Iñapi (ou Iñapari), no Peru, e Brasiléia a Cobija, na Bolívia, onde os brasileiros, moradores dos municípios de Brasiléia e Epitaciolândia vão trabalhar. É grande também a atividade de extrativismo realizada por brasileiros em áreas bolivianas, gerando um fluxo permanente de pessoas e de negócios entre os dois países. Pelo fato de Cobija se constituir uma zona de livre comércio, a população brasileira se desloca para o outro lado a fim de adquirir produtos importados e, com isso, o comércio do lado brasileiro acaba sendo prejudicado com a concorrência (BECKER, 2007. p. 64).
\end{abstract}

Para Arsênio Oswaldo Sevá Filho (2010) a região MAP é fruto de uma criação de regiões visando à implementação de corredores globais de desenvolvimento e escoamento da produção. De acordo com este autor a Iniciativa MAP:

tem origem na Universidade da Flórida, Estados Unidos, que celebrou um convênio com a Fundação Zoobotânica da Universidade Federal do Acre, na qual fica sediado o núcleo inspirador da iniciativa trinacional. Há alguns anos, em 2001, cerca de 20 ONGs e os prefeitos de Assis Brasil (Acre, Brasil) e Iñapari (Madre de Dios, Peru) lançaram a "Carta de Assis Brasil: 
construindo o desenvolvimento sustentável na fronteira trinacional", recomendando o fortalecimento e a expansão de um "comitê de fronteira", para compatibilizar os zoneamentos econômicos e ecológicos, com as leis, "otimizando o manejo de recursos naturais regionais". Dentre as funções desse novo ente MAP, na mesma época já aparecia uma outra, valiosa para o capital: a função de ajudar a "equacionar" prejuízos e benefícios do pacote de obras que vai se implantando nesses locais, concretizando ali um dos eixos da mencionada IIRSA. Destacam-se nesse eixo: a ligação rodoviária chamada interoceânica, através de Rio Branco e Assis Brasil com Arequipa e o litoral sul peruano, e a construção de mega-hidrelétricas no Rio Madeira, em Rondônia e na divisa Brasil-Bolívia, e nos seus principais formadores, os rios Mamoré e Beni, na Bolívia (SEVÁ FILHO, 2010, p. 136-137).

Becker (2007) chama a atenção para os planos de integração regional na região MAP que têm gerado impactos negativos sobre os recursos naturais e ecossistemas. Ela vê a Iniciativa MAP como um processo inovador que visa o desenvolvimento e a proteção ambiental. A autora conclui que "é, portanto, na fronteira acreana que parecem mais avançadas as iniciativas locais para a integração continental” (BECKER, 2007, p. $65)$.

Como parte dos processos de integração regional na América do Sul a IIRSA tem se destacado com a perspectiva da integração da infraestrutura física regional. $O$ Eixo de integração Peru-Brasil-Bolívia da IIRSA abarca uma área em que a região MAP está incluída. Este Eixo compreende departamentos peruanos de Tacna, Moquegua, Arequipa, Apurimac, Cusco, Puno y Madre de Dios, três departamentos bolivianos, La Paz, Pando e Beni, e dois estados do Brasil, Acre e Rondônia. Como um eixo transversal ele abarca três Grupos de Projetos. O Grupo 1 corresponde ao Corredor Porto Velho - Rio Branco - Puerto Asís - Puerto Maldonado - Cusco - Juliana - Portos do Pacífico. O Grupo 2 consiste no corredor Rio Branco - Cobija - Riberalta - Yucumo - La Paz. E o Grupo 3 compreende o corredor fluvial Madeira - Madre de Dios - Beni. O projeto âncora do Grupo 1 é a pavimentação dos trechos Iñapari - Puerto Maldonado Inambari - Juliana / Inambari - Cusco, que se conecta com a rodovia BR - 317 do lado brasileiro, e foi denominada Estrada do Pacífico ou Rodovia Interoceânica, pois conecta o Brasil aos portos peruanos no Pacífico.

A rodovia BR - 317 já está asfaltada no Brasil e a pavimentação do lado peruano já foi concluída até Cusco, e contou com o financiamento do BNDES, da CAF e do governo peruano. Neste trajeto tiveram que ser construídas pontes sobre o rio Acre, entre Assis Brasil e Iñapari, chamada de Ponte da Integração (Foto 2), e também sobre o rio Madre de Dios em Puerto Maldonado no Peru (Foto 3). Esta rodovia também está 
conectada com a Bolívia, pois passa por Brasiléia, cidade gêmea de Cobija na Bolívia, que são conectadas por uma ponte sobre o rio Acre.

O Eixo Peru-Brasil-Bolívia (Mapa 2) possui 25 projetos nos três grupos e o investimento estimado para sua implementação é de 28,8 bilhões de dólares (IIRSA, 2008). No Grupo 1 além do projeto âncora também foram previstos: a linha de transmissão entre Puerto Maldonado e a fronteira com o Brasil, a linha de transmissão San Gabán - Puerto Maldonado, o melhoramento do aeroporto de Arequipa, o melhoramento do aeroporto de Juliana, o melhoramento do aeroporto de Puerto Maldonado, a ponte sobre o rio Acre, e a construção do centro binacional de atenção de fronteira (CEBAF) entre Peru e Brasil.

O Grupo 2 tem como projeto âncora a ponte binacional sobre o rio Mamoré entre Guajará-Mirim e Guayaramerín, e compreende também os projetos: estrada Cobija - El Choro - Riberalta, estrada Cobija - Extrema, estrada Guayaramerín - Riberalta / Yucumo - La Paz, estrada Yucumo - Trindade, o posto de fiscalização de fronteira entre Bolívia e Peru (Extrema), e o posto de fronteira entre Epitaciolândia (Brasil) e Cobija (Bolívia).

O Grupo 3 conta com o projeto âncora de navegação do rio Madeira entre Porto Velho e Guajará-Mirim, e também inclui outros projetos: o complexo hidrelétrico do rio Madeira (usinas Santo Antônia e Jirau), a hidrelétrica binacional Bolívia-Brasil, a hidrelétrica Cachuela Esperanza no rio Madre de Dios na Bolívia, a hidrovia IchiloMamoré, a hidrovia Madre de Dios e um Porto Fluvial, a navegabilidade do rio Beni, e a linha de transmissão entre as duas centrais hidrelétricas do rio Madeira e o Sistema Central. 


\section{Eixo Peru-Brasil-Bolívia}

\section{Grupos de Projetos}

I $\mathbf{R}$ S A

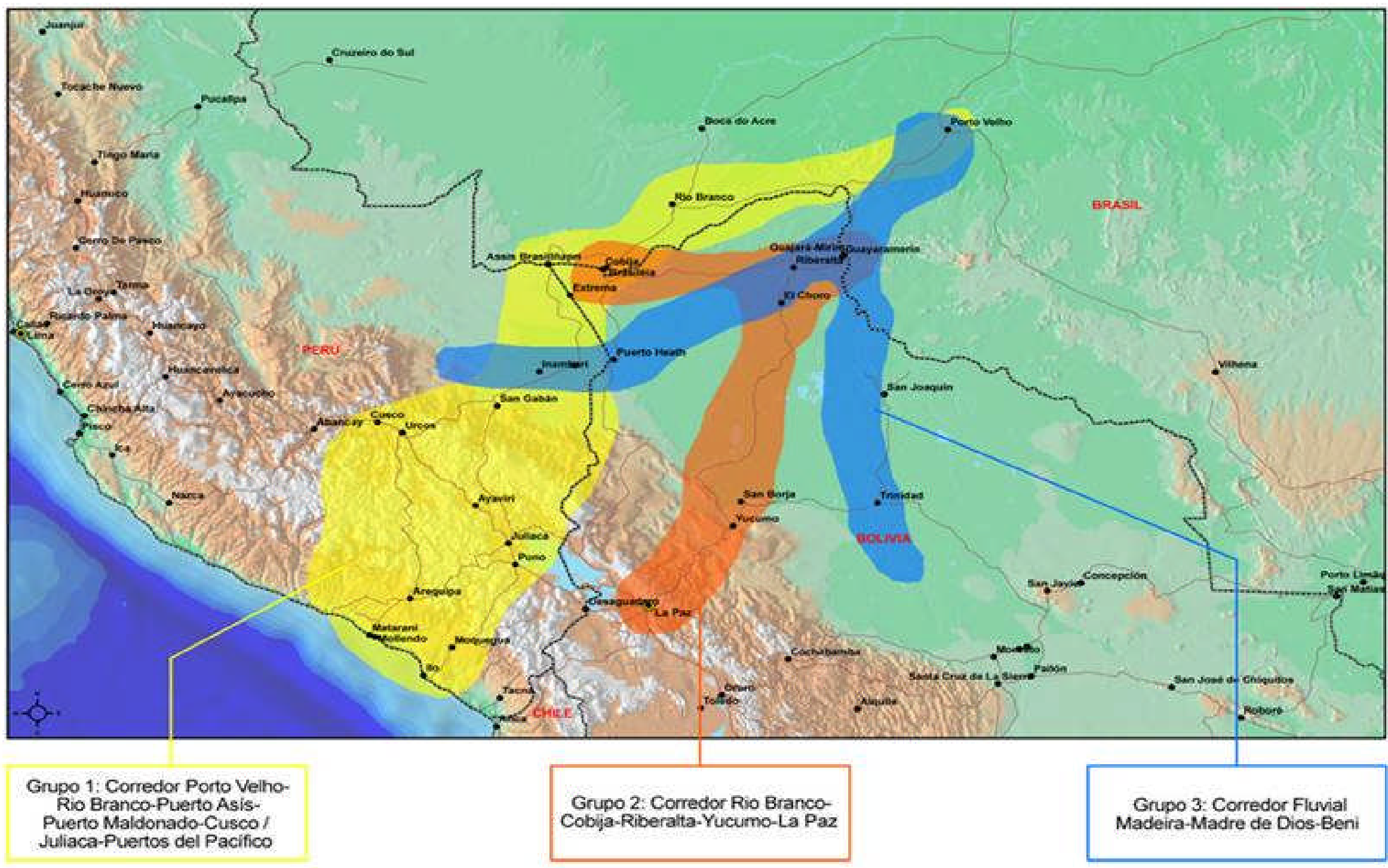

Fonte: IIRSA, 2008

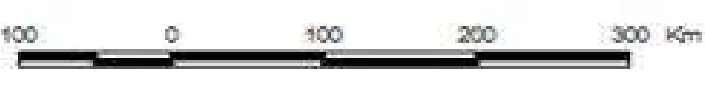

米 
O projeto da Estrada do Pacífico (Foto 4) apesar de ter sido concluído sob os auspícios da IIRSA, seu planejamento é anterior a esta iniciativa. Llosa (2001), em seu estudo sobre a integração entre o Peru e o Acre, no Brasil, argumenta que no Tratado de Amizade e Cooperação assinado entre Peru e Brasil em 1979 já mencionava desenvolver o transporte de exportações e importações do Peru para o Oceano Atlântico via Brasil. Em outro Acordo entre os dois países assinado em Lima em 1981, que complementa o primeiro, está presente a decisão de estabelecer uma interconexão entre os sistemas viários dos dois países, determinando como ponto prioritário que esta interconexão passe pelas localidades de Assis Brasil e Iñapari. E o Relatório da Comissão Interministerial para Sistematizar as Informações dos Diversos Grupos e Comissões Existentes sobre Corredores de Transportes Bioceânicos, de 1996, também mencionava esta interconexão. No ano 2001, esta interconexão vial entre o Acre e os portos peruanos no Pacífico volta à agenda, quando em julho é aberto concurso para selecionar uma empresa construtora para elaborar um Estudo de Pré-factibilidade da rodovia Iñapari- Puente Inambari - Puerto Marítimo. Para Llosa, chama atenção:

[...] que el controvertido "corredor bioceánico" (tal cual fuera concebido y acordado, hace más de 20 años) sea "resucitado" con premura inusitada. Efectivamente, varios hechos ocurridos demuestran que, por un lado ha habido, inicialmente, improvisación y luego, un manejo irresponsable de los acontecimientos generados y, por otro, un despertar de intereses en torno a la concreción del proyecto, incubado por expectativas regionales y locales, antiguas y nuevas, expresados en diversas modalidades de presión, diversas en índole y calibre. [...] Expresiones de presión que van desde el aprovechamiento de las instalaciones del Congreso de la Republica (mes de agosto de 2001) para, en una prolongada maratón de exposiciones, se abunde sobre la importancia del "corredor" [...] sin mencionar, en ningún momento y por ningún expositor, las restricciones de diversa naturaleza existentes para su concreción; sin considerar, "con mirada grande" las otras alternativas posibles debidamente ponderadas (2001, p. 6-7).

Llosa (2001) argumenta que a conexão entre o Acre e o Peru é apenas uma conexão fronteiriça e que não possui um caráter bi-oceânico como defendeu o governo brasileiro. Para ele, o interesse do Brasil na construção da Rodovia interoceânica pelo Acre e a conexão com o Peru é garantir mais uma via para a exportação dos grãos produzidos nos estados de Mato Grosso e Rondônia pelos portos do Pacífico, o que ainda não se concretizou.

Amayo (1993) argumentou, ainda na década de 1990, que existiam três possibilidades para esta interconexão, pelo norte, centro ou sul do Peu. E também alertava para as condições em que seria negociado e elaborado o plano para a interconexão com a construção de uma estrada: 
O caminho terá que ser quase totalmente construído, provavelmente como uma rodovia, apesar da possiblidade de um sistema intermodal. Além de realizar eficazmente a união pretendida, deverá ser o menos destrutivo; a ciência e a técnica atuais o permitem. A escolha deverá ser feita por uma comissão binacional (Brasil e Peru), que conte com a assessoria dos melhores cientistas conhecedores da área, independentemente de suas nacionalidades. É importante que a opção tenha o aval dos setores organizados da sociedade civil com destaque para os representantes das populações por onde a estrada passará (1993, p. 149-150).

No começo da década de 1990 a Comissão Técnica do TCA para infraestrutura e transporte considerou quatorze corredores prioritários para a integração física da Amazônia. Amayo (2007) considera que cinco deles eram os mais importantes como possibilidades do Brasil conseguir uma saída para o Pacífico:

Corredor Belém-Iquitos, pelo norte do Peru, [...]; Corredor Inter-oceânico, que sai de Belém, passa por Manaus e toma o Rio Putumayo (fronteira Colômbia/Peru), chega ao Equador, cruza Quito, termina no Porto de Esmeraldas, OP (Oceano Pacífico); Corredor Rio Negro, ligando o Brasil com Colômbia e Venezuela; Corredor Cáceres-Santa Cruz, unindo Mato Grosso à Bolívia; e Corredor Trans-oceânico desde Rio Branco (Acre-Brasil) até Iñapari (Madre de Dios - Peru) para dali cruzar os Andes e terminar em portos do sul peruano $(2007$, p.110).

Foi o corredor Trans-oceânico o que primeiro se concretizou com a construção da Estrada do Pacífico, que completa o corredor até os portos peruanos e foi conectada pela Ponte da Integração entre Assis Brasil e Iñapari (foto 2). Este corredor conta também com outras obras importantes como a ponte sobre o rio Madre de Dios, no Peru (foto 3), que neste momento já encontra-se concluída.

Foto2: Ponte da Integração entre Assis Brasil, Brasil, e Iñapari, Peru, vista desde Iñapari.

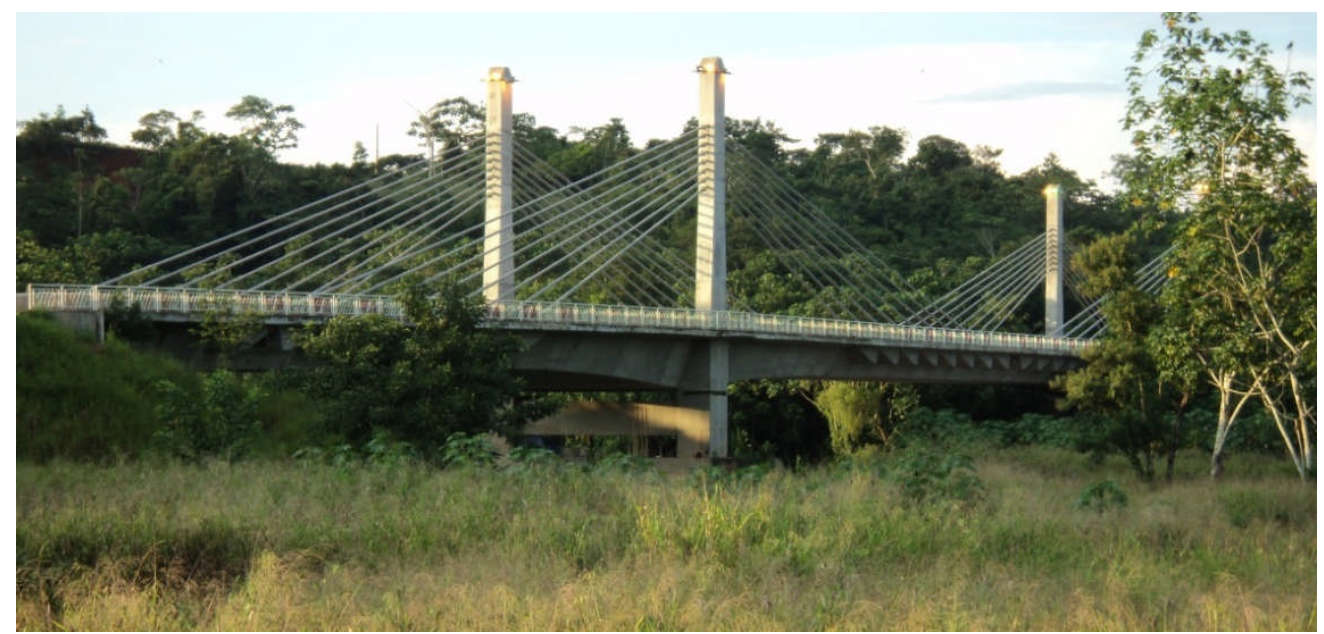

Fernanda Mello Sant'Anna, 2011. A ponte sobre o rio Acre é utilizada, na maior parte das vezes, para o trânsito da população das cidades vizinhas. 
Foto 3: Ponte sobre o rio Madre de Dios, em Puerto Maldonado, Peru.

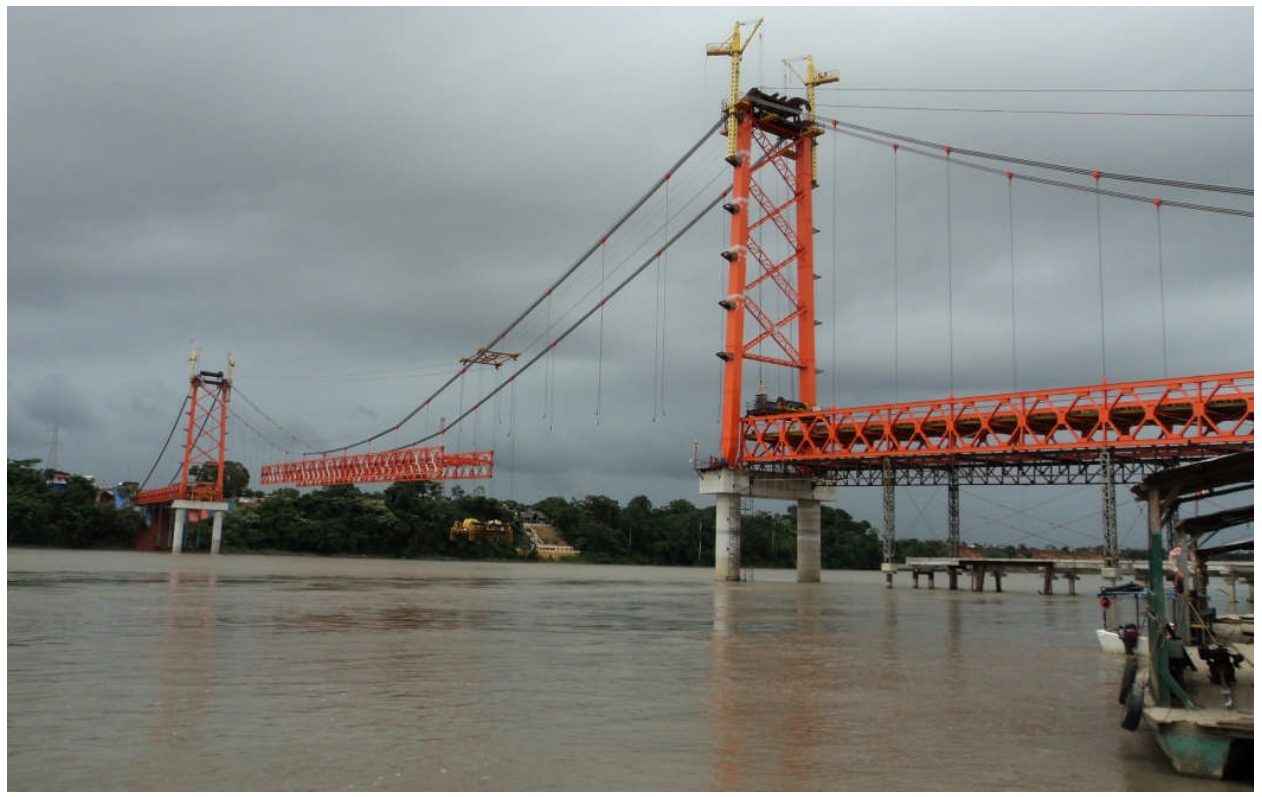

Fernanda Mello Sant'Anna, 2011. A ponte sobre o rio Madre de Dios, na foto em fase final de construção e hoje já concluída, facilitou o transporte para a capital Puerto Maldonado que antes era feita através de balsas em condições precárias.

Na época do planejamento e da construção (pavimentação) desta estrada, houve várias resistências por parte de movimentos sociais e ONGs que apontavam os impactos socioambientais que seriam causados. É importante notar que a estrada passa próxima à Terras Indígenas, inclusive de povos isolados, e Áreas de Proteção Ambiental. Santa Cruz (2009) aponta também a existência de outros questionamentos que surgiram em torno da construção da estrada no Peru:

\begin{abstract}
las modalidades y los plazos adoptados para la aprobación en el Perú del proyecto de la carretera Interoceánica del Sur han suscitado cuestionamientos de algunos especialistas e instituciones técnicas de la sociedad nacional. Tales posiciones reconocen la transcendencia y necesidad de la carretera como un factor de desarrollo para el sur del país, pero orientan sus críticas hacia dos aspectos fundamentales: a) las características técnicas del proyecto vial y los procedimientos para su aprobación; y b) la urgencia de dotarse de un marco de desarrollo integral, cuya inexistencia esta ya dando lugar a un deficiente tratamiento a los impactos socioambientales de la carretera Interoceánica del Sur (p. 42).
\end{abstract}

A preocupação socioambiental em relação a esta estrada (Foto 4) esteve centrada nos impactos que poderia causar, como a intensificação do desmatamento e dos incêndios florestais. Para Dourojeanni (2001) entre os impactos da estrada destaca-se: desmatamento, aumento dos riscos de incêndios, caça ilegal, erosão dos solos, invasão de áreas protegidas, perda de biodiversidade, aumento das atividades ilegais como o 
narcotráfico, formação de favelas, entre outros. De acordo com este autor o Peru está menos preparado institucionalmente para lidar com estes impactos do que o Brasil. No Peru as instituições responsáveis pela preservação ambiental, o Ministério da Agricultura e o Instituto Nacional de Recursos Naturais (INRENA), possuem conflitos de interesses. No entanto, o Acre é o estado da região MAP que apresenta a maior taxa de desmatamento e de degradação de seus recursos naturais ${ }^{21}$ : "a região leste do Acre já compõe a parte ocidental do chamado 'Arco do Fogo', onde ocorrem os maiores índices de desmatamento, sendo que $80 \%$ da área desmatada no Estado ocorre nessa região" (BRITO, 2007, p. 165).

Foto 4: Estrada do Pacífico vista desde Assis Brasil, Brasil.

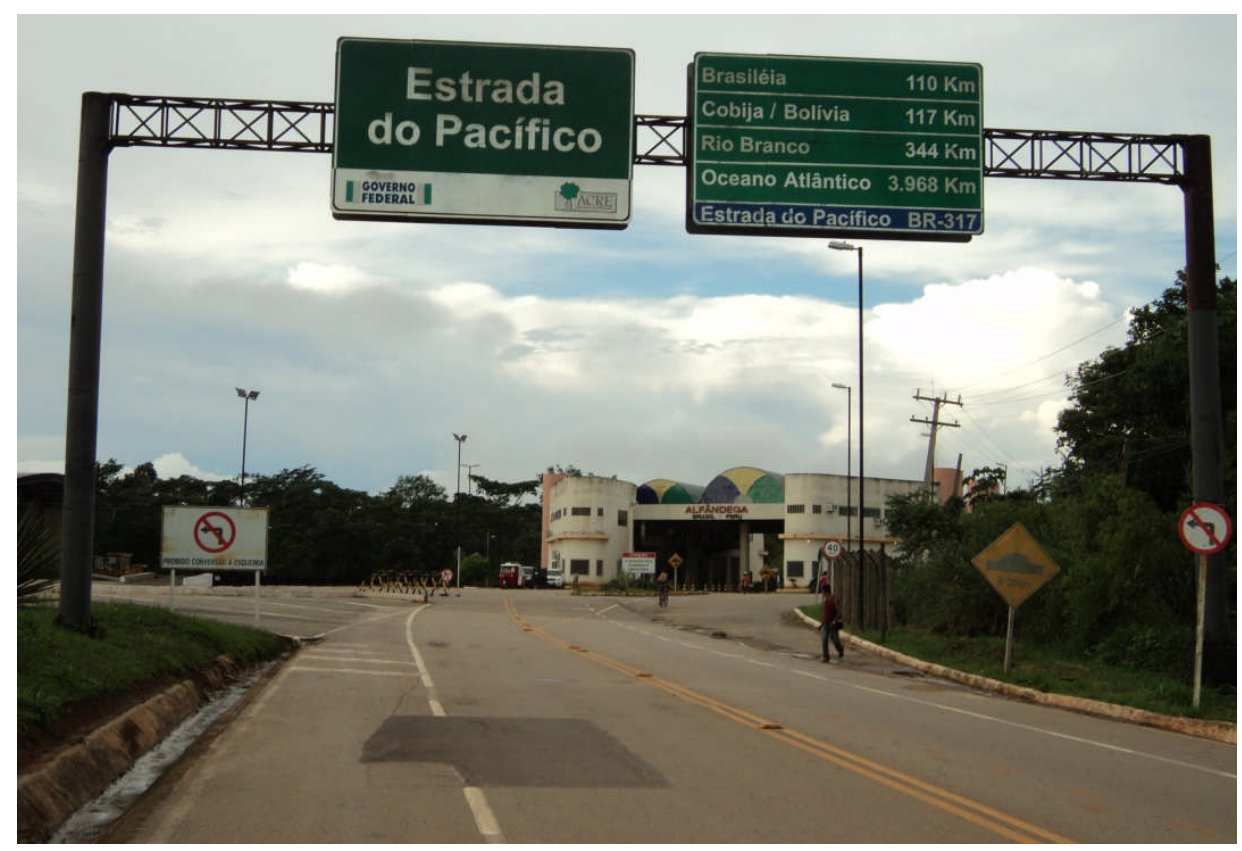

Fernanda Mello Sant'Anna, 2011. Apesar de inconclusa, no Brasil já aparece a indicação da Estrada do Pacífico, que hoje chega até Cuzco. Observa-se o posto da Aduana Brasileira ao fundo, pouco antes da chegada à fronteira com o Peru.

\footnotetext{
${ }^{21}$ Em 2005 uma grande queimada, agravada pela seca de três meses na região, despertou a preocupação da população. Detectou-se mais de 15.000 focos de calor, grande parte no Acre, concentrando-se ao redor da Estrada do Pacífico. Também se detectou incêndios em áreas fronteiriças como Cobija e Ibéria, próxima a Reserva Nacional Tampopata (Madre de Dios). Neste ano, ocorreu um longo período de estiagem, o que resultou em problemas de abastecimento na cidade de Rio Branco (Acre). A bacia do rio Acre, que abastece esta cidade, apresenta certo grau de degradação, cerca de 68\% de sua área já foi desmatada (BROW, 2006; BRITO, 2007).
} 


\section{PROJETOS DE INFRAESTRUTURA NA REGIÃO "MAP"}

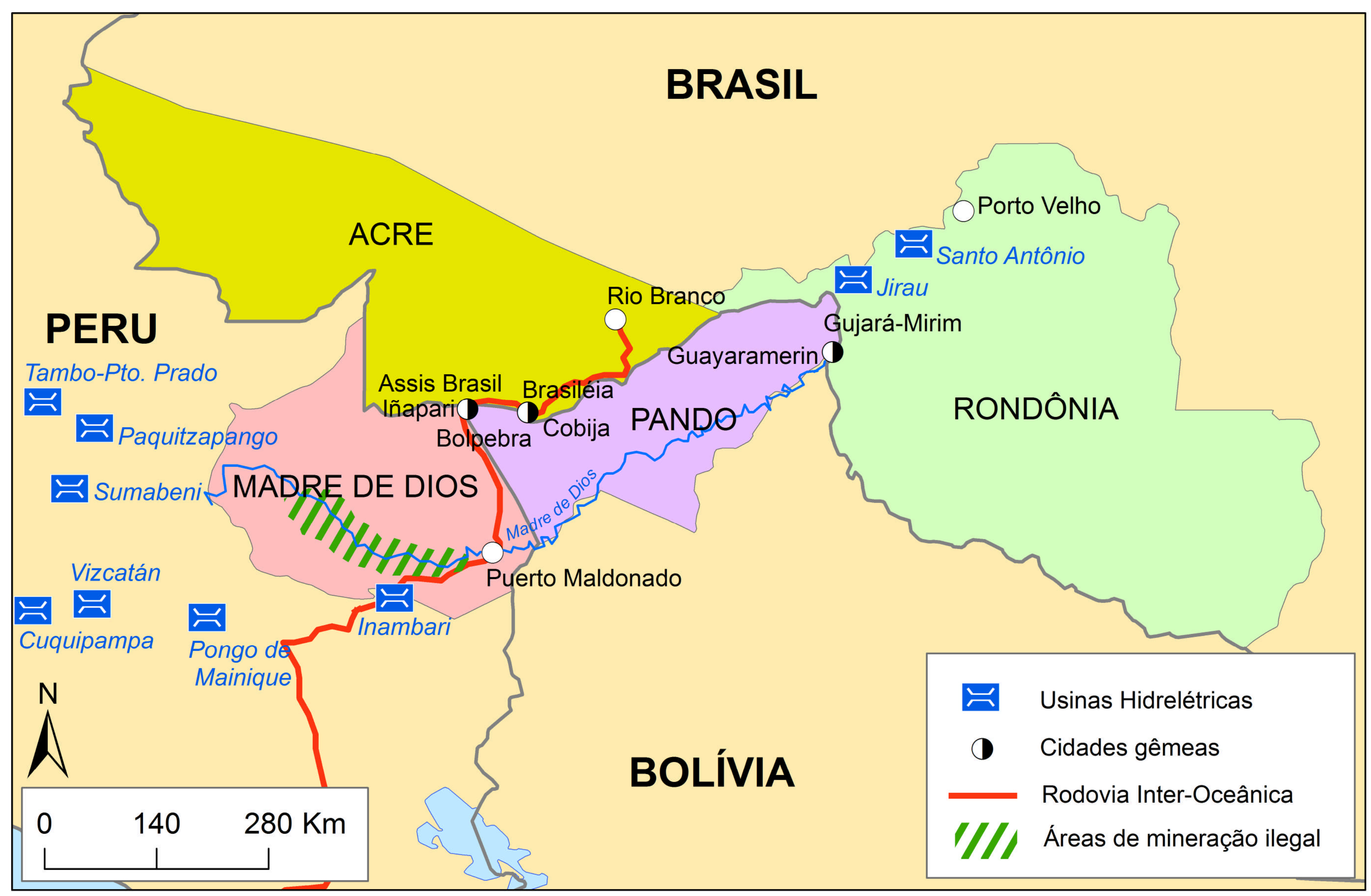

Autor: Fernanda Mello Sant'Anna

Elaboração: Tito Lívio Barcellos Pereira 
Além da IIRSA outros projetos de infraestrutura (Mapa 3) que tem impactado as relações bilaterais entre Brasil e Peru, e também na região MAP são frutos do acordo energético assinado entre os dois países em 2010, como já foi abordado no segundo capítulo deste trabalho. Este acordo prevê a construção de centrais hidrelétricas na Amazônia peruana com a exportação de energia para o Brasil.

O mais controverso dos projetos previstos é o da central hidrelétrica de Inambari, que não está localizada na região MAP, e sim na fronteira entre os Departamentos de Madre de Dios, Cuzco e Puno, a uma distância de $300 \mathrm{~km}$ da fronteira do Acre, no rio Inambari, na Bacia do rio Madre de Dios. Esta central terá uma capacidade instalada de 2.200 MW e é possível que a construção desta central inunde parte da recém-inaugurada Estrada do Pacífico em território peruano (ALVAREZ e FADIGAS, 2010).

A região MAP apresentada é onde está localizada a bacia transfronteiriça do Rio Acre e que enfrenta os problemas relacionados ao uso compartilhado dos recursos hídricos transfronteiriços, que serão discutidos a seguir.

\subsection{Principais problemas socioambientais relacionados aos recursos hídricos transfronteiriços da Bacia do rio Acre}

$\mathrm{Na}$ bacia do rio Acre, os principais problemas relacionados ao uso dos recursos hídricos transfronteiriços podem ser condensados em cinco: as enchentes na época da estação chuvosa e suas consequências; as secas no período de estiagem, que contribuem para o alastramento de incêndios, e a consequente crise de abastecimento; a pesca, decorrente das diferenças nas legislações; a poluição hídrica devido, principalmente, à falta de saneamento básico nas áreas urbanas; e o fato do rio ser a linha divisória entre os países, que por estar em constante mudança de curso nos meandros ocasiona problemas para as cidades gêmeas. Outros problemas que também afetam as relações bilaterais entre os países da região, mas que estão fora da Bacia do rio Acre, são: a contaminação devido à mineração ilegal de ouro na Bacia do rio Madre de Díos (Peru), as hidrelétricas na Bacia do rio Madeira (Brasil), e a hidrelétrica de Inambari (Peru).

Esta relação dos principais problemas relacionados ao uso e à gestão da água na bacia foi feita com base nas entrevistas com representantes das instituições públicas e 
privadas da região $\mathrm{MAP}^{22}$, bem como com base nos trabalhos de campo e discussões do Grupo de Trabalho do rio Acre (GT Acre).

As enchentes são um problema constante que afeta principalmente os municípios localizados nas margens do rio Acre, pois a inundação afeta as residências e as infraestruturas, levando muitas pessoas a ficarem desabrigadas. Em fevereiro de 2012 o rio Acre chegou ao nível de 17,64 metros na capital Rio Branco, atingindo 99.608 pessoas, das quais 6.400 estão em abrigos públicos (BRASIL, 2012). O atual prefeito de Rio Branco, Raimundo Angelim, decretou calamidade pública em 37 bairros e 22 comunidades rurais. O município de Brasiléia também foi afetado e declarou calamidade pública. De acordo com Nascimento:

o Rio Acre apresenta, na Cidade de Rio Branco, uma cota de alerta de 13,5m. Isso significa dizer que o curso d'água começa a extrapolar seu leito maior e a enchente está na iminência de ocorrer. Já sua cota de transbordamento está ao nível de $14 \mathrm{~m}$. Ao atingir tal nível, a planície de inundação começa a ser invadida pela água e o processo de inundação se concretiza (2011, p. 172).

Em um estudo realizado por Espinoza et al. (2006), sobre os perigos de origem natural em Iñapari, foram identificados os seguintes fenômenos de origem climática de maior ocorrência:

\footnotetext{
-inundação ou encharcamentos de água em depressões, zonas planas sem drenagem natural, por presença de chuvas intensas;

-inundação por transbordamento dos rios Acre e Yaverija em épocas de enchentes ordinárias e extraordinárias;

-mobilidade fluvial dos rios Acre e Yaverija;

-erosão por ocorrência de altas velocidades de fluxo de escoamento superficial nas margens dos meandros dos rios Acre e Yaverija;

-erosão laminar e transporte de sedimentos devido ao fluxo de escoamento superficial (p. 63).
}

Este estudo também apresentou propostas de mitigação dos efeitos das inundações recorrentes com a identificação de seis projetos prioritários que incluem a construção de: um sistema integral de drenagem fluvial, um sistema de defesa ribeirinha, um sistema de drenagem sub-superficial; além da ampliação do muro de proteção da Avenida León Velarde e da aplicação de um tratamento de cimentação sobre solos expansivos e capacitação em técnicas construtivas (Espinoza et al., 2006).

Por outro lado as secas também tem afetado a Bacia do rio Acre, ou seja, a diminuição dos caudais mínimos do rio nas épocas de vazante. De acordo com Duarte (2007) a deterioração da cobertura florestal (Foto 5) nas áreas da bacia tem contribuído

\footnotetext{
${ }^{22}$ A região MAP é como ficou conhecida esta região formada pelo Departamento de Madre de Dios (Peru), o estado do Acre (Brasil), e o Departamento de Pando (Bolívia).
} 
para a diminuição das chuvas, pois as mudanças no uso do solo na área da bacia têm causado alterações no regime de chuvas nas últimas décadas. Isto ficou evidente nos episódios ocorridos em 2005 e 2006:

Não obstante só recentemente após a severa seca do ano 2005 na Amazônia e a enchente de fevereiro de 2006 do Rio Acre na cidade de Rio Branco, que a consciência sobre as condições do Rio Acre e da população que mora perto de suas margens, se viu sacudida pelas calamidades (DUARTE, 2007).

Foto 5: Fazenda de gado vista da rodovia BR - 317 no Acre, Brasil.

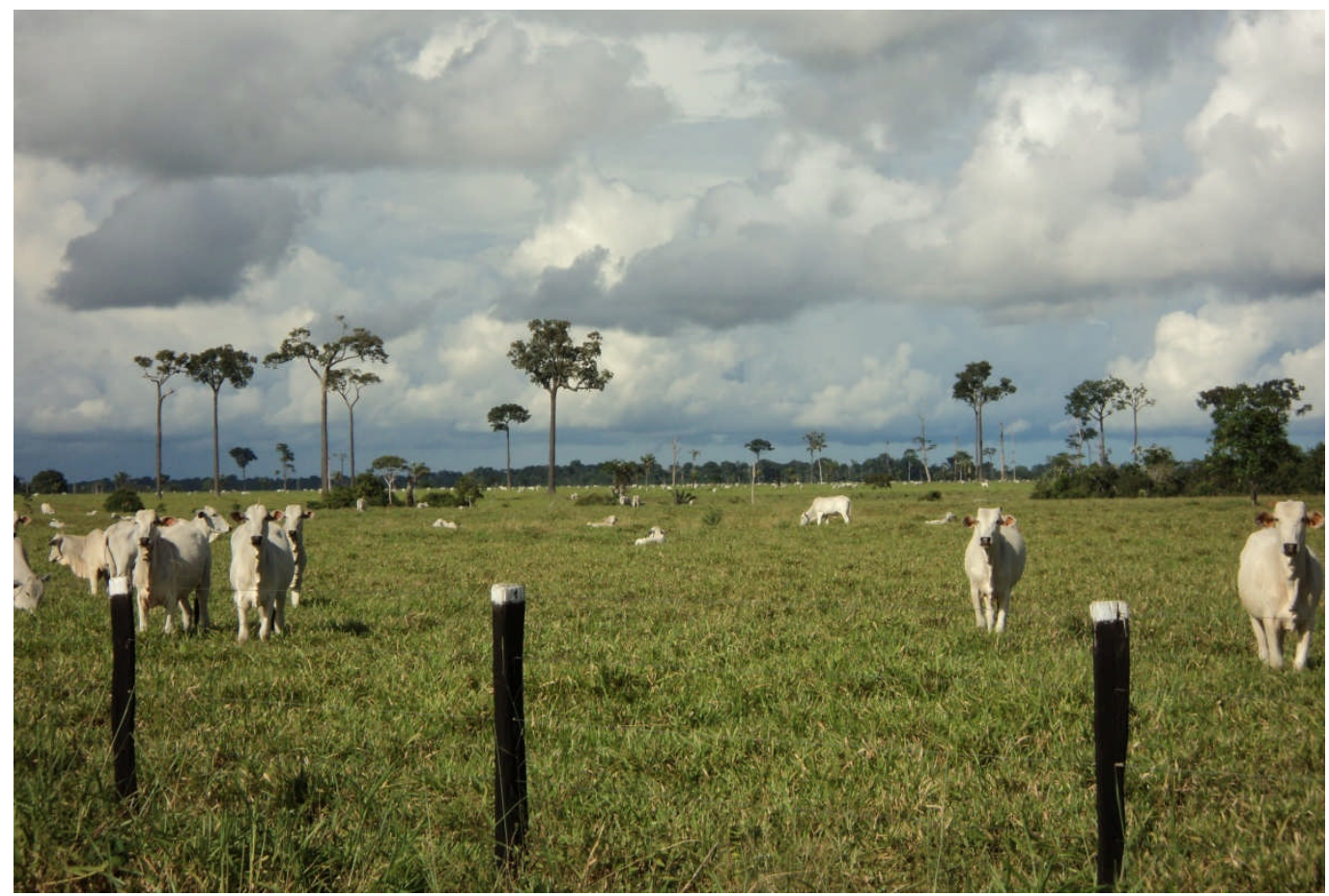

Fernanda Mello Sant'Anna, 2012. Observam-se ao longo de toda a BR-317 no Acre áreas desmatadas em sua maioria para a criação de gado. As árvores que restaram no pasto são castanheiras ${ }^{23}$ que não podem ser cortadas conforme a legislação ambiental.

Nascimento (2011) afirma em sua pesquisa que existem flutuações sazonais no regime de chuvas na Amazônia Ocidental que foram identificadas ao longo de sua história. No entanto, identifica elementos que tem contribuído para os episódios de secas, como a de 2005:

o processo de supressão de floresta e sua substituição por pastagem, que, via de regra ocorre com o desmatamento na bacia do rio Acre, implica na diminuição de núcleos de condensação de nuvens rasas. Assim, consequentemente, tal mecanismo estaria influenciando na diminuição das precipitações na época chuvosa tanto a nível local, quanto em outras regiões. No período da seca as concentrações de aerossóis alteram o balanço de radiação fazendo com que o perfil de variação da temperatura da atmosfera

\footnotetext{
${ }^{23}$ No Brasil a castanheira (Bertholetia excelsa) é protegida pelo Decreto ${ }^{\circ} 5975 / 2006$ que proíbe a comercialização de sua madeira, assim como a seringueira (Hevea spp) e o mogno (Swietenia macrophylla).
} 
com a altura seja modificado no sentido de dificultar a formação de nuvens (NASCIMENTO, 2011, p. 163).

$\mathrm{Na}$ época de seca também irrompem incêndios que destroem centenas de milhares de hectares de floresta, como ocorreu em 2005. Para Marengo et al. (2008), o número de incêndios florestais naquele ano foi $30 \%$ maior do que no ano anterior devido à baixa umidade:

\begin{abstract}
a seca de 2005 na região contígua de Madre de Dios, Peru - Acre, Brasil Pando, Bolívia (MAP), serviu como demonstração do que pode acontecer quando perturbação climática soma-se à crescente vulnerabilidade social, resultante de crescimento populacional e desflorestamento. Suprimentos de água para os principais centros urbanos quase cessaram, incêndios se alastraram por mais de 200.000 hectares em áreas abertas e consumiram mais de 340.000 hectares de áreas florestais no Acre ocidental, afetando muitas comunidades florestais (NASCIMENTO, 2011, p. 170).
\end{abstract}

Este quadro de eventos extremos como secas, enchentes e incêndios que tem ocorrido na Bacia do rio Acre são agravados devido à falta de estrutura institucional para prevenir os impactos decorrentes, bem como assistir a população afetada, o que indica um grau de alta vulnerabilidade social (NASCIMENTO, 2011).

Além destes problemas ocasionados por eventos extremos tem sido relatado pelas associações de pescadores na Bacia do rio Acre a diminuição da quantidade de peixes e também de espécies encontradas, por exemplo, no rio Acre. Jeremias da Silva, vice-presidente da Associação de Pescadores de Assis Brasil, relatou que tem observado uma diminuição do caudal do rio Acre no período de estiagem, o que tem afetado à pesca, conforme entrevista realizada em 2011. Ele também apontou a existência de um conflito entre pescadores brasileiros, bolivianos e peruanos, que compartem o rio Acre, já que este é a linha de fronteira entre estes países. A diferença entre as legislações nacionais contribui para a situação de conflito, pois enquanto o Brasil paga um segurodefeso para os pescadores não pescarem no período da desova dos peixes, que dura de novembro a março, os outros países não fazem o mesmo. Assim, os pescadores bolivianos e peruanos continuam pescando neste período, contribuindo para a diminuição da quantidade de peixes no rio. Afirma que pelo menos três espécies de peixes praticamente não são mais encontradas, sendo necessário de 10 a 15 pescarias para achar 1 ou 2 exemplares destas espécies.

A Associação possui cerca de 150 a 160 membros que pagam uma mensalidade para a manutenção da Sede e contam com uma máquina de gelo para a conservação do pescado, que foi comprada pelo governo. O vice-presidente da Associação também 
relatou a existência de um comércio transnacional importante, pois os pescadores brasileiros vendem para o Peru, principalmente o peixe Piranambu, que apresenta um alto consumo de pescado.

Em relação ao conflito transfronteiriço pelos recursos pesqueiros, foi relatado que o IBAMA estaria em negociação com as instituições correspondentes no Peru e na Bolívia para a elaboração e assinatura de um Acordo para a proibição da pesca no período da desova em rios transfronteiriços. O maior desafio para a elaboração e implementação de um acordo deste tipo é que a Bolívia e o Peru não teriam condições de pagar o correspondente ao seguro-defeso neste período para os pescadores. Jeremias também alegou que o IBAMA estaria elaborando um projeto que cessaria por completo a pesca no rio Acre por um período de 5 anos com o objetivo de recompor as espécies no rio, e realizar um constante monitoramento para verificar a necessidade de extensão deste prazo. Este projeto foi abordado em uma reunião realizada em Rio Branco, em 2010, com órgãos do governo e as associações de pescadores da Bacia do rio Acre.

De acordo com o estudo realizado por Freitas, Reis e Apel (2010, p.2-3):

\begin{abstract}
situações de conflito no uso dos recursos pesqueiros na região da tríplice fronteira entre o Estado do Acre (Brasil) e os Departamentos de Pando (Bolívia) e Madre de Dios (Peru) foram relatadas pelo governo brasileiro (Instituto Chico Mendes de Conservação da Biodiversidade - ICMBio), imprensa e pescadores desde 2008. Nos últimos quatro anos, uma espécie de peixe pouco apreciada no Brasil, o Piranambu (Pinirampus pirinampu), foi descoberto como ideal na preparação de um prato tradicional no Peru, o ceviche, em função de possuir poucos espinhos e de "pegar" o tempero. A relativa abundância da espécie no Rio Acre, aliado a facilidade de captura e a abertura de mercado em Puerto Maldonado, induzida pela conclusão do asfaltamento do trecho Iñapari-Puerto Maldonado da Rodovia do Pacífico, seduziu os peruanos, a partir do final de 2008, a praticarem a pesca desta espécie durante o Inverno Amazônico (Estação chuvosa). Este período coincide com a época em que ocorre a maior quantidade de Piranambus e com a suspensão da pesca no Brasil, pelo período de quatro meses (15 de novembro a 15 de março), em que é fornecido o seguro-defeso.
\end{abstract}

Este conflito transfronteiriço pelos recursos pesqueiros do rio Acre está relacionado com a pesca comercial da espécie Piranambu e a proibição da pesca, chamada de defeso, no lado brasileiro. Os pescadores peruanos de Iñapari acreditam que tem sofrido abuso de autoridade por parte dos órgãos de fiscalização brasileiros, e não consideram viável a instituição do defeso para o lado peruano. Uma ação do ICMBio em 2009 acompanhada pela Polícia Federal demonstrou que o problema deve agora buscar uma resolução por via diplomática: "uma vez que o rio é compartilhado entre brasileiros e peruanos, e a legislação peruana não os proíbe de pescar durante o período 
do defeso brasileiro e os pescadores peruanos não estão sujeitos a fiscalização brasileira" (FREITAS, REIS e APEL, 2010, p. 16).

Foi constatado também que os pescadores do rio Acre acreditam existir uma crise na pesca, com uma diminuição da quantidade de peixes e espécies consumidas nos últimos dez anos, principalmente as espécies de peixes grandes que alegaram ser devido ao rio encontrar-se mais "raso":

\begin{abstract}
a falta de água no Rio está diretamente relacionada a escassez das espécies citadas, ao desmatamento, a colocação de Malhadeiras na foz do Rio Acre, a proliferação de açudes, a elevada quantidade de pescadores no Rio e ao uso de artes de pesca ilegais. Este contexto de ausência de direitos de propriedade bem definidos, evidencia que o regime de apropriação (OSTROM, 1990; BROMLEY, 1992; FEENY et al. 1990) dos recursos pesqueiros realizado no Rio Acre encontra-se na situação de livre acesso (FREITAS, REIS e APEL, 2010, p. 10).
\end{abstract}

Além do conflito transfronteiriço que inclui a pesca do Piranambu, outro conflito se dá entre os pescadores comerciais e os pescadores de subsistência da Reserva Extrativista (Resex) Chico Mendes e de Terras Indígenas (TI), no Brasil, e da Comunidade Nativa Bélgica, no Peru, que são regulados pelas normas de uso de Áreas Protegidas. Os pescadores da Resex e das TIs, que estão à montante da tríplice fronteira, responsabilizam os pescadores comerciais dos municípios pela diminuição da quantidade de peixes do rio. Entre 2006 e 2007 o ICMBio intermediou a negociação entre os pescadores e como resultado estabeleceu, por meio da instrução normativa 156/07, que os indígenas tem exclusividade sobre a pesca na área da TI e os extrativistas na área da Resex, enquanto que os pescadores profissionais poderiam pescar apenas no trecho a jusante da Resex. Entretanto, esses pescadores profissionais não tem reconhecido o Acordo de pesca, pois alegam que os indígenas e extrativistas pescam em áreas fora das TIs e Resex (FREITAS, REIS e APEL, 2010).

Outro problema relacionado aos recursos hídricos transfronteiriços da Bacia do rio Acre é a questão do rio como linha de fronteira entre os países. De acordo com o secretário do CONDIAC Silton Melo ${ }^{24}$, a mudança do curso do rio Acre, isto é, nos seus meandros, e os desbarrancamentos (processos erosivos das margens do rio) tem causado prejuízos para a população que vive em suas margens. Em Brasiléia, que é cidade gêmea com Cobija, existe um bairro que pode ficar ilhado pela mudança no curso do rio, que abandonaria um meandro, deixando o bairro em território boliviano, já que o rio

\footnotetext{
${ }^{24}$ A entrevista com o secretário do CONDIAC Silton Melo ocorreu no dia 27 de janeiro de $2011 \mathrm{em}$ Epitaciolândia (AC - Brasil).
} 
é o limite entre os países. A distância entre um braço do rio e o outro neste meandro é de apenas um metro. Por isso, o CONDIAC e o município de Brasiléia estavam buscando alternativas para a elaboração de um projeto para evitar que o rio mude o seu curso e o meandro seja abandonado (Foto 6).

Foto 6: As cidades gêmeas de Brasiléia (Brasil) e Cobija (Bolívia) cortadas pelo rio Acre.

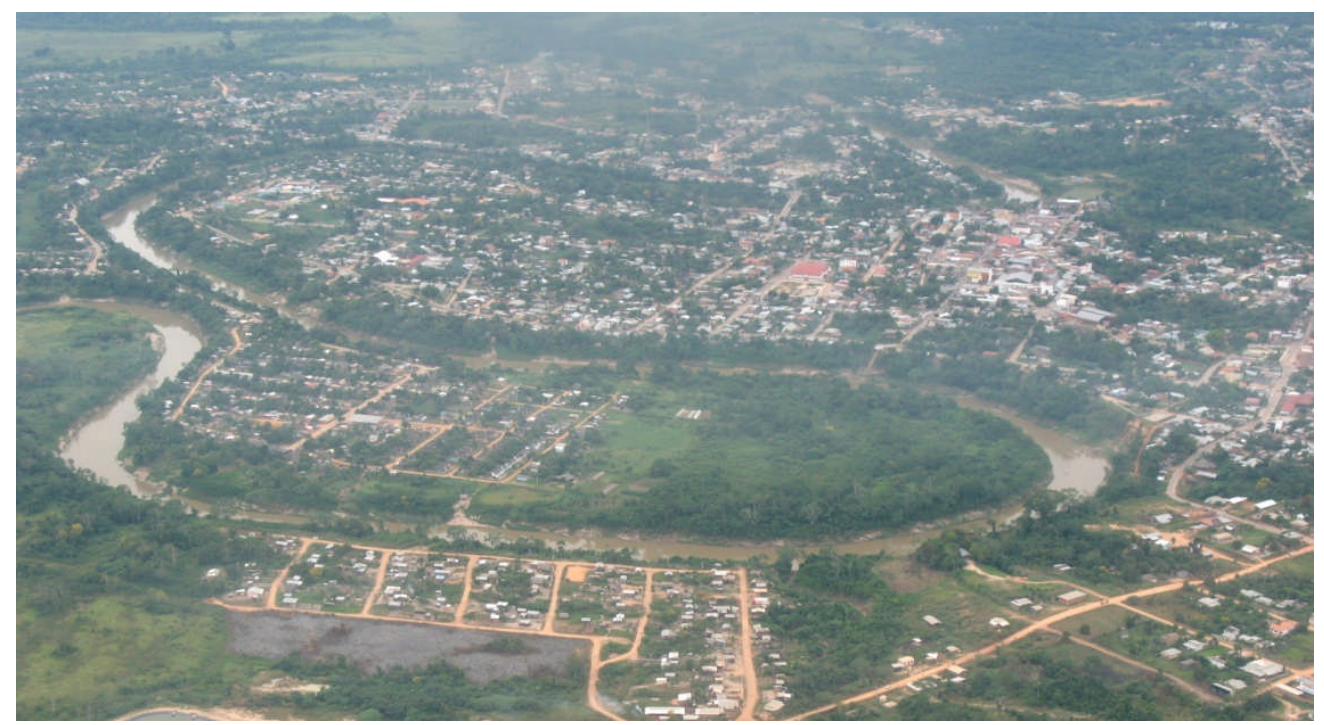

Fonte: CONDIAC, 2010. Nesta foto nota-se o bairro de Brasiléia que será cortado pelo rio Acre, ao abandonar o meandro, deixando-o em território boliviano na cidade de Cobija.

A falta de saneamento e acesso à água potável é também considerada um problema relacionado aos recursos hídricos transfronteiriços da Bacia do rio Acre, principalmente devido à existência de cidades gêmeas. De acordo com Luz Marina Menezes $^{25}$, da Prefeitura de Brasiléia, o rio Acre tem sofrido com os impactos causados pelo esgoto e lixo urbano que são vertidos diretamente no rio. O problema do lixo foi considerado como grave na cidade, pois apesar da iniciativa da "Campanha por uma cidade mais limpa" e a coleta de lixo, que é feita pela Secretaria de Obras com um calendário por bairro, ainda sim o lixo é jogado nos terrenos vazios, como foi relatado em entrevista pela Coordenadora de Meio Ambiente de Brasiléia Marines Ferreira ${ }^{26}$.

Nos municípios do Acre, nota-se em muitos domicílios a presença de poços rasos próximos às fossas e sumidouros, o que apresenta alto risco para a saúde, pois os

\footnotetext{
${ }^{25}$ A entrevista com Luz Marina Menezes, chefe de Gabinete da Prefeitura de Brasiléia (AC) foi realizada dia 31 de janeiro de 2011, na Prefeitura de Brasiléia.

${ }^{26}$ Marines Ferreira, Coordenadora de Meio Ambiente de Brasiléia (AC), foi entrevistada no dia 31 de janeiro de 2011, na Coordenadoria de Meio Ambiente da Prefeitura de Brasiléia.
} 
sumidouros não são adequados nesta região devido à baixa profundidade do lençol freático em diversos bairros, onde ocorre, muitas vezes, o afloramento do lençol freático em função das cheias do rio Acre. Observa-se também a presença de esgoto e resíduos sólidos nas valas utilizadas para a drenagem das águas pluviais, o que contribui para a contaminação da água (MATTOS e IMAI, 2006).

O município de Assis Brasil também apresenta problemas em relação aos recursos hídricos do rio Acre, como apontado pelo Secretario de Planejamento da Prefeitura de Assis Brasil Edmilson Lopes Pereira Junior e pelo Secretario de Meio Ambiente Manoel Vicente Mendonça ${ }^{27}$, tais como o assoreamento, a ausência de mata ciliar nos igarapés e nascentes, o desaparecimento da fauna aquática como os quelônios e jacarés, a inexistência da época de defeso nos países fronteiriços, e as secas drásticas dos últimos anos. Afirmaram que a cidade de Assis Brasil é abastecida em 99\% pelo Departamento Estadual de Águas e Saneamento (DEAS) e, apenas uma área, com cerca de 40 casas, ao longo da BR-317 no município ainda não era abastecida por esse sistema. Não há coleta nem tratamento de esgoto no município, apesar de a FUNASA ter financiado a construção de fossas sépticas, ainda assim a maioria dos domicílios despeja o esgoto diretamente ao rio. Para reverter esse quadro a Prefeitura elaborou um Projeto de Saneamento para a coleta e tratamento de esgoto em parceria com a FUNASA, orçado em 6 milhões de reais, a ser financiado com recursos do PAC. Em relação aos resíduos sólidos a cidade possui um lixão e coleta diária de lixo, mas o lixão está localizado próximo a um igarapé, onde há risco de contaminação dos recursos hídricos. A Prefeitura ainda não havia encontrado um lugar adequado para a construção de um aterro sanitário, pois o terreno que havia sido cotado não foi considerado apto e não foi autorizado pelo Instituto de Meio Ambiente do Acre (IMAC).

A cidade gêmea de Assis Brasil é Iñapari, no Peru, que conta com abastecimento de água por meio de poços e captação de água em nascentes que é levada para um reservatório e distribuída na área urbana, e não conta com uma rede de coleta e nem tratamento de esgoto, conforme relatado por Jorge Honorato Pita Barra ${ }^{28}$, Gerente de Meio Ambiente da Municipalidad Provincial de Tahuamanu, em Iñapari. Havia um acordo com uma empresa responsável pelo saneamento da cidade, mas com a nova

\footnotetext{
${ }^{27}$ A entrevista com Secretario de Planejamento Edmilson Lopes Pereira Junior e com o Secretario de Meio Ambiente de Assis Brasil (AC) Manoel Vicente Mendonça ocorreu no dia 02 de fevereiro de 2011, na Prefeitura de Assis Brasil.

${ }^{28}$ A entrevista com o Gerente de Meio Ambiente prof. Jorge Honorato Pita Barra ${ }^{28}$ da Municipalidad Provincial de Tahuamanu, em Iñapari (Peru), ocorreu no dia 02 de fevereiro de 2011, em Iñapari.
} 
administração da municipalidade, o acordo foi desfeito e o saneamento voltou a ser responsabilidade do município.

Como a bacia do Rio Acre é transfronteiriça e compartilhada por três países, é preciso compreender o quadro institucional e jurídico da gestão dos recursos hídricos nestes países. Só então será possível entender os desafios e esforços conjuntos para a governança desta bacia compartilhada. A seguir serão estudas as políticas de gestão dos recursos hídricos nas escalas nacionais e estaduais/departamentais.

\title{
3.4 Arcabouço institucional da gestão dos recursos hídricos na Bolívia
}

A primeira e única Lei de Águas da Bolívia foi a Lei de Domínio e Aproveitamento de Águas de 1906. Trata-se de um decreto que foi promulgado em 1879 e elevado a lei em 1906:

\begin{abstract}
la ley de aguas en Bolivia regulaba el derecho de aprovechamiento del recurso en calidad de concesión o autorización. Sin embargo, no existía un sistema que permitiera registrar debidamente los derechos de agua que se hubieren otorgado. En caso de litigio, los interesados debían recurrir a inscripciones de propiedad de herencia y de propiedad de terrenos (Hendriks 2006). Por esa fuerte ligación entre títulos de propiedad de tierra y derechos de agua se consideraba implícitamente que el derecho de acceso al agua era transferible entre privados, siempre y cuando ello no afectara la lógica de derechos colectivos sobre un determinado sistema (ORÉ, 2009, p. 93-94).
\end{abstract}

Outra norma importante foi o Regulamento de Águas para Irrigação, estabelecido pelo Decreto Supremo ${ }^{\circ}$ 21067, em 1967, que regulava a concessão da água para a irrigação e a criação das Juntas de "Regantes"29, e também determinava como de domínio público as águas subterrâneas e encarregava as municipalidades de conceder as permissões para a construção de poços (ORÉ, 2009).

Na década de 1990 ocorrem mudanças importantes no contexto político da Bolívia que afetam a regulação dos usos da água. Uma das mudanças se refere ao maior reconhecimento dos direitos coletivos e dos povos indígenas no país com a ratificação da Convenção $169^{30}$ da Organização Internacional do Trabalho (OIT) e com as reformas constitucionais de 1994, pelas quais a Bolívia passou a ser definida como um Estado multiétnico e pluricultural. Também são estabelecidas novas leis setoriais que tratam de

\footnotetext{
${ }^{29}$ Organizações de camponeses que utilizam e gerenciam sistemas de irrigação.

30 A Convenção ${ }^{\circ} 169$ sobre povos indígenas e tribais foi adotada, em 1989, na $76^{\text {a }}$ Conferência Internacional do Trabalho e revê a Convenção n ${ }^{\circ} 107$ : "os conceitos básicos que norteiam a interpretação das disposições da Convenção são a consulta e a participação dos povos interessados e o direito desses povos de definir suas próprias prioridades de desenvolvimento na medida em que afetem suas vidas, crenças, instituições, valores espirituais e a própria terra que ocupam ou utilizam” (OIT, 2011, p. 7).
} 
aspectos relacionados à gestão dos recursos naturais, como a Lei de Meio Ambiente de 1992. Foram elaborados projetos e anteprojetos de uma nova Lei de Águas por diversas instituições e também houve grande mobilização de diferentes setores da sociedade civil, como organizações indígenas, organizações camponesas, redes e plataformas.

Neste contexto político marcado também pelos conflitos relacionados à privatização dos serviços de água e saneamento em Cochabamba e El Alto é que foi elaborada a nova legislação sobre a irrigação e a criação de novas instituições para o gerenciamento dos recursos hídricos na Bolívia. A mobilização social resultante do fracasso dos processos de privatização das águas iniciados na década de 1990 em vários países latino-americanos e do agravamento de um quadro de exclusão hídrica, atingiu de forma intensa a Bolívia, gerando conflitos violentos. A "guerra da água" em Cochabamba, no ano 2000, foi o conflito resultante da mobilização da população contra a empresa Aguas del Tunari pelo aumento das tarifas de água, e o mesmo tipo de conflito ocorreu em El Alto, no ano de 2004, contra a empresa Aguas del Illimani. Os objetivos da luta social eram a defesa de uma gestão coletiva e pública dos serviços de água e a proibição de sua privatização, a defesa do direito humano a água, onde esta estaria situada entre um bem comum e um bem público (ACHI, 2010). Além desses movimentos sociais rechaçarem as políticas neoliberais de privatização e mercantilização da água, que foram discutidas no primeiro capítulo, eles também estavam direcionados contra as grandes empresas transnacionais que tem dominado o mercado da água no mundo, pois a Aguas del Tunari era uma subsidiária da Brechtel, e a Aguas del Illimani pertencia à Suez Lyonnaise des Eaux.

A Lei de Descentralização Administrativa, de 1994, e a Lei de Participação Social, de 1995, também afetaram o processo de gestão, pois concedeu maior poder e funções aos municípios, bem como estabeleceu mecanismos para a participação social nos processos de desenvolvimento em sua localidade (ORÉ, 2009). A Lei de Recondução da Reforma Agrária, conhecida como Lei INRA n ${ }^{\circ}$ 1715/1996, também é importante por ter definido as Terras Comunitarias de Origen, reconhecendo às comunidades indígenas suas terras e autonomia para geri-las (ACHI, 2010).

No final da década de 1990, é aprovada a Lei 2029/1999 de Serviços de Agua Potável e Esgoto, mas que foi modificada pela Lei de Água Potável e Saneamento ${ }^{\circ}$ 2066 de 2000 que introduziu a proteção aos sistemas autogeridos para consumo humano, mas ainda permitia a concessão e protegia os interesses do setor privado. Este marco jurídico foi reformado com a adoção da nova Constituição Política do Estado 
(CPE), aprovada em 2009, e de novas regulamentações que criaram a Autoridade de Fiscalização e Controle Social de Água Potável e Saneamento (AAPS), substituindo a antiga Superintendência de Água e Saneamento Básico. A AAPS está vinculada ao Ministério de Meio Ambiente e Água (MMAyA) como uma instituição técnica e operativa que fiscaliza, controla, supervisiona e regula as atividades de Água Potável e Saneamento Básico, de acordo com as leis 2066, 2878 e a CPE.

Uma nova Lei de Irrigação foi aprovada em 2004, a Lei de Promoção e Apoio ao Setor de Irrigação ${ }^{\circ}$ 2878, que só entrou em vigor em 2006 no governo do presidente Evo Morales a partir da promulgação dos regulamentos que permitiram sua operacionalização e outorgava assessoria jurídica às comunidades indígenas (ORÉ, 2009). Na opinião de Gentes e Ruiz (2008), esta lei foi um dos processos de construção legal com maior participação dos atores locais do setor de recursos hídricos. O processo de consulta e elaboração da lei envolveu diversas organizações populares, camponesas, indígenas e ONGs, mas, principalmente, as organizações de regantes ${ }^{31}$ :

\begin{abstract}
mediante este cuerpo normativo, las iniciativas emprendidas por las organizaciones rurales han logrado incorporar un régimen de derechos de agua favorables para comunidades y familias campesinas e indígenas, y principios para establecer políticas públicas y comunitarias. No obstante, la normativa existente tiende a privilegiar y favorecer determinados grupos de derechotenientes, según el momento de su aprobación, sin constituir una respuesta a los problemas estructurales - de erosión, salinización e ineficiencia en el uso, entre otras - por los que atraviesa el país. También para el sector hídrico cuenta que debería ser la Ley General de Aguas la norma que defina los incentivos concretos dirigidos a aplicar la GIRH a nivel local, y no una ley sectorial que además otorga al Viceministerio de Riego potestades de control e intervención, por ejemplo, en las cabeceras de cuencas (2008, p. 48).
\end{abstract}

A Lei de Irrigação atendeu às demandas sociais do momento de sua elaboração, como a garantia de uma segurança jurídica do uso social da água contra as iniciativas de sua mercantilização e reconhecimento dos direitos coletivos e dos povos indígenas de autogestão de seus recursos hídricos e sistemas de irrigação. No entanto, esta lei deixou alguns aspectos da gestão sem regulação, tais como o registro por parte do Estado dos detentores de direitos para o uso da água (ACHI, 2010, p. 89). Entre outros aspectos:

- La ley no considera el reto de una mayor equidad en el acceso al agua mas, el reconocimiento de los usos y costumbres de los actuales detentores de derechos al agua congela a la dinámica de permanente conflicto para que excluidos del agua puedan acceder a ella.

\footnotetext{
${ }^{31}$ Regante é uma palavra da língua espanhola que se refere ao camponês que utiliza e gerencia sistemas de irrigação, e é um termo muito utilizado nos países latino-americanos de língua espanhola como Bolívia, Peru, e Equador.
} 
- La ley sobredimensionaría la capacidad de los usos y costumbres como mecanismo de resolución consensuada de los conflictos dentro de un sistema y entre sistemas en espacios más grandes como la cuenca.

- Con la irrevocabilidad del registro, el Estado no podría sancionar la constitución de mercados de agua; tampoco se prevé mecanismos para enfrentar un posible cambio de uso del agua (urbanización).

La ley presume que cualquier sistema comunitario es ambientalmente sustentable a priori (ACHI, 2010, p. 90).

As mobilizações da sociedade boliviana das últimas décadas por mudanças na gestão dos recursos hídricos levou a criação do Ministério da Água, em 2006, pelo presidente Evo Morales. Nos anos 2007 e 2008 também foi estabelecida a Assembleia Constituinte com o intuito de elaborar a nova Constituição.

O Ministério da Água foi estabelecido pelo Decreto Supremo $n^{\circ} 28.631$, entretanto, ele foi reformulado pelo Decreto Supremo n 29894 de fevereiro de 2009, a partir do qual este passa a ser o Ministério de Meio Ambiente e Água (MMAyA). Desde sua criação o Ministério esteve trabalhando na elaboração de uma nova lei de agua chamada de "Água para a Vida" a partir de um processo de construção participativo com diferentes atores da sociedade civil (ACHI, 2010, p. 90).

O Decreto de 2009 estabelece a subdivisão do MMAyA em: Vice ministérios de Água Potável e Saneamento Básico, Vice ministério de Recursos Hídricos e Irrigação, e Vice ministério de Meio Ambiente, Biodiversidade e Mudanças Climáticas. O Vice ministério de Recursos Hídricos e Irrigação está subdivido em uma Direção Geral de Irrigação e uma Direção Geral de Bacias e Recursos Hídricos, que tem como objetivo executar programas e projetos de gerenciamento integrado de bacias.

A gestão integrada das bacias hidrográficas contou com um instrumento técnico e financeiro para sua implementação, o Programa Nacional de Bacia. Os investimentos neste programa alcançaram os 4.298.486 dólares no período 2005-2006, dos quais 1.991.070 dólares foram aplicados em projetos nas bacias amazônicas (DIAZ, 2007). Este programa contou com o financiamento de organismos internacionais e agências de desenvolvimento. O Plano Nacional de Bacia (PNC - Plan Nacional de Cuenca) também conta com o financiamento externo. Para conseguir este tipo de financiamento o governo deve se adequar ao modelo de gestão integrada dos recursos hídricos por bacia hidrográfica utilizado por essas instituições internacionais como já foi discutido no primeiro capítulo deste trabalho. O governo alemão, por exemplo, financiou vários projetos relacionados à gestão de bacias na Bolívia, nos últimos vinte anos, e assessorou o MMAyA na implementação do PNC (HEILAND e BAUDACH, 2010). 
Com a nova CPE aprovada em 2009, a tendência de reconhecimento dos direitos coletivos e dos povos indígenas se reforçou com a definição da Bolívia como um Estado plurinacional. A CPE trouxe inovações para a gestão da água no país, pois estabeleceu o direito humano à água. A partir de então a Bolívia se tornou um ator fundamental para a promoção e aprovação da Resolução da Assembleia Geral das Nações Unidas nº 64/292 de 2010, intitulada o direito humano a água e ao saneamento, que foi abordada no primeiro capítulo deste trabalho.

A CPE estabeleceu que o acesso universal e equitativo aos serviços básicos de água potável e esgoto é um direito humano e não pode ser objeto de concessão e privatização. O Estado é o responsável por prover esses serviços à população em todos os níveis de governo por meio de entidades públicas, mistas, cooperativas ou comunitárias, desde que contem com mecanismos de participação e controle social. A gestão da água também é responsabilidade do Estado, mas se respeita os usos e costumes das comunidades e organizações indígenas e camponesas em seu direito de autogestão no uso da água:

\begin{abstract}
por un lado, esta disposición marca la victoria de la concepción del agua como un bien comunitario sobre la visión del agua como bien público, en el marco de una revolución institucional: la autonomía jurisdiccional de los pueblos indígena originario campesinos (Art. 30). Esta disposición apuesta por que las instancias comunitarias, caracterizadas por su descentralización y sus formas de participación directa y de control social, sean los mejores garantes de un derecho fundamentalísimo para la vida cuya instancia pública, caracterizada por su centralización y por un ejercicio del poder representativo - cuando no es dictatorial, como en el pasado - a lo mejor ya demostró su falibilidad frente a la captación, por parte de intereses elitistas, y a tentación de mercantilizar el agua (ACHI, 2010, p. 101).
\end{abstract}

Os movimentos camponeses e indígenas, enquanto rechaçam a ingerência legal na gestão interna dos sistemas de água comunitários e tradicionais, adotam uma estratégia para sua relação com os atores externos que inclui a defesa do acesso à água contra outros setores e usos poderosos, a capitação de investimento público e o direito a participar em instâncias oficiais de decisão. Devido às dificuldades para a incorporação dos usos e costumes dessas comunidades em uma lei nacional, outra estratégia compreende manter-se na ilegalidade, o que apresenta um alto risco, pois, na ausência de segurança garantida pela lei, as mobilizações nas ruas são o único instrumento para se defender (ACHI, 2010).

Ao assegurar o direito das comunidades indígenas e camponeses de gerir seus recursos conforme seus usos e costumes, implica que o recurso água: 
puede ser explotado o manejado de manera excluyente aun por un grupo comunitario amparado por sus usos y costumbres. En este sentido, la nueva Constitución Política del Estado parece pecar con la mismo candidez que el campo académico cuando tiende a idealizar la armonía comunitaria y a negar el conflicto y las divisiones de clases, género, ectcétera, dentro de los sistemas comunitarios, entre sistemas comunitarios, o entre un sistema comunitario e actores externos (usuarios del agua potable en particular) (ACHI, 2010, p. 101).

Por isso, estas novas instituições para a gestão dos recursos hídricos na Bolívia indicam avanços, principalmente, ao reconhecer os direitos comunitários dos camponeses e indígenas, mas não resolvem todos os conflitos pelo acesso e uso da água que incluem também os problemas ambientais relacionados ao uso, tais como a contaminação hídrica (por exemplo, pelo uso de fertilizantes e defensivos agrícolas), a salinização, a erosão e o assoreamento de cursos d'água, que tem impactado grande parte do país.

Além das instituições nacionais, na escala local, os municípios se encontram incapacitados para cumprir suas funções de gestão ambiental, que vão aumentando e passaram a incluir novas responsabilidades como o controle florestal, o cadastro de prédios rurais, a administração de áreas protegidas locais, entre outros. No entanto, o que se observa é que os prefeitos priorizam ações que aumentem a sua popularidade como a manutenção de parques urbanos, ao invés de se preocuparem como uma gestão integral do ambiente. A falta de capacidade técnica nas instituições, principalmente, municipais, é compensada em parte pelas ONGs que conseguem recursos financeiros da cooperação internacional e contam com um melhor quadro técnico: su principal aporte ocurre a nivel local, asesorando la formulación de
políticas diferenciales o la elaboración de instrumentos técnicos que
contribuyan a la aplicación legal. Pero su presencia ocurre en el marco de la
"lógica de su proyecto" que está dirigido a "producir resultados" sectoriales y
dejan de lado una análisis sustentativa e una estrategia para la "cultura de
cambio". En el área de conservación, a pesar de la retórica sobre la
"participación", la mayoría de las iniciativas aún se verifican de arriba hacia
abajo, dirigidas por enfoques externos que ven a la población local como
parte del problema y no como parte de la solución (RUIZ e GENTES, 2008,
p. 51).

As dificuldades da governança dos recursos hídricos na escala local na Bolívia estão além da falta de técnicos e recursos financeiros, pois requer também mecanismos de participação e controle social. A seguir será discutido o contexto institucional da gestão dos recursos hídricos no Departamento de Pando, localizado no extremo norte da Bolívia. 


\subsubsection{Instituições e a gestão dos recursos hídricos em Pando}

O Departamento de Pando, Bolívia, foi criado em 1938 por decreto supremo. Ele tem uma extensão de $63.827 \mathrm{~km}^{2}$ e uma população com cerca de 52.525 habitantes, e tem como capital Cobija. Este departamento é praticamente todo coberto por florestas, o que explica as atividades econômicas estarem voltadas para o setor florestal, sendo as principais delas o extrativismo da castanha e da borracha e a exploração madeireira (BRITO, 2007; PEREIRA, 2007).

A área urbana corresponde a $153 \mathrm{~km}^{2}$ (apenas $0,24 \%$ da superfície total da área do departamento), o restante corresponde a área rural com $62.106 \mathrm{~km}^{2}(97,32 \%$ da área total). Isto indica que Pando é essencialmente um departamento rural onde a concentração urbana está basicamente em Cobija e em outras poucas localidades que ou são capitais de províncias ou municipais (ROJAS, 2010). Apesar do crescimento da urbanização em Pando, apenas $40 \%$ de sua população vive na capital Cobija e outras concentrações urbanas (OOSTEN, 2004).

O departamento de Pando, assim como o restante do território boliviano, passou por reformas para a descentralização do Estado boliviano. Em Pando apesar da Lei do Diálogo Nacional que permitia o planejamento participativo, esta não conseguiu atingir seus objetivos. A coordenação entre o governo de Pando e as prefeituras é deficiente, assim como a aplicação dos recursos municipais (BRITO, 2007). Depois que Cobija se tornou a capital do Departamento o setor público cresceu e Cobija ganhou importância como resultado do processo de descentralização. O gasto público passou a ser responsável pelo rápido crescimento da cidade, influenciada pela migração da área rural para a urbana, mas também especialmente pelos imigrantes vindos da região andina em busca de melhores condições econômicas (OOSTEN, 2004).

A economia de Pando esteve sempre baseada na floresta. Desde o começo do ciclo da borracha ele tem sido um provedor de matérias-primas que era enviado para Riberalta para ser processado. A base da economia foi inicialmente a exploração da borracha, mas, atualmente, a exploração da castanha tem sido um dos pilares da economia em Pando. No entanto, recentemente a produção de madeira tem se aumentado e ganhado importância. Apesar de Riberalta pertencer ao departamento de Beni e não à Pando, com seus 60.000 habitantes, ela é importante para a economia de Pando, pois é onde se processa e vende a produção de castanha. Riberalta tem um base 
industrial importante e um significado histórico no processamento da borracha e castanha explorados em Pando (OOSTEN, 2004).

A produção agrícola em Pando é incipiente, porém a pecuária vêm crescendo e já conta com cerca de 47.000 cabeças de gado e 342 estabelecimentos. Ainda é um número muito menor se comparado com o Acre, que têm na pecuária uma de suas principais atividades econômicas, e um rebanho de mais de 2 milhões de cabeças de gado (BRITO, 2007).

Até recentemente uma das principais questões políticas em Pando era a propriedade da terra. A reforma agrária do anos 1950 não teve muito impacto na parte amazônica do território boliviano. Foi somente em 1996 que a distribuição e a propriedade da terra se tornou uma política em Pando e dez anos depois recebeu um novo impulso por meio da reforma agrária que beneficiou, principalmente, as comunidades de camponeses e indígenas. Foi estabelecido que a propriedade agrária por família seria de 500 ha. Isto foi decidido depois de um processo de consulta e discussão que levou em consideração as necessidades das famílias para o extrativismo da castanha e outros produtos florestais. Pando foi o primeiro Departamento a terminar a distribuição e propriedade de terras, depois da criação da Comissão de Resolução de Conflitos, e já identificou 182 comunidades camponesas e indígenas (ROJAS, 2010).

De acordo com César Aguillar, representante da ONG Herencia, em entrevista realizada em Cobija, no dia 28 de janeiro de 2011, a principal dificuldade para a gestão de águas na Bolívia é a cultura política, pois com a troca de governo nas eleições as autoridades e todo o quadro técnico do governo sofrem alterações, o que leva a uma mudança na política e projetos que estavam sendo realizados. Portanto, não há uma continuidade dos projetos e da visão sobre o tema dos recursos hídricos. Tanto César Aguillar com a ONG Herencia fazem parte da Iniciativa MAP e da iniciativa de gestão dos recursos hídricos transfronteiriços da Bacia do Alto Rio Acre.

Aguillar afirmou que a Iniciativa MAP convidou o Ministério de Meio Ambiente e Água para participar das reuniões sobre o rio Acre, porém a instituição não mostrou interesse. Para Aguillar, o Ministério não tem experiência em trabalhar com as bacias hidrográficas na Amazônia, pois está voltado para as situações de escassez de água no Altiplano, por isso a Bacia Amazônica não é uma prioridade do governo nacional, somente em relação ao aproveitamento energético.

Os serviços públicos na região, como, por exemplo, de água e saneamento, são deficientes, especialmente nas zonas rurais. A urbanização recente e não planejada 
resultou em cidades onde o acesso aos serviços sociais é insuficiente, tal como ocorre em Cobija (BRITO, 2007). As iniciativas para a gestão dos recursos hídricos em Pando se concentraram no município de Cobija, na Bacia do Arroyo Bahia que é um afluente do rio Acre e abastece grande parte da população da cidade.

Entre 2009 e 2010 o Centro Agua, da Universidade Mayor de San Simon (UMSS) em um convênio com a ONG Conservação Internacional - Bolívia e o Programa Amazônico Trinacional (financiado pela Embaixada do Reino dos Países Baixos), realizou um estudo de diagnóstico socioambiental da Bacia do Arroyo Bahia, a partir de outros estudos já existentes realizados pela ONG Herencia, Natura e SERGEOTECMIN, e de trabalhos de campo. Este diagnóstico foi a base para a elaboração de um Programa de Ações Estratégicas (PAE), que propõe ações específicas para uma gestão integral da bacia (CENTRO AGUA, 2010).

Neste estudo foi diagnosticado como os dois principais problemas em relação à gestão da água a sua má qualidade e baixa disponibilidade, entendida como acesso a rede pública de distribuição de água potável. De acordo com o estudo, apesar da existência de muitos usuários e usos para os recursos hídricos da bacia, nenhum destes usos está regulado e controlado. Na zona rural da bacia não existe nenhum tipo de associação para o abastecimento de água, sendo realizado de forma individual (CENTRO AGUA, 2010).

A Empresa Pública Social de Agua (EPSA) de Cobija tem uma cobertura urbana de distribuição de água potável de $68 \%$ e de coleta de esgota de $40 \%$. De acordo com este estudo (CENTRO AGUA, 2010), a captação de água do Arroyo Bahia para o abastecimento está a jusante, praticamente na desembocadura do Arroyo Bahia, por isso, recebe água de todos os afluentes e também esgoto das casas, além do efluente proveniente do lixão da cidade. Outros problemas a infraestrutura e a manutenção da planta de tratamento e as fugas da rede que interrompem o abastecimento ou geram a baixa pressão da mesma. Desde meados de 2009 a planta de tratamento de água da cidade se tornou pequena para tratar e abastecer a demanda crescente da cobertura urbana de Cobija. Para Franco (2010), a água que sai da planta de tratamento é de boa qualidade e apta para o consumo humano, o problema que gera a sua contaminação é a rede de distribuição que devido ao seu mau estado de conservação permite a contaminação e a água que chega para a população não é potável, o que resulta em novos gastos por parte da população para torna-la potável novamente. Assim: 


\begin{abstract}
La empresa privada encargada de la prestación del servicio de agua en Cobija presenta una serie de deficiencias y problemas técnicos, económicos e institucionales que no le permiten brindar un servicio de calidad a los usuarios de Cobija, aspectos tales como la mala instalación de la red de cañerías que hacen que esta se contamine, la falta de control y mantenimiento de dicha red y los instrumentos que conforman la misma, las deficiencias en la entrega y distribución de agua mediante cisternas a los pobladores que viven alejados de la red de distribución entre otros han ocasionado que los habitantes de la cuidad de Cobija opten por no cancelar sus facturas de agua, realicen instalaciones clandestinas para proveer de agua, tengan que gastar mayores recursos económicos para obtener agua potable en botellas, deban comprar garrafas de GLP a precios elevados con la finalidad de hervir el agua para consumirla, entre otras acciones más, para poder finalmente acceder a agua para el consumo (FRANCO, 2010, p. 5).
\end{abstract}

O PAE para a gestão integrada da Bacia do Arroyo Bahia identificou doze ações prioritárias: 1) apoio a constituição de um Organismo Gestor de Bacia; 2) promoção do planejamento concertado e racional do território; 3) proteção da floresta na área da bacia; 4) proteção das fontes de água; 5) melhoramento do sistema de água potável e saneamento de Cobija; 6) gestão de resíduos sólidos; 7) educação ambiental; 8) criação de um sistema de informação como suporte à gestão da bacia; 9) criação de uma programa de pesquisa sobre a bacia; 10) criação de um programa de capacitação em Gestão Integrada de Recursos Hídricos (GIRH) para a bacia; 11) criação de um programa de monitoramento ambiental; 12) disposição final das águas residuais na bacia. De acordo com a Plataforma Setorial do Plano Nacional de Bacia do governo boliviano, consta como um projeto parte deste Plano o "Manejo Integral da Bacia do Arroyo Bahia",32 (PNC, 2013).

Este diagnóstico e o PAE foram formulados sem considerar o caráter transfronteiriço dos recursos hídricos da Bacia do Arroyo Bahia, que faz parte da Bacia do rio Acre, e envolve também parte do território do Brasil e do Peru.

\title{
3.5 Arcabouço institucional da gestão dos recursos hídricos no Brasil
}

A institucionalização da gestão dos recursos hídricos no Brasil nasceu atrelada ao setor energético, pois o Código de Águas de 1934 apesar de apresentar um escopo de regulação amplo, a criação das instituições para implementar esta regulação foi baseada na regulação da produção de energia elétrica (RAVENA, 2012).

\footnotetext{
${ }^{32}$ A Plataforma Setorial do Plano Nacional de Bacia está disponível: <http://www.cuencasbolivia.org/proyectos/209/manejo_integral_de_la_cuenca_del_arroyo_bahia/50>. Acesso em: maio 2013.
} 
A partir da Constituição Federal Brasileira de 1988 a dominialidade dos corpos de água em território nacional é definida em seu artigo 20, que diz serem de domínio da União os "lagos, rios e quaisquer correntes de água em terrenos de seu domínio, ou que banhem mais de um estado, sirvam de limites, ou se estendam a territórios estrangeiros ou deles provenham bem como os terrenos marginais e as praias fluviais". São de domínio dos estados as águas superficiais e subterrâneas, presentes em seu território, fluentes, emergentes e em depósito, ressalvadas, nesse caso, na forma da lei, as decorrentes de obras da União. E cabe aos municípios a administração dos serviços de abastecimento de água e saneamento. Neste caso brasileiro, de uma federação a dominialidade sobre os corpos de água é divida entre os entes da federação, por isso, torna-se necessária uma articulação entre todos os seus entes federados para a gestão dos recursos hídricos em todo território nacional.

O gerenciamento dos recursos hídricos no Brasil, atualmente, possui um arcabouço institucional recente que teve início com a criação da Política Nacional de Recursos Hídricos (PNRH) pela Lei $n^{\circ} 9.443$ de 1997. A PNRH foi considerada bastante inovadora no país, ao se inspirar no modelo de gestão de águas francês (MARTINS, 2012). Ela instituiu o Sistema Nacional de Gerenciamento de Recursos Hídricos (SINGRH), cuja implementação teve início efetivo com a criação da Agência Nacional de Águas (ANA) no ano 2000. É importante lembrar que a Política Estadual de Recursos Hídricos do estado de São Paulo foi instituída em 1991, portanto, anterior a política nacional, e foi o primeiro estado a avançar na descentralização da gestão e instaurar a bacia hidrográfica como unidade de planejamento e gestão, com a criação de comitês de bacias (MARTINS, 2012).

A ANA está vinculada ao Ministério de Meio Ambiente na condição de uma autarquia sob regime especial, com a função de implementar o SINGRH em parceria com os governos estaduais, municipais, usuários e a sociedade civil (BRAGA et al, 2006). Martins afirma em relação à ANA que ela:

[...] foi criada para dar suporte às atividades operacionais dos comitês de bacias hidrográficas criados no domínio dos rios federais. Sua principal meta era contribuir para a implementação dos instrumentos de gestão da Lei de Águas, com atenção especial ao estímulo à criação de Comitês de Bacias Hidrográficas e à elaboração de estratégias de valoração econômica dos recursos hídricos. A Agência assumiu, portanto, a meta maior de garantir a implementação plena do novo sistema gestor, sendo que o alcance desta meta dependia do entrelaçamento da questão hídrica com suas implicações econômicas (2012, p. 475). 
As instituições que fazem parte do SINGRH são: o Conselho Nacional de Recursos Hídricos (CNRH), a Secretaria de Recursos Hídricos (SRH/MMA), a ANA, os Conselhos de Recursos Hídricos dos estados e do Distrito Federal, os Comitês de Bacias Hidrográficas $(\mathrm{CBH})$ e as Agências de Bacia. Este sistema buscou descentralizar o processo de planejamento e gestão dos recursos hídricos no Brasil e criar mecanismos para a participação da sociedade na gestão dos recursos hídricos.

O CNRH seria o órgão mais elevado na hierarquia do sistema e cuja função seria decidir sobre as grandes questões do setor (MENDONÇA e SANTOS, 2006). Ele conta com Câmaras Técnicas sobre diferentes temas que auxiliam a tomada de decisão do conselho. A Câmara Técnica de Gerenciamento de Recursos Hídricos Transfronteiriços é presidida por um representante do Ministério das Relações Exteriores e conta com a participação de outros Ministérios e da sociedade civil organizada.

Os CBH são entidades deliberativas em que participam governo, usuários e a sociedade civil organizada. Os instrumentos que podem ser usados na gestão dos recursos hídricos pelo $\mathrm{CBH}$ são: os planos de bacia hidrográfica; o enquadramento dos corpos de água; a outorga de direito de uso; a cobrança pelo uso da água; e o sistema de informações sobre recursos hídricos. Os $\mathrm{CBH}$ têm competência para aprovar o plano de bacia e estabelecer os mecanismos de cobrança pelo uso da água.

De acordo com Jacobi , a institucionalização plena instaurada pela nova política de gestão dos recursos hídricos ainda não se completou e os resultados e alcances das experiências onde já se implantaram os $\mathrm{CBH}$ e os instrumentos de gestão tem sido desiguais. Para ele:

\begin{abstract}
Os principais instrumentos de gestão dos recursos hídricos são os planos de recursos hídricos (elaborados por bacia hidrográfica), a outorga do direito do uso da água, a cobrança pela água, o enquadramento dos corpos d'água em classes de uso e o Sistema Nacional de Informação de Recursos Hídricos. A fórmula proposta é uma gestão pública colegiada dos recursos hídricos, com negociação sociotécnica, através dos CBHs (Guivant \& Jacobi, 2003), e se reserva à sociedade civil uma responsabilidade central na condução da política e da gestão dos recursos hídricos. Os usuários da água terão fundamentalmente que se organizar e participar ativamente dos comitês, defender seus interesses quanto aos preços a serem cobrados pelo uso, assim como sobre a aplicação dos recursos arrecadados e sobre a concessão justa das outorgas dos direitos de uso. Obviamente, estes acertos e soluções serão conseguidos a partir de complexos processos de negociações e resolução de conflitos diversos (JACOBI, 2009, p. 45).
\end{abstract}

Os CBH como órgãos colegiados apresentam uma dinâmica que favorece maior transparência na interação entre os atores sociais, porém não elimina a possibilidade de manipulação de interesses por parte do Executivo, o que depende da capacidade de 
mobilização e organização da sociedade civil (JACOBI, 2009). Nestes órgãos o papel dos técnicos ou peritos é muito importante, porque a legislação brasileira criou mecanismo de participação social mas pressupõe que a sociedade civil tem acesso às informações técnicas necessárias para sua participação. Como observa Jacobi:

[...] apesar dos avanços, a lei 9.433/97 coloca em primeiro plano a importância do corpo técnico-científico e do conhecimento produzido por ele nas relações de força no interior dos espaços decisórios da bacia, o que limita o envolvimento da comunidade das atividades dos CBHs. Assim, de fato, mantém o poder decisório entre os que detém o conhecimento técnicocientífico (2009, p. 48).

Norma Valencio (2009) também concorda com Jacobi (2009) ao se referir ao Plano Nacional de Recursos Hídricos, aprovado em 2006 pelo CNRH, que foi apresentado como o fruto de um processo participativo de planejamento, no entanto:

[...] analisando criticamente o referido documento, percebe-se que a problemática socioambiental ali elencada, bem como as diretrizes para seu enfretamento, continuam sob a hegemonia interpretativa de um meio técnico impermeável a concepções de progresso que transcendam a sua própria. [...] A questão central é que, no tocante ao planejamento do PNRH, as interações promovidas não redundaram no estabelecimento de um tipo de participação consistente, fundada numa hermenêutica diatópica, isto é, não foram passíveis de interseccionar argumentos oriundos dos diferentes setores da sociedade (2009, p. 63-64).

Percebe-se que a legislação e a PNRH brasileira tiveram forte influência dos modelos pregados pelas instituições internacionais como a ONU, o GWP, o Banco Mundial, como foi exposto no primeiro capítulo deste trabalho. A política brasileira prevê a gestão integrada por bacia hidrográfica, o que foi impulsionado também pelas instituições de peritos, isto é, pela comunidade epistêmica dos recursos hídricos. Ela também considera a água um bem econômico, cujos serviços a ela relacionados podem ser privatizados, de acordo com as prerrogativas prescritas pelo Banco Mundial. Isto se evidencia na proximidade entre os funcionários da ANA e o Banco Mundial, como apontado por Martins:

no caso brasileiro, em particular, a trajetória dos agentes envolvidos na modernização do sistema gestor das águas indica, portanto, um importante entrelaçamento da questão ambiental com a consolidação da autonomia do campo econômico nas relações de poder em tempo de modernidade. E as relações estabelecidas por agentes e instituições brasileiras com o Banco Mundial tiveram relevância para a partilha de certos juízos e concepções sobre o sistema francês, identificado como modelo de gestão descentralizada e econômica do recurso. Isto é, como modelo de aproximação dos desenhos disciplinares da economia e da engenharia para a gestão ambiental (2012, p. 477).

Assim: 
[...] a reprodução do discurso de gestão racional da água, sustentado no diagnóstico de sua relevância econômica contemporânea, relaciona-se também com uma ordem institucional que envolveu, por exemplo, corporações com instituições multilaterais - caso do Banco Mundial. Mas deve-se, sobretudo, ao reconhecimento dos agentes no discurso (como gestores, técnicos, engenheiros e/ou economistas) e à capacidade destes agentes em transformar o mesmo discurso em recurso de poder, calçando situações de distinção social na nova gestão democrática e participativa da água (2012, p. 486).

Ribeiro (2009), ressalta que, apesar das dificuldades em implementar a participação social de forma democrática com a inserção dos grupos marginalizados na gestão dos recursos hídricos no Brasil, a existência dos CBHs já é um passo importante, pois "permite a capacitação da sociedade para a cidadania. Resta agora capacitar os governos para serem mais permeáveis às vozes da sociedade” (p. 129).

Nos estados da Amazônia brasileira percebe-se um esforço para a regulação do uso dos recursos hídricos a nível estadual, pois:

\begin{abstract}
dispõem de leis estaduais sobre gerenciamento de recursos hídricos na Região Hidrográfica Amazônica, os estados de Mato Grosso, Lei n 6.945 de 05 de novembro de 1997; Pará, Lei $n^{\circ}$ 6.381, de 25 de julho de 2001; Amazonas, Lei $\mathrm{n}^{\circ} 2.712$, de 28 de dezembro de 2001; Rondônia, Decreto $\mathrm{n}^{\circ}$ 10.114, de 20 de setembro de 2002; Amapá, Lei n ${ }^{\circ}$ 0686, de 07 de junho de 2002; e Acre, Lei $\mathrm{n}^{\circ} 1.500$, de 15 de julho de 2003. O estado de Roraima ainda não possui estabelecida sua política estadual, que está em fase de amadurecimento para posterior aprovação (MAGALHÃES e BARP, 2009, p.182).
\end{abstract}

Em todas estas leis estaduais está prevista a existência de um Conselho Estadual de Recursos Hídricos e Comitês de Bacias. Somente alguns estados, no entanto, optaram pelas Agências de Água, outros incorporaram o regime de autarquia das Agências de Água. No geral, as políticas estaduais de recursos hídricos dos estados amazônicos contém os mesmos instrumentos da PNRH: com exceção da compensação a municípios, que foi objeto de veto na
aprovação da Lei 9.433/97 e que foi previsto na Lei do Pará e Amapá. Por
outro lado, os estados do Amazonas, Rondônia, Acre e Amapá previram um
Fundo de Recursos Hídricos como organismos de suporte financeiro de suas
políticas estaduais. Outra particularidade encontrada e que mostra uma
diferença entre a Lei Nacional de Água e as leis estaduais de recursos
hídricos da Região Hidrográfica Amazônica foi a inclusão da gestão das
águas subterrâneas nos Estados do Pará, Amazonas, Mato Grosso, Rondônia,
Acre. Somente o Estado do Amapá não incluiu gerenciamento das águas
subterrâneas em sua lei de recursos hídricos (MAGALHÃES e BARP, 2009,
p.182).

Alguns instrumentos de gestão da legislação federal são de difícil implementação na região amazônica, como o pagamento pelo uso da água, devido à sua abundância, na maior parte dela. Outra dificuldade é a criação de comitês em bacias de 
grande extensão territorial, bem como a definição de usuário com relação à população ribeirinha. Os estados amazônicos localizados na faixa de fronteira também têm dificuldades para a criação de comitês, pois muitas de suas bacias hidrográficas são de rios internacionais, o que exigiria comissões bi ou tri-nacionais, como é o caso do estado do Acre.

\subsubsection{Instituições e gestão dos recursos hídricos no Acre}

O estado do Acre é maior em extensão do que os Departamentos de Madre de Dios e Pando, pois tem $152.581 \mathrm{~km}^{2}$ de área. Conta ainda com 22 municípios, uma população estimada (2007) de 655.385 habitantes e densidade demográfica de aproximadamente 0,3 habitantes por $\mathrm{km}^{2}$ (IBGE, 2008b). Sua população é majoritariamente urbana $(70 \%)$ e a capital, Rio Branco, concentra praticamente a metade da população de todo o estado. Quase a metade de seu território é composta por áreas protegidas, tais como unidades de conservação e terras indígenas (IBGE, 2008b).

O estado do Acre passou por muitas mudanças ao longo de sua história, de território boliviano à brasileiro, estas mudanças afetaram a sua organização territorial, bem como as condições de sua população. No período do ciclo da borracha, sua população era composta por, basicamente, indígenas e imigrantes de outras regiões que passaram a trabalhar como seringueiros, e demais trabalhos relacionados à produção da borracha. Com a decadência da borracha o estado do Acre e sua população são "abandonados" pelo governo nacional até meados da década de 1970 quando o governo federal criou incentivos fiscais para atrair investimentos nacionais e estrangeiros para a região amazônica, incluindo o estado do Acre.

Estes incentivos levaram a uma migração de brasileiros de outras regiões para o estado, o que gerou uma forte especulação e concentração de terras, levando à expulsão de parte da população de posseiros e ex-seringueiros para as cidades em situações precárias de existência. Os imigrantes que chegaram converteram uma parte das terras para a criação de gado, e a outra parte continuou com o mesmo sistema dos seringais particulares. (BEZERRA, 2006; DUARTE, 1987).

A situação dos seringueiros e posseiros ficou cada vez mais difícil e aumentaram os conflitos destes com os fazendeiros recém-chegados. Os seringueiros se organizaram para lutar pela posse da terra, um dos líderes deste movimento foi Chico Mendes. O 
resultado desta luta foi a criação da modalidade de unidade de conservação da Reserva Extrativista, que garantia o uso da terra para os seringueiros (ALLEGRETTI, 1994).

No estado do Acre existem também diversas etnias de populações indígenas, inclusive populações isoladas que não tem contato com a FUNAI. Atualmente existem quatorze povos indígenas no estado do Acre e trinta e cinco Terras Indígenas (TI), das quais vinte e quatro são regularizadas, duas homologadas, uma delimitada, uma declarada e sete em estudo (FUNAI, 2007).

Com incentivo do governo federal foi dado um passo importante no planejamento territorial do estado do Acre com o Zoneamento Ecológico Econômico (ZEE) que foi criado através do decreto estadual n. 503 de abril de 1999, que instituiu o Programa Estadual de Zoneamento Ecológico-Econômico do Acre. Este programa ficou sob a coordenação da Secretaria de Estado de Planejamento e Desenvolvimento Econômico-Sustentável, e como secretaria executiva a Secretaria de Estado de Meio Ambiente e Recursos Naturais, e como órgãos executores o Instituto de Meio Ambiente do Acre e a Fundação de Tecnologia do Estado do Acre.

A primeira fase do programa foi iniciada em 1999 para a realização do diagnóstico do território do estado do Acre, que resultou em produtos cartográficos na escala de 1:1.000.000. Esta fase possibilitou compilação de um conjunto de informações para a tomada de decisões para o ordenamento territorial do estado e também trouxe subsídios para elaboração de projetos e programas como: o Programa de Desenvolvimento Sustentável do Acre (com recursos do Banco Interamericano de Desenvolvimento) e o Programa de Gestão Ambiental Integrada (PGAI/ SPRN, com o financiamento da cooperação alemã), entre outros.

Além disso, o ZEE forneceu instrumentos para a regularização de TI, e contribuiu para a criação da Lei Estadual Florestal (n. 1.426 de 27 de dezembro de 2001) que estabelece o Sistema Estadual de Áreas Naturais Protegidas (SEANP), com a criação de UC que integram o Corredor do Oeste da Amazônia (do PPG7), e da Lei Estadual n. 1.500 de 2003 que instituiu a Política Estadual de Recursos Hídricos. O ZEE também produziu trabalhos educativos como o "Guia para o Uso da Terra Acreana com Sabedoria", realizado pelo IMAC, em parceria com a Secretaria de Estado de Educação e uma equipe técnica contratada pela WWF - Brasil.

A segunda fase do ZEE teve como um dos seus principais resultados o Mapa de Gestão Territorial do Estado do Acre, na escala 1:250.000, que foi elaborado com o cruzamento dos eixos Recursos Naturais, Sócio-economia e Cultural-político. O Mapa 
de Gestão Territorial pode servir como instrumento para a formulação de diretrizes para a gestão de áreas já destinadas formalmente, como, por exemplo, de assentamentos rurais, terras indígenas, entre outras, e espaços territoriais ainda sem destinação específica. Este mapa estratifica o território acreano em quatro grandes zonas: Zona 1 de consolidação de sistemas de produção sustentáveis; Zona 2 de uso sustentável dos recursos naturais e proteção ambiental; Zona 3 de áreas prioritárias para o ordenamento territorial; Zona 4 de cidades florestais.

Em relação aos recursos hídricos o Acre conta com uma Política Estadual de Recursos Hídricos, Lei n. 1500, de 15 julho de 2003, e um Plano Estadual de Recursos Hídricos concluído em 2012. Em comparação com a legislação federal de recursos hídricos:

\begin{abstract}
o Estado do Acre apresenta uma particularidade com relação ao regime institucional adotado, instituindo uma Câmara Técnica de Recursos Hídricos no Conselho Estadual de Meio Ambiente, Ciência e Tecnologia do Acre, um organismo com poderes de Conselho Estadual de Recursos Hídricos. Observa-se que a Política Estadual de Meio Ambiente do Acre incorporou a Política Estadual de Recursos Hídricos, principalmente no que tange aos instrumentos e o sistema de gerenciamento (MAGALHÃES e BARP, 2009, p.182).
\end{abstract}

O Conselho Estadual de Meio Ambiente, Ciência e Tecnologia (CEMACT) do Acre foi criado em 1992 e é o "órgão colegiado deliberativo e normativo, que integra o Sistema Estadual de Meio Ambiente, Ciência e Tecnologia - SISMACT, na condição de órgão superior" (AMEIDA, REIS e SILVA, 2009, p. 24). Faz parte do CEMACT a Câmara Técnica de Recursos Hídricos que é o órgão colegiado responsável por "apreciar tecnicamente todas as matérias dependentes de deliberação do CAMACT, inclusive propondo solução para conflitos entre os integrantes do Sistema Estadual de Recursos Hídricos e entre usuários de recursos hídricos" (AMEIDA, REIS e SILVA, 2009, p. 25).

Em 2007 o gabinete dos senadores Tião Viana e Sibá Machado elaborou um Plano de Recuperação da Bacia do rio Acre para ser implementado de forma participativa e integrada numa parceria entre os atores sociais, governos municipais, estadual e federal. Este Plano levou a assinatura de um Pacto para a recuperação da Bacia hidrográfica do Rio Acre assinado entre o gabinete dos senadores e o município de Brasiléia. Neste mesmo ano a Secretaria Estadual de Meio Ambiente (SEMA) foi reestruturada com a criação de novos departamentos, entre eles o Departamento de 
Águas e Recursos Hídricos, composto pela Divisão de Gestão de Bacias Hidrográficas e a Divisão de Monitoramento da Qualidade da Água.

De acordo com o Plano Estadual de Recursos Hídricos do Acre (PERH):

A Política Estadual de Recursos Hídricos delineada pela Lei Estadual n. 1500/2003 está diretamente vinculada à Política Estadual de Meio Ambiente. Está inserida no Sistema Estadual de Meio Ambiente, Ciência e Tecnologia (Sismact), prevista na Lei Estadual n. 1.117, de 1994 e em conformidade com a Lei Federal n. 9433, de 1997. Para o Acre, este arranjo representou um significativo avanço em termos de gestão integrada dos recursos hídricos (SEMA, 2012, p. 48).

No PERH o estado do Acre foi dividido em seis Unidades de Gestão de Recursos Hídricos (UGRH): UGRH Acre-Iquiri, UGRH Abunã, UGRH Alto Juruá, UGRH Taruacá, e UGRH Envira-Jurupari. A outorga de direito de uso da água no Acre é realizada pelo Instituto de Meio Ambiente do Acre (IMAC), por meio da Resolução n. 4 de 17 de agosto de 2010 do CEMACT, que regula a concessão de outorga provisória e direito de uso dos recursos hídricos no estado.

De acordo com a técnica de meio ambiente Maria Marli ${ }^{33}$, da SEMA, esta Secretaria, após a criação da legislação estadual de recursos hídricos em 2003, trabalhou na formulação do Plano Estadual de Recursos Hídricos (PERH), que contou com uma metodologia de participação social e com um Grupo de Trabalho Institucional que incluía o grupo da professora da Universidade Federal do Acre (UFAC) Vera Reis e da Secretaria de Recursos Hídricos e Urbanos (SRHU) do Ministério de Meio Ambiente. O financiamento do diagnóstico foi feito pelo BID e o prognóstico contou com o financiamento da SRHU. A participação social para a elaboração do PERH ocorreu a partir de um processo de validação do diagnóstico dos recursos hídricos do estado, e do prognóstico por meio da criação de um Grupo de Trabalho e uma Comissão Técnica, e de Grupos de Trabalho Regional, para cada UGRH, formados por representantes dos municípios do estado, por usuários e por membros da sociedade civil. Estes grupos proporcionaram subsídios para a construção do Plano. O prazo para a implementação do Plano é 2030 para o qual foram construídos três cenários: 1) águas insustentáveis; 2) águas no limite; 3) águas sustentáveis. O Plano prevê, entre outras ações, a criação de um Sistema de Informação em Recursos Hídricos que reúna informações para formatar um banco de dados georreferenciados por UGRH (SEMA, 2012).

\footnotetext{
${ }^{33}$ A entrevista com a técnica Maria Marli da SEMA foi realizada no dia 24 de janeiro de 2011, em Rio Branco, no Acre.
} 
A primeira tentativa de criação de um Comitê de Bacia Hidrográfica no estado do Acre foi no Igarapé Judia, localizado entre as cidades de Rio Branco e Senador Guiomar. As águas deste Igarapé são utilizadas para abastecer uma pequena parte do da área urbana de Rio Branco. No entanto, este abastecimento deveria acabar nos próximos anos, pois o Igarapé já encontra-se contaminado acima do recomendado para o sistema de tratamento para o consumo humano, de acordo com o que foi informado pela técnica em 2011. A área da bacia deste Igarapé conserva apenas 8\% de mata ciliar, o que provocado o assoreamento do mesmo. A principal atividade econômica na área da bacia é a criação de gado, trata-se do maior polo de gado leiteiro do estado do Acre. Nesta bacia ocorre ainda a utilização e comércio de água subterrânea. Um dos motivos para este igarapé ter sido escolhido para a criação de um Comitê se deve ao fato de que não se trata de um rio internacional, abastece a cidade de Rio Branco e já encontra-se com um grau de degradação preocupante.

Foi criado um Conselho Gestor da bacia do Igarapé Judia que conta com 15 instituições, e como ele é paritário participam cinco instituições da sociedade civil, cinco do governo e cinco são usuários. A ideia na época de sua criação era transformar este conselho no primeiro comitê de bacia do estado do Acre, mas teria que ser aprovado pelo Conselho Estadual de Meio Ambiente e sua Câmara Técnica de Recursos Hídricos.

Em 2011 já haviam sido elaborados três Planos de bacia para afluentes do rio Acre que previam instrumentos de participação social. Para Maria Marli da SEMA, é mais fácil para o governo do Acre trabalhar para a criação de comitês de rios que estão totalmente no estado do Acre pois não envolve organismos federais, pois, no caso de rios que atravessam fronteiras entre estados e rios transfronteiriços como é o caso do rio Acre, estes pertencem a União e exigem a participação da ANA nos comitês. Por isso, a SEMA está trabalhando primeiramente com rios estaduais e com o reflorestamento de matas ciliares por meio de projetos financiados pelo Fundo Nacional de Meio Ambiente. Como a área da Bacia do Alto rio Acre está gravemente desmatada e com fazendas de gado, muitas nascentes e igarapés estão secando, por isso, a prioridade e necessidade do trabalho de recuperação das matas ciliares de nascentes e igarapés tanto em propriedades rurais como também na área urbana, principalmente nos novos loteamentos.

O tratamento e a distribuição de água potável no estado do Acre são feitos pelo Departamento Estadual de Águas (DEAS), que tem uma outorga junto ao Instituto de 
Meio Ambiente do Acre (IMAC). O DEAS está presente nos 22 municípios do Acre, incluindo a capital Rio Branco. O DEAS trabalha com base em uma demanda social pois inclui municípios que não permitiriam o ganho de lucro, já que a obtenção de lucro só pode ser atingida em municípios com mais de 5.000 habitantes e com uma clientela de mais de 1.000 clientes. Para o engenheiro Julio Mattos ${ }^{34}$, do DEAS, a ANA trabalha com uma política de escassez que direciona a prioridade de sua atuação, portanto, a Amazônia não é uma prioridade para esta instituição. Ele explica que, neste sentido de trabalhar pensando na disponibilidade de água, não existe no país um Plano para gerenciamento e mitigação de enchentes. A demanda pela atuação do DEAS nos municípios do interior da Acre está aumentando, pois muitos começaram a elaborar os seus Planos Municipais de Saneamento já que agora existe recursos por parte do governo federal do PAC, Mattos informou que em 2011 foram 12 municípios.

Mattos também apontou um tipo de conflito que tem ocorrido pelo uso dos recursos hídricos em Rio Branco, tratou-se de um conflito industrial onde dois frigoríficos, que utilizam as águas do Igarapé Belo Jardim, precisavam se adequar frente a legislação de recursos hídricos e as resoluções do Conselho Nacional de Meio Ambiente (CONAMA) quanto aos efluentes jogados no rio, e também devido ao grande volume de água captado pelas empresas, que na época de estiagem se torna quase inviável, pois reduz a quase zero o caudal do corpo d'água. Este tipo de conflito poderia se intensificar com a iniciativa de criação de Zonas de Produção de Exportação, como uma proposta para a área da Bacia do Alto rio Acre, levantada pelo governo estadual, com linhas de montagem e o incremento do parque industrial.

Para Mattos, a principal dificuldade para a gestão dos recursos hídricos transfronteiriços da Bacia do rio Acre é a compatibilização das legislações de recursos hídricos e a adoção de um Índice de Qualidade Ambiental (IQA) comum entre os três países que compartilham a bacia. Atualmente, o saneamento no estado do Acre que estava um pouco paralisado ganhou novo impulso com os recursos do governo federal que irá financiar alguns projetos de saneamento no estado do Acre, através da FUNASA, mas seria necessário que os outros países também contassem com projetos de saneamento, principalmente nas áreas de concentração populacional.

\subsection{Arcabouço institucional da gestão dos recursos hídricos no Peru}

\footnotetext{
${ }^{34}$ A entrevista com o engenheiro Julio Mattos do DEAS foi realizada no dia 24 de janeiro de 2011 na sede do DEAS em Rio Branco, Acre.
} 
A primeira lei de águas do Peru foi o Código de Águas de 1902, e neste período os grandes fazendeiros da costa e da serra detinham o controle da água no setor agrícola. Nos anos seguintes ocorreu uma maior intervenção do Estado e a criação de novas normas e instituições. Em 1969 foi promulgada a Lei de Reforma Agraria e a Lei Geral de Águas, pela qual o Estado assumiu o controle das terras e da água. O Ministério da Agricultura foi designado como autoridade de águas, por meio de seu Instituto Nacional de Recursos Naturais (INRENA). Desde então a gestão de águas foi se fragmentando e nove ministérios chegaram a ter funções relacionadas com os recursos hídricos sem nenhuma coordenação entre eles

Nos anos 1990, no governo de Fujimori, foi estabelecida a Lei de Promoção Agrária que modificou vários aspectos da Lei de Águas de 1969, enfraquecendo as instituições encarregadas da gestão dos recursos hídricos e várias de suas funções foram transferidas para as organizações de regantes (ORÉ, 2009). Em 1991 também foi promulgado um decreto legislativo que permitia o investimento privado nos serviços de água potável e saneamento por meio da modalidade de concessões. Estes serviços foram transferidos para as municipalidades provinciais sem planejamento adequado de suas capacidades para assumir esta função. A quebra das empresas municipais abriu caminho a sua privatização. A partir deste quadro:

\footnotetext{
Los organismos internacionales ejercieron presión para modificar la Ley General de Aguas. Desde 1993 hasta alrededor del año 2000 se elaboraron cerca de quince anteproyectos de Ley. La intención era manifiesta: crear derechos "reales" de agua que pudieran transferirse de manera independiente del predio y dar lugar a la formación de un mercado de aguas. La oposición de las organizaciones de regantes y los cambios en las orientaciones de la política internacional impidieron concretar estos planes (ORÈ, 2009, p. 52$53)$.
}

O processo de descentralização que começou a partir de 2003, com a Lei Orgânica de Governos Regionais, estabeleceu que a gestão sustentável dos recursos naturais e o melhoramento da qualidade ambiental são competências compartilhadas entre o governo nacional e os departamentos. Em 2008 foi criado o Ministério de Meio Ambiente, substituindo o Conselho Nacional de Meio Ambiente (CONAM) como órgão executivo máximo deste setor.

A alteração da legislação e das instituições responsáveis pela gestão dos recursos hídricos ocorreu finalmente com a criação da Autoridad Nacional de Aguas (ANAPeru) pelo Decreto Legislativo n. 997 de 2008. A Lei de Recursos Hídricos, n. 29338, 
foi aprovada em 31 de março de 2009, e estabeleceu o Sistema Nacional de Gestão dos Recursos Hídricos (SNGRH), do qual fazem parte: a ANA-Peru, o Ministério de Meio Ambiente, Ministério da Agricultura, Ministério da Vivienda, Construção e Saneamento, Ministério da Saúde, Ministério de Produção, Ministério de Energia e Minas, as entidades públicas vinculadas com a gestão dos recursos hídricos, instituições dos governos regionais e locais, os Conselhos de Bacias, as entidades de operadores dos sistemas hidráulicos públicos e privados de caráter setorial e multi-setorial, comunidades camponesas, comunidades indígenas e as organizações de usuários de água agrárias e não-agrárias. A delimitação das Unidades Hidrográficas do país foi aprovada pela Resolução Ministerial n. 033-2008-AG em 2009.

A Lei de Recursos Hídricos estabeleceu que a água tem valor sociocultural, valor econômico e valor ambiental, e que seu uso deve estar baseado na gestão integrada e no equilíbrio entre estes valores. Também estabeleceu que o Estado crie mecanismos de participação dos usuários e da sociedade civil organizada nas decisões que afetem os recursos hídricos. Instituiu o respeito aos usos e costumes das comunidades camponesas e nativas e seu direito de utilizar os recursos hídricos em suas terras, desde que não se oponham a lei.

A ANA-Peru, autoridade máxima do SNGRH, é um organismo anexo ao Ministério da Agricultura e responsável por ditar as normas e estabelecer os procedimentos para a gestão integrada dos recursos hídricos. A estrutura orgânica da ANA-Peru é composta por: órgãos de Alta Direção (Conselho Diretivo, Chefia, e Secretaria Geral), órgãos de Controle Institucional, órgãos jurisdicional administrativos, órgãos de assessoramento, órgãos de apoio, órgãos de linha (Direção de Gestão do Conhecimento e Coordenação Interinstitucional, Direção de Administração de Recursos Hídricos, Direção de Conservação e Planejamento de Recursos Hídricos e Direção de Estudos de Projetos Hidráulicos), e órgãos desconcentrados que são as Autoridades Administrativas de Água (AAA) e as Administrações Locais de Água (ALA).

De acordo com a ANA-Peru, "las AAA establecidas en cada una de las demarcaciones hidrográficas, constituyen las unidades operativas y funcionales para efectos de la gestión integrada y multisectorial de los recursos hídricos en el país" (2010, p. 33). O país apresenta três vertentes hidrográficas (Pacífico, Atlântico e Titicaca) e foi dividido em 159 unidades hidrográficas pela ANA-Peru, que exerce suas funções de forma desconcentrada em suas 14 AAAs, cinco na Região Hidrográfica do Pacífico, oito na Região Hidrográfica do Amazonas, e uma na Região Hidrográfica do 
Titicaca. Dentro das AAAs se encontram as ALAs que são suas unidades orgânicas que administram as águas de uso agrário e não-agrário em seus âmbitos territoriais que podem incluir mais de uma unidade hidrográfica e devem ser aprovadas por resolução ministerial (ANA-Peru DCPRH, 2011).

Os Conselhos de Bacias são organismos de natureza permanente vinculados à ANA-Peru e criados pelos Governos regionais por meio de decretos supremos, para que possam participar de seu planejamento, gestão e coordenação do aproveitamento e uso dos recursos hídricos. Os Conselhos podem ser de duas classes: Conselho Regional (quando a bacia está integralmente no território de um só governo regional), ou Conselho Interregional (quando a área da bacia abarca o território de mais de um governo regional) (DOUROJEANNI, 2009).

As organizações de usuários são de três níveis: Juntas de Usuários, Comissões de Usuários e Comitê de Usuários. A Junta Nacional de Usuários dos Distritos de Irrigação do Peru é uma organização que representa os usuários de uso agrário a nível nacional.

Nos últimos anos a ANA-Peru vem realizando estudos sobre as Unidades Hidrográficas e as principais bacias hidrográficas do país para a formulação de atividades e estratégias de gestão dos recursos hídricos, e entre eles realizou durante o ano de 2010 um diagnóstico sobre a bacia do rio de Madre de Dios, que será analisado a seguir.

\subsubsection{Instituições e gestão dos recursos hídricos em Madre de Dios}

O departamento de Madre de Dios no Peru tem uma extensão de aproximadamente $85.063 \mathrm{~km}^{2}$, uma população de 109.555 habitantes (no ano 2007) e uma densidade demográfica de 1,29 habitantes por $\mathrm{km}^{2}$. Dentro dele a chamada "Intercuenca Alto Acre", que corresponde a Bacia do rio Acre em território peruano", tem uma superfície de $2.492 \mathrm{~km}^{2}$, uma população estimada em 2007 de 1.288 habitantes e uma densidade demográfica de 0,52 habitantes por $\mathrm{km}^{2}$ (ANA-PERU DCPRH, 2011). Cerca de $62 \%$ da população total do departamento vive na capital, Puerto Maldonado, e $70 \%$ são migrantes das terras altas. Mais da metade de seu território é declarado como reserva nacional, como a Reserva Nacional Tambopata e o Parque Nacional Manu, considerado Patrimônio Natural da Humanidade pela UNESCO (BRITO, 2007; PEREIRA, 2007; LA TORRE, 1998). 
A partir da década de 1960 foi descoberto ouro e petróleo neste departamento, o que impulsionou ainda mais a imigração de pessoas vindas de outras partes do Peru. Na década de 1980 a imigração de lavradores de ouro aumentou não só pela alto do preço do ouro, mas também devido às novas tecnologias que permitem aumentar a produção, trata-se das balsas-dragas, que ainda hoje continuam sendo empregadas (CTAR-Madre de Dios e IIAP, 2001).

A exploração de petróleo em Madre de Dios começou no final da década de 1960, atingindo seu auge entre os anos 1973-1987, quando foram perfurados dez poços exploratórios pelas empresas Cities Service, Andes Petroleum, Shell e International Petroleum Company, que acabaram se retirando da área (LA TORRE, 1998). Em 1996 o governo peruano assinou um contrato de licença com um consórcio formado pelas empresas Mobil, Exxon e ELF Aquitaine para realizar operações de exploração de hidrocarbonetos nos lotes 77 e 78 totalizando uma área de quase três milhões de hectares. O lote 77 se sobrepõe as terras dos indígenas yora, amahuaca e mashco-piro, e a grupos isolados o que resultou diversos conflitos (LA TORRE, 1998).

Atualmente, o Departamento conta com quatro lotes concessionados, os lotes 111 e 113 à empresa Sapet Development Peru Inc, Sucursal Peru, subsidiária da empresa China National Petroleum Corp, o lote 76 cuja concessão é da empresa Hunt Oil Company of Peru L.L.C., Sucursal do Peru e o lote 157 que está concessionado para a estatal Perupetro. O lote 113 se sobrepunha a "Reserva Territorial de Pueblos Indígenas em Aislamiento de Madre de Dios" o que levou a Federação Nativa do rio Madre de Dios e Afluentes (FENAMAD) começar uma campanha para a exclusão da área da reserva do Lote 113. A área deste lote abarca as cabeceiras das Bacias do rio Acre, Tahuamanu, parte das Bacias de las Piedras e Alto Madre de Dios. Em 2005 a empresa concessionária do lote declarou que se comprometia a não explorar a área correspondente a reserva e no ano seguinte é promulgado um decreto do governo peruano excluindo a reserva da área do Lote 113. No entanto, o lote 111 que abarca parte das Bacias do Acre, Tahuamanu. Médio Madre de Dios e Tambopata, também se sobrepõe à área da reserva (ANA-Peru DCPRH, 2011).

A exploração madeireira é uma atividade importante no Departamento que começou com a exploração de três espécies mais valiosas como o cedro, e conforme estas espécies foram se esgotando outras começaram também a ser utilizadas:

En toda la región la extracción maderera se ha incrementado desde 1992, pasando de una producción de 8 millones de pies tablares en ese año a un promedio de 25 millones de pies tablares en los últimos años 
(GESUREMAD, 1998). Lo que representa cerca del 7\% de la producción maderera nacional. Es previsible que en la medida en que mejoren las carreteras de interconexión hacia otros departamentos, esta actividad se dinamice substantivamente. Aunque de seguirse su aprovechamiento en la forma actual, se incrementará también los problemas socioambientales regionales derivados de su aprovechamiento desordenado (CTAR-Madre de Dios e IIAP, 2001, p. 29).

Entre os produtos florestais não-madeiráveis explorados no departamento, destaca-se a seringa e a castanha, tal como no lado brasileiro e boliviano. A expansão agrícola desde os anos 1950 estava concentrada ao longo das vias fluviais e com a construção da estrada Cusco-Pilcopata-Shintuya na década de 1960 a frente agrícola se expande também ao longo das vias terrestres (CTAR-Madre de Dios e IIAP, 2001). De acordo com o diagnóstico da ANA-Peru, na Bacia do rio Acre em território peruano predomina a atividade produtiva da pecuária bovina associada à produção agrícola para subsistência e a produção madeireira com a presença de centros de transformação primária da madeira. Neste diagnóstico também é afirmado que espera-se que a produção agrícola no departamento aumente com a finalização da Estrada do Pacífico (ANA-PERU DCPRH, 2011).

Por ser uma área remota do país e com ausência de instituições do Estado, o Departamento de Madre de Dios foi ocupado por ações da guerrilha "Sendero Luminoso", o que resultou em um alto nível de ilegalidade na área. Neste período uma parte da economia no departamento estava dedicada a atividades ilegais. Esta situação de pouca influência do governo e da existência de atividade ilegais contribuiu para obstruir a formação de organizações sociais e governança regional. A partir dos anos 1990 este quadro foi se alterando com a criação de sistemas de governos regionais democráticos e de um processo de planejamento do desenvolvimento regional participativo (OOSTEN, 2004).

Neste período de aumento de atividades ilegais no Departamento, a produção de coca e cocaína se intensificou, mas atualmente a área plantada de Coca é maior no Departamento de Puno, vizinho à Madre de Dios (BRITO, 2007; ANA-Peru DCPRH, 2011).

Durante o ano de 2010 a ANA-Peru em parceria com a ALA Maldonado realizou um estudo de diagnóstico da gestão dos recursos hídricos na Bacia Hidrográfica do rio Madre de Dios. Este estudo abarcou a área do Departamento de Madre de Dios, bem como uma parte dos Departamentos de Puno e Cusco, o que incluiu a área da Bacia 
do rio Acre, embora este não pertença à Bacia do Madre de Dios. Este diagnóstico concluiu que:

\begin{abstract}
-las características químicas-biológicas de las aguas en el horizonte del período de estudio muestran altos valores en coliformes y nutrientes, que pueden limitar su uso en el futuro como agua potable y de recreación, por los procesos de eutrofización que han generado.

-la calidad del agua en la cuenca del Río Madre de Dios se encuentra deteriorada y en otros casos con riesgos de deterioro y su utilización podría ser restringida para algunos otros usos. La principal fuente de alteración son las aguas servidas y los releves mineros que dan lugar a una contaminación evidente y visible a la percepción visual, la cual podría ser confirmada con las muestras de análisis que registren los laboratorios autorizados.[...] -por la magnitud de la exploración y explotación de oro en la mayor parte del área de estudio, se recomienda el análisis químico de metales pesados, a efecto de determinar la existencia de metales pesados en el agua y en el bentos y también se debe realizar análisis sedimentométricos. [...]

-con el objetivo de proteger la salud de las personas, afrontar la problemática social e incentivar la economía del departamento de Madre de Dios, Cusco y Puno se deben aprobar medidas que permitan el aprovechamiento sostenible y ordenado de los recursos naturales, que propicien una mayor recaudación fiscal a favor del financiamiento de inversiones públicas orientadas especialmente a la recuperación de las áreas afectadas por la actividad sostenible; y, a evitar la desvalorización de su patrimonio natural (ANA-Peru DCPRH, 2011, 161-162).
\end{abstract}

A contaminação e a degradação causadas pela exploração de ouro são consideradas os piores problemas relacionados aos recursos hídricos no Departamento de Madre de Dios. O engenheiro Jorge Benites, Diretor de Conservação e Planejamento de Recursos Hídricos, e o engenheiro Juan Pablo Salen Miranda Nina, coordenador do estudo sobre a Unidade Hidrográfica de Madre de Dios da ANA-Peru ${ }^{35}$, afirmaram que a exploração do ouro no departamento gerou diversos conflitos de difícil resolução por parte do governo, que cogitou, inclusive, enviar as Forças Armadas para destruírem os maquinários ilegais existentes na área. Um dos desafios é que a atividade mineira aurífera constituiu a principal fonte de riqueza do Departamento cuja produção anual é de cerca de quinze toneladas orçado em aproximadamente um bilhão de soles, o que representa 30\% do PIB departamental. De 1990 a 2005 a área ocupada pela atividade passou de 6.809 para 16.728 hectares e em 2006 haviam 1.993 concessões mineiras.

A tecnologia utilizada nesta atividade inclui as dragas que retiram a areia do leito dos rios e utilizam o mercúrio para separar o ouro dos outros metais finos. $\mathrm{O}$ mercúrio é uma neurotoxina que se ingerida em grandes quantidades pode levar até a morte. Este mercúrio ao ser vertido nos corpos d'água contaminam não só a água mas também toda a fauna aquática e os peixes que são consumidos em grande quantidade

\footnotetext{
${ }^{35}$ Esta entrevista foi realizada em Lima na sede da ANA-Peru no dia 21 de fevereiro de 2012.
} 
pela população local que pode ser contaminada aos consumi-los. Além disso, também pode haver contaminação hídrica pelos combustíveis e óleos utilizados pelo maquinário e também pelos outros elementos químicos utilizados como detergentes, cianureto de sódio, entre outros (LA TORRE, 1998; ANA-Peru DCPRH, 2011).

No momento, as instituições nacionais, ANA-Peru e Ministério do Meio Ambiente, têm auxiliado o Departamento de Madre de Dios na resolução dos conflitos relacionados à mineração ilegal e sua regulação e fiscalização. Entretanto, outros problemas afetam também a gestão dos recursos hídricos na região como a falta de saneamento, principalmente nas áreas urbanas e em Puerto Maldonado, que serão agravados com os planos de construção de hidrelétricas, como a de Inambari. Os conflitos presentes no departamento e o grau de contaminação hídrica evidenciam uma gestão precária dos recursos hídricos.

A partir do quadro institucional dos três países e departamentos/estados onde está localizada a Bacia do rio Acre, se pode visualizar o contexto da gestão de recursos hídricos que incide sobre a bacia. A seguir será discutida a formação de um processo de governança transnacional para a gestão dos recursos hídricos transfronteiriços da Bacia do rio Acre.

\subsection{Formação do processo de governança transnacional da Bacia do rio Acre}

No final da década de 1990 e início do ano 2000, uma mobilização de pesquisadores sobre a Amazônia realizam reuniões no estado do Acre, o que incentivou a participação de pesquisadores das universidades locais como a UFAC e a Universidade de Pando, que se mobilizaram sobre os problemas socioambientais da região. De acordo com esses pesquisadores:

\footnotetext{
em 2000 durante o workshop sobre "Indicadores de Usos da Terra" em Rio Branco-AC, com a participação de instituições da Bolívia, Brasil e do Peru surgiu o nome MAP (Madre de Dios/ Peru, Acre/ Brasil, Pando /Bolívia), caracterizando-se como a primeira reunião MAP (MAP I). O segundo workshop sobre "Avaliação ambiental estratégica ocorreu em Puerto Maldonado, Madre de Dios -Per-, em abril de 2001 (MAP II) e contou com a participação de 75 pessoas (REIS e RIOS, 2007, p. 129).
}

Assim formou-se a Iniciativa MAP:

que não é um setor do poder público nem uma organização nãogovernamental, nem instituição pública ou privada. É um grupo de pessoas bolivianas, brasileiras e peruanas interessadas em gerar situações que levem a evitar problemas sociais ou a mitigar os existentes na região (FRANCISCO, 2007, p. 21). 
A Iniciativa MAP está organizada em encontros anuais, denominados Fóruns MAP, e em grupos de trabalhos que são chamados de "mini-MAPs". Eles tratam de questões especificas e são gerenciados por um representante de cada um dos três países. Os mini-MAPs estão divididos em quatro grandes temas: eqüidade social, conservação ambiental, desenvolvimento econômico e políticas públicas. Dentro do tema conservação ambiental foi criado o mini-MAP bacias.

Durante o III fórum MAP, em 2002, surgiu a proposta de um Programa de Gestão Integrada da Bacia Trinacional do Alto Rio Acre de demandas apresentadas pelas comunidades regionais dos três países da Região MAP, em 2002, no III Fórum MAP, realizado pela Iniciativa $\mathrm{MAP}^{36}$, em Cobija. Este fórum teve como objetivo principal o fortalecimento das ações colaborativas e de integração regional, cujo documento final apresenta como Recomendação (n. 8): “priorizar el plan trinacional de manejo integral de la Cuenca del Rio Acre como punto de partida para la protección de las otras cuencas hidrográficas, cursos y cuerpos de água de la Región MAP" (MINIMAP BACIA, 2007, sem página). A partir desta reunião foi realizado um levantamento preliminar da realidade socioambiental da bacia.

Este diagnóstico, que evidenciou os principais problemas socioambientais existentes na bacia, despertou o interesse dos governos locais para a resolução de problemas comuns transfronteiriços de forma conjunta. O Comitê Bi-fronteiriço Assis Brasil-Iñapari $^{37}$ encaminhou uma carta consulta a Organização do Tratado de Cooperação Amazônica (OTCA) solicitando informações sobre a formação de um Comitê Trinacional da Bacia do Alto Rio Acre (REIS e RIOS, 2007). Todavia, apesar da OTCA ter enviando um representante para acompanhar as atividades, nada de concreto, ou de apoio técnico ou financeiro foi oferecido pela organização para nenhuma atividade da Iniciativa MAP.

\footnotetext{
${ }^{36}$ A Iniciativa MAP é um movimento informal da sociedade civil que congrega organizações e grupos sociais, bem como governos municipais dos três países (Bolívia, Brasil e Peru).

${ }^{37}$ Este Comitê foi criado em 1999 por meio de um Acordo, por troca de Notas, para a criação de Comitês de Fronteira $\mathrm{n}^{\circ}$ 186, entre Brasil e Peru. Conforme consta no acordo: "[...] os Comitês de Fronteira deverão atuar como instâncias prévias do Grupo de Trabalho da Comissão de Vizinhança Brasil-Peru sobre Cooperação Amazônica e Desenvolvimento Fronteiriço ou de outros Grupos de Trabalho, em função da temática de que trate, de forma a resolver, no âmbito local, e quando legalmente habilitados para tanto, questões do interesse das suas respectivas comunidades fronteiriças. O primeiro desses mecanismos operativos atenderá às localidades fronteiriças de Iñapari-Assis Brasil, podendo-se, futuramente, estabelecer comitês semelhantes em outras áreas de fronteira em que se julgue conveniente" (DAI-MRE, 2013).
} 
De acordo com Professora Dra. Vera Reis ${ }^{38}$, da Universidade Federal do Acre, a participação da OTCA nas atividades da Iniciativa MAP sempre foi incipiente. No início da iniciativa foi enviada uma carta à OTCA solicitando sua participação na Oficina sobre a gestão do rio Acre realizada em 2006. A Iniciativa tinha a esperança de que a OTCA pudesse guiá-los e fornecer subsídios para a cooperação na gestão conjunta da Bacia do rio Acre. Isto, no entanto, não ocorreu, apesar da participação da Secretariageral da OTCA na época, Rosalia Arteaga, não houve maior incentivo por parte da organização. Na opinião da profa. Vera Reis isso se deve ao fato de que a OTCA depende sempre da aprovação dos países-membros para a realização de projetos e atividades, além do que, não possui técnicos suficientes para prestarem assistência e nem recursos financeiros suficientes para dar suporte a iniciativas deste tipo, só para a realização de projetos específicos.

Em 2003, começou a ser elaborado o Programa de Gestão Integrada da Bacia Trinacional do Alto Rio Acre, quando também foi criado o Consórcio de Desenvolvimento Intermunicipal do Alto Acre e Capixaba (CONDIAC). O CONDIAC começou a funcionar oficialmente em 2004 juntamente com a estruturação da Comissão de Integração Regional e Internacional.

A criação de um Comitê Trinacional seria o próximo passo para que os consórcios municipais firmassem acordos para atividades na região da tríplice fronteira. Foi então proposta a criação do Comitê dos Municípios de Fronteira da Região MAP que será referido neste trabalho como Comitê Trinacional. Este comitê seria formado por um grupo de cinco municípios de cada país, no Brasil pelo CONDIAC (municípios de Assis Brasil, Brasiléia, Capixaba, Epitaciolândia e Xapuri), na Bolívia pela MANCOMUNIDAD TAHUAMANU (municípios de Bolpebra, Bella Flor, Cobija, Filadélfia e Porvenir), e no Peru pelo consórcio AMFROMAD (municípios de Iñapari, Ibéria, San Lorenzo, LasPiedras e Puerto Maldonado). Esta proposta contou com o apoio da ANA, da Secretaria Nacional de Recursos Hídricos do MMA, da Conágua, SOS Mata Atlântica, WWF-Brasil, UFAC, Consórcio Lagos São João-RJ. Este comitê também contaria com a participação de representantes dos Ministérios das Relações Exteriores dos três países e de representantes da sociedade civil.

Cabe ressaltar que a experiência do Comitê Bi-nacional Assis Brasil - Iñapari foi relatada como de pouco impacto para a região, pois tem se reunido poucas vezes e,

\footnotetext{
${ }^{38}$ A entrevista com a Professora Dra. Vera Reis, da Universidade Federal do Acre (UFAC), foi realizada em Rio Branco (AC), no dia 25 de janeiro de 2011.
} 
apesar de ser uma oportunidade de trocas de informações, os municípios não tem competência para a realização de muitas ações conjuntas. Este relato foi feito durante entrevistas com funcionários das Prefeituras de Assis Brasil e Iñapari realizadas durante a pesquisa de campo em janeiro de 2011.

No quinto Fórum MAP, realizado em 2004, em Puerto Maldonado (Peru), foi assinado um Convênio Marco entre instituições dos três países para desenvolver e implementar atividades e projetos de pesquisa e de desenvolvimento sustentável, promover a troca de informações sobre a região, entre outros objetivos. As instituições envolvidas no convênio (Universidade Federal do Acre, Instituto Nacional de Desarrollo, Instituto de Investigación de la Amazônia Peruana, Dirrección Regional de Producción de Madre de Dios, Asociación de Municipalidades de Pando, Interdisciplinaria para el DesarrolloSostenible e Universidad Amazonica de Pando) estabeleceram um Plano de Trabalho para a gestão da Bacia Trinacional do Alto Rio Acre, articulado dentro do mini-MAP bacias. Este Plano envolvia os seguintes subprogramas:

\footnotetext{
- Diagnóstico sócio-econômico e ambiental (cenários e articulação das instituições e atores loais): modelos de recomposição e cenários de evolução da ocupação, uso e aproveitamento da Bacia Trinacional do Alto Rio Acre;

- Plano Piloto de recuperação da vegetação degradada, (Igarapé Encrenca e Igarapé Bahia), envolvendo moradores, técnicos, professores e estudantes;

- Programa de Educação Ambiental: capacitação de multiplicadores (professores, campesinos e ribeirinhos) em ferramentas para gestão de recursos naturais (mapeamento, uso de imagens de satélite e monitoramento de recursos hídricos), para a composição dos quadros locais de vigilância ambiental e manejo de propriedades;

- Monitoramento participativo da qualidade e quantidade de água;

- Manejo e aproveitamento participativo de Pesca/quelônios;

- Fortalecimento Institucional - (oficinas de sensibilização nos municípios de fronteira, estruturação dos Consórcios, legalização do Comitê Trinacional, Agenda 21 local e Agenda 21 regional);

- Realização de campanhas educativas de sensibilização, divulgação e socialização dos resultados;

- Plano de controle de erosão e sedimentação do Rio Acre (MINIMAP BACIAS, 2007).
}

A Iniciativa MAP chegou a construiu uma página na internet, que neste momento não se encontra mais disponível, mas que teve um papel importante para a disponibilização e troca de informações sobre a região MAP e as ações da Iniciativa. O mini-MAP Bacias possuía uma páginal própria vinculado a da Iniciativa. O portal (www.map-amazonia.net) foi criado em 2004 e contou com o apoio da cooperação alemã em um convênio com a ONG Amazonlink (SCHMIDLEHNER, MACUCO e 
REIS, 2007). Uma avaliação sobre este processo de comunicação pela internet conclui que:

\begin{abstract}
-o trabalho de comunicação é de vital interesse para a Iniciativa MAP, ou seja, o processo MAP é na sua essência um ensaio de comunicação.

-o uso da internet é essencial para o futuro da Iniciativa MAP. Não só pela praticidade, eficiência e baixo custo, mas principalmente pela democratização da informação: Direito de Saber e Direito de Participar.

-a viabilização técnica de ferramentas de comunicação on-line não é suficiente. Pessoas precisam se conhecer pessoalmente e reunir-se para que a tecnologia seja adotada e o processo de gestão de conhecimento se inicie.

-vimos que muitos integrantes da Iniciativa MAP não conhecem o portal ou sequer tem acesso à internet. Estas pessoas precisam ser incluídas no fluxo de informação através de outros meios de comunicação.

-os comunicadores sociais da Iniciativa MAP têm um papel decisivo na construção da governança transfronteiriça da região.

-o MAP precisa de estratégias de comunicação (SCHMIDLEHNER, MACUCO e REIS, 2007, p. 67).
\end{abstract}

No workshop realizado em 2006, que contou com o apoio da WWF-Brasil (World Wild Fund) e com a presença de instituições dos três países, o objetivo era discutir os aspectos legais da gestão dos recursos hídricos transfronteiriços na Região MAP. Esta reunião contou com a presença de representantes da ANA, e resultou em um primeiro rascunho sobre as linhas gerais a serem seguidas na gestão da bacia do rio Acre, proporcionando uma articulação da iniciativa MAP com instituições federais do Brasil.

Esta articulação possibilitou a criação de um Grupo de Trabalho (GT) do rio Acre, apoiado pela ANA, que ao ter participado da Oficina de 2006 se sensibilizou com o tema e a mobilização dos atores sociais e resolveu impulsionar a criação de um GT para a discussão da gestão transfronteiriça do rio Acre. O GT do rio Acre, foi criado em 2006 no Brasil, junto a Câmara Técnica de Gestão de Recursos Hídricos Transfronteiriços (CTGRHT) do Conselho Nacional de Recursos Hídricos (CNRH). Ele conta com a participação de representantes da ANA, do Ministério das Relações Exteriores, do governo estadual, dos governos municipais e de representantes da sociedade civil. Este grupo funcionou até 2010, quando foram encerrados os trabalhos e um relatório foi apresentado à CTGRHT para ser analisado, e ele contém as seguintes recomendações:

O Grupo de Trabalho do Rio Acre, em vista do exposto acima, e com o principal objetivo de contribuir para o desenvolvimento da gestão integrada de recursos hídricos compartilhados entre Brasil, Peru e Bolívia na bacia hidrográfica do Rio Acre, propõe à CTGRHT o seguinte curso de ação: a) envio de moção ao CNRH para mobiliar os atores pertinentes a assinarem acordo trilateral para a gestão integrada da bacia hidrográfica do Rio Acre (Anexo I); b) negociação e assinatura de acordo bilateral nos moldes da proposta apresentada no Anexo II; c) após a assinatura do acordo, realização 
de seminário trinacional para a mobilização dos atores nacionais e locais para a implantação do acordo assinado (SAMPAIO, 2010).

A esperança dos membros da Iniciativa MAP, em especial do mini-MAP bacias era de que esse GT pudesse ser a base para a criação de um Comitê da bacia do rio Acre, pelo menos do lado brasileiro. Nas reuniões que se seguiram foram discutidas e apresentado o diagnóstico sobre a bacia e sobre as legislações ambientais e de recursos hídricos dos países envolvidos, Bolívia e Peru. Na última reunião do GT Acre a professora Vera Reis não pode participar e quem a representou foi o funcionário da SEMA Claudemir Mesquita. Nesta última reunião realizada em setembro de 2010 foi submetido e aprovado o Relatório Final do GT que depois foi submetido à CTRHT e depois ao CNRH.

O GT do Rio Acre apontou como principais conflitos na bacia:
a) a dificuldade de abastecimento urbano e de navegação nas épocas de seca; b) enchentes nas épocas de cheia; c) conflitos sobre a pesca na época da defesa, por disparidade na legislação a respeito nos três países; d) deslocamento do leito do Rio Acre nos meandros ocasionando mudança física nas fronteiras, com a possibilidade de transferência de comunidades inteiras para o país vizinho; e) uso irregular da navegação para transporte de produtos ilegais; f) necessidade de manutenção do caudal ecológico nas épocas de seca (SAMPAIO, 2010).

Na opinião de Claudemir Mesquita ${ }^{39}$, o GT foi uma iniciativa importante, porém dependia da aprovação de outras instituições em um processo que é moroso, principalmente por envolver o MRE. Para ele a Iniciativa MAP teve um papel importante para gerar e difundir informações sobre o rio Acre nos três países, e para a educação ambiental de algumas comunidades e do próprio poder público local. No entanto, ainda não foi possível realizar ações concretas de recuperação da bacia do rio Acre que, em suas palavras, "só ficou no papel".

Elsa Mendonza ${ }^{40}$, que faz parte da ONG Instituto de Pesquisa Ambiental da Amazônia (IPAM), que tem uma forte presença no Acre e em especial na Iniciativa MAP, explicou que o envolvimento do IPAM com a iniciativa de gestão do rio Acre começou no Mini-MAP bacias. No entanto, com o envolvimento do poder público o IPAM passou a trabalhar com outras bacias no estado do Acre, em especial com a bacia do rio Juruá, no norte do estado, onde trabalham com mobilização social das comunidades, como no Igarapé Liberdade. O foco principal do IPAM na região MAP

\footnotetext{
${ }^{39}$ A entrevista com Claudimir Mesquita, que é funcionário da SEMA, foi realizada no dia 25 de janeiro de 2011 na sede da SEMA em Rio Branco.

${ }^{40}$ A entrevista com Elsa Mendonza do IPAM ocorreu em Brasiléia (AC) no dia 27 de janeiro de 2011.
} 
está nos impactos das estradas e em especial da Estrada do Pacífico, onde se pode observar um aumento do desmatamento e o assoreamento de nascentes e igarapés.

Em sua análise sobre a Iniciativa MAP, Oosten (2007) afirma que esta deve ser entendida não como um movimento social, mas como uma aliança multi-setorial, uma aliança de investigação ou política. E este tipo de aliança comporta riscos potenciais, pois agrega atores com interesses muito variados e que investem recursos (financeiros ou humanos) esperando alcançar benefícios comuns. No entanto, isto pode gerar conflito na medida em que cada ator persiga seus interesses e agendas individuais impedindo a busca de um objetivo comum. Outro risco é resultante da assimetria entre os atores, que pode levar o ator mais poderoso a dominar o processo a partir de seus interesses aportando recursos financeiros e humanos, e a perda dos atores que não compartilham os mesmos interesses. Há também o risco de que por trás de um discurso forte dominante da aliança, se ocultem interesses alternativos que geram agendas ocultas de um grupo de atores, o que afetaria a transparência e a credibilidade da aliança.

$\mathrm{Na}$ Iniciativa MAP estes riscos estão presentes, pois é uma aliança que agrega atores de todos os setores da sociedade dos três países da região. No entanto, os participantes estão divididos em quatro temas: conservação ambiental, desenvolvimento econômico, equidade social e políticas públicas, com interesses e discursos diferentes, limitando um debate mais amplo interdisciplinar:

\begin{abstract}
La división en cuatros rubros, divide los participantes y sus alianzas en cuatro grupos de interés, con cuatro discursos diferentes, limitando así el debate intersectorial. Una agenda regional que toma en cuenta las prioridades de grupos de intereses opuestos no es más que una agenda de "hacer-milesflores-florecer", con escenarios de "todo-es-posible" y que no cumplen a las exigencias de una agenda de una región bajo tantas presiones como la Amazonia Suroccidental, que se requiere la toma de decisiones políticas drásticas (OOSTEN, 2007, p. 35).
\end{abstract}

Existe ainda uma assimetria de poder dentro da Iniciativa MAP, pois o grupo da “conservação ambiental" conseguiu apoio da cooperação internacional holandesa e passou a dominar o discurso principal da Iniciativa, ocasionando a saída de alguns grupos locais que não partilhavam do mesmo discurso. Isto demonstra que os interesses internos estão divergindo e ocasionando rupturas. Ainda assim, Oosten aponta a Iniciativa MAP como uma experiência importante, pois:

En la búsqueda de una nueva estructura que pueda llenar el vació de gobernanza transfronteriza, creada y suportada por los pueblos de la misma región y enfocada al manejo de su patrimonio natural compartido, el MAP puede servir como ejemplo importante como proceso participativo, multi- 
actor y multi-sectorial, aun fragmentado, explícitamente enfocado al tema de desarrollo sostenible y con objetivo principal de informar y movilizar a los pueblos de las tres áreas fronterizas, dando cuerpo a una nueva vivencia regional. Considerando que el está llenando el vacío en el manejo democrático de recursos naturales transfronterizos, el MAP tiene importancia vital, y amerita un estudio profundo de su funcionamiento y de sus resultados con el objetivo de ver si la experiencia puede servir a las otras regiones fronterizas en el mundo que igualmente cuentan con grandes recursos naturales, enfrentando la incorporación rápida en las cadenas comerciales globales (2007, p. 36)

Diante deste contexto apresentado neste capítulo não é possível afirmar a existência de um processo de governança transnacional da bacia do rio Acre (Figura 2), trata-se do início de um processo político que pode se tornar uma forma de governança se incluir de mecanismos democráticos de participação social. Esta experiência será comparada com o caso da Bacia do rio Napo, compartilhada entre Peru e Equador que será analisada no capítulo quatro a seguir. 


\section{Figura 3: Governança multi-escalar dos recursos hídricos transfronteiriços da Bacia do rio Acre}

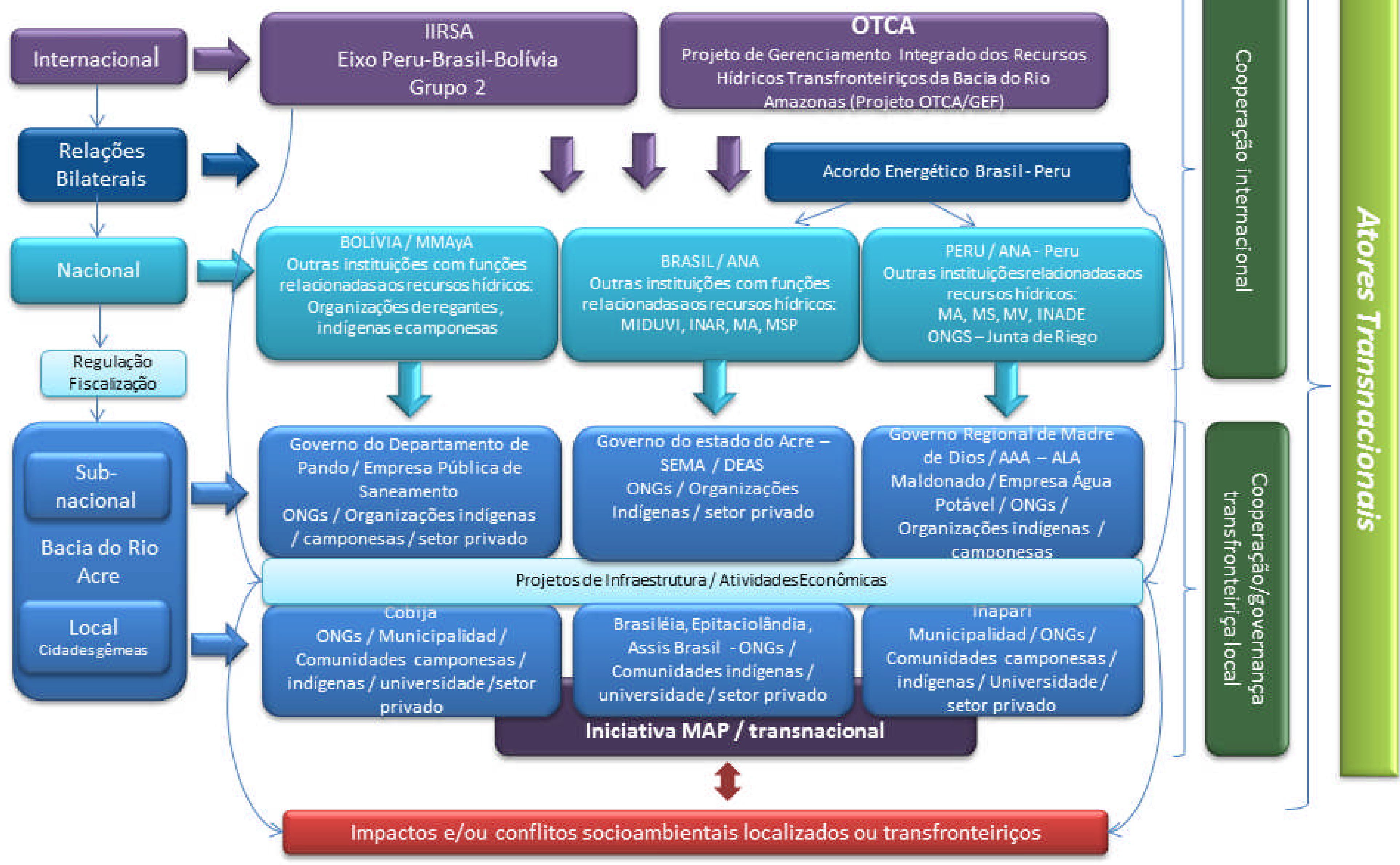




\section{BACIA DO RIO NAPO: CONFLITOS SOCIOAMBIENTAIS E A CONSTRUÇÃO DA GOVERNANÇA}

Este capítulo tem como objetivo analisar os conflitos socioambientais e o processo de construção da governança dos recursos hídricos transfronteiriços na Bacia do rio Napo, que abarca parte dos territórios do Equador e do Peru. O contexto desta bacia transfronteiriça diferencia-se em relação à Bacia do rio Acre devido ao conflito entre os dois países no qual a fronteira foi alvo de disputa por várias décadas, o que dificultou a integração fronteiriça. $\mathrm{Na}$ área da bacia ocorrem conflitos socioambientais relacionados aos usos, e seus efeitos, dos recursos hídricos, dos quais destacam-se: o conflito devido aos impactos das obras de acesso à hidrovia do rio Napo e o melhoramento de sua navegabilidade, o conflito devido à contaminação hídrica resultante da exploração do petróleo e gás natural, o conflito relacionado aos impactos da construção de usinas hidrelétricas e o conflito devido à contaminação pela mineração ilegal do ouro. A construção da governança dos recursos hídricos nesta bacia tem como desafio buscar alternativas para a resolução destes conflitos, porém a fragilidade institucional dos países, o grau de mobilização social e a pouca articulação transnacional da sociedade civil, resultaram em uma governança incipiente.

\subsection{A bacia do rio Napo: quadro físico e social}

A bacia do rio Napo está localizada no extremo oeste da Amazônia Ocidental, e se estende por uma área ${ }^{41}$ de $100.500 \mathrm{~km}^{2}$ (LARAQUE et al., 2009), ocupando parte dos territórios do Equador (cerca de 59,6\% da área total da bacia), do Peru (40\% da área total da bacia) e Colômbia ( $0,4 \%$ da área total da bacia). A bacia do rio Napo ocupa $41 \%$ da Bacia amazônica no território do Equador, e 4,15\% da Bacia Amazônica no Peru (mapa 4). Ela se encontra entre os paralelos 0045' 59', e $03^{\circ} 33^{\prime} 01^{\prime \prime}$ ' de latitude sul e entre os meridianos 72 $38^{\prime} 27^{\prime}$ ' e 78 $18^{\prime} 23^{\prime}$ ' de longitude oeste (CARDINI, 2010).

\footnotetext{
${ }^{41}$ Outro autor apresenta a área da Bacia do rio Napo com $99.349,9$ km² (CARDINI, 2010).
} 


\section{BACIA HIDROGRÁFICA DO RIO NAPO}

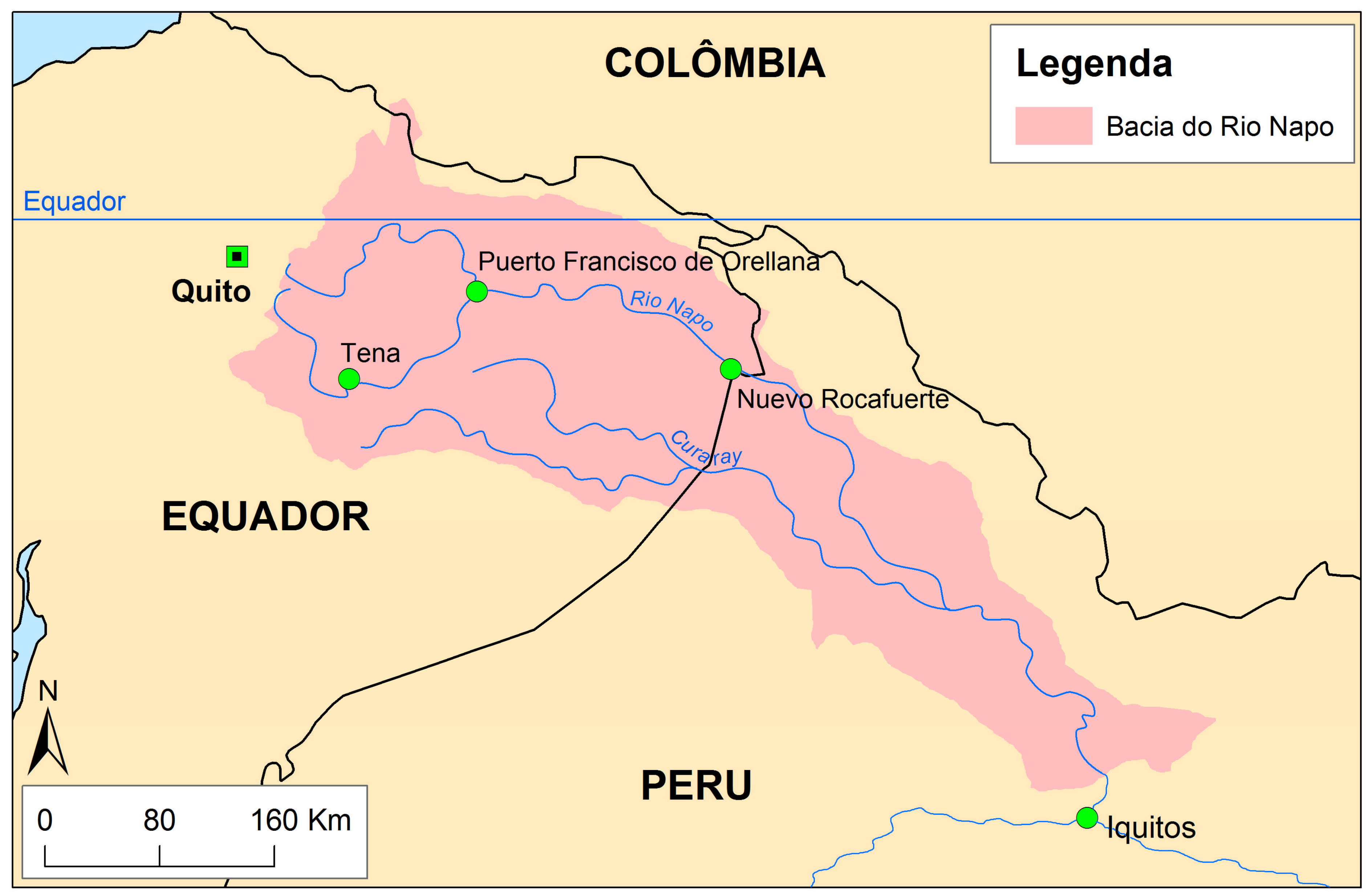


Equador e Peru compartilham vários sistemas fluviais internacionais. São as bacias do Amazonas, do Zarumilla, do Tumbes e do Chira. Vários rios da bacia amazônica são inclusive os limites fronteiriços entre Equador e Peru como os rios: Conchis/Blanco (45km de águas limítrofes), o São Francisco (20 km), o Napo (25 km), o Aguarico (35 km), o Lagartococha (75 km) e o Guepi (40 km).

A bacia do rio Napo está localizada, portanto, na zona de fronteira entre Equador e Peru. Em território peruano ela abarca os distritos de Napo, Tores Causana e Mazán, da província de Maynas, no departamento de Loreto. No Equador, a bacia abarca as províncias de Napo, Sucumbíos, Orellana e parte da província de Pastaza. A navegação do rio Napo na época de cheia ocorre com embarcações de até quatro pés de calado $(1,2$ $\mathrm{m})$, e durante a vazante o rio é navegável por embarcações de até três pés de calado $(0,9$ m) até Cabo Pantoja (Peru) e Nuevo Rocafuerte (Equador), na linha de fronteira; com dois pés e meio de calado $(0,75 \mathrm{~m})$ até Providencia-Itaya (Equador); e com 2 pés de calado (0,6 m) até Francisco de Orellana (Equador) (CARDINI, 2010). Devido às muitas ilhas existentes ao longo do rio, recomenda-se a navegação somente durante o dia.

O rio Napo é um afluente da margem esquerda do rio Amazonas. Sua origem está nas montanhas da Cordilheira Oriental dos Andes no Equador, próximo ao vulcão Cotopaxi, no Parque Nacional Cotopaxi, a uma altura de aproximadamente 6000m de altitude. Ao chegar a $100 \mathrm{~km}$ de extensão, está situado a 500m de altitude. Sua bacia se divide em Alto Napo e Baixo Napo. O Alto Napo compreende desde a nascente até a desembocadura do rio Coca (em território equatoriano, próximo à cidade de Francisco de Orellana), quando tem início o Baixo Napo chegando até a sua desembocadura no rio Amazonas, próximo à Iquitos, no Peru. A largura do rio Napo é variável, de 1000 a $2000 \mathrm{~m}$, e sua maior parte é espraiada, com leitos de areia e lama, e apresenta grande quantidade de ilhas. O rio Napo se forma:

a partir de la unión de varios cursos de agua (entre los cuales destacan los
ríos Mulato y Antisana), discurre, en dirección general NE, por las
proximidades de la ciudad de Tena, capital de la provincia de Napo, y, tras
abandonar el área de la cordillera Oriental, alcanza la localidad de Francisco
de Orellana donde recibe, por su margen izquierda, a dos de sus afluentes: los
ríos Payamino y Coca (o Papallacta). Desde la localidad de Francisco de
Orellana (en Ecuador) y, luego de recibir las aguas del río Tiputini, alcanza la
localidad de Nuevo Rocafuerte (en las proximidades del límite con la
República del Perú) donde recibe las aguas del río Yasuní. Aguas abajo, y
por varios kilómetros, actúa como límite entre las Repúblicas de Ecuador y
Peru. Tras recibir las aguas del río Aguarico, uno de sus principales afluentes,
que, en su tramo final, también actúa como límite entre las Repúblicas de
Ecuador y Perú, discurre francamente en dirección SE, atravesando la
provincia de Maynas (departamento de Loreto, Perú) donde recibe las aguas 
de los ríos Curaray, Tacsha Curaray, Tamboryacu y Mazán (otros de sus principales afluentes) para desembocar en el río Amazonas aguas debajo de la localidad de Iquitos (CARDINI, 2010, p. 8-9).

Entre os principais afluentes da margem esquerda do rio Napo em território equatoriano estão: o rio Payamino, o rio Coca, os córregos Yanayacu, Huamayacu, Quinchayacu e Quillu Pacai, o riacho Jibono, o córrego Capucui, o rio Itaya, os córregos Guarzayacu, Mandiyacu e Challuayacu, o rio Pañayacu, o rio Baqueroyacu e o rio Aguarico. E os da margem direita: o córrego Biroteyacu, o rio Indillama, os córregos Añanguyacu e Aucayacu, o rio Yuturi, o córrego Pavayacu e Huiririma, o rio Tiputini e o rio Yasuní. Os principais afluentes da margem esquerda do rio Napo em território peruano são: os córregos Santa María, Loro Caparina, Tarapoto e Corpal Urco, o rio Tamboryacu, os córregos Cacarita Moron, Bolívar, Papaya, Zapote, Yanayacu, Copal, Suni Miraño, Urco Miraño, Llachapa, Sucusari e Marichin. Na margem direita estão: os córregos Yanayacu e Torres Causana, o rio Aushiri, o rio Curaray, os córregos Huiririma, Tacsha Curaray, Turapishco e Oro Blanco, o rio Mazán e o córrego Yuracyacu (CARDINI, 2010).

O período de cheia do rio Napo começa em fevereiro e atinge seu caudal máximo nos meses de junho, julho e agosto. Já a vazante tem início em setembro e seu caudal mínimo é em dezembro, podendo se prolongar até fevereiro. Na época de vazante se formam muitas praias de areia e argila, além das já existentes ilhas, principalmente na parte peruana da Bacia do rio Napo (ECORAE e INADE, 2002).

A pluviosidade média anual na parte equatoriana da bacia é de $3100 \mathrm{~mm}$, mas pode chegar até $6173 \mathrm{~mm}$ por ano na estação Reventador (LARAQUE et al., 2007). A temperatura na área da bacia varia bastante, principalmente devido a fatores de altitude e topográficos. A temperatura na parte oriental da Cordilheira dos Andes varia regularmente em função inversa à altitude, passando de uma média anual de $10^{\circ} \mathrm{C}$ a $3.000 \mathrm{~m}$ até $25^{\circ} \mathrm{C}$ a $200 \mathrm{~m}$ de altitude (LARAQUE, CUYOT e POALBOSA, 2004). A temperatura média na área total da bacia é ligeiramente mais baixa do que no restante da Selva Baixa ${ }^{42}$. A vegetação predominante da planície é a floresta equatorial úmida. Laraque, Cuyot e Poalbosa (2004) afirmam que o interesse e importância de se estudar a Bacia do rio Napo, advém também de sua geodinâmica que influencia fortemente seus

\footnotetext{
${ }^{42} \mathrm{O}$ termo Selva Baixa, também conhecida como Baixa Amazônia se refere à planície amazônica coberta, em geral, por floresta tropical ou equatorial úmida, enquanto que a Selva Alta, ou Alta Amazônia se refere à parte andina. Trata-se de uma terminologia usada principalmente nos países andino-amazônicos. $\mathrm{Na}$ Alta Amazônia encontram-se inúmeras nascentes de rios amazônicos.
} 
fluxos de sedimentos. Estes sedimentos são originários da vertente oriental da Cordilheira andina que, apesar de corresponder a apenas $12 \%$ da superfície total da Bacia Amazônica é responsável por 95\% do material sólido transportado e exportado para o Oceano Atlântico pelo rio Amazonas. No caso da Bacia do rio Napo em território equatoriano, os autores apontam que:

\begin{abstract}
presenta una gran variabilidad en los regímenes climáticos e hidrológicos, a veces unimodales, otras veces bimodales. Las precipitaciones aumentan, desde la Cordillera hacia la planicie amazónica, donde alcanzan promedios interanuales de $3000 \mathrm{~mm} / \mathrm{año}$, con regímenes más regulares que en los Andes. La variación espacial de los escurrimientos se evidencia a través de los caudales específicos que varian de 6,6 (Andes) hasta $1101 . \mathrm{s}^{-1} \mathrm{~km} \mathrm{-{ } ^ { 2 }}$. Un total anual de $150 \times 10 \mathrm{~m}^{3}$ de agua sale de las principales estaciones hidrológicas de las cuatro cuencas orientales más importantes. La cuenca del Napo es la mayor cuenca, con un caudal anual promedio de $2100 \mathrm{~m}^{3} . \mathrm{s}-1$ (LARAQUE, CUYOT, e POALBOSA, 2004, p. 148-149).
\end{abstract}

De acordo com a pesquisa de Laraque, Cuyot e Poalbosa (2004) sobre a hidrosedimentologia da Bacia do rio Napo, que avaliaram a quantidade de sedimentos transportada entre as localidades de Francisco de Orellana e Nuevo Rocafuerte, ambas no Equador, a uma distância de $200 \mathrm{~km}$, durante o período de 2001 a 2002, o rio Napo exporta anualmente $63 \times 10^{9} \mathrm{~m}^{3}$ de fluxo hídrico e $24 \times 10^{3}$ toneladas de fluxo sólido, deste último $45 \%$ corresponde a remoção de sedimentos fluviais finos. O que demonstra que esta bacia carrega uma importante carga de sedimentos devido à pluviosidade na Cordilheira Oriental e a erosão que carregam esses sedimentos para a Bacia do rio Napo e este para o rio Amazonas.

A partir da contextualização do quadro físico da bacia serão apresentadas a seguir as principais características da presença humana na área da Bacia do rio Napo no Equador e no Peru a partir da colonização europeia.

Quando os colonizadores espanhóis chegaram à Bacia do rio Napo ainda no século XVI, ela estava povoada por diferentes comunidades indígenas. O espanhol Francisco de Orellana foi o primeiro europeu a percorrer o rio Amazonas em uma expedição liderada por Gonzalo Pizarro, que em 1542, alcançou a sua foz. A expedição partiu de onde hoje seria a cidade de Quito e, depois de cruzar os Andes, percorreu o rio Napo até chegar ao rio Amazonas e sua foz.

Durante grande parte da colonização espanhola esta parte da Bacia Amazônica ficou quase intocada pelo governo espanhol. Foram as missões religiosas que pouco a pouco penetraram nesta área e "capturaram" os indígenas para evangeliza-los em suas missões. Com a exploração do caucho no século XIX, os indígenas foram utilizados 
como mão-de-obra praticamente escrava na sua produção. O ciclo do caucho ainda não conseguiu integrar esta parte da Amazônia aos territórios equatorianos e peruanos. Esta atividade beneficiou mais os peruanos que possuíam uma frota a vapor e controlavam os tributários do rio Amazonas, como o Napo, o Putumayo, o Pastaza e o Morona, a partir dos quais a produção seguia para Iquitos, Manaus e Belém, e depois para os mercados europeus e norte-americano. É somente com a exploração do petróleo que realmente a Bacia do rio Napo vai integrar-se à economia nacional, principalmente no Equador.

$\mathrm{O}$ conflito entre Equador e Peru que emergiu na primeira metade do século XX fez com que o governo equatoriano buscasse delimitar sua área amazônica e subdividila em províncias e distritos:

\begin{abstract}
en teoría, la inserción de la Amazonía en la gestión administrativa y política del país acabó en la década del veinte, lo que coincidió con el inicio de la actividad petrolera. Pero tan solo en la década del cuarenta, el Estado rompió con la tradicional política de bajo perfil en la región. [...] Según Zavala, el conflicto de 1942 resultó de las rivalidades entre dos empresas petroleras, Jersey Standard y Anglo Ecuadorian Oil, de las cuales la primera había sido expulsa del Ecuador bajo presión por parte de la segunda y se había establecido en la Amazonía peruana (J. Zavala, 1972). [...] Desde el día siguiente a la guerra de 1941, el Estado ecuatoriano multiplicó los proyectos de vías de comunicación para reforzar su presencia en la región fronteriza, a través de una operación llamada "fronteras vivas". Cierto es que, tanto el proyecto de ferrocarril hacia Curaray como el de la carretera al Puyo quedaron en planes hasta la colonización masiva que arrancó en década de sesenta (FONTAINE, 2007, p. 270).
\end{abstract}

Na década de 1940, se torna violento o conflito fronteiriço entre Equador e Peru, que disputavam as fronteiras amazônicas, o que contribuiu para a política das "fronteiras vivas" em ambos os países e também para políticas de integração territorial. Este conflito só vai se encerrar por completo em 1998 com o acordo de paz.

A exploração de petróleo, os projetos de colonização agraria, e as primeiras leis de reforma agrária, implantadas e apoiadas pelo Estado equatoriano desde a década de 1960 incentivaram os colonos a desmatarem 50\% das terras para obterem sua legalização. Esta política, em conjunto com outros elementos, causou um grande desmatamento da área amazônica no Equador. Para Fontaine, o objetivo da colonização:

[...] venía de la necesidad de aumentar la producción agrícola nacional y de corregir los desequilibrios regionales en la repartición de la población, además de ocupar las zonas fronterizas por razones de seguridad. [...] La repartición espacial de las tierras adquiridas se transforma en un obstáculo mayor para el desarrollo de una agricultura rentable. De hecho, el eje de distribución de esas tierras sigue la carretera construida por las empresas petroleras, a lo largo de la cual cada finca no debe ocupar más de $250 \mathrm{~m}$. Entonces, para cubrir $50 \mathrm{ha}$, cada finca tiene que penetrar $2.000 \mathrm{~m}$ de tierra adentro (2007, p. 275). 
No Peru, neste mesmo período o governo nacional também incentivou a ocupação da área amazônica no país. A construção de vias de integração, os projetos de colonização agrícola e a exploração de petróleo incentivaram a vinda de imigrantes de outras partes do país para a área da bacia e também a sua integração à economia nacional:

\begin{abstract}
La carretera Lima-Pucallpa, aunque, dificultosa para el tránsito, particularmente durante algunas épocas del año, se convirtió en un eje activo, favoreciendo la salida en el comercio. Con eso se aseguró la demanda de algunos productos de la selva y se estabilizaron los precios, independizándose de la demanda externa con sus vaivenes y fluctuaciones periódicas. En contrapartida, la selva recibió otros artículos, particularmente verduras y artículos manufacturados. Lugar neurálgico de la integración económica fue Pucallpa. [...] Y, en su empuje comercial de integración económica, arrastró a Iquitos, que pasó a una situación de dependencia, y, con Iquitos, a toda la selva baja (SAN ROMÁN, 1994, p. 202).
\end{abstract}

Grande parte dos indígenas que vivia na Bacia do rio Napo foi extinta durante a colonização espanhola, porém ainda existem grupos indígenas que vivem na área da Bacia, como os quíchuas. Eles são a maior parte da população indígena na Bacia do rio Napo atualmente (ECORAE, 1997).

De acordo com La Torre, os Quíchuas ${ }^{43}$ :

Identificados étnicamente por el idioma, constituyen un grupo humano conformado originalmente por la fusión de sobrevivientes de una gran diversidad de grupos de pueblos sometidos a reducción (canelo, urarina, Arabela, murato, achuar, etc.). Suman en total unas cincuenta mil personas, dispersas en las cuencas del Tigre, Pastaza, Napo y en el departamento de San Martín, dnde están los quichuas de Lamas. También viven en un número no determinado de caseríos mestizos ubicados en los ríos Tigre, Curaray y Arabela (LA TORRE, 1998, p. 48).

De acordo com o Instituto para el Bien Común (IBC) que fez um atlas das comunidades nativas e áreas protegidas do Nordeste da Amazônia peruana:

\begin{abstract}
En la parte norte de Loreto, en los ríos Napo, Putumayo y Tigre, se encuentra un pueblo bautizado como Quechua del Napo o Kichwaruna, que es producto de un largo proceso histórico de homogeneización lingüística de pueblos con identidades e idiomas particulares. La lengua quéchua, o kichwa, se expandió desde las partes altas de las cuencas de los ríos Napo y Tigre, que corresponden a territorio ecuatoriano, hacia las partes bajas, e influyó no solo en los pueblos indígenas que allí se encontraban, sino también en la configuración del castellano regional de Loreto, que igualmente recibió esta influencia desde Lamas, en San Martín (CHIRIF, 2010, p. 63).
\end{abstract}

Em território equatoriano da Bacia do rio Napo vivem diferentes grupos indígenas além dos quíchuas, que são a maioria, tais como: shuar, achuar, cofanes,

\footnotetext{
${ }^{43} \mathrm{O}$ nome quíchua também pode ser encontrado com outras grafias como Kichwa, e se refere à mesma etnia (grupo) indígena que vive, entre outras localidades, na Bacia do rio Napo no Equador e no Peru.
} 
secoyas, sionas, huaranis. Também encontram-se alguns grupos indígenas em situação de isolamento $^{44}$ (ECORAE e INADE, 2002; ECORAE, 1997).

Ao longo do rio Napo em território peruano, existem muitas comunidades quíchuas, em sua maioria titulada, e poucas que ainda estão pleiteando a titulação de suas terras. Também se encontram comunidades dos grupos orejón (mai juna), huitoto, ashuar e yaguas. Nesta parte da bacia existem alguns grupos isolados como os arabelas e huaranis (IBC, 2011; ECORAE e INADE, 2002; LA TORRE, 1998).

Com a imigração, principalmente incentivada pela colonização agrícola fomentada pelo Estado e também pela exploração de petróleo e gás natural, muitas pessoas vindas de outras partes do Equador e do Peru migram para a Bacia do rio Napo e seus arredores.

Os dados demográficos no Equador e no Peru são organizados por província e departamento, o que dificulta a delimitação da população que vive atualmente nesta bacia, já que os limites desta não coincidem com os limites político-administrativos. No caso do território equatoriano, a Bacia do rio Napo ocupa as províncias de Sucumbíos, Napo, Orellana e parte da província de Pastaza. No Peru, a bacia ocupa os distritos de Napo, Mazán e Torres Causana, na província de Maynas, do departamento de Loreto. De acordo com dados do Instituto para o Desenvolvimento Regional Amazônico (ECORAE, 2007), a população da província de Sucumbíos, em 2007, era composta por 152.587 habitantes, a da província de Napo por 91.041 habitantes e a da província de Orellana por 103.032 habitantes. Já no lado peruano, a província de Maynas, no departamento de Loreto possuía, em 2007, uma população de 492.992 habitantes (INEI, 2009), mas o distrito de Mazán contava com 13.938 habitantes, o distrito de Napo com 16.221 habitantes e o distrito de Torres Causana com 5.187 habitantes, em 2012 (INEI, 2012).

As principais concentrações populacionais ${ }^{45}$ localizadas na Bacia do rio Napo em território equatoriano são Tena (província de Napo,) com 22.179 hab., Nueva Loja (mais conhecida como Lago Agrio) com 32.816 hab., Joya de los Sachas com 10.571 hab., Shushufindi (província de Sucumbíos) com 25.748 hab., e Francisco de Orellana

\footnotetext{
${ }^{44}$ Grupos indígenas em isolamento, também chamados de indígenas em isolamento voluntário, índios não-contatados ou tribos isoladas, são aqueles grupos que não querem ter contato com o governo do país em que vivem e seus cidadãos.

${ }^{45}$ Foram encontradas as seguintes categorias para as localidades ou concentrações urbanas: capital de Distrito (Peru), centro povoado menor (Peru), casario (Peru), comunidade campesina (Peru), comunidade nativa indígena (Peru), capital Provincial (Equador), capital Cantonal (Equador), paróquias (Equador), associação de colonos (Equador), comunidade indígena (Equador) (CARDINI, 2010).
} 
(mais conhecida como El Coca, na província de Orellana) com 22.122 hab. (Foto 7) (ECORAE, 2007). Na parte peruana, destacam-se algumas localidades como Santa Clotilde (Foto 8) e Mazán, que sofrem grande influência de Iquitos (capital do departamento de Loreto, que está localizada no rio Amazonas).

Foto 7: Vista aérea de parte da cidade de Francisco de Orellana, no Equador.

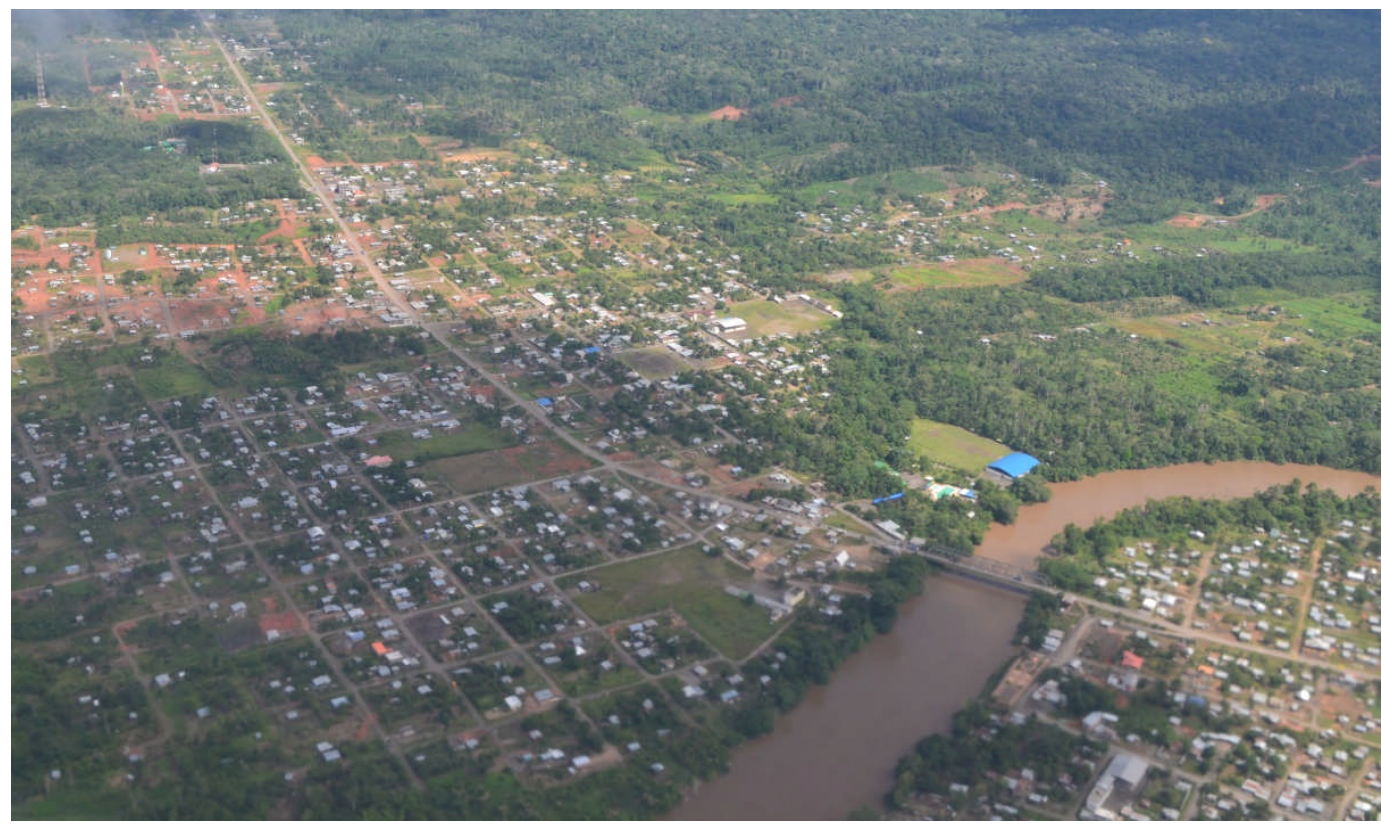

Fernanda Mello Sant'Anna, 2012. Nesta foto observa-se uma maior concentração populacional junto ao rio até a estrada, que é pavimentada, que liga Orellana a Sucumbios.

Foto 8: Embarcadouro fluvial de Santa Clotilde na margem do rio Napo, no Peru. 


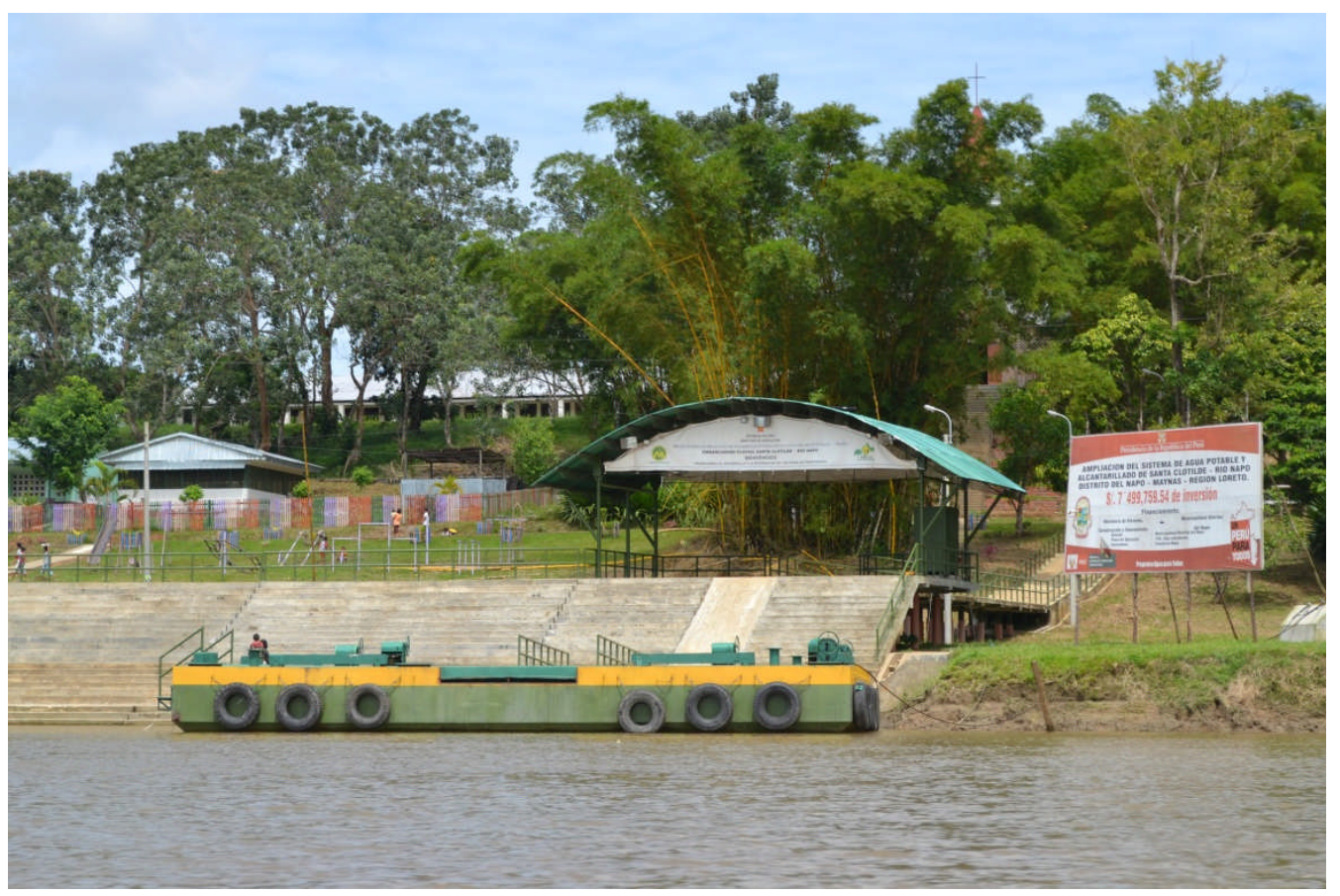

Fernanda Mello Sant'Anna, 2012. Trata-se do "Embarcadero Fluvial Santa Clotilde - Rio Napo", construído com fundos de um Projeto Binacional, e apresenta melhores condições de infraestrutura do que as outras localidades ao longo do rio Napo.

A economia na Bacia do rio Napo está fortemente ligada à exploração do petróleo na parte equatoriana, com uma grande presença de empresas que prestam serviços para as empresas petroleiras, mas também existe trabalho informal. Nota-se que em grande parte das concentrações urbanas, como Francisco de Orellana, a maior parte da população vive com pouco acesso a serviços básicos e de infraestrutura, principalmente de abastecimento de água e saneamento. Para Bustamante e Jarrín, que analisaram as condições de vida da população das áreas petroleiras da Amazônia equatoriana:

encontramos muy fuertes desventajas en lo relativo al acceso a los servicios, a la educación y a la infraestructura. En relación al tema de la pobreza debemos señalar que la variable más deficitaria es la presencia de un porcentaje de personas con ingresos bajo el umbral de pobreza mayor a los promedios nacionales y regionales. En cambio los indicadores relativos a la indigencia y la severidad de la pobreza son prácticamente iguales a las medias regionales. Esto podría corresponder a una situación en la cual las zonas petroleras atraen a población pobre, y esta sufre la carencia de infraestructura. Dado que el resto de la Amazonia muestra estas mismas características, pero de manera menos aguda, la comparación de las zonas petroleras con el resto de la región muestra desventajas en los mismos rubros pero menores. $\mathrm{Si}$ revisamos las principales variables encontramos lo siguiente: El crescimento demográfico sería el efecto social más directo que la actividad petrolera habría provocado $(2007, \mathrm{p}, 65)$.

Bustamante e Jarrín (2007) observaram que, nas áreas de exploração de petróleo da Amazônia equatoriana, predomina uma alta informalidade na economia, onde 
dominam as atividades que visam satisfazer as necessidades da produção petroleira, e há um descaso sistemático em relação às necessidades da população. Os autores afirmam que a atividade petroleira cria uma estrutura social e econômica específica, mas que não é estudada em comparação com a literatura existente sobre os problemas da produção petroleira como os conflitos socioambientais causados por ela. Eles destacam que:

\begin{abstract}
el aumento de los flujos monetarios generados por la extracción de hidrocarburos no reduce los niveles de pobreza. [...] Nos puede llevar a pensar en el modelo de desarrollo de la actividad hidrocarburífera, en el cual, la operación petrolera, se ha reducido a núcleos empresariales, pequeños que se movilizan semanal o quincenalmente desde Quito, y que utilizan una gran gama de trabajadores a través de procesos de tercerización, con grados de formalización de sus trabajos bajos, y relacionados a una población flotante que está a la expectativa de las oportunidades, y que tiene malas condiciones de vida, inclusive poca seguridad" (BUSTAMANTE e JARRÍN, 2007, p. $67)$.
\end{abstract}

Do lado peruano, está começando a exploração de petróleo na Bacia do rio Napo no Lote 67, cujo transporte será realizado pelo rio até a primeira estação do oleoduto Norperuano. Porém, nas Bacias dos rios Tigre, Corrientes e Pastaza esta exploração já tem pelo menos quatro décadas.

Uma parte da População Economicamente Ativa (PEA) das províncias equatorianas, que compõem a Bacia do rio Napo, também se dedica à agropecuária, como a criação de bovinos, aves, suínos e também às culturas do café, palma africana, milho, banana (que diferencia entre "banano" e "plátano"), arroz, cacau, naranjilla, yuca, entre outros (ECORAE e INADE, 2002).

$\mathrm{Na}$ parte peruana da bacia o maior incentivo à produção agropecuária vem da cidade de Iquitos, que é o maior mercado consumidor, e requer grandes quantidades de alimentos, mas:

en general la agricultura presenta bajos niveles de producción, productividad y rentabilidad de los cultivos, siendo loa mejores suelos los de distritos de Torres Causana y Napo, aunque dichos suelos son altamente aluviales y sólo permiten el cultivo de productos de corto período, ante el riesgo de ser afectado por las inundaciones, lo que obliga también, a una agricultura migratoria de subsistencia (ECORAE e INADE, 2002, p. 24).

Na província de Maynas, no Peru, destacam-se os cultivos de yuca, banana, arroz, milho, cana-de-açúcar, feijão, frutas, etc. Destacam-se também a criação de búfalos, além de bovinos, suínos e aves (ECORAE e INADE, 2002).

Por meio da observação no trabalho de campo e em entrevistas com moradores, nota-se que a pesca é uma atividade muito importante, tanto para a subsistência quanto como atividade econômica. Pode-se observar que uma grande parte dos mercados e 
feiras nas principais localidades ao longo da Bacia do rio Napo no Equador e no Peru oferecem pescado à venda. Como afirmado no documento do ECORAE e INADE, a pesca "constituye una de las actividades más importantes, y el pescado es elemento esencial de la dieta del poblador amazónico" (2002, p. 27).

Outra atividade importante na Bacia do rio Napo é a madeireira, que em sua maior parte não é registrada. Estima-se que apenas um terço da madeira comercial retirada da Bacia Amazônica em território equatoriano é legalizada segundo informou a técnica responsável pelo setor florestal da Oficina Regional de Orellana do Ministério de Meio Ambiente do Equador, em entrevista realizada em julho de 2012. Os dados oficiais do Ministério são somente sobre a quantidade de madeira produzida legalmente. O mesmo ocorre do lado peruano, onde existem áreas de concessão florestal:

\begin{abstract}
en la cuenca del río Napo, las primeras actividades económicas fueron la tala y extracción desproporcionada del cedro y palo rosa, hasta que los volúmenes descendieron a niveles no rentables, iniciándose la extracción de maderas de segunda categoría como bolaina blanca, capirona, ishpingo, pino chuncho y yacushapana. En conclusión la actividad forestal es principalmente de carácter extractivo, sin una política integral de reforestación, está afrontando los problemas propios de una explotación que sólo se orientó a las especies de mayor valor y mejores expectativas a la zona (ECORAE e INADE, 2002, p. 26).
\end{abstract}

Além das terras indígenas também existem áreas naturais protegidas na extensão da Bacia do rio Napo. No Equador, destaca-se o Parque Nacional de Yasuní, onde existe uma sobreposição com a terra de grupos indígenas isolados como os huaranis, e a Reserva de Produção Faunística Cuyabeno, o Parque Nacional Sumaco Napo Galeras e a Reserva Biológica Limoncocha. Na parte peruana da Bacia não há áreas naturais protegidas, apenas terras indígenas tituladas na Bacia do rio Napo, porém existem nas bacias adjacentes. Muitas dessas áreas naturais protegidas são atravessadas ou se sobrepõe a lotes de concessão petroleira e mineira, e a projetos de infraestrutura do corredor multimodal Manta-Manaus, da IIRSA (BUITRÓN, 2007). Em seguida serão analisados os Planos Binacionais entre Equador e Peru e os projetos da IIRSA na área da Bacia do rio Napo.

\title{
4.2 Os projetos da IIRSA e os planos binacionais
}

Como ocorre em outros países sul-americanos, vários projetos nacionais e binacionais foram incluídos na IIRSA. Eles tiveram início em diferentes momentos. O 
Equador e Peru também incluíram na agenda de projetos da IIRSA alguns de seus projetos nacionais e binacionais referentes à integração física e energética.

Parte da fronteira entre Equador e Peru foi palco de violentos conflitos entre os países, o que já foi abordado no segundo capítulo deste trabalho. Esta situação conflitiva perdurou da década de 1940 até a assinatura do acordo de paz em 1998. Nesta ocasião, os dois países assinaram o Acordo Amplo Peruano-Equatoriano de Integração Fronteiriça, Desenvolvimento e Vizinhança, no qual está inserido o Plano Binacional de Desenvolvimento da Região Fronteiriça (PBDRF), que conta com um Fundo Binacional Peru-Equador. Neste mesmo ano também foi assinado o Tratado de Comércio e Navegação entre Equador e Peru.

O Tratado de Comércio e Navegação visa assegurar a navegação pacífica e o comércio no rio Amazonas e seus afluentes, permitindo que o Equador utilize os rios que dão acesso ao rio Amazonas em território peruano. Este tratado contempla a igualdade de tratamento e reciprocidade na navegação fluvial, no transito terrestre e no comércio entre os dois países. Ainda prevê um sistema de solução de controvérsias com o estabelecimento de uma comissão Peruano-Equatoriana de Comércio e Navegação que tem competência para resolver os conflitos.

No PBDRF estão inseridos inúmeros projetos que visam o desenvolvimento das regiões fronteiriças entre estes países. Nele estão previstos projetos binacionais e programas nacionais para serem executados nas regiões fronteiriças. Durante o ano de 2001 foi desenvolvido o Projeto "Desenvolvimento Sustentável da Área Fronteiriça Amazônica Peruano-Equatoriana", com recursos do Fundo Especial Multilateral do Conselho Interamericano para o Desenvolvimento Integral (FEMCIDI), da OEA. Dentro deste Projeto foi realizado um estudo pelo Instituto Nacional de Desenvolvimento (INADE) e o Instituto para o Desenvolvimento Regional Amazônico (ECORAE) denominado Plano Binacional Peruano-Equatoriano para o Desenvolvimento das Bacias dos rios Napo, Tigre e Pastaza (EQUADOR e PERU, 2010). No período de realização deste projeto a principal meta:

\footnotetext{
fue la compatibilización de la zonificación ecológica-económica con el ordenamiento territorial del área fronteriza, a través de los estudios de prefactibilidad de mejoramiento de las condiciones de navegabilidad del río Napo, de la infraestructura económica necesaria para propiciar el desarrollo regional, de investigación y transferencia de tecnología, de gestión y organización institucional, de elaboración del Plan de Desarrollo Integral, con las políticas y estrategias de desarrollo sostenible y la gestión financiera de los Proyectos Binacionales (GREGORASCHUK, 2003, p. 4).
} 
De acordo com a avaliação da execução do Projeto (GREGORASCHUK, 2003), as demandas mais comuns da população da região fronteiriça amazônica peruanaequatoriana podem ser resumidas nas necessidades de água potável e saneamento básico, provisão de energia elétrica e atenção à saúde. As principais obras realizadas pelo INADE foram a construção de infraestrutura de abastecimento de agua em Santa Clotilde e Mazán (Peru), e a construção de complexos educativos em Santa Clotilde e Francisco de Orellana (Peru).

Neste projeto o estudo sobre a navegabilidade do rio Napo concluiu que:

\begin{abstract}
la navegación en un río de cauce instable y de profundidad escasa en muchos sectores establece condiciones particulares que hacen inviable obras $o$ mantenimiento para solucionar estas dificultades. Los programas elaborados para la capacitación de navegantes por parte de patrones de embarcación con probada experiencia en el conocimiento del río Napo, considerando la inexistencia de estaciones de control en pasos de reducido tirante, parece atinada para una primera etapa (GREGORASCHUK, 2003, p. 13).
\end{abstract}

Um dos objetivos do PBDRF é o melhoramento da navegação nas bacias hidrográficas comuns a ambos os países. Destacam-se projetos como os "Estudos hidromorfológicos para Navegação", que está sob a responsabilidade do Ministério de Transportes, Comunicação, Habitação e construção do Peru, e da Oficina do Plano Binacional de Desenvolvimento da Região Fronteiriça na parte equatoriana. Estes estudos têm como objetivo servir de base para a possibilidade da utilização comercial do sistema fluvial peruano-equatoriano, que poderia contar com um corredor de transporte fluvial que conecte ambos Estados e destes com outros dentro da Bacia Amazônica. São objetos destes estudos as bacias dos rios Napo, Tigre, Corrientes, Pastaza, Marañón e Santiago. (QUEROL, 2003).

Na bacia do rio Napo está prevista a implantação de projetos da IIRSA, como o acesso a hidrovia do rio Napo. Estes projetos fazem parte do Eixo de Integração do Amazonas, do corredor multimodal Manta-Manaus. Estão inseridos neste Eixo o Brasil, a Colômbia, o Equador e o Peru, em uma extensão de 5,7 milhões de km² (Mapa 5). Este corredor é um mega-projeto que inclui a construção, ampliação, melhoramento e manutenção de vias terrestres, portos marítimos como o de Manta, portos fluviais como de Francisco de Orellana, aeroportos, e hidrovias (MANCHENO e PIEDRA, 2008). 


\section{Grupos de Projetos}

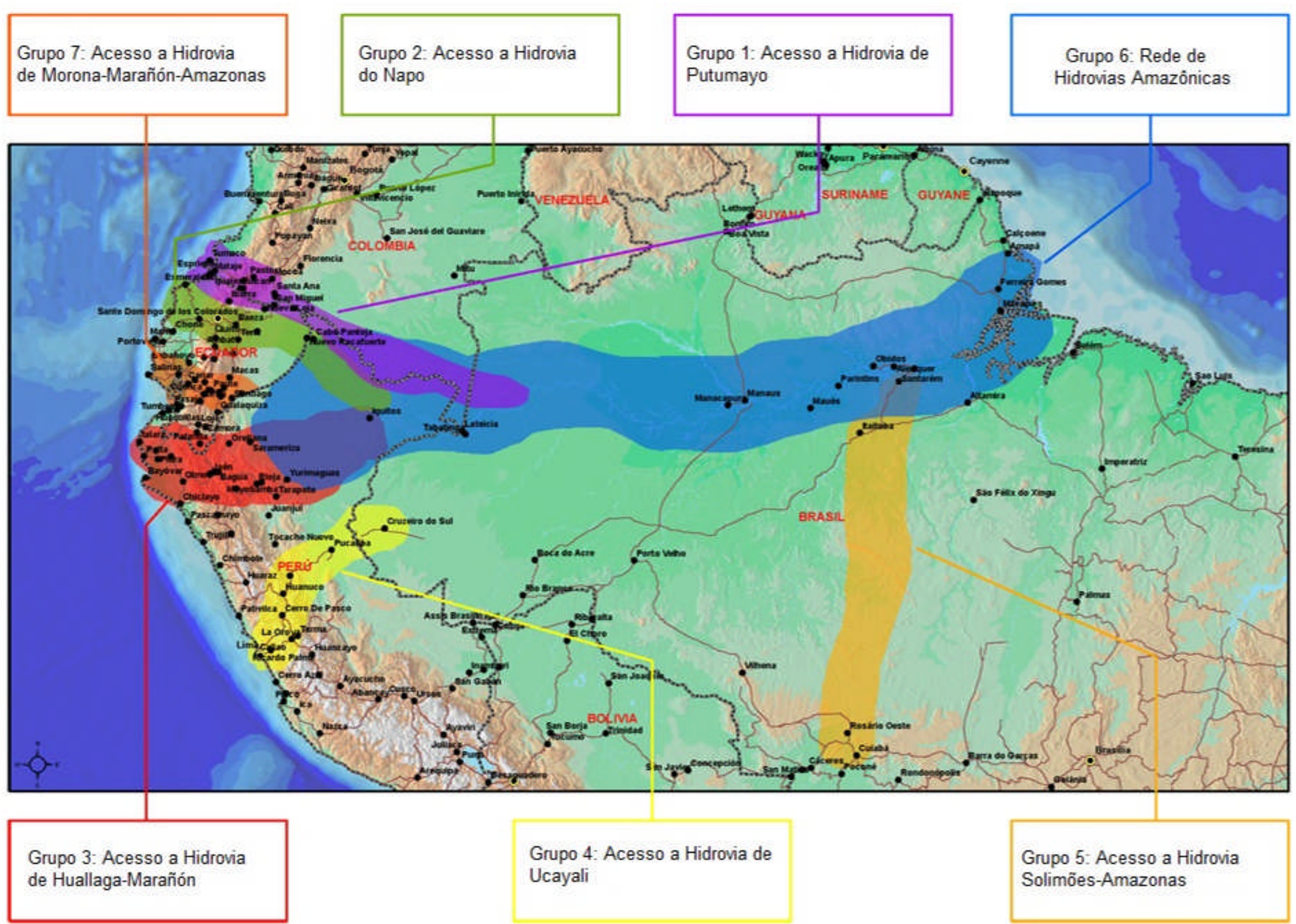


O Eixo do Amazonas conta com o Grupo de Projetos $n^{\circ} 6$ "Rede de Hidrovias Amazônicas", cujo objetivo é melhorar a navegabilidade dos rios Amazonas, Solimões, Ica, Putumayo, Huallaga, Marañon, Ucayali, Napo e Morona, em uma extensão estimada de $8.500 \mathrm{~km}$, e o Grupo de Projetos n 2 "Acesso à Hidrovia do Napo" (IIRSA, 2008).

O Grupo 2 tem como projeto âncora o Porto de Francisco de Orellana (Foto 9), que conta com a função estratégica de fortalecer a integração nacional equatoriana em sua porção amazônica, nas províncias de Napo e Orellana com a serra e a costa, e também permite consolidar uma via fluvial até Manaus contribuindo para a integração regional amazônica e também conectando-a ao Pacífico. Também conta com os seguintes projetos: Centro Binacional de Atenção de Fronteira (CEBAF) Nuevo Rocafuerte (Equador) - Cabo Pantoja (Peru); a construção do novo aeroporto de Tena; a implementação do novo aeroporto de Francisco de Orellana (El Coca); e o melhoramento do Porto de Esmeraldas e do Porto de Manta (IIRSA, 2008).

O trajeto entre Manta e Manaus corresponde a $578 \mathrm{~km}$ por via terrestre, e mais $2860 \mathrm{~km}$ por via fluvial. Desse trecho, $260 \mathrm{~km}$ estão na parte equatoriana desde Francisco de Orellana até Nuevo Rocafuerte, na fronteira com o Peru. A parte do corredor em território equatoriano ainda apresenta desafios, principalmente em relação às vias terrestres na parte amazônica:

\footnotetext{
El recorrido del proyecto inicia en el Puerto de Manta, provincia de Manabí, en las costas ecuatorianas del Oceáno Pacífico. [...] La ruta continua por Portoviejo y Quevedo; desde ahí inicia su ascenso a los Andes Ecuatorianos, pasando por la Maná y Zumbahua, este último en la provincia de Cotopaxi, de ahí sigue por Pujilí hasta llegar a Latacunga, capital de la provincia. A partir de aquí el proyecto no tiene una definición clara existiendo dos opciones: la primera es seguir en dirección a Quito y tomar la salida oriental de Papallacta para después continuar por la vía hasta el Tema - donde está prevista la construcción de un aeropuerto internacional de carga - en la provincia del Napo, en la región amazónica del Ecuador; la segunda opción y la más controversial es la que iría de Latacunga a Salcedo y de ahí pasaría directamente hasta Tena; este último tramo, como la indica Varillas (sf) lleva más de 40 años de construcción, la geografía de la zona es de muy difícil acceso y se encuentra cerca del Parque Nacional Llanganates. El seguinete tramo planificado por vía terrestre es el proyecto entre la ciudad de Tena y Francisco de Orellana - el Coca - en donde si bien existe la opción de mejorar la vía actual, se ha planificado construir una carretera de $138 \mathrm{~km}$ de extensión a orillas del río Napo. Según lo indica Varillas (2008) en los dos casos la vía pasaría muy cerca del Parque Nacional Sumaco Napo Galeras" (MANCHENO e PIEDRAS, 2008, p. 31).
} 
Foto 9: Porto de Francisco de Orellana no rio Napo, no Equador.

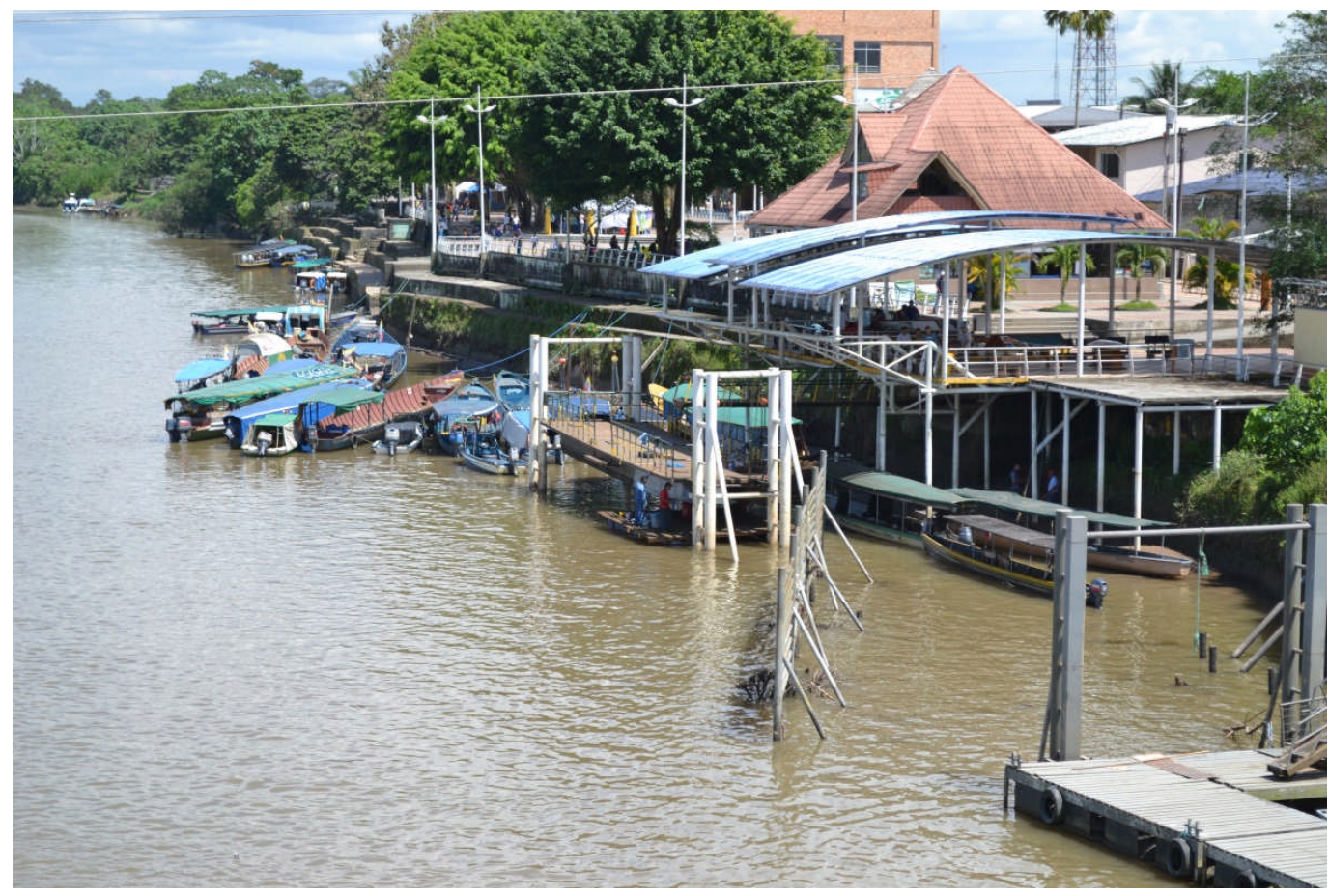

Fernanda Mello Sant'Anna, 2012. Nesta foto observa-se as condições da instalação portuária de Francisco de Orellana, e as embarcações que transportam passageiros e cargas.

A parte fluvial do trajeto começa no rio Napo em Francisco de Orellana, dando início a hidrovia do Napo, onde está prevista a construção de um porto de transferência de carga, o que inclui a construção de zonas de armazenamento e descarga, para as embarcações que subiriam e partiriam pelo rio Napo. No entanto, existem ainda algumas dúvidas sobre onde seria a localização exata deste porto:

[...] algunos estudios han determinado que la mejor ubicación para este proyecto es en la localidad de El Belén (Varillas, 2008). En este sentido existe información poco clara, ya que el Ministerio de Transporte y Obras Públicas (MTOP) en comunicado de prensa publicado el martes 22 de abril de 2008 indicó que Puerto Providencia sería el puerto que unirá los trayectos terrestre y fluvial de la Manta-Manaos; Puerto Providencia se encuentra ubicado a $80 \mathrm{~km}$ de Shushufindi y $40 \mathrm{~km}$ de Francisco de Orellana. Por otro lado, la IIRSA mantiene en su página web a Puerto Francisco de Orellana como "proyecto ancla", es decir el principal proyecto del Grupo 2 del Eje del Amazonas. Cualquiera que sea la opción a tomar, todas se ubican en una zona de altamente frágil por encontrar-se cerca del Parque Nacional Yasuní (MANCHENO e PIEDRAS, 2008, p. 32).

Embora os autores (MANCHENO e PIEDRAS, 2008) levantarem várias possibilidades para onde deveria ser construído o porto de transferência de carga, o Estudo sobre o melhoramento da navegabilidade do rio Napo aponta que:

las zonas que tentativamente se consideran para la construcción de estas instalaciones aduaneras son Belén/Providencia (como punto de origen/destino principal ecuatoriano de las cargas de tráfico internacional), 
Nuevo Rocafuerte (durante el tiempo en que se mantenga esta localidad como punto de transferencia de carga para el sector inferior del tramo ecuatoriano), el nuevo embarcadero a construir para el trasbordo de cargas en inmediaciones de la frontera, Cabo Pantoja (como punto de recepción de mercaderías ecuatorianas con destino al sector superior del tramo peruano distritos de Torres Causana y Napo) y en la localidad Mazán (para mercaderías con destino al municipio homónimo y a la operación de comercio internacional en Fase 1, cuando esté habilitada la carretera Iquitos Mazán) (CARDINI, 2010f, p. 113)

A hidrovia do Napo partiria então de Francisco de Orellana, passaria por Panacocha e Tiputino, e chegaria a Nuevo Rocafuerte, na fronteira com o Peru, onde seria construído um Centro Binacional de Atenção de Fronteira, e um aeroporto tanto de turismo como de transferência de carga. Este trajeto passa por áreas de grande importância socioambiental como Terras Indígenas, a Reserva Biológica Limoncocha, o Parque Nacional Yasuní e a Reserva de Produção Faunística de Cuyabeno (MANCHENO e PIEDRA, 2008). Em território peruano a hidrovia continua desde Cabo Pantoja, na fronteira com o Equador, até a sua desembocadura no rio Amazonas, próximo a Iquitos.

Mancheno e Piedra (2008) afirmam que o Eixo do Amazonas da IIRSA poderia ser analisado com base em quatro tipos de fluxos fluviais: locais, nacionais, regionais e internacionais. Na parte equatoriana do Eixo os maiores fluxos são locais, depois os nacionais, e quase nenhum fluxo regional ou internacional, assim, a produção e comercio desta área não apresenta condições de aproveitar as economias de escala que o corredor proporcionaria, o único que teria condições de aproveitá-las seria o Brasil:

[...] en términos de los flujos del comercio existente en Brasil, desde y hacia la Cuenca del Pacífico, como al interior del Eje, existe una potencialidad, porque en términos muy generales, como se demostró anteriormente, las exportaciones desde el Brasil hacia la Cuenca del Pacífico por esta vía bordearía los USD 9.000 millones en el año 2006, mientras que las importaciones totales de Brasil desde esa región llegaría a los USD 23.000 millones, el flujo comercial -exportaciones más importaciones- entre los países del Eje estaría en alrededor de los USD 10.000 millones en el mismo año; valores que al compararlos con el costo total estimado de las obras del Eje de USD 2.000 millones, parecería ser que es totalmente rentable (MANCHENO e PIEDRA, 2008, p. 53).

O comércio e os fluxos que transitam pelo rio Napo em sua parte equatoriana são em sua maioria locais, e o sistema fluvial é precário, altamente informal e com inadequada ou nenhuma infraestrutura portuária, de armazenagem, navegação e comunicações:

las mercancías que se transportan por esta vía son muy reducidas y comúnmente destinadas al consumo familiar o al comercio local. La principal carga movilizada para este objetivo está conformada por alimentos y 
materiales de construcción. El comercio regional e internacional es actualmente escaso o inexistente; según los autores el mínimo flujo que pudo ser percibido se relaciona con productos madereros, de hidrocarburos y pequeños intercambios familiares transfronterizos. Además de los elevados costos de transporte, otro obstáculo encontrado para el comercio regional e internacional es la falta de presencia de autoridades aduaneras en la frontera entre Ecuador y Perú, o en Francisco de Orellana, por lo cual, el comercio debe ser registrado en Quito, creando así un grave problema institucional. Es importante mencionar que no existen estadísticas en ninguna entidad del Estado ecuatoriano sobre el valor, la producción local o el comercio realizado por el río (MANCHENO e PIEDRAS, 2008, p. 45).

Durante o trabalho de campo realizado na Bacia do rio Napo em julho de 2012, foi possível entrevistar um grupo de trabalhadores brasileiros de transporte fluvial (Foto 10) que estavam em Nuevo Rocafuerte, no Equador, na fronteira com o Peru. De acordo com o capitão eles vieram de Manaus e entregaram um maquinário de geração de energia elétrica de uma empresa finlandesa para uma empresa petroleira em um lote próximo à Francisco de Orellana ${ }^{46}$. No momento da entrevista, eles estavam aguardando em Nuevo Rocafuerte a liberação da documentação para atravessarem a fronteira e poderem retornar à Manaus. No entanto, já esperavam havia dias para a liberação. O capitão também comentou sobre as dificuldades de navegar pelo rio Napo no Equador, como, por exemplo, a baixa profundidade do rio em alguns trechos, a presença de troncos de árvores no leito do rio, e também o tempo para a liberação do transporte internacional nas fronteiras.

\footnotetext{
${ }^{46}$ Foi solicitado pelo entrevistado o sigilo sobre seu nome e o nome da empresa petroleira.
} 
Foto 10: Embarcação brasileira no rio Napo, na fronteira entre Equador e Peru.

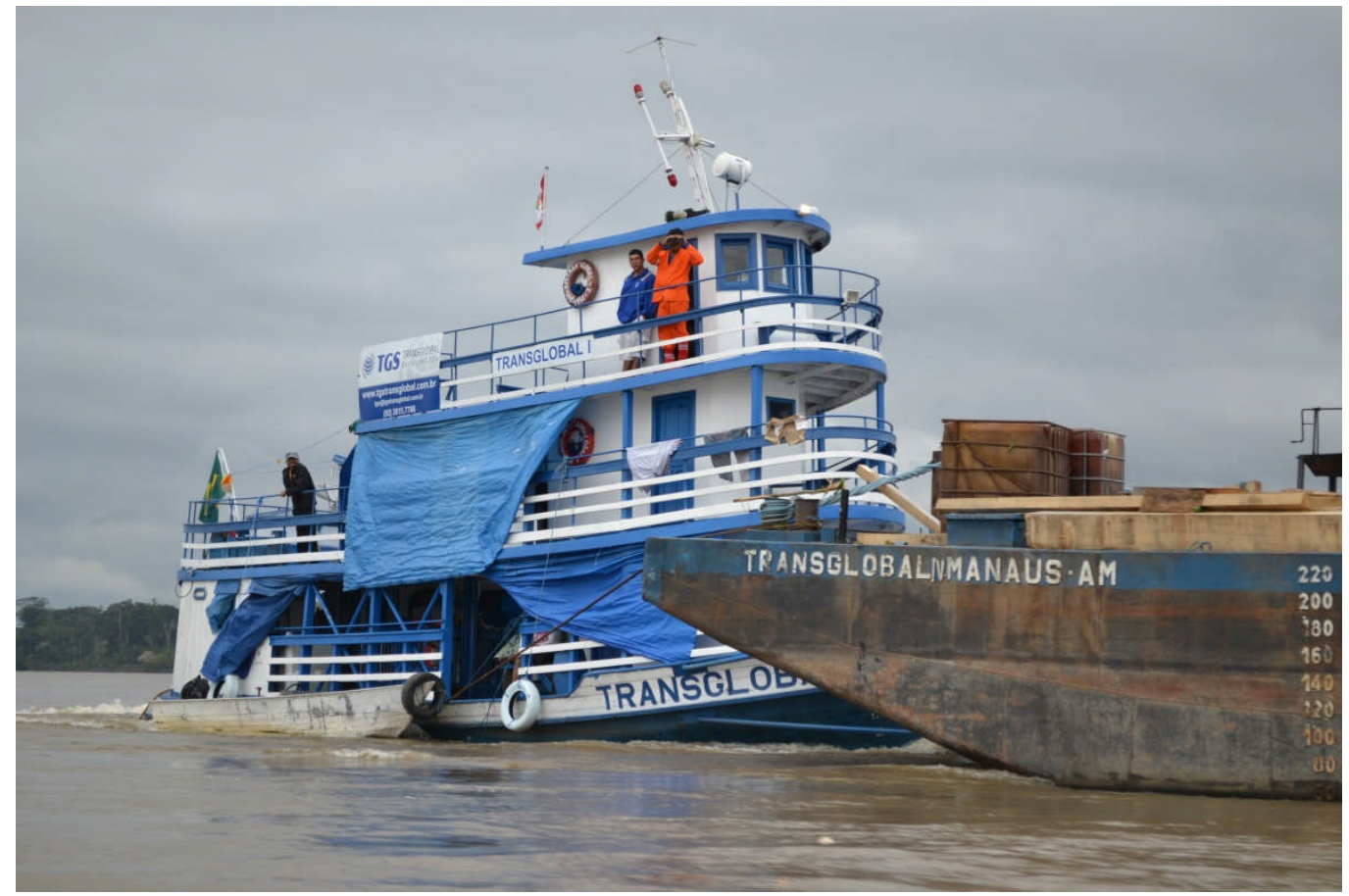

Fernanda Mello Sant'Anna, 2012. Nesta embarcação brasileira, cujo capitão foi entrevistado em Nuevo Rocafuerte (Equador), observa-se uma das balsas em que foi transportado um maquinário para uma empresa petroleira no Equador.

Em 1999 os governos do Equador e do Peru apresentaram à OEA a proposta para formular um "Plano Peruano-Equatoriano para o Desenvolvimento Integral das Bacias dos Rios Napo - Tigre - Pastaza", que foi aprovada e publicada em 2002 pelo ECORAE do Equador e pelo INADE. O principal objetivo do Plano é: "contribuir a aliviar las condiciones de pobreza, detener los procesos de deterioro y degradación ambiental, y promover la ocupación ordenada, el desarrollo sostenible, y la integración del área fronteriza de la región amazónica" (ECORAE e INADE, 2002, p. 11). Neste Plano foram identificados, para sua execução, os seguintes componentes:

\footnotetext{
I. Estudio de Zonificación Ecológica Económica Compatibilizada para el área fronteriza.

II. Programas de Inversiones:

II.1 Fomento del Comerio Fronterizo.

II.2 Infraestructura Económica.

II.3 Aprovechamiento y Manejo Forestal.

II.4 Comunidades Nativas/Indígenas.

II.5 Parques y/o Reservas Naturales Binacionales

II.6 Mejoramiento de la Navegabilidad del Río Napo.

II.7 Investigación y Transferencia de Tecnología.

II.8 Gestión y Organización Institucional. (ECORAE e INADE, 2002).
}

Para o componente de "Melhoramento da Navegabilidade do Rio Napo", o Plano previu a elaboração de um Estudo, que foi realizado por um consórcio entre a 
empresa SERMAN \& Asociados AS (proveniente da República Argentina) e a empresa CSI Ingenieros AS (da República Oriental do Uruguai), que realizou o serviço de consultoria para elaboração do "Estudo Binacional de Navegabilidade do Rio Napo, desde o Porto de Francisco de Orellana (El Coca - República do Equador) até a confluência com o Rio Amazonas (República do Peru)" (CARDINI, 2010). Esta elaboração ocorreu no período de 2009 a 2010 e contou com o financiamento do Fundo para o Financiamento de Operação de Cooperação Técnica para Iniciativas para a Integração da Infraestrutura (FIRII) do BID no valor de 743.860 dólares. E contou com a participação e coordenação de várias instituições dos governos equatoriano e peruano, em especial, do Ministério de Transporte e Obras Públicas do Equador, e do Ministério de Relações Exteriores e do Ministério de Transporte e Comunicação do Peru.

O Informe Final deste Estudo Binacional possui seis volumes: I) Estado Atual da Navegação; II) Investigações de Campo; III) Estudo da Hidráulica Fluvial; IV) Estudo Socio-Econômico; V) Análise Ambiental e Social; e VI) Propostas e Plano de Investimentos.

Este Estudo apresentou algumas propostas para melhorar a navegação do rio Napo, que estão divididas em ações não-estruturais e ações estruturais. Entre as ações não-estruturais destacam-se: a) medidas de ajuda à navegação; b) implantação de uma rede de Estações Hidrométricas com transmissão de dados em tempo real; c) realização de prognóstico de variação de níveis hidrométricos a curto prazo. As ações estruturais consistem em: a) limpeza de troncos, ramos e paliçadas do leito do rio; b) medidas para melhorar as infraestruturas de embarque e desembarque (melhoria de escalinatas para as comunidades ribeirinhas menores, construção de pequenos embarcadouros para as localidades medianas, construção de embarcadouros de maior envergadura com equipamento para transferência de cargas, reabilitação, manutenção e/ou melhora da infraestrutura de embarque existente); c) medidas para o melhoramento e adaptação da frota fluvial (com diferenças para o tramo equatoriano e o peruano do rio Napo).

Cabe destacar que este Estudo desconsidera a dragagem como uma medida viável para o melhoramento da navegabilidade, o que diminui muito o impacto socioambiental das obras de infraestruturas que devem ser implementadas. De acordo com o Estudo:

El hecho de que el análisis técnico-económico haya concluido en descartar la posibilidad de realizar dragados para mantener las condiciones de navegación en los "malos pasos" durante das condiciones de estiaje, elimina la mayor parte de los impactos negativos significativos que podría haber tenido el proyecto; así como la mayor fuente de la potencial resistencia al mismo por 
parte de la sociedad, particularmente de las comunidades ribereñas del río Napo. Si bien en algún momento futuro podría plantearse la necesidad de realizar un dragado puntual en algún embarcadero que se vea en una condición crítica por pérdida de profundidades al pie (debido a la variabilidad del río), dicha situación ameritará realizar un análisis de factibilidad, dado que la evaluación ambiental no muestra la existencia de afectaciones ambientales significativas si los dragados son de baja escala y se realizan adecuadamente, reinsertando los sedimentos en un sitio profundo cercano del propio cauce. Queda claro a partir del estudio objeto de la presente consultoría, que este tipo de acciones - de existir - será muy puntual y no se aplicará a la profundización y mantenimiento generalizado de los "malos pasos", dado que esta es una acción técnicamente muy ineficiente (debido a las condiciones hidrológicas y sedimentológicas particulares del río Napo) que la transforman en económicamente inconveniente (CARDINI, 2010e, p. 371-372).

\section{Mancheno demonstrou preocupação em relação à questão da dragagem do leito} do rio Napo, devido:

las características naturales del río Napo que tiene poca profundidad con una alta variabilidad de su curso que depende de las estaciones climáticas; a este curso inestable se suma los latos índices de sedimentación y acumulación de materiales que se constituyen en barreras naturales para la navegación de calada relativamente profundo (MANCHENO, 2011, p. 207).

Outros problemas referentes a dragagem do rio também devem ser levados em conta, pois:

[...] no se han tomado en cuenta los efectos que se podrían ocasionar en caso de dragarse el río Napo a fin de mejorar su navegabilidad. A pesar que el proyecto formal no habla de actividades de dragado, la navegabilidad del río Napo en su parte cercana a la población de Lago Agrio presenta muchos obstáculos naturales. Entre estos están: 1) grandes cantidades de sedimentos que son arrastrados de forma natural (y que han aumentado en los últimos años debido a los procesos de erosión fomentados por los cambios de cobertura vegetal en las cuencas que alimentan los distintos afluentes del río Napo); 2) cambio de curso del río en especial en la época de lluvias en las partes altas de las cuencas, lo que hace que muchas veces el tráfico de embarcaciones se dificulte o incluso se interrumpa temporalmente; 3) bajas profundidades a lo largo del río, formación de bajos debido a los bancos de arena y sedimentos que dificultan la navegación inclusive de pequeñas embarcaciones. Por lo tanto, resulta difícil pensar en actividades de dragado, porque, los procesos naturales habrían que dichas actividades no tengan una duración de largo plazo y resulte muy costoso mantener las condiciones que aseguren la navegabilidad a través de grandes embarcaciones. Sin embargo, el incremento de embarcaciones de cualquier tipo generaría impactos sobre especies de agua dulce (las que sirven de alimento a la población local), se generan procesos de contaminación de aguas por derrames de combustibles y residuos, el ruido afecta y ahuyenta a las especies, las especies de mayor volumen se alejan de estos sitios, se originan también varios cambios en la vegetación junto al río, por la necesidad de muelles, canales, puertos y demás infraestructuras" (GONZALEZ, GUEVARA e RON, 2011, p. 192). 
Entre os potenciais impactos sociais e ambientais das obras que devem ser realizadas para o melhoramento da navegabilidade do rio Napo, o Estudo, aponta como um dos principais a interferência na qualidade da água, pois:

La calidad del agua superficial del río Napo podría verse mínimamente afectada durante la fase de implementación por las tareas de construcción y mejora de infraestructuras de embarque y acopio de mercaderías. En tanto, durante la fase de operación las acciones del proyecto que podrían afectarla sería la implementación del sistema de remoción, extracción y trozado de palizadas (también un grado muy leve) y el aumento del tránsito de embarcaciones. Dado que la afectación más importante sobre la calidad del agua podría generarse por pérdidas o derrames involuntarios de combustibles, aceites y lubrificantes, así como por la disposición de residuos y efluentes líquidos, se debe acompañar el incremento de la navegación con un correspondiente refuerzo de las instituciones de control de la contaminación asociadas a las actividades náuticas (CARDINI, 2010e, p. 372).

Os outros impactos sobre o meio físico e sobre a biota são considerados leves, enquanto que os impactos sociais, econômicos e culturais são considerados, em geral, como positivos, pois aumentariam as atividades econômicas na área de influência do Estudo, o que melhoraria as condições de vida da população se forem implementadas as ações propostas no Estudo, assim os impactos:

\begin{abstract}
son positivos para las poblaciones de la zona más aún si los mismos son acompañados por medidas de promoción del comercio, de control de la navegación, de manejo de contingencias y de participación comunitaria, que serán descriptos al tratar los lineamientos del Plan de Manejo Ambiental [...], los cuales permitirán controlar los posibles impactos negativos que se podrían generar sobre la biota acuática y terrestre (CARDINI, 2010e, p. 376).
\end{abstract}

O grande problema é que o Equador e o Peru, assim como a maioria dos países latino-americanos e amazônicos, têm fragilidades institucionais, o que dificultaria a implementação de muitos aspectos levantados no Estudo. Isto é, em muitos casos, notase que muitas instituições não conseguem cumprir seus papéis de reguladoras e fiscalizadoras, o que gera uma desorganização e as medidas de prevenção e mitigação de impactos socioambientais não são executadas.

O projeto de melhoramento da navegabilidade do rio Napo apresenta resistência por parte de alguns grupos organizados como a Rede de Comunidades do rio Napo que são contra a construção da hidrovia, pois consideram prejudicial para as populações amazônicas. De acordo com o próprio levantamento presente no quinto volume do Informe Final do Estudo Binacional (CARDINI, 2010e), foram realizadas reuniões informativas com grupos de interesses levantados ao longo do estudo que são: instituições do Estado, governos locais, organizações da sociedade civil e organizações indígenas. As reuniões foram na cidade de Iquitos, no Peru, mas durante a realização do 
estudo também foram realizadas entrevistas com autoridades governamentais, representantes de organizações e federações indígenas, dirigentes, pessoas residentes, colonos, indígenas, entre outros, durante as visitas de campo ao longo do rio Napo. Durante a reunião de Iquitos foram expostas informações sobre a IIRSA pelo Ministro Augusto Arzubiaga (Diretor Nacional da IIRSA no MRE do Peru), sobre o Estudo Binacional pelo seu diretor Julio Cardini, e sobre a "Estrada IIRSA Norte" pelo engenheiro Fernando Llanos representante da empresa Oderecht. Após as exposições foi realizada uma mesa-redonda com perguntas e respostas e depois todos os participantes preencheram formulários com perguntas e comentários. O próprio estudo concluiu a partir da participação dos diferentes atores sociais na reunião informativa que:

\begin{abstract}
previo al presente estudio poco se conocía sobre el dragado del río, uno de los temas que en ambos países desencadenó la más fuerte oposición a cualquier actividad afín; no obstante, del estudio objeto de la presente consultoría ha quedado claro que el dragado es imposible de realizar, al menos en condiciones técnicas y económicas razonables. [...] Se hizo énfasis en que las acciones relacionadas con la mejora de las condiciones de navegabilidad del río Napo, que incluyen el desarrollo de la infraestructura portuaria en diferentes categorías y la navegación de embarcaciones adaptadas a las características del río, induciría importantes efectos en las economías comunales y en la mejora de sus condiciones sociales. [...] Las opiniones de los participantes fueron diversas, desde un reconocimiento al esfuerzo y a los objetivos del estudio hasta una oposición, en general no intransigente, que, en algunos casos, se origina en las arraigadas concepciones políticas en contra de los Acuerdos de Paz firmados entre ambos países (Ecuador y Perú) y, en otros casos, en una férrea oposición contra el megaproyecto Manta-Manaos (CARDINI, 2010e, p. 424).
\end{abstract}

Em seguida serão analisados os principais conflitos que envolvem os recursos hídricos da Bacia do rio Napo, tanto no Equador quanto no Peru, bem como os impactos transfronteiriços. Os impactos devido à construção de projetos de infraestrutura como o de melhoramento da navegação da hidrovia do rio Napo já foram abordados acima.

\title{
4.3 Os principais conflitos e impactos socioambientais pelo uso dos recursos hídricos
}

$\mathrm{Na}$ bacia do rio Napo encontram-se uma diversidade de conflitos socioambientais ${ }^{47}$. Podem-se destacar os gerados pela exploração do petróleo e do gás natural, pela geração de energia elétrica por meio da construção de hidrelétricas, pela

\footnotetext{
${ }^{47}$ Para aprofundar a discussão sobre conflitos socioambientais, ver: ZHOURI e LASCHEFSKI, 2010; ACSELRAD, 2004; MARTINEZ-ALIER, 2007. Nesse trabalho assume-se que os conflitos socioambientais são definidos como aqueles que resultam de embates políticos, econômicos e sociais pelo uso, e seus impactos, dos recursos naturais (RIBEIRO, 2010).
} 
infraestrutura da hidrovia e pela mineração ilegal com a utilização de dragas. Alguns ocorrem próximos à fronteira, mas estão na escala nacional. Mas encontram-se também conflitos transfronteiriços.

Atualmente, o Equador depende do petróleo e gás natural para suprir sua demanda de energia. De acordo com López:

\begin{abstract}
puesto que el Ecuador exporta el 70\% del crudo que extrae de la Amazonia, e importa derivados de petróleo y electricidad para complementar una oferta total de energía dependiente de combustibles fósiles en $90 \%$ - con alto costo económico y ambiental -, se evidencia que en materia energética el país es no sostenible (2011, p. 1).
\end{abstract}

Fontaine complementa com os dados sobre o peso da produção nacional:

\begin{abstract}
Exportador neto de petróleo desde 1972, el Ecuador ocupa un rango intermedio en la geopolítica de los hidrocarburos en América Latina. Sus reservas de crudo convencional alcanzan actualmente 5.060 millones de barriles (OLADE, 2006) y se ubican en el $4^{\circ}$ rango regional, por cierto lejos detrás de Venezuela, Brasil y México. Sus exportaciones alcanzaron apenas 130 millones de barriles en 2004 y 2005, en comparación con unos 755 millones de barriles para Venezuela (OLADE, 2006: 21). Los principales países de destino son Estados Unidos (74,35\%), Perú (11,65\%) y Chile $(6,16 \%)(\mathrm{DNH}, 2007)$. En cambio, la importancia de los ingresos procedentes del petróleo en la economía nacional es bastante significativa. En efecto, en 2003 , las exportaciones de crudo y derivados representaron un $43 \%$ en valor de todas las exportaciones; la renta y los ingresos por concepto de exportación de derivados representaron un 33\% del presupuesto del Estado (Ministerio de Energía y Minas 2004). Además de ser la primera fuente de ingresos del país, constituyen también la principal fuente de financiamiento para el pago de la deuda externa [...]. En 2006, el nivel de la renta alcanzó 4.283 millones de USD (FONTAINE, 2008, p. 172-173).
\end{abstract}

No Peru, os combustíveis fósseis (petróleo, gás e carvão) correspondem a 75\% da produção de energia primária em 2007, e somente a participação do petróleo corresponde a aproximadamente 60\% (FONTAINE, 2010).

A exploração de petróleo e gás natural na Amazônia equatoriana e peruana tem gerado impactos socioambientais nas áreas em que está localizada, o que tem resultado em conflitos socioambientais. Esta exploração remonta à década de 1920 no Equador, quando começaram as primeiras pesquisas e prospecções, mas foi na década de 1970 que ela se intensificou em ambos os países.

No Equador, o governo militar, que chegou ao poder em 1963, realizou algumas mudanças referentes à exploração do petróleo no país como a criação da Corporación Estatal Petrolera del Ecuador (CEPE), em 1967, que permitiu que o governo participasse diretamente da exploração de petróleo. A CEPE é convertida em Petroecuador em 1989. 
En 1977, la nueva junta militar expidió la Ley de Colonización de la Región Amazónica Ecuatoriana [...]. A través de esas medidas, el Estado intentaba entrar definitivamente en la Amazonía e integrar la región al mercado nacional e internacional, mientras reforzaba la soberanía nacional en la frontera con Perú (FONTAINE, 2007, p. 272-273).

A irrupção da indústria petroleira no Equador foi chamada de "segunda conquista", pois gerou uma nova onda de imigração e colonização na Amazônia. Diferentemente da primeira colonização, os indígenas não foram capturados para ser mão-de-obra, apesar de existir indígenas trabalhando como operários assalariados para as empresas petroleiras, mas ambas as conquistas tiveram em comum, de acordo com David Maybury-Lewis (apud FONTAINE, 2007), a usurpação dos territórios indígenas e a destruição das suas estruturas sociais comunais.

Os impactos da atividade petroleira ocorrem desde a primeira fase, a exploratória, até a utilização dos produtos derivados do petróleo, passando pelas outras fases de exploração, transporte, armazenamento e refinamento. Um dos motivos para os conflitos socioambientais que tem ocorrido na Amazônia equatoriana é que os lotes de exploração de petróleo se sobrepõem, muitas vezes, às terras indígenas e áreas naturais protegidas (Mapa 6). De acordo com Velasco (2009), do total de povos indígenas do Equador:

\begin{abstract}
muchos de ellos están asentados en la Amazonia y, por tanto, propensos a la actividad petrolera. La Vicepresidencia Corporativa de Responsabilidad Ambiental, Social, Seguridad y Salud de Petroecuador informó que al 25 de noviembre de 2008 existía una sobre posición de bloques petroleros que impactaba el habitad de los pueblos Kichwas, Manta-Huancavilo y MantaHuancavilca. Y que, además, había incidencia sobre los territorios de las nacionalidades Shuar, Huaorani, Shiwiar, Achuar, Zapara y Secoya, entre otras. En muchos casos, el impacto de la actividad petrolera no sólo se limita a la ocupación de un área para la explotación de un yacimiento, sino al tendido de un gaseoducto o un oleoducto, que implica la deforestación, o al derrame de petróleo en la zona, tal como ocurrió el 14 de febrero de este año en la localidad amazónica de Santa Rosa (p. 7-8).
\end{abstract}

As atividades ligadas à exploração do petróleo geram grandes impactos que começam com o desmatamento para a construção de estradas para se chegar aos lotes e depois para construir a plataforma de exploração e portos (Foto 11). Em seguida, são desmatadas as áreas para os oleodutos, muitas vezes dispersos pelo território sem planejamento (Foto 12). Além disso, o afluxo de pessoas que vão trabalhar nesta atividade, também provoca desmatamento. Mas o principal impacto ambiental da atividade de exploração do petróleo é a contaminação, do ar, da água, do solo, dos animais, afetando, inclusive a saúde humana. 
Foto 11: Porto de empresa petroleira na margem do rio Napo, no Equador.

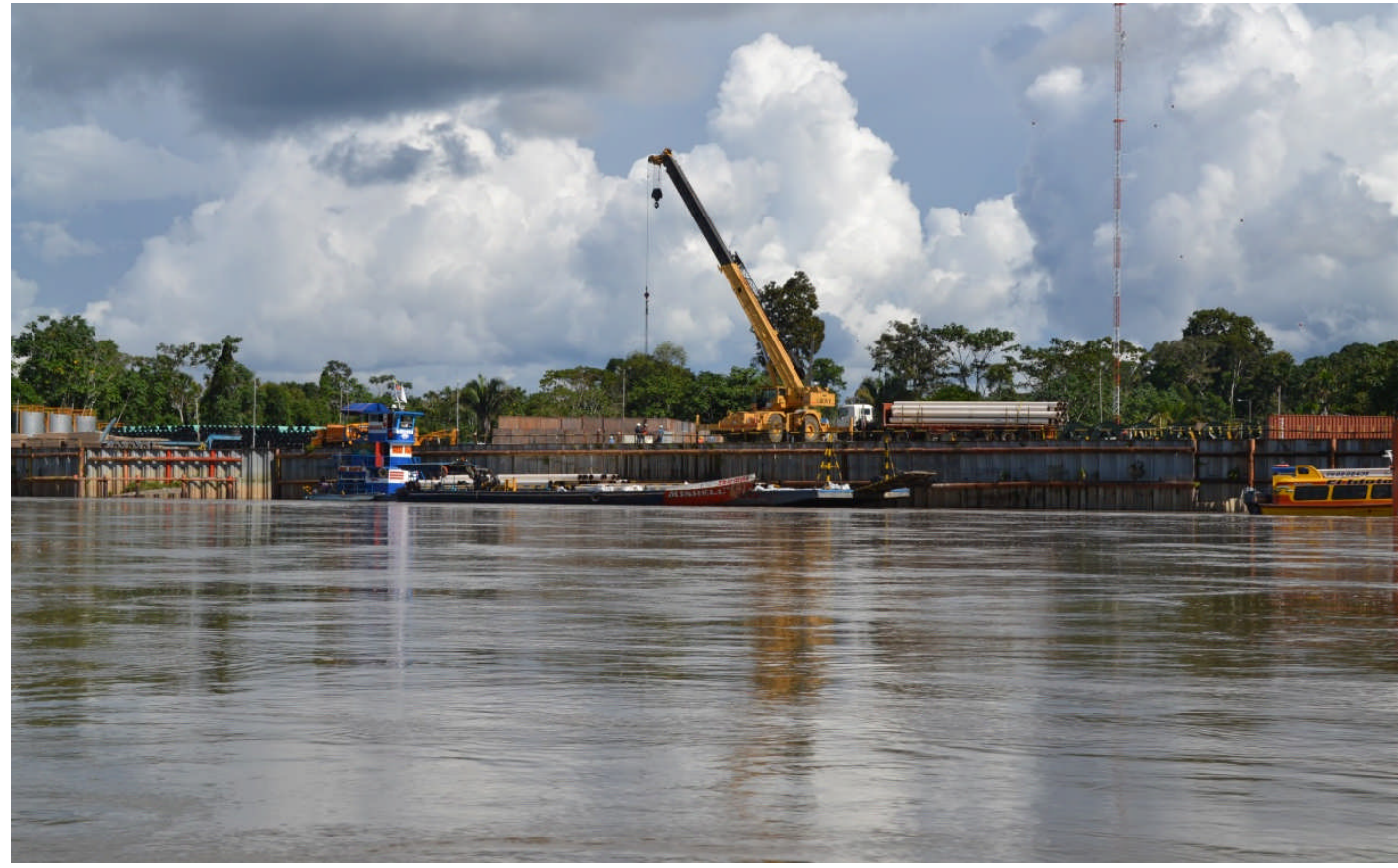

Fernanda Mello Sant'Anna, 2012. Observa-se que esta empresa petroleira possui uma estrutura portuária em boas condições.

Foto 12: Oleoduto na estrada que liga Nueva Loja (Lago Agrio) a Francisco de Orellana, no Equador.

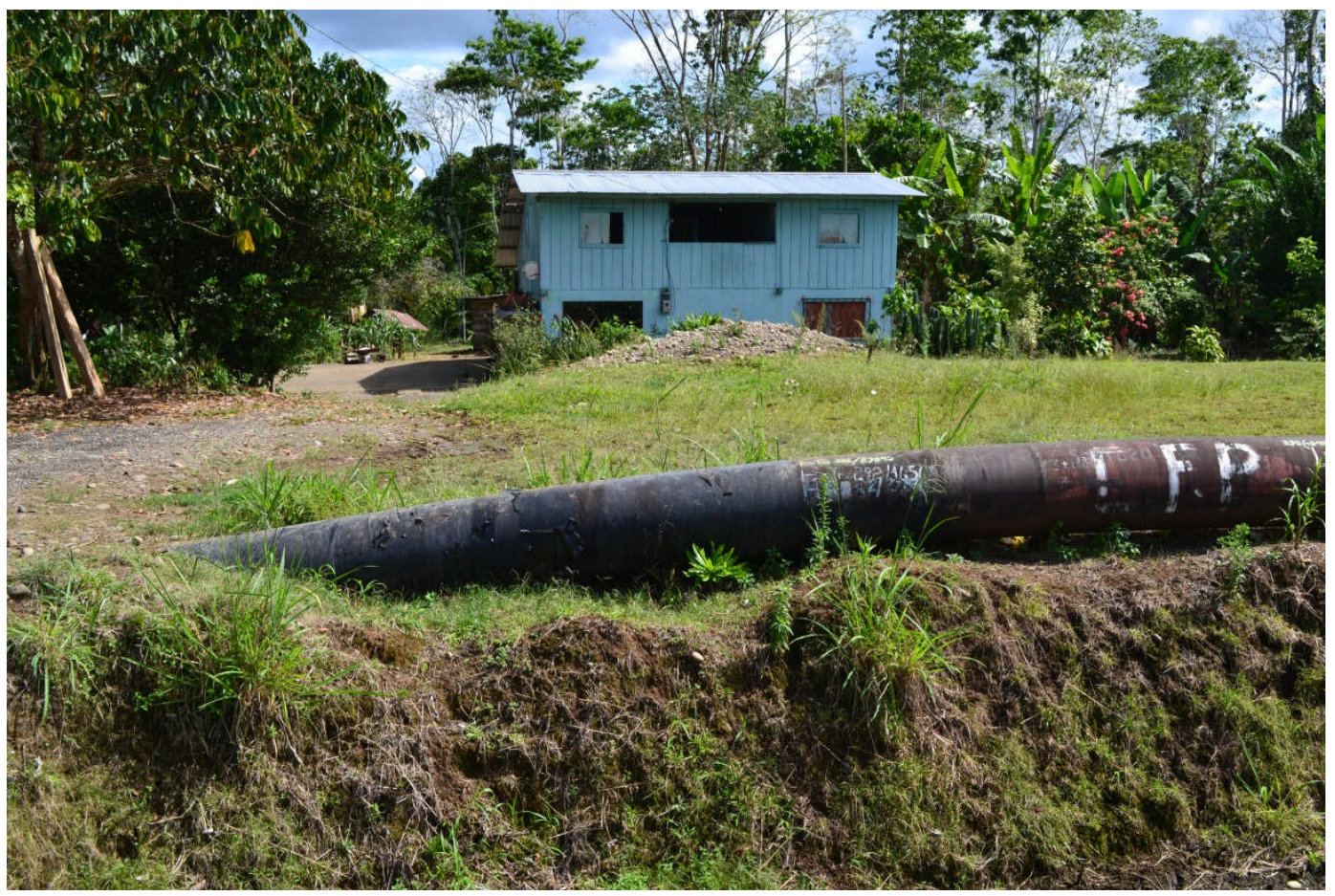

Fernanda Mello Sant'Anna, 2012. Oleoduto passa em frente a uma residência, na margem da estrada próxima a Nueva Loja (Lago Agrio), no Equador. Em caso de vazamento, a população seria afetada diretamente. 


\section{PROJETOS DE EXPLORAÇÃO ECONÔMICA NA BACIA DO RIO NAPO NA FRONTEIRA ENTRE EQUADOR E PERU}

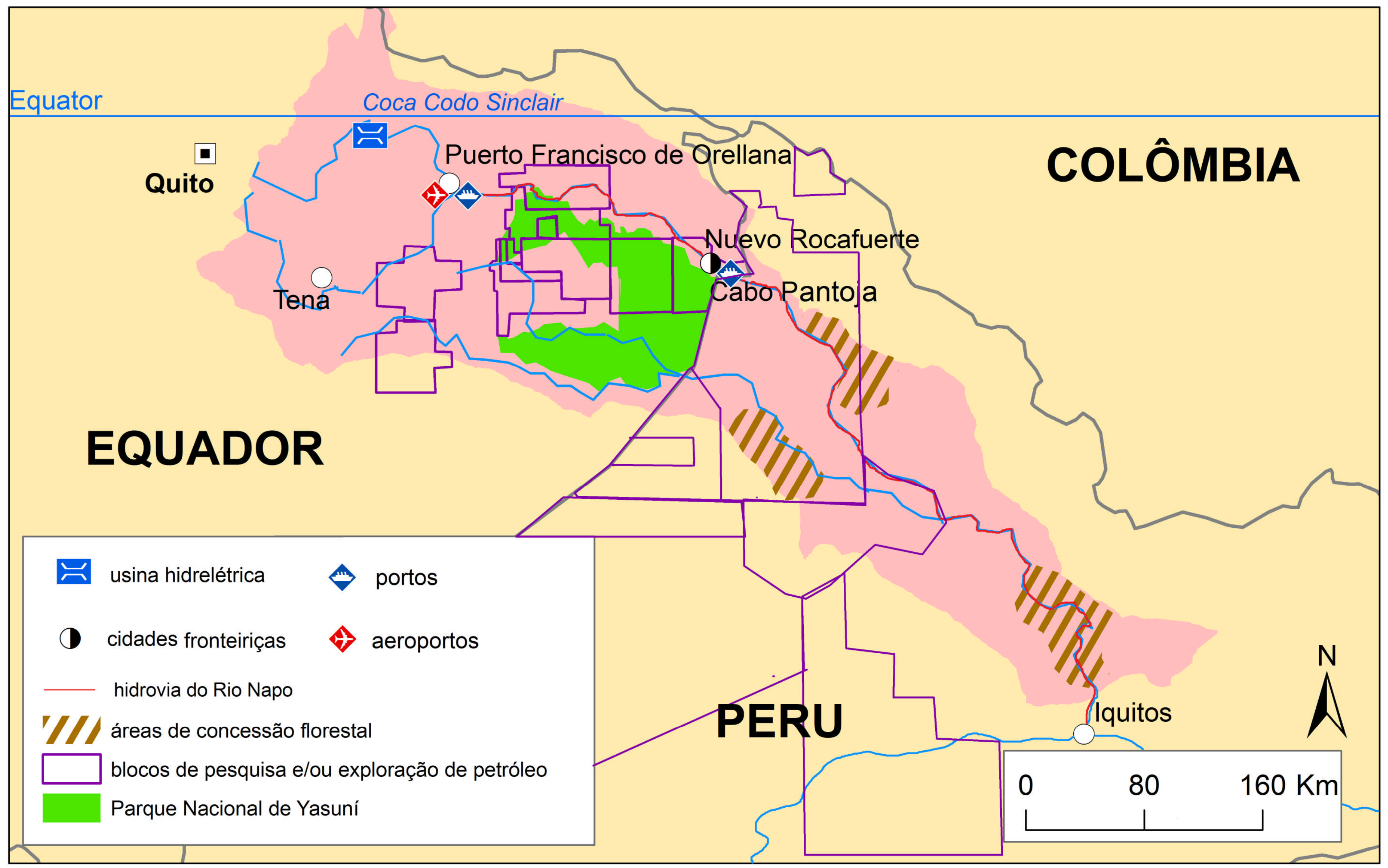

Autor: Fernanda Mello Sant'Anna

Elaboração: Tito Lívio Barcellos Pereira 
Fontaine (2007) sintetiza os impactos ligados a cada parte da atividade de exploração do petróleo, que contaminam todo o ecossistema ao redor:

la perforación de pozos genera en primer lugar la producción de lodos tóxicos y desechos sólidos no biodegradables que se almacenan alrededor. Luego, la estación de bombeo se vuelve un complejo sistema de extracción del petróleo, que opera una primera separación del producto pesado, del agua y del gas natural. Cada día, una estación de producción evacua un promedio de 72.000 barriles de agua contaminada por los productos químicos que sirven para el tratamiento del crudo. Digamos que, de manera esquemática, cada estación dispone de dos piscinas donde recogen, de una parte, las aguas de formación con fuerte composición en sales y componentes tóxicos, de la otra, las aguas residuales con fuerte composición en hidrocarburos. El gas es incinerado in situ, lo que genera una constante contaminación atmosférica. Cuando las aguas salinas son almacenadas a cielo abierto, contribuyen al secamiento del suelo y atraen a los animales domésticos o salvajes, que pueden entonces envenenarse. Por su parte, las aguas residuales pueden, bien derramarse cuando la lluvia hace subir el nivel de las piscinas y de la capa freática, o bien infiltrarse en el subsuelo y envenenar las redes hídricas vecinas. La cremación de estas piscinas, que a veces se practica para eliminar los hidrocarburos, es otra fuente de contaminación atmosférica. A esta contaminación crónica, se agregan la contaminación sonora, el calentamiento de la capa freática o de los ríos y esteros, que modifica el ecosistema, así como la contaminación de las aguas y suelos provocada por accidentes y las tareas de mantenimiento del sistema de oleoductos y de las estaciones de producción (FONTAINE, 2007, p. 278-279).

Os impactos para as comunidades indígenas são, em primeiro lugar, representados pela invasão de seus territórios e áreas de residência. As obras para a exploração do petróleo como o traçado de linhas sísmicas, a construção de plataformas e a própria exploração podem gerar resíduos que contaminam o ar, a água, o solo, os peixes, entre outros recursos naturais dos quais estas populações dependem para sobreviver. Outro tipo de impacto para as populações indígenas são as relações clientelistas e paternalistas que se formam entre estas e as empresas de petróleo. Um terceiro tipo de impacto

procede de la división de las comunidades indígenas, fomentada por las negociaciones con las empresas para el acceso a recursos, la cual significa a menudo una instrumentalización de las organizaciones sociales de base. Además, estas relaciones pueden tener efectos perversos en lo que atañe a la protección del medio ambiente por las comunidades afectadas, si éstas eligen percibir indemnizaciones por los daños ambientales, en vez de anticiparlos y evitarlos. Por otra parte, la organización social se afecta por la irrupción de nuevas posibilidades de trabajo y por la presencia de actores exógenos en el seno de las comunidades. La creación de empleos temporales, relativamente atractivos por su remuneración, puede generar una dependencia económica, no sólo al introducir una redefinición del trabajo en el seno de la comunidad sino también al provocar un efecto inflacionario sobre la economía local (FONTAINE, 2007, p. 279).

As populações camponesas e de colonos também são afetadas pelas atividades da exploração do petróleo, cujos efeitos podem ser percebidos na precariedade das 
condições de vida. Elas são, em geral, provenientes de outras regiões de seus países de origem, como, por exemplo, da região andina, e estão despreparadas para viver na Amazônia. São comunidades altamente dependentes das atividades e empresas ligadas à exploração do petróleo:

una consecuencia de esta dependencia es la formación de enclaves urbanos con servicios públicos deficientes debido al crecimiento demográfico mal controlado. Esta urbanización acelerada se acompaña de los fenómenos sociales conocidos: concentración de emigrantes pobres en los barrios mal equipados en infraestructura, violencia, prostitución, alcoholismo, etc. (FONTAINE, 2007, p. 280).

Um conflito que ficou bastante conhecido devido às suas consequências judiciais, bem como pela sua repercussão internacional, foi o das comunidades afetadas contra a empresa Texaco, que foi depois comprada pela Chevron, empresa que assumiu todos os passivos ambientais da anterior. Este conflito ocorreu em uma área na Amazônia equatoriana, na Bacia do rio Napo, que foi explorada durante muitos anos, próxima a cidade de Nueva Loja, mais conhecida como Lago Agrio. Como apontou Fontaine, no entanto, a contaminação pelas atividades petroleiras no norte da Amazônia equatoriana era "particularmente concentrada en los campos más antiguos y más productivos de la Amazonia ecuatoriana: Sacha e Shushufindi” (2005, p. 37), próximas a cidade de Nueva Loja.

O conflito entre a empresa Texaco e as comunidades afetadas foi institucionalizado na década de 1990 com a criação da "Unión de los Afetacdos y Afestadas por las Operaciones de la Petrolera Texaco" (UAAOPT). Esta união é formada por associações de base das comunidades afetadas, tais como os secoyas ${ }^{48}$, sionas $^{49}$, cofáns $^{50}$, huaranis ${ }^{51}$ e colonos das províncias de Orellana e Sucumbios, que formaram, em 1994, a Frente de Defensa de la Amazonia (FDA). A FDA representa a Assembleia dos Afetados pela Texaco e coordena a Assembleia de Delegados e executa as diretrizes do Comitê executivo da UAAOPT (FDA, 2013).

Foi em 1993 que estas comunidades afetadas entraram com uma "ação de classe" contra a Petroleira Texaco na Corte do Distrito Sul de Nova Iorque (Estados Unidos). Este processo judicial tem como causa os impactos sociais e ambientais da exploração de petróleo pela empresa que teve início em 1967 no Equador:

\footnotetext{
${ }^{48}$ Representados pela Organização Indígena Secoya do Equador (OISE).

${ }^{49}$ Representados pela Federação da Nacionalidade Siona do Equador.

${ }^{50}$ Representados pela Federação Indígena da Nacionalidade Indígena Cofán do Equador (FEINCE).

${ }^{51}$ Representados pela Organização da Nacionalidade Huarani do Equador.
} 
En 1964 se celebra el contrato entre el Estado ecuatoriano y la Texas Petroleum Company, el cual consiste en la concesión de aproximadamente un millón y medio de hectáreas en la región oriental, dedicados a la exploración y explotación de hidrocarburos durante 58 años, como máximo, a la Texaco del Ecuador C.A. y a la Gulf Ecuatoriana de Petróleo S.A.. [...] En 1967, después de tres años de exploración, la Texaco-Gulf encuentra petróleo [...] de buena calidad y en cantidades comerciables. El pozo Lago Agrio 1 arrojó una producción de 2.640 barriles por dia. [...] En 1976 el Consorcio TexacoGulf pasó a denominarse Consorcio CEPE-Texaco, el cual perforó entre 1967 y 1986 un total de 28 pozos exploratorios, de los cuales 18 fueron productivos (LASSO, 2010, p. 37-38).

Como já foi mencionado a CEPE se torna a Petroecuador que com o fim do contrato com a Texaco se torna dona exclusiva das instalações do antigo consórcio. Em 1995, depois da ação judicial já iniciada pelas comunidades afetadas, a Texaco assina um acordo com o governo equatoriano para a reabilitação da área e se isentando de maiores responsabilidades. Em 1996 entra em execução a "reparação ambiental" do acordo "con la colaboración de los municípios de Nueva Loja, Sushufindi, Joya de los Sachas y Coca, así como del Consejo Provincial de Sucumbíos, por un costo total de 40 millones de dólares" (FONTAINE, 2007, p. 287). Em 2002, a Corte de Nova Iorque resolve que a ação deveria ocorrer no Equador. Os afetados decidem então entrar com uma ação judicial na Corte Superior de Nueva Loja em 2003:

Dentro del proceso judicial, los demandantes se preocuparon por probar, como en derecho se requiere, todas las acusaciones contra la petrolera. Gran parte de la prueba que reposa en el juicio fue producida y pagada por la misma empresa demandada. En el record o expediente, se acumularon más de 230.000 páginas de información, se receptaron más de 40 testimonios de personas afectadas por las operaciones de Texaco, se incorporaron 106 informes periciales, 60 de los cuales fueron pagados totalmente por Chevron; se produjeron más de 80.000 resultados químicos de las muestras tomadas en el suelo, aguas o sedimentos; se entregaron a los jueces varios estudios de salud elaborados en forma independiente por expertos extranjeros. El juez inspeccionó y verificó directamente los daños causados en 54 sitios operados por la petrolera (FDA, 2013, sem página).

No ano 2000 a empresa Texaco foi comprada pela empresa estadunidense Chevron, que passou a ser sujeito da ação judicial. No ano 2011, O juiz Nicolás Zambrano da Corte Provincial de Sucumbíos, emitiu a primeira sentença contra a Chevron, que deveria pagar uma indenização de 9,5 milhões de dólares para a reparação do dano ambiental, incluindo a limpeza dos solos, a implantação de sistemas de água e saúde para as comunidades afetadas. Na sentença o juiz também impôs que a empresa pedisse desculpas públicas para os afetados em um prazo de 15 dias da divulgação da sentença. E se a empresa não se desculpasse a sanção seria duplicada (FDA, 2013).

Foram apontadas as causas da contaminação durante o contencioso contra a Texaco / Chevron: 
dentre as causas da contaminação, que elevou as taxas de mortalidade por câncer e doenças respiratórias, além de problemas reprodutivos e defeitos congênitos, estão: a) destinação completamente errada do enorme volume de água de formação [...] que deveria ter sido reinjetada no subsolo profundo; b) derrames de óleo inevitáveis nessa etapa industrial, frequentes no transporte por dutos [...]; c) disseminação de bacias de rejeitos ao ar livre, sem impermeabilização e vazadas diretamente na rede hídrica; a Texaco aterrou muitas delas para que desaparecessem da vista das equipes de vistoria; d) queimas de hidrocarboneto nas tochas de alívio e nos incêndios absurdos feitos para "limpar" bacias de rejeitos (SEVÁ FILHO, 2010, p. 123).

Para Fontaine:

[...] el caso Texaco no es un conflicto en el que se oponen exclusivamente comunidades indígenas y una empresa multinacional. En realidad, los campesinos colonos se constituyen la gran mayoría de los firmantes de la demanda presentada en Nueva York y de la población que pretendió defenderse en la "acción de clase". En realidad, [...], se trata de un caso típico de convergencia entre los movimientos ecologista, indígena y campesino, que se concretó con la creación, el 15 de mayo de 1994, del Frente de Defensa de la Amazonia (FDA) (2007, p. 287-288).

A FDA é uma organização da sociedade civil que tem atuado para além da ação judicial contra a Texaco / Chevron, capacitando e buscando fortalecer as organizações e comunidades de base contra os impactos socioambientais de certas atividades na Amazônia equatoriana.

Foram realizadas entrevistas com pessoas chave da FDA em Quito, em Nueva Loja e em Francisco de Orellana ${ }^{52}$, em julho de 2012. Pablo Fajardo, um dos advogados que tem atuado no processo judicial das comunidades contaminadas contra a Texaco-Chevron, afirmou, em entrevista, que o processo é uma ação coletiva das comunidades afetadas pela contaminação resultante da exploração de petróleo na região, que buscam que a empresa repare os danos, tanto ambientais como de saúde que afetaram a população. Durante o processo foram realizadas análises de amostras de água e solo das áreas contaminadas. O governo equatoriano não participou deste processo, pois tentou fazer um acordo com a empresa para a reparação de algumas áreas contaminadas. Explicou que uma vez o Congresso peruano fez uma Carta pedindo ao governo equatoriano para fazer uma análise da contaminação na bacia do rio Napo, em 1984, para saber se esta contaminação estava chegando ao Peru. No ano de 2012 a FDA entrou com um pedido na justiça brasileira para congelar os ativos e bens da Chevron no

\footnotetext{
${ }^{52}$ Foi entrevistado Pablo Fajardo, um dos advogados do caso contra a Texaco em Quito, em cinco de julho de 2012; também foi entrevistado Juan Espejos em Francisco de Orellana e o presidente da FDA, Wilmen Meneses, em Nueva Loja, também em julho de 2012.
} 
Brasil enquanto tramita o processo no Equador, pois o Brasil e o Equador tem um acordo que facilita a execução recíproca de sentenças entre os países.

Segundo o diretor provincial Juan Espejo da FDA de Orellana, em entrevista, as empresas privadas de petróleo não permitem que os técnicos da FDA façam coleta de amostras de água e solo para análise. Por este motivo, eles precisam passar pelos trâmites legais e burocráticos junto ao Ministério do Ambiente para solicitar as análises. Em alguns locais onde foram coletadas amostras para análise, os resultados das amostras da FDA divergiram dos apresentados pelo Ministério do Ambiente e pelas próprias empresas petroleiras, inclusive a Petroecuador (estatal). Uma das maiores dificuldades no trabalho da FDA é constatar a contaminação, pois tanto o governo como as comunidades utilizam o mesmo laboratório, e, em geral, as coletas são realizadas muitos dias depois das denúncias, o que diminui o seu efeito de detecção, por exemplo, na água, no exame laboratorial. Também apontou que, além do contencioso com a Texaco-Chevron, a FDA tem atuado para detectar a contaminação pela exploração de petróleo de outras empresas que atuam na Amazônia. Espejo afirmou que algumas vezes são feitas denúncias contra as comunidades no caso de acidentes e derramamento de petróleo, por exemplo, quando um duto se rompe alguns líderes das comunidades são acusados de sabotagem e terrorismo.

O advogado Wilmer Meneses, presidente da FDA, explicou que a FDA proporciona assistência jurídica para as comunidades, mas elas decidem o que querem fazer, se querem um acordo com a empresa petroleira que gerou o passivo ambiental, ou só um processo administrativo, ou um processo legal. Quando questionado sobre o repasse de verbas derivadas dos impostos e royalties pagos pela exploração do petróleo, afirmou que, na prática, muito pouco desta verba chega às comunidades afetadas. Afirmou que, nos últimos anos, ocorreram mudanças na legislação sobre os investimentos nas áreas onde se extraem petróleo, com a criação da instituição Equador Estratégico $^{53}$, cujo papel é receber projetos e financiar a sua implantação nas comunidades afetadas pela exploração de petróleo. Esta instituição teria a verba de $12 \%$ do valor do que é produzido de petróleo pelas empresas. No entanto, considera que o processo é demorado, os projetos tem que ser aprovados pelos técnicos do governo para comprovarem a sua viabilidade e muitas comunidades não tem como desenvolver este tipo de projeto por falta de técnicos capacitados. Apontou também o problema dos

\footnotetext{
53 Para maiores informações sobre a Ecuador Estratégico ver: <http://www.ecuadorestrategicoep.gob.ec/institucion/ecuador-estrategico>. Acesso em junho de 2013.
} 
Laboratórios e da divergência dos resultados das análises de amostras realizadas pela FDA, pelo governo e pelas empresas. Também afirmou, reiterando o relatado por Espejo, que atualmente as empresas de petróleo têm mudado sua tática de ação no caso de rompimento de oleodutos e contaminação, alegando que o rompimento foi resultado de atos de terrorismo e vandalismo por parte de líderes das comunidades afetadas. Essas ações resultaram na prisão de alguns líderes e, tiveram um efeito negativo sobre as comunidades, que estão com medo fazer novas denúncias de contaminação.

Alguns estudos demonstraram que este tipo de contaminação da atividade de exploração do petróleo e gás gerou diversas resistências, principalmente de organizações indígenas e de camponeses (FONTAINE, 2005; FONTAINE, 2007; LA TORRE, 1998; BUSTAMANTE e JARRÍN, 2007). Da mesma forma como ocorreu no Equador, às organizações indígenas afetadas por essa atividade no Peru também têm se mobilizado. De acordo com o pronunciamento da Organização Kichwaruna Wangurina do Alto Napo, localizada no Departamento de Loreto no Peru, as novas concessões realizadas pelo governo do ex-presidente Alan Garcia Pérez às empresas petroleiras em territórios indígenas, sem a consulta das populações, é um desrespeito aos direitos destes povos, em suas palavras:

\footnotetext{
Si queremos hacer un poco de historia, no queremos volver a vivir las consecuencias de lo que sucedió en la época del caucho. No queremos sufrir las consecuencias que hoy viven nuestros hermanos del río Corrientes y Pastaza. Queremos evitar que nuestro Napo, centro de nuestro vida, se vea una vez más afectado por el derrame petrolero, como así lo sufrieron los hermanos Kichwas del Ecuador, y como así lo vivieron hace poco nuestros hermanos del río Marañon (OKWAN, 2010).
}

Esta organização dos quíchuas da Bacia do rio Napo em território peruano se referem aos impactos negativos sofridos por outros povos indígenas nas bacias hidrográficas próximas à do Napo, que foram bastante impactadas pela exploração de petróleo, como a Bacia do rio Corrientes, do rio Tigre e do rio Pastaza. Em um estudo sobre o impacto das atividades petroleiras nas terras indígenas do Peru, La Torre (1998) analisou principalmente as áreas das bacias dos rios Corrientes, Tigre e Pastaza, na selva norte do Peru, e também o caso do gás de Camisea, na Bacia do rio Urubamba, e também na selva sul, no Departamento de Madre de Dios. No caso da selva norte:

a inicios de los setenta, las tierras ancestrales de las comunidades indígenas achuar, quíchua y urarina ubicadas em la parte nor-central de la Amazonia peruana, em las províncias de Loreto y Alto Amazonas, em el departamento de Loreto, fueron encuadradas al interior de dos lotes de explotación petroleira: el lote $1 \mathrm{AB}$, em las cuencas altas de los ríos Pastaza, Corrientes y Tigre, operado por Occidental Petroleum Corporation del Perú (OXY) y el lote conformado por la unidad operativa 8 y $8 X$, ubicado em las cuencas 
medias y baja del río Corrientes, con pozos de producción desconcentrados en la cuenca del río Chambira y en la "Reserva Nacional Pacaya Samiria", bajo conducción de la empresa nacional Petroperú (LA TORRE, 1998, p. 39).

Desde este período as empresas foram vertendo os resíduos da produção nos cursos d'água menores que chegavam aos rios Tigre, Corrientes e Pastaza. A água salgada, que é um dos dejetos da produção, era vertida nestes cursos d'água, que também foram contaminados por hidrocarbonetos e elementos tóxicos como metais pesados (chumbo, cromo hexavalente, entre outros). Estes metais se acumulam nos peixes e via cadeia alimentar contaminam as populações que viviam na área, o que ocasionou doenças e até mesmo morte por intoxicação (LA TORRE, 1998).

Em 2012, a plataforma "Pueblos Indígenas Unidos en Defensa de sus Territorios" (PUNAMUDT) publicou um mapa com as informações sobre o "Conjunto de Proyectos de Inversión em Hidrocarburos en Loreto". Neste mapa consta que a produção do Lote 67 será realizada via transporte fluvial pelos rios Napo, Curaray e Amazonas, até a Estação 1 do Oleoduto Norperuano, na Bacia do rio Marañon (SERVINDI, 2012). De acordo com a Petroperu (2013), a empresa Perenco que tem a concessão deste lote começará a transportar por esta via sua produção em julho de 2013.

Os impactos da atividade de exploração do petróleo também são transfronteiriços como foi o caso do acidente que ocorreu em junho de 2013 no Oleoduto Transecuatoriano, cujo derrame de petróleo no rio Napo atingiu e atravessou a fronteira com o Peru:

La Capitanía de Puerto de Iquitos y la compañía Petroperú confirmaron que una mancha de petróleo ha ingresado al río Napo, luego de que el pasado 31 de mayo, el deslizamiento de tierra y piedras del volcán Reventador afectará más de 100 metros de ductor del Sistema Oleoducto Transecuatoriano. Producto de esta situación, más de 100 barriles de petróleo cayeron al río Coca, afluente del río Napo, informó el corresponsal de RPP Noticias. Por lo pronto, trabajadores de la Capitanía y de Petroperú se encuentran en el centro poblado de Roca Fuerte para evitar que el petróleo siga avanzando y genere la muerte masiva de peces (RPP Notícias, 2013).

Apesar dos meios de comunicação terem informado sobre o dano transfronteiriço, os Ministérios de Meio Ambiente tanto do Equador como do Peru, informaram que não foi constatado dano transfronteiriço em sua página da internet (MINAM, 2013; MRRE, 2013).

Cabe também destacar um fato interessante sobre a exploração de petróleo na Bacia do rio Napo, no Equador, que é o caso que ficou conhecido como ITT-Yasuní, sobre os lotes de petróleo que ficam dentro dos limites do Parque Nacional de Yasuní. 
ITT se refere aos campos: Ishpingo, Tambococha e Tiputini, que foram descobertos na década de 1990. A possibilidade de explorar petróleo nesta área protegida e os impactos socioambientais decorrentes gerou grande mobilização da sociedade civil contrária a esta exploração. Foi então que em junho de 2007, o presidente da época, Rafael Correa:

[...] hizo pública uma propuesta "alternativa", que consiste em conservar los yacimientos de ITT in situ, a cambio de um pago por servicios ambientales, cobrado a la comunidade internacional. Inmediatamente, esta propuesta encontro uma buena acogida, sin lugar a duda por la toma de consciência al nível mundial de los efectos del cambio climático y la participación de hidrocarburos en la emisión de gases invernaderos (FONTAINE, 2008, p. 170).

Outro tipo de impacto socioambiental na área da Bacia do rio Napo é a construção de grandes hidrelétricas, como é o caso do projeto da central hidrelétrica Coca Codo Sinclair (CCS), na Alta Amazônia do Equador. Como o Equador é um país altamente dependente de combustíveis fósseis como fonte de energia, a exploração de fontes renováveis de energia tem sido considerada como essencial para atingir os objetivos expressos na Constituição e no Plano do Bem Viver para o desenvolvimento de energias renováveis. Para Chamoro (2012), o governo de Rafael Correa, atual presidente do Equador, tem uma visão de diversificação da matriz energética do país com base na expansão da hidroeletricidade. Várias instituições do governo declararam ser de alta prioridade nacional os projetos de construção de centrais hidrelétricas, e o maior deles é o CCS (CHAMORO, 2012).

Desde os anos 1970 e 1980, o governo equatoriano, por meio do, já extinto, Instituto Equatoriano de Eletrificação (INECEL), estudou o potencial hidrelétrico do país e as características hidroelétricas da Bacia do rio Napo, especialmente do rio Coca, seu tributário, que está localizado próximo à Cordilheira Oriental e possui cascatas e declives que poderiam ser aproveitados para geração de energia. A partir destes estudos se formulou o inventário energético dos rios Quijos e Coca, que foi desenvolvido e culminou na elaboração do projeto denominado Coca Codo Sinclair. Este projeto hidrelétrico foi definido como o aproveitamento hidrelétrico mais atrativo nesta bacia, e um dos maiores projetos de geração de energia por fontes renováveis do Equador (CCS, 2013).

O INECEL decidiu, com o propósito de definir a melhor alternativa e aproveitar a capacidade total de Coca Codo Sinclair, contratar um consórcio de empresas de construção para a elaboração dos Estudos de Factibilidade, foram elas: 
ELECTROCONSULT e RODIO da Itália, TRACTIONEL da Bélgica e as Equatorianas ASTEC, INGECONSULT e CAMINOS e CANALES (CCS, 2013).

De acordo com a empresa responsável pelo projeto, foi definido:

[...] el desarrollo del proyecto en dos etapas continuas, con capacidades de 432 y $427 \mathrm{MW}$, respectivamente, lo que sumaba $859 \mathrm{MW}$, según el estudio concluido en 1992. El CONELEC consideró que si bien el proyecto, concebido inicialmente con una capacidad de $859 \mathrm{MW}$, permite el desarrollo del sector eléctrico, el incremento de la demanda y el alto costo de la generación actual, exige el desarrollo de un proyecto de mayor magnitud y capacidad de generación. En 2008, se actualizaron los estudios que avalan la factibilidad técnica para una capacidad de $1500 \mathrm{MW}$ basado en el caudal de agua disponible. Este proyecto está considerado como prioritario y de alto interés nacional, con el objeto de cubrir en forma adecuada la demanda de potencia y energía en los próximos años, e incluso tener la posibilidad de exportar energía a los países vecinos" (CCS, 2013, sem página).

Trata-se de uma obra de infraestrutura localizada na confluência dos rios Quijos e Salado, pertencentes à sub-bacia do rio Coca, afluente do rio Napo. Ela abarca as províncias de Sucumbíos e Napo, no Equador. A central hidrelétrica terá uma potência de 1.500MW e um custo de 2,2 bilhões de dólares. As empresas que fazem parte do projeto são: Andritz; Compañia Energía Argentina S.A. (ENARSA); Compañia Hidroeléctrica Coca Codo Sinclair S/A; Termopichincha S.A.; e a chinesa Sinohydro Corp. (CCS, 2013). No Plano Mestre de Eletrificação estava previsto que a central começaria a operar sua última turbina em junho de 2014, no entanto, este prazo teve que ser alargado e atualmente sua construção tem um avanço de 7,5\% e a previsão é que suas turbinas comecem a operar em 2015 e as últimas no final do ano 2016 (CHAMORO, 2012).

De acordo com López (2009c), a água que será usada na central CCS provém da área de drenagem de diferentes unidades do Sistema Nacional de Áreas Protegidas (SNAP) do Equador e outras áreas florestadas, que chegam a cobrir $80 \%$ da área da subbacia do rio Coca. Ele alerta para o fato de que a regulação hidrológica desta central depende da existência destas áreas florestadas que estão em uma zona de elevada instabilidade geomorfológica e de grandes precipitações (LÓPEZ, 2009c). Os principais impactos da construção da central CCS são:

La captación del caudal en el Salado afectará a la cascada San Rafael, en un estimado del $60 \%$ de su caudal promedio, siendo este uno de los principales impactos del CCS, ya que se trata del mayor salto de agua del país. Del estudio de impacto ambiental preliminar del proyecto CCS, extraemos los principales impactos para la central hidroeléctrica, ya que no se menciona casi nada sobre las líneas de transmisión:

- Afectación permanente por procesos morfo-dinámicos activos.

- Impactos de vías de acceso [...]

- $\quad$ Impactos en turismo rafting [...] 
- Cambio en escorrentía subterránea

- Variación de caudales de ríos

- Asentamientos e inundaciones

- Aumento en la sedimentación

- Incremento en consumo de agua doméstica

- $\quad$ Proliferación de vectores (LÓPEZ, 2009c, p. 6).

É preciso também incluir como impactos socioambientais o desmatamento gerado pela construção da infraestrutura da central e dos assentamentos dos trabalhadores e, depois, pelas linhas de transmissão. Outros impactos incluem pressão e deterioração de ecossistemas hídricos e terrestres locais, o incentivo à colonização por vias de penetração e pressão sobre os centros urbanos que já sofrem com a falta de infraestrutura e serviços básicos (LÓPEZ, 2009c.). López (2009c) considera que a população residente na área impactada pela central, bem como as autoridades locais estavam preocupadas com a falta de informações sobre o projeto, tais como: os dados sobre o regime de precipitações na bacia, o que poderia levar a um superdimensionamento da central e das linhas de transmissão; os dados sobre o caudal ecológico; e o traçado definitivo das linhas de transmissão a Pifo e a Lago Agrio, e, também, informação clara sobre os propósitos desta linha ser de duplo circuito. Cabe ressaltar que apesar de existência de projetos de infraestrutura como este da hidrelétrica CCS, o governo equatoriano:

[...] no evidencia la incorporación de derechos de aguas y/o régimen de propiedad de la tierra como factores clave para la gobernanza energética. Así, falta entender el rol de la autoridad única del agua en el Ecuador (SENAGUA) en la gestión energética, sobre todo en la Amazonía, que a pesar de concentrar el $70 \%$ del agua dulce del país, no cuenta con instituciones ni regulación específicas para el manejo integrado de cuencas (LÓPEZ, 2011, p. 2).

Outro projeto de construção de uma central hidrelétrica na Bacia do rio Napo é a central Mazán, em território peruano. De acordo com o Protifólio de Projetos de Geração e Transmissão no Sistema Elétrico Interconectado Nacional (SEIN) do Peru, de 2008, a Central Hidrelétrica Napo Mazán está em fase de estúdio (concessão temporária) e aproveitará o potencial dos rios Napo e Mazán, na Província de Maynas, distritos de Maynas e Indiana, no Departamento de Loreto, com potência instalada de 154 MW (MEM, 2008). A empresa titular desta concessão de dois anos para a fase de estudos foi a IQUITOS HEPP S.A. No Portfólio também consta a Central Hidrelétrica Mazán, aproveitando também os caudais dos rios Napo e Mazán, com potência instalada de $150 \mathrm{MW}$, e a empresa titular da concessão temporária é a Electro Oriente S. A. 
(MEM, 2008). De acordo com a Resolución Directoral nº 059 de 28 de maio de 2013 da ANA, esta outorgou ao Governo Regional de Loreto a autorização para a elaboração de estudos para o aproveitamento hídrico com fins energéticos dos rios Mazán e Napo para a geração de energia (ANA-Peru, 2013). A central hidrelétrica nos rios Napo e Mazán encontra-se ainda em fase de estudos.

De acordo com Panduro (2012), os primeiros estudos para a construção da hidrelétrica Mazán foram realizados na década de 1980 com o objetivo de utilizar o caudal do rio Mazán, afuente do rio Napo. Mas em 2002, a empresa de consultoria internacional Canadian Executive Services Organization (CESO) realizou um estudo em que apresentava a incorporação do caudal do rio Napo ao projeto que passou a se chamar Napo-Mazán para aumentar a potência da central e a rentabilidade financeira. Em 2007 e 2008 também foram concedidas outorgas para a realização de novos estudos para as empresas Iquitos Hepp S.A. e Electro Oriente. O projeto desenvolvido pela CESO considera a captação de águas tanto do rio Napo quanto do rio Mazán e a construção de barragens de onze metros de altura e 175 metros de largura, bem como a construção de canais de condução das águas, casa de máquinas, abastecimento e equipamento das subestações e linhas de transmissão.

Para Panduro (2012), são inúmeros os impactos e desafios desta central hidrelétrica, pois, em primeiro lugar ela afetaria a navegabilidade do rio Napo no seu trajeto final, entre Mazán e Francisco de Orellana (no Peru), de 88,5 km. A construção do canal de derivação poderia acarretar um redirecionamento da corrente do rio Napo, convertendo o canal em braço principal do rio, desembocando no rio Amazonas perto da localidade de Indiana, lembrando que a distância entre os dois rios é de apenas $4 \mathrm{~km}$. Como resultado, a população que está assentada nesta parte das margens do rio Napo ficaria ilhada. Panduro (2012) também aponta outros questionamentos técnicos acerca do projeto relacionados ao potencial estimado. O caudal necessário para a geração de energia seria de $3.000 \mathrm{~m}^{3} / \mathrm{s}$, mas na época de vazante o nível do rio Napo diminui, e este caudal representaria entre $70 \%$ a $90 \%$ dos caudais mínimos do rio, o que ocasionaria a provável secagem do rio no trajeto entre Mazán e sua desembocadura no rio Amazonas, o que afetaria diretamente a população das margens do rio Napo, mais a dinâmica hidrológica do rio Amazonas a jusante. Além do que, a flutuação dos níveis das águas dos rios Napo e Amazonas é diferente, ou seja, quando o rio Napo está em seu nível mínimo, o rio Amazonas está em seu nível máximo, e a diferença de altitude entre eles oscilaria apenas de 2 a 4 metros. Esses fatores, de acordo com cálculos realizados pelo 
Colégio de Engenheiros do Peru, dificilmente tornariam o projeto da central hidrelétrica Napo-Mazán viável, e não alcançaria a potência de 150 MW (PANDURO, 2012).

A quantidade de sedimentos carregada anualmente pelo rio Napo é muito elevada, o que exigiria a dragagem permanente de sedimentos, aumentando o custo de operação do canal de derivação. Panduro (2012) defende que, ao invés de se construir hidrelétricas na Amazônia Baixa, seria preferível aproveitar o potencial hidrelétrico da Amazônia Alta, que é muito maior, e conectar Iquitos ao Sistema Elétrico Interconectado Nacional (SEIN), para atender a demanda crescente por eletricidade em Iquitos, além de também utilizar outras fontes renováveis de energia, como a solar.

Além da construção de hidrelétricas, outro impacto socioambiental que atinge a Bacia do rio Napo é causado pela mineração de ouro por meio da utilização de dragas, em especial na parte peruana do rio Napo. De acordo com o jornal peruano El Comercio de 27 de março de 2012, a Polícia Ambiental e a Marinha de Guerra do Peru destruíram sete dragas ilegais no rio Napo e prenderam 40 mineiros próximos à localidade de Santa Clotilde, esta operação foi denominada de Oro I. As dragas sugam a areia do leito do rio e a misturam com mercúrio para a extração de ouro e, de acordo com a Direção Regional de Energia e Minas de Loreto, se estima que na região de Loreto existam cem dragas artesanais do tipo balsa nos rios Napo, Marañon y Putumayo. Em uma jornada de 20 horas de trabalho com a draga se estima que seja extraída 15 gramas de ouro, que está cotado a 130 soles em Santa Clotilde, podendo chegar a 180 soles em Iquitos (RODRICH, 2012).

Para Alvares (2012), as dragas podem ser consideradas como de alto impacto, pois destroem o leito dos rios e contaminam com mercúrio a água e os peixes, deixando a população amazônica altamente vulnerável devido ao consumo elevado de pescado. Ele considera como um progresso nesta questão a aprovação do Decreto Legislativo n. 1100 de dezoito de fevereiro de 2012 que regula a interdição da mineração ilegal e estabelece medidas complementares. Este decreto proíbe, no âmbito da mineração artesanal e pequena mineração, o uso de dragas e outros artefatos semelhantes em todos os cursos d’água. Com as operações de fiscalização e destruição de dragas ilegais no rio Napo, e demais rios de Loreto, espera-se evitar a contaminação e a destruição que este tipo de mineração ocasionou no departamento de Madre de Dios (STRATEGIA, 2011).

A transposição de águas de uma bacia hidrográfica a outra também tem gerado tensões na parte equatoriana da Bacia do rio Napo. Com a implantação do Projeto Rios Orientais, o Distrito Metropolitano de Quito, no Equador, que se encontra da Bacia Alta 
do rio Guayllabamba, tem parte de sua demanda por água satisfeita por meio de uma transposição dos recursos hídricos de bacias da Cordilheira Oriental amazônica, a Oyacachi, Papallacta e Antisana, onde estão as Reservas Ecológicas Cayambe-Coca e Antisana. Esta transposição é operada pela Empresa Municipal de Agua Potável e Saneamento de Quito (EMAAP-Q). Como uma parte do Projeto impactaria o Vale de Quijos, sete governos municipais da região (seis da província de Napo e um da província de Sucumbíos) se mobilizaram no período de planejamento do Projeto para discutir tais impactos (LÓPEZ, 2009b).

Como exposto, os principais impactos socioambientais na Bacia do rio Napo compreendem aqueles oriundos das obras necessárias para o acesso à hidrovia do rio Napo e o melhoramento de sua navegabilidade, da contaminação hídrica resultante da exploração petrolífera, da construção de hidrelétricas e da contaminação por metais pesados usados na mineração do ouro. Apesar de ações em escala nacional e subnacional, como o decreto 1100, citado acima, elas ainda são insuficientes, como mostra a mobilização da Frente de Defesa da Amazônia.

Será discutida, em seguida, a governança dos recursos hídricos no Equador, em especial, nas províncias de Sucumbíos, Napo e Orellana, onde está localizada a Bacia do rio Napo. Isto irá permitir uma maior compreensão dos aspectos legais e institucionais envolvidos na governança dos recursos hídricos da Bacia do rio Napo em uma perspectiva multi-escalar.

\subsection{Arcabouço institucional da gestão dos recursos hídricos no Equador}

No Equador, a gestão dos recursos hídricos, em seu início, estava fortemente ligada à irrigação e, portanto, às atividades agropecuárias. Sua institucionalização foi, primeiramente, vinculada às instituições do setor agrário. A primeira norma legislativa sobre água no Equador foi promulgada em 1832 e tinha como objetivo principal a regulação do acesso à água por meio de um sistema de aquedutos e canais. (ORÉ, 2009, p. 130).

A segunda Lei de Águas foi promulgada em 1936, e criou a Direção de Obras Públicas, encarregada da sondagem dos recursos hídricos subterrâneos. O Ministério de Agricultura tinha o papel de aprovar as tarifas de aproveitamento de águas. Os juízes eram os responsáveis por controlar a concessão da água por meio de sentenças judiciais, enquanto que os municípios foram convertidos em usuários de água, ainda que com 
propriedades de prestação de serviços. Esta norma era mais completa que a anterior por incorporar disposições claras sobre as funções, e no referente ao acesso e uso da água (ORÉ, 2009).

Na década de 1940 o Ministério de Agricultura ampliou suas funções e passou a regulamentar a construção de estrutura de contenção em terras erodidas pelas águas. Em 1944 se cria a Lei de Irrigação e Saneamento do Solo, que incluía também o Ministério de Obras Públicas na gestão dos recursos hídricos. Até a década de 1960 a propriedade das águas era privada e a Direção de Recursos Hidráulicos e Eletrificação do Ministério de Fomento somente tentava resolver as controvérsias entre usuários, autorizar o uso da água e realizar estudos. Todavia, em 1960 uma nova Lei de Aguas é expedida e trata a água pela primeira vez como um bem nacional.

Em 1966 é criado o Instituto de Recursos Hidráulicos (INERHI) e quase todas as funções de gestão dos recursos hídricos se concentraram em uma única entidade: a Caixa Nacional de Irrigação, em sua Direção de Recursos Hidráulicos. A criação do INERHI é considerada como um avanço para a época, pois permitiu a gestão planejada pelo Estado (ORÉ, 2009).

Atualmente está vigente no Equador a Lei de Aguas de 1972, promulgada no governo do general Guillermo Rodriguez Lara. De acordo com esta lei, as águas continentais do país são de domínio público. Ela também introduz novas políticas para a gestão eficiente da água, e impossibilitou a propriedade privada sobre as fontes e caudais naturais. Assim, todas as águas em propriedade particular passaram a ser de domínio público e seus proprietários se transformaram em meros titulares de direito de uso. Para Oré:

en términos de técnica jurídica, la Ley de Aguas de 1972 mostró un enorme avance frente a las normas legales que la antecedieron . Estableció con mayor claridad el rol del Estado en la administración del recurso a través del sistema de concesiones de derechos del aprovechamiento de aguas, cuya dirección fue encargada al INERHI (2009, p. 135).

Em 1979 foi criado o Instituto Nacional de Meteorologia e Hidrologia com a função de gerar e disponibilizar informação sobre o caráter hidrológico, meteorológico, de qualidade de água, de contaminação de corpos d'água e de usos da água, que possam subsidiar os processos de tomada de decisão. No entanto:

el INAMHI no ha podido cumplir todas las funciones y tareas asignadas ya que enfrenta serias dificultades para generar datos confiables y oportunos. Su red básica de estaciones es muy antigua, con observadores que perciben remuneraciones extremadamente bajas y sin recursos económicos para la operación y mantenimiento de los equipos. Además, su estructura orgánica 
funcional es obsoleta y entorpece la realización efectiva de los objetivos institucionales. Su ubicación actual como organismo adscrito al Ministerio de Energía y Minas no obedece a ningún criterio técnico ni es coherente con las actividades que desempeña (RECALDE, 2007, p. 104).

Na década de 1990, o Banco Mundial propagou a necessidade de se reformar o sistema institucional dos países latino-americanos, o que implicava a redução do aparato estatal e a sua descentralização. Esse quadro também se encontra no Equador, que criou novas exigências ao aparato administrativo do Estado: con la aprobación de la Ley de Modernización del Estado, Privatizaciones y
Prestación de Servicios por parte de la Iniciativa Privada, ley 50 , se inició un
período de reestructuración estatal, descentralizando las funciones de las
entidades nacionales con sede en la capital. Lamentablemente, los procesos
de modernización no generaron cambios estructurales sino, más bien,
desarticularon gran parte de la función reguladora del Estado (ORÉ, 2009, p.
135).

A instituição coordenadora da gestão dos recursos hídricos no Equador era o Conselho Nacional de Recursos Hídricos (CNRH), que foi criado por decreto presidencial em 1994, assim:

a partir de esta norma y otras posteriores se modificó el marco institucional y legal de la gestión del agua. Desaparecido el INERHI, sus funciones fueron distribuidas entre el nuevo CNRH y las corporaciones regionales de desarrollo. De esta forma, las funciones reguladoras y normativas se concentraron en el organismo rector de los recursos hídricos, el CNRH, mientras las corporaciones regionales fueron encargadas de la administración de la infraestructura de riego, el control de la contaminación y la conservación de las cuencas hidrográficas (ORÉ, 2009, p. 136).

De acordo com Oré (2009), este processo de modernização das instituições do Estado não contou com uma visão integral e um planejamento adequado, pois ocasionou a criação de uma entidade reguladora débil, o CNRH. As reformas empreendidas não estabeleceram uma distribuição clara das responsabilidades das instituições vinculadas aos recursos hídricos. Além do que, o $\mathrm{CNRH}$ não conseguiu financiamento para desenvolver um programa de gestão de bacias, apesar da elaboração de alguns estudos, eles não foram executados. O conselho não conseguiu desenvolver programas para a solução de problemas importantes como a contaminação da água, as enchentes, e a construção de obras para atender a demanda crescente por recursos hídricos.

A Constituição Política de 1998 trouxe mudanças, pois estabeleceu que as águas eram bens nacionais de uso público e seu domínio e aproveitamento correspondia ao Estado. Entre os anos de 1997 e 2000 foram realizadas consultas públicas e esforços para modificarem as estratégias do setor hídrico e elaborar uma proposta política de 
gestão da água. Entretanto, fracassaram os esforços para realizar reformas na Lei de águas.

A gestão dos recursos hídricos no Equador estava centrada no CNRH que concentrava as decisões sobre todos os aproveitamentos e usos da água: água potável, saneamento, hidrelétrico, indústrias petroleiras, mineração, agroindústria, uso recreativo, águas sagradas e caudal ecológico. Junto à Secretaria do CNRH funcionava o Conselho Consultivo de Aguas (CCA), cuja função era resolver os conflitos de outorga de direito de uso da água, em segunda instância. O CNRH operava por meio de onze Agências de Agua (AGA) distribuídas pelo país.

Com os Decretos 1088/2008 e 90/2009, o CNRH é substituído pela Secretaria Nacional de Água (SENAGUA), que é, atualmente, a instituição coordenadora da gestão dos recursos hídricos no Equador, criada pelo Decreto de 2008 e regulamentada pelo de 2009, quando ela assumiu todas as suas funções do CNRH, exceto a de irrigação. É uma entidade ligada à Presidência da República e com nível de ministério. Seu objetivo é gerir de forma integral e integrada o recurso estratégico água. A gestão integrada dos recursos hídricos passa a ser de forma desconcentrada por bacia hidrográfica. Cabe à SENAGUA: exercer a direção nacional em gestão e administração da água; estabelecer as políticas públicas de gestão da água e determinar as normas e regras para sua aplicação; formular o plano nacional de gestão da água e assegurar que os programas e projetos de aproveitamento de água estejam de acordo com o Plano Nacional do Bem Viver (PNBV); estabelecer políticas de recuperação do uso da água, mediante tarifas; e ditar normas para o manejo de bacias no que concerne aos recursos hídricos (EQUADOR, 2008). A Constituição da República do Equador de 2008 declara que a agua é um direito humano fundamental e irrenunciável e constitui patrimônio nacional estratégico de uso público. Assim:

\footnotetext{
para su gestión identifica a cuenca hidrográfica como el espacio natural de trabajo, define una autoridad única nacional para ejercer su control, desde su planificación hasta sus usos e impide su privatización y la posiciona como un bien estratégico que merece una alta prioridad en la planificación y su gestión (LLORET, 2009, p. 20).
}

Para López e Balarezo (2012), a consagração do direito humano à água na Constituição de 2008 trouxe alguns avanços que foram traduzidos em políticas governamentais, além de ter aumentado o investimento público em água potável e saneamento, prioritariamente na área urbana. No entanto, para esses autores, o governo mantém uma concepção deste direito baseada no acesso, com o aumento da construção 
de infraestruturas, porém não há investimentos para garantirem a qualidade da água e não há um enfoque integral e que envolva todas as comunidades nos processos de gestão.

A grande preocupação da SENAGUA tem sido a aprovação de uma nova Lei de Águas, pois as mudanças na gestão introduzidas pela Constituição ficam impossibilitadas de se executar em sua plenitude se não forem modificados alguns aspectos da Lei de Águas. A SENAGUA apresentou em 2009 o Projeto de Lei Orgânica dos Recursos Hídricos, Uso e Aproveitamento de Água. Além disso, López e Balarezo (2012) apontam que não foram realizados investimentos para outros aspectos da gestão dos recursos hídricos como medições ambientais, estudos de valorização para determinar oferta e demanda hídrica, entre outros. Uma das grandes polêmicas para a aprovação de uma nova Lei de Águas é o tema das concessões:

\begin{abstract}
es posible que al finalizar esta gestión se cuente con un Plan Nacional Hídricos y que el Inventario de Recursos Hídricos que la SENAGUA está realizando dé cuenta del total de las concesiones y así ejecutar el mandato constitucional que, a través de su vigésimo séptima disposición transitoria, establece que se "revisará la situación de acceso al agua de riego con el fin de reorganizar el otorgamiento de las concesiones, evitar el abuso y las inequidades en las tarifas de uso, y garantizar una distribución y acceso más equitativo, en particular a los pequeños y medianos productores agropecuarios" (LÓPEZ e BALAREZO, 2012, p. 9).
\end{abstract}

Outros problemas levantados sobre a implementação das novas regras para a gestão dos recursos hídricos pela SENAGUA foram, por exemplo, a não estatização das empresas privadas que tem a concessão para o abastecimento de água em algumas cidades equatorianas. A falta de conhecimento estatal sobre os sistemas autogeridos pelas comunidades é outro problema já que o Estado não consegue inclui-las na nova proposta de lei, e também não abre espaço para uma maior participação, por exemplo, das juntas de agua $^{54}$ e de irrigação (LÓPEZ e BALAREZO, 2012). Fernandez e Buitrón (2011), apontam também que ainda persiste uma sobreposição de responsabilidades e políticas entre diferentes instituições do governo nacional, como o Ministério do Ambiente, o Ministério de Desenvolvimento Urbano e Vivenda (MIDUVI), o Ministério de Saúde Pública (MSP) e a Instituto Nacional de Irrigação (INAR).

Existe também na escala nacional no Equador o "Foro de los Recursos Hídricos", no qual participam os cidadãos e organizações da sociedade civil, trata-se de

\footnotetext{
${ }^{54}$ As juntas de água são descritas por López e Balarezo (2012) como instâncias de organização autônoma onde as comunidades contribuem na construção de sistemas de água e saneamento por meio do trabalho autogerido, ou seja, colaborativo e gratuito, chamado de "minga".
} 
um "espacio ciudadano de gran convocatória y cobertura nacional" (LLORET, 2009, p. 20). O Foro foi criado em 2001 como uma plataforma de construção coletiva, democrática e plural, que analisa e propõe políticas públicas e alternativas para a gestão integral da água. Ele é coordenado pelo Consórcio de Capacitação para o Manejo dos Recursos Naturais Renováveis (CAMAREN) (LÓPEZ e BALAREZO, 2012). E tanto a SENAGUA quanto o Foro estão debatendo, analisando e discutindo, nos últimos anos, as propostas para uma nova lei de águas (LLORET, 2009).

O Diretor Regional do escritório regional da SENAGUA em Francisco de Orellana, assim como o técnico Júlio Quilumba, afirmaram em entrevista realizada em julho de 2012, que não existirem muitos dados sobre a Bacia do rio Napo, apesar de já ter sido realizada a demarcação hidrográfica da área da bacia. Com o processo de descentralização os governos municipais ficaram encarregados de realizar a gestão ambiental do município, mas não possuem recursos financeiros e nem capacidade técnica suficiente para realizar um trabalho eficiente. Em muitos casos, o pessoal técnico não tem consegue elaborar projetos para receber recursos de fundos do governo central. Eles informaram que também é preciso capacitar os técnicos que trabalham na região amazônica em técnicas específicas para monitorar e estudar os rios da Amazônia, pois não se pode aplicar, em muitos casos, as mesmas técnicas de outras regiões na Bacia do rio Napo, por exemplo.

O chefe de qualidade ambiental do Governo Municipal de Francisco de Orellana, o engenheiro Marcos Baño, informou em entrevista realizada em julho de 2012, que o governo municipal tem buscado monitorar a qualidade de água no município. Ele forneceu os relatórios com os dados de qualidade da água em vários pontos de monitoramento. Naquele momento uma das grandes preocupações do governo municipal era a elaboração de um projeto para a construção de um aterro sanitário no município.

A contaminação da água e demais recursos naturais também é responsabilidade do Ministério do Ambiente (MA). A engenheira Claudia Fernandez explicou, em entrevista realizada em julho de 2012 em Quito, que é função do MA monitorar os casos de contaminação, os passivos ambientais e cobrar a sua reparação, por meio do 
Programa de Reparação Ambiental e Social (PRAS) ${ }^{55}$ e do Sistema de Indicadores de Passivos Ambientais e Sociais (SIPAS) ${ }^{56}$.

Ao analisar o marco institucional nacional para a governança dos recursos hídricos no Equador nota-se que a temática dos recursos hídricos tem sido pautada, principalmente, pelo contexto andino e da área costeira equatoriana, onde está concentrada a maior parte da população do país. Existe uma grande mobilização social representada pelo Foro de Recursos Hídricos, e também o reconhecimento da água como um direito humano na Constituição de 2008. No entanto, a autoridade central do governo para a gestão da água não tem recursos para implementar todas as ações necessárias para cumprir suas amplas funções. Enquanto isso, a descentralização da gestão ambiental também é acompanhada por falta de recursos financeiros e técnicos para realiza-la nos níveis subnacionais como o provincial e municipal, no que se refere a parte amazônica, especialmente na Bacia do rio Napo. Todavia, a Bacia possui áreas bastante afetadas por contaminação devido à exploração do petróleo e gás natural, e conflitos socioambientais decorrentes.

Em suma, observa-se que o país está em uma transição institucional a partir do governo Correa, ou seja, desde a Constituição de 2008. O reconhecimento do Direito Humano à água e a implementação de ações previstas nos decretos de 2008 e de 2009 que envolvem a SENAGUA, se executada em coordenação com os níveis subnacionais, podem constituir um processo de governança, desde que conte com a presença do Foro de Recursos Hidricos.

A seguir serão discutidas as instituições da governança dos recursos hídricos na parte peruana da Bacia do rio Napo, que corresponde ao Departamento de Loreto.

\subsection{Arcabouço institucional da gestão dos recursos hídricos em Loreto - Peru.}

Como a governança dos recursos hídricos no Peru já foi abordado no capítulo três, não será necessário retomá-la aqui, apenas discutir como ela se insere no Departamento de Loreto, onde está localizada a Bacia do rio Napo em território peruano. É importante lembrar que a ANA-Peru é a responsável pela gestão dos

\footnotetext{
${ }^{55}$ Maiores informações sobre este programa podem ser encontradas em sua página na internet, disponível em: <http://www.ambiente-pras.gob.ec/>. Acesso em junho de 2013.

${ }_{56}$ Maiores informações sobre o SIPAS estão disponíveis em: <http://www.ambiente-pras.gob.ec/sipas/>. Acesso em: junho de 2013.
} 
recursos hídricos no país, e possui agências descentralizadas nas unidades hidrográficas do território peruano.

A agência local da ANA-Peru para a Bacia hidrográfica do Amazonas tem sua sede em Iquitos, Departamento de Loreto (Autoridade Administrativa de Água Amazonas - Administração Local de Água - Iquitos). E, de acordo, com o diretor responsável pela agência, o engenheiro Héctor Hugo Barbales ${ }^{57}$, até aquele momento (julho de 2012), não existia nenhum estudo atualizado sobre as condições socioambientais da Bacia hidrográfica do rio Napo, realizado pelo governo peruano. No entanto, em janeiro de 2013, técnicos da ANA-Peru e da empresa de consultoria Infraestrutura e Ecologia (Infraeco) se reuniram em Iquitos com especialistas em recursos hídricos de instituições estatais e privadas dos Departamentos de Amazonas e Loreto, com o objetivo de elaborar um diagnóstico dos recursos hídricos desta zona da Amazônia peruana. Este diagnóstico servirá de base para a elaboração da parte sobre a Bacia Amazônica do Plano Nacional de Recursos Hídricos do Peru (ANDINA ${ }^{58}, 2013$ ).

O Governo Regional de Loreto (GRL) possui uma Gerência Regional de Recursos Naturais e Gestão do Meio Ambiente. No dia 25 de julho de 2012 foram entrevistados nesta gerência o diretor Wilfredo Panduro Cárdenas e engenheiro Ronald Manuel Panduro Tejado que apontaram a realização de um estudo por parte desta gerência sobre as dragas de mineração de ouro ilegais existentes no rio Napo. No entanto, no momento este estudo ainda não havia sido aprovado pelas instâncias superiores para ser disponibilizado. Nos últimos anos diversos jornais peruanos da região noticiaram a destruição de dragas ilegais ao longo do rio Napo, em uma parceria entre a Marinha e a Polícia Ambiental, como já foi apontado neste trabalho.

Em 2008, o Governo Regional elaborou um Plano de Desenvolvimento Regional de Loreto de 2008 a 2021. Neste plano consta como um objetivo promover o uso e produção sustentável dos recursos naturais com valor agregado, com base no Zoneamento Ecológico Econômica (ZEE) e no Ordenamento Territorial (OT). Neste ano foi declarado de interesse regional o OT de Loreto (Ordenanza Regional $n^{\circ}$ 0262008-GRL-CR) baseado no ZEE e outros instrumentos de OT vigentes. O OT é responsabilidade da Gerência Regional de Planejamento, Orçamento e Organização

\footnotetext{
${ }^{57}$ A entrevista com o engenheiro Hector Hugo Barbales, da Adminsitração Local da ANA em Iquitos, foi realizada no dia 25 de julho de 2012 .

${ }^{58}$ Esta notícia pode ser lida no jornal Andina, disponível em: <http://www.andina.com.pe/Espanol/noticia-elaboraran-diagnostico-recursos-hidricos-de-amazoniaperuana-442671.aspx\#.UdQxEfnql1w>. Acesso em: junho de 2013.
} 
Territorial por meio da Comissão Técnica Regional (CTR) de ZEE para o OT de Loreto, em coordenação com a Gerência Regional de Recursos Naturais e Gestão do Meio Ambiente (GRRNGMA) e a Gerência Regional de Desenvolvimento Econômico (GRDE) que estão desenvolvendo o Projeto de Desenvolvimento de Capacidades para o OT no Departamento de Loreto ${ }^{59}$. Também participam do projeto os governos locais, o Instituto de Investigação da Amazônia Peruana (IIAP) e outras instituições regionais.

Entre os programas listados no Plano de Desenvolvimento Regional de Loreto consta o Sub-programa de Saneamento Básico e o Integração e Desenvolvimento Fronteiriço (GRL, 2009). Como já foi apontado neste trabalho um dos grandes problemas que afeta a população de Loreto e, especificamente, da Bacia do rio Napo, é a falta de serviços de água potável e saneamento. Em 2001, o INADE implementou algumas infraestruturas de abastecimento de água na Bacia do rio Napo, em Loreto. O GRL busca ampliar a construção deste tipo de infraestrutura. Além disso, o GRL também procura desenvolver cadeias produtivas na região e acredita que o Eixo de integração Multimodal do Amazonas, da IIRSA, representa um avanço ao integrar os países amazônicos (GRL, 2009).

De acordo com o Estudo sobre a Navegabilidade do rio Napo (CARDINI, 2010), as localidades ao longo do rio Napo em território peruano apresentam problemas de saúde relacionados ao consumo de água não potável e a falta de infraestruturas de saneamento básico. As doenças do sistema gastrointestinal agudas estão relacionadas ao consumo da água do rio sem qualquer tratamento, o que ocorre na maioria das localidades.

\subsection{Formação de um processo de governança dos recursos hídricos transfronteiriços na Bacia do rio Napo}

Observa-se que a governança da água, definida como o processo político de tomada de decisão em que diversos atores determinam os valores e objetivos que direcionam o gerenciamento da água e a escolha dos meios para se chegar a estes objetivos, na Bacia do rio Napo é incipiente. A existência de conflitos socioambientais resultantes do uso dos recursos hídricos e seus efeitos demonstra a falta de regulação sobre as atividades econômicas que causam impactos diretos sobre os recursos hídricos

\footnotetext{
${ }^{59}$ Maiores informações sobre este projeto estão disponíveis em: <http://www.regionloreto.gob.pe/pag_sig/index.htm>. Acesso em junho de 2013.
} 
da Bacia do rio Napo. Também nota-se que não são todos os atores sociais que participam da tomada de decisões nas diferentes escalas sobre o uso e a gestão dos recursos hídricos da bacia. A falta de articulação entre as instituições e atores sociais presentes nas diversas escalas e, principalmente, a falta de articulação transnacional em rede da sociedade civil na bacia dificultam a construção da governança. A inexistência de cidades gêmeas, a distancia entre as comunidades na Bacia do rio Napo e o fato da fronteira ter sido fechada por quase um século pode ter contribuído para a falta de articulação transnacional.

No caso do Plano Binacional de melhoramento da navegabilidade do rio Napo, apesar de um início com resistência da população local e das comunidades indígenas, estas perceberam que a melhoria das condições de navegação traria impactos positivos para esta população.

$\mathrm{Na}$ escala nacional o Equador tem empreendido mudanças a partir da Constituição de 2008 e da criação da SENAGUA que se implementadas em articulação com as instituições subnacionais e com a participação de todos os atores sociais envolvidos, pode se consolidar como um processo democrático de governança que busque solucionar os conflitos socioambientais existentes na Bacia do rio Napo. Atualmente, ainda é preciso articular e coordenar as ações dos atores nas diferentes escalas. A mobilização da população afetada pela contaminação petroleira poderia ser aproveitada para o processo de governança mais abrangente que envolvesse toda a Bacia do rio Napo e a problemática em torno de sua gestão.

No Peru o processo de governança é ainda mais incipiente do que Equador, pois a população local que vive na parte peruana da Bacia do rio Napo não está articulada para apresentar demandas e participar em conjunto com as instituições do governo e demais atores sociais em um processo de governança. Quando existe canais de participação da sociedade civil, como foi o caso das reuniões informativas do Estudo Binacional sobre o melhoramento da navegabilidade do rio Napo, a população articulou demandas, principalmente, para a construção de infraestruturas de abastecimento de água potável e saneamento.

A Figura 4 mostra a governança incipiente existente na Bacia do rio Napo onde os atores nas escalas não estão muito articulados. Os impactos e conflitos socioambientais ocorrem na escala subnacional, enquanto que existem projetos que são frutos de inciativas internacionais como a IIRSA, a OTCA, e o Plano Binacional. A cooperação internacional entre Equador e Peru envolve, até o momento, apenas as 
escalas nacional e internacional, pois não tem envolvido as instituições e atores subnacionais da Bacia do rio Napo. 


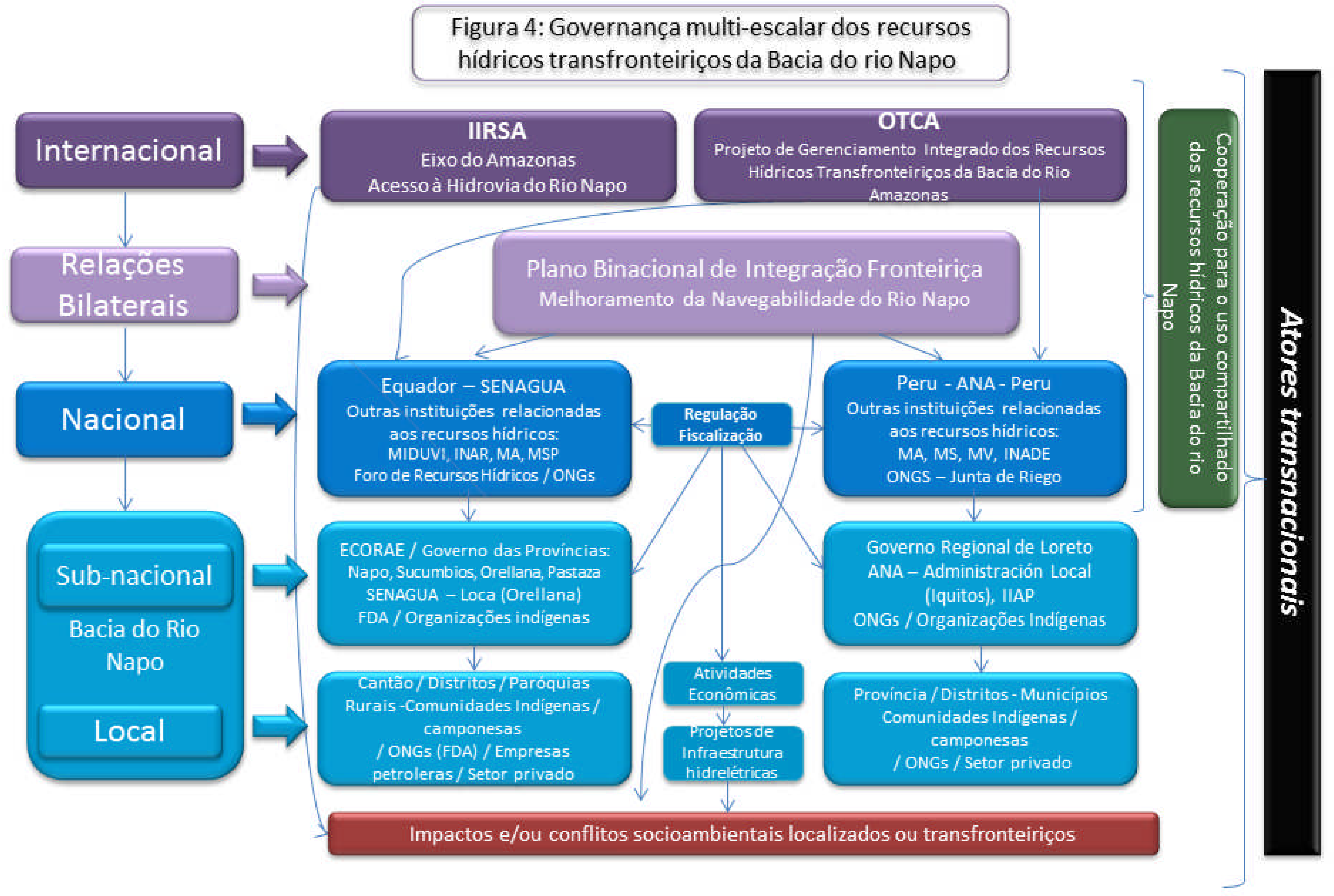




\section{CONSIDERAÇÕES FINAIS}

Este trabalho buscou analisar o processo de governança dos recursos hídricos transfronteiriços na Bacia Amazônica em uma perspectiva multi-escalar. A hipótese que norteou a pesquisa era de que a cooperação internacional seria necessária para a construção de um processo de governança multi-escalar desta bacia transfronteiriça. Este estudo demonstrou que em um contexto onde não há cooperação internacional o aproveitamento conjunto dos recursos hídricos compartilhados está prejudicado, bem como qualquer outra ação conjunta relativa a eles. No entanto, a existência da cooperação entre os países que compartilham a Bacia Amazônica não garante a construção de um processo de governança visto que a cooperação visa, principalmente, o desenvolvimento de projetos comuns de infraestrutura, como hidrelétricas e hidrovias, o que por si só não constitui um processo de governança.

A governança da água foi definida neste trabalho como o processo político de tomada de decisão, em que participam os diversos atores envolvidos com a questão dos recursos hídricos, que determina os valores e objetivos para a regulação e o gerenciamento do uso da água. No caso de uma bacia transfronteiriça como a amazônica a cooperação entre os países deveria estar inserida neste processo de tomada de decisão democrático em coordenação com as outras escalas pertinentes como a nacional e a local. Os projetos elaborados no âmbito da cooperação internacional são realizados na escala local, muitas vezes sem qualquer processo de debate e articulação com as instituições e atores locais onde incidem os projetos, o que vai contra a ideia de governança da água.

A governança dos recursos hídricos de uma bacia transfronteiriça só pode ser multi-escalar, pois há uma sobreposição de escalas em que atuam diferentes atores. Nas Bacias amazônicas estudas não existe uma coordenação entre as escalas internacional, nacional e local que constitua um processo de governança. Na escala internacional existem iniciativas de cooperação internacional como a OTCA e a IIRSA que não se articulam com as esferas locais em que são realizados seus projetos. A falta de articulação se reflete desde o planejamento dos projetos que não contam com a participação de todos os atores envolvidos e que seriam impactados por eles.

$\mathrm{Na}$ Bacia do rio Napo a cooperação internacional para uso compartilhado dos recursos hídricos transfronteiriços ocorre através do projeto de melhoramento da hidrovia do rio Napo trazendo benefícios para ambos países. Na Bacia do rio Acre a 
cooperação internacional entre os três países que a compartilham ocorre com os projetos de infraestrutura como a Estrada do Pacífico, mas não envolve o compartilhamento dos recursos hídricos. A cooperação internacional para o aproveitamento conjunto dos recursos hídricos ocorre nas bacias próximas a do rio Acre, como os projetos das hidrelétricas no rio Madeira e no rio Inambari.

Existem assimetrias nas relações de poder em ambos os casos, mas que não podem ser consideradas como um tipo de hidro-hegemonia. Na Bacia do rio Napo o Estado a montante é o Equador que tem vantagens por controlar as cabeceiras do rio e também pelo fato de não receber contaminação transfronteiriça. O Peru que está a jusante sofre com a contaminação hídrica transfronteiriça resultante da exploração do petróleo, entretanto, no que concerne a navegação o país apresenta vantagem já que controla o acesso ao rio Amazonas e pode limitar o comércio internacional do Equador. Isto não acontece devido aos acordos assinados pelos países em 1998 que garantem a livre navegação entre eles.

$\mathrm{Na}$ Bacia do rio Acre o Brasil possui maior poder econômico e melhor infraestrutura institucional para a gestão ambiental e dos recursos hídricos em relação ao Peru e à Bolívia. No entanto, está situado a jusante o que acarreta desvantagens, já que a falta dessas infraestruturas nos demais países impacta o Brasil como, por exemplo, a questão dos recursos pesqueiros.

As teorias discutidas no primeiro capítulo deste trabalho mostraram que apesar de não existir guerras internacionais pela água, a disputa entre Estados pelos usos dos recursos hídricos pode contribuir para o agravamento de tensões no seio de relações já conflituosas. Esta situação poderia ocorrer no caso da Bacia do rio Napo, pois existe um risco de contaminação hídrica transfronteiriça envolvendo dois países que estiveram em conflito por quase um século e cujo acordo de paz é recente. A governança da bacia ao envolver todos os atores sociais poderia contribuir para solucionar problemas comuns e fortalecer a cooperação prevenindo conflitos.

Iniciativas locais de governança, como o caso da Iniciativa MAP, podem emergir mesmo sem o apoio das organizações de cooperação multilateral, como a OTCA. Na Bacia do rio Acre a governança transfronteiriça está concentrada nos esforços para a gestão conjunta com o intuito de reverter os processos de degradação, como pode ser observado nas ações e objetivos da Iniciativa MAP.

O modelo de governança global da água fomentado por instituições como a ONU, o GWP e os Fóruns Mundiais da Água, é seguido, em maior ou menor grau, 
pelos quatro países estudados. A ideia de gestão integrada utilizando a bacia hidrográfica como unidade de planejamento e gestão faz parte da política de recursos hídricos nos quatro países. No Brasil e no Peru a água é vista como um bem com valor econômico e permitem a privatização dos serviços de água e saneamento e a cobrança pelo seu uso. Na Bolívia e no Equador foi reconhecido o direito humano à água e a proibição da privatização dos seus serviços. Os quatro países possuem projetos financiados com recursos de organizações internacionais como o BID, agências de cooperação internacional e ONGs, por isso devem se adequar aos moldes destas instituições para receberem financiamento.

É interessante observar que o TCA foi assinado com vistas a garantir a soberania dos países amazônicos sobre seus territórios e recursos naturais. No entanto, no decorrer dos anos de funcionamento e com a criação da OTCA grande parte das atividades da Organização são financiadas por países e instituições internacionais externos à região amazônica. O que parece contraditório, já que a intenção do TCA era manter os interesses externos e suas propostas de internacionalização da Amazônia afastados. Atualmente a maior parte dos projetos da OTCA são financiados com recursos externos.

O Projeto OTCA/GEF de gerenciamento conjunto dos recursos hídricos da Bacia Amazônica é financiado pelo GEF e foi formulado de acordo com suas exigências e modelo de gestão. Um dos grandes problemas para o sucesso deste Projeto poderia ser a incompatibilidade de interesses nacionais em relação ao processo de integração regional, bem como as mudanças de governo nos países que podem alterar as percepções e interesses em relação ao projeto. Por outro lado, um dos pontos positivos do Projeto OTCA/GEF é o financiamento de pesquisas sobre a bacia, o que poderia servir como um incentivo para a formação de redes de pesquisadores e de pesquisa, ou para o fortalecimento das já existentes como a UNAMAZ. No entanto, esta iniciativa precisa estar relacionada com incentivos por parte dos Estados para as pesquisas na Bacia Amazônica pensando em uma política de longo prazo.

A história da formação das fronteiras na Bacia Amazônica permitiu compreender o contexto em que tem se desenvolveu a cooperação entre os países amazônicos tanto bilateral quanto multilateral e sua relação com suas respectivas porções amazônicas. As regiões fronteiriças possuem atualmente um potencial para estimular a integração transfronteiriça e atuam diretamente com o compartilhamento dos recursos hídricos. Elas são afetadas pelos projetos das iniciativas de integração regional como a IIRSA, que impactam a governança dos recursos hídricos na escala local. 
$\mathrm{Na}$ escala internacional atuam principalmente os países amazônicos em suas relações bilaterais e multilaterais, organizações intergovernamentais regionais que são a OTCA e a IIRSA (como parte da UNASUL), organizações internacionais que são o GEF, o PNUMA e a OEA, a COICA como organização indígena transnacional e ONGs com atuação também transnacional. Nesta escala foi elaborado o projeto OTCA/GEF e os projetos de infraestrutura da IIRSA, sem a participação dos atores locais. Os projetos de infraestrutura apoiados pelos governos dos países amazônicos encontram resistências por parte de movimentos indígenas e ONGs, demonstrando conflitos de interesses entre os atores.

A comparação entre as duas bacias hidrográficas estudadas permite concluir que nelas não existe uma governança consolidada. Na Bacia do rio Acre existe a formação de um processo de governança iniciada pela Iniciativa MAP e na Bacia do rio Napo esta formação é incipiente, pois apesar de existir mobilização da sociedade civil ela não é transfronteiriça. A tabela 1 a seguir mostra a comparação entre as bacias nos aspectos da governança analisados neste trabalho.

Tabela 2: Análise comparada da governança das Bacias dos rios Acre e Napo.

\begin{tabular}{|l|l|l|}
\hline ASPECTOS DA GOVERNANÇA & \multicolumn{1}{|c|}{ BACIA DO RIO ACRE } & \multicolumn{1}{|c|}{ BACIA DO RIO NAPO } \\
\hline 1) Conflito fronteiriço & $\begin{array}{l}\text { Solucionado em } \\
1903 / 1904 .\end{array}$ & Solucionado em 1998. \\
\hline $\begin{array}{l}\text { 2) Relações Bilaterais no } \\
\text { contexto atual }\end{array}$ & Cooperativas. & Cooperativas. \\
\hline 3) Países membros da OTCA & Sim. & Sim. \\
\hline $\begin{array}{l}\text { 4) Participação no Projeto } \\
\text { OTCA/GEF }\end{array}$ & $\begin{array}{l}\text { Sim. Consta como projeto } \\
\text { piloto para adaptação às } \\
\text { mudanças climáticas. }\end{array}$ & $\begin{array}{l}\text { Não está presente no } \\
\text { Projeto. }\end{array}$ \\
\hline $\begin{array}{l}\text { 5) Impactos socioambientais } \\
\text { na Bacia }\end{array}$ & $\begin{array}{l}\text { Desmatamento, } \\
\text { contaminação hídrica pela } \\
\text { falta de saneamento, secas } \\
\text { e enchentes, diminuição } \\
\text { dos recursos pesqueiros. }\end{array}$ & $\begin{array}{l}\text { Desmatamento, } \\
\text { contaminação hídrica } \\
\text { pela falta de saneamento, } \\
\text { pela exploração de } \\
\text { hidrocarbonetos e pela } \\
\text { exploração mineira. }\end{array}$ \\
\hline $\begin{array}{l}\text { 6) Projetos de Infraestrutura } \\
\text { da IIRSA }\end{array}$ & $\begin{array}{l}\text { Estrada do Pacífico (Eixo } \\
\text { Peru-Bolívia-Brasil) }\end{array}$ & $\begin{array}{l}\text { Acesso à Hidrovia do } \\
\text { Napo (Eixo do } \\
\text { Amazonas) }\end{array}$ \\
\hline $\begin{array}{l}\text { 7) Projetos de Infraestrutura } \\
\text { Bilaterais }\end{array}$ & $\begin{array}{l}\text { Acordo energético Peru- } \\
\text { Brasil - hidrelétrica de } \\
\text { Inambari }\end{array}$ & $\begin{array}{l}\text { Melhoramento da } \\
\text { Hidrovia do Napo (Plano } \\
\text { Binacional) }\end{array}$ \\
\hline $\begin{array}{l}\text { 8) Legislação e instituição } \\
\text { nacional para a gestão da } \\
\text { água. }\end{array}$ & $\begin{array}{l}\text { Sim. No Brasil a gestão é } \\
\text { mais descentralizada, mas } \\
\text { recentemente Peru e } \\
\text { Bolívia estão promovendo }\end{array}$ & $\begin{array}{l}\text { Sim. No Peru existe um } \\
\text { esforço de } \\
\text { descentralização. No } \\
\text { Equador a gestão ainda é }\end{array}$ \\
\hline
\end{tabular}




\begin{tabular}{|c|c|c|}
\hline & $\begin{array}{l}\text { uma maior } \\
\text { descentralização da gestão. }\end{array}$ & $\begin{array}{l}\text { centralizada com a } \\
\text { presença de órgãos } \\
\text { desconcentrados nas } \\
\text { bacias. }\end{array}$ \\
\hline $\begin{array}{l}\text { 9) Gestão da água e } \\
\text { ambiental em órgãos } \\
\text { subnacionais. }\end{array}$ & $\begin{array}{l}\text { Descentralizada. No Brasil } \\
\text { se prevê a existência de } \\
\text { CBH e no Peru podem ser } \\
\text { criados os Conselhos de } \\
\text { Cuenca. No entanto, a } \\
\text { Bacia do rio Acre não } \\
\text { conta com nenhum comitê } \\
\text { ou conselho. }\end{array}$ & $\begin{array}{l}\text { Descentralizada a gestão } \\
\text { ambiental. A gestão da } \\
\text { água ainda está em } \\
\text { processo de } \\
\text { descentralização. No Peru } \\
\text { foi criada a ALA } \\
\text { Amazonas e no Equador } \\
\text { existe uma oficina } \\
\text { desconcentrada da } \\
\text { SENAGUA. }\end{array}$ \\
\hline $\begin{array}{l}\text { 10) Água Potável e } \\
\text { Saneamento nas } \\
\text { concentrações urbanas }\end{array}$ & $\begin{array}{l}\text { Existem empresas que } \\
\text { distribuem água potável } \\
\text { nas cidades, mas não há } \\
\text { iniciativas para melhorar a } \\
\text { sua qualidade. } \\
\text { Praticamente não existe } \\
\text { coleta e tratamento de } \\
\text { esgoto. }\end{array}$ & $\begin{array}{l}\text { Em poucas localidades } \\
\text { existem empresas que } \\
\text { distribuem água potável, } \\
\text { mas não há iniciativas } \\
\text { para melhorar a sua } \\
\text { qualidade. Praticamente } \\
\text { não existe coleta e } \\
\text { tratamento de esgoto. }\end{array}$ \\
\hline $\begin{array}{l}\text { 11) Contaminação hídrica } \\
\text { transfronteiriça. }\end{array}$ & $\begin{array}{l}\text { Existe na área das cidades } \\
\text { gêmeas (Cobija-Brasiléia- } \\
\text { Epitaciolândia, Assis } \\
\text { Brasil-Iñapari) resultante } \\
\text { da falta de saneamento. }\end{array}$ & $\begin{array}{l}\text { Existe por causa da } \\
\text { exploração de } \\
\text { hidrocarbonetos e do } \\
\text { rompimento de oleodutos } \\
\text { e também pela falta } \\
\text { saneamento. }\end{array}$ \\
\hline $\begin{array}{l}\text { 12) Iniciativas de governança } \\
\text { transfronteiriça na escala } \\
\text { local }\end{array}$ & Existe - Iniciativa MAP. & $\begin{array}{l}\text { Não existe. Apenas } \\
\text { circunscritas ao território } \\
\text { nacional. }\end{array}$ \\
\hline $\begin{array}{l}\text { 13) Mobilização da } \\
\text { sociedade civil }\end{array}$ & $\begin{array}{l}\text { No Acre por seringueiros e } \\
\text { indígenas levou a criação } \\
\text { das Resex e TIs. Em } \\
\text { Pando com a reforma } \\
\text { agrária para terras } \\
\text { comunitárias. Em Madre } \\
\text { de Dios, principalmente as } \\
\text { organizações indígenas. E } \\
\text { como mobilização } \\
\text { transfronteiriça a Iniciativa } \\
\text { MAP. }\end{array}$ & $\begin{array}{l}\text { No Equador contra a } \\
\text { contaminação causada } \\
\text { pelas empresas } \\
\text { petroleiras, a FDA. E } \\
\text { também algumas } \\
\text { Organizações indígenas } \\
\text { se mobilizaram contra o } \\
\text { corredor Manta-Manaus e } \\
\text { a dragagem do rio Napo. }\end{array}$ \\
\hline
\end{tabular}

A Bacia do Rio Acre está localizada em uma tríplice fronteira delimitada na primeira década do século vinte, enquanto que o conflito fronteiriço entre Equador e Peru onde está a Bacia do rio Napo só terminou com o Acordo de Paz na última década do século vinte. Existe uma diferença de quase um século na consolidação das fronteiras 
nos dois casos estudados. Isto pode ter algum impacto sobre o aparecimento da iniciativa de governança transnacional no Acre, enquanto que este tipo de iniciativa não surgiu na Bacia do rio Napo. No entanto, outros fatores estão envolvidos como o grau de mobilização social, a presença de ONGs transnacionais e de universidades, a existência de um grupo de pesquisadores interessados nos acontecimentos da região, entre outros, o que requer maiores estudos para sua confirmação.

Além disso, a presença de universidades na região MAP contribuiu para o surgimento de uma iniciativa de governança transfronteiriça, visto que as primeiras reuniões que deram origem à Iniciativa foram impulsionadas por pesquisadores da região. A proximidade resultante da existência de cidades gêmeas também contribuiu para a articulação transnacional. Na Bacia do rio Napo as comunidades estão muito mais isoladas uma da outra, não existem cidades gêmeas e o transporte pelos rios é precário, o que dificulta a comunicação e a articulação da sociedade civil. 


\section{REFERÊNCIAS BIBLIOGRÁFICAS}

ABC. Cooperação Triangular. Disponível em:

$<$ http://www.abc.gov.br/projetos/cooperacaoPrestadaTriangular.asp >. Acesso em set 2011.

ACHI, A. El agua como bien comunal: síntesis de las investigaciones en Bolívia. In: BUSTAMANTE, R. (ed.). Lo colectivo y el agua: entre los derechos y las prácticas. Lima: IEP; Concertación, 2010, p. 75-108.

ACSERALD. H. Conflitos ambientais no Brasil. Rio de Janeiro: Relume Dumará, 2004.

ACTA PRESIDENCIAL. Acta Presidencial de Brasília (26 de octubre de 1998). Registro Oficial n. 137. Quito: 1999.

ADEMAF. Agencia para el Desarrollo de las Macroregiones y Zonas Fronterizas. Disponível em: 〈http://www.ademaf.gob.bo/ml.php〉. Acesso em fevereiro 2013.

AGNEW, John. Waterpower: politics and the geography of water provision. Annals of the Association of American Geographers. V. 101, n. 3, 2011, pp. 463-476.

ALAM, U.; DIONE, O. e JEFFREY, P. The benefit-sharing principle: implementing sovereignty bargains on water. Political Geography. V. 28, 2009, p. 90-100.

ALEM, Alfonso Rojo. Geo Titicaca: perspectivas del Medio Ambiente en el Sistema Hídrico Titicaca-Desaguadero-Poopó-Salar de Coipasa (TDPS). Ciudad de Panamá: PNUMA, 2011. Disponível em:

<http://www.unep.org/dewa/Portals/67/pdf/Geo_Titicaca.pdf>. Acesso: 10 dez 2012.

ALLAN, Tony. Virtual Water: tackling the threat to our planet's most precious resource. London: I. B Tauris, 2011.

ALLAN, J. A. The Middle East water question: Hydropolitics and the global economy. Londres: I.B. Tauris \& CO, 2001.

ALMEIDA, A. W. The Growing Pains of an Unprecedented Civil Society-Government Partnership in the Brazilian Amazon: The Case of the Amazon Working Group (GTA). In: ANDERSON, M. (ed.). Thinking Out Loud II: innovative case studies on participatory instruments. Washington: LAC Civil Society Team, World Bank, 2000, p. 55-66.

ALMEIDA, J. S.; REIS, V. L. e SILVA, M. M. F. Estado do Acre. In: Governança Pública das Águas: experiência dos estados brasileiros. Salvador: IICA, INGÁ-Bahia, 2009.

ALT. Autoridad Binacional Autonoma del Sistema Hidrico del Lago Titicaca, rio Desaguadero, Lago Poopó y Salar Coipasa - ALT. Disponível em; <http://www.altperubolivia.org/web/>. Acesso: $10 \mathrm{dez} 2012$. 
ALVAREZ W. e FADIGAS, E. A. F. A. Análisis del processo de integración elétrica Perú-Brasil. 2010.

ALVARES, J. A. Las dragas son asesinas. . El Comercio. Loreto: El Comercio, 27 de março de 2012, p. A11.

AMAYO, E. Z. Por qué estudiar la formación historica y la problemática actual de la Amazonia? Espiral Estudios sobre Estado y Sociedad. Guadalajara (México):

Universidad de Guadalajara, n. 15, 1999, p. 73-105.

AMAYO, E. Z. Da Amazônia ao Pacífico cruzando os Andes. Estudos Avançados. São Paulo: IEA, 1993, 117-152.

AMAYO, E. Z. O impacto da globalização na Amazônia e no Pacífico Sul-Americano. In: AYERBE, L. F. (coord.). Integração Latino-americana e Caribenha. São Paulo: Fundação Memorial da América Latina, Imprensa Oficial do Estado de São Paulo, 2007, p. 79-114.

ANA-Peru. Autoridad Nacional del Agua de Perú. Recursos Hídricos en Perú. Lima: ANA, 2010.

ANA-Peru. Autoridad Nacional del Agua de Perú. Resolución Directoral n $059-2013$ - ANA - DARH. Lima: ANA, 2013.

ANA-Peru DCPRH. Autoridad Nacional del Agua Peru - Dirección de Conservación y Planeamiento de Recursos Hídricos. Diagnóstico y Plan de Gestión de los Recursos Hídricos en la Cuenca de Madre de Dios. Fase I. Puerto Maldonado: ANA-Peru, 2011.

ANDINA. ANA y consultora reunirán a especialistas de Loreto y Amazonas. ANDINA. 9 de janeiro de 2013. Disponível em: <http://www.andina.com.pe/Espanol/noticiaelaboraran-diagnostico-recursos-hidricos-de-amazonia-peruana442671.aspx\#.UdQxEfnql1w>. Acesso em: junho de 2013.

ANDRADE, K. M. EL Parque Yasuní y la Iniciativa Yasuní-ITT: frente a la exploración petrolera. Conservación o explotación? In: KRAINER, A. e MORA, M. F. (comp.). Retos y amenazas en el Yasuní. Quito: FLACSO, 2011, p. 43-69.

ANTIQUERA, Daniel C. A Amazônia e a política externa brasileira: análise do Tratado de Cooperação Amazônica (TCA) e sua transformação em organização internacional (1978-2002). Dissertação (Mestrado em Relações Internacionais). Programa San Tiago Dantas, Convênio PUC-SP/UNESP/UNICAMP. Campinas, 2006.

APOLO, W. B. Agua y desarrollo en la zona Andino-amazónica del Ecuador. In: ZAMUDIO, H. B. et al. (eds.). Amazonia y Agua: desarrollo sostenible en el siglo XXI. Bilbao: Universidad del País Vasco, OTCA, UA, UNAMAZ, 2009, p. 275-283.

AQUINO, M. J. S. “A casa dos nossos Gens”: um estudo sobre ONGs ambientalistas na Amazônia. Tese (Doutorado em Sociologia). Instituto de Filosofia e Ciências Sociais, Universidade Federal do Rio de Janeiro. Rio de Janeiro, 2003. 
ARAGÓN, L. E. The Amazon as a study object. Monografia apresentada ao Institute of Latin American Studies. Estocolmo: Stokholm University, 1994.

ARAGÓN, L. E. CLÜSENER-GODT, M. (org.). Problemática do uso local e global da água da Amazônia. Belém: NAEA, 2003.

ARNÉZ, A. M. et al. Bajo el caudal: el impacto de las represas del río Madera en Bolívia. La Paz: FOBOMADE, 2009.

ARTEAGA, R. A Organização do Tratado de Cooperação Amazônica (OTCA): um desafio permanente. Diplomacia, Estratégia e Política. Brasília: FUNAG, n. 4, 2006, p. 86-100.

AXEROLD, R. The evolution of cooperation. New York: Basic Books, 1984

BANDEIRA, L. A. M. O Barão de Rothschild e a questão do Acre. Revista Brasileira de Política Internacional. V. 43, n. 2, 2000, p. 150-169.

BAUD, M. State-building and borderlands. In: CEDLA. Fronteras: towards a borderless Latin America. Amsterdam: CEDLA, 2000, p. 41-79.

BECKER, B. Amazônia: geopolítica na virada do III milênio. Rio de Janeiro:

Garamond, 2007.

BECKER, B. Geopolítica da Amazônia. Estudos Avançados - USP. São Paulo: Instituto de Estudos Avançados, v. 19, n. 53, jan/abril, 2005, p. 71-86.

BECKER, B. Inserção da Amazônia na geopolítica da água. In: ARAGÓN, L. E.; CLÜSENER-GODT, M. (org.). Problemática do uso local e global da água da Amazônia. Belém: NAEA, 2003, p. 273-298.

BECKER, B. e STENNER, C. Um futuro para a Amazônia. São Paulo: Oficina de Textos, 2008.

BERMANN, Célio; WITTMANN, Douglas; HERNANDEZ, Francisco del Moral; RODRIGUEZ, Larissa Araújo. Usinas hidrelétricas na Amazônia - o futuro sob as águas. In: Seminário Políticas Públicas e obras de infraestrutura na Amazônia, 2010. Brasília. Anais Cenários e desafios para a governança socioambiental. Brasília: Inesc, 2010, p. 1-37.

BEZERRA, M. J. Invenções do Acre: de território a estado - um olhar social. Tese de doutorado apresentado ao Programa de Pós-Graduação em História Social. São Paulo: Faculdade de Filosofia, Letras e Ciências Humanas, Universidade de São Paulo, 2006.

BISWAS, A. K. Integrated Water Resources Management: is it working? Water Resources Development. V. 24, n. 1, 2008, p. 5-22.

BOELENS, R. e ZWARTEVEEN, M. Prices and politics in Andean Water Reforms. Development and change. V. 36, n. 4, 2005, p. 735-758. 
BOELENS, R. Water rights politics. In: WARNER, J. e WEGERICH, K. (eds.). The politics of water: a survey. Londres: Routledge, 2010, p. 161-183.

BOELENS, R. e URTEAGA, P. (ed.). Derechos colectivos y políticas hídricas em la región andina. Lima: IEP, WALIR, 2006.

BOELENS, R. e HOODENGAM, P. (eds.). Derechos de agua y acción colectiva. Lima: IEP, WALIR, 2007.

BONILLA, A. Procesos políticos e intereses nacionales em el conflito Ecuador-Peru. Nueva Sociedade. N. 143, 1996, p. 30-40.

BONILLA, A. Seguridad, defensa y desarrollo diez años después. In: DONOSO, C. (compiladora). Ecuador-Perú: evaluación de una década de paz y desarrollo. Quito: Flasco, 2009p. 203-208.

BONILLA, A. (ed.). Ecuador-Perú: horizontes de la negociación y el conflicto. Quito: Flacso-Ecuador, 1999.

BRAGA, B.; FLECHA, R.; PENA, D. S. e KELMAN, J. A reforma institucional do setor de recursos hídricos. In: BRAGA, B.; REBOUÇAS, A. C. e TUNDISI, J. G. (orgs.). Águas Doces do Brasil: capital ecológico, uso e conservação. São Paulo: Escrituras, 2006.

BRASIL, Ivo. Gestão dos recursos hídricos como elemento de transformação da sociedade amazônica. In: ARAGÓN, L. E.; CLÜSENER-GODT, M. (org.). Problemática do uso local e global da água da Amazônia. Belém: NAEA, 2003.

BRASIL, K. Cheias no Estado atingiram mais de 131 mil pessoas. Folha de São Paulo. 27 de fevereiro de 2012.

BROWN, I. F. et al. O MAP uma sigla de esforço e colaboração na região da amazônia sul-ocidental. In: COY, M e KOHLHEPP, G. (coord.). Amazônia Sustentável: desenvolvimento sustentável entre políticas públicas, estratégias inovadoras e experiências locais. Rio de Janeiro: Garamond, 2005.

BROWN, I. F. Queimadas na Região MAP: uma ameaça emergente. Redução deste risco como meio de desenvolvimento. 68 slides. 2006. Apresentado no Fórum MAP VI. 21 jul.2006. In: MAP. Base eletrônica de dados. Disponível em:

<http://www.mapamazonia.net/index.php?lang=pt\&page=arquivos >. Acesso em: 21 out 2006.

BUITRÓN, R. C. Reconquista del espacio latino-americano. Corredores biológicos y corredores multimodales en el Ecuador. Informe final del concurso: ALCA, procesos de dominación y alternativas de integración regional. Programa Regional de Becas CLACSO, 2007.2 Disponível em: <http://bibliotecavirtual.claso.org.ar/ar/libros/semi/2004/buitron.pdf.>. Acesso em: setembro 2009. 
BULL, H. A sociedade anárquica. Brasília: Unb e IPRI. São Paulo: Imprensa Oficial, 2002.

BUSTAMENTE, T. e JARRÍN, C. Indicadores sociales y petróleo em la Amazonía. In: BUSTAMANTE, T. (ed.). Detrás de la cortina de humo: dinámicas sociales y petróleo en el Ecuador. Quito: FLACSO, 2007, p. 21-95.

BUSTAMANTE, R. El difícil camino de la formulación de una nueva Ley de Aguas para Bolivia. Cochabamba: Centro Agua, 2004.

BUZAN, B. People, States and Fear: an agenda for international security studies in the Post-Cold War era. Hemel Hempstead: Harvester-Wheatsheaf, 1991.

BUZAN, B.; WAEVER, O.; e WILDE, J. Security: a new framework for analysis. Boulder: Lynne Rienner, 1998.

BUZAN, B. e WAEVER, O. Regions and Powers: the structure of international security. Cambridge: Cambridge University Press, 2003.

CAMARGO, E.; PEREIRA, M. R. S. e SANT'ANA, D. Q. Marco institucional e legal para a gestão de recursos hídricos na região MAP. In: REIS, V. (org.). Rumo à gestão participativa da Bacia do Alto Rio Acre: diagnóstico e avanços. Rio Branco: WWF / UFAC, 2007, p. 43-57.

CAN. Comunidad Andina de Naciones. Banco de Proyectos de Integración y Desarrollo Fronterizo. Disponível em: <http://www.comunidadandina.org/fronteras/bpif.htm>. Acesso em: maio 2013.

CARDINI, J. (diretor). Estudio Binacional de Navegabilidad del Rio Napo (EcuadorPerú). Informe Final, Volume 1. Lima: BID, 2010. Disponível em: <http://www.mtc.gob.pe/portal/transporte/acuaticos_nosotros/BinNavNapo.html>. Acesso: fevereiro 2013a.

CARDINI, J. (diretor). Estudio Binacional de Navegabilidad del Rio Napo (EcuadorPerú). Informe Final, Volume 2. Lima: BID, 2010. Disponível em: <http://www.mtc.gob.pe/portal/transporte/acuaticos_nosotros/BinNavNapo.html>. Acesso: fevereiro 2013b.

CARDINI, J. (diretor). Estudio Binacional de Navegabilidad del Rio Napo (EcuadorPerú). Informe Final, Volume 3. Lima: BID, 2010. Disponível em: <http://www.mtc.gob.pe/portal/transporte/acuaticos_nosotros/BinNavNapo.html>. Acesso: fevereiro 2013c.

CARDINI, J. (diretor). Estudio Binacional de Navegabilidad del Rio Napo (EcuadorPerú). Informe Final, Volume 4. Lima: BID, 2010. Disponível em: <http://www.mtc.gob.pe/portal/transporte/acuaticos_nosotros/BinNavNapo.html>. Acesso: fevereiro 2013d.

CARDINI, J. (diretor). Estudio Binacional de Navegabilidad del Rio Napo (EcuadorPerú). Informe Final, Volume 5. Lima: BID, 2010. Disponível em: 
<http://www.mtc.gob.pe/portal/transporte/acuaticos_nosotros/BinNavNapo.html>. Acesso: fevereiro $2013 \mathrm{e}$.

CARDINI, J. (diretor). Estudio Binacional de Navegabilidad del Rio Napo (EcuadorPerú). Informe Final, Volume 6. Lima: BID, 2010. Disponível em: <http://www.mtc.gob.pe/portal/transporte/acuaticos_nosotros/BinNavNapo.html>. Acesso: fevereiro 2013f.

CARDINI, J. (diretor). Estudio Binacional de Navegabilidad del Rio Napo (EcuadorPerú). Resumen Ejecutivo. Lima: BID, 2010. Disponível em: <http://www.mtc.gob.pe/portal/transporte/acuaticos_nosotros/BinNavNapo.html>. Acesso: fevereiro $2013 \mathrm{~g}$.

CARNEIRO, M. S. A construção social do mercado de madeiras certificadas na Amazônia brasileira: a atuação das ONGs ambientalistas e das empresas pioneiras. Sociedade e Estado. Brasília: v. 22, n. 3, 2007, p. 681-713.

CARRIÓN, F. M. La Paz por Dentro: Ecuador- Perú: testimonio de una negociación. Quito: Flacso-Ecuador, 2008.

CASTRO, E. Geopolítica da água e novos dilemas a propósito da Amazônia e seus recursos naturais. In: ARAGÓN, L. E.; CLÜSENER-GODT, M. (org.). Problemática do uso local e global da água da Amazônia. Belém: NAEA, 2003, p. 321-339.

CASTRO, I.E. O problema da escala. In: CASTRO, I. E.; GOMES, P. C. C. e CORREA, R. L. (orgs.). Geografia: conceitos e temas. Rio de Janeiro: Bertrand Brasil, 2007, p. 117-140.

CASTRO, I. E. Geografia e política: território, escalas de ação e instituições. Rio de Janeiro: Bertrand Brasil, 2005.

CASTRO, J. E. Water governance in the twentieth first century. Ambiente \& Sociedade. Campinas. V. X, n. 2, 2007, p. 97-118

CASTRO, J. E. Apuntes sobre el proceso de mercantilización del agua: un examen de la privatización en perspectiva histórica. In: CGIAB. Justicia Ambiental y Sustentabilidad hídrica. Cochabamba: CGIAB, 2009, p. 11-29.

CAUBET, Christian. G. A água doce nas relações internacionais. Barueri: Manole, 2006.

CENTRO AGUA. Programa de Acciones Estrategicas para la gestión del agua y el manejo de la cuenca Arroyo Bahia - Cobija, Pando. Cobija: Centro Agua, CI, CARE, PTA, 2010.

CEPAL. Cooperación CEPAL - Proyecto Mesoamérica: aportes a la facilitación del comercio y el transporte en Mesoamérica. Boletin FAL. CEPAL: edición v. 253, n. 5, 2009. 
COELHO, Pedro M. P. Fronteiras na Amazônia: um espaço integrado. Brasília, DF: Fundação Alexandre de Gusmão, 1992.

COHEN, J. C. P.; ROCHA, E. J. P. e SOUZA, J. R. S. Avaliação dos impactos antropogênicos no ciclo da água na Amazônia: In: ARAGÓN, L. E.; CLÜSENERGODT, M. (org.). Problemática do uso local e global da água da Amazônia. Belém: NAEA, 2003, p. 69-94.

COMEGNA, M. A. e LUCHINO, M. M. R. F. Novas territorialidades e conflitos na Amazônia: a IIRSA e o eixo Peru-Brasil-Bolivia. In: La planificación territorial y el urbanismo desde el dialogo y la participación. Actas del XI Coloquio Internacional de Geocritica. Buenos Aires: 2010. Disponível em: <http://www.filo.uba.ar/contenidos/investigacion/institutos/geo/geocritica2010/672.htm $1>$.

CADMA. Comisión Amazónica de Desarrollo y Medio Ambiente. Amazonia sin mitos. BID, PNUD, TCA Secretaria Pro-Tempore, 1992.

CHAMORO, A. S. L. Los instrumentos del cambio de política eléctrica en el Ecuador (2007-2010). Dissertação (Mestrado em Ciências Sociais - Governança Energética), Faculdade Latino-Americana de Ciências Sociais (FLACSO). Quito: FLACSO, 2012.

CHIRIF, A. Pueblos indígenas del nordeste de la Amazonia peruana, demografía y problemas. In: BENAVIDES, M. Atlas de comunidades nativas y áreas naturales protegidas del nordeste de la Amazonia peruana. Lima: IBC, 2010.

COCA CODO SINCLAIR. Proyecto Hidroeléctrico Coca Codo Sinclair. Disponível em:

$<$ http://www.ccs.gob.ec/index.php?option=com_content\&view=article\&id=11\&Itemid= 171>. Acesso em: maio 2013.

COELHO, P. M. P. Fronteiras na Amazônia: um espaço integrado. Brasília, DF:

Fundação Alexandre de Gusmão, 1992.

CONCA, Ken. Governing water: contentious transnational politics and global institution building. Massachusetts: MIT Press, 2006.

CONEJO, B. Logros y perspectivas: diez años de integración fronteriza Ecuador-Peru. In: DONOSO, C. (compiladora). Ecuador-Perú: evaluación de una década de paz y desarrollo. Quito: Flasco, 2009, p. 167-190.

COOK, C. e BAKKER, K. Water security: debating and emerging paradigm. Global Environmental Change. V. 22, 2012, p. 94-102.

COSTA, W. M. Geografia Política e Geopolítica: discursos sobre o território e o poder. São Paulo: Hucitec / EdUSP, 1992

COSTA, W. M. Ordenamento Territorial e Amazônia: vinte anos de experiência de zoneamento ecológico econômico. In; BATISTELA, M.; MORAN, E. e ALVES, D. 
(org.). Amazônia: natureza e sociedade em transformação. São Paulo: Edusp, 2008, p. 241-274.

COSTA, W. M. O Brasil e a América do Sul: cenários geopolíticos e os desafios da integração. CONFINS. N. 7, 2009. Disponível em: <http://confins.revues.org/6107>. Acesso em novembro 2012.

COSTA, P. S. M. e VLACH, V. R. F. Brasil: geopolítica de ocupação efetiva, poder perceptível e dinâmica territorial atual. In: XI Encuentro de Geógrafos de América Latina, 2007, Bogotá. Geopolítica, globalización y cambio ambiental: retos en el desarrollo latinoamericano. Bogotá: Universidad Nacional de Colombia, 2007. v. 1. p. $1-20$.

COSTA-FILHO, A. Uma nova "OTCA" sob a velha ótica? In: ARAGÓN, L. E. and M. CLUSENER-GODT (org.). Problemática do uso local e global da água da Amazônia. Belém, 2003, p. 383-393.

CRESPO, A. M. La cuenca del Lago Titicaca. In: UNESCO. Encuentros sobre el agua. Paris: UNESCO, 2004, p. 17-21. Disponível em:

<http://www.bvsde.paho.org/bvsacd/cd59/crespo.pdf>. Acesso: 10 dez 2012.

CTAR Madre de Dios e IIAP. Madre de Dios: caminho al desarrollo sostenible. Propuesta de Zonificación Ecológica Económica como base para el Ordenamiento Territorial. Puerto Maldonado: BID, BIOFOR-USAID, IIAP, CTAR-Madre de Dios, 2001.

CUNHA, H. B. e PASCOALOTO, D. Hidroquímica dos rios da Amazônia. Manaus: Centro Cultural dos Povos da amazônia, 2006.

CUISINIER-RAYNAL, Arnaud. La frontier au Pérou entre fronts et synopses. L'Espace geographique. V 3, 2001, pp. 213-229.

DAI-MRE. Divisão de Atos Internacionais do Ministério das Relações Exteriores. Acordo por troca de Notas, para a criação de Comitês de Fronteria. 1999. Disponível em: <http://dai-mre.serpro.gov.br/atos-internacionais/bilaterais/1999/b_35/>. Acesso em: abril 2013.

DAOUDY, Marwa. Getting beyond the environment-conflict trap: benefit sharing in international river basins. In: EARLE, A.; JÄGERSKOG, A; e ÖJENDAL, J. (eds.). Transboundary water management: principles and practice. London: Earthscan, 2010, pp. 43-55.

DAVIDSEN, P. A. Hydrosolidarity as water security in the Okavango River Basin. In: WARNER, J. e WEGERICH, K. (eds.). The politics of water: a survey. Londres: Routledge, 2010, p. 68-95.

DECLARAÇÃO dos governos da República Federativa do Brasil e da República do Peru sobre Integração Física e Conservação do Meio Ambiente. Assis Brasil, 2006. Disponível em: <http://dai-mre.serpro.gov.br/atos-internacionais/bilaterais/2006/b_5>. Acesso em: março de 2010. 
DELLI PRISCOLI, J. e WOLF, A. Managing and transforming water conflicts. New York: Cambridge University Press, 2009.

DIAZ, C. E. (coord.). Visión Boliviana de la Cuenca Amazónica. Informe Final. La Paz: SENAMHI, 2007. Disponível em:

<http://www.otca.info/gefam/index.php?page=HomePage\&cat=39>. Acesso em: abril 2007.

DIEGUES, A. C. Introdução. In:m DIEGUES, A. C. (org.). A ecologia política das grandes ONGs transnacionais conservacionistas. São Paulo: NUPAUB/USP, 2008.

DOMINGUEZ, Camilo. Importância dos rios no sistema de transporte da Amazônia. In: ARAGÓN, Luis E. e CLÜSENER-GODT, Miguel (orgs.). Problemática do uso local e global da água na Amazônia. Belém: NAEA, 2003, p. 161-190.

DONOSO, C. Ecuador-Perú: evaluación de una década de paz y desarrollo. In: DONOSO, C. (compiladora). Ecuador-Perú: evaluación de una década de paz y desarrollo. Quito: Flasco, 2009, p. 27-35.

DOUROJEANNI, A. Water management at the river basin level: challenges in Latin America. Santiago (Chile): Natural Resources and Infrastructure Division CEPAL, 2001a.

DOUROJEANNI, A. Impactos socioambientales probables de la carretera transoceánica (Rio Branco - Puerto Maldonado - Ilo) y la capacidad de respuesta del Perú. Arequipa (Peru), 2001b.

DOUROJEANNI, A. C. Análisis crítico de la creación de organismos de cuenca en América Latina y Caribe. Trabalho apresentado no $1^{\circ}$ Encontro de Organismos de Bacias Hidrográficas da América Latina e Caribe. Foz do Iguaçu: 2004.

DOUROJEANNI, A. C. Análisis de la situación de la creación de entidades de cuencas en América Latina. Santiago de Chile: CEPAL, 2009.

DOUROJEANNI, M. J. Médio siglo de desarrollo em la Amazonía: ?existen esperanzas para su desarrollo sustentable?. Estudos Avançados. São Paulo, v. 12, n 34, p. 187-218, 1998.

DOUROJEANNI, M. J. Impactos socioambientales probables de la carretera transoceánica (Rio Branco - Puerto Maldonado - Ilo) y la capacidad de respuesta del Perú. Arequipa (Peru): Set 2001c.

DOUROJEANNI, A. e JOURALEV, A. Evolución de políticas hídricas en América Latina y el Caribe. Bahia Análise e Dados. Salvador, V. 13, n. Especial, 2003, p. 347355.

DOUROJEANNI, A. e JOURALEV, A. Crisis de gobernabilidad em la gestión del agua. Santiago de Chile: CEPAL/ECLAC, 2001. 
DOUROJEANNI, A. E JOURALEV, A. Evolución de políticas hídricas en América Latina y el Caribe. Análise e Dados. Salvador, v. 13, n. Especial, 2003, p. 347-355.

DUARTE, A. F. Medições de vazão e pluviometria na bacia do rio Acre, amostragem e análise físico-química da água. Relatório 1. Rio Branco: Universidade Federal do Acre, 2007.

DUARTE, A. F. Ficha descritiva de estação fluviométrica. Disponível em: <http://www.acrebioclima.pro.br/Estacao_fluviometrica_13610000_Porto_Acre.pdf>. Acesso em: dez 2008.

DUARTE, E. G. Conflitos pela terra no Acre: a resistência dos seringueiros de Xapuri. Rio Branco: Casa da Amazônia, 1987.

DUBASH, N. K.; DUPAR, M.; KOTHARI, S. e LISSU, T. A Watershed in Global Governance? An Independent Assessment of the World Comission on Dams. World Resources Institute, 2001.

DUBLIN Statement on Water and Sustainable Development. 1992. Disponível em: <http://www.wmo.int/pages/prog/hwrp/documents/english/icwedece.html>. Acesso em: mar 2013.

DUDA, A. M.; UITTO, J. I. Management of transboundary water resources: lessos from internacional cooperation for conflict prevention. The Geographical Journal, v. 168 , n. 4, dez, 2002, p. 365-378.

DYER, Hugh C. Environmental security as a universal value: implications for international theory. In: VOGLER, J. e IMBER, M. F. (eds.). The environment and international relations. London/New York: Routledge, 1996, p. 22-40.

ECORAE. Diagnóstico integral de la Región Amazónica Ecuatoriana. Quito: ECORAE, 1997.

ECORAE. (Re) construir la Región Amazónica Ecuatoriana: una perspectiva regional desde lo local y comunitario. ECORAE, 2003.

ECORAE e INADE. Plan Peruano-Ecuatoriano para el desarrollo integral de las cuencas de los ríos Napo-Tigre-Pastaza. Lima: INADE, ECORAE, 2002.

ECUADOR ESTRATEGICO. Ecuador Estratégico. Disponível em: <http://www.ecuadorestrategicoep.gob.ec/institucion/ecuador-estrategico>. Acesso em: junho de 2013.

ELLIOT, L. The Global Politics of the Environment. New York: New York University Press, 2004.

EQUADOR. Decreto n 1088 de 27 de março de 2008. Registro Oficial n. 346.

EQUADOR. Visión nacional para la gestión integrada de los Recursos hídricos en la cuenca del río amazonas. Informe Final. Disponível em: 
$<$ http://www.otca.info/gefam/index.php?page=HomePage \&cat=39>. Acesso em: abril 2009.

ESCHLE, C. e STAMMERS, N. Taking part: social movements, INGOs, and global change. Alternatives, n. 29, 2004, p. 333-372.

ESCOBAR, S. ZEE de la Amazonia Ecuatoriana. La Amazonia Ecuatoriana en cifras. Quito: ECORAE, 2007.

ESPINOZA, E. M. et al. Experiências de mitigação de impactos na bacia do rio Acre: mapa de perigos da cidade de Iñapari - Peru. In: REIS, V. (org.). Rumo à gestão participativa da Bacia do Alto Rio Acre: diagnóstico e avanços. Rio Branco: WWF / UFAC, 2007, p. 59-87.

EVA, H. D. e HUBER, O. A Proposal for defining the geographical boundaries of Amazonia. Luxembourg: Office for Official Publications of the European Communities, 2005.

FAME. Foro Alternativo Mundial del Agua. Disponível em: <http://www.fame2012.org/es/>. Acesso em: abril 2013.

FDA. Frente de Defensa de la Amazonia. Texaco Tóxico. Disponível em: $<$ http://www.texacotoxico.org/union-de-afectados-y-afectadas/>. Acesso em fevereiro de 2013.

FENZL, N. e MATHIS, A. Poluição dos recursos hídricos naturais da Amazônia: fontes, riscos e conseqüências. In: ARAGÓN, L. E.; CLÜSENER-GODT, M. (org.). Problemática do uso local e global da água da Amazônia. Belém: NAEA, 2003, p. 117141.

FENZL, N. Integração Institucional para o Manejo sustentável dos Recursos Hídricos da Bacia do Rio Amazonas. In: ZAMUDIO, H. B. et al. (eds.). Amazonia y Agua: desarrollo sostenible en el siglo XXI. Bilbao: Universidad del País Vasco, OTCA, UA, UNAMAZ, 2009, p. 483-493.

FERNANDEZ, N. e BUITRÓN, R. C. Derecho al agua em Ecuador: avances, limites y retos. In: Programa Andino de Derechos Humanos (compilador). Develando el desencanto. Informe sobre derechos humanos Ecuador 2010. Quito: Abya Yala, 2011.

FERREIRA, A. M. M. e SALATI, E. Forças de transformação do ecossistema amazônico. Estudos Avançados. São Paulo: IEA-USP, v. 19, n. 54, maio/agosto 2005, p. $25-44$.

FERRO, G. Três lados, três histórias: os esforços para manejar a bacia trinacional do Rio Acre. Disponível: 〈http://www. map-amazonia.net>. Acesso em: jan 2008.

FERRO, G. Three sides, three stories: the efforts to manage the tri-national basin of the Acre river. Dissertação de Mestrado. International Development Studies. Utrecht University, 2007. 
FONTAINE, G. La globalización de la Amazonia: una perspectiva andina. Iconos Revista de Ciencias Sociales. Quito (Equador): FLACSO, n. 25, 2006, p. 25-36.

FONTAINE, G. El precio del petróleo: conflictos socio-ambientales y gobernabilidad en la región amazónica. Quito: FLACSO, IFEA, Abya-Yala, 2007.

FONTAINE, G. ITT: un problema de gobernanza para el Ecuador. In: FONTAINE G. e PUYANA, A. (coord.). La guerra del fuego: políticas petroleras y crisis energética en América Latina. Quito: FLACSO, 2008, p. 169-193.

FONTAINE, G. Petropolítica: una tería de la gobernanza energética. Quito: FLACSO, IEP, Abya-Yala, 2010.

FOUCHER, M. Obsessão por fronteiras. São Paulo: Radical Livros, 2009.

FRANCISCO, M. Iniciativa MAP: por uma política regional na Amazônia SulOcidental: um olhar sobre a educação. Mapiense. UFAC, Herencia, n. 1, 2007, p. 21-29.

FRANCO, E. B. Pando, donde el agua es más que un lujo. Breve análisis de la problemática ambiental y su afectación sobre la calidad del agua en la cuenca arroyo Bahia. Santa Cruz de la Sierra (Bolivia): Fundación Natura, 2010a.

FRANCO, E. Evaluando el potencial de los servicios ambientales hídricos como parte de un plan de manejo integral en la cuenca de Arroyo Bahía - Pando. Santa Cruz de la Sierra (Bolivia): Fundación Natura, 2010b.

FREITAS, R. R.; REIS, V. L. e APEL, M. Governança dos recursos pesqueiros na Bacia do rio Acre com ênfase na tríplice fronteira (Brasil, Peru e Bolívia). Trabalho apresentado no V Encontro Nacional da ANPPAS, Florianópolis, 2010. Disponível em: <http://www.anppas.org.br/encontro5/cd/artigos/GT18-742-791-20100903230456.pdf>. Acesso em fevereiro de 2011.

FURLONG, K. Hidden theories, troubled Waters: international relations, the 'territorial trap', and the Southern African Development Community's transboundary Waters.

Political Geography. N. 25, 2006, p. 438-458.

FURLONG, K. Hidden theories, troubled waters: response to critics. Political Geography. V. 27, 2008, p. 811-814.

FURTADO, F. Quem financia uma obra tão polêmica? In: SWITKES, G. (org.). Águas Turvas: alertas sobre as consequências de barrar o maior afluente do Amazonas. São Paulo: International Rivers, 2008, pp. 26-48.

GADELHA, R. M. A. F. Conquista e ocupação da Amazônia: a fronteira norte do Brasil. Estudos Avançados. São Paulo: IEA, v. 16, n. 45, 2002, p. 63-79.

GAFNER-ROJAS, C. El Nuevo reto de la cooperación internacional en el marco de la cuenca del río Amazonas: la gestión integrada. In: DARIO, O. A. N. e GARCIA M. P. (org.). Gestión Integrada de los Recursos Hídricos: la propiedad del agua, estado em Iberoamérica. Tomo II. Bogotá: Universidad Externado de Colombia, 2007, p. 241-282. 
GAMBOA, C. L. B. (In)sostenibilidad de los hidrocarburos en la cuenca amazónica peruana. In: FONTAINE, G. e PUYANA, A. (coord..). La guerra del fuego: políticas petroleras y crisis energética en América Latina. Quito: FLACSO, Ministerio de Cultura de Ecuador, 2008.

GEF. Integrated and Sustainable Management of Transboundary Water Resources in the Amazon River Basin Considering Climate Variability and Climate Change Project.

2009. Disponível em:

<http://www.thegef.org/gef/sites/thegef.org/files/repository/Regional_05-20-

09_GEFID_2364_Regiona_Integrated_Sust_Mgt_Amazon.pdf >. Acesso em dezembro 2009.

GERLAK, A. K. Lesson learning and trans-boundary waters: a look at the Global Environment Facility's international water programs. Water Policy. N. 9, 2007, p. 5572.

GIORDANO, Meredith A.; WOLF, Aaron. Sharing waters: Post-Rio internacional water management. Natural Resources Forum. Oxford, Malden: Blackwell Publihing, 2003, n. 27, p. 163-171.

GIORDANO, M. A.; WOLF, A. Sharing waters: Post-Rio internacional water management. Natural Resources Forum. Oxford, Malden: Blackwell Publihing, 2003, n. 27, p. $163-171$.

GIORDANO, M. International River Basin Management: Global Principles and Basin Practice. Dissertação de Ph.D em Geografia apresentada ao Departamento de Geociências da Universidade do Estado de Oregon (EUA). 2002. Disponível em: <http://www.transboundarywaters.orst.edu/publications/Giordano-Meredith-2002.pdf $>$. Acesso em: dez. 2007.

GIORDANO, M.; WOLF, Aaron. The world's international freshwater agreements. Disponível em:

<http://www.transboundarywaters.orst.edu/publications/atlas/atlas_html/foreword/intern ationalAgreements.html>. Acesso em: 10 fev 2008.

GLEDITSCH, N. P.; HEGRE, H.; LACINA, B. A.; OWEN, T e FURLONG, K. Conflicts over shared rivers: resource scarcity or fuzzy boundaries? Politcal Geography. V. 25, 2006, p. 361-382.

GLEDITSCH, N. P. e BROCHMANN, M. Shared river - a reconsideration. Political Geography. V. 31, 2012, p. 519-527.

GLEICK, P. Water in crisis: a guide to the world's freshwater resources. New York: Oxford University Press, 1993.

GLEICK, P. Water and conflict: freshwater resources and international security. International Security. MIT Press, v. 19, n. 1, 1993, pp. 79-112. 
GLEICK, P. Water Conflict Chronology. Disponível em: http://www.worldwater.org/conflict/list/. Acesso em: 14 março 2013.

GLEICK, P. The changing water paradigm: a look at twenty-first century water resources development. Water Internacional. V. 25, n. 1, 2000, pp. 127-138.

GOICOCHEA, Zaniel I Novoa. El origen del rio Amazonas. Lima: Sociedad Geográfica de Lima e PUCP, 2010.

GOMES, D. IIRSA, el eje multimodal Manta-Manaos y el Qhapaq Ñan. In: KRAINER, A. e MORA, M. F. (comp.). Retos y amenazas en el Yasuní. Quito: FLACSO, 2011, p. 155-181.

GONÇALVES, C. W. P. Amazônia, Amazônias. São Paulo: Contexto, 2001.

GONZÁlEZ, J. C. T.; GUEVARA, M. N. e RON, C. Proyecto IIRSA multimodal Manta-Manaos: consideraciones ambientales. In: KRAINER, A. e MORA, M. F. (comp.). Retos y amenazas en el Yasuní. Quito: FLACSO, 2011, p. 183-197.

GRASA, R. Los conflictos "verdes": su dimensión interna e internacional. Ecologia Política. Barcelona: FUHEM / Icaria, v. 8, 1994, p. 25-40.

GREGORASCHUK, J. S. Desarrollo Sostenible del área fronteriza amazónica peruano ecuatoriano. FEMCIDI evaluación de Proyectos 2001. Informe Final. Montevideo (Uruguai): 2003.

GRL. Gobierno Regional de Loreto. Plan de Desarrollo Regional Concertado de Loreto 2008-2021. Iquitos: GRL, 2009.

GTIIF. Grupo de Trabalho Interfederativo de Integração Fronteiriça. Bases para uma Proposta de Desenvolvimento e Integração da Faixa de Fronteira. Brasília: GTIIF, 2010.

GUPTA, J.; AHLERS, R. e AHMED, L. The Human Right to Water: moving towards consensus in a fragmented world. RECIEL. V. 19, n. 3, 2010, p. 294-305.

GWP. GLOBAL WATER PARTNERSHIP. History. Disponível em:

<http://www.gwp.org/en/About-GWP/History/>. Acesso em: abril 2013.

GWP. Towards water security: a framwork for action. Estocolmo: GWP, 2000a.

GWP. Integrated Water Resources Management. TAC background Papers n. 4. Estocolmo: GWP, 2000b.

HAAS, P. Introduction: epistemic communities and international policy coordination. International Organization. V.46, n. 1, 1992, pp. 1-35.

HAESBAERT, R. O mito da desterritorialização: do "fim dos territórios" à multiterritorialidade. Rio de Janeiro, Bertrand Brasil, 2004. 
HAESBAERT, R. Regional-Global: dilemas da região e da regionalização na geografia contemporânea. Rio de Janeiro: Bertrand Brasil, 2010.

HCPO. Honorable Consejo Provincial de Orellana. Línea Base Ambiental de la Provincia de Orellana. Francisco de Orellana: Departamento del Ambiente, 2005.

HEILAND, S. e BAUDACH, K. Introducción. In: Cooperación Alemana. Experiencias de la cooperación alemana en el manejo integral de cuencas y la gestión integral de recursos hídricos en Bolivia. La Paz: DED, GTZ, PROAGRO, p. 14-15.

HEMMING, J. Fronteira Amazônica: a derrota dos índios brasileiros. São Paulo: EdUSP, 2009.

HENSEL, P. R.; MITCHELL, S. M. e SOWERS II, T. E. Conflict management of riparian disputes. Political Geography. V. 25, 2006, pp. 383-411.

HERZ, M. Política e Relações Internacionais do Peru. In: ARAÚJO, H. V. (org.). Os países da Comunidade Andina. V. 1. Brasília: FUNAG, IPRI, 2004, p. 515-536.

HOMER-DIXON, T. F. Environmental scarcities and violent conflict: evidence from cases. International Security. MIT Press, V. 19, n. 1, 1994, pp. 5-40.

ICOLD. Hystory. Disponível em: 〈http://www.icold-cigb.net/GB/ICOLD/history.asp>. Acesso em: abr. 2013.

IIRSA. Iniciativa para a Integração da Infra-estrutura Regional Sul-Americana. . Disponível em: <http://www.iirsa.org>. Acesso em: jul 2008.

IIRSA. Consejo Suramericano de Infraestructura y Planeamiento (COSIPLAN). Disponível em: 〈http://www.iirsa.org/Page/Detail?menuItemId=45>. Acesso em março 2011.

INADE. Plan Estratégico de Desarrollo de las cuencas de los ríos Putumayo, Napo, Bajo Amazonas y Bajo Yavari. Lima: INADE, 2004.

INEI. Instituto Nacional de Estadística y Informática. Perfil Sociodemográfico del Departamento de Loreto. Lima: INEI, 2009. Disponível em: <http://www.inei.gob.pe/biblioineipub/bancopub/Est/Lib0838/libro05/Libro.pdf>. Acesso em: maio de 2013.

INEI. Instituto Nacional de Estadística y Informática. Departamento de Loreto: superfície, población total proyectada, densidad poblacional y ubicación geografía de la capital legal según provincia y distrito. Lima: INEI, 2012. Disponível em: <http://www.inei.gob.pe/biblioineipub/bancopub/Est/Lib1018/cuadros/loreto/loreto_16_ 5.xls>. Acesso em: junho 2013.

INTERNATIONAL Rivers. Barragens na Amazônia. Disponível em: $<$ http://www.dams-info.org/pt>. Acesso em abril de 2013a. 
INTERNATIONAL Rivers. Amazônia Viva. Disponível em: $<$ http://www.internationalrivers.org/campaigns/amaz\%C3\%B4nia-viva>. Acesso em abril de 2013b.

IWRA. International Water Resources Association. About us. Disponível em: <http://www.iwra.org/index.php?page=58>. Acesso em abril de 2013.

JACOBI, P. Governança da água no Brasil. In: RIBEIRO, W. C. (org.). Governança da água no Brasil: uma visão interdisciplinar. São Paulo: Annablume, Fapesp, CNPq, 2009, p. 35-59.

JANSKY, L., NAKAYAMA, M., e PACHOVA, N. I. Introduction: from domestic to international water security. In: JANSKY, L., NAKAYAMA, M., e PACHOVA, N. I. (eds.). International water security: domestic threats and opportunities. New York: United Nations University Press, 2008, p. 1-5.

JARVIS, Todd e WOLF, Aaron. Managing Water Negotiations and Conflicts in Concept and Pratice. In: EARLE, A.; JÄGERSKOG, A; e ÖJENDAL, J. (eds.). Transboundary water management: principles and practice. London: Earthscan, 2010, pp. 125-141.

KEOHANE, R. O. After hegemony: cooperation and discord in the world political economy. Princeton: Princeton University Press, 1984.

KHAGRAM, S.; RIKER, J. V.; SIKKINK, K. From Santiago to Seatle: transnational advocacy groups restructuring world politics. In: Restructuring world politics: transnational social movements, networks and norms. University of Minnesota Press, 2002, p. 3-23.

KOHLHEPP, Gerd. Desenvolvimento sustentável na Amazônia? Dúvidas na consolidação do Programa Piloto, as recentes estratégias e a realidade amazônica. In: COY, M. e KOHLHEPP, G. (coord.). Amazônia sustentável: desenvolvimento sustentável entre políticas públicas, estratégias e experiências locais. Rio de Janeiro: Garamond, 2005.

KRUKOSKI, W. R. M. Levantamento da estrutura Geodésia Relativa a hidrovia do rio Madeira. Disponível em: <http://info.lncc.br/madeira.html>. Acesso em março 2013.

LAFERRIERE, E. e STOETT, P. J. Introduction: Exploring International Ecopolitical Theory. LAFERRIERE, E. e STOETT, P. J. (ed.). International Ecopolitical Theory: critical approaches. Vancouver: University of British Columbia, 2006, p. 3-16.

LA RAZÓN. Evo considera estratégica la vía hacia Ilo y decide acelerar obras. $L a$ Razón. Disponível em: <http://www.la-razon.com/nacional/Evo-considera-estrategicaIlo-acelerar_0_1811218881.html>. Acesso em maio 2013.

LARAQUE, A. et al. Sediment Budget of the Napo River, Amazon Basin, Ecuador and Peru. Hydrological Processes. V. 23, n. 25, 2009, p. 3509-3524. 
LARAQUE, A. et al. Spatial and temporal variability of the hydroclimatic features of the ecuadorian Amazon basin. In: UNESCO. V Conferencia Mundial FRIEND. La Habana, Cuba, 2006. Impactos Hidrológicos de la Variabilidad y el Cambio Climatico - Selección de Trabajos de América Latina y el Caribe. - Documento Técnico PHILAC, n. 11, 2007, p. 81-96.

LARAQUE, A.; CUYOT, J. Ç. E POALBOSA, R. Hidroclimatologia del Oriente e Hidrosedimentologia de la Cuenca del Napo. In: BABY, P.; RIVADENEIR, M. e BARRAGÁN, R. (eds.). La cuenca del Oriente: Geología y Petroleo. Quito: IFEA, IRD, Petroecuador, 2004, p. 131-151.

LA TORRE, L. L. Sólo queremos vivir en paz! Experiencias petroleras en territorios indígenas de la Amazonía peruana. Copenhague: Grupo Internacional de Trabajo sobre Assuntos Indígenas e Grupo de trabajo "Racismos de Ungurahui”, 1998.

LASSO, L. La industria petrolera en la historia del Ecuador. In: SANTILLÁN, P. C. (ed.). La problemática socioambiental alrededor de la industria petrolera en el Ecuador: revisión de lo más destacado por cientistas sociales y actores locales. Quito: FDA e Fundación Metis, 2010, p.12-41.

LAUTZE, J. et. al. Putting the cart before the horse: water governance and IWRM. Natural Resources Forum. N. 35, 2011, p. 1-8.

LEAL, A. C. Gestão urbana e regional em bacias hidrográficas: interfaces com o gerenciamento de recursos hídricos. In: BRAGA, R. e CARVALHO, P. F. (org). Recursos hídricos e planejamento urbano e regional. Rio Claro: Laboratório de Planejamento Municipal/DEPLAN/UNESP/IGCE, 2003. p.65 - 85.

LE PRESTRE, P. Ecopolítica Internacional. São Paulo: SENAC, 2000.

LEVY, J. S. Theory, Evidence and Politics in the Evolution of International Relations Research Programs. In: LEBOW, R. N. e LICHBACH, M. I. (org.). Theory and Evidence in Comparative Politics and International Relations. New York: Palmgrave Macmillan, 2007, p. 177-197.

LIPIETZ, A. A Ecologia Política, solução para a crise da instância política? In: ALIMONDA, H. (org.). Ecologia Política: natureza, sociedade y utopia. Buenos Aires: CLACSO, 2003.

LLORET, P. Z. La gestión del agua y la nueva Ley de Aguas. Letras Verdes. Quito: FLACSO, n. 4, 2009, p. 19-20.

LLOSA, J. L. La integración Fronteriza del Perú con el Estado de Acre en el Brasil (la via mal llamada interoceánica). Seria: Construyendo el Consenso. Lima: PRO-A-SUR, 2001.

LÓPEZ, L. T. e BENITO, P. del P. Geografía Política. Madrid: Cátedra, 1999.

LÓPEZ, E. I. La gestión de los recursos hídricos en el Ecuador. REGA. V. 6, n. 2, 2009a, p. 33-48. 
LÓPEZ, V. A. Agua, energía y políticas públicas en la Amazonia ecuatoriana. In: ZAMUDIO, H. B. et al. (eds.). Amazonia y Agua: desarrollo sostenible en el siglo XXI. Bilbao: Universidad del País Vasco, OTCA, UA, UNAMAZ, 2009b, p. 471-482.

LÓPEZ, V. A. No solo “...una forma inteligente de sembrar el agua para cosechar energía” - Implicaciones del proyecto Coca Codo Sinclair para la Amazonía ecuatoriana. In: Memoria del 5to Encuentro Nacional del Foro de los Recursos Hídricos. Quito, 2009c.

LÓPEZ, V. A. El proyecto hidroeléctrico Coca Codo Sinclair y la gobernanza energética en la Amazonia ecuatoriana. Letras Verdes. Quito: FLACSO, 2011, p. 1-3.

LÓPEZ, C. P. e BALAREZO, D. V. El derecho humano al agua y la justicia ambiental en Ecuador. Quito: Proyecto Planeta Azul, 2012. Disponível em: <http://www.blueplanetproject.net/documents/RTW/RTW-Ecuador-1.pdf >. Acesso em: fevereiro de 2013.

LOURENÇO, J. S. O primeiro decênio da UNAMAZ: a construção da solidariedade Pan-Amazônica. In: MARIN, R. E. A. (org.). UNAMAZ: um projeto de cooperação PanAmazônica. Belém: Associação de Universidades Amazônicas, 2003.

MA, J.; KEITH, H.; MITALI, D. e CAI, J. Transboundary water policies: assessment, comparison and enhancement. Water Resources Management. N.22, 2008, p. 10691087.

MacCHAPIN. Um desafio aos conservacionistas. In: DIEGUES, A. C. (org.). A ecologia política das grandes ONGs transnacionais conservacionistas. São Paulo: NUPAUB/USP, 2008.

MACHADO, L. O. Mitos e realidades da Amazônia Brasileira no contexto geopolítico internacional. Tese (Doutorado em Geografia) Departamento de Geografia, Universidade de Barcelona. Barcelona: 1989.

MACHADO, L. O. O controle intermitente do território Amazônico. Terra Livre. 1997, p. 19-32.

MACHADO, L. O. Sistemas, fronteiras e território. Rio de Janeiro: UFRJ, 2002.

MACHADO, L. O. Interações na fronteira Brasiléia - Cobija, Brasil - Bolívia. Rio de Janeiro: UFRJ, 2001.

MACHADO, L. O. e STEIMAN, R. Limites e fronteiras internacionais: uma discussão histórico-geográfica. Rio de Janeiro: UFRJ, 2002.

MACHADO, L. O. Estado, territorialidade, redes. Cidades gêmeas na zona de fronteira sul-americana. In: SILVEIRA, M. L. (org.). Continente em chamas: globalização e território na América Latina. Rio de Janeiro: Civilização Brasileira, 2005, p. 243-284. 
MACHADO, P. A. L. Direito dos cursos de água internacionais. São Paulo: Malheiros Editores, 2009.

MAGALHÃES, R. C. e BARP, A. R. B. Subsídios para a construção de cenários prospectivos dos recursos hídricos na Amazônia brasileira. In: ARAGÓN, L. E. e OLIVEIRA, J. A. (orgs.). Amazônia no cenário Sul-Americano. Manaus: Ed. UFAM, 2009, p. 172-188.

MALDONADO, M. J. R. MAP Initiative, Infrastructure and Energy: challenges for green governance in southwestern Amazonia.

MANCHENO, D. P. La Manta-Manaos una evaluación de los impactos económicos. In: KRAINER, A. e MORA, M. F. (comp.). Retos y amenazas en el Yasuní. Quito: FLACSO, 2011, p. 199-228.

MANCHENO, D. P. e PIEDRA, A. C. La Manta-Manaos, estúdio económico regional: alcances, riesgos y potencialidades. Quito: Grupo FARO, 2008.

MAP. Inicitiva MAP. Disponível em: <http://www.map-amazonia.net>. Acesso em: jan 2007.

MARENGO, J. A. et al. Hydro-climatic and ecological behavior of the drought of Amazônia in 2005. Philosophical Transactions of the Royal Society of London. V. 363, 2008, p. 1773-1778.

MARTIN, A. R. Fronteiras e nações. São Paulo: Contexto, 1992.

MARTINS, R. C. De bem comum a ouro azul: a crença na gestão racional da água. Contemporânea. V. 2, n. 2, 2012, p.465-488.

MARTINEZ-ALIER. J. O ecologismo dos pobres: conflitos ambientais e linguagens de valoração. São Paulo: Contexto, 2007.

MATTOS, C. M. Uma geopolítica Pan-Amazônica. Rio de Janeiro: Biblioteca do Exército, 1980, v. 181.

MATTOS, A. M. Pacto Amazônico: cooperação e integração. Belém: UFPA, 1982.

MATTOS, J. C. P. e IMAI, L. Y. Diagnóstico de saneamento ambiental - coleta e tratamento de esgotamento sanitário nos municípios de Assis Brasil, Brasiléia e Epitaciolândia. Rio Branco: DEAS, 2006

McINTYRE, Owen. International Water Law: concepts, evolution and development. In: EARLE, A.; JÄGERSKOG, A; e ÖJENDAL, J. (eds.). Transboundary water management: principles and practice. London: Earthscan, 2010, pp. 59-71.

MEADOWCROFT, J. Politics and scale: some implications for environmental governance. Landscape and Urban planning. N. 61, 2002, p. 169-179.

MELLO, N. A. Políticas Territoriais na Amazônia. São Paulo: AnnaBlume, 2006. 
MELLO, N. A. Contradições Territoriais: signos do modelo aplicado na Amazônia. Sociedade e Estado. Brasília: Departamento de Sociologia da Universidade de Brasília, v. $18, \mathrm{n}^{\circ} 1 \frac{1}{2}$, jan/dez, 2003, p. 339-360.

MEM. Ministerio de Energia y Minas. Portfólio de Projetos de Geração e Transmissão no Sistema Elétrico Interligado Nacional. Lima: MEM, 2008.

MENDONÇA, F. e SANTOS, L. J.C. Gestão da água e dos recursos hídricos no Brasil: avanços e desafios a partir das bacias hidrográficas - uma abordagem geográfica. Geografia. V. 31, n. 1, 2006, p. 103-117.

MERREY, D. J. African models for transnational river basin organizations in Africa: an unexplored dimension. Water Alternatives. V. 2, n. 2, 2009, p. 183-204.

MEZA, N. M. Espacios Regionales Fronterizos: integración más allá del discurso político. Palibrio, 2011.

MILLER, F. e HIRSCH, P. Civil society and internationalized river basin management. Working Paper n. 7. Sidney (Austrália): Australian Mekong Resource Centre, University of Sidney, jun. 2003.

MILNER, Helen. International theories of cooperation among nations: strengths and weaknesses. World Politics. John Hopkins University Press, v. 144, n. 3, apr. 1992, p. 466-496.

MIN. Ministério da Integração Nacional. Proposta de Reestruturação do Programa de Desenvolvimento da Faixa de Fronteira. Bases de uma Política Integrada de Desenvolvimento Regional para a Faixa de Fronteira. Brasília: Ministério da Integração Nacional, 2005.

MINAM. Ministério del Medio Ambiente de Perú. Comunicado del MINAM. Disponível em: <http://www.minam.gob.pe>. Acesso em junho de 2013.

MRRE. Ministerio de Relaciones Exteriores de Ecuador. Ecuador despliega esfuerzos para reparar daño ambiental en la frontera con el Perú.

Disponível em: <http://cancilleria.gob.ec/es/ecuador-despliega-esfuerzospara-reparar-dano-ambiental-en-frontera-con-el-peru/ $\geq$. Acesso 10 junho 2013.

MIRUMACHI, N. Domestic issues in developing international waters in Lesotho: ensuring water security amidst political instability. In: JANSKY, L., NAKAYAMA, M., e PACHOVA, N. I. (eds.). International water security: domestic threats and opportunities. New York: United Nations University Press, 2008, p. 35-60.

MIRUMACHI, Naho e ALLAN, J. A. Revisiting transboundary water governance: power, conflict, cooperation and political economy. Proceedings from CAIWA International Conference on Adaptative and Integrated Water Management: coping with scarcity, 12-15 November, Basel, Switzerland, 2007. 
MIRUMACHI, N. e ALLAN, J. A. Why negotiate? Asymetric Endowments, Asymetric Power and the Invisible Nexus of Water, Trade and Power that brigs Apparent Water Security. In: EARLE, A.; JÄGERSKOG, A; e ÖJENDAL, J. (eds.). Transboundary water management: principles and practice. London: Earthscan, 2010, pp. 13-26.

MITCHELL, R. B. Of course international institutions matter: but when and how? In: BREIT, H., et al. (eds). How institutions change: perspectives on social learning in global and local environmental contexts. Opladen (Alemanha): 2003, p. 35-52.

MOLINA, J. C. Analisis de los estúdios de impacto ambiental del complejo hidroelétrico del rio Madera. Hidrilogía y Sedimentos. La Paz: abril 2006.

MOLLE, F. Scale and power in river basin management: the Chao Phraya River in Thailand. The Geographical Journal. V. 173, n. 4, 2007, p. 358-373.

MOLLINGA, Peter P. Water Policy-Water Politics: social engineering and strategic action in water sector reform. In: SCHEUMANN, W.; NEUBERT, S. e KIPPING, M. (eds.). Water Politics and Development Cooperation: local power plays and global governance. Berlim: Springer, 2008, p. 1-29.

MOORE, D.; DORE, J. e GYAWALI, D. The World Commission on Dams + 10: Revisiting the Large Dam Controversy. Water Alternatives. V. 3, n. 2, 2010, p. 3-13.

MORAES, A. C. R. (org.). Ratzel. São Paulo: Ática, 1990.

MORAES, A. C. R. Bases da Formação Territorial do Brasil: o território colonial brasileiro no longo século XVI. São Paulo: Hucitec, 2000.

MORAES, A. C. R. Território e história no Brasil. São Paulo: Annablume, 2005.

MORAES, A. C. R. Território, região e formação colonial: apontamentos em torno da geografia histórica da independência brasileira. Ciência e Ambiente. Santa María: Universidade Federal de Santa Maria, n 33, jul/dez 2006.

MORAES, A. C. R. Geografia histórica do Brasil: cinco ensaios, uma proposta e uma crítica. São Paulo: Annablume, 2009.

MORALES, R. E. Los desafios de la paz entre Ecuador y Peru para la seguridade y desarrollo nacional. Dissertação (Mestrado em Segurança e Desenvolvimento. Instituto de Altos Estudos. Quito: Instituto de Altos Estudos, 1999.

MOSS, T. Solving Problems of 'Fit' at the Expense of Problems of 'Interplay'? The Spatial Reorganization of Water Management following the EU Water Framework Directive. In: BREIT, H., et al. (eds). How institutions change: perspectives on social learning in global and local environmental contexts. Opladen (Alemanha): 2003, p. 85121.

MOSS, T. The governance of land use in river basins: prospects for overcoming problems of institutional interplay with the EU Water Framework Directive. Land Use Policy. N. 21, 2004, p. 85-94. 
MOSS, T. and J. Newig. Multilevel water governance and problems of scale: setting the stage for a broader debate. Environmental Management. n. 46, 2010, pp. 1-6.

MT Ministério dos Transportes. Informações detalhadas sobre o rio Acre. Disponível em: <http://www.transportes.gov.br/bit/hidro/detrioacre.htm>. Acesso em: dez 2008.

MYLOPOULOS, Y. A. and E. G. KOLOKYTHA (2008): Integrated water management in shared water resources: The EU Water Framework Directive implementation in Greece. Physics and Chemistry of the Earth. N. 33, p. 347-353.

NAJAM, Adil; PAPA, Mihaela; e TAIYAB, Nadaa. Global Environmental Governance: a reform agenda. Winnipeg: IISD, 2006.

NARVÁEZ, I. Yasuní y derechos colectivos indígenas en el Estado constitucional de derechos, intercultural y plurinacional, ecuatoriano. In: KRAINER, A. e MORA, M. F. (comp.). Retos y amenazas en el Yasuní. Quito: FLACSO, 2011, p. 19-41.

NASCIMENTO, J. A. S. Vulnerabilidade a eventos climáticos extremos na Amazônia Ocidental: uma visão integrada na Bacia do Rio Acre. Tese (Doutorado em Planejamento Energético e Ambiental) apresentada ao Instituto Alberto Luiz Coimbra de Pós-Graduação e Pesquisa em Engenharia - COPPE da Universidade Federal do Rio de Janeiro. Rio de Janeiro: UFRJ, 2011.

NOVAK, F. e NAMIHAS, S. Perú-Ecuador: uma experiência exitosa de paz y buena vecindad. Lima: Konrad Adenauer Stifung e IDEI, 2010.

OIT. Organização Internacional do Trabalho. Convenção $n^{\circ} 169$ sobre povos indígenas e tribais e Resolução referente à ação da OIT. Brasília: OIT, 2011.

OKWAN. Organização Kichwaruna Wangurina do Alto Napo. Asambleia Extraordinaria. Comunicado. 2010. Disponível em:

<http://radiolvs.cnr.org.pe/ninterna.html?x=9633>. Acesso em dezembro 2010.

OLIVEIRA, C. F. Água e Saneamento Básico: a atuação do Grupo Suez em Limeira e Manaus. Tese (Doutorado em Geografia Humana) Faculdade de Filosofia Letras e Ciências Humanas, Universidade de São Paulo. São Paulo: USP, 2007.

OOSTEN van C. J. Fading Frontiers? Local development and Cross-border Partnerships in Southwest Amazonia. Utrecht (Países Baixos): Universidade de Utrecht, 2004.

OOSTEN van C. J. De "cambios climáticos" a "sociedades locales diseñando soluciones regionales", la formación de un espacio de gobernanza en la Amazonia Suroccidental. Mapiense. UFAC, Herencia, n. 1, 2007, p. 31-37.

ORÉ. M. T. (coord.). El agua ante nuevos desafios. Actores e iniciativas em Ecuador, Perú y Bolívia. Lima: IEP, Oxfam Internacional, 2009. 
ORIAS, R. A.; SEOANE, A. F. e TORRES, W. A. Bolivia país de contatos: um análisis de la política vecinal contemporânea. La Paz: FUNDEMOS, 2001.

ORTIZ, B. B. Evolución de la Política Internacional del Ecuador. In: ARAÚJO, H. V. (org.). Os países da Comunidade Andina. V. 1. Brasília: FUNAG, IPRI, 2004, p. 669

OSTROM, E. Governing the commons: the evolution of institutions for collective action. Cambridge (Reino Unido): Cambridge University Press, 1990.

OTCA. La OTCA y los desafíos de la Amazonía. Brasilia: Organización del Tratado de Cooperación Amazonica, Secretaria Permanente, 2004.1 CD-ROM.

OTCA. Integrando la Amazonía Continental: Informe de Gestión de mayo de 2004 a octubre de 2005. Dispinível em: <http://www.otca.org.br/br/integrando.php>. Acesso em: ago 2006.

OTCA. Projeto de Gerenciamento Integrado e Sustentável dos Recursos Hídricos Transfronteiriços na Bacia do Rio Amazonas Considerando a Variabilidade e as Mudanças Climáticas. Disponível em:

$<$ http://www.otca.org.br/gefam/index.php?page=HomePage\&cat=34>. Acesso em: 23 jul. 2007a.

OTCA. Integrando a Amazônia Continental: Relatório de Gestão de novembro de 2005 a outubro de 2006. Disponível em: 〈http://www.otca.org.br/br/integrando.php〉. Acesso em: jun 2007b.

OTCA. Relatório de Gestão: julho de 2007 a julho de 2008. Disponível em: $<\mathrm{http}: / /$ www. otca.org.br/br/>. Acesso em: jan 2009b.

OTCA. Agenda Estratégica de Cooperação Amazônica. Brasília: OTCA, 2010a.

OTCA. RES/X MRE-OTCA/7. Lima: OTCA, 2010b.

OTCA. Representantes governamentais debatem projeto para manejo de recursos hídricos do Amazonas. Disponível em: <http://www.otca.info/portal/noticiainterna.php?id=285>. Acesso em: out 2011a.

OTCA. Coordenadoria de Meio Ambiente. Plano de Trabalho Anual 2011. Disponível em: 〈http://www.otca.info/portal/admin/_upload/plano_trabalho/622-ambiente.pt.pdf>. Acesso em: abril 2011b.

OTCA. Coordenadoria de Meio Ambiente. Plano de Trabalho Anual 2013. Disponível em: 〈http://www.otca.info/portal/admin/_upload/plano_trabalho/822-ambiente.pt.pdf>. Acesso em: abril 2013.

OTCA e MMA. Plano de Ação Regional para a prevenção e controle da contaminação por mercúrio nos ecossistemas amazônicos. Disponível em:

<http://www.otca.org.br/br/>. Acesso em: dez 2006. 
PACHOVA, N. I. e JANSKY, L. Domestic drivers of international water security on the Danube. In: JANSKY, L., NAKAYAMA, M., e PACHOVA, N. I. (eds.). International water security: domestic threats and opportunities. New York: United Nations University Press, 2008, p. 61-78.

PAHL-WOSTL, Claudia et. al. Governance and the global water system: a theoretical exploration. Global Governance. V. 14, 2008, p. 419-435.

PALM, P. R. A abertura do rio Amazonas à navegação internacional e o parlamento brasileiro. Brasília: Fundação Alexandre de Gusmão, 2009.

PANDURO, M. C. Mazán, la hidroeléctrica cuestionada. KANATARI. Iquitos: CETA, n. 1454,2012 , p. $8260-8262$.

PAREDES, O. Amazonia 500 años. Cusco: Universidad Nacional de San Antonio Abad del Cusco, 1994.

PARODI, C. A. The politics of South American boundaries. Westport (EUA): PRAEGER, 2002.

PAULA, E. A. e SOUZA, I. P. D. Ambientalização, territorialização/desterritorialização, na fonteira trinacional amazônica (Peru, Brasil e Bolívia). Trabalho apresentado no IV Encontro Nacional da ANPPAS. Brasília: 2008.

PCDL. Primeira Comissão Brasileira Demarcadora de Limites. Fronteira Brasil/Peru Resumo Histórico. Brasília: Ministério de Relações Exteriores. Disponível em: $<$ http://sistemas.mre.gov.br/kitweb/datafiles/Pcdl/ptbr/file/Fronteiras/Peru/Resumo\%20Hist\%C3\%B3rico.pdf >. Acesso em: março 2013.

PEREIRA, M. R. S. Iniciativa MAP: um emergente movimento social transfronteiriço e sua gestão no desenvolvimento sustentável na região da Amazônia Sul Ocidental. Dissertação (Mestrado em Direito). Programa Interinstitucional UFSC/UFAC. Universidade Federal de Santa Catarina. Florianópolis, 2007.

PERU. Bases para una visión nacional común de Desarrollo de la Amazonia Peruana. Informe Final. Disponível em: Disponível em:

<http://www.otca.info/gefam/index.php?page=HomePage\&cat=39>. Acesso em: abril 2007.

PETROPERU. Proyecto transporte de crudos pesados. Disponível em: <http://www2.petroperu.com.pe/ptcp/descripcion.php>. Acesso em junho 2013.

PIECK, S. K. Beyond postdevelopment: civic response to regional integration in the Amazon. Journal of Cultural Geography. V. 28, n. 1, 2011, p. 179-202.

PLANO Estratégico 2004/12. Disponível em: 〈http://www.otca.org.br/br/plano.php>. Acesso em: 10 fev. 2004. 
PNC. Plan Nacional de Cuencas. Proyectos. Disponível em:

$<$ http://www.cuencasbolivia.org/proyectos/209/manejo_integral_de_la_cuenca_del_arro yo_bahia/50/>. Acesso em: maio de 2013.

PNUMA, OTCA e CIUP. Geo Amazônia. Disponível em:

<http://www.pnuma.org/deat1/geoamazonia/>. Acesso em: fev 2009.

PNUD. Relatório de Desenvolvimento Humano. A água para lá da escassez: poder, pobreza e a crise mundial da água. Nova Iorque: PNUD, 2006.

PORTO, M. F. A. e PORTO, R. L. Gestão de bacias hidrográficas. Estudos Avançados. V. 22, n. 63, 2008, p. 43-60.

PRESCOTT, J. R. V. The geography of frontiers and boundaries. Londres: Hutchinson \& Co., 1965.

PRISCOLI, Jerome Delli e WOLF, Aaron T. Managing and Transforming Water Conflicts. Cambridge: Cambridge University Press, 2009.

PROTOCOLO de Emenda. Disponível em:

<http://www.otca.org.br/br/intitucional/index.php?id=11> . Acesso em: 10 fev. 2004.

QUEIRÓZ, F. A. Hidropolítica e segurança: as bacias platina e amazônica em perspectiva comparada. Brasília: FUNAG, 2012.

QUEROL, Maria. Estudio sobre los convenios e acuerdos de cooperación entre los países de América Latina y el Caribe, en relación con sistemas hídricos y cuerpos de agua transfronteirizos. Serie Recursos Naturales e Infraestructura. Santiago de Chile: CEPAL, 2003.

QUIJANO, A. Colonialidade e modernidade-racionalidade. In: BONILLA, H. (org.). Os conquistados: 1492, e a população indígena das Américas. São Paulo: Hucitec, 2006.

RAFFESTIN, C. Por uma geografia do poder. São Paulo: Ática, 1990.

RAVENA, N. et al.. Gestão das Águas na Amazônia: atores sociais, marcos regulatórios e escalas. Trabalho apresentado no IV Encontro Nacional da ANPPAS. Brasília: 2008.

RAVENA, N. et al. Gestão das Águas na Amazônia: atores sociais, marcos regulatórios e escalas. In: ZAMUDIO, H. B. et al. (eds.). Amazonia y Agua: desarrollo sostenible en el siglo XXI. Bilbao: Universidad del País Vasco, OTCA, UA, UNAMAZ, 2009, p. 445-456.

RAVENA, N. Os caminhos da regulação da água no Brasil: demiurgia institucional ou criação burocrática? Curitiba: Appris, 2012.

RECALDE, J. Visión general de recursos hídricos en el Ecuador y caracterización de los conflictos entre la legislación nacional y la gestión local del agua. In: BOELENS, R.; GUEVARA, A. G.; HENDRIKS, J. e HOOGESTEGER, J. (compiladores). 
Pluralismo legal, reforma hídrica y políticas de reconocimiento. Congeso Internacional WALIR. Wageningen/Cusco: WALIR, 2007.

REGENASS, A. L. The sustainable development paradigma shift: financing a long term vision in the Amazon River Basin. Certificate Thesis. Environmental Diplomacy. Zurique: SCENAM, 2008. Disponível em:

<http://scenam.org/pdf/4.\%20Amazon\%20Paradox.pdf>. Acesso em: março 2013.

REIS, V. (org.). Rumo à gestão participativa da Bacia do Alto Rio Acre: diagnóstico e avanços. Rio Branco: WWF / UFAC, 2007.

REIS V. L. e RIOS, M. Iniciativas de gestão na Bacia transfronteiriça do rio Acre. In: REIS, V. (org.). Rumo à gestão participativa da Bacia do Alto Rio Acre: diagnóstico e avanços. Rio Branco: WWF / UFAC, 2007, p 129-131.

REIS, V. et al. Aspectos Biogeofísicos da Bacia do Alto Rio Acre. In: REIS, V. (org.). Rumo à gestão participativa da Bacia do Alto Rio Acre: diagnóstico e avanços. Rio Branco: WWF / UFAC, 2007, p. 7-24.

RIBEIRO, W. C. A ordem ambiental internacional. São Paulo: Contexto, 2001.

RIBEIRO, W. C. Ecologia política: ativismo com rigor acadêmico. Biblio $3 \mathrm{~W}$. Barcelona: v. 7, n.364, 2002, p. 1-20.

RIBEIRO, W. C. Geografia Política da Água. São Paulo: Annablume, 2008.

RIBEIRO, W. C. Geografia Política e Recursos Naturais. Mercator. UFC, v. 3, n. 5, 2004a, p. 73-78.

RIBEIRO, W. C. Impasses da governança da água no Brasil. In: RIBEIRO, W. C. (org.). Governança da água no Brasil: uma visão interdisciplinar. São Paulo: Annablume, Fapesp, CNPq, 2009.

RIBEIRO, W. C. Teorias socioambientais: em busca de uma nova sociedade. Estudos Avançados. São Paulo: IEA, v. 24, n. 68, 2010, p. 9-13.

RISSE-KAPPEN, T. Bringing transnacional actors back in: an introduction. In: RISSEKAPPEN, T. Bringing transnational relations actors back in. Cambridge: Cambridge University Press, 1995, p. 3-33.

RODRICH, R. La policía destruye siete dragas ilegales en el río Napo y detiene a 40 mineros. El Comercio. Loreto: El Comercio, 27 de março de 2012, p. A11.

ROGERS, Peter e HALL, Alan W. Effective Water Governance. TEC Background Papers, n. 7. Stockholm: GWP, 2003.

ROJAS, J. C. C. (coord.). Pando: tierra saneada con la reconducción comunitaria. La Paz, INRA, 2010. 
ROMAN, Mikael. The implementation of international regimes: the case of the Amazon Cooperation Treaty. Uppsala: Uppsala University Press, 1998.

ROSENAU, James e CZEMPIEL, Ernest-Otto. Governança sem governo: ordem e transformação na política mundial. Brasília: UNB, 2000.

ROSENAU, J. Governança, ordem e transformação na política mundial. In: ROSENAU, J.; CZEMPIEL, E. Governança sem governo: ordem e transformação na política mundial. São Paulo: Imprensa Oficial, 2000.

ROUX, J. C. De los límites a la frontera: a los malentendidos de la geopolítica amzónica. Revista de Indias. V. LXI, n. 223, 2001.

RPP Notícias. Loreto: reportan ingresso de mancha de petróleo al río Napo. Disponível em: <http://www.rpp.com.pe/2013-06-04-loreto-reportan-ingreso-de-mancha-depetroleo-al-rio-napo-noticia_601072.html Acesso em : junho 2013.

RREE PERU. Ministerio de Relaciones Exteriores de Peru. Desarrollo e Integración Fronteriza. Lima: $\quad 2012 . \quad$ DREE, Disponível em: $<$ http://www.rree.gob.pe/politicaexterior/Documents/Propuesta\%20contenido\%20follet o\%20DDF\%20(29MAY12).pdf>. Acesso em março 2013.

RUIZ, S. A. e GENTES, I. G. Retos y perspectivas de la gobernanza del agua y gestión integral de recursos hídricos en Bolívia. Europeuan Review of Latin American and Caribbean Studies. V. 85, outubro de 2008, p. 41-59.

SACKS, R. D. Human Territorialy: its theory and history. Cambridge: Cambridge University Press, 1986.

SAMPAIO, C. H. S. Relatório do Grupo de Trabalho do Rio Acre. Rio Branco: Conselho Nacional de Recursos Hídricos, 2010.

SAN ROMÁN, J. Perfiles historicos de la Amazonia peruana. Iquitos: CETA, CAAAP e IIAP, 1994.

SÁNCHEZ, Joan-Eugeni. Geografia Política. Madrid: Editorial Síntesis, 1992.

SÁNCHEZ, J. De la seguridad compartida a la seguridad ecológica. Ecología política. V. 15, 1998, p. 11-30.

SANTA CRUZ, J. F. C. IIRSA y desarrollo territorial em el Perú: el caso de la Intercoeánica del Sur. Lima: Grupo Propuesta Ciudadana, 2009.

SANTANA, W. A. e TACHIBANA, T. Caracterização dos elementos de um projeto hidroviário, vantagens, aspectos e impactos ambientais para a proposição de metodologias técnico-ambientais para o desenvolvimento do transporte comercial de cargas nas hidrovias brasileiras. ENGEVISA. V. 6, n. 3, 2004, p. 75-85. 
SANT'ANNA, F. M. Cooperação internacional e gestão transfronteiriça da água na Amazônia. Dissertação (Mestrado em Geografia Humana) Faculdade de Filosofia Letras e Ciências Humanas, Universidade de São Paulo. São Paulo: USP, 2009.

SANT'ANNA, F. M. Inequality and water in the Amazon Basin: the difficulties of cooperation and sustainable management. Kieler Geographische Schriften. Kiel (Alemanha): Geographischen Instituts der Universität Kiel, v. 123, 2012a, p. 237-261.

SANT'ANNA, F. M. Cooperação internacional e os recursos hídricos transfronteiriços: soberania e instituições internacionais. GEOUSP Espaço e Tempo. São Paulo: USP, edição especial, 2009, p. 183-210.

SANT'ANNA, F. M. Tensões e conflitos na governança dos recursos hídricos amazônicos transfronteiriços. GEOUSP Espaço e Tempo. São Paulo: USP, n. 31 especial, p. 132-145.

SCDL. Segunda Comissão Demarcadora de Limites. Disponível em: <http://scdl.itamaraty.gov.br/pt-br/fronteiras_da_scdl.xml>. Acesso abril 2012.

SCHMIDLEHNER, M. F.; MACUCO R. e REIS, V. L. Map-amazonia.net contribuindo para a construção de uma nova cultura de comunicação na Amazônia Sulocidental. Mapiense. UFAC, Herencia, n. 1, 2007, p. 57-68.

SCHULZ, M. Turkey, Syria and Iraq: a Hydropolitical Security Complex. In:

OHLSSON, L. (ed.). Hydropolitics: conflicts over water as development-constraint. Londres: Zed a Book, 1995.

SELA. Sistema Econômico Latino Americano, Secretaria Permanente. La integración Fronteriza em el Marco del Proceso Regional de América Latina y Caribe. SP/Di n. 0511. Caracas (Venezuela): SELA, 2011.

SEMA. Secretaria Estadual de Meio Ambiente do Acre. Plano Estadual de Recursos Hídricos do Acre. Rio Branco: SEMA, 2012.

SEOANE, A. F.; ORIAS, R. A. e TORRES, W. A. Desarrollo fronterizo: construyendo una nueva agenda. La Paz: Universidad de la Cordillera, 2009.

SEOANE, A. F. Integración Económica y Fronteras: Bases para un Enfoque Renovado. In: SEOANE, A. F.; ORIAS, R. A. e TORRES, W. A. Desarrollo fronterizo: construyendo una nueva agenda. La Paz: Universidad de la Cordillera, 2009, p. 35-123.

SERJE, M. R. O. El revés de la nación: territorios salvajes, fronteras y tierras de nadie. Bogotá: Universidad de los Andes, 2011.

SERVINDI. Perú: crescimento de la frontera petroleira en Loreto afectan territórios indígenas y ANP. 2012. Disponível em: <http://servindi.org/actualidad/75728>. Acesso em junho 2013.

SEVÁ FILHO, A. O. Problemas intrínsecos e graves da expansão mineral, metalúrgica, petrolífera e hidrelétrica nas Amazônias. In: ZHOURI, A. e LASCHEFSKI, K. (orgs.). 
Desenvolvimento e conflitos ambientais. Belo Horizonte: Editora UFMG, 2010, p. 114147.

SILVEIRA, E. D. Direito Socioambiental: Tratado de Cooperação Amazônica.

Curitiba: Juruá, 2005.

SLATER, David. Repensando as especialidades dos movimentos sociais: questões de fronteira, cultura e política em tempos globais. In: ALVAREZ, S. E.; DAGNINO, E.; ESCOBAR, A. (org.). Cultura e política nos movimentos sociais latino-americanos: novas leituras. Belo Horizonte: Ed. UFMG, 2000, p. 503-533.

SMITH, N. Scale bending and the fate of the national. In: SHEPPARD, E. e MCMASTER, R. B. (eds.). Scale \& Geography Inquiry: nature, society and method. Oxford: Blackwell Publishing, 2004, p.192-212.

SNEDDON, C e FOX, C. Rethinking transboundary waters: a critical hydropolitics of the Mekong basin. Political Geography. V. 25, 2006, p. 181-202.

SOARES-FILHO, B. S. et al. Cenários de desmatamento para a Amazônia. Estudos Avançados. São Paulo: IEA-USP, v. 19, n. 54, maio/agosto 2005, p. 137-152.

SOARES, G. F. S. A interdependência dos Estados no campo da proteção internacional ao meio ambiente. In: OLIVEIRA, O e RI JÚNIOR, A. D. (org.). Relações

Internacionais: interdependência e sociedade global. Ijuí: unijuí, 2003, p. 599-627.

SMOUTS, Marie-Claude. A cooperação internacional: da coexistência à governança mundial. In: SMOUTS, Marie-Claude (org.). As novas relações internacionais: práticas e teorias. Brasília: Ed. Universidade de Brasília, 2004, p. 129-153.

Tropical forests, international jungle: the underside of global ecopolitics. New York: Palgrave Macmillan, 2003.

ST JOHN, R. B. Ecuador-Peru Endgame. IBRU Boundary and Security Bulletin. Winter 1998-1999.

ST JOHN, R. B. Conflict in the Cordillera del Cóndor: the Ecuador-Peru Dispute. IBRU Boundary and Security Bulletin. Spring 1996.

STEFANO, L.; EDWARDS, P.; SILVA, L. e WOLF, A. T. Tracking cooperation and conflict in international basins: historic and recente trends. Water Policy. N. 12, 2010, p. 871-884.

STRATEGIA. Madre de Dios... cuando la minería mata. Revista Strategia. Lima: CENTRUM PUC-Peru, ano 6, n. 22, junho de 2011, p. 66-69. Disponível em: <http://www.k-dreams.cl/revistas/strategia/edicion-22-junio-2011/FlipK.html>. Acesso em: janeiro de 2013.

SWITKES, G. (org.) e BONILLA, P. (ed.). Águas Turvas: alertas sobre as consequências de barrar o maior influente do Amazonas. São Paulo: International Rivers, 2008. 
SWYNGEDOUW, Eric. Scaled geographies: nature, place and the politics of scale. In: SHEPPARD, E. e MCMASTER, R. B. (eds.). Scale \& Geography Inquiry: nature, society and method. Oxford: Blackwell Publishing, 2004, p. 129-153.

TARROW. Sidney. The new transnational activism. Cambridge: Cambridge University Press, 2005.

TCA. Tratado de Cooperação Amazônica. Disponível em:

<http://www.otca.org.br/br/institucional/index.php?id=10> . Acesso em: 10 fev. 2004.

THÉRY, H. e MELLO, N. A. Atlas do Brasil: disparidades e dinâmicas do território. São Paulo; EdUSP, 2005.

TOCHE, E. Integración fronteriza, democracia y sociedade em el Perú; diez años de paz entre Perú y Ecuador. In: DONOSO, C. (compiladora). Ecuador-Perú: evaluación de una década de paz y desarrollo. Quito: Flasco, 2009, p. 145-165.

TORRES, W. A. Bolívia y las Águas Internacionales como factor de integración:

Hidrovia Paraguay-Paraná. Conferência apresentada em "Foro de las Américas, Año del Agua, 2003". Laz Paz, 2003. Disponível em:

<http://www.bvsde.paho.org/bvsacg/fulltext/willi.pdf>. Acesso em abril 2013.

TROTTIER, J. The need for multiscalar analysis in the management of shared water resources. In: HASSAN, F. A. et al. History and future of shared water resources.

UNESCO, International Hydrological Programme, 2003.

TURTON, A. R. A South African perspective on possible benefit-sharing approach for transboundary water in the SADC region. Water Alternatives. V. 1, n. 2, 2008, p. 180200.

TURTON, A. R. The political aspects of institutional development in the water sector: South African and its international river basin. Tese (Doutorado em Política Internacional) Faculty of Humanities, University of Pretoria. Pretoria (África do Sul): University of Pretoria, 2003.

UGARTE, A. S. Sertões de Bárbaros: o mundo natural e as sociedades indígenas na Amazônia na visão dos cronistas ibéricos (séculos XVI-XVII). Manaus: Valer, 2009.

UNESCO. World Water Assessment Program (WWAP). Disponível em: <http://www.unesco.org/new/en/natural-sciences/environment/water/wwap/wwdr/>. Acesso em abril 2013.

UN-Water. Transboundary Waters: sharing benefits, sharing responsibilities. Thematic Paper. 2008.

VALENCIO, N. F. L. S. Governança das águas: a participação social como quimera. In: RIBEIRO, W. C. (org.). Governança da água no Brasil: uma visão interdisciplinar. São Paulo: Annablume, Fapesp, CNPq, 2009, p. 61-90. 
VELASCO, S. P. La integración de la Comunidad Andina en el debate de la explotación petrolera en territorios indígenas. Dissertação (Mestrado em Governança Energética). Facultad Latino-Americana de Ciencias Sociales - FLACSO. Quito: FLACSO, 2009.

VERGARA, M. R. Ciência, fronteiras e nação: comissões brasileiras na demarcação dos limites territoriais entre Brasil e Bolívia, 1895-1901. Boletim Museu Paraense Emilio Goeldi. Belém: Museu Paraense Emílio Goeldi, v. 5, n. 2, 2010, p. 345-361.

VIZENTINI, P. G. F. As Relações Internacionais da Bolívia: os desafios da globalização e integração. In: ARAÚJO, H. V. (org.). Os países da Comunidade Andina. V. 1. Brasília: FUNAG, IPRI, 2004, p. 351-396.

WARNER, J. e GRANJA, S. I. B. A hidropolítica e o federalismo: possibilidade de construção da subsidiariedade na gestão das águas no Brasil? Revista de Administração Pública. V. 40, n. 6, 2006, p. 1097-1121.

WARNER, J. e WEGERICH, K. Is water politics? Towards international water relations. In: WARNER, J. e WEGERICH, K. (eds.). The politics of water: a survey. Londres: Routledge, 2010, p. 3-17.

WARNER, J. e ZEITOUN, M. International relations theory and water do mix: a response to Furlong's troubled Waters, hydro-hegemony and international water relations. Political Geography. N. 27, 2008, p. 802-810.

WATERBURY, J. Hydropolitics of the Nile Valey. Syracuse: Syracuse University Press, 1979.

WOLF, Aaron; STAHL, Kerstin.; MACOMBER, F. Macomber. Conflict and cooperation within international river basins: the importance of institutional capacity. Annual meeting of the International Studies Association. Portland, 2003. Disponível em: <http://www.transboundarywaters.orst.edu/publications/conflict_coop/>. Acesso em: dez. 2007.

WWC. World Water Council. Disponível em: $<$ http://www.worldwatercouncil.org/about-us/vision-mission-strategy/>. Acesso em março 2013.

WWC. World Water Vision: making water everybody's business. Londres: Earthscan, 2000 .

YOFFE, S.; FISKE, G.; GIORDANO, M.; GIORDANO, M.; KELLI, L.; STAHL, K. e WOLF, A. Geography of international water conflict and cooperation: data sets and application. Water Resources Research. V. 40, 2004.

ZEE. Programa Estadual de Zoneamento Ecológico-Econômico do Acre. Disponível em:

$<$ http://www.ac.gov.br/index.php?option=com_docman\&task=cat_view\&gid=35\&Itemi $\mathrm{d}=165>$. Acesso em: $12 \mathrm{dez} 2009$. 
ZEITOUN, M. e WARNER, J. Hydro-hegemony - a framework for analysis of transboundary water conflicts. Water Policy. N. 8, 2006, p. 435-460.

ZEITOUN, M. e MIRUMACHI, N. Transboundary water interaction: reconsidering conflict and co-operation. In: WARNER, J. e WEGERICH, K. (eds.). The politics of water: a survey. Londres: Routledge, 2010, p. 96-118.

ZEITOUN, M.; MIRUMACHI, N. e WARNER, J. Transboundary water interaction II: the influence of 'soft power'. International Environments Agreements. N. 11, 2011, p. 159-178.

ZHOURI, A. e OLIVEIRA, R. Quando o lugar resiste ao espaço: colonialidade, modernidade e processos de territorialização. In: ZHOURI, A. e LASCHEFSKI, K. (orgs.). Desenvolvimento e conflitos ambientais. Belo Horizonte: Editora UFMG, 2010, p. 439-462.

ZHOURI, A. e LASCHEFSKI, K. Desenvolvimento e conflitos ambientais: um novo campo de investigação. In: ZHOURI, A. e LASCHEFSKI, K. (orgs.). Desenvolvimento e conflitos ambientais. Belo Horizonte: Editora UFMG, 2010, p. 11-33.

ZUMAETA, Carlos Hernan Vasquez. Valoración económica del agua potable en las comunidades rurales de la cuenca del río Napo, departamento de Loreto, Peru. Iquitos: Universidad Nacional de la Amazonia Peruana. 